Johannes Gerken

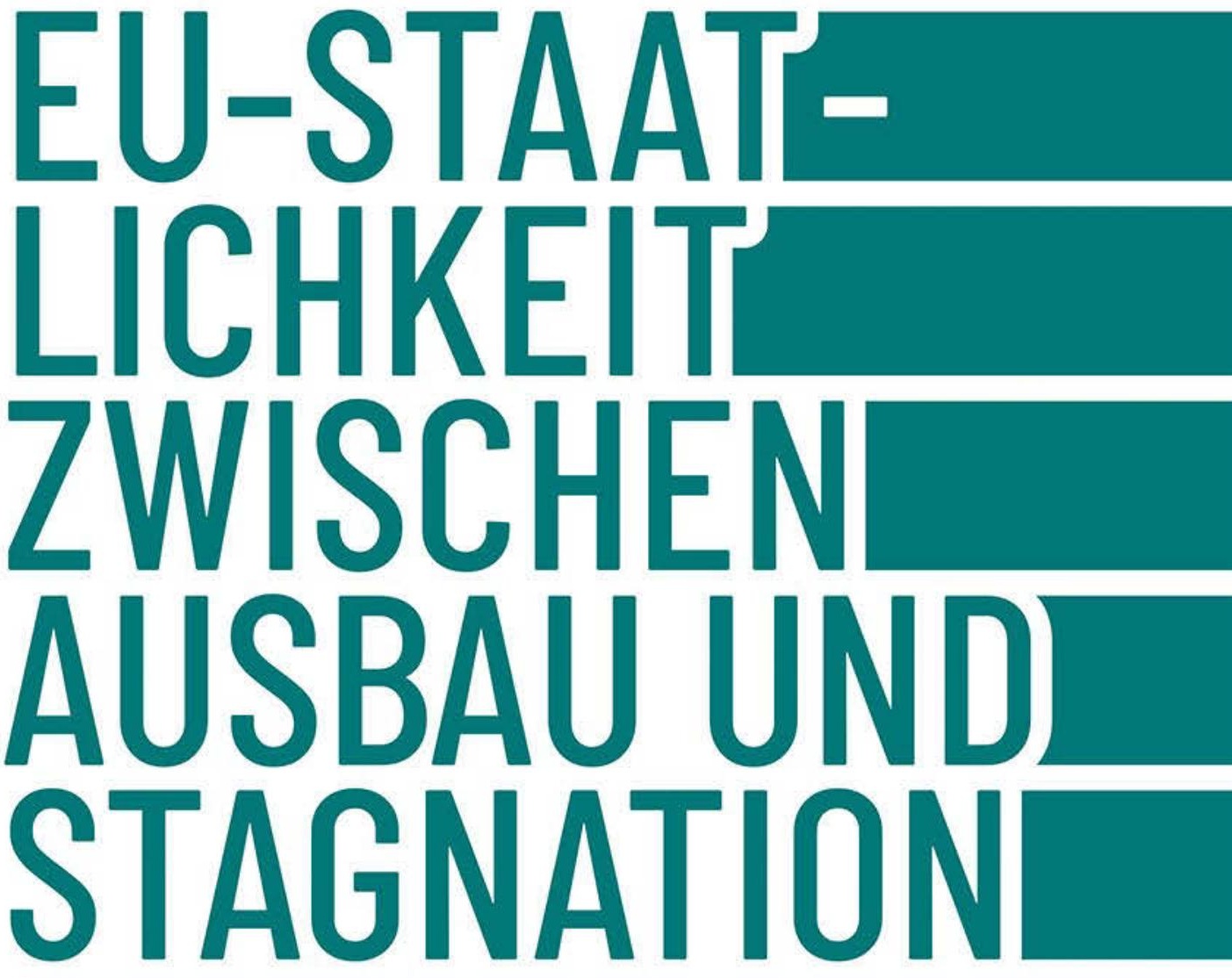

Kritische Perspektiven auf die Transformationsprozesse in der Euro-Krise

[transcript] Edition Politik 
Johannes Gerken

EU-Staatlichkeit zwischen Ausbau und Stagnation

Edition Politik | Band 122 
Die freie Verfügbarkeit der E-Book-Ausgabe dieser Publikation wurde ermöglicht durch den Fachinformationsdienst Politikwissenschaft POLLUX

\section{POLLUXX Informationsdienst}

und einem Netzwerk wissenschaftlicher Bibliotheken zur Förderung von Open Access in den Sozial- und Geisteswissenschaften (transcript, Politikwissenschaft 2021)

Die Publikation beachtet die Qualitätsstandards für die Open-Access-Publikation von Büchern (Nationaler Open-Access-Kontaktpunkt et al. 2018), Phase 1 https://oa2020-de.org/blog/2018/07/31/empfehlungen_qualitätsstandards_oabücher/

Hauptsponsor: Staats- und Universitätsbibliothek Bremen (POLLUX - Informationsdienst Politikwissenschaft)

Vollsponsoren: Universitätsbibliothek Bayreuth | Universitätsbibliothek der HumboldtUniversität zu Berlin | Freie Universität Berlin - Universitätsbibliothek | Staatsbibliothek zu Berlin | Universitätsbibliothek Bielefeld | Universitätsbibliothek der Ruhr-Universität Bochum (RUB) | Universitäts- und Landesbibliothek Bonn | Vorarlberger Landesbibliothek | Universitätsbibliothek der Technischen Universität Chemnitz | Universitäts- und Landesbibliothek Darmstadt | Sächsische Landesbibliothek Staats- und Universitätsbibliothek Dresden (SLUB) | Universitätsbibliothek Duisburg-Essen | Universitäts- und Landesbibliothek Düsseldorf | Universitätsbibliothek Erlangen-Nürnberg | Universitätsbibliothek Frankfurt/M. | Niedersächsische Staats- und Universitätsbibliothek Göttingen | Universitätsbibliothek Greifswald | Universitätsbibliothek der FernUniversität in Hagen | Staatsund Universitätsbibliothek Carl von Ossietzky, Hamburg | TIB - Leibniz-Informationszentrum Technik und Naturwissenschaften und
Universitätsbibliothek | Gottfried Wilhelm Leibniz Bibliothek - Niedersächsische Landesbibliothek | Universitätsbibliothek Heidelberg | Universitätsbibliothek Kassel | Universitätsbibliothek Kiel (CAU) | Universitätsbibliothek Koblenz - Landau | Universitäts- und Stadtbibliothek Köln | Universitätsbibliothek Leipzig | Zentral- und Hochschulbibliothek Luzern | Universitätsbibliothek Otto-von-Guericke-Universität Magdeburg | Universitätsbibliothek Marburg | Max Planck Digital Library (MPDL) | Universitäts- und Landesbibliothek Münster | Universitätsbibliothek der Carl von Ossietzky-Universität, Oldenburg | Universitätsbibliothek Osnabrück | Universitätsbibliothek Passau | Universitätsbibliothek St. Gallen | Universitätsbibliothek Vechta | Universitätsbibliothek Wien | Universitätsbibliothek Wuppertal | Zentralbibliothek Zürich Sponsoring Light: Bundesministerium der Verteidigung | Landesbibliothek Oldenburg Mikrosponsoring: Stiftung Wissenschaft und Politik (SWP) - Deutsches Institut für Internationale Politik und Sicherheit | Leibniz-Institut für Europäische Geschichte, Mainz

Johannes Gerken, geb. 1989, promovierte am Fachbereich Gesellschaftswissenschaften an der Universität Kassel. Seine Forschungsschwerpunkte liegen in der Europäischen Integrationsforschung, der Staatlichkeitstheorie sowie der kritischen EU- und Bildungsforschung. 
Johannes Gerken

\section{EU-Staatlichkeit zwischen Ausbau und Stagnation}

Kritische Perspektiven auf die Transformationsprozesse in der Euro-Krise 
Die vorliegende Arbeit wurde an der Universität Kassel, Fachbereich Gesellschaftswissenschaften, mit dem Titel »Der Ausbau der EU-Staatlichkeit in der Euro-Krise. Über die Staatlichkeitsgenese der Europäischen Union im Kontext einer Dekade des kriseninduzierten Transformationsprozesses« als Dissertation eingereicht. Tag der Disputation: 23 . September 2020.

\section{Bibliografische Information der Deutschen Nationalbibliothek}

Die Deutsche Nationalbibliothek verzeichnet diese Publikation in der Deutschen Nationalbibliografie; detaillierte bibliografische Daten sind im Internet über http:// dnb.d-nb.de abrufbar.

\section{(c) $(1)(9)$}

Dieses Werk ist lizenziert unter der Creative Commons Attribution-NonCommercial-NoDerivs 4.0 Lizenz (BY-NC-ND). Diese Lizenz erlaubt die private Nutzung, gestattet aber keine Bearbeitung und keine kommerzielle Nutzung. Weitere Informationen finden Sie unter https://creativecommons.org/licenses/by-nc-nd/4.o/deed.de

Um Genehmigungen für Adaptionen, Übersetzungen, Derivate oder Wiederverwendung zu kommerziellen Zwecken einzuholen, wenden Sie sich bitte an rights@transcript-publishing. com

Die Bedingungen der Creative-Commons-Lizenz gelten nur für Originalmaterial. Die Wiederverwendung von Material aus anderen Quellen (gekennzeichnet mit Quellenangabe) wie z.B. Schaubilder, Abbildungen, Fotos und Textauszüge erfordert ggf. weitere Nutzungsgenehmigungen durch den jeweiligen Rechteinhaber.

\section{(ㄷ) 2021 transcript Verlag, Bielefeld}

Umschlaggestaltung: Maria Arndt, Bielefeld

Druck: Majuskel Medienproduktion $\mathrm{GmbH}$, Wetzlar

Print-ISBN 978-3-8376-5822-4

PDF-ISBN 978-3-8394-5822-8

EPUB-ISBN 978-3-7328-5822-4

https://doi.org/10.14361/9783839458228

Buchreihen-ISSN: 2702-9050

Buchreihen-eISSN: 2702-9069

Gedruckt auf alterungsbeständigem Papier mit chlorfrei gebleichtem Zellstoff.

Besuchen Sie uns im Internet: https://www.transcript-verlag.de

Unsere aktuelle Vorschau finden Sie unter www.transcript-verlag.de/vorschau-download 


\section{Inhalt}

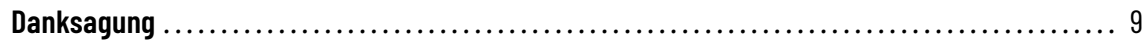

1 Der Ausbau der EU-Staatlichkeit in der Euro-Krise .......................... 11

2 Die Staatlichkeit der Europäischen Union ............................... 21

2.1 Über die Staatlichkeitspraxis des EU-»Staatsapparate-Ensembles « ................... 22

2.2 Über die »Konzentration und Monopolisierung symbolischer Macht« im Prozess

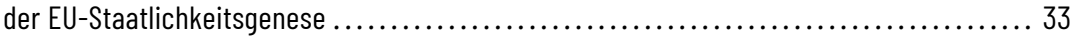

2.3 Über »Kräfteverhältnisse«, »Hegemonie« und die »integrale Staatlichkeit« der EU ....... 36

2.4 Über »Staatsprojekte«, »Akkumulationsstrategien « und das EU-Staatlichkeitstelos ...... 44

2.5 Die EU-Staatlichkeit als Praxis, Prozess, Verhältnis und Projekt .................... 47

2.6 Krisen als Kristallisationspunkt der Reproduktion und Transformation von Staatlichkeit ... 48

3 Historisch-materialistische Staatlichkeitsanalyse ........................... 53

3.1 Rekonstruktive Konstitutionalisierungsanalyse ........................... 55

3.2 Kräfteverhältnisanalyse .......................................... 58

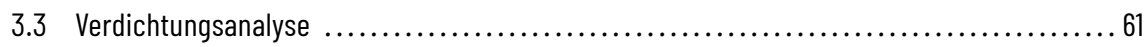

3.4 Analytisches Vorgehen und Darstellungsform ............................. 62

4 EU-Staatlichkeitsgenese vor der Euro-Krise und die EWWU im Zentrum neoliberaler Hegemonie ............................................ 65

4.1 Die politischen Projekte auf dem Weg zur EWWU ........................... 65

4.2 Vertragliche Grundlagen der EWWU und die EU-Wirtschaftsverfassung................ 74

4.3 Die Akkumulationsstrategie und das Staatsprojekt der EU unter neoliberalen Vorzeichen .. 79

5 Die Euro-Krise als Funktionskrise der neoliberalen EWWU ....................... 89

5.1 Die transatlantische Finanzmarktkrise als Ausgangspunkt ......................... 89

5.2 Von der transatlantischen Finanzmarkt- zur europäischen Bankenkrise ............... 92

5.3 Von der europäischen Banken- zur staatlichen Refinanzierungskrise ................. 95

5.4 Die Euro- als EWWU-Funktionskrise .................................... 97 
6 Strategische Suchprozesse und neoliberale Rückeroberungen .................... 101

6.1 Die Umdeutung zur Staatsschuldenkrise als erstes strategisch-diskursives Moment neoliberaler Rückeroberung 104

6.2 Der exzeptionelle Charakter der Krise und das Rettungsdispositiv als zweites strategisch-diskursives Moment neoliberaler Rückeroberung

6.3 »Europe 2020 « und die Wettbewerbsfähigkeitsdoktrin als drittes strategisch-diskursives Moment neoliberaler Rückeroberung ..................... 110

7 Reaktiver Staatlichkeitsausbau in der Euro-Krise ............................. 121

7.1 Das EUSA-Krisennarrativ und die sich verdichtende Reformagenda des reaktiven EU-Staatlichkeitsausbaus ................................... 121

7.2 Implementierung einer außerunionsvertraglichen Notstandsverfassung ............... 140

7.3 Fortentwicklung der vertragsbasierten Wirtschafts- und Fiskalverfassung .............. 153

7.4 Aufbau einer (impliziten) Finanzstabilisierungsverfassung ......................... 197

7.5 Die ausgebaute EU-Interventionsstaatlichkeit und ihr Herrschaftsmodus der (Selbst-)Disziplinierung ......................................... 213

7.6 Die fortschreitende Hegemoniekrise in der Phase des reaktiven EU-Staatlichkeitsausbaus

8 Inkrementeller Staatlichkeitsausbau in der sich abschwächenden Euro-Krise ........ 235

8.1 Das Scheitern der erweiterten Reformagenda 2012/13 .......................... 236

8.2 »Vertiefung durch Handeln« als neue Devise ................................. 248

8.3 Konsolidierung des fiskalpolitischen Regierens ............................... 254

8.4 Konsolidierung des wirtschaftspolitischen Regierens ......................... 262

8.5 Die inkrementell ausgebaute EU-Interventionsstaatlichkeit ....................... 273

8.6 Allianzwechsel und die Strategie der nachholenden hegemonialen Absicherung in der Phase inkrementellen Staatlichkeitsausbaus .......................... 274

9 Stagnierender Staatlichkeitsausbau im Anschluss an die Euro-Krise ...............281

9.1 Die »Zukunft Europas« und die »Vollendung der EWWU« ............................281

9.2 Das Nikolauspaket und die Diskussion um die Fiskalunion ......................... 293

9.3 Der EU-Staatlichkeitsausbau zwischen Ambition und Stagnation ...................... 310

10 Die Genese der EU-Staatlichkeit in der Euro-Krise und ihre Fragilität im Status quo ...................................... 315

10.1 Auf der Suche nach einem kohärenten Staatsprojekt in der Euro-Krise und die Persistenz seiner neoliberalen Variante. .315

10.2 Zwischen Fragilität, Lethargie und latenter Staatlichkeitskrise -

Die EU nach 10 Jahren Euro-Krise . .................................... 320

10.3 Die Corona- als neue Durchsetzungskrise des EU-Staatlichkeitsausbaus? ............. 324

Abkürzungsverzeichnis 333 
Literatur- und Quellenverzeichnis .

339

Anhang 



\section{Danksagung}

Der Weg von der ersten Idee über die Entwicklung eines Exposés bis zum fertigen Produkt ist manchmal steinig, mindestens aber langwierig und wartet mit einigen unerwarteten Untiefen auf. Ich möchte mich deshalb an dieser Stelle bei allen Wegbegleiter*innen bedanken, die mir entweder an unübersichtlichen Kreuzungen den Weg wiesen oder am Wegesrand standen, um Motivation zu spenden.

Ein besonderer Dank gilt meiner Betreuerin und Erstgutachterin Sonja Buckel, die durch ihre Gedanken und Anregungen immer wieder neue Impulse geben konnte und nicht nur an einer der besagten Kreuzungen wichtige Orientierungspunkte setze. Nicht weniger gilt dies für das gesamte Promotionskolloquium des Fachgebiets Politische Theorie an der Universität Kassel, das durch sein konstruktives Klima sowie die vielen spannenden Persönlichkeiten und ihren Projekten immer wieder zu neuen, produktiven Gedankengängen beigetragen hat. Stellvertretend für das Kolloquium möchte ich dabei besonders Carol danken, die auch abseits des Kolloquiums immer wieder eine wertvolle Beraterin war.

Als steter Begleiterin durch die kleineren oder größeren Krisen des Forschungsund Schreibprozesses gebührt insbesondere Anki ein großer Dank, die sich über all die Jahre geduldig jedes Problem anhörte, um gemeinsam nach Lösungen zu suchen. Nicht weniger gilt ein solch ganz besonderer Dank auch Tom, der seit nunmehr fünf Jahren mein Leben begleitet und ohne dessen Unterstützung so manche Krise nicht $\mathrm{zu}$ meistern gewesen wäre!

Abschließend möchte ich stellvertretend für alle weiteren Personen, die mich auf dem Weg begleitet haben, Sünje für das Lektorat und ihre permanente Motivationsstiftung, Andreas Eis für seine Bereitschaft, die Zweitbegutachtung zu übernehmen und nicht zuletzt auch Natalia und Ellen danken, die insbesondere auf den letzten Metern mit Rat und Tat zur Seite standen.

$\mathrm{Zu}$ guter Letzt gilt ein besonderer Dank der Friedrich-Ebert-Stiftung, die durch die Zuerkennung eines Promotionsstipendiums überhaupt erst die wirtschaftliche Grundlage für die nötigen Freiräume zur Arbeit an einer Promotion geschaffen hat. 



\section{Der Ausbau der EU-Staatlichkeit in der Euro-Krise}

Als am 20. Oktober 2009 in Luxemburg der Rat der Europäischen Union für Wirtschaft und Finanzen (ECOFIN) zusammentraf, lag die Pleite der US-Investmentbank Lehman Brothers, einer der sichtbarsten Ausdrücke der globalen Finanzkrise, bereits gut ein Jahr zurück. Anzeichen dafür, dass sich die allgemeine Wirtschaftslage wieder verbesserte, veranlasste die Finanzminister*innen sogar dazu, bereits über eine »Ausstiegsstrategie« aus den »zur Bewältigung der Wirtschafts- und Finanzkrise ergriffenen Maßnahmen « (ECOFIN 2009, 2) zu diskutieren und entsprechende Grundsätze für eine solche Strategie dem Europäischen Rat vorzulegen. Dass man sich ein halbes Jahr später wieder in einem akuten Krisenmodus mit ad-hoc-Treffen, Nachtsitzungen und informellen Runden befinden würde, hatte aber wohl zum damaligen Zeitpunkt niemand antizipiert. Bereits am Abend zuvor informierte allerdings der neue griechische Finanzminister seine Amtskolleg*innen der Euro-Gruppe darüber, dass Griechenland die prognostizierten Defizitzahlen im laufenden Jahr nicht werde einhalten können. Statt dem eigentlich nach dem Stabilitäts- und Wachstumspakt (SWP) zulässigen Defizit von $3 \%$ des Bruttoinlandsprodukts (BIP) und dem im bereits gegen Griechenland laufenden Verfahren bei einem übermäßigen Defizit (VÜD) festgelegten Ziel von maximal 3,7\%, das zwischenzeitlich auf $6 \%$ korrigiert wurde, stand im Oktober 2009 gar eine Lücke von 12 bis $13 \%$ zur Diskussion (vgl. FAZ, 21.10.2009).

Der griechischen Ankündigung folgten eine Reihe von negativen Entwicklungen auf den Märkten für staatliche Schuldtitel, in denen sich schließlich im Laufe des Herbsts 2009 und Frühjahrs 2010 nach der transatlantischen Finanz-, der europäischen Bankensowie der realwirtschaftlichen Krise eine erneute, genuin europäische Krise verdichten sollte, die den europäischen Integrationsprozess für annähernd eine Dekade fest bestimmte: Die Euro-Krise war geboren. Erstes Symptom, wenn auch nicht ihre Ursache, dieser noch frischen Krise war, wie im Falle Griechenlands, eine staatliche Refinanzierungskrise, von der eine Reihe weiterer Mitgliedstaaten betroffen war. Die betroffenen Länder konnten ihre Haushaltsdefizite nur noch unter immer stärker steigenden Zinsaufschlägen auf den Finanzmärkten refinanzieren und drohten letztlich in einen Staatsbankrott zu geraten. Schnell sprach man diffamierend von den >PIIGS< (Portugal, Irland, Italien, Griechenland, Spanien) und hatte - in neoklassischer Sichtweise bereits die Krisenursache und die Schuldigen gefunden: die exzessive Fiskalpolitik der 
betroffenen Mitgliedstaaten, die jahrelang ıüber ihre Verhältnisse gelebt hätten` (vgl. van Treeck 2017) und deren Bonität nun aufgrund ihrer angeblich zu hohen Schuldenund Defizitpositionen zwangsläufig von den Finanzmarktakteur*innen neu bewertet werden musste. Marktdisziplin hieß das Schlüsselwort, der die EU-Mitgliedstaaten laut Unionsrecht unterworfen sind und die »Schuldenpartys« (Knipping 2011) abrupt beenden sollte. Dass diese neoklassische Problemperzeption einseitig auf einer fehlgeleiteten Verallgemeinerung des griechischen Falls basierte und weiträumig außer Acht ließ, dass es zuvor zumeist die selben Staaten waren, die in der Finanz- und Bankenkrise Institute retteten und Konjunkturprogramme lancierten, soll an dieser Stelle nur in aller Kürze Erwähnung finden. Die eigentlichen Ursachen für die Refinanzierungskrise sind dabei vor sehr unterschiedlichen länderspezifischen Hintergründen zu betrachten, bleiben aber überdies von einer starken europäischen Dimension gerahmt und bestimmt. In ihr zeigte sich, in einer stärker keynesianisch geprägten Sichtweise, nicht weniger als eine Funktionskrise der Europäischen Wirtschafts- und Währungsunion (EWWU), die durch ihre fehlkonstruierte Institutionalisierung und ihre politische wie ökonomische Programmierung (neoliberale EU-Wirtschaftsverfassung) die Euro-Krise erst ermöglichte (vgl. u.a. Zinn 2013; De Grauwe 2013; Bontrup 2013; Enderlein 2016).

Nachdem sich die politisch Handelnden in der Europäischen Union (EU) dennoch vorerst zurücklehnten und in der sich weiter verschärfenden Krisensituation im Herbst/Winter 2009 die Karte der »mitgliedstaatlichen Eigenverantwortung « und des vertraglich verankerten »No-Bailout-Gebots« (Art. 125 Vertrag über die Arbeitsweise der Europäischen Union [AEUV]) spielten, nahm der Problemdruck im Frühjahr 2010 bedeutend $\mathrm{zu}$. Es war eine bewusste Vorgehensweise der politisch Verantwortlichen - ob Taktik oder Unvermögen sei an dieser Stelle dahingestellt -, die vorerst nicht bereit schienen, europäische Krisenlösungen zu offerieren. Schließlich musste selbst die Brüsseler Politik im Frühjahr 2010 anerkennen, dass die Krisen im Euroraum - die doch längst durch eine europäische Krise überformt waren - nicht allein auf mitgliedstaatlicher Ebene bewältigt werden konnten. Infolgedessen setzte ein europäischer Politikzyklus ein, der durch eine Reihe von ad-hoc-Krisentreffen geprägt war und in dem immer neue, wenn auch vorerst nur kurzfristige oder befristete, Maßnahmen diskutiert und beschlossen wurden, um der Krise zu begegnen.

\section{Ein Jahrzehnt des EU-Staatlichkeitsausbaus}

Langsam, aber immer deutlicher schien man sich in Brüssel der wahren europäischen Dimension der Krise und der gemeinsamen Verantwortung bewusst zu werden. Neben den aktionistisch-wirkenden Maßnahmen der ersten Stunden wurde deshalb bereits im Laufe des Jahres 2010 eine Diskussion über langfristig angelegte Reformmaßnahmen angestoßen, die der EWWU schließlich einen neuen institutionellen Rahmen verleihen sollten. Sie waren Ausgangspunkt für eine »Phase der vielleicht schnellsten Integrationsvertiefung seit der Gründung der Europäischen Gemeinschaften« (Kelemen 2015, 197; Übers. J. G.). Wie es im späteren Bericht der fünf Präsidenten von Europäischer Kommission, Europäischem Rat, Europäischer Zentralbank, Euro-Gruppe und Europäischem Parlament heißt, wurden hierbei »weitreichende Entscheidungen oft sehr schnell getroffen [...], manchmal über Nacht. In einigen Fällen wurden zwi- 
schenstaatliche Lösungen gewählt, um Entscheidungen zu beschleunigen oder Widerstände zu überwinden." (Juncker et al. 2015b, 19) Dass die schon zuvor als defizitär angemahnte demokratische Legitimation der EU (für einen Überblick siehe Schmidt 2010, 399ff.) unter den Vorzeichen einer solch aktionistisch-wirkenden Krisenbewältigungspolitik (>über Nacht<, >Entscheidungen beschleunigen<, >Widerstände überwinden $`$ weiter strapaziert wurde, sei an dieser Stelle nur am Rande bemerkt (vgl. bspw. Solty \& Gill 2013; Bieling, Haas \& Lux 2013, 238; Guérot 2013; Abbas, Förster \& Richter 2015). Nicht nur die Liste der Nachtsitzungen, Verhandlungsmarathons und informellen Abendessen, »die als das Erfolgsgeheimnis der Union erscheinen«, so die Mystifizierung des damaligen Ratspräsidenten Van Rompuy (2011, 6; Übers. J. G.), sondern auch die Liste der Maßnahmen zur Krisenbewältigung wurde länger. Sie reichte, um nur einige und hier insbesondere die frühen Maßnahmen in den Jahren 2010/11 zu benennen, von den sogenannten >Rettungsschirmen über die Reformierung des Stabilitätsund Wachstumspaktes (SWP), die Etablierung eines Verfahrens bei makroökonomischen Ungleichgewichten (MIP; Macroeconomic Imbalance Procedure) bis hin zu einer Neudefinition der Rolle der Europäischen Zentralbank (EZB) in ihrer Funktion als Stabilisatorin der Gemeinschaftswährung. Es werden viele weitere Initiativen, Maßnahmenpakete und Verordnungs- wie Vertragstexte folgen, die ein Jahrzehnt der institutionellen Reformen an der EWWU und der EU im Gesamten anleiten werden. Oder anders ausgedrückt: die ein Jahrzehnt des EU-Staatlichkeitsausbaus begründen.

Die im >Ausnahmezustand der Euro-Krise` (vgl. u.a. Brachthäuser \& Haffner 2017) eingeleiteten Maßnahmen des Staatlichkeitsausbaus, ausgestattet mit einer scheinbaren Krisenlegitimität, transformierten hierbei die Politikmodi, Infrastrukturen, Herrschaftsbeziehungen und Staatlichkeitspraxen in der EU nachhaltig. Qualifizierungen hierfür finden sich zahlreich in der politikwissenschaftlichen Literatur. Über die EuroKrise, die Politik zu ihrer Bewältigung sowie die hieraus resultierenden und antizipierten Folgewirkungen ist insgesamt viel geschrieben und geforscht worden. Eine Systematisierung der gesamten Forschungsdiskussion ist aufgrund der schieren Fülle an Beiträgen herausfordernd (vgl. z.B. Bieling \& Guntrum 2019, 3-5). Wenn man sich vor Augen führt, dass im Laufe der Krise gar der Zusammenbruch der EWWU und mit ihr das Auseinanderbrechen der gesamten EU öffentlich diskutiert wurde, verwundert der Umfang der Forschungstätigkeiten allerdings wenig. Die Euro-Krise wurde zu einer EU-»Existenzkrise« (Schneider 2012, 326; Bieling 2013b, 89; 2019, 294) stilisiert (vgl. u.a. auch Decker 2011, 303; Verdun 2013, 30) und regte insofern geradewegs dazu an, diskursiv zu intervenieren. Letztlich sind Krisen doch schon "per Definition Konstellationen, in denen etablierte Muster gesellschaftlicher Entwicklung erschüttert und infrage gestellt werden«. (Bieling, Jäger \& Ryner 2016, 65; Übers. J. G.) In ihnen werden somit auch die inneren Widersprüche kapitalistischer Reproduktionsregime offensichtlich, weshalb sie »historisch immer wieder Auslöser neuer innerkapitalistischer Entwicklungsmodelle« (Buckel, Fischer-Lescano \& Oberndorfer 2010, 375) und demnach nicht nur reine ökonomische, sondern »zugleich immer auch politische, kulturelle und rechtliche Krisen« (ebd.) gewesen seien. Dies verdeutlichte, wie gezeigt werden soll, auch die Euro-Krise im besonderen Maße.

In der kritischen Europaforschung lassen sich derweil rund um die Euro-Krise unterschiedliche Forschungsstränge identifizieren, deren Umfang ebenfalls unübersicht- 
lich erscheint. Einer dieser Stränge fokussiert dabei insbesondere auf die politischen Wirkungen und sozialen Folgen der Krisenbewältigungspolitik in den sogenannten Programmländern. In ihm findet unter anderem eine (polit-)ökonomische (vgl. z.B. Flassbeck \& Lapavitsas 2015a) und rechtliche (vgl. z.B. Fischer-Lescano 2014; Hoffmann \& Krajewski 2012) Auseinandersetzung mit den Austeritätsprogrammen und dem Austeritätsdiktat der Troika statt, mit denen einschneidende fiskalische Restriktionen (»Haushaltskonsolidierung«), transformative Reformprozesse (»Strukturreformen«) und eine weitere Flexibilisierung der Arbeitsmärkte (»interne Abwertung«) durchgesetzt wurden (vgl. u.a. Evans \& McBride 2017, 8). Auch Untersuchungen aus dem Feld der sozialen Bewegungsforschung haben in diesem Strang einen großen Umfang angenommen (vgl. bspw. Roose 2016). Der Fokus in der deutschsprachigen Diskussion zu den Folgewirkungen der Euro-Krise in den Programmländern liegt dabei häufig auf Griechenland (vgl. z.B. Kritidis 2014) und Spanien (vgl. z.B. Huke 2016). Insgesamt markiert >Austerität`als Untersuchungsgegenstand und zugleich kritisches Diskursfragment in diesem und zwischen den diversen Forschungssträngen der kritischen Europaforschung eine zentrale Verbindungslinie (vgl. u.a. Blyth 2014; Stützle 2014; Krugman 2013).

Weiterhin lassen sich Forschungsaktivitäten beschreiben, die sich mit einzelnen Maßnahmen der Krisenbewältigungspolitik näher auseinandersetzen beziehungsweise einzelne Politikfelder eingehender beleuchten. Häufig steht hier die Lohnpolitik, als ein zentraler Indikator für Abhängigkeitsverhältnisse in einer kapitalistischen Gesellschaftsformation, im Zentrum der Betrachtung (vgl. bspw. Müller, Schulten \& Van Gyes 2016; Bibow \& Flassbeck 2018; Sablowski, Schneider \& Syrovatka 2018). Schulten \& Müller (2013) attestieren beispielhaft in diesem Politikfeld einen »neuen europäischen Interventionismus«, der nicht nur in den Programmländern anzutreffen sei, sondern auch in Form der sogenannten »länderspezifischen Empfehlungen « - als ein in der Euro-Krise gestärktes Herrschaftsinstrument der EU-Staatsapparate (EUSA) - deutlich sichtbar werde. Von einem ähnlichen Standpunkt aus untersucht unter anderem auch das European Trade Union Institute (ETUI) jährlich die sozial- und arbeitsmarktpolitischen Implikationen der an die Mitgliedstaaten adressierten Empfehlungen im Rahmen des EU-Wirtschaftsregierens eingehender (vgl. u.a. Clauwaert 2019; 2018; 2017) und fördert hierdurch den ausgreifenden Charakter der Empfehlungen auch auf Politikbereiche zu Tage, in denen der EU vertraglich eigentlich keine Kompetenz zufällt.

Wichtige Einsichten im Kontext der Krisenbewältigungspolitik und ihrer Wirkung auf die Verfasstheit der EU generierte des Weiteren auch der kritische Rechtsdiskurs, der an vielen Stellen eine implizite Verfassungsbildung beschreibt (vgl. u.a. Joerges 2012; 2013; 2016; Brunkhorst 2014b). Gerade für eine Betrachtung der Euro-Krise unter der Zuschreibung eines Jahrzehnts des EU-Staatlichkeitsausbaus sind die Erkenntnisse und Debatten des juridischen Forschungsstrangs besonders bedeutsam. Insbesondere, wenn man unter Staatlichkeit ein komplexes Ensemble vertraglicher, politischer und zivilgesellschaftlicher Praxen versteht, das entscheidend auch juristisch mediiert wird (vgl. Bourdieu 2017, 574).

Gerade die Zusammenführung der (verfassungs-)rechtlichen Diskussion mit dem überaus bedeutsamen Strang kritischer Europaforschung, in dem die gesellschaftlichen Kräfte- und Hegemonieverhältnisse als Erklärungsvariablen der vollzogenen Krisenbe- 
wältigungspolitik im Zentrum der Forschungsaktivität stehen (vgl. u.a. Buckel et al. 2012; Georgi \& Kannankulam 2015), erscheint dabei besonders fruchtbar. In diesem Forschungsstrang wird die Euro-Krise unter anderem als eine neoliberale Hegemoniekrise beschrieben (vgl. u.a. Oberndorfer $2012 \mathrm{a}$ oder van Apeldoorn 2014), in der letztlich konsensuale Herrschaftsmomente durch Zwang ersetzt worden seien. An dieser Diagnose setzt auch die Beschreibung eines autoritären Etatismus, der in den Maßnahmen der Krisenbewältigungspolitik sichtbar werde, an (vgl. z.B. Kannankulam 2013; 2017; Sandbeck \& Schneider 2013). Dieser materialistische Forschungsstrang speist sich insbesondere aus den Theoriefragmenten Antonio Gramscis (1991-2002) und ist von der neo-gramscianischen Internationalen Politischen Ökonomie inspiriert. Neo-gramscianische Ansätze der Integrations- und Europaforschung fragen speziell

»nach den gesellschaftlichen Kräften sowie den Auseinandersetzungen in der ökonomischen, politisch-institutionellen und ideologischen Sphäre, um die Dynamik und Reproduktion des [...] zunehmend auf transnationalen Kräften und supranationalen Institutionen beruhenden Integrationspfades zu erklären.«(Bohle 2012, 165)

Die gramscianische Theorietradition stellt für diese Arbeit einen außerordentlich wichtigen Referenzpunkt dar, der in der kritischen Europaforschung häufig durch weitere Bezüge zur materialistischen Staatstheorie, unter anderem zu Poulantzas' (2002) Verständnis des `Staats als soziales Verhältnis`, erweitert wird (vgl. Buckel et al. 2014).

\section{Konstitutionalisierungsprozesse und EU-Staatlichkeitsgenese}

Die vorliegende Arbeit greift die soeben beschriebene Theoriediskussion auf und setzt an der Schnittstellte zwischen dem neo-gramscianischen und dem juridischen Forschungsstrang an, indem sie ausgehend hiervon den Versuch unternimmt, die kriseninduzierten Ausbau- und Transformationsprozesse der EU-Staatlichkeit in einen Gesamtzusammenhang der Staatlichkeitsgenese einzuordnen. Mit Hans-Jürgen Bieling $(2011,88)$ könnte man einen solchen Ansatz als »konstitutionalistischen Neogramscianismus« bezeichnen, der ein solches Paradigma wiederum aus den Forschungsaktivitäten Stephen Gills herleitet. Dieser sprach bei den Integrationsdynamiken der 1980er und goer Jahren von einem »neuen Konstitutionalismus«, mit dem erfolgreich ein »disziplinierender Neoliberalismus« in die europäischen Institutionen einzuschreiben versucht worden sei (vgl. Gill 1998). Gill (2000, 41) stellt dabei das Postulat auf, nach dem »jede Theorie der europäischen Integration nur dann vollständig ist, wenn sie die Analyse des Kräfteverhältnisses in einem Kontext platziert, der den Zusammenhang von Vergangenheit, Gegenwart und Zukunft und von globaler, regionaler, nationaler und lokaler Politik umschließt.« Bieling (2013a; 2013b) greift Gills Gedanken im Kontext der Euro-Krise begrifflich als »europäischen Krisenkonstitutionalismus« erneut auf. Durch diesen wird aufzuzeigen versucht, wie sich durch die Krisenbewältigungspolitik gesellschaftliche Kräfteverhältnisse in ein Setting aus staatlichen Institutionen und Normen übersetzen und hierüber eine eigene Materialität erhalten.

Im Sinne dieser Forschungslinien und der entsprechenden Selbstverortung hierin wird forschungsleitend für diese Arbeit ein kriseninduzierter Ausbau der EU-Staatlichkeit angenommen, der sich in veränderten Herrschaftspraxen und gewandelten Herrschaftsbeziehungen innerhalb der EU und ihrem "multiskalaren Staatsapparate- 
Ensemble« (u.a. Buckel et al. 2012) ausdrückt und dabei deutlich hervorstechende Formen einer Interventionsstaatlichkeit annimmt, die durch entsprechende Konstitutionalisierungsprozesse rechtlich abgesichert werden, die wiederum auf Grundlage gesellschaftlicher Kräfteverhältnisse zu beschreiben sind. Die vorliegende Arbeit stellt hierbei eine an vielen Stellen historisch-akzentuierte Arbeit dar, auch wenn sie dabei den Anspruch verfolgt, die derzeitige >Verfasstheit< der EU-Staatlichkeit klären zu helfen. Staatlichkeit, ihre Verfasstheit und ihre Einbettung in die zivilgesellschaftlichen Verarbeitungsformen sind dabei nie statistisch, sondern anhaltenden Veränderungen ausgesetzt, die durch stetige soziale, rechtliche und politische Kämpfe und permanente Aushandlungsprozesse charakterisiert sind (vgl. Gramsci 1991-2002; Poulantzas 2002). Nicht zuletzt deshalb erscheint es notwendig, die langfristigen Wirkungen der EuroKrise vor einem historisch-situierten Kontext zu reflektieren, um retrospektiv einen Gesamteindruck der Ausbau- und Transformationsprozesse gewinnen zu können. Es geht letztlich darum, vom Standpunkt der Staatlichkeit aus ein Fazit unter einer Dekade (Herbst 2009 bis Herbst 2019) des durch die Euro-Krise dominierten Integrationsprozesses in der EU und insbesondere in der Eurozone zu ziehen. Dabei sind die Transformationen und der Ausbau der EU-Staatlichkeit aus den sich vollzogenen Verdichtungsprozessen im EU-Staatlichkeits-Zivilgesellschafts-Komplex im Rahmen einer qualitativen Analyse herauszudestillieren. Einschränkend gilt es dabei darauf hinzuweisen, dass hierbei nicht alle Facetten der Euro-Krise und ihrer Bewältigungspolitik in derselben Tiefe und Breite bearbeitet werden können. Der Fokus in dieser Arbeit wird auf die unionsvertraglich abgesteckte Wirtschafts- und Währungsunion gelegt, wie sie in Titel VII des dritten Teils des Vertrags über die Arbeitsweise der Europäischen Union (AEUV) kodiert ist. Dies soll aber nicht bedeuten, dass nicht auch über diesen Kernbereich hinaus Aspekte, soweit sich relevante gegenseitige Wechselwirkungen ergeben, einbezogen werden. Die Bankenunion stellt in diesem Sinne beispielsweise einen weithin sichtbaren Ausdruck für den EU-Staatlichkeitsausbau dar und findet demnach auch Eingang, kann aber in seiner ganzen Regulationsbreite (insb. das sog. "Single Rulebook«) nicht im selben Maße in dieser Arbeit untersucht werden, wie zum Beispiel die SWP-Reform, das MIP-Verfahren oder die Rettungsschirme. Hinzu kommt, dass die Implementierung der Bankenunion auf Grundlage des Titels I des dritten Teils (»Der Binnenmarkt«) und nicht des Titels VII des dritten Teils des AEUV erfolgte.

\section{Die EU-Staatlichkeit als Forschungsgegenstand}

Indem der Versuch unternommen wird, die Staatlichkeitsgenese der letzten Dekade nachzuzeichnen und zu reflektieren, steht die EU-Staatlichkeit am analytischen Ausgangspunkt und im Zentrum dieser Arbeit. Sie wendet sich damit stärker dem institutionalisierten Herrschaftscharakter der EU zu, ohne dabei in ein reduktionistisches Staatlichkeitsverständnis zu verfallen, wie bereits durch die Selbstverortung im neo-gramscianisischen Theoriediskurs unterstrichen wurde. Grundlage hierfür ist, dass sich die europäische Ebene von Staatlichkeit bereits

»im Verlaufe der 8oer Jahre zur immer wichtigeren politischen Arena [entwickelte], in der zentrale Initiativen geschmiedet wurden und von der direkte und indirekte Im- 
pulse in Richtung post-keynesianischer, post-korporatistischer Staatlichkeit ausgingen und ausgehen, die inzwischen fast alle Bereiche der Staatstätigkeit in Europa erfasst haben«,

so Patrick Ziltener $(1999,2)$. Seine »zentrale staatstheoretische Schlussfolgerung« lautete deshalb bereits im auslaufenden Jahrtausend, »dass eine Analyse der Umbauprozesse von Staatlichkeit in Europa ohne Blick auf die Rolle der europäischen Integration darin unmöglich ist." (Ebd.; Herv. i. O.) Aufgabe einer sich als kritisch verstehenden Europaforschung ist es demnach, die durch die Euro-Krise ausgelösten Transformations- und Ausbauprozesse der EU-Staatlichkeit direkt in den Blick zu nehmen und die sich hierin ausdrückenden Herrschaftsverhältnisse zu analysieren (vgl. van Apeldoorn, Overbeek \& Ryner 2003). Genau ein solches Erkenntnisinteresse liegt dieser Arbeit zugrunde. Durch einen staatstheoretischen Fokus auf europäische Integrationsprozesse können dabei überhaupt erst die aktuellen Veränderungen und hiermit verbundene Verschiebungen der politischen Räume in Gänze erfasst werden (vgl. u.a. Hirsch \& Kannankulam 2009). Die in politikwissenschaftliche Debatten eingebrachten Diagnosen wie beispielsweise Habermas' (2011a) "postdemokratischer Exekutivföderalismus « oder die Diskussionen über die (als notwendig erachtete) Etablierung einer »Europäischen Wirtschaftsregierung«, die letztlich auf einen exekutiven Staatlichkeitsausbau auf suprastaatlicher Ebene abzielen (vgl. bspw. Schneider 2012; Antpöhler 2012; Klatzer \& Schlager 2011; Cremer 2016), verdeutlichen die gebotene Auseinandersetzung mit staatstheoretischen Fragestellungen im Kontext der Euro-Krise zusätzlich. Auch die weitverbreitete und teilweise unreflektierte Verwendung des Terminus der >European Economic Governance ${ }^{1}$ im Kontext der Euro-Krise (vgl. u.a. Oberndorfer 2012a; Konecny 2012; Verdun 2013; Fabbrini 2015; Rittberger 2014 uvm.) offenbart die Notwendigkeit einer staatstheoretischen Einordnung. Die Relevanz staatstheoretischer Reflexionen der EU im Allgemeinen und der Politik zur Bewältigung der Euro-Krise im Besonderen leitet sich letztlich aber auch aus einer Grundkonstante jedweden politischen Handelns ab. So kann analytisch angenommen werden, dass allen konkreten politischen Initiativen und Maßnahmen im- und/oder explizite Staatlichkeitsvorstellungen inhärent sind. Diese Annahme stützt sich auf der zentralen Erkenntnis, dass jede Form von Politik entweder bestehende Herrschaftsstrukturen reproduziert, solche zum Teil restrukturiert, sie neu etabliert oder letztlich gar infragestellt (vgl. u.a. Deppe 2015; Althusser 2010; 2012; Poulantzas 2002).

Im Rahmen dieser Arbeit wird dabei ein theoriebasiertes Verständnis der EUStaatlichkeit entwickelt, das sich den zuvor präsentierten Forschungssträngen kritischer Europaforschung verpflichtet fühlt, dabei aber den Anspruch verfolgt, partiell über sie hinauszugehen und die EU-Staatlichkeit aus vier Blickwinkeln heraus theoretisch zu fundieren. Hierbei steht zu Beginn die Erkenntnis, dass die Genese von Staatlichkeit per se einen langwierigen, permanenten und gesellschaftlich umkämpften Prozess darstellt (vgl. u.a. Bourdieau 2017). In einem solchen Verständnis geht es nicht

Teilweise wird eräquivalent zur»Europäischen Wirtschaftsregierung «bzw. dem französischen Terminus der »gouvernement économique« verwendet. Zugleich wird er an anderer Stelle hingegen explizit in Bezug zum Covernance-Diskurs in der Politikwissenschaft gesetzt, weshalb in diesen Fällen teilweise auch ein ^normativer Mehrwert<impliziert ist (ausführlich s.u.). 
darum, klassische Verfassungsakte (quasi staatliche Gründungsakte) zu betrachten, sondern insbesondere fortwährende Konstitutionalisierungsprozesse darzustellen, durch die sich die EU-Staatlichkeit fortentwickelt. Letztlich ist die EU kein >fertiger Staat<, weist aber Formen und Merkmale von Staatlichkeit auf (vgl. u.a. Bieling \& Große Hüttmann 2016). Dabei ist ein konkreter Ausdruck der Staatlichkeitsgenese bereits die Herrschafts- und Staatlichkeitspraxis der EU, die aufgrund ihrer materiellvertraglichen aber auch verfassungs-realiten Grundlagen wirkt. Verstehen kann man diese Herrschafts- und Staatlichkeitspraxis allerdings nicht ohne ihre zivilgesellschaftliche Einbettung, durch die sie wie zuvor bereits die Genese der Staatlichkeit vor dem Hintergrund von gesellschaftlichen Kräfte- und Hegemonieverhältnissen zu beschreiben sind (vgl. Gramsci 1991-2002). Letztlich verweist der Herrschaftsmodus der Hegemonie auch auf einen weiteren Aspekt, den es in der Analyse von Staatlichkeit $\mathrm{zu}$ adressieren gilt. Hierbei handelt es sich um eine spezifische Organisationsleistung, wie sie sich in einem Staatsprojekt ausdrückt (vgl. u.a. Jessop 2002), mit der die Einheit der Staatlichkeit sichergestellt und ihre doch insgesamt untereinander konkurrierenden Kräfte und Apparate auf ein gemeinsames Telos - also einer konsensual verankerten Ziel- und Zweckbestimmung - verpflichtet werden sollen. Es ist ein solches Staatlichkeitsverständnis, das in dieser Arbeit entwickelt wird und vor dessen Hintergrund die Transformationen und der Ausbau der EU-Staatlichkeit im Kontext der Euro-Krise analysiert und dargestellt werden. Dabei sind die einzelnen Aspekte dieses Verständnisses in der bisherigen Forschung zwar nicht unberücksichtigt, aber soweit bekannt - in dieser Form und in der hier zur Anwendung gebrachten zeitlichen Perspektive noch nicht zusammengeführt worden.

\section{Zum Aufbau der Arbeit}

$\mathrm{Zu}$ Beginn dieser Arbeit wird in Kapitel 2 das zuvor bereits in der gebotenen Kürze skizzierte Staatlichkeitsverständnis näher ausgeführt und die Staatlichkeit der Europäischen Union hierüber $\mathrm{zu}$ fundieren versucht. Hierbei wird im Sinne von EU-Staatlichkeit als Praxis noch einmal expliziert, weshalb es angebracht erscheint, im Kontext der Europäischen Union einen Anwendungsfall von Staatlichkeit zu diagnostizieren. Weiterhin gilt es, im Rahmen des Theoriekapitels ein Krisenverständnis $\mathrm{zu}$ entwickeln, das wiederum in ein produktives Verhältnis zur EU-Staatlichkeit zu stellen ist. Im anschließenden dritten Kapitel werden die theoretischen Überlegungen methodisch zu plausibilisieren versucht. In dieser Arbeit wird dabei eine historischmaterialistische Staatlichkeitsanalyse zur Anwendung gebracht, die zu einem Großteil auf den Vorarbeiten der Forschungsgruppe sStaatsprojekt Europa und ihrer historisch-materialistischen Politikanalyse (HMPA) beruht (vgl. Buckel et al. 2014). Anschließend an die methodologischen Verortungen und die Darstellung des methodischen Vorgehens wird im vierten Kapitel kurz die Staatlichkeitsgenese der EU vor der Euro-Krise resümiert, um hierdurch historische (Dis-)Kontinuitätslinien abbilden $\mathrm{zu}$ können. In Kapitel 5 wiederum wird die Euro-Krise in den Mittelpunkt gestellt und das dieser Arbeit zugrunde liegende Krisenverständnis offengelegt. Im Kern, so die Argumentation, stellt die Euro-Krise hierbei eine politische Krise dar und markiert nicht weniger als eine Funktionskrise der neoliberalen EWWU. Vor dem Einstieg 
in die Darstellung der konkreten Transformations- und Ausbauprozesse der EUStaatlichkeit im Kontext der Euro-Krise wird im sechsten Kapitel auf die Suchprozesse nach einer Krisenbewältigungsstrategie im gesellschaftlichen Kräftefeld eingegangen. Diese mündeten letztlich in drei strategisch-diskursiven Rückeroberungsmomenten neoliberaler Akteur*innen, die infolgedessen den Staatlichkeitsausbau während der Krise maßgeblich prägen sollten. In den Kapiteln 7, 8 und 9 werden schließlich drei Phasen des EU-Staatlichkeitsausbaus im Kontext der Euro-Krise herausgearbeitet und eingehender analysiert. Diese drei Kapitel stellen zusammengenommen das empirische Herzstück dieser Arbeit dar. In ihnen wird der Ausbau der EU-Staatlichkeit in all seinen Dimensionen beleuchtet, wobei zum Schluss - in Kapitel 10 - noch einmal ein Gesamtfazit, insbesondere unter dem Diktum von Staatlichkeit als Projekt, gezogen werden soll. Im Laufe der Arbeit wird sich dabei insgesamt eine Zustandsbeschreibung der EU-Staatlichkeit zusammensetzen, die trotz oder vielleicht gerade wegen der Dekade des kriseninduzierten Staatlichkeitsausbaus im Kontext der Euro-Krise in einem persistenten Zustand verharrt, der von Fragilität, Lethargie und Ansätzen einer tiefwurzelnden Staatlichkeitskrise geprägt ist. 



\section{Die Staatlichkeit der Europäischen Union}

Die Europäische Union als eine Form von Staatlichkeit zu begreifen, erscheint auf den ersten Blick begründungsbedürftig. Hierbei bedarf es einer Reihe theoretischer Reflexionen, insbesondere über den Terminus der Staatlichkeit und seiner Verknüpfung zu dem Arrangement, das uns mit der Europäischen Union entgegentritt. Ich möchte einen solchen Staatlichkeitszugang auf die EU mit Rückgriff auf Theorieansätze kritischer Sozial- und Gesellschaftswissenschaft begründen. Hierdurch soll verständlich gemacht werden, warum es angemessen erscheint, die EU als eine Form von Staatlichkeit aufzufassen, und dargelegt werden, wie sie eingebunden ist in ein komplexes Geflecht

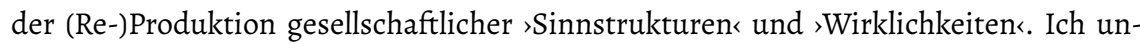
ternehme diesen Verständnisversuch anhand vierer Blickwinkel und begreife die EUStaatlichkeit dabei als Praxis, als Prozess, als Verhältnis und als Projekt. In einem ersten Schritt (Kapitel 2.1) geht es um konkrete Erscheinungsformen der EU-Staatlichkeit, also um Staatlichkeit als Ausdruck gesellschaftlicher und sozialer Praxen, die sich durch eine netzwerkartige Struktur miteinander verflochtener (genuin europäischer und mitgliedstaatlicher) Staatsapparaten ausdrückt. In einem zweiten Schritt (Kapitel 2.2) soll der Prozesscharakter der EU-Staatlichkeit näher beleuchtet werden. Die Genese von Staatlichkeit beruht demgemäß auf einem Konzentrations- und Monopolisierungsprozess, wie er für den >modernen Staat herausgearbeitet wurde. Anschließend hieran (Kapitel 2.3) soll ein Staatlichkeitsverständnis entwickelt werden, das die durch die EU und ihre Staatlichkeit vermittelten Herrschaftspraxen in ihre gesamtgesellschaftliche Totalität einbettet. Staatlichkeit als soziales Verhältnis zu begreifen, verweist auf eine zentrale Herrschaftskategorie, die sich im Begriff der Hegemonie verdichtet. Schließlich geht es dabei um die wesentliche Frage, welche Akteur*innen sich in die Materialität der EU-Staatlichkeit einschreiben können; oder anders gesagt: in wessen Namen Herrschaft im Rahmen der Staatlichkeit ausgeübt wird. Nicht die Verselbstständigung von Staatlichkeit, sondern ihre Rückgebundenheit an die (zivil-)gesellschaftlichen Strukturen stehen dabei im Zentrum. Eng verknüpft ist eine solche Perspektive schließlich mit der Beschreibung der EU-Staatlichkeit als Projekt (Kapitel 2.4). Der Projektcharakter von Staatlichkeit speist sich dabei aus der notwendigen Herstellung einer imaginierten Einheit der Staatlichkeit. Eng verknüpft ist dieser Herstellungsprozess mit der Verallgemeinerung partikularer Interessen, die im Kontext der gesellschaftlichen Kämpfe 
um Hegemonie in Form des Staatsprojekts der Staatlichkeit eine Art Telos einschreibt. An diesen Versuch, die Staatlichkeit der Europäischen Union theoretisch zu fundieren, schließt sich in einem weiteren Schritt die Darstellung eines theoriebasierten Krisenverständnisses an, das es ermöglicht, die Euro-Krise in ihrem Kern als eine politische Krise zu begreifen und sie somit in einen direkten (Re-)Produktionszusammenhang zur EU-Staatlichkeit zu stellen (Kapitel 2.6).

\section{1 Über die Staatlichkeitspraxis des EU-»Staatsapparate-Ensembles“}

Die Europäische Union ist mehr als ein Staatenbund oder eine internationale Organisation, aber doch auch kein Staat nach klassischem Vorbild ihrer Mitgliedstaaten. Sie konzeptionell zu fassen, ist seit Jahren Ausgangspunkt für verschiedene Begriffsbestimmungen und mündet oft in der Zuschreibung, dass die EU ein »System >besonderer Art « (Kohler-Koch, Conzelmann \& Knodt 2004, 130) sei. Eine solche Chiffre offenbart allerdings lediglich, dass es vielen schwerfällt die EU begrifflich zu fassen, denn »wo die vertrauten Begriffe versagen, hilft sich der Jurist mit der Qualifikation als Sache sui generis«, wie Isensee $(2009,255$, Herv. i. O.) es trefflich fasst. Der sui-generis-Begriff beschreibt demnach lediglich »den Charme des Unfertigen« (ebd.) und bleibt dabei so vage, dass er alles und nichts definiert (vgl. Puntscher Riekmann 2004, 12). Zugleich verengt er durch den Schleier der angeblichen Einzigartigkeit die analytische Auseinandersetzung mit der EU und dem europäischen Integrationsprozess, welche bei genauer Betrachtung durchaus mit vorhandenen Begrifflichkeiten beschreibbar gemacht werden können oder mit anderweitigen historischen Entwicklungen vergleichbar sind (vgl. bspw. Mann 2009; Schönberger 2010; Lequesne 2016) und somit nicht zwangsläufig eine gänzlich reigene Art - soweit politische Prozesse aufgrund ihrer historischen Situiertheit immer Eigenartigkeiten aufweisen - besitzt:

»Being a hybrid polity does not mean that this polity cannot be compared to other existing models. There is a huge difference between underlying this hybridisation and stressing the so-called sui generis nature of the EU. The latter does not make sense, as all polities can be regarded as sui generis. «(Lequesne 2016, 45)

Die sui-generis-Chiffre ist also nicht mehr als eine »begriffliche Bankrotterklärung« (Möllers 2008, 88) oder eine »Verlegenheitslösung« (Bieling \& Große Hüttmann 2016,

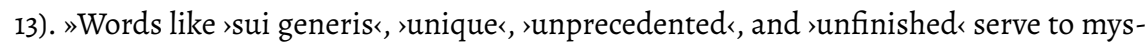
tify the EU rather than enabling serious analysis. (Shore 2006, 717; Herv. i. O.). Denn schließlich seien die »sui-generis Formeln [...] hauptsächlich damit beschäftigt, die Europäische Union durch das zu definieren, was sie nicht ist: eben kein Staat.« (Schönberger 2010, 88) Dass die EU nicht als Staat zu bezeichnen ist, bleibt eine richtige Erkenntnis, die es aber zugleich mit den Mechanismen staatlicher Herrschaftsausübung zu kontrastieren gilt. Tut man dies, kommt man schnell zu der Einsicht, dass keine Zweifel bestehen, »dass die EU ein staatsähnliches Gebilde ist.« (Börzel 2013, 3) Börzel führt weiter aus, dass die EU weniger einzigartig sei, als es die wissenschaftliche Auseinandersetzung häufig glauben machen wolle, und schlägt daher vor, »dass sich das Konzept der Staatlichkeit in hervorragender Weise eignet, das Wesen der EU als 
Herrschaftsordnung freizulegen, ohne sie zum Wesen eigener Art zu erklären.« (Ebd.) Sie argumentiert, dass die EU in den Bereichen, in denen sie hoheitliche Aufgaben wahrnimmt, diese hierarchisch organisiert und trotz fehlenden (physischen) Gewaltmonopols »aufgrund des Vorrangs und der unmittelbaren Anwendbarkeit europarechtlicher Normen in den vergemeinschafteten Bereichen auf rechtlichen Zwang rekurrieren kann.« (Ebd., 9) Eine ähnliche Diagnose lässt sich bereits in den 9oer Jahren bei Wessels $(1992,36)$ finden, der »eine beträchtliche Ausdehnung bei der Wahrnehmung traditioneller und neuer staatlicher Aufgaben« durch die EU konstatiert, »die sich in der sektoriellen Breite [...] denen der westeuropäischen Staaten annähert.« Das Zusammendenken von Staat, Staatlichkeit und europäischer Integration ist daher keine neue Herangehensweise, weist aber im Besonderen auf das Herrschaftsmoment (vgl. u.a. van Apeldorn, Overbeeck \& Ryner 2003, 17) - die Ausübung von Herrschaft durch die und im Rahmen der suprastaatliche(n) EU (vgl. bspw. auch Zürn 2011, 618) - hin, die insbesondere mit Rückgriff auf Ansätze kritischer Staatstheorie unter dem Label >Europäische Staatlichkeit< (vgl. u.a. Bieling 2018) oder konkreter als EU-Staatlichkeit gefasst und der politikwissenschaftlichen Analyse zugänglich gemacht werden kann.

Seit Mitte der 8oer Jahre kann dabei von einer sukzessiven Herausbildung einer supranationalen Staatlichkeit auf europäischer Ebene gesprochen werden (vgl. Bieling 2001a, 27). So hat Ziltener $(1999,198)$ den Integrationsschub der 8oer und 9oer Jahre als »Staatsbildung〈 im Sinne der weiteren Ausdifferenzierung eines europäischen politischen Mehrebenensystems« interpretiert, bei der »die Bedeutung europäischer Instanzen und Verfahren [...] zu[nahm] « und Genschel \& Jachtenfuchs $(2015,1)$ sprechen von einer >Integration in Kernbereichen staatlicher Hoheitsaufgaben $\triangleleft$ »By this we mean the increasing involvement of EU institutions in key functions of sovereign government including money and fiscal affairs, defense and foreign policy, migration, citizenship, and internal security.« (Ebd.; vgl. dies. 2014, 2018) Ergebnis ist, dass der Europäischen Union heute eine Reihe vertraglich fixierter Kompetenzen zufällt, die man zugleich als »staatliche Kernaufgaben« oder »klassische Staatsaufgaben« kennzeichnen kann (Bieling \& Große Hüttmann 2016, 12; vgl. auch Benz 2001, 277; Bieling \& Lerch 2012, 9). Die Reichweite und Intensität der EU-Staatlichkeit und die Rolle ihrer Institutionen bei der Rechtsetzung und dem Exekutieren des gesetzten Rechts (vgl. Curtin 2014, 1) lassen die Beschreibung $\mathrm{zu}$, nach der sich jenseits des (National-)Staates zentrale Elemente von Staatlichkeit etabliert haben (vgl. Nullmeier 2013, 39). Dies kann als Ausdruck einer transformierten und sich weiter transformierenden Nationalstaatlichkeit im Sinne Leibfrieds \& Zürns $(2006,41)$ interpretiert werden, die von einer »Zerfaserung klassischer Staatlichkeit« sprechen. Wie der `klassische Staat` muss dabei auch Staatlichkeit - im allgemeinen Sinne - als »autonome Sphäre der Praxis in einem integralen Ganzen, der kapitalistischen Produktionsweise« (Demirović, Hirsch \& Jessop 2002, 8; Herv. J. G.), begriffen werden. Dabei gilt für die EU: Auch wenn sie zur Durchsetzung der von ihr herbeigeführten Entscheidungen und Regelungen in einem hohen Maße auf die Mitgliedstaaten mit ihren Apparaten angewiesen ist, die ihre Staatlichkeit absichern (vgl. Börzel 2013, 9; Bieling 2006, 236; Ziltener 1999, 22ff.), werden doch beispielsweise Legislativmaßnahmen auf Unionsebene beschlossen, die entweder direkte Wirkungsmacht entfalten (Verordnungen) oder ziemlich geräuschlos in mitgliedstaatliches Recht überführt werden (Richtlinien) und teilweise sogar zu einer Erweiterung 
europäischer Regulierungskompetenzen (ultra-vires-Rechtsakte) führen. Weiterhin legen beispielsweise mitgliedstaatliche Gerichte dem Europäischen Gerichtshof (EuGH) Rechtssprechungsakte zur Entscheidung vor, die anschließend in die mitgliedstaatliche Rechtsprechung übernommen werden. Eine ganze integrationstheoretische Schule befasst sich mit dieser juristischen Seite der europäischen Integration (vgl. Haltern 2012). In der EU hat sich eine "spezifische transnationale Teilrechtsordnung" (Bieling 2006, 236 in Rückgriff auf Buckel 2003a \& 2003b) herausgebildet, die sogar den Rechtsvorrang des Unions- vor mitgliedstaatlichem Recht anerkennt (vgl. auch Buckel 2013, 29ff.). Dabei habe sich eine »kooperative Rechtspraxis« zwischen EuGH und mitgliedstaatlichen Gerichten entwickelt und »derart verfestigt, dass die Frage des fehlenden Gewaltmonopols de facto suspendiert ist «, so Buckel (2003a, 188). Das Europarecht ist $\mathrm{zu}$ einem »eigenständige[n] Ort rechtsförmiger Hegemonieproduktion« (Oberndorfer 2010, 108; Herv. i. O.) geworden. Puntscher Riekmann (2004, 13; Übers. J. G.) kommt zu der zutreffenden Diagnose, dass »der Vorrang des Europarechts und die Macht des Europäischen Gerichtshofs die vielleicht sichtbarsten Kennzeichen einer Europäischen Staatlichkeit sind.« Mit Schuppert (2015, 41; vgl. 2014) kann man vor diesem Hintergrund demgemäß bei der EU von einem Anwendungsfall »verflochtener Staatlichkeit« sprechen. Es scheint geradezu geboten, will man die politischen Prozesse innerhalb der Europäischen Union analysieren und die europäischen Herrschaftspraxen verstehen, die EU als eine Form von Staatlichkeit zu begreifen, deren Staatsapparate mit denen der mitgliedstaatlichen Ebene aufs Engste verwoben sind, und die sich durch »[d]ie permanente Wiederholung und Reproduktion routinisierter Praxis« (Buckel et al. 2014, 33) zu einer gesellschaftlichen Struktur verstetigt. Eine solche - im Moment noch - diffusanmutende Form von Supra-Staatlichkeit, die zudem in einigen Bereichen durch informelle Züge geprägt ist (vgl. Altvater \& Mahnkopf 2007, 87f.), bleibt schwer zu greifen, weshalb sie von einigen eher negiert wird, statt sie als solche zu benennen.

Die EU als eine Form von Staatlichkeit aufzufassen, führt zu einer Reihe von Auseinandersetzungen mit den tradierten Staatstheorien. Sie sind zwar einerseits notwendigerweise heranzuziehen, um ein umfassendes Verständnis der Staatlichkeits- und Herrschaftspraxen der EU zu gewinnen, andererseits versperren sie sich aber häufig durch ihren bisweilen starren Fokus auf eine »nationale[n] Konfiguration von Staatlichkeit im Goldenen Zeitalter« (Leibfried \& Zürn 2006, 23) den Blick für Prozesse der Exekutierung institutionalisierter Macht- und Herrschaftsverhältnisse jenseits des selbstreferentiellen Referenzpunktes des Nationalstaates. So wies bereits 1975 Gerda Zellentin (1975, 215; Herv. J. G.) darauf hin, dass

» [j] me hr der europäische Integrationsprozeß [...] fortschreitet und die Interessen verschiedener nationaler und transnationaler Produzentengruppen berührt, desto größer wird das Bedürfnis, die Kriterien und Mechanismen der Steuerung dieses Vorgangs, die dabei auftretenden Veränderungen des Staatsapparats und seiner Funktionen sowie die Beziehungen zwischen den staatlichen und überstaatlichen Bürokratien und privaten Unternehmen zu erkennen.«

Entsprechend braucht es die Weitung des Verständnisses, nach dem sich Staatlichkeit lediglich in festen und tradierten Ordnungsmustern - also dem historischen Anwendungsfall des Nationalstaates - denken ließe (aus globalgeschichtlicher Perspektive vgl. 
bspw. Plaßmann 2017). Anders formuliert lässt sich sagen, dass der Nationalstaat des 20. Jahrhunderts lediglich ein historischer, wenn auch bis heute prägender, Kulminationspunkt der Institutionalisierung von Staatlichkeit und der mit ihr verbundenen Herrschaftsfunktionen darstellte. Dieses Bild, verstärkt durch die gängigen Staatsdefinitionen, die sich größtenteils vor knapp hundert Jahren herausgebildet haben (vgl. Nullmeier 2009, 37), prägt allerdings weiterhin die staatswissenschaftliche Diskussion. Schuppert $(2010,128)$ spricht insofern zurecht von einer »theoretischen Verengung « und Ellwein (1992) von einer »Verständnisbarriere«, die durch den klassischen Staatsbegriff entstehe. Schuppert $(2010,128)$ schlägt daher vor,

»dass man Staat und Staatlichkeit nicht synonym verwenden sollte, sondern dass mit der Verwendung des Begriffs der Staatlichkeit auch Gebilde erfasst werden können [...], die im Rechtssinne keine Staaten sind oder aber nur teilweise oder defizitär das erfüllen, was wir normalerweise mit dem Staatsbegriff verbinden«.

Wird bei der EU in diesem Sinne von Staatlichkeit gesprochen, impliziert dies nicht zwangsläufig die Existenz eines reuropäischen (Bundes-)Staates $<$. Bezugnehmend auf Kategorien klassischer Staatstheorien, wie beispielsweise von Max Webers (2008, 39), kann die EU für sich genommen eben nicht das »Monopol legitimen physischen Zwanges für die Durchführung der Ordnungen in Anspruch« nehmen und stellt damit auch in Jellineks (1905) Drei-Elemente-Lehre (Trias Staatsvolk - Staatsgebiet - Staatsgewalt) keinen Staat dar. Auch wenn Hennis $(1965,431)$ bereits zu Beginn der staatswissenschaftlichen Diskussion der bundesrepublikanischen Politikwissenschaft in den 6oer Jahren darauf verwies, dass »eine realistische Regierungslehre [...] mit dem autoritären Wahn aufzuräumen [hätte], mit der Vorstellung nämlich, man könne den Staat vom Monopol der legitimen Gewaltsamkeit her verstehen« (vgl. auch Shore 2006, 713), stellt doch gerade das staatliche Gewaltmonopol (im Sinne physischer Gewaltsamkeit) als eine Art Letztbegründung bis heute einen dominanten Bezugsrahmen dar und definiert aus sich heraus, was als Staat(lichkeit) zu gelten habe.

\section{Internationalisierung des Staates und das staatliche Gewaltmonopol}

Laut Joachim Hirsch (2005), der aus Perspektive materialistischer Staatstheorie argumentiert, sieht sich der Nationalstaat bereits seit geraumer Zeit mit der Herausforderung seiner Internationalisierung konfrontiert. Er extrahiert diese aus einer politökonomischen Betrachtung ökonomischer Globalisierungsprozesse, die sich unter anderem in einer verstärkten Abhängigkeit nationaler Staatsapparate von internationalen Finanz- und Kapitalmärkten widerspiegele (vgl. ebd., 145ff.). Hirsch verweist auf zwei grundsätzliche Überlegungen, die die Internationalisierung des Nationalstaates beschreiben: So lasse sich eine räumlich-soziale Diversifizierung staatlicher Ebenen und Funktionen beobachten, die allerdings rückgebunden bleibe an die Zentralität des Nationalstaates für die Herausbildung von Staat und Staatlichkeit (vgl. ebd., 145). Nach Hirsch $(2005,151 ; 153)$ bilde sich dabei im Prozess der Internationalisierung eine neue Raummatrix des Politischen heraus. Mit Wissel $(2007,15)$ kann man argumentieren, dass hierbei mittlerweile auch ein »transnationales Feld entstanden [ist], das mehr ist als die Summe der Nationalstaaten, die auf internationaler Ebene agieren. "Von Transnationalisierung lässt sich dann sprechen, wenn damit "gesellschaftliche Phänomene 
als Ganzes gemeint sind, d.h. ökonomische, politische, soziale, kulturelle, technische und ökologische Aspekte des sozialen Lebens insgesamt.«(Pries 2010, 16) Wird demnach von Transnationalisierung gesprochen, impliziert dies zugleich auch die Herausbildung spezifischer sozialer Akteurs- und Interessenkonstellationen, die als Triebkräfte innerhalb der von Hirsch beschriebenen >neuen Raummatrix des Politischen wirken. Die Raummatrix sei dabei durch ein komplexes, wenngleich relativ inkohärentes Regulationsnetzwerk gekennzeichnet, was Hirsch $(2005,153)$ insbesondere mit dem Fehlen eines zentralisierten Gewaltapparats auf globaler Ebene begründet. Dass sich ein solcher Gewaltapparat international nicht herausbilde, liege wiederum in der strukturellen Logik kapitalistischer Staatlichkeit begründet, so jedenfalls Hirsch (2002, 133; Herv. J. G.): »Das staatliche >Gewaltmonopok verschwindet [...] keinesfalls allgemein und kann dies auch nicht, solange die Reproduktion und Regulation der kapitalistischen Klassenbeziehungen darauf beruht.«

$\mathrm{Ob}$ die theoretische Herleitung von Staat und Staatlichkeit auf Grundlage des staatlichen Gewaltmonopols allerdings aufrechterhalten werden kann, ist, wie ColliotThélène $(2016,47)$ sagt, unter den Bedingungen der Internationalisierung, Transnationalisierung und Europäisierung »einer neuen Prüfung bedürftig«. Grundsätzlich bleibt dabei zu konstatieren, dass »das Kapitalverhältnis als Herrschaftsverhältnis immer auch der Absicherung durch Gewalt [bedarf] - was die Staatsgewalt in einzigartiger >Legitimität auch zu leisten vermag.«(Wolf 2012, 373) Zugleich weist Wolf aber mit seiner weiterführenden Frage »nach der Art und Weise« des auf der Staatsgewalt basierenden Interventionismus konkret auf das »Verhältnis von repressiven, d.h. Unterwerfung erzwingenden, zu ideologischen, d.h. zur Unterwerfung überzeugenden, Momenten « (ebd.) hin. Er beschreibt damit eine Wirkungszusammenhang von Staatlichkeit und Gewaltmonopol, der bereits auf den später noch genauer darzulegenden Hegemoniebegriff Gramscis abzielt. Wolfs Hinweis verdeutlicht, dass die Gewaltsamkeit des Staates sich nicht ausschließlich auf die repressive Anwendung von Gewalt beschränken lässt, sondern vielmehr auch durch andere Formen (Ideologie \& Hegemonie) wirkt und nah an dem ist, was Bourdieu (2017) schließlich als Komplementär zum repressiven Gewaltmonopol als Monopol symbolischer Gewalt bezeichnen würde (s.u.). Bleiben wir aber zunächst bei der Bestimmung der repressiven Gewaltsamkeit von Staatlichkeit, die im allgemeinen Sinne oder jedenfalls im Anschluss an Weber (2008), der in diesem Zusammenhang von »physischer Gewalt« spricht, unter »Gewaltmonopol« verstanden wird. In der deutschen Politikwissenschaft wird wie bei Hirsch vorrangig die Auffassung vertreten, dass es außerhalb des einzelnen Staates kein Gewaltmonopol gebe (vgl. Jachtenfuchs 2006, 70), zumal in absehbarer Zeit eine umfangreichere Internationalisierung oder Europäisierung der beiden Kernbereiche repressiver Gewaltsamkeit (Militär und Polizei) als unrealistisch abgetan werden. ${ }^{1}$ "Daraus zu schließen, daß sich Staatlichkeit zwar generell wandelt, beim Gewaltmonopol - und damit beim Kern des Staates - aber alles beim alten bleibt, wäre jedoch voreilig«, so Jachtenfuchs $(2006,71)$. Grundproblem stellt für ihn die kategoriale Verengung des Gewaltmonopols auf ein

1 Für aktuelle Bemühungen in der EU siehe PESCO (Permanent Structured Cooperation), mit der eine Intensivierung der militärischen Zusammenarbeit forciert wird. 
vollständiges Vorhandensein oder einer vollständigen Abwesenheit im Staate dar. Hierdurch könnten wichtige Veränderungen nicht wahrgenommen werden: »Diese geraten nur in den Blick, wenn man Zwischenstufen annimmt, bei denen das Gewaltmonopol in internationale Institutionen eingebettet, aber nicht vollständig an sie übergegangen ist.« (Ebd., 81) Als Beispiele für solche Zwischenstufen benennt er auf militärischer Ebene die Strukturen der NATO (vgl. auch Brand 2009b, 233) und im polizeilichen Bereich die Kooperationsformen innerhalb der EU (Europol, Europäischer Haftbefehl usw.). Allerdings

»[gehen d]ie von den europäischen Institutionen in Anspruch genommenen Befugnisse und Kompetenzen [...] nicht automatisch den Mitgliedstaaten verloren. Vielmehr bettet die EU das mitgliedstaatliche Cewaltmonopol in ein immer dichteres und verpflichtenderes Geflecht von Institutionen ein.« (Jachtenfuchs 2006, 86)

So kommt Jachtenfuchs $(2006,89)$ zu zwei zentralen Schlussfolgerungen: Zum einen werde das Gewaltmonopol zwar nicht an internationale/europäische Institutionen delegiert, zum anderen werde es aber soweit in ein Institutionengeflecht eingebettet, in dessen Folge innerhalb der EU »das Gewaltmonopol teilweise von den Staaten gemeinsam [...] und nicht mehr wie früher vollständig in alleiniger staatlicher Autonomie [ausgeübt wird].«(Vgl. u.a. auch Wissel 2007, 143) Unklar bleibt bei einer solchen Beschreibung jedoch die genaue Funktionsweise, obwohl Jachtenfuchs $(2006,71) \mathrm{zu}$ Beginn seiner Ausführungen eine interessante Unterscheidung vornimmt, indem er zwischen dem faktischen Gebrauch der Gewaltmittel und der Legitimation ihres Einsatzes unterscheidet. Wenn man diesen Gedanken fortführt, lässt sich das Gewaltmonopol definieren als die Verfügung über die spezifischen Mittel der Gewaltsamkeit einerseits und der legitimen Anwendung dieser Mittel durch staatliche Apparate andererseits. In Bezug auf die EU lässt sich vor diesem Hintergrund festhalten, dass die Mitgliedstaaten weiterhin über das Monopol der Gewaltmittel verfügen, da die genuinen EUStaatsapparate (EUSA) ihrerseits davon abhängig sind, dass sie ihnen entsprechende Ressourcen für bestimmte Zwecke überlassen (s. FRONTEX im Bereich der Grenzsicherung). Die EU selbst verfügt über keine eigenen Gewaltmittel, auch wenn europäische Akteur*innen seit geraumer Zeit darauf bedacht sind, diesen Zustand zu überwinden (vgl. Buckel 2018).

Anders gestaltet es sich hingegen bei der Ausübung von Gewalt. Durch die Einbettung der mitgliedstaatlichen Apparate in die europäischen Netzwerkstrukturen aus Apparaten und Institutionen wird die Anwendbarkeit von Gewalt zum Teil gemeinsam definiert und somit im Rahmen der EU-Staatlichkeit ausgeübt. Diese Unterscheidung verdeutlicht, dass der Begriff des Monopols für die Zuschreibung staatlicher Gewaltsamkeit irreführend sein kann. Allenfalls kann es sich auf ein Monopol der Gewaltmittel beziehen, aber nicht auf ein Monopol der Gewaltanwendung, welche im Falle der EU durch rechtliche und justizierbare Normsetzungen auch durch die suprastaatliche Ebene ausgeübt wird. So urteilt beispielsweise McNamara (2018, 1516): »[P]olitical Authority in the EU has become transnational.« Übersehen werden darf hierbei gewiss nicht - und so soll der oben angeführte Einwand von Hirsch verstanden werden -, dass die Mitgliedstaaten weiterhin Möglichkeiten haben, auch die Bereiche der vergemeinschafteten Gewaltausübung wieder an sich zu ziehen, indem sie sich zum Beispiel 
Opt-Out-Klauseln sichern oder, wie im Falle des Vereinigten Königreichs, den Weg eines EU-Austritts wählen. Die EU (in diesem Falle als rein suprastaatliche Ebene betrachtet) kann ihrerseits solche Maßnahmen nicht durch den Einsatz von Gewaltmitteln verhindern. Insofern bleibt die Gewaltsamkeit der Europäischen Union (im Ganzen) prekär und das mitgliedstaatliche "Gewaltmonopol (im engen Weberschen Sinne der physischen Gewaltsamkeit) als Letztbegründung auch für die EU-Staatlichkeit bestehen, wenngleich es, wie deutlich werden sollte, Transformationsprozessen ausgesetzt ist, die den Monopolcharakter fortwährend in Frage stellen.

\section{Verdichtung zweiter Ordnung und das EU-Staatsapparate-Ensemble}

Wie die Auseinandersetzung mit dem Gewaltmonopol zeigt, bleiben die Ebenen der Mitglieds- und ihrer Teilstaaten praktisch wie staatstheoretisch nicht unberührt, wenn die Ausbildung einer EU-Staatlichkeit konstatiert wird. Hierauf wies bereits der Terminus der »verflochtenen« oder »verwobenen« Staatlichkeit hin. Brand, Görg \& Wissen (2007, 228f.) haben vor dem Hintergrund der Internationalisierung des Nationalstaates das Konzept der Verdichtung zweiter Ordnung entwickelt, das auch für die Analyse von EU-Staatlichkeit nützlich erscheint:

»Weit davon entfernt, ein notwendigerweise lineares bzw. hierarchisches Verhältnis zwischen verschiedenen räumlichen Maßstabsebenen zu bezeichnen, steht der Begriff der Verdichtung zweiter Ordnung [...] für ein komplexes Verhältnis von Verdichtungen über mehrere Maßstabsebenen hinweg. Die starre Dichotomie zwischen nationalen und internationalen Prozessen (wie auch subnationalen) wird dadurch überwunden, ohne dabei [...] Gefahr zu laufen, die Zentralität des Nationalstaates [...] für die Bearbeitung gesellschaftlicher Widersprüche aus den Augen zu verlieren.«

Hieraus ergibt sich, dass es voreilig wäre, davon auszugehen, die Mitgliedstaaten müssten durch die Ausbildung der EU-Staatlichkeit lediglich eigene politische Handlungsmöglichkeiten einbüßen. Vielmehr bleibt die EU-Staatlichkeit an die Mitgliedstaaten rückgebunden (vgl. Müller 2009). Nach Bieling (2007, 147) sei »die Annahme, gemäß derer die nationalen Staats-Zivilgesellschafts-Komplexe durch die ökonomische Globalisierung und internationale Regulierungsvorgaben pauschal geschwächt und beeinträchtigt werden« mit Vorsicht zu betrachten. Vielmehr verhielten sich »die (zivil-)gesellschaftlichen Reorganisationsprozesse, (national-)staatlichen Regulationsformen und internationalen Arrangements [...] vielfach komplementär zueinander, stützen sich also [...] durchaus wechselseitig ab.« (Ebd.) Durch die verflochtene und multiskalar verdichtete EU-Staatlichkeit entsteht aber zugleich auch eine neue Unübersichtlichkeit, die bei den Suchprozessen nach den Triebkräften der Staatlichkeitspraxen und die hiermit verbundene Herrschaftsausübung auf den unterschiedlichen Maßstabsebenen (»scales«) von Staatlichkeit und zwischen verschiedenen Räumen beziehungsweise Settings der politischen Auseinandersetzung und Entscheidungsfindung (»forums«) in der EU einzubeziehen ist. Dabei können die >scales und >forums im Sinne eines »forum-shiftings « oder »scale-jumpings (vgl. u.a. Brand, Görg \& Wissen 2007, 41) selbst wiederum zum strategischen Gegenstand von Metagovernanceprozessen (s.u.) politischer Akteur*innen werden. 
Für die zuvor angedeuteten Verdichtungsleistungen im Kontext der EU-Staatlichkeit lässt sich im Anschluss an die >Forschungsgruppe Staatsprojekt Europa< der eingängige Begriff des »multiskalaren Staatsapparate-Ensembles« (u.a. Buckel 2017, 36) heranziehen. $\mathrm{Zu}$ einem solchen Ensemble von Staatsapparaten, verstanden als ein "politisch apparatives Netzwerk« (Wissel 2015, 11), zählen genuine EU-Staatsapparate, wie die Kommission oder die EZB, zugleich sind in das Ensemble aber auch mitgliedstaatliche Staatsapparate eingeflochten und weiterhin können - je nach Politikfeld -internationale (wie der Internationale Währungsfonds (IWF) im Fall der Euro-Krise) oder transnationale Apparate (wie bspw. der Europäische Gerichtshof für Menschenrechte (EGMR)) Bestandteil des Ensembles sein (vgl. ebd., 27). Innerhalb eines solchen Ensembles bildet sich eine neue Hierarchie zwischen unterschiedlichen Apparaten und Institutionen heraus (vgl. Buckel et al. 2012, 14), die eine skalare Staatlichkeitsstruktur beschreibt, dabei aber je nach Politikfeld gewisse Variationen aufweisen kann. Die Übersetzung der EU-Staatlichkeit in ein multiskalares Ensemble von Staatsapparaten weist dabei gewisse Ähnlichkeiten zum in der Politikwissenschaft mittlerweile stark vertretenen Multi-Level-Governance-Ansatz (MLG) (vgl. u.a. Marks, Hooghe \& Blank 1996; Knodt \& Große Hüttmann 2012) auf, der seit den 9oer Jahren einen wichtigen Qualitätssprung im Feld der europäischen Integrationstheorien markiert: weg von der Beschreibung der »Integration als Prozess«, hin zur Beschreibung der »Integration als Zustand « (Bieling \& Lerch 2012, 12). Allerdings wird durch die Beschreibung als Staatsapparate-Ensemble - im Unterschied zum häufig normativ geprägten Governance-Begriff (ausführlich s.u.) - die Herrschaftsausübung stärker in den Mittelpunkt gestellt. Das Ensemble stützt sich hierbei auf die bereits angeführte »spezifische transnationale Teilrechtsordnung« (Bieling 2006; vgl. Buckel 2003a; 2003b). Dabei besteht

»die rechtliche Gesamtverfassung dieses Ensembles [...] in Form einer Verfahrensordnung sowie einer rechtlichen Programmierung der Apparate, das heißt ihrer Bindung an die Cesetze, die gerichtlich auf der Crundlage subjektiver Rechte der ihnen Unterworfenen überprüft und erzwungen werden kann.«(Buckel 2013, 41)

Das EU-Staatsapparate-Ensemble stellt insofern eine konkrete Ausdrucks- und Erscheinungsform materialisierter EU-Staatlichkeit dar, durch die sie wirkt und durch die in der Praxis Herrschaft exekutiert wird. Staatlichkeit umschreibt in diesem Sinne folglich einen institutionalisierten Modus der Herrschaftsausübung, der durch vertraglichjustizierbare (oder: verfassungsrechtliche) Rahmen abgesteckt ist und über diesen legalisiert beziehungsweise legitimiert wird. Das Ensemble lässt sich demnach als Verobjektivierung der EU-Staatlichkeit verstehen, dessen innere Wirkungszusammenhänge es in den weiteren Schritten noch eingehender zu extrahieren gilt. Hierzu wird später mit Rückgriff auf Ansätze der materialistischen Staatstheorie die EU-Staatlichkeit und das EU-Staatsapparate-Ensemble in die gesellschaftlichen Bedingungen eingebettet, in denen sie sich (re-)produzieren (Staatlichkeit als Verhältnis). Zuvor soll allerdings noch ein Blick auf die Herrschaftsausübung geworfen werden, die sich zentral an einem Begriff mit ausgesprochen hoher Konjunktur in der Politikwissenschaft (vgl. Grande 2012) ausrichtet. 


\section{Vom nationalstaatlichen Government zur suprastaatlichen Governance?}

Im Zusammenhang mit der sich transformierenden Nationalstaatlichkeit und der Beschreibung neuer Formen von Staatlichkeit jenseits des Nationalstaates hat sich eine prominente Diagnose Raum gebahnt. Unter dem Schlagwort des »Wandels von Government $\mathrm{zu}$ Governance« werden hierbei neue Steuerungsmodelle diskutiert, die der angeblich bis dato vorherrschenden hierarchischen und staatszentrierten Steuerung (Government) >neuartige politische Gestaltungsformen (Governance) zur Seite stellt. Ein solcher Wandel

»beinhaltet eine Bewegung weg von der zentralen Rolle offizieller Staatsapparate bei der Sicherung staatlich geförderter ökonomischer und sozialer Projekte sowie der politischen Hegemonie hin zur Betonung verschiedener Formen der Partnerschaft zwischen gouvernementalen, paragouvernementalen und nichtgouvernementalen Organisationen, in denen die Staatsapparate bestenfalls als primus inter pares zu betrachten sind.« (Jessop 1997, 53)

Durch die breite Rezeption, die dem Governanceparadigma zuteil wurde (vgl. bspw. Benz \& Dose 2010), scheint es, »als ob ‘Governance derzeit die Allzweckwaffe der Politikwissenschaft für jede Art von gesellschaftlichem Regelungsproblem ist « (Grande 2012, 53f.). Dies spiegelt auch die Konjunktur des Begriffes im Rahmen der Europaforschung und die offizielle Verwendung selbst in deutschsprachigen EU-Dokumenten wider. Nicht nur die Theorieschule der MLG greift den Governance-Terminus prominent auf, vielmehr wird Governance im Kontext europäischer Integrationsprozesse selber zu einer Art neuem Leitbild, mit dem zugleich normative Fragen nach einer Steigerung von Legitimität europäischen Regierens aufgegriffen werden (vgl. u.a. Schmitter 2006; kritisch Demirović \& Walk 2011, 13). Nicht zuletzt unter dem Eindruck der schwellenden Legitimationsdiskussion antizipierte die Europäische Kommission ([KOM] 2001) die Governance-Debatte und schlug in einem Weißbuch zum seuropäischen Regieren Maßnahmen vor, welche die Staatlichkeits- und Herrschaftspraxen der EU stärker an den Grundsätzen >guten Regierens` verorten sollte. Für die Kommission zählen zu diesen Grundsätzen Offenheit, Partizipation, Verantwortlichkeit, Effektivität und Kohärenz (vgl. ebd., 7). Sie entwickelt im Weißbuch somit ihr eigenes Bild einer >Good Governance<, also von normativen Zielkriterien, welche es im Prozess der europäischen Politikgestaltung zu beachten gelte. Diese normativ-geprägte Diskussion über gutes Regieren spiegelt einen Teilaspekt des politikwissenschaftlichen Diskurses über den Governance-Begriff wider (vgl. u.a. Rhodes 1996, 653), den es im Sinne einer umfassenden Darstellung der Theoriediskussion um weitere Aspekte zu erweitern gilt.

Wurde Governance laut Mayntz $(2010,37)$ in ihrem ursprünglichen Kontext meist sprachlich mit »Regieren « über- beziehungsweise gleichgesetzt, begann sich die Wortbedeutung schrittweise zu erweitern. So führten die politikwissenschaftlichen Diskussionen dazu, dass der Begriff der Governance zusehends »schillernd « und »mehrdeutig« und somit schwieriger zu fassen wurde (vgl. ebd.). Oder um es mit Demirović (2011a, 73) zu sagen: Die Governance-Forschung »weiß nicht genau, was genau eigentlich der Begriff der Governance meint.«(Vgl. auch Offe 2008) Mayntz $(2010,38)$ selber versteht ihn »als Oberbegriff aller Formen sozialer Handlungskoordination, als Gegenbegriff zu hierarchischer Steuerung und zur Bezeichnung der Gesamtheit aller in einem Gemein- 
wesen bestehenden und miteinander verschränkten Formen der kollektiven Regelung gesellschaftlicher Sachverhalte«. Dabei lässt sich der Governance-Begriff je nach fachlicher Domäne beziehungsweise je nach Zugriff auf die Steuerungsthematik in jeweils spezifischen Diskurssträngen der Governance-Debatte einbetten (vgl. Sack 2011). Grande $(2012,566)$ versucht hingegen generelle Merkmale zu benennen, die den »konzeptionellen Kern des Governance-Konzepts in der Politikwissenschaft « abzubilden versucht. Für ihn stellt das wichtigste Merkmal die Betonung nicht-hierarchischer Formen der Produktion öffentlicher Güter dar, mit der im Weiteren eine Kritik am Staat verbunden sei:

»Für die Governance-Konzepte charakteristisch ist - sei es als normatives Postulat, sei es als empirische Beobachtung -, dass nicht-staatliche Akteure und Organisationen und das Zusammenwirken von staatlichen und nicht-staatlichen Akteuren in verschiedensten Formen der >Public-Private-Partnership an Bedeutung gewinnen.« (Ebd.)

Dabei könne ein solcher Einbezug privater Akteure als eine »notwendige Folge von Interdependenzen interpretiert « (ebd., 567) werden, die sich unter anderem aus der fortschreitenden Globalisierung herleiten lasse. Infolgedessen und aufgrund des Bedeutungsverlusts territorialer und funktionaler Handlungsgrenzen sei somit die Komplexität des politischen Handelns erheblich gestiegen (vgl. ebd.). Zusammengenommen folge hieraus schließlich, »dass die Notwendigkeit und die Bedeutung von Kooperation und Koordination zwischen verschiedensten Akteuren erheblich zunehmen« (ebd.) würden. Hieran wird deutlich, dass Governance je nach Konnotation mal weniger, mal stärker mit normativen Parametern operiert, welche einer staatszentrieren Steuerung neue - >nicht-hierarchische - Formen des Regierens gegenüberstellt, die wiederum der scheinbaren Komplexitäten moderner Gesellschaften besser gerecht und somit zu einer effektiveren Politikgestaltung beitragen würden. Gerade aus materialistischer Perspektive gilt es, notwendigerweise darauf hinzuweisen, dass ein solcher Ansatz Gefahr laufen kann, den der Governance inhärenten Herrschaftsstrukturen zu wenig Aufmerksamkeit zu schenken. Dass aber Governance-Ansätze nicht zwangsläufig mit einem herrschaftstheoretischen Defizit ausgestattet sein müssen, zeigt der shistorisch-materialistische Governance-Strangく (vgl. Sack 2011, 25), der an Governance grundsätzlichere Fragen adressiert und sie somit in einen ideologie- und herrschaftskritischen Zusammenhang stellt (vgl. Jessop 2011, 43; vgl. van Apeldoorn, Overbeek \& Ryner 2003).

Im später genauer einzuführenden integralen Verständnis von Staat und Staatlichkeit ist gerade die Perspektivenweitung auf die Rolle der Zivilgesellschaft bei der (Re-)Produktion von Herrschafts- und Ideologiestrukturen ein entscheidendes Analysemoment. Pointiert gefasst lässt sich deshalb sagen, dass »bereits in den 1920er Jahren [...] Gramsci sozusagen den Übergang von `Government zu Governanceくvollzogen [hatte].« (Buckel et al. 2014, 31) Jessop (2011, 54) geht gar noch einen Schritt weiter:

»In Analogie zu Cramscis Definition vertrete ich die These, dass >der Staat im integralen Sinn $<$ auch als >Regierung + Covernance im Schatten der Hierarchie definiert werden könnte. So verstanden umfasst staatliche Macht nicht nur die Ausübung von Kompetenzen, die spezifisch zum Staat gehören [...], sondern greift auch auf Praktiken der 
Kollibration zurück, also auf ein Ausbalancieren von verschiedenen Formen der Governance innerhalb und jenseits des Staates im Schatten der Hierarchie.«

Der Governance-Diskurs offenbart insofern für eine materialistische Betrachtung von Staatlichkeit und Herrschaft die Einsicht, dass die unter Governance subsumierten Phänomene nicht gänzlich neu sind, sondern vielmehr kritische Ansätze in den Mainstream der Politikwissenschaft übernommen wurden. Oder mit Demirović (2011a, 102) gesagt: »Aus dem Blickwinkel der materialistischen Staatstheorie bestätigt Governance eine ihrer wesentlichen Einsichten nachdrücklich, daß der Staat ein gesellschaftliches Kräfteverhältnis ist und die Trennlinie zwischen Staat und Gesellschaft nur ein strategischer Einsatz. « Dabei werden in materialistischen Governance-Analysen »die Grundlagen verschiedener Koordinationsweisen und die Zusammensetzung unterschiedlicher Governanceziele zum Gegenstand der Untersuchung« (Jessop 2014). Entsprechend spielt in der materialistischen Diskussion zur Erfassung der grundlegenden strukturellen Bedingungen von Governance die Thematik der Meta-Governance eine besondere Rolle. Dem Sinn nach umschreibt diese »die Governance von Governance« (Jessop 2011, 44) und verdeutlicht damit, dass Governanceprozesse durch strukturelle und strategische Kontexte determiniert sind und nicht aus einer positivistischen Betrachtung eines überhöhten »Steuerungsoptimismus« (vgl. u.a. Deitelhoff \& Steffek 2009, 12) herzuleiten sind. Vielmehr gilt es, die materialistischen Grundlagen von Governance als solche beschreibbar zu machen und diese explizit zu benennen.

Im Rahmen der Meta-Governance bleiben auch klassische Staatsapparate zentral, so Bell \& Hindermoor (2009, If.): »In particular, states have not been hollowed out and the exercise of state authority remains central to most governance strategies. «Unter der Überschrift »Rethinking Governance« erarbeiten sie dabei einen staatszentrierten, relationalen Governance-Ansatz, den sie dem Ansatz gesellschaftszentrierter Governance gegenüberstellen:

»One of our key arguments [...] is that governance through hierarchical control imposed by the state is alive and well. In some arenas [...] policies continue to be made and implemented hierarchically by the state and consultation is non-existent or extremely limited. And when governments have chosen to govern in alternative ways, we argue that the state usually retains a pre-eminent position. On this basis we argue that states and governments remain critical players in governance and that governance is also about state-society relationships, whatever the governance arrangements in place.« (Ebd., 10; Herv. i. O.)

Übertragen auf die EU-Staatlichkeit lautet der Kerngedanke einer solchen Überlegung, dass mitgliedstaatliche ebenso wie genuine EU-Staatsapparate zentral für die Ausgestaltung und Legitimierung etablierter Governance-Prozesse bleiben. Sie fungieren dabei, mit Genschel \& Zangel (2008, 431) gesprochen, als eine Art »Herrschaftsmanager«, die »die Herrschaftsakte nicht-staatlicher Akteure aktivier[en], komplementier[en] und synchronisier[en]«. Entsprechend ist auch die positivistische Interpretation des Governance-Begriffs im Sinne erhöhter Output-Legitimation zurückzuweisen. Stattdessen wäre besser davon auszugehen, dass »wenn er von überstaatlichen Verwaltungen benutzt wird, dazu dient, deren Demokratiedefizit als Ausdruck einer notwen- 
digen >Neuheit< der Strukturen zu verdecken« (Möllers 2008, 95f.). In einem solchen Verständnis von Governance sind entsprechend jene Tätigkeiten, die in ihrem Namen stattfinden oder in ihren Schleier gehüllt werden, letztlich als das zu bezeichnen, was sie eigentlich sind: Staatlichkeitspraxen im Sinne klassischer Herrschaftsakte, die rückgebunden sind an staatliche Akteur*innen und Apparate. Analog zu Governance ist deshalb auch weiterhin besser von »Regieren« zu sprechen.

\section{2 Über die "Konzentration und Monopolisierung symbolischer Macht" im Prozess der EU-Staatlichkeitsgenese}

In seinen Vorlesungen über den Staat, die er in den Jahren 1989 bis 1992 am Collège de France hielt, unternimmt Pierre Bourdieu $(2017,126)$ den Versuch, die Genese des modernen Staates nachzuzeichnen, die er als langwierigen Konzentrationsprozess von Machtressourcen versteht. Für ihn sei »Konzentration = Universalisierung + Monopolisierung. « (Ebd., 350) Als Machtressourcen sind dabei im Bourdieu'schen Vokabular die verschiedenen Kapitalsorten zu betrachten (vgl. grundsätzlich: Bourdieu 1983), deren Konzentration im Zentrum der Genese steht: »Der Staat ist das Produkt der fortschreitenden Akkumulation unterschiedlicher Kapitalsorten, von ökonomischem Kapital, physischer Gewalt, symbolischem, kulturellem oder Informationskapital (Bourdieu 2017, 329), wobei »[d]ie Akkumulation der verschiedenen Kapitalsorten durch dieselbe Zentralmacht [...] eine Art von Metakapital [erzeugt], das heißt ein Kapital, das die besondere Eigenschaft hat, Macht über das Kapital auszuüben.« (Ebd., 347) Den Prozess der Konzentration beim dynastischen Staat beginnend, beschreibt Bourdieu einen langwierigen Transformationsprozess, der die private Kapital-Konzentration (in Gestalt eines personifizierten Herrschers) im modernen Staat in eine öffentliche Konzentration überführt (vgl. ebd., 329ff.) oder anders ausgedrückt: aus dem privaten ein öffentliches Monopol werden lässt (vgl. ebd., 231). Bourdieus Staatsdefinition greift hier diejenige Max Webers auf, der gesagt habe, »der Staat sei das Monopol der legitimen Gewalt. Und ich korrigiere und sage: Er ist das Monopol der legitimen physischen und symbolischen Gewalt « (ebd., 601; Herv. J. G.). Der Staat ist demnach eine »symbolische Macht«, die

»Zentralbank des symbolischen Kapitals‘, dieser Ort, an dem all das Zeichengeld, das in der sozialen Welt umläuft, und all die Realitäten, die man als Fetische bezeichnen kann, generiert und garantiert werden, handele es sich um einen Schulabschluß, um die legitime Kultur oder Bildung, die Nation, den Begriff der Grenze oder die Orthographie.«(Ebd., 222.) ${ }^{2}$

"Dreh- und Angelpunkt « sind für ihn »sowohl die Prozesse symbolischer Gewalt als auch die Kämpfe um symbolische Herrschaft.« (Bozay 2016, 49) Bourdieu (2016, 10), der den sozialen Raum als Kräftefeld, »das heißt als ein Ensemble objektiver Kräfteverhältnisse« begreift, weist entsprechend darauf hin, dass symbolische Systeme

2 Es sei darauf hingewiesen, dass Bourdieu die Termini ssymbolische Macht<, `symbolisches Kapitel<, ssymbolische Gewalt « und `symbolische Herrschaft « nicht trennscharf voneinander abgegrenzt (vgl. Martin 2019, 150). 
»gerade in ihrer Eigenschaft als strukturierte und strukturierende Instrumente der Kommunikation und der Erkenntnis [...] ihre politische Funktion von Instrumenten der Durchsetzung oder der Legitimation von Herrschaft [erfüllen], die zur Absicherung der Herrschaft einer Klasse über eine andere (symbolische Cewalt) beitragen, indem sie die Verstärkung ihrer eigenen Kraft den Kräfteverhältnissen, die ihnen zugrunde liegen, hinzufügen und so, nach dem Wort Webers, zur >Domestikation der Beherrschten< beitragen.«(Bourdieu 1997, 560)

Ähnlichkeiten zu den Vorstellungen Gramscis und Poulantzas, die im nächsten Unterkapitel im Zentrum stehen, werden hier offensichtlich, auch wenn Bourdieu (u.a. 2017, 21) selbst explizit auf Distanz zu Ansätzen materialistischer Staatstheorie geht. Voigt $(2017,36)$ hält hingegen fest, dass »Bourdieus Theorie der symbolischen Gewalt [...] gewissermaßen auf der Hegemonietheorie Gramscis auf[setzt] « und auch Bozay (2016, 39; vgl. ebd., 53) attestiert eine Verbindungslinie, in der beide »[a]us der Perspektive der symbolischen Ordnung [...] zu erklären [versuchen], warum Beherrschte unakzeptable Existenzbedingungen akzeptieren und selber an der Aufrechterhaltung der Herrschaftsverhältnisse mitwirken.«An dieser Stelle lediglich auf die Verbindunglinie im Geiste zwischen Bourdieu und Gramsci hinweisend (vgl. bspw. auch Martin 2019 oder Hirsch \& Voigt 2017 12), soll der Fokus hier auf zwei zentrale Erkenntnisse Bourdieus gelegt werden, die für die Analyse der EU-Staatlichkeit besonders fruchtbar erscheinen.

Die Erweiterung der Weber'schen Staatsdefinition um das symbolische Gewaltmonopol markiert für Hirsch \& Voigt $(2017,12)$ »einen epochalen Einschnitt im politischen Denken der Gegenwart « und stellt auch für die Analyse der oben andiskutierten Transformationsprozesse aus Perspektive der Internationalisierung des Staates sowie der mit ihr verbundenen Zerfaserung klassischer Staatlichkeit eine bedeutsame Erweiterung dar. Es wurde bereits darauf verwiesen, dass das Monopol physischer Gewaltsamkeit schon heute in Teilen eine suprastaatliche Einhegung beziehungsweise Einbettung erfährt, indem zwar das Monopol der physischen Gewaltmittel weiterhin im (National-)Staat verbleibt, aber nicht mehr vorbehaltslos auch von einem Monopol der Gewaltanwendung im Sinne der Definitionsmacht über die legitime Anwendbarkeit von Gewalt besteht. Dieser Gedanke lässt sich vom Standpunkt des symbolischen Gewaltmonopols aus noch plastischer beschreiben; schließlich rückt es ins Zentrum der Analyse, indem es auf Staatlichkeits- und Herrschaftspraxen verweist, die außerhalb der Bezugsmacht physischer Gewaltmittel stehen. Kurzum: Es geht um die Ausbildung eines symbolischen Gewaltmonopols (in Bourdieus weitem Verständnis des Symbolischen) als eine weitere konkrete Erscheinungsform der EU-Staatlichkeit. Die Genese von Staatlichkeit ist demnach als ein umkämpfter Monopolisierungsprozess zu begreifen, der hilft, den Ausbau ebenso wie die fortlaufende Transformation der EU-Staatlichkeit zu verstehen. Bourdieu (2017, 218f.) - der die >Genese des modernen Staates` vor Augen hatte - verdeutlicht einen solchen Monopolisierungprozess beispielhaft am Thema Sprache und Rechtschreibung, indem er beschreibt, wie sich

»eine symbolische Ausdrucksweise [...] monopolistisch durchsetzt: Man muß korrekt und nur so sprechen. Es ist der Staat, der die[...] Vereinheitlichung des sprachlichen Marktes, die[...] Vereinheitlichung des Marktes der Schreibungen herstellt, die mit dem Staat deckungsgleich ist und die er herstellt, indem er sich herstellt. Die Schaffung ei- 
ner normalisierten Orthographie, normalisierter Gewichte und Maße, eines normalisierten Rechts, [...] all das sind für den Staat Weisen, sich selbst zu erschaffen.«

Es ist insofern der »Prozeß der Vereinheitlichung, Zentralisierung, Standardisierung, Homogenisierung, durch den der Staat sich zum Staat macht « (ebd., 219). Die oben angeführte Teilrechtsordnung, die sich innerhalb der EU herausgebildet hat, ließe sich beispielsweise als Ergebnis eines solchen Monopolisierungs- und Konzentrationsprozesses verstehen, an dessen Ende der Rechtsvorrang des Unionsrechts vor dem der Mitgliedstaaten und weithin sichtbar als Hüterin dieser Rechtsordnung der EuGH steht. Gerade die Verselbstständigung des juridischen Feldes deutet zugleich auf eine spannende Kontinuitätslinie zwischen der Genese des modernen Staates und jener der EU-Staatlichkeit hin (vgl. ebd., 111ff.), in welcher der »außerordentliche[...] Beitrag« zu beschreiben wäre, »den die Juristen gemeinschaftlich bei der Arbeit an [ihrer; J. G.] Konstruktion [...] geleistet haben, insbesondere dank jener Ressourcen, die das Kapital an Worten darstellt.« (Ebd., 574) »Für die Konzentration der symbolischen Macht im Staat ist das Recht von zentraler Bedeutung «, so Martin (2019, 145) in seiner Bourdieu-Rezeption. Weiter schreibt er: „Die Kämpfe um den Gebrauch der symbolischen Gewalt des Staates sind auf rechtlich abgesicherte Positionen angewiesen.« (Ebd.) Letztlich erfordert dies eine Übersetzung der Monopolisierungs- und Konzentrationsbemühungen in Formen des Rechts. Prozesse der Monopolisierung und Konzentration symbolischer Macht in der Genese von Staatlichkeit sind insofern immer auch Konstitutionalisierungsprozesse. Durch sie wird das symbolische Gewaltmonopol in eine rechtliche Entsprechung überführt, die letztlich auf eine implizite Verfassung verweist. Dieses »Verfassungsmachen beruht auf einzelnen Schritten, die auf jenen unbestimmten Punkt zusteuern, an dem eine Verfassung vorliegt«, so Somek (2010, 137). Die Herausbildung eines symbolischen Gewaltmonopols basiert deshalb nicht nur auf einzelnen Großakten, sondern auf einer schrittweisen, mitunter langwierigen Konstitutionalisierung (vgl. Möller 2017, 182; 189f.). Bei diesen Konstitutionalisierungprozessen der Vereinheitlichung, Zentralisierung, Standardisierung und Homogenisierung - also der Monopolisierung - durch die sich die EU-Staatlichkeit herausbildet und fortentwickelt, kommt es im Kern zu einer Bündelung der Definitions- oder, in den Worten Bourdieus (2016, 19), "Benennungsmacht«, also der »Fähigkeit, bestimmte Begriffe und Kategorien sowie Wahrnehmungs- und Repräsentationsschemata $\mathrm{zu}$ beeinflussen, $\mathrm{zu}$ autorisieren und ihnen quasioffiziellen Charakter zu verleihen « (Mau 2017, 185). In ihrer vollkommensten Form erscheine diese >Macht unhinterfragt als offenbar unumstößliche Realität oder als »Doxa«:

»Die soziale Welt ist im Modus der doxa gegeben, jener Art von Glauben, die sich selbst nicht als Clauben wahrnimmt. Die soziale Welt ist ein historisches Artefakt, ein Produkt der Ceschichte, das dank seiner Amnesie der Cenese, die alle sozialen Schöpfungen betrifft, in seiner Cenese vergessen ist.«(Bourdieu 2017, 326; Herv. i. O.)

Der Staat ist für Bourdieu ein Beispiel für ein solch doxisches Produkt; er ist ein $>\mathrm{Na}-$ turalisierungseffekt symbolischer Macht $<$ (vgl. ebd., 208): Der Staat werde

»als historischer verkannt und mit uneingeschränkter Anerkennung, die die Anerkennung der Verkennung ist, anerkannt. Es gibt keine vollkommenere Anerkennung als 
die Anerkennung der doxa, weil sie sich als Anerkennung nicht wahrnimmt. Doxa heißt eine Frage bejahen, die ich nicht gestellt habe.«(Ebd., 326; Herv. i. O.)

Nicht nur die Ausführungen Bourdieus zur symbolischen Gewalt, sondern auch seine Äußerungen zur Doxa verdeutlichen, wie stark die Verbindungslinien zwischen Gramscis Hegemonietheorie und Bourdieus Theorie des Symbolischen sind, schließlich versuchen beide in ähnlicher Weise auf die inkorporierten Formen der Herrschaft hinzuweisen, in denen entweder im Modus vollkommener Hegemonie als auch im Zustand der Doxa die Anerkennung der gegebenen Ordnung und der durch ihr ausgedrückten Herrschaftsverhältnisse bejaht werden, ohne dass sich die Beherrschten immer dieser Verhältnisse bewusst wären. Gerade diese Geschichtlichkeit einer scheinbaren, objektiven und unumstößlichen Realität offenzulegen und zu hinterfragen, bleibt dabei Motiv sowohl von Bourdieu als auch von Gramsci, dessen staatstheoretische Überlegungen im Nachfolgenden im Zentrum stehen werden.

\section{3 Über "Kräfteverhältnisse«, "Hegemonie« und die »integrale Staatlichkeit» der EU}

"Im Unterschied zur herrschenden Politikwissenschaft kommt es bei der materialistischen Staatstheorie« nach Hirsch, Kannankulam \& Wissel (2008a, 16; Herv. J. G.) »nicht nur darauf an, das politische System und den Staat als etwas Gegebenes zu analysieren und ihre Funktionsweise zu erklären, sondern als Ausdruck gesellschaftlicher Herrschaftsverhältnisse zu begreifen«. Kritische Gesellschaftswissenschaft ziele infolgedessen

»nicht auf das bessere Funktionieren der bestehenden Herrschaftsverhältnisse ab, vielmehr wird der bestehende Rahmen der gesellschaftlichen Verhältnisse in den Blick genommen und daraufhin befragt, ob er denn tatsächlich so notwendig und alternativlos ist, wie dies von einer unkritischen Wissenschaft explizit oder implizit unterstellt wird.«(Heinrich 2008, 60)

Kurz gesagt: Der Herrschaftscharakter des Staates wird adressiert (vgl. Brand 2010, 145). Trotz dieser Verbindungslinie stellt die materialistische Staatstheorie allerdings kein geschlossenes Theoriegebäude dar, sondern umfasst vielmehr sehr unterschiedliche Ansätze (vgl. Hirsch 2005, 15). Einen Ansatzpunkt, die gesellschaftlichen Herrschaftsverhältnisse in Form des Staates zu beschreiben, bildet für Brand $(2010,147)$ der Rückbezug zu Marx, indem anerkannt werde, »dass die Grundlage von Gesellschaftlichkeit aus der alltäglichen Notwendigkeit der Individuen besteht, sich materiell $\mathrm{zu}$ reproduzieren.« Marx selbst schrieb im Vorwort >Zur Kritik der Politischen Ökonomie aus dem Jahr 1859: „Die Produktionsweise des materiellen Lebens bedingt den sozialen, politischen und geistigen Lebensprozeß überhaupt. Es ist nicht das Bewusstsein der Menschen, das ihr Sein, sondern umgekehrt ihr gesellschaftliches Sein, das ihr Bewusstsein bestimmt.« (MEW 13, 8f.) Bereits sieben Jahre zuvor schrieb Marx im $>18$. Brumaire des Weiteren, dass "[d]ie Menschen [...] ihre eigene Geschichte [machen], aber sie machen sie nicht aus freien Stücken, nicht unter selbstgewählten, sondern unter unmittelbar vorgefundenen, gegebenen und überlieferten Umständen.« (MEW 
8, 115) Für kritische sozialwissenschaftliche Analysen bedeutet dies zusammengenommen, »dass Rechtsverhältnisse wie Staatsformen weder aus sich selbst zu begreifen sind noch aus der sogenannten allgemeinen Entwicklung des menschlichen Geistes, sondern vielmehr in den materiellen Lebensverhältnissen wurzeln [...].« (MEW 13, 8) Materialismus bezeichnet im Anschluss hieran eine »Forschungsstrategie« (Heinrich 2008, 66), in der die Forschungsprozesse und Analysen durch die Rückbindung des Untersuchungsgegenstands an die materiellen und historischen Grundlagen der Gesellschaft und ihrer Produktions- und Reproduktionsbedingungen eingebettet werden (vgl. u.a. Overbeek 2000, 164; van Apeldoorn, Overbeek \& Ryner 2003, 33). Dies gilt im Besonderen für den Staat und die Staatlichkeit als soziale Formen. "Als soziale Form bezeichnet Marx die in einer >naturwüchsig`arbeitsteiligen Gesellschaft sich hinter dem Rücken der Subjekte herstellende und von ihnen nicht unmittelbar durchschaubare Verobjektivierung sozialer Beziehungen. (Hirsch 2001, 104) Dabei bestimmen soziale Formen »strukturell die allgemeinen gesellschaftlichen Wahrnehmungs- und Verhaltensorientierungen. Diese konkretisieren sich in gesellschaftlichen Institutionen. (Hirsch \& Kannankulam 2009, 185) Marx beschreibt in diesem Sinne beispielsweise die Wert-, Waren- oder Geldform als besondere Strukturmerkmale der kapitalistischen Gesellschaftsformation. »Der Begriff soziale Form bezeichnet somit den Vermittlungszusammenhang zwischen gesellschaftlicher Struktur, Institutionen und sozialem Handeln« (ebd., 186; Herv. i. O.), in dem sich »[d]as scheinbar Konkrete, wie z.B. die Ware oder das Geld, [...] als abstrakter Ausdruck komplexer gesellschaftlicher Zusammenhänge [erweist].« (Hirsch, Kannankulam \& Wissel 2008a, 13)

Als eine der zu definierenden sozialen Formen sticht der Staat hervor - also die politische Form der gegebenen Gesellschaftsformation. Dabei weist die politische Form insofern eine strukturelle Besonderheit auf, als dass sie sich nicht als eine eindeutig durch die ökonomische Sphäre determinierte Form bestimmen lässt. In der materialistischen Staatstheorie werden hierfür die komplementären Begrifflichkeiten der Besonderung und der relativen Autonomie des Staates zur Beschreibung herangezogen, welche sich aus der fortwährenden Diskussionen über die unterschiedlichen Begründungszusammenhänge (Staatsableitung/Formanalyse vs. Strukturalismus) zur Entwicklung der politischen Form aus den materiellen Lebensverhältnissen speisen. Beide Begriffe vereint, dass es ihnen im Kern darum geht, »die Form der Herrschaft im Kapitalismus zu begreifen, deren Spezifität in der Trennung von Staat und Gesellschaft und der von Politik und Ökonomie liegt. «(Keil 2015, 42) Auch wenn sich die Konzepte der Besonderung und der relativen Autonomie gegen einen starren Ökonomismus im Sinne der Beschreibung des Staates als bloßes durch die ökonomische >Basis< determiniertes politisches ,Überbau<-Phänomen wenden, dürften sie nicht

»derart missverstanden werden, dass der Staat der (kapitalistischen) Ökonomie tatsächlich äußerlich und neutral gegenübersteht. Die Trennung bzw. Besonderung ist vielmehr die Form der konstitutiven Präsenz des Politischen in den kapitalistischen Reproduktionsverhältnissen, «(Hirsch, Kannankulam \& Wissel 2008b, 109)

durch die »die antagonistischen Klassen- und Konkurrenzverhältnisse in einer Weise prozessierbar gemacht [werden], dass die damit verbundenen Konflikte nicht permanent aufbrechen und offen ausgetragen werden.« (Ebd., 110) Der Staat wird in der 
materialistischen Staatstheorie deshalb nicht »einfach nur als verselbstständigte Institution konzeptualisiert, sondern als soziales Verhältnis betrachtet (Wissel \& Wöhl 2008, 9; Herv. J. G.), als eine Art Kulminationspunkt gesellschaftlicher Kräfteverhältnisse.

Das Staatsverständnis, das sich auf den in den Staatsapparaten verdichtenden Kräfteverhältnissen begründet, geht insbesondere auf Nicos Poulantzas zurück, der sich die Frage stellte, »wie der Klassenkampf, spezieller der politische Kampf und die politische Herrschaft, im institutionellen Gerüst des Staates eingeschrieben sind [...], und zwar so, dass die unterschiedlichen Formen und historischen Transformationen dieses Staates erklärt werden können.« (Poulantzas 2002, 157) Er begreift dabei den »kapitalistischen Staat, "nicht als ein in sich abgeschlossenes Wesen [...], sondern, wie auch das >Kapitak, als ein Verhältnis, genauer als die materielle Verdichtung eines Kräfteverhältnisses zwischen Klassen und Klassenfraktionen, das sich im Staat immer in spezifischer Form ausdrückt.«(Ebd., 159) Demnach sei

»der Staat in der kapitalistischen Cesellschaft [...] weder das bewusst geschaffene Instrument der herrschenden Klasse, noch die Verkörperung eines demokratischen >Volkswillens` und auch kein selbständig handelndes Subjekt. Er ist vielmehr ein soziales Verhältnis zwischen Individuen, Gruppen und Klassen [...].« (Hirsch 2002, 26, Herv. i. O.)

In einer solchen Argumentation seien die kapitalistischen Klassenverhältnisse dem Staat nicht vorgelagert, sondern in die Form des kapitalistischen Staates selbst eingelassen (vgl. Brand 2005, 50). Poulantzas (2002, 160) wendet sich mit seiner Konzeptualisierung gegen die Vorstellung des Staates als "passive[s], wenn nicht sogar neutrale[s] Werkzeug « auf der einen und der Vorstellung auf der anderen Seite, der Staat sei als »Vernunftinstanz der bürgerlichen Gesellschaft« zu begreifen (vgl. u.a. auch Wissel \& Wöhl 2008, 11). Staat und Staatlichkeit verkörpern eine antagonistische Widersprüchlichkeit und sind dementsprechend immer auch umkämpftes politisches Terrain: »Die Form, oder Materialität, gesellschaftlicher Verhältnisse reproduziert sich durch die Kämpfe hindurch. Das Verhältnis von Form und Kampf findet seine Vermittlung in der Institutionalisierung, wobei insbesondere diejenige politischer Herrschaft im Staat im Fokus zu stehen hat.« (Keil 2015, 69) Mit Poulantzas (2002, 167f.) ließe sich in dieser Logik der Staat als strategisches Feld und strategischen Prozess fassen, »in dem sich Machtknoten und Machtnetze kreuzen, die sich sowohl verbinden als auch Widersprüche und Abstufungen zeigen. Daraus ergeben sich bewegliche und widersprüchliche Taktiken, deren Allgemeinziel und institutionelle Kristallisierung in den Staatsapparaten Form annehmen." Jessop (ausführlich 2008) beschreibt ein solches Staatsverständnis als ein >strategisch-relationales`, bei dem »Staatsmacht als formbestimmte Verdichtung eines wechselnden Verhältnisses von Kräften« fassbar werde, "die an politischen und politisch bedeutsamen Kämpfen im und jenseits des Staates beteiligt sind.«(Jessop 2015, 93)

Neben dem Verdienst Poulantzas', den Staat als ein soziales beziehungsweise gesellschaftliches Verhältnis zu fassen, das Jessop $(2007,153)$ als seinen wichtigsten theoretischen Beitrag begreift, verweisen Poulantzas' Ausführungen für die Analyse von Staat und Staatlichkeit auf drei weitere zentrale begriffliche Zuspitzungen: Verdichtung, Materialität und Selektivität. Trotz der Zentralität des Verdichtungs-Begriffs in den Arbeiten 
Poulantzas', habe er diesen allerdings nicht explizit zu definieren versucht (vgl. Demirović 2007a, 226). Nach Demirović $(2007 a, 226)$ nimmt Poulantzas mit ihm in den Fokus, »wie gesellschaftliche Widersprüche und Konflikte im Staat zu einer selbst wiederum widersprüchlichen Einheit zusammengefasst und erkannt werden können.« Wird von Verdichtung gesprochen, impliziert dies entsprechend nicht die einfache Überführung gesellschaftlicher Konfliktlinien in staatliche Apparate, sondern beschreibt einen Prozess, in dem sich ein Kräfteverhältnis in einer »spezifischen Form« (Poulantzas 2002) materialisiert, quasi in die Apparate übersetzt wird. "Das Kräfteverhältnis wird verdichtet, weil die unterschiedlichen Interessen und symbolischen Ordnungen nicht unmittelbar vertreten sind, sondern repräsentiert und gebündelt, also verdichtet werden «, so Fisahn $(2008,222)$. Entsprechend gilt es an dieser Stelle, Poulantzas' obige Ausführungen zum strategischen Feld und Prozess mitzudenken. Er führt aus, dass "sich bewegliche und widersprüchliche Taktiken [ergeben], deren Allgemeinziel und institutionelle Kristallisierung in den Staatsapparaten Form annehmen.«(Poulantzas 2002, 167f.) Poulantzas $(2002,168)$ relativiert aber zugleich, dass

»der Staat [...] ebensowenig ein einfacher Verband von abtrennbaren Einzelteilen [ist]. Er besitzt einen einheitlichen Apparat, was man gewöhnlich mit dem Terminus Zentralisation oder Zentralismus bezeichnet; eine Einheitlichkeit bzw. Einheit, die sich diesmal auf die Staatsmacht, über ihre Risse hinweg, bezieht. Diese Staatsmacht drückt sich in seiner globalen und massiven Politik zugunsten der hegemonialen Klasse oder Fraktion [...] aus.«

Dennoch hebt der Verdichtungs-Begriff zugleich »hervor, dass die subalternen Kräfte im Staat präsent sind und sich ihre Präsenz in der Arbeitsweise von Staatsapparaten spiegelt.« (Gallas 2016, 149f.) Die Materialität des Staates ließe sich demgemäß als Konsequenz der Einschreibungen der dem Staate zugrundeliegenden verdichteten Verhältnisse begreifen und sie »ist von [...] unerbittlichen und vielgestaltigen Kämpfen gezeichnet." (Poulantzas 2002, 176) Neben der dargestellten Beschreibung der Materialität als das Verhältnis zwischen politischen Subjekten und staatlichen Apparaten diskutiert Poulantzas zweitens

»mit Hilfe des Begriffs die spezifische Organisationsform kapitalistischer Staatlichkeit im Verhältnis zur kapitalistisch organisierten Ökonomie. Und drittens bezeichnet er mit Materialität die >Widerstandskraft< staatlicher Institutionen gegenüber den Strategien und Interessen politischer Akteure. (Bretthauer 2006, 82)

Insbesondere die zuletzt genannte Begriffsbestimmung verdeutlicht noch einmal Poulantzas' (2002, 167) Ausführungen zum strategischen Feld und strategischen Prozess und die hiermit aus der staatlichen Materialität herzuleitende »strukturelle Selektivität« (ebd., 165). Sie wirkt, indem staatliche Institutionen »strukturell oder strategisch [...] derart operieren, daß bestimmte Akteure und Themen gar nicht erst im Horizont der Staatsapparate und ihrer Funktionsträger auftauchen und deswegen im Entscheidungsprozeß nicht berücksichtigt werden.«(Demirović 2007a, 243) Dabei können die strukturellen Selektivitäten innerhalb eines Staatsapparate-Ensembles durchaus variieren, sodass eine Nichtbeachtung einzelner Akteur"innen durch einzelne Staatsapparate sich nicht zwangsläufig für das gesamte Ensemble verallgemeinern lassen. Vielmehr 
scheint hier die analytische Frage berechtigt, welches Kräfteverhältnis sich in einzelnen Apparaten verdichtet, um zu beschreiben, weshalb die einzelnen Apparate unterschiedliche Selektivitäten aufweisen, anhand derer sich wiederum politische Anschlussfähigkeiten beschrieben lassen. Schließlich resultiere die Selektivität »sowohl aus der Materialität und [der; J. G.] Geschichte jedes Apparates [...] als auch aus der spezifischen Vertretung von Sonderinteressen innerhalb der Apparate, also aus ihrer Stellung in der Konfiguration des Kräfteverhältnisses." (Poulantzas 2002, 165, Herv. J. G.) Anders gesagt, verkörpern sich verschiedene Bündnisse, Kompromisse und somit eben Kräfteverhältnisse im »Gerüst des Staatsapparates « (ebd., 173), wobei eben auch »die internen Widersprüche und Spaltungen des Staates im Inneren der verschiedenen Zweige und Apparate und zwischen ihnen, sowie die Widersprüche und Spaltungen im Personal des Staates [...] auch durch die Existenz von Volkskämpfen im Staat bedingt [sind].« (Ebd., 173) Insofern verweist Poulantzas' Ausarbeitung der spezifischen materiellen Verdichtungseffekte des Staates auch darauf, »dass die strategischen Ziele politischer Kräfte [...] durch die institutionelle Materialität des Staates und der sie stützenden Kräfte verstärkt, gebrochen, umgeleitet oder auch abgewehrt werden können.« (Bretthauer 2006, 98). An dieser Stelle wird abermals deutlich, dass Poulantzas' Analyse des Staates nicht ohne die Rezeption Gramscis und sein Verständnis des integralen Staates sowie des in ihm wirkenden Kampfes um Hegemonie zu denken ist (vgl. u.a. Thomas 2006, 307).

\section{Das erweiterte Staatsverständnis Antonio Gramscis}

"Staat und Gesellschaft nicht als dualistisch voneinander getrennte Sphären zu verstehen«, ermögliche es der materialistischen Staatstheorie nach Wissel \& Wöhl $(2008,9)$, »im Gegensatz zu vielen in der Politikwissenschaft geführten Debatten, ökonomische und politische Veränderungen im Zusammenhang zu diskutieren und Macht nicht auf politische Macht zu reduzieren.« Aufs Engste verbunden ist ein solches Verständnis mit Antonio Gramsci, der als Vordenker des erweiterten oder integralen Staates gilt, den er mit der wohlbekannten Formel umschreibt: »daß Staat = politische Gesellschaft + Zivilgesellschaft, das heißt Hegemonie, gepanzert mit Zwang« (Gramsci 1991-2002, 783) sei.

Ausgangslage für Gramscis theoretische Überlegungen zum Staat war das Scheitern der italienischen (im weiteren Sinne der westeuropäischen) Arbeiter*innenbewegung im 20. Jahrhundert durch den Siegeszug des Faschismus in Italien, anderer faschistoider und nazistischer Bewegungen in Europa und das Scheitern sozialistischer Revolutionsbewegungen in West- und Mitteleuropa im Gegensatz zur serfolgreichen Revolution in Russland. Gramscis Erklärung hierfür ist eindeutig:

»Im Osten war der Staat alles, die Zivilgesellschaft war in ihren Anfängen und gallertenhaft; im Westen bestand zwischen Staat und Zivilgesellschaft ein richtiges Verhältnis, und beim Wanken des Staates gewahrte man sogleich eine robuste Struktur der Zivilgesellschaft. Der Staat war nur ein vorgeschobener Schützengraben, hinter welchem sich eine robuste Kette von Festungen und Kasematten befand.«(Ebd., 874)

Gramsci liefert mit seinem Verständnis des integralen Staates somit eine Beschreibung für die Wirkungsweise der Herrschaftsformation im Inneren des Staates, die er anhand seiner begrifflichen Gegenüberstellung von politischer und ziviler Gesellschaft 
analytisch zugänglich macht. Gramscis Begriff der Zivilgesellschaft ist dabei als ein rein analytischer Begriff zu verstehen (vgl. Fisahn 2008, 114; Opratko 2014, 41), da »im konkreten historischen Leben [...] politische Gesellschaft und Zivilgesellschaft ein und dasselbe [sind].«(Gramsci 1991-2002, 499) Nach Bieling (2011,90) unterstreiche der Begriff der Zivilgesellschaft zwei zentrale Einsichten in die Funktionslogik von Herrschaftsverhältnissen im Staate:

„Zum einen wird erkennbar, dass die staatliche Machtpolitik ein breites Arsenal unterschiedlicher Instrumente - diese reichen von der Gesetzgebung, über die exekutiven Überwachungs- und Repressionstechniken bis hin zu den vielfältigen zivilgesellschaftlichen Formen der Überzeugung, kulturellen Vereinnahmung oder sogar Manipulation - umschließt; und zum anderen sorgt die politökonomische Fundierung der Staatskonzeption zugleich dafür, dass die sozialen Voraussetzungen staatlicher und zivilgesellschaftlicher Prozesse und letztlich auch deren sozialer (Klassen-)Charakter reflektiert werden.«

Entsprechend kann man mit Gramsci Herrschaft als ein organisiertes Produkt verstehen, welches sich auch auf Konsens und Akzeptanz stützt. »Herrschaft ist demnach vor allem in der politischen Gesellschaft, Hegemonie in der zivilen Gesellschaft angesiedelt. Und eine stabile Herrschaft müsse sich auf Hegemonie stützen.« (Neubert 2001, 65) Demirović (2007b, 25) konkretisiert: »Die spezifische Art und Weise der Herrschaftsausübung in der Zivilgesellschaft ist die Hegemonie«, wobei die Zivilgesellschaft in Gramscis Überlegungen nicht als »ein offenes Feld der Kommunikation« missverstanden werden dürfe, sondern »vielmehr eine vermachtete Arena [darstelle; J. G.], in der konkurrierende [...] soziale Blöcke um Einfluss und Gestaltungsmacht ringen, also den öffentlichen Diskurs zu bestimmten versuchen.«(Bieling 2011, 90) Hegemonie im Sinne Gramscis sei demnach

»die Fähigkeit, verallgemeinerte, Klassen und soziale Gruppen übergreifende Vorstellungen von der richtigen Ordnung und Entwicklung der Cesellschaft durchzusetzen, d.h. dem Glauben eine Grundlage zu verleihen, die bestehende Ordnung und ihre Entwicklungsperspektiven seien im allgemeinen, auch untergeordnete Teile der Cesellschaft einbeziehenden Interesse.«(Hirsch 2005, 97)

Hegemoniale Verhältnisse weisen für Hirsch $(2005,97)$ dabei drei Dimensionen auf: eine ideologische (die durchgesetzten Wert- und Ordnungsvorstellungen), eine politische (die Fähigkeit, solche Vorstellungen in die Praxis umzusetzen) und eine institutionelle Dimension (Bestimmungen und Zugang des Aushandlungs- und Entscheidungsprozesses). Voraussetzung der Hegemonie ist für Gramsci (1991-2002, 1567),

»daß den Interessen und Tendenzen der Cruppierungen, über welche die Hegemonie ausgeübt werden soll, Rechnung getragen wird, daß sich ein gewisses Cleichgewicht des Kompromisses herausbildet, daß also die führende Gruppe Opfer korporativökonomischer Art bringt, aber es besteht kein Zweifel, daß solche Opfer und ein solcher Kompromiß nicht das Wesentliche betreffen könne, denn wenn die Hegemonie politisch-ethisch ist, dann kann sie nicht umhin, auch ökonomisch zu sein, kann nicht umhin, ihre materille Crundlage in der entscheidenden Funktion zu haben, welche 
die führende Gruppe im entscheidenden Kernbereich der ökonomischen Aktivität ausübt.«

Ist ein solcher Zustand der Hegemonie erreicht, in dem eine Gruppe ihre Herrschaft in den »Strukturen« und »Superstrukturen« (wie Gramsci das Begriffspaar Basis-Überbau benennt) organisieren und reproduzieren kann, spricht Gramsci von einem "geschichtlichen« oder »historischen Block« (vgl. ebd., 1045).

»Hegemonie ist aber [...] nicht bloß Modus bürgerlicher Herrschaft, sondern ein umkämpftes Verhältnis, auf das sich auch die politischen Kräfte der Subalternen einzulassen haben. Das erschließt sich nicht zuletzt aus Gramscis Behandlung des >Alltagsverstandsく, worunter er eine >Weltauffassung versteht, ein Selbst- und Weltbild, das nicht nur das Bewusstsein, sondern alltägliche Praxen, routinisierte Handlungen und auch unbewusste Dispositionen umfasst.« (Opratko 2014, 44)

Der politische Kampf um Hegemonie muss somit auch gesellschaftliche Praxen umfassen, welche selber als ein Bestandteil der eigentlichen hegemonialen Zustandsbeschreibung gelten können. Die Materialität dieser Praxen ist Ausgangs- und Ansatzpunkt für die Reproduktion hegemonialer Kräfteverhältnisse oder aber der Etablierung neuer hegemonialer Kompromiss- und Konsensstrukturen. Hierzu ist es notwendig, den Alltagsverstand und seine Praxen als eine ideologische Form zu verstehen, die durch Intellektuelle fortwährend bearbeitet wird. Gramscis Intellektuellenverständnis geht dabei weit über ein klassisches Verständnis hinaus:

»Unter Intellektuellen muss man nicht nur die gemeinhin unter dieser Bezeichnung begriffenen Schichten verstehen, sondern im allgemeinen die ganze Gesellschaftsschicht, die organisierende Funktionen in weitem Sinne sowohl auf dem Cebiet der Produktion als auch auf dem der Kultur und auf politisch-administrativem Gebiet ausübt« (Gramsci 1991-2002, 1975).

Es handelt sich hier um eine ideologische Praxis, deren Materialität Gramsci unter dem Begriff des Hegemonieapparats (vgl. ebd. u.a. 120) fasst, also »einer organisatorischen an Selbsterhaltung interessierten, institutionellen Verdichtung, die eine relationale Autonomie gegenüber den gesellschaftlichen Kräfteverhältnissen aufweist.«(Buckel \& Fischer-Lescano 2007, 91) Für Gramsci handelt es sich hierbei um jene zivilgesellschaftlichen Apparate, in denen Hegemonie hergestellt wird; so beispielsweise Schule, Universität, Kirche, Medien etc. (vgl. ebd.). In der Rezeptionsgeschichte Gramscis griff insbesondere Althusser (u.a. 2010) diesen Gedanken in Form einer Unterscheidung repressiver und ideologischer Staatsapparate auf.

Trotz der Fragmentierung in unterschiedliche Apparate bleibt aber noch einmal auf die notwendige Kohärenz im Inneren des Staates/der Staatlichkeit hinzuweisen, auf die Gramscis Hegemonie-Begriff ebenso verweist. Demgemäß liegt im Kampf um Hegemonie auch die Aufgabe begründet, die Einheit des Staates beziehungsweise der Staatlichkeit, wie in den Ausführungen zu Poulantzas schon deutlich wurde, herzustellen beziehungsweise zu wahren. Um in der Begriffssphäre Gramscis zu bleiben, braucht es einer Übersetzung der Hegemonie als Kampfplatz der Zivilgesellschaft in ein Äquivalent innerhalb der politischen Gesellschaft, verstanden als Staat beziehungsweise Staatlich- 
keit `im engeren Sinne «. Insbesondere die Überlegungen Bob Jessops bieten eine solche Übersetzungsleistung im Terminus des sogenannten Staatsprojekts an, der im nachfolgenden Unterkapitel eingehender behandelt wird. Zuvor soll aber kurz auf die Frage eingegangen werden, ob es auf Grundlage des bisher gesagten zutreffend erscheint, die EU-Staatlichkeit als integral im Sinne Gramscis zu beschreiben.

\section{Integrale EU-Staatlichkeit}

Zentraler Bezugspunkt im Sinne der Erweiterung zum integralen Staate stellt in Gramscis Denken die Zivilgesellschaft dar. Autor*innen wie Wissel (2012, 10; 2017, 30f.), Georgi \& Kannankulam $(2012,5)$ oder Buckel et al. $(2012,16)$ konstatieren dabei, dass sich eine europäische Zivilgesellschaft bisher nur rudimentär und partiell herausgebildet habe und das europäische Staatsapparate-Ensemble deshalb verglichen mit den Mitgliedstaaten weniger integral abgesichert sei. Es scheint also bei der EU auf den ersten Blick ein Fall prekärer Staatlichkeit vorzuliegen, der sich von einer Konstellation vollkommener Staatlichkeit dadurch unterscheidet, dass genuin europäische Hegemonie- oder ideologische Staatsapparate, in denen sich die (zivil-)gesellschaftlichen Kräfteverhältnisse materialisieren, nur rudimentär vorhanden scheinen, was die hegemoniale Absicherung europäischer Staatlichkeit im Sinne Gramscis erschwert. So argumentiert Bihr $(2012,40)$, dass es, in Gramscis Kategorien gedacht, »keine oder kaum Hegemonie im seuropäischen Aufbau« "gebe. Zwar könne man zum Beispiel die Bemühungen der Europäischen Kommission im Kontext ihrer Überlegungen zur verstärkten Etablierung sogenannter Governance-Strukturen (o.g. Weißbuch von 2001) in dem Sinne werten, zivilgesellschaftliche Akteur*innen stärker in die Herrschaftsausübung der EU einzubinden. Allerdings, darauf weisen Kohler-Koch \& Quittkat (2011) hin, lassen sich für diese Strategie eher ernüchternde Befunde feststellen. Zugleich wirke nach Demirović (2001, 144) hierbei eine »Repräsentationsparadoxie«, bei der die Repräsentierten häufig erst durch zivilgesellschaftliche Repräsentant*innen erzeugt würden. Die eigentlich angestrebte Interessenverallgemeinerung, verstanden als ein Übersetzungsprozess zwischen ziviler und politischer Gesellschaft, bliebe somit aus.

Trotz der beschriebenen zivilgesellschaftlichen Prekarität der EU soll dennoch davor gewarnt werden, vorschnell eine Abwesenheit der zivilen Gesellschaft zu attestieren oder wie Bihr $(2012,40)$ gar davon auszugehen, dass sich Hegemonie nur im nationalen Rahmen herstellen könne. Dies soll durch zweierlei Erkenntnisse gestützt werden: Erstens weisen auch die eingangs zitierten Autor*innen, die lediglich rudimentäre zivilgesellschaftliche Strukturen attestiert haben, darauf hin, dass sich im supraund transnationalen Raum zunehmend zivilgesellschaftliche Akteur"innen herausbildeten (vgl. Wissel 2012, 10; Georgi \& Kannankulam 2012, 5 \& Buckel et al. 2012,16). Auch wenn die derzeitige seuropäische Zivilgesellschaft Schwachstellen aufweist, die sich beispielsweise in einem Überhang an wirtschaftsnahen Vereinigungen (Stichwort: Lobbyismus) und wenigen genuin-europäischen Organisationen und Akteur*innen (als Gegenpol zu bloßen »Dachverbänden«) ${ }^{3}$ zeigen, so repräsentieren die Genannten doch zugleich den Ausgangspunkt einer eigenständigen, verflochtenen europäischen Öffentlichkeit, die von einer kontinuierlichen Intensivierung zivilgesellschaftlicher Aktivitä- 
ten geprägt ist (vgl. u.a. Knodt \& Finke 2003, 419). Weiterhin lässt sich argumentieren, dass sich die EU-Zivilgesellschaft zusätzlich vermittelt durch die zivilen Gesellschaften der Mitgliedstaaten darstellen lässt. Im Sinne der hegemonialen Absicherung der EUStaatlichkeitsstrukturen, ist diese ebenso auf eine Verankerung in den mitgliedstaatlichen Zivilgesellschaften angewiesen. Hierauf verweist auch der lange in der Europawissenschaft attestierte >permissive Konsens . Somit sollte in Analogie zu ihren Staatsapparaten auch die Zivilgesellschaft der EU als ein multiskalares Ensemble betrachtet werden, da letztlich »die Rede von der Multiskalierung des Staates [...] nicht nur auf eine Ver- bzw. Auslagerung von Staatlichkeit auf sub- und suprastaatliche Ebenen, sondern auf deren gegenseitige Durchdringung« (Georgi, Kannankulam \& Wolff 2014, 90; Herv. J. G.) ziele. Auch die Zivilgesellschaften werden »in ein hegemoniales Verhältnis zueinander gesetzt und so vernetzt, dass es zu Verdichtungen und Knotenpunkten kommt.« (Demirović 2001, 166) Das in der politischen Soziologie häufig beschriebene Phänomen der >Europäisierung`verdeutlicht dies zusätzlich. Mit ihm wird der Prozess beschrieben, »in dem sich Nationalstaaten, ihre Institutionen und die politischen Kulturen in umfassender Weise durch die Orientierung an der EU- Ebene transformieren.« (Beichelt 2006, 171; vgl. ders. 2015) Insofern scheint es plausibel, bei der Europäischen Union von einem multiskalaren Staatlichkeits-Zivilgesellschafts-Komplex zu sprechen, der vor dem Hintergrund integraler Staatlichkeit im institutionellen Inneren einer tiefgreifenden Europäisierung unterzogen wurde, die in den unterschiedlichen zivilgesellschaftlichen Arrangements, Kontexten und Maßstabsebenen eingebettet ist. Im Sinne von Trenz ließe sich gar sagen, dass Fragen nach der Existenz einer EU-Zivilgesellschaft unangemessen erscheinen. Er argumentiert stattdessen, dass die Zusammenhänge zwischen Herrschaft, ziviler Gesellschaft und Öffentlichkeit auch in der EU schlichtweg nicht hintergangen werden könnten (vgl. Trenz 2005, 57). Hierbei

»handelt es sich weniger um das normative Postulat einer notwendigen Rückkoppelung an willentlich zu gestaltende demokratische Verfahren, als vielmehr um einen selbstkonstitutiven Zusammenhang, der sich in der dynamischen Auseinandersetzung von Öffentlichkeit und Zivilgesellschaft mit einer prinzipiell legitimationsbedürftigen und legitimitätsherausfordernden Herrschaft entfaltet.« (Ebd.; Herv. J. G.)

\section{4 Über "Staatsprojekte «, "Akkumulationsstrategien « und das EU-Staatlichkeitstelos}

Hegemonie lässt sich nach Gramsci als "zentrale[r] Modus bürgerlicher Herrschaft « begreifen, der »es dominanten gesellschaftlichen Kräften erlaubt, politische Führung zu erlangen.« (Buckel 2013, 18) Hegemonie beschreibt somit die Fähigkeit, im Prozess der »Universalisierung« einer »partikularen Position«

»eine `Weltauffassung « zu entwickeln, einen `common sense`, der sich in allen gesellschaftlichen Bereichen manifestiert. Sie ist demnach eine Art zu leben und zu denken; sie bestimmt die Vorlieben, den Ceschmack, die Mode sowie die moralischen und rechtlichen Normen. Sie organisiert das Verhältnis von Wissen und Wahrheit.« (Ebd., 
Wird Hegemonie so gefasst, ist augenscheinlich, dass sie eine "Organisationsleistung « voraussetzt (vgl. ebd., 18). In diesem Sinne lässt sich auch Hirschs $(2005,97)$ Hinweis auf die »politische Dimension« hegemonialer Verhältnisse verstehen, mit der er die Fähigkeit beschreibt, Werte- und Ordnungsvorstellungen in der Praxis umsetzen zu können (s.o.). Für die empirische Untersuchung hegemonialer Verhältnisse bleibt bis dato allerdings offen, wie sich ein solcher Prozess der Verallgemeinerung partikularer Werte- und Ordnungsvorstellungen analytisch fassen lässt. In der - später im Detail darzustellenden - historisch-materialistischen Politikanalyse (HMPA), deren Kern die forschungspraktische Verknüpfung von Gramscis Hegemoniekonzept und Poulantzas' Verständnis des Staates als soziales Verhältnis darstellt, wird eine solche Operationalisierung mit Rückgriff auf den Terminus des Projekts geleistet, der aus der neo-gramscianisch inspirierten Internationalen Politischen Ökonomie (IPÖ) aufgegriffen und von den Forscher*innen der >Forschungsgruppe Staatsprojekt Europa< weiterentwickelt wurde. Wie bereits der Name der Forschungsgruppe andeutet, spielt dabei das Staatsprojekt eine besondere Rolle im Kontext dieser notwendigen Organisationsleistung, verstanden als Verdichtungsprozess gesellschaftlicher Kräfteverhältnisse in den Staat oder äquivalenter Staatlichkeits-Formen und ihrer Apparate.

Das Staatsprojekt lässt sich als ein Projekt verstehen, welches die Einheit des Staates/der Staatlichkeit gewährleisten soll (vgl. Buckel 2011, 640). Es ist entsprechend Voraussetzung für die Wahrnehmung der Vielschichtigkeit des Staates/der Staatlichkeit und all seiner (sich zum Teil antagonistisch gegenüberstehenden) Teile und differenzierten Staatsapparate in Form eines sich verbindenden »einheitlichen Apparats«, wie man in Anlehnung an Poulantzas (s.o.) sagen könnte. Demnach verdichten sich »[i]n einem Staatsprojekt [...] all die gesellschaftlichen Strategien, die sich auf die institutionelle Struktur der politischen Apparate bzw. des Staates beziehen und die versuchen, dem Ensemble auf die eine oder andere Weise eine kohärente Struktur zu verleihen." (Wissel 2015, 28) Mit Staatsprojekten lässt sich somit der »institutionspolitische Kampf « (Ziltener 2000, 83) um die Staatlichkeit der EU begreifbar machen, der in der hegemonialen Auseinandersetzung permanent (mit) ausgetragen wird. Diese Permanenz ergibt sich aus der logischen Folgerung, dass sich das dominierende/hegemoniale Staatsprojekt durch die alltägliche Politikgestaltung (re-)produziert und dies auch muss, um Bestand haben zu können (vgl. Deppe 2015, 15). Das Staatsprojekt beziehungsweise die »konkurrierenden Staatsprojekte« (Jessop 1990, 9; Übers. J. G.) sind demnach selbst ein zentraler Gegenstand hegemonialer Kämpfe. Diese Funktion wird auch von Bob Jessop $(2002,6)$ beschrieben, der in seinen staatstheoretischen Schriften die Bedeutsamkeit von Staatsprojekten hervorgehoben hat:

»Following Gramsci's pioneering work, I argue that a key role in the exercise of hegemony and construction of an historic bloc is played by intellectuals who develop alternative economic strategies, state projects and hegemonic visions and my thereby help to consolidate an unstable equilibrium of compromise among different social forces around a given economic, political and social order.« (Vgl. auch Jessop 2008, 44)

Insofern werden durch Staatsprojekte Leitbilder, verstanden als bedeutsame Wahrnehmungs- und Deutungsmuster (vgl. Schneider 1992, 4), prozessierbar gemacht und in die Materialität der Staatlichkeit eingeschrieben. Weiter schreibt Jessop $(1990,9)$ über 
den Begriff des Staatsprojekts: »Its essential theoretical function is to sensitize us to the inherent improbability of the existence of a unified state and to indicate the need to examine the structural and strategic factors which contribute to the existence of state effectsı.«

Neben den Staatsprojekten, die insbesondere juristisch-politische Legitimationsaspekte zum Gegenstand haben (vgl. ebd., 219), verweist Jessop auf das Vorhandensein einer Akkumulationsstrategie als notwendige Voraussetzung zur erfolgreichen Herstellung eines hegemonialen Zustandes (vgl. ebd., 209).

»Accumulation strategies involve efforts to resolve conflicts between the needs of capital in general and particular capitals by constructing an imagined sgeneral economic interest « that will always and necessarily marginalize some capitalist interest. Economic hegemony exists where a given accumulation strategy is the basis for an institutionalized compromise between opposed social forces for coordinating, governing or guiding activities within and across different institutional orders around the pursuit of a particular economic trajectory.« (Jessop 2008, 30)

Anders ausgedrückt: »An raccumulation strategy< defines a specific economic >growth model complete with its various extra-economic preconditions and also outlines a general strategy appropriate to its realization.« (Jessop 1990, 198) Liegt die Organisationsleistung des Staatsprojekts in der wirkmächtigen Suggestion der Einheit der Staatlichkeit und in der Zuschreibung eines allgemeingültigen Staatlichkeitstelos, verweist die Akkumulationsstrategie auf eine Entsprechung im Raum des Produktionsprozesses und der Kapitalverwertung (vgl. ebd., 315).

In einem staatlichkeitstheoretischen Verständnis der Europäischen Union verweisen die Termini der Akkumulationsstrategie und insbesondere des Staatsprojekts folglich auf die notwendige Herstellung staatlicher Einheit im Inneren und der aufs Engste hiermit verbundenen Kohärenzbedürftigkeit nach außen. Anders gesagt, geht es, in Erinnerung an die oben angeführten Worte Buckels, um die Universalisierung partikularer Strategien und Interessen einzelner Akteur*innen - heuristisch darstellbar in Form sogenannter Hegemonieprojekte (s.u.) - und deren Einschreibung in die Staatlichkeitsstrukturen hinter dem Schleier eines sallgemeinen Interesses $\triangleleft$. Wie dargestellt darf eine solche Universalisierung nicht missverstanden werden als die reine Übersetzung partikularer Vorstellungen, Interessen und Leitbilder in die allgemeinen Strukturen. In Anlehnung an die skizzierten Verdichtungsprozesse und Hegemoniekämpfe in der Zivilgesellschaft handelt es sich hierbei stattdessen um die Genese eines Kompromisses, der allerdings darauf bedacht ist, seinen Kompromisscharakter im Interesse der >Einheit<, nicht öffentlich und wenn dann nur als >Konsens` zur Schau zu stellen. Hierbei bleibt aber ebenso erkennbar, dass trotz dieser Suggestion aufgrund der beschriebenen Selektivitäten und insbesondere sich wandelnder Kräfteverhältnisse letztlich die staatlichen Politiken nie eine vollkomme Kohärenz erreichen können und in sich konfliktorisch verbleiben müssen (vgl. Hirsch 2003, 18). 


\subsection{Die EU-Staatlichkeit als Praxis, Prozess, Verhältnis und Projekt}

In den vorausgegangenen Ausführungen wurde versucht, die Staatlichkeit der Europäischen Union anhand vierer Blickwinkel theoretisch fass- und analytisch begreifbar zu machen. Wie bereits Gramsci (1991-2002, 499) für sein integrales Verständnis des Staates bemerkte, beschreiben auch die hier präsentierten Blickwinkel auf die EUStaatlichkeit "im konkreten historischen Leben« den selben Gegenstand. Sie dienen in diesem Sinne der Akzentuierung zentraler Aspekte eines umfassenden analytischen Begriffsverständnisses, in dem sie sich gegenseitig durchringen und aufeinander bezogen sind. Die vier Blickwinkel stellen somit eine Einheit dar, in der die Materialität der EU-Staatlichkeit und somit ihre Gestalt und ihre Charakteristika sichtbar werden sollten.

Den Auftakt bildete hierbei die Entwicklung eines Verständnisses von der EUStaatlichkeit als Praxis, in dem sie als eine konkrete, reale Form sozialen Handelns aufgefasst wird. Es wurde einleitend auf die Zerfaserung klassischer NationalStaatlichkeit, wie Leibfried \& Zürn es umschreiben, hingewiesen und mit Schuppert darauf aufmerksam gemacht, dass durch eine Unterscheidung zwischen Staat und Staatlichkeit letztere nicht nur in Form einer nationalen Konfiguration denkbar ist. Staatlichkeit braucht in einer solchen Betrachtungsweise keinen (National-)Staat, um wirkmächtig zu sein, auch wenn sie bisher zumeist an den Anwendungsfall des modernen (National-)Staates rückgekoppelt bleibt (Verdichtung zweiter Ordnung \& Multiskalarität). Staatlichkeit ist demnach als ein institutionalisierter Modus der Herrschaftsausübung zu begreifen, der durch justizierbare Rahmen abgesteckt ist und über diesen legalisiert beziehungsweise legitimiert wird. Die räumliche Maßstabsebene, auf der ein solcher Herrschaftsmodus angesiedelt ist, lässt diese Definition hingegen bewusst offen. Auf Ebene konkreter, materialisierter Erscheinungsformen der EU-Staatlichkeit wurde auf das EU-Staatsapparate-Ensemble hingewiesen, das den institutionellen Staatlichkeitsrahmen beschreibt und durch Staatlichkeitsakte (u.a. durch die Gesetzgebung) und ihre Herrschaftsarrangements der EU-Staatlichkeit eine konkrete Erscheinungsform verleiht.

Unter dem Diktum der EU-Staatlichkeit als Prozess sollte verdeutlicht werden, dass die Genese von Staatlichkeit als ein langwieriger Kampf um die Akkumulation von Machtressourcen verstanden werden kann. Der von Bourdieu beschriebene Konzentrations- und Monopolisierungsprozess symbolischer Gewalt im Staate, der die Genese moderner Staatlichkeit begreifbar macht, zeigt, wie man auch die Herausbildung, die Transformation und den (künftigen) Ausbau der EU-Staatlichkeit analytisch verstehen kann. Im Prozess der Genese geht es folglich darum, die allgemein akzeptierte Fähigkeit zu erlangen, in einem spezifischen Bereich Vereinheitlichung, Zentralisierung, Standardisierung und Homogenisierung durchzusetzen, also das Monopol auf die legitime symbolische Gewalt zu erlangen und dieses zu konstitutionalisieren.

Die Staatlichkeit der EU als Verhältnis zu begreifen, heißt, sie und die sie fortentwickelnden Konstitutionalisierungsprozesse in ihren gesellschaftlich situierten Kontext zu stellen, in den sie hineinwirken und dessen Produkt sie letztlich sind. Es sind schlussendlich gesellschaftliche Kräfteverhältnisse, die sich in den Ausdrucksformen 
und den Strukturen der EU-Staatlichkeit in all ihrer antagonistischen Widersprüchlichkeit verdichten und ihr hierüber eine eigene Materialität verleihen. Staatlichkeit lässt sich demnach als eine soziale Form, genauer: politische Form, beschreiben, als eine Verobjektivierung sozialer Verhältnisse, die sich in den staatlichen Institutionen darstellt und sie konstituiert. Staatlichkeit als Verhältnis ist im Anschluss an Gramsci als eine integrale Staatlichkeit zu verstehen, die sich im Kampf um Hegemonie - also im Kampf um die Deutungshoheit in der sozialen Welt - materialisiert. Staatlichkeit setzt insofern eine Organisationsleistung in Form herzustellender Überzeugungen, Kompromisse, Konsens, Akzeptanz und einer kulturellen Vereinnahmung durch die führenden Akteur*innen voraus. Die hegemoniale Verankerung von Staatlichkeit in der Zivilgesellschaft kann als Voraussetzung für die Stabilität von Herrschaft verstanden werden. Vollkommene Staatlichkeit wirkt dort, wo sie sowohl in die politische wie auch in die zivile Gesellschaft eingeschrieben ist und sich möglichst ohne Repression - also ohne physische Gewaltsamkeit - reproduzieren kann.

Mit der Betrachtung der EU-Staatlichkeit als Projekt sollte zusätzlich verdeutlicht werden, dass im Sinne der Kämpfe um Hegemonie (Staatlichkeit als Verhältnis) zwischen der zivilgesellschaftlichen Sphäre, den konkreten Staatlichkeitspraxen sowie der Konzentrationsprozesse eine notwendige Brücke zu schlagen ist. Insofern bedarf es verbindender Elemente in Sinne einer Akkumulationsstrategie und eines Staatsprojektes, die den konkreten Erscheinungsformen der Staatlichkeit eine Sinn- und Zweck-Bestimmung einschreiben (Staatlichkeitstelos). Anders gesagt: Die Ausübung von Herrschaft auf Grundlage des symbolischen Gewaltmonopols wird durch das Staatsprojekt legitimiert, welches wiederum eine der besonderen Organisationsleistungen zur Erlangung der Hegemonie durch eine Akteursgruppe zur Voraussetzung hat.

Auf Grundlage der theoretischen Fundierung anhand der vier Blickwinkel bringt der Begriff der EU-Staatlichkeit somit insgesamt die konkreten Ausdrucksformen und Wirkungszusammenhänge der Herrschaftspraxen der Europäischen Union zur Geltung, die durch die gesellschaftlichen Kämpfe in einem kontingenten Raum an der Schnittstelle zwischen dem sich transformierenden (National-)Staat und der prozessualen Herausbildung einer politischen Form auf europäischer Ebene wirken. Schließlich wendet er sich als dynamischer Begriff gegen die Mystifizierung der EU als etwas gänzlich Eigenes ohne dabei dem Staat oder der Staatlichkeit einen ahistorischen und apodiktischen Geist zu bescheinigen, sondern stattdessen den historisch situierten Staatlichkeitscharakter der EU und ihre Materialität offenzulegen.

\subsection{Krisen als Kristallisationspunkt der Reproduktion und Transformation von Staatlichkeit}

Staatlichkeit ist, dies sollte aus den vorherigen Ausführungen deutlich geworden sein, darauf angewiesen, sich permanent zu reproduzieren. In >Normalzeiten $<$ geschieht dies über die alltägliche Politikgestaltung unterhalb der Oberflächenphänomene und verweist insofern auf einen Zustand vollkommener Staatlichkeit. Die grundsätzlichen Reproduktionsvoraussetzungen sind dabei bereits angesprochen: Hegemonie und das 
sich im Kampf um Hegemonie verdichtende Staatsprojekt. Zugleich ist der Reproduktionsprozess kein perpetuum mobile sondern bleibt in sich umkämpft, wie mit Verweis auf die gesellschaftlichen Kräfteverhältnisse betont wurde. Der beschriebene Reproduktionszusammenhang ist insofern bereits aus sich heraus aber insbesondere auch durch äußerliche Einflüsse störanfällig. Gerade in solchen Störungsmomenten sieht Bourdieu $(2017,208)$ die Voraussetzung gegeben, zuvor unhinterfragte und als selbstverständlich aufgefasste doxische Praxen in Frage zu stellen. Geschieht dies, ist eine Krise des Reproduktionszusammenhangs am Werk, die sich als eine "Zwischenzeit" auffassen ließe, »in de[r] die gewohnte Ordnung nicht mehr funktioniert, aber noch keine neue Regelungsweise gefunden ist.« (Haug 2010, 2121) In einer solchen Konnotation verweist Haug auf Krisenerscheinungen im >politischen Überbau<, der - wie auch im Falle der Euro-Krise - häufig ökonomische Krisenerscheinungen vorausgehen.

Meist wird »[d]er Begriff >Krise< [...] als eine Zustandsbeschreibung verwendet. Im Allgemeinen bezeichnet er ein System, das dysfunktional und daher gefährdet ist « (Thiel 2016). Unter einer Krise werde demzufolge eine Konstellation verstanden, »in der ein Systembestand mit mehr Problemen konfrontiert ist, als er in seinem status quo zu lösen vermag, so dass unter Zeitdruck Veränderungen vorgenommen werden müssen, um den Systembestand zu erhalten; und in der ungewiss ist, ob dies gelingt." (Vobruba $2015,45)$ Konstitutiv für den Krisenbegriff seien dabei fünf Bedingungen: »Die Überforderung der Problemlösungskapazität eines Systembestandes, Zeitdruck, relevante Akteure und deren handlungsleitende Kriseninterpretationen und Offenheit der Konstellation.« (Ebd.) Zurecht wird darauf hingewiesen, dass Krisen und insbesondere ihr Diagnostizieren stets als ein politischer Akt zu verstehen sind:

»Wer von der Krise spricht [...], will zum Handeln anregen. Er erachtet eine Situation als untragbar und behauptet, dass der Status Quo nicht fortgeführt werden kann. Krise impliziert Negativität und Bedrohung; von der Krise zu sprechen spitzt eine Situation auf eine Entscheidung hin zu: Entweder muss es Veränderung geben oder aber es droht der Untergang. Eine Krise ist umfassend, sie stellt eine systemweite Bedrohung dar und unterminiert charakteristische Handlungsmuster und Routinen. Krise suggeriert Dringlichkeit, sie ist eine Ausnahmesituation und für die Lösung der Krise stehen daher Mittel bereit, die weit über das hinausgehen, was im Normalmodus selbst angelegt ist oder auch nur für möglich erachtet wird. Jede Krisendiagnose hat daher eine performative Kraft: Wird sie geteilt, so ist sie unmittelbar handlungsrelevant. « (Thiel 2015, 101f.; vgl. Thiel 2016; Brand 2009a, 2; Bieling, Haas \& Lux 2013, 234)

Ausgehend von einer solchen allgemeinen Umschreibung lassen sich Krisen anhand diverser räumlicher, zeitlicher und kategorialer Aspekte sowie ihrer jeweiligen Tiefe und Intensität voneinander unterscheiden.

Der Bereich des Ökonomischen ist wohl jener, der am ehesten mit dem Terminus der Krise verbunden wird. Das Aufkommen von Schwankungen im konjunkturellen Kreislauf kapitalistischen Wirtschaftens ist evident und insbesondere für ein marxistisch-orientiertes Ökonomieverständnis »keine Abweichung von einem Gleichgewichtspfad« (Heinrich 2010, 140), sondern ein den Kapitalismus charakterisierendes Merkmal (vgl. auch Buckel, Fischer-Lescano \& Oberndorfer 2010, 376). Dabei lassen sich »zyklische ökonomische Krise[n] (Demirović 2007a, 158) beziehungsweise »kon- 
junkturelle [...] von großen Krisen unterscheiden.«(Bader et al. 2011, 11) Konjunkturelle Krisen treten »in einem Rhythmus von vier oder fünf Jahren auf [...]. Sie sind eingebettet in einen längeren Rhythmus von 40 bis 60 Jahren, in dem sich die gesellschaftlichen Widersprüche zu Strukturkrisen aufschaukeln und entladen.« (Ebd.) In einer solchen großen ökonomischen Krise kommen schließlich

»die widersprüchlichen Entwicklungen von Produktion und Konsumtion zum Eklat. Es findet eine gewaltsame, aber nur momentane Auflösung des Widerspruchs zwischen Produktion und Konsumtion statt: in der Regel durch die Vernichtung nicht nur bereits produzierter Güter, sondern auch eines Teils der Produktionsanlagen durch Bankrotte und Kapitalentwertungen. Auf der gewaltsam reduzierten Grundlage kann die Akkumulation des Kapitals dann erneut beginnen - bis zum nächsten Crash.« (Heinrich 2010, 142)

Dabei darf nicht übersehen werden, dass ökonomische Krisen, egal ob konjunkturell oder im Sinne größerer Wirtschaftskrisen, immer in einem engen Verhältnis zu den Prozessen des >politischen Überbaus stehen. Ökonomische und politische Krisen sind in einer »jeweils spezifischen Form miteinander artikuliert.« (Demirović 2007a, 153) Dies ergibt sich aus den wechselseitigen Beziehungen zwischen ökonomischer Basis und politischem Überbau und der Notwendigkeit der »Reproduktion der Produktionsbedingungen« (Althusser 2010, 37) durch die Mechanismen im politischen Überbau:

"Zwischen der Reproduktion des Kapitals und der Reproduktion der autonomen gesellschaftlichen Bereiche besteht trotz Autonomie ein inneres Abhängigkeitsverhältnis, das sich daraus ergibt, dass keiner dieser Bereiche sich über längere Zeit reproduzieren kann, wenn er nicht selbst wiederum durch gesellschaftliche Arbeit reproduziert würde.«(Bader et al. 2011, 12)

Es wäre aber falsch, anzunehmen, dass ökonomische Krisen zwangsläufig auch zu politischen Krisen führen müssten. Vielmehr ließe sich ein elementares Interesse der Herrschenden beschreiben, "zu verhindern, dass die Krisendynamik von einem Bereich auf andere übergreift und dadurch jeweils noch verschärft wird.«(Ebd.) Deshalb lassen sich politische Krisen nicht einfach als eine Fortsetzung ökonomischer Krisen begreifen. Demirović $(2007 a, 158)$ beschreibt zutreffend, dass »[d]ie politische Krise [...] vielmehr auf eine besondere Situation der Verdichtung der Widersprüche im Bereich der Politik einschließlich der Staatsapparate hin[weist]« (vgl. auch Demirović 2011b, 65). Politische Krisen lassen sich wiederum in unterschiedlicher Art und Weise auffassen, weshalb auch in den Diskursen rund um die Euro-Krise eine große Bandbreite an Beschreibungsformeln zu finden ist.

Gramsci (1991-2002, 1069f.) unterscheidet konjunkturell-zyklische Krisen im obigen, ökonomischen Sinne von sogenannten organischen Krisen, in denen es »zu einer Verdichtung und Verschränkung unterschiedlicher Krisen [kommt], die zu Konflikten und Blockierungen innerhalb des Blocks an der Macht führen." (Candeias 2011, 46) Eine solche Krisenkonstellation »lässt sich innerhalb der gegebenen Regulationsweise nicht ausreichend bearbeiten, obwohl Modifikationen ihre krisenhafte Verdichtung verzögern können«, so Candeias $(2011,47)$. Der herrschende Machtblock habe in einer solchen Krise dieser »keine produktiven Lösungen mehr entgegenzusetzen, die die 
Interessen der Subalternen und damit den aktiven Konsens [...] wieder herstellen könnten.«(Ebd., 59) Gramsci (1991-2002, 1578) spricht hierbei von einer »Autoritätskrise«, die darauf verweist, dass es sich bei der organischen Krise letztlich um eine Hegemoniekrise handelt, bei der an die Stelle der Krisenauflösung ein Krisenmanagement tritt, welches den Kollaps zwar verhindere, zugleich aber »ein Prozessieren der Krise auf anderen Ebenen« (Candeias 2011, 59) befördere:

»Wenn die herrschende Klasse den Konsens verloren hat, das heißt nicht mehr sührend ‘, sondern einzig sherrschend ist, Inhaberin der reinen Zwangsgewalt, bedeutet das gerade, daß die großen Massen sich von den traditionellen Ideologien entfernt haben, nicht mehr an das glauben, woran sie zuvor glaubten usw. Die Krise besteht gerade in der Tatsache, daß das Alte stirbt und das Neue nicht zur Welt kommen kann [...].«(Gramsci 1991-2002, 354)

Gramsci bezeichnet eine solche historische Phase als »Interregnum« (ebd.).

Eine etwas differenziertere, auf Gramsci aufbauende Betrachtungsweise politischer Krisen lässt sich bei Poulantzas finden, der politische Krisen als Situationen versteht, "in denen der bestehende Modus der politischen Herrschaft in Frage gestellt wird." (Sablowski 2006, 260) Charakteristisch für eine politische Krise sei, dass sich Widersprüche zwischen den Fraktionen im Machtblock verschärfen und politisieren würden (vgl. Demirović 2011b, 71; 2007a, 158f.; Sablowski 2006, 260). In einer solchen Situation wird die Hegemonie des Machtblocks beziehungsweise der Akteur*innen des hegemonialen Projekts in Frage gestellt. Es entstehe eine »hegemoniale Instabilität (Demirović 2011b, 71), die bereits in Gramscis Krisenverständnis hervorgehoben wurde. Poulantzas unterscheidet von einer solchen Hegemoniekrise im Sinne Gramscis als eine weitere konkrete Erscheinungsform die Staatskrise. Sie »ist ein Element der politischen Krise, denn die Veränderungen in den Kräfteverhältnissen wirken sich im Inneren der Staatsapparate aus, führen zu Konflikten in den einzelnen Apparaten und zwischen ihnen « (Demirović 2007a, 159). Sie stelle eine Situation dar, in der »der Staat nicht mehr seine Funktion erfüllen kann, den Machtblock zu organisieren und die beherrschten Klassen zu desorganisieren. (Sablowski 2006, 261) Poulantzas schafft demnach für die Analyse eine wichtige Unterscheidung zwischen Hegemonie- und Staatskrisen, die darin begründet liegt, Krisenphänomene in beiden Sphären des integralen Staates besser fassbar zu machen, auch wenn die politische und somit auch die Staatskrise für Poulantzas immer auch mit einer ideologischen Krise (Hegemonie) verbunden ist (vgl. ebd., 263).

Auf Grundlage der präsentierten allgemeinen Krisendefinitionen soll für die Terminologie dieser Arbeit folgendes Verständnis politischer Krisen zu Anwendung kommen, in das schließlich die Analysen zur Euro-Krise und der kriseninduzierten Staatlichkeitstransformationen eingebettet sind: Erstens gilt es darauf hinzuweisen, dass politische Krisen sich nicht zwangsläufig zu systemischen Krisen im Sinne einer umfassenden Hegemonie- oder Staatlichkeitskrise verdichten müssen. Wenn politische Krisen(erscheinungen) konstatiert werden, also ein Handlungsdruck, der aufgrund seiner zeitlichen Dringlichkeit beziehungsweise seines unerwarteten Auftretens, entsteht, können diese gegebenenfalls bereits im bestehenden Rahmen der Staatlichkeit gelöst werden, ohne hierbei den Fortbestand des Staates beziehungsweise des StaatsapparateEnsembles oder die Hegemonie in Frage zu stellen. Eine solche Feststellung ist zwar 
durchaus auch bei Gramsci und Poulantzas enthalten, sie soll an dieser Stelle aber noch einmal explizit gemacht werden. Erst wenn sich eine Krisenkonstellation innerhalb der bestehenden Strukturen nicht auflösen lässt, äußert sich - zweitens - in einer politischen Krise eine Funktionskrise, in der es die eigentlich zur Krisenlösung vorgesehenen Instanzen und Apparate nicht schaffen, die Krise zu überwinden. Eine Funktionskrise muss dabei aber noch nicht zwangsläufig die Hegemonie in Frage stellen, vielmehr lässt sich annehmen, dass eine solche Krisensituation beispielsweise dadurch überwunden werden kann, dass eine andere Fraktion im Block an der Macht beziehungsweise im Inneren des führenden Hegemonieprojekts die Führung übernimmt, die dabei aber den ideologischen Grundkonsens (Staatsprojekt) weitestgehend beibehält. Daher lässt sich eine Funktionskrise lösen, ohne dass sich größere Veränderungen in den hegemonialen, durchaus aber in den Kräfteverhältnissen vollziehen. Artikulieren sich in einer akuten politischen Krise - drittens - hingegen auch in der ideologischen Sphäre Krisenerscheinungen, lässt sich von einer umfassenden Hegemoniekrise nach Gramscis sprechen. In einer solchen Situation existiert nicht nur eine Krise im Sinne fehlgeleiteter und handlungsunfähiger Herrschaftsausübung, sondern findet vielmehr auch die Infragestellung der bis dato vorherrschenden Rechtfertigungsmodi für die Herrschaftsausübung statt. Phänotypisch können sich dabei die ideologische oder Hegemoniekrisen auch in weiteren Formen wie Legitimations- oder Partizipationskrisen zeigen. Die beiden letztgenannten fügen sich aber in die zwei vorgenannten ein. Schließlich - viertens - bliebe im Anschluss an Poulantzas am Ende der Krisenkaskade eine umfassende Staatlichkeitskrise zu beschreiben, bei der es die Staatsapparate und die handelnden Akteur*innen im Machtblock selbst nicht mehr schaffen, die innere Einheit des Blocks beziehungsweise des dominierenden Hegemonieprojekts herzustellen. Diese Instabilität eröffnet ein Möglichkeitsfenster radikaler Veränderung, führt zugleich aber auch zu Auflösungserscheinungen des symbolischen Gewaltmonopols und damit zur grundsätzlichen Infragestellung der Staatlichkeit.

Abbildung 1: Potenzielle Krisenkaskade

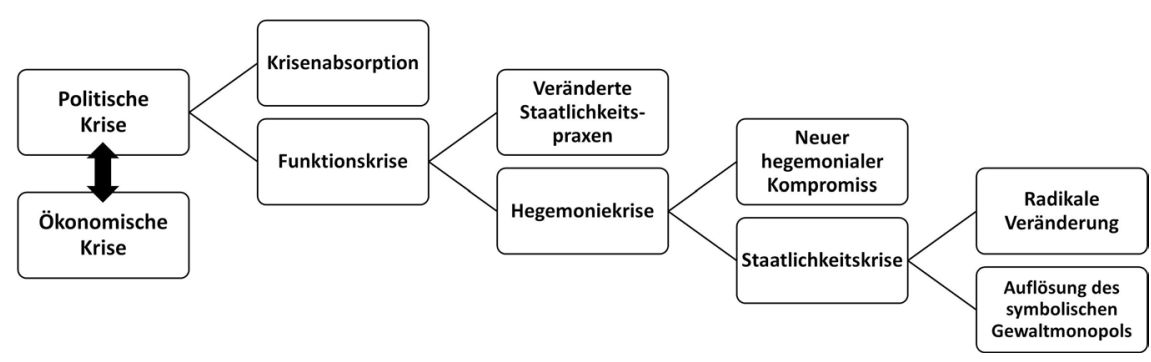

Quelle: Eigene Darstellung 


\section{Historisch-materialistische Staatlichkeitsanalyse}

Im Rahmen dieser Arbeit wird ein Untersuchungsansatz verfolgt, der als historisch-materialistische Staatlichkeitsanalyse bezeichnet werden soll. Er lehnt sich an der von der Forschungsgruppe >Staatsprojekt Europar entwickelten shistorisch-materialistischen Politikanalyse (HMPA) an (vgl. Buckel et al. 2014; Buckel 2013; Kannankulam \& Georgi 2012; vgl. auch Brand 2013), wird aber angereichert, um die Transformation und den Ausbau der EU-Staatlichkeit in der Euro-Krise stärker in den Fokus zu rücken. Die HMPA als methodisches Grundgerüst bietet sich insbesondere deshalb an, da sie entwickelt wurde, um die Erkenntnisse materialistischer Staatstheorie für die empirische Arbeit zu operationalisieren (vgl. Buckel et al. 2014, 43). Vorleistungen zu diesem kritischen Forschungsparadigma gehen unter anderem auf Bob Jessop (z.B. 1990), Bastian van Apeldoorn (u.a. 2000; 2002) sowie Hans-Jürgen Bieling \& Jochen Steinhilber (bspw. 2000b) zurück. Infolgedessen weist die HMPA auch direkte Bezüge zum eingangs dargestellten >konstitutionalistischen Neogramscianismus der Internationalen Politischen Ökonomie auf (vgl. Buckel et al. 2014, 34ff.).

In der Europaforschung fragen neo-gramscianische Ansätze indes »nach den gesellschaftlichen Kräften sowie den Auseinandersetzungen in der ökonomischen, politisch-institutionellen und ideologischen Sphäre (Bohle 2012, 165), auf deren Grundlage sie die Dynamiken und Reproduktionsbedingungen europäischer Integrationsprozesse erklären. Auch die HMPA fühlt sich diesem Ansatz verpflichtet. Sie

»analysiert Kontext, Akteur_innen und Prozesse gesellschaftlicher Auseinandersetzungen über bestimmte Politiken, um aufzudecken, mit welchen gesellschaftlichen Widersprüchen, Dynamiken sozialer und politischer Kämpfe und mit welchen gesellschaftlichen Kräfteverhältnissen diese Politiken verbunden sind.« (Forschungsgruppe >Staatsprojekt Europa<2014, 10)

Die klassische HMPA gliedert sich dabei anhand dreier Schritte: der Kontext-, der Akteurs- und der Prozessanalyse (vgl. Buckel et al. 2014, 53). Je nach Forschungsfokus können sich dabei die jeweiligen Teilanalysen in Aufbau und Tiefe voneinander unterscheiden, was nicht zuletzt in einer mit der HMPA verbundenen Überkomplexitätsherausforderung (vgl. ebd.) und den meist limitierten Ressourcen ihrer Anwender*innen (vgl. ebd., 59) begründet liegt. 
Im Zentrum der HMPA steht die Analyse von gesellschaftlichen Kräfteverhältnissen. Pointiert gesagt, könnte man sie dementsprechend auch als Kräfteverhältnisanalyse bezeichnen (vgl. Kannankulam \& Georgi 2012, 37; Wissel 2015, 56). Im Rahmen der vorliegenden Arbeit bilden vor dem Hintergrund der theoretischen Vorüberlegungen zur Staatlichkeit als Verhältnis gerade die durch die HMPA zu extrahierenden gesellschaftlichen Kräfte- und Hegemonieverhältnisse eine entscheidende Erklärungsvariable zum Verständnis der kriseninduzierten Transformations- und Ausbauprozesse der EU-Staatlichkeit. Allerdings erscheint die Durchführung einer reinen HMPA der Politik zur Bewältigung der Euro-Krise nicht hinreichend, um diese Prozesse in ihrer vollen Breite analytisch $\mathrm{zu}$ adressieren. So weisen bereits Kannankulam \& Georgi $(2012,37)$, selber Mitglieder der Forschungsgruppe, darauf hin, dass in einem vierten Schritt "schließlich die materielle Verdichtung [...] in die politischen und juridischen Institutionen und Apparate mit deren jeweiligen strukturellen Selektivitäten untersucht werden [muss].« Dieser Hinweis erscheint zielführend, weshalb unter Bezugnahme auf Staatlichkeit als Projekt eine an die drei Teilschritte der HMPA anschließende Verdichtungsanalyse vorgenommen werden soll. Bevor allerdings überhaupt in diese vier Analyseschritte eingestiegen werden kann, bedarf es eingangs einer umfassenden Analyse der kriseninduzierten Konstitutionalisierungsprozesse. Im ersten Analyseschritt werden demgemäß die im Kontext der Euro-Krise vollzogenen Konstitutionalisierungen im Prozess der Monopolisierung und Konzentration symbolischer Gewaltsamkeit im Inneren der EU-Staatlichkeit (Staatlichkeit als Prozess) und ihrer konkreten Herrschaftsmodi (Staatlichkeit als Praxis) zu dechiffrieren versucht. Dieser Untersuchungsschritt soll als rekonstruktive Konstitutionalisierungsanalyse bezeichnet werden:

Abbildung 2: Idealtypische Abfolge der historisch-materialistischen Staatlichkeitsanalyse

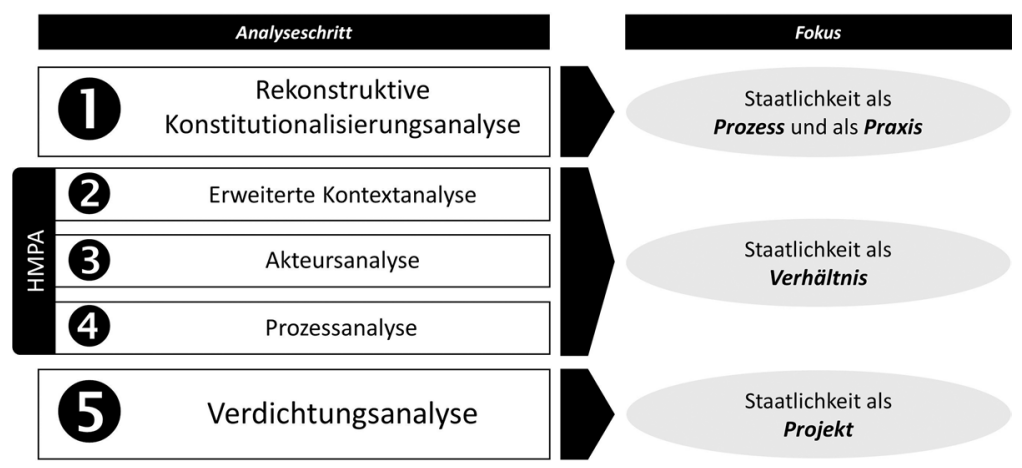

Quelle: Eigene Darstellung 


\subsection{Rekonstruktive Konstitutionalisierungsanalyse}

Im Rahmen der rekonstruktiven Konstitutionalisierungsanalyse gilt es herauszuarbeiten, welche Konstitutionalisierungsprozesse sich im Kontext der Politik zur Bewältigung der Euro-Krise vollzogen haben und wie sich die Staatlichkeit der EU durch diese verändert hat. Die Identifizierung und Charakterisierung von Transformationen der EU-Staatlichkeit als Praxis und Prozess stehen hierbei im Zentrum. Demnach geht es darum, mögliche Konzentrations- und Monopolisierungsprozesse in der Genese der EU-Staatlichkeit $\mathrm{zu}$ identifizieren und sie in ihrer praktischen Wirkungsweise in die Herrschaftspraxen einzuordnen. Konkreter ausgedrückt geht es darum, nachzuzeichnen, welche Herrschaftsbefugnisse durch die Krisenbewältigungspolitik einerseits der suprastaatlichen Ebene eingeschrieben werden und andererseits herauszustellen, wo diese im EU-Staatapparate-Ensemble lokalisiert werden können. Neben dieser manifesten Staatlichkeitsebene - im Sinne von Staatlichkeitspraxen - fördert die Analyse zugleich auch erste Eindrücke latenter Deutungszusammenhänge zu Tage, die auf ein Staatlichkeitstelos im Sinne der EU-Staatlichkeit als Projekt schließen lassen. Schließlich gilt es ferner, auf Ebene des Staatsapparate-Ensembles die Auseinandersetzung zwischen einzelnen Staatsapparaten mit in die Rekonstruktion einfließen zu lassen, um bereits erste Hinweise auf gesellschaftliche Konfliktlinien und Kräfteverhältnisse zu generieren.

Datengrundlage der rekonstruktiven Konstitutionalisierungsanalyse stellen offizielle EU-Dokumente dar, die anhand der Methodik einer politikwissenschaftlichen Quellenund Dokumentenanalyse untersucht werden. Generell sind dabei all jene Dokumente von Interesse, die der Bewältigungspolitik im Rahmen der Euro-Krise zuzuordnen sind. Inhaltlich lässt sich dieses Feld mithilfe der unionsvertragsrechtlichen Eingrenzung auf die Europäische Wirtschafts- und Währungsunion (EWWU), wie sie in Titel VII des dritten Teils des Vertrags über die Arbeitsweise der Europäischen Union (AEUV) kodiert ist, beschränken, wenngleich die Querbezüge zu anderen Politikfeldern immer wieder auch einen partiellen Einbezug von Dokumenten angrenzender Bereiche erfordert. Dies wird zum Beispiel in Bezug auf die sogenannte Bankenunion deutlich, die sich vertraglich auf den Titel I des dritten AEUV-Teils (»Der Binnenmarkt«) stützt.

Mit der Benennung der Fragestellungen und der später noch ausführlicher darzulegenden Auswahl der Dokumente sind nach Reh $(1995,212 \mathrm{f}$.) bereits die ersten beiden Teilschritte einer politikwissenschaftlichen Quellen- beziehungsweise Dokumentanalyse absolviert. Die eigentliche Analyse beginnt mit der ıäußeren Kritikı, »die zur Klarheit über Entstehungszeit, Entstehungsort, Verfasser, Adressat, Textstatus und Herkunft des Dokuments führen soll.« (Ebd., 213) Im vorliegenden Fall gilt es hierbei kurz auf drei unterschiedliche Dokumentengattungen einzugehen, die in die Analyse einfließen: 
Tabelle 1: Gattungen von EU-Dokumenten

\begin{tabular}{|c|c|c|c|}
\hline & $\begin{array}{l}\text { Legislative } \\
\text { Dokumente }\end{array}$ & $\begin{array}{l}\text { Leitbildliche } \\
\text { Dokumente }\end{array}$ & $\begin{array}{c}\text { Prozessgenerierte } \\
\text { Dokumente }\end{array}$ \\
\hline $\begin{array}{l}\text { Beschreib- } \\
\text { ung }\end{array}$ & $\begin{array}{l}\text { Bei diesen Dokumenten } \\
\text { handelt es sich um Ce- } \\
\text { setzgebungs- oder Ver- } \\
\text { tragsakte. Mit ihnen geht } \\
\text { eine direkte Rechtsver- } \\
\text { bindlichkeit einher. }\end{array}$ & $\begin{array}{l}\text { In solchen Dokumenten } \\
\text { werden politische Maß- } \\
\text { nahmen in einen über- } \\
\text { greifenden Zusammenhang } \\
\text { eingeordnet. } \\
\text { Sie liefern Hinweise auf } \\
\text { leitbildliche Verortungen. }\end{array}$ & $\begin{array}{l}\text { Prozessgenerierte Doku- } \\
\text { mente werden beiläufig } \\
\text { im politischen Prozess } \\
\text { produziert und dienen un- } \\
\text { terschiedlichen Zwecken } \\
\text { (bspw. der Vorbereitung } \\
\text { oder Kommunikation). }\end{array}$ \\
\hline Beispiele & $\begin{array}{l}\text { Verordnungen, Richtlinien } \\
\text { Verträge, völkerrechtliche } \\
\text { Erklärungen, ... }\end{array}$ & $\begin{array}{l}\text { Weißbücher, Perspektiv- } \\
\text { papiere, Initiativstellung- } \\
\text { nahmen, ... }\end{array}$ & $\begin{array}{l}\text { Protokolle, Sitzungsunter- } \\
\text { lagen, Briefe, Pressemittei- } \\
\text { lungen, ... }\end{array}$ \\
\hline $\begin{array}{l}\text { Analy- } \\
\text { tische } \\
\text { Relevanz }\end{array}$ & $\begin{array}{l}\text { Diese Dokumentengattung } \\
\text { steht bei der Beschreib- } \\
\text { ung von Konstitutionali- } \\
\text { sierungsprozessen im } \\
\text { Mittelpunkt. }\end{array}$ & $\begin{array}{l}\text { Sie bilden meist den Auf- } \\
\text { takt von Konstitutionalisier- } \\
\text { ungsprozessen und bieten } \\
\text { Hinweise auf das Telos } \\
\text { von Konstitutionalisierungs- } \\
\text { prozessen. }\end{array}$ & $\begin{array}{l}\text { Die sitzungsbegleitenden } \\
\text { Prozessdokumente dienen } \\
\text { zur Rekonstruktion. }\end{array}$ \\
\hline
\end{tabular}

Quelle: Eigene Zusammenstellung

Der >äußeren ‘ folgt die >innere Kritik`, die einerseits eine sprachliche und andererseits eine sachliche Aufschlüsselung umfasst (vgl. ebd., 215f.). Die sachliche Aufschlüsselung erfolgt zum einen in Form einer Zusammenfassung, mit dem Ziel einer Reduktion des Textmaterials, zum anderen in Form einer Explikation, mit dem Ziel zusätzliches erläuterndes, erklärendes oder deutendes Material heranzuziehen und das Verständnis zu erweitern und/oder schließlich in Form einer Strukturierung, bei der »nach der eigenen Fragestellung relevante Aspekte [...] unter vorher festgelegten inhaltlichen Gesichtspunkten aus dem Material herausgearbeitet bzw. dieses daraufhin ausgewertet werden [sollen].« (Ebd., 216) Dabei gilt es, in der Analyse zwischen den manifesten und latenten Sinnstrukturen innerhalb der herangezogenen Dokumente zu unterscheiden (vgl. Salheiser 2014, 815; Heckmann 1992, 143). Während sich auf der manifesten Sinnebene konkrete Veränderungen beschreiben lassen, die direkt interpretierbar sind, werden die latenten Sinnzusammenhänge im besten Fall noch angedeutet und daher erst durch die Interpretation des Forschenden sichtbar. Hierbei handelt es sich zugleich um subjektiven Sinn, dessen Verstehen »eine Rekonstruktion von Motiven, Einstellungen, Erwartungen, Deutungen und >Weltsichten $<$ einer Person [bedeutet], die sich in einem Text äußert« (Heckmann 1992, 143). Zugleich heiße »Verstehen des >objektiven Sinns in subjektiven Äußerungen [...] Aussagen zu machen über die Entstehung, Bedeutung und Wirkung von in Texten repräsentiertem subjektivem Sinn für bestimmte soziale und individuelle Strukturen und Prozesse«, so Heckmann (1992, 143f.) weiter. Bei der Darstellung der Analyseergebnisse gilt es, hiermit transparent umzugehen, zumal eine Dokumentenanalyse immer auch »mit einer Rekonstruktion des Entstehung- und Nutzungskontextes des Dokumentes einhergehen [muss] (Salheiser 2014, 816). Reh (1995, 217f.) bezeichnet diese Notwendigkeit als fünften Teilschritt (`historische Kritik`), dem 
bereits im Rahmen der rekonstruktiven Konstitutionalisierungsanalyse durch ergänzend heranzuziehende Sekundärliteraturbestände Rechnung getragen wird. Vollumfänglich wird dieser Schritt aber erst in der sich anschließenden erweiterten Kontextanalyse - als erster Schritt der klassischen HMPA - abgeschlossen. Beide Analyseschritte sind hierbei aufs Engste miteinander verwoben. Neben Sekundärbeständen dienen insbesondere auch prozessgenerierte Dokumente der Anreicherung der historischen Situiertheit der zentralen legislativen und leitbildlichen EU-Dokumente.

Neben den genannten methodischen Parametern einer politikwissenschaftlichen Quellen- und Dokumentenanalyse orientiert sich das vorgestellte Vorgehen zudem an einem grundständigen Verständnis hermeneutischer Interpretationsverfahren (vgl. Simonis \& Elbers 2011, 123f.), wodurch insgesamt der strukturelle und sinnbildende Inhalt der Dokumente erfasst, verstehbar und für die weiteren Analyseschritte interpretierbar gemacht werden soll. Heckmann (1992) formuliert insgesamt 19 Interpretationsregeln, die es bei der Auswertung von Texten unter Heranziehung eines hermeneutischen Grundverständnisses in der empirischen Sozialforschung zu berücksichtigen gelte. Angelehnt an eine Essenz der Heckmann'schen Regeln, die gewisse Redundanzen eliminiert, wird innerhalb dieser Arbeit mit den in der Tabelle 2 hinterlegten 13 Leitlinien operiert. Es gilt darauf hinzuweisen, dass diese allerdings »kein technisches Instrumentarium « (ebd., 146) darstellen, sondern als Art Metaverortung der eigenen Interpretationstätigkeit zu verstehen sind, bei der die genannten Leitlinien oder »Prinzipien« so ausgestaltet sind, dass sie »bestimmte Voraussetzungen und Verfahren für die Annäherung an intersubjektiv kontrollierbare Interpretation qualitativer Daten beinhalten.« (Ebd., 142)

Tabelle 2: Sozialwissenschaftliche Leitlinien hermeneutischer Interpretation

\begin{tabular}{|c|c|c|c|}
\hline Linguistische & Soziale & Inhaltliche & Methodische \\
\hline \multicolumn{4}{|c|}{ Leitlinien } \\
\hline $\begin{array}{l}\text { a) Kenntnis des text- } \\
\text { und kontextuellen } \\
\text { Symbol- \& Sprach- } \\
\text { musters } \\
\text { b) Beachtung der } \\
\text { Texttotalität (Textteile } \\
\text { vs.Cesamttext) } \\
\text { c) Textualität der } \\
\text { Bedeutung } \\
\text { (sprachlich: Wort> } \\
\text { Satz> Text) }\end{array}$ & $\begin{array}{l}\text { d) Soziale Eingebun- } \\
\text { denheit desInterpre- } \\
\text { tationsgegenstandes } \\
\text { e) Kulturelle Rückge- } \\
\text { bundenheit } \\
\text { f) Eingebundenheit } \\
\text { im Kommunikations- } \\
\text { prozess } \\
\text { g) Kontextualität der } \\
\text { Bedeutung und des } \\
\text { Entstehungszusam- } \\
\text { menhangs }\end{array}$ & $\begin{array}{l}\text { h) Bewusstsein über } \\
\text { Vorverständnisse } \\
\text { i) Kenntnis des } \\
\text { Gegenstandsbereichs }\end{array}$ & $\begin{array}{l}\text { j) Extrahierung statt } \\
\text { Hineinlegung des } \\
\text { Sinns in den Interpre- } \\
\text { tationsgegenstand } \\
\text { k) Grundlegende } \\
\text { Offenheit und Toleranz } \\
\text { I) Aufmerksamkeit, } \\
\text { Sensibilität \& Inten- } \\
\text { sität } \\
\text { m) Verstehenszirkel }\end{array}$ \\
\hline
\end{tabular}

Quelle: Eigene Zusammenstellung auf Grundlage von Heckmann (1992) 


\subsection{Kräfteverhältnisanalyse}

Im Anschluss an die rekonstruktive Konstitutionalisierungsanalyse und in Ergänzung dieser beabsichtigt die erweiterte Kontextanalyse den »historisch-dynamischen und strukturellen Kontext« (Buckel et al. 2014, 54), in den sich die herausgearbeiteten Staatlichkeitstransformationen einbetten, erweitert herauszuarbeiten. Die Erweiterung der historischen Kritik im Rahmen der politikwissenschaftlichen Dokumentenanalyse ergibt sich dabei aus dem Verständnis von Staatlichkeit als soziales Verhältnis. Mit ihm erweitert sich der Fokus vom institutionell-apparatlichen zum gesamtgesellschaftlichen Kontext; schließlich bildet die Kontextanalyse den ersten Schritt der HMPA, deren Kernanliegen die Untersuchung gesellschaftlicher Kräfteverhältnisse darstellt. Dabei dient sie dem Ziel, »unterschiedliche historisch-strategische Prozesse [zu] identifizieren, welche zusammengenommen zentrale Elemente der historischen Situation beschreiben, auf die Akteur_innen mit politischen Projekten institutioneller Veränderung strategischrekursiv reagieren.« (Ebd., 55)

Die Aufarbeitung der "geschichtlichen und strukturellen Schichten« (ebd.) erfolgt sekundäranalytisch anhand vier spezifischer Betrachtungsfokusse. So gilt es, im ersten Schritt den historisch-politischen Kontext aufzuarbeiten. Die historische Verwurzelung der Staatlichkeitstransformationen in Zeiten der Euro-Krise kann dabei mit Rückbezug auf sogenannte politische Projekte dargestellt werden. Es handelt sich in der Terminologie der HMPA bei politischen Projekten »um besondere, konkrete politische Initiativen [...], die sich selbst als Lösungen von drängenden sozialen, ökonomischen und politischen Problemen darstellen« (Bieling \& Steinhilber 2000b, 16; vgl. Buckel et al. 2014, 48). Politische Projekte stellen in gewisser Weise Medien des Kampfes um Hegemonie dar. Sie dienen der Durchsetzung »begrenzte[r], konkrete[r] politische[r] Vorhaben« (Buckel et al. 2014, 48) und sind als solche die Operationseinheit für die als Hegemonieprojekte zu bezeichnenden übergeordneten Kräftekonstellationen (vgl. ebd., 47; s.u.). Politische Projekte sind »zugleich Terrain und Durchsetzungsvehikel« (ebd., 48) und beschreiben nicht nur (historische) politische Dynamiken, sondern auch die der Staatlichkeit durch sie eingeschriebenen, partikularen Ordnungs- und leitbildlichen Vorstellungen. Die politischen Projekte, die den Weg zur EWWU - so wie sie uns am Vorabend der Euro-Krise entgegentritt - ebneten, bilden insofern zugleich auch historische Kräfteverhältnisse $\mathrm{ab}$ und bieten einen Eindruck der verdichteten Materialität im Inneren der EU-Staatlichkeit. Diese gilt es im zweiten Teilschritt anhand der Beschreibung des juristischen Kontextes darzustellen, der sich aus dem gegebenen EU-Rechtsrahmen ergibt. Nur wenn die EU-Staatlichkeit in ihrer vertraglich-fixierten Verfasstheit einbezogen wird, lassen sich die Staatlichkeitsveränderungen in Zeiten der Euro-Krise empirisch nachzeichnen. Der juristische Rahmen verweist bereits auf den ökonomischen Kontext, da in den Verträgen jene wirtschaftspolitischen Ordnungsvorstellungen kodiert werden, die in den der Euro-Krise vorausgegangenen ökonomischdominierten Krisenphasen von Bedeutung sind, insbesondere wenn hierdurch das bis dato propagierte Wachstumsmodell, beziehungsweise die Akkumulationsstrategie ins Wanken gerät. In diesem Zusammenhang sind auch die unterschiedlichen wirtschaftspolitischen Traditionen auf Ebene der Mitgliedstaaten von nicht geringer Brisanz, da ihnen einerseits bereits Kompromisse bei der Kodierung der EU-Wirtschaftsverfassung 
abverlangt wurden, die andererseits bei der Formulierung eines neuen Wachstumsmodells im Anschluss an eine Krise zu Blockadehaltungen führen können. Schließlich sind es die wirtschaftlichen Herausforderungen einer Krise, die nicht zuletzt auch den ökonomischen Kontext determinieren. Dieser wiederum steht im engen Bezug zu den gesellschaftlich-politischen Kontextbedingungen. Hierbei spielen neben aktuellen politischen Mehrheitsverhältnissen in den politischen Institutionen insbesondere gesellschaftliche Konjunkturen, Diskurse und Stimmungslagen eine wichtige Rolle im Rahmen der Kontextfaktoren. Alle vier Aspekte - historisch-politischer, juristischer, ökonomischer und gesellschaftlich-politischer Kontext - repräsentieren zusammengenommen jene historische Konstellation, auf die politisch zu reagieren ist, um in diesem Fall die Euro-Krise >bewältigen` zu können.

Anschließend an die herausgearbeiteten historisch-dynamischen und strukturellen Kontextbedingungen schließt sich in der Abfolge der HMPA die Akteursanalyse an. Ihr liegt das Ziel zu Grunde, die gesellschaftliche Akteurskonstellation zu identifizieren, innerhalb der die einzelnen Akteur*innen unterschiedlich auf den dargestellten Kontext reagieren. In den Worten von Buckel et al. $(2014,56)$ geht es in diesem Teilschritt entsprechend darum, die "gegensätzlichen Strategien zu identifizieren, mit denen gesellschaftliche Kräfte rekursiv auf die in der Kontextanalyse herausgearbeitete[n] historische[n] Situation bzw. auf die zentralen Probleme und Fragen im Mittelpunkt des Konfliktes reagiert haben.«In der HMPA nehmen hierbei sogenannte Hegemonieprojekte eine zentrale Stellung ein, anhand derer »die herausgearbeiteten Strategien und ihre Protagonist_innen [...] zusammengefasst werden.«(Ebd.) Die genaue Analyse der Hegemonieprojekte und insbesondere ihrer Machtressourcen wiederum ermögliche es, eine »Einschätzung der relativen Position der Hegemonieprojekte im gesellschaftlichen Kräfteverhältnis [...] zu entwickeln.« (Ebd., 57) Hegemonieprojekte lassen sich als »Verdichtungen bzw. die meist unbewussten und indirekten Verknüpfungen einer Vielzahl unterschiedlicher Taktiken und Strategien, die sich auf konkrete politische Projekte oder breitere gesellschaftliche Problemlagen richten« (Kannankulam \& Georgi 2012, 34), charakterisieren. Mit dieser Definition klingt bereits an, wodurch sich die konkurrierenden Hegemonieprojekte voneinander unterscheiden: Die Forschungsgruppe `Staatsprojekt Europar schlägt vor,

»die Vielfalt von gesellschaftlichen und politischen Kämpfen entlang jener Strategien analytisch zu ordnen, die Akteur_innen in dem durch die Forscherin untersuchten Konflikt verfolgen. Diese Strategien bilden sich vor dem Hintergrund der jeweiligen Situations- und Problemanalyse [...] von Akteur_innen heraus, aus denen wiederum spezifische politische Rationalitäten zur Erreichung ihrer - auch längerfristig angelegten - Ziele resultieren.« (Buckel et al. 2014, 45f.)

Hegemonieprojekte stellen somit »Bündel von Strategien« (ebd.) dar. Dabei gilt es definitorisch darauf hinzuweisen, dass sich die Hegemonieprojekte als politikfeldübergreifende Kräftekonstellationen begreifen lassen, die »in unterschiedlichen Politikfeldern große Ähnlichkeiten auf[weisen]«, deren verfolgte »Strategien [...] sich jedoch in unterschiedlichen Politikfeldern und Konflikten spezifisch aus[prägen]« (ebd., 47) können. Noch einmal anders formuliert, versuchen die an den Hegemonieprojekten »beteiligten AkteurInnen [...], ihre partikularen Interessen zum Allgemeininteresse 
$\mathrm{zu}$ machen« (Kannankulam \& Georgi 2012, 34) und das Hegemonieprojekt so $\mathrm{zu}$ einem hegemonialen Projekt werden zu lassen. Wichtig dabei festzuhalten ist, dass die Handlungen der Akteur*innen eines Hegemonieprojekts »in den hegemonialen Vorstellungen und Praxen in der Zivilgesellschaft und im Alltagsverstand konsensual verankert sind und dort eine Entsprechung haben« (Buckel et al. 2014, 46) müssen, damit ein Hegemonieprojekt zu einem hegemonialen Projekt werden kann. Hegemoniale Projekte verweisen entsprechend auf erfolgreich operierende Hegemonieprojekte, die ihre partikularen Werte- und Ordnungsvorstellungen in der gesellschaftlichen Auseinandersetzung verallgemeinern, konsensualisieren und durchsetzen oder kurzgefasst: eine hegemoniale Stellung einnehmen konnten. In »diskursiven (Deutungs-)Kämpfen « stelle sich dabei schließlich heraus, »ob und in welchem Maße [...] Projekte eine gewisse hegemoniale Ausstrahlungsfähigkeit erlangen« (Bieling, Haas \& Lux 2013, 235f.) können.

Innerhalb der einzelnen Hegemonieprojekte gilt es im Sinne ihres Verdichtungscharakters des Weiteren darauf hinzuweisen, dass sie nicht als "einheitlich und homogen« (Buckel et al. 2014, 47) angesehen werden können, da sich in ihnen »die Strategien unterschiedlicher Akteur_innen miteinander verknüpfen« (ebd.). Hegemonieprojekte stellen selber Kompromissstrukturen dar, in denen sich die unterschiedlichen Fraktionen unter der Führung einer dieser Fraktionen gemeinsam in Richtung auf die geteilten Vorstellungen vereinen (vgl. ebd.). Wichtig für das Verständnis der HMPAAnalysekategorien ist, zu erwähnen, dass Hegemonieprojekte lediglich »in der Auseinandersetzung [existieren] (ebd., 49) und daher »nur anhand des Engagements ihrer Akteur_innen im Kampf um konkrete Projekte analysiert werden können.« (Ebd., 48f.) Eine umfassende, primärquellengestützte Akteursanalyse im Sinne der HMPA würde dabei vier aufeinander aufbauenden Teilschritten folgen (vgl. ebd., 56ff.). In der vorliegenden Arbeit soll hingegen lediglich eine reduzierte Form zur Anwendung kommen, die sich auf Sekundärquellen stützt. Die gesellschaftlichen Hegemonie- und Kräfteverhältnisse in Zeiten der Euro-Krise werden dabei aus bereits vorliegenden Untersuchungen rekonstruiert und aufbereitet, um hieraus »eine Einschätzung der relativen Position der Hegemonieprojekte im gesellschaftlichen Kräfteverhältnis im untersuchten Konflikt « - also der Auseinandersetzung um die kriseninduzierten Transformations- und aus Ausbauprozesse der EU-Staatlichkeit - »zu entwickeln.« (Ebd., 57) Hierbei sollten zugleich die relevanten und »zentralen Akteur_innen des Hegemonieprojekts benannt werden, also Gruppen, Organisationen, Verbände, Parteien bzw. Vereinigungen oder Flügel innerhalb von Parteien, soziale Bewegungen, Medien, Think Tanks, Netzwerke, Unternehmen, Kapitalfraktionen und deren Sprecher_innen.«(Ebd.)

In der die HMPA-abschließenden Prozessanalyse werden die Ergebnisse der Kontextund der Akteursanalyse zueinander in Beziehung gesetzt, um »die komplexen Kampfprozesse, in denen sich der Konflikt durch verschiedene Phasen entwickelt« (ebd., 58), rekonstruieren zu können. Die Prozessanalyse bildet das Herzstück der dreischrittigen HMPA, da sich erst in ihr ein vollständiges Bild zusammensetzt. Der »Prozess« sei demnach ausgehend

»von den (unterschiedlichen) Problemdefinitionen zentraler Akteure, über die politische[n] Projekte zu ihrer Lösung und den entsprechenden gesellschaftlichen Kämpfen 
um eine Politik hin zu der Fixierung eines vorläufigen Kräfteverhältnisses und schließlich zu dessen materieller Verdichtung in Institutionen, Gesetzen und Staatsapparaten« (Kannankulam \& Ceorgi 2012, 40)

nachzuzeichnen. Eine solche Rekonstruktion liefert somit eine fundierte Erklärung dafür, wie sich die Transformationen und der Ausbau der EU-Staatlichkeit als Ausdruck dieser materiellen Verdichtungsprozesse einordnen lassen.

\subsection{Verdichtungsanalyse}

Wie bereits einleitend dargestellt, bedarf es für eine historisch-materialistische Politikanalyse, die sich als Staatlichkeitsanalyse begreift, anschließend an die drei klassischen HMPA-Schritte eines weiteren Analyseschrittes, der die materiellen Verdichtungen in den Apparaten abschließend noch einmal eingehender beleuchtet (vgl. Kannankulam \& Georgi 2012, 37). Der hier gesetzte Fokus liegt auf der theoretisch hergeleiteten Notwendigkeit zur Herstellung der Einheit der Staatlichkeit. In der hier vorgeschlagenen Variante einer Verdichtungsanalyse wird dabei beabsichtigt, die gewonnenen Erkenntnisse der vorausgegangenen Prozessanalyse - also den Verdichtungsprozessen gesellschaftlicher Kräfteverhältnisse in der konkreten Auseinandersetzung über die Euro-Krisenbewältigungspolitik und der in ihr angelegten Staatlichkeitstransformationen - mit den Ergebnissen der rekonstruktiven Konstitutionalisierungsanalyse $\mathrm{zu}$ kontrastieren. Es drängt sich dabei die Frage auf, inwiefern im Sinne vollkommener Staatlichkeit und der Überlegungen zu den Krisentheorien die extrahierten EUStaatlichkeitsveränderungen in Zeiten der Euro-Krise einem expliziten Narrativ oder einem verbindenden Staatlichkeitstelos folgen. Oder in den theoretisch hergeleiteten Termini dieser Arbeit ausgedrückt: Inwiefern sich die Staatlichkeitstransformationen an einem Staatsprojekt orientieren, das sich entsprechend durch die Politik zur Krisenbewältigung in der krisentransformierten EU-Staatlichkeit verdichten konnte.

Im Anschluss an die theoretischen Einführungen zum Staatsprojekt (Kap. 2.4) und den im Rahmen der HMPA-Operationalisierung dargestellten Ausführungen zur Untersuchung von Hegemonieverhältnissen lässt sich annehmen, dass das Staatsprojekt in gewisser Weise von dem Hegemonieprojekt initiiert wird, welches durch die erfolgreiche Implementierung politischer Projekte zu einem hegemonialen Projekt werden konnte, dass es gar eine notwendige Voraussetzung eines Hegemonieprojekts ist, über eine Akkumulationsstrategie und eine »konkrete Strategie zur Anordnung der politischen Institutionen« zu verfügen, um überhaupt hegemonial werden zu können (Buckel et al. 2014, 45). Somit wird bereits durch den Kampf um politische Projekte der Boden für ein Staatsprojekt bereitet. Die Auseinandersetzung um die Politik zur Bewältigung der Euro-Krise kann dementsprechend als ein Teil der sozialen Praxis zur Implementierung von Staatlichkeitsvorstellungen und der damit verbundenen Zielbestimmung von Staatlichkeit gelten (vgl. Wissel 2019, 45). Letztlich wird »ein hegemoniales Staatsprojekt [...] in der Regel von einem hegemonialen Projekt dominiert, gleichwohl schreibt sich [aber zugleich; J.G.] eine Vielzahl gesellschaftlicher Kräfte in das Staatsprojekt ein.« (Wissel 2015, 28) Die Verallgemeinerung und Konsensualisierung des Staatlichkeitstelos 
ist entsprechend eine wichtige Grundlage für die Herausbildung eines hegemonialen Staatsprojekts, dessen Effekt es sei, »die Einheit des Staates zu gewährleisten, obwohl dieser ein heterogenes Ensemble von konkurrierenden Staatsapparaten ist, in welche sich die unterschiedlichen Kräfte einschreiben« (Buckel 2011, 640).

\subsection{Analytisches Vorgehen und Darstellungsform}

Die soeben vorgestellte Struktur der historisch-materialistischen Staatlichkeitsanalyse wirkt auf den ersten Blick sehr kleinteilig und bisweilen sogar redundant. Beide Eindrücke sind durchaus berechtigt, auch wenn die kleinteilige - idealtypische - Darstellungsweise lediglich dazu dienen sollte, transparent zu machen, welche Schlüsselaspekte es in einer historisch-materialistischen Analyse von Staatlichkeit zu berücksichtigen gilt. In der Forschungspraxis sind hingegen die einzelnen Teilanalysen fließend miteinander verbunden (dies gilt im Besonderen für die rekonstruktive Konstitutionalisierungs- und die erweiterte Kontextanalyse), wodurch nicht zuletzt an einigen Stellen der Eindruck von Redundanz entsteht. Im Sinne der Leser*innen soll unter anderem auch deshalb Abstand davon genommen werden, bei der Ergebnisdarstellung der Analysestruktur zu streng zu folgen. So folgt die Darstellung der Ergebnisse nicht in jedem Fall der analytischen Abfolge der einzelnen Teilanalysen.

Begonnen wird im Anschluss an das Methodenkapitel mit der Darstellung des historischen Kontextes in Form der politischen Projekte auf dem Weg zur EWWU, ihrer svertraglichen Grundlage und der sich in dieser materialisierenden >EUWirtschaftsverfassungく, bevor schließlich die verdichtete Akkumulationsstrategie und das hegemoniale EU-Staatsprojektes vor der Euro-Krise dargestellt werden (Kapitel 4). Hieran anschließend wird der ökonomische Kontext der Euro-Krise näher beschrieben und in das Krisenverständnis dieser Arbeit eingeordnet (Kapitel 5). Letztlich wird vor dem Hintergrund dieser beiden den Kontext beschreibenden Kapiteln ein erster Blick auf die sich in der Krise wandelnden Kräfteverhältnisse geworfen (Kapitel 6), um die sich hieran anschließenden Krisenbewältigungsmaßnahmen einordnen zu können. Die empirischen Erkenntnisse - insbesondere aus der rekonstruktiven Konstitutionalisierungsanalyse - werden anhand einer chronologischen Phaseneinteilung präsentiert (Kapitel 7, 8 \& 9), die selbst schon ein Ergebnis der Analyse darstellt. Der Einstieg bildet hierbei die Hochphase der Euro-Krise (Kapitel 7), die im Jahr 2010 einsetzte und bis etwa zur Jahresmitte 2013 reichte und in der letztlich drei Konstitutionalisierungsprozesse eines reaktiven EU-Staatlichkeitsausbaus identifiziert werden konnten. Diese Phase des reaktiven Staatlichkeitsausbaus nimmt in den nachfolgenden Ausführungen den größten Raum ein, da sie wie eingangs beschrieben den Ausgangspunkt für die Fragestellung und das Erkenntnisinteresse dieser Arbeit markiert. An die Phase des reaktiven schloss sich ab Mitte des Jahres 2013 eine Phase des inkrementellen Staatlichkeitsausbaus an, die bis etwa zum Jahre 2015 reichte (Kapitel 8) und von einer Phase der Diskussion um einen weiteren ambitionierten, letztlich aber stagnierenden Staatlichkeitsausbau abgelöst wurde (Kapitel 9). Dabei gilt es, zu beachten, dass die Übergänge zwischen den Phasen nicht immer von klar abgrenzbaren Ereignissen gekennzeichnet werden können, die für einen abrupten Wechsel 
von der einen in die andere Phase sprechen, sondern in diesem Sinne meist ohne starren Anfangs- und Endpunkt auskommen müssen. Vielmehr sind die Übergänge als ein schleichender Prozess, gestützt durch einzelne Schlüsselereignisse, und die Phaseneinteilung insbesondere als strukturierendes Element der Analyse zu verstehen, um unterschiedliche Akzentuierungen im Laufe der Euro-Krise deutlicher herausstellen zu können. Insofern trägt die vorgenommene Phaseneinteilung den Charme des Ahistorischen in sich, soweit die geschichtlichen und gesellschaftlichen Prozesse sich nicht von außen gesetzten Grenzziehungen unterwerfen lassen, sondern diese in Übergangsphasen quasi beiläufig selbst produzieren. Innerhalb dieser drei Kapitel wird dem Grunde nach jeweils für die beschriebene Phase eine historisch-materialistische Staatlichkeitsanalyse präsentiert, an deren Gesamtschau und vor dem Hintergrund der herausgearbeiteten Kräfte- und Hegemonieverhältnisse sich letztlich eine übergeordnete Verdichtungsanalyse anschließt (Kapitel 10). In dieser wird die ausgebaute EU-Staatlichkeit vor dem Hintergrund der ihr eingeschriebenen >Verdichtungen gesellschaftlicher Kämpfe und Kräfteverhältnisse auf ihr Gehalt für eine Transformation des Staatlichkeitstelos in Form einer dominierenden Akkumulationsstrategie und des Staatsprojekts hin abschließend bewertet. 



\section{EU-Staatlichkeitsgenese vor der Euro-Krise und die EWWU im Zentrum neoliberaler Hegemonie}

Mit den Integrationsschritten der 8oer und 9oer Jahre vollzog sich ein Akt der »Staatsbildung im Sinne der weiteren Ausdifferenzierung eines europäischen politischen Mehrebenensystems«, bei der »die Bedeutung europäischer Instanzen und Verfahren [...] zu[nahm] « (Ziltener 1999, 198). Insbesondere mit der Europäischen Wirtschaftsund Währungsunion (EWWU) wurde im Vertrag von Maastricht (1992) hierbei ein neuer Qualitätssprung in der Genese der EU-Staatlichkeit vollzogen. Die vormals eigenständigen Währungen und Geldpolitiken, eine klassische Staatsdomäne, wurden zugunsten des Euros vergemeinschaftet. Im Verständnis von Staatlichkeit als Prozess lässt sich dies als ein weiterer Schritt zur Konzentration und Monopolisierung symbolischer Gewaltsamkeit in den Staatlichkeitsstrukturen der EU verstehen, der sich auf Grundlage gesellschaftlicher Kämpfe im Maastrichter Vertrag materialisierte. In einem `Schnelldurchlauf^einer Staatlichkeitsanalyse gilt es demnach die Grundlagen der EU-Staatlichkeit - mit der EWWU in deren Zentrum - vor dem Ausbruch der Euro-Krise herauszuarbeiten. Insgesamt steht dabei die EWWU nicht nur im Zentrum der EU-Staatlichkeit, sondern ebenso im Zentrum neoliberaler Hegemonie. Sie basierte auf einer Abfolge "politischer Projekte neoliberaler Restrukturierung" (Bieling \& Steinhilber 200ob), angefangen bei der Errichtung des Europäischen Währungssystems (EWS) über die Schaffung des Binnenmarktes hin zur Einführung der Währungsunion. Durch diese politischen Projekte verdichtete sich schließlich auch ein EU-Staatsprojekt, das durch das neoliberale Hegemonieprojekt dominiert wurde.

\subsection{Die politischen Projekte auf dem Weg zur EWWU}

Bereits 1970 hatte die damalige Europäische Wirtschaftsgemeinschaft (EWG) mit dem sogenannten Werner-Plan ein ambitioniertes Programm zur Einführung einer europäischen Gemeinschaftswährung vorgelegt. Er war als Kind seiner Zeit von einem »keynesianistischen Selbstverständnis« geprägt, was sich unter anderem im Ziel äußerte, durch eine potentielle Währungsunion auch »die gesamtwirtschaftli- 
chen Ungleichgewichte zwischen den Mitgliedsländern abzubauen." (Stützle 2014, 145) So waren neben der Synchronisierung der mitgliedstaatlichen Haushaltsverfahren und einer steuerlichen Harmonisierung insbesondere auch eine koordinierte Konjunkturpolitik vorgesehen, die durch ein supranationales wirtschaftspolitisches Entscheidungsgremium vorgenommen werden sollte (vgl. Hacker \& Koch 2016, 89). Neben der französischen Skepsis gegenüber der Verlagerung weitreichender währungsund wirtschaftspolitischer Kompetenzen auf die Gemeinschaftsebene (vgl. Hilpold 2014, 16) waren es aber insbesondere die ökonomischen Verwerfungen der Ölkrise und der Zusammenbruch des Bretton-Woods-Währungsregimes, die schließlich den keynesianisch geprägten Werner-Plan scheitern ließen. Mit dem Ende von BrettonWoods, das dem transatlantischen und innereuropäischen Handel feste Wechselkurse garantierte, standen die handelnden politischen Akteur*innen der EWG indes vor der Frage, wie eine Währungsordnung geschaffen werden könne, die auch künftig Wechselkursrisiken zu minimieren helfe. Nachdem die Mitgliedstaaten zunächst mit jeweils eigenen geldpolitischen Reaktionen auf die veränderte Situation reagierten (vgl. Kühnhardt 2012, 19), wurde schließlich 1979 das Europäische Währungssystem (EWS) aus der Taufe gehoben. »The European Monetary System [...] was the first element of a new type of integration, with an objective of limiting the monetary uncertainty, of stabilizing of the conditions of concurrence on the market, and of achieving a lasting reduction of inflation « (Hunout \& Ziltener 1999, 3f.). Zwar sei das EWS primär eine defensive und technokratische Initiative gewesen (vgl. Bieling \& Steinhilber 2000b, 111), zugleich aber gelang es Akteur*innen der internationalen Kapitalmärkte vermittelt über das EWS einen neoliberalen Diskurs zu stimulieren, »der die meisten Regierungen inspirierte beziehungsweise darin bestärkte, die Märkte zu deregulieren und die Staatsquote durch massive Privatisierungen zu senken.« (Ebd., 112) Flassbeck \& Steinhardt $(2018,19 f$.) beschreiben die Gemengelange und die Diskursverschiebung jener Zeit wie folgt:

»Als im Cefolge der Ölpreisexplosion [...] hohe Inflation und hohe Arbeitslosigkeit zugleich auftraten (die berühmte Stagflation), war die Stunde der Liberalen gekommen. Nun konnten sie scheinbar überzeugend belegen, dass Systeme, in denen der wichtigste Preis einer Marktwirtschaft, der Preis für Arbeit [...], inflexibel ist, unlösbare Konflikte schaffen, die mit den Rezepten des Keynesianismus nicht zu bekämpfen sind. Nur flexible Preise und unabhängige Notenbanken, so die Botschaft des >neuen Wirtschaftsliberalismus`, würden die Bedingungen schaffen, die es erlaubten, diese Probleme in den Criff zu bekommen. Der Neoliberalismus verband sich mit dem Monetarismus und schuf auf diese Weise ein nur schwer zu überwindendes theoretisches Bollwerk.«

Offener noch als beim EWS-Projekt trat der neoliberale Diskurs mit dem BinnenmarktProjekt zu Tage, das mit der Einheitlichen Europäischen Akte (EEA) 1986 Einzug in das europäische Vertragswerk fand. Dabei wurde die Diskussion über die Vertragsrevision entscheidend durch den European Roundtable of Industrialists (ERT) ${ }^{1}$ vorbereitet 
und geprägt (vgl. Hunout \& Ziltener 1999, 4). Die EEA war schließlich das Ergebnis einer grundsätzlichen integrationspolitischen Diskussion, die weiterhin im Zeichen der damaligen ökonomischen Krisenkonstellation stand. Nachdem die EWG-Staaten zunächst im nationalen Rahmen »auf den Anpassungsdruck, der durch die Transformation des globalen Kapitalismus hervorgerufen wurde, reagierten « (Bieling \& Steinhilber 2000b, 112), fassten gerade neoliberale Akteur*innen »die Wiederbelebung des Integrationsprozesses als eine Gelegenheit« auf, »die europäische Region gegenüber der globalisierten Weltökonomie weiter zu öffnen.« (Van Apeldoorn 2000, 200) Hiermit sei das Ziel verbunden gewesen, »die Deregulierung und Privatisierung der europäischen Ökonomien « zu beschleunigen, »um die `nutzbringenden« Marktkräfte von den Fesseln der Regierungsintervention und anderen starren Institutionen, die die notwendigen Anpassungen an eine veränderte globale Umwelt behindern, zu befreien.« (Ebd.) Diese Zielvorgaben verbanden sich letztlich mit dem Binnenmarktprojekt, das zwar bereits seit vielen Jahren von der Kommission protegiert wurde, es bis dato aber nicht auf die politische Agenda schaffte (vgl. ebd., 202). Erst mit dem Engagement des ERT nahm die politische Diskussion um den Binnenmarkt an Fahrt auf. Die ERT-Kampagne begann 1983; erste Entwürfe für ein detailliertes Programm zur Erreichung des Binnenmarkts wurden 1984 und 1985 von einzelnen ERT-Mitgliedern der Öffentlichkeit vorgestellt und von weiteren Akteur*innen des neoliberalen Hegemonieprojekts offensiv aufgegriffen (vgl. ebd., 201f.). Auch das Binnenmarkt-Weißbuch der Kommission aus dem Jahre 1985 sei direkt von den ERT-Vorschlägen inspiriert gewesen (vgl. ebd., 202). Vorausgegangen war diesem bereits die weitestgehende Durchsetzung einer weltmarktorientierten Liberalisierungsagenda im Zentrum des Binnenmarkt-Projekts gegenüber den Zielvorstellungen neo-merkantilistischer Kapitalfraktionen, die mit dem Binnenmarktprojekt insbesondere die Stärkung des europäischen »Heimatmarktes« verbanden (vgl. ebd., 203). Auch die sozialdemokratische Hoffnung, nach der sich durch die weitere Marktintegration und ihrer sozialen Regulation die föderale Staatswerdung Europas beschleunigen lasse (vgl. ebd., 201), verpuffte - retrospektiv betrachtet - weitgehend (vgl. Ziltener 1999, 180-183). Inhaltlich und integrationstheoretisch bedeutete die Verwirklichung des Binnenmarktes bis zum Jahre 1992 - so wie mit der EEA beabsichtigt - daher zuvorderst die Deregulierung der mitgliedstaatlichen Märkte »und damit die strategische Priorität der ökonomischen Integration - in Gestalt der sog. >vier Freiheiten [...] - durchzusetzen.« (Bieling \& Steinhilber 200ob, 113) Mittel der Wahl war der Ansatz der >negativen Integration<, mit der »die gegenseitige Anerkennung der nationalen Normen und Standards zum vorherrschenden Prinzip« (ebd., 113f.) wurde. Legitimiert werden sollte das Binnenmarkt-Projekt durch den vom gemeinsamen Markt zu erwartenden ökonomischen Erfolg, was zumindest durch den wirtschaftlichen Aufschwung, der sich in der zweiten Hälfte der 8oer Jahre einstellte, auch zeitweise gelang (vgl. ebd., 114). Aber selbst darüber hinaus gelang es ideologisch, den Binnenmarkt als Mythos zu etablieren, der dafür Sorge trage, dass die EG in einer globalisierten Ökonomie wettbewerbsfähig bleibe und zugleich im Inneren Europas für neue Wachstumsschübe sorge (vgl. ebd., 115). Nicht zuletzt deshalb sprechen Bieling \& Steinhilber (2000b, 112) zurecht von einer Phase des »euphorische[n] Neoliberalismus«, der die politische Auseinandersetzung der 8oer und der beginnenden 9oer Jahre prägte und zugleich einen breiten gesellschaftlichen Rückhalt genoss. 


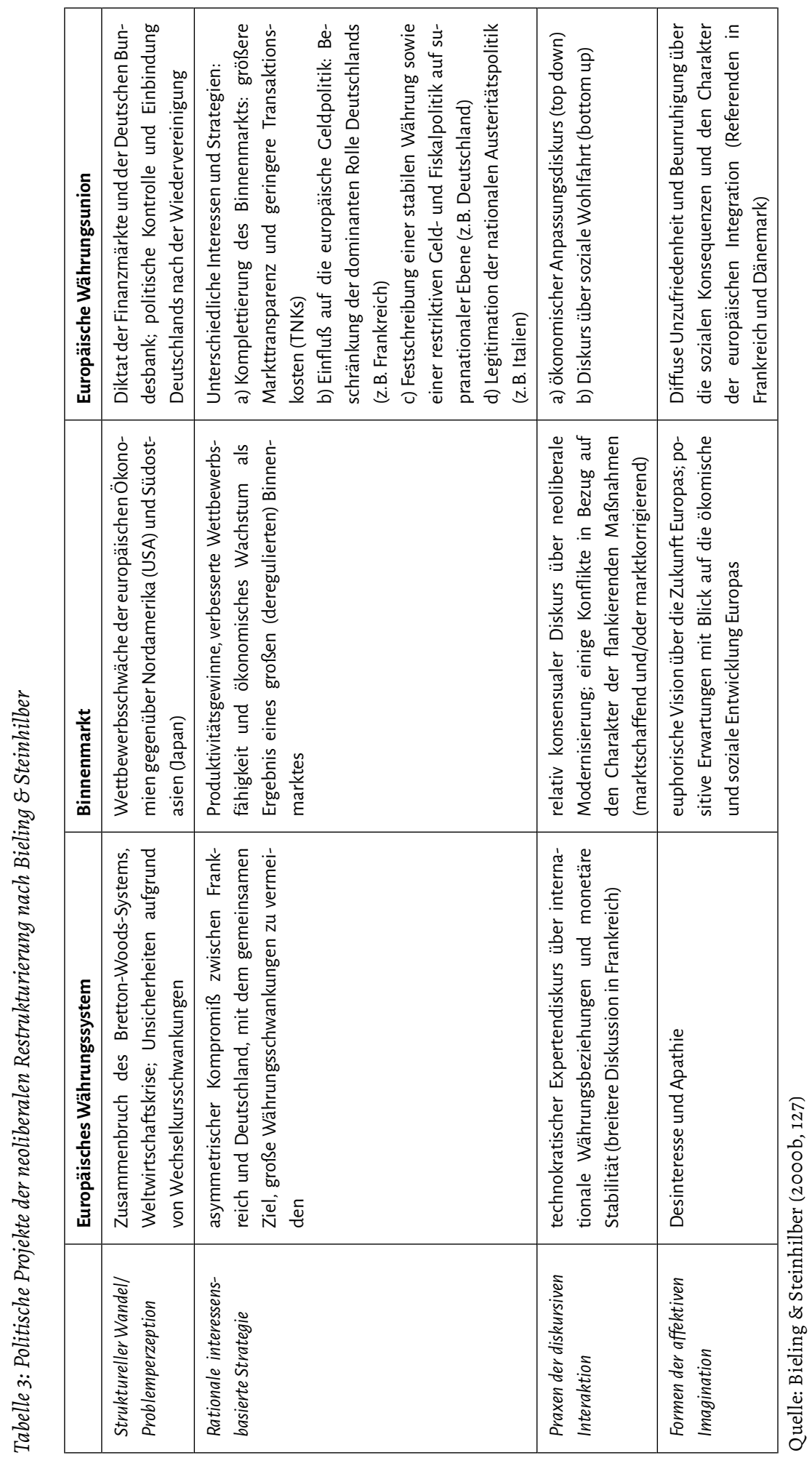


Auch im Kontext des politischen Projekts zur Etablierung einer Europäischen Währungsunion konnten neoliberale Akteur*innen die Agenda entscheidend mitbestimmten. Hier war es die Association for Monetary Union of Europe (AMUE), eine Organisation, welche sich hauptsächlich aus ERT-Mitgliedern speiste, die ab 1987 aktiv für eine Währungsunion warb und ihren Einfluss auf die Politik geltend zu machen versuchte, bevor das Thema überhaupt auf der politischen Agenda stand (vgl. van Apeldoorn 2014, 192; 2000, 205). Dass allerdings nicht der ERT selbst das Zentrum der neoliberalen Bewegung darstellte, liegt darin begründet, dass sich die unterschiedlichen Kapitalfraktionen innerhalb des ERT zu Beginn der Diskussion uneins waren (vgl. van Apeldoorn 2000, 204). Eine Währungsunion, die den freien Währungswettbewerb einschränke, entsprach dabei nicht den Ordnungsvorstellungen neoliberaler Hardliner*innen. Eine europäische Währungsunion wurde daher »nicht nur durch Hayek«, als ein bekannter Vertreter des Neoliberalismus, »abgelehnt, sondern auch durch die Mehrheit der liberalen und neoklassischen Ökonomen, die [...] für ein System konkurrierender nationaler Währungen plädierten [...].« (Deutschmann 2014, 8) Letztlich sehen die (neo-)liberalen Ökonomie-Vertreter*innen »in der Konkurrenz nationaler Währungen den wirksamsten Mechanismus, um einen in ihrer Sicht sheilsamen Disziplinierungsdruck der Finanzmärkte über die nationale Haushaltspolitik und exzessive Ausgabenwünsche demokratischer Politiker sicherzustellen.« (Ebd.; Herv. J. G.) Dass im Gegensatz hierzu eine Währungsunion für transnational agierende Unternehmen aufgrund des Wegfalls von Wechselkursrisiken und somit berechenbarerer transnationaler Wertschöpfungsketten dennoch sinnvoll erscheinen kann, mag erklären, weshalb sich einzelne Kapitalfraktionen stärker für die Währungsunion engagierten als andere. Aufgrund des fehlenden internen ERT-Konsenses übernahm schließlich die AMUE die neoliberale Lobbyfunktion. Im Unterschied zum Binnenmarkt-Projekt ging die Dynamik dieser Initiative allerdings sehr schnell in die Verantwortung europäischer Politiker*innen über (vgl. van Apeldoorn 2000, 204). Ursächlich hierfür mag die neue geopolitische Lage in Europa und auch innerhalb der EG gewesen sein, die sich Ende der 8oer und zu Beginn der 9oer Jahre herauskristallisierte und insbesondere in der aufkommenden Frage der deutschen Wiedervereinigung kumulierte. Die Währungsunion konkretisierte sich vor diesem Hintergrund, da die Wiedervereinigung "sowohl eine politische als auch eine ökonomische Herausforderung für die hegemoniale Struktur der Europäischen Union darstellte« (Bieling \& Steinhilber 2000b, 115). Insbesondere Frankreich habe nun auf die Etablierung der Währungsunion insistiert, um ein wiedervereinigtes Deutschland stärker in europäische Strukturen einzubinden (vgl. bspw. ebd., 115; Schulmeister 2018, 54). Einmal vom gemeinsamen Ziel abgesehen, »die durch die erhöhte Kapitalmobilität induzierte Instabilität im EWS-System aufzufangen und die Transaktionskosten im intra-europäischen Handel zu reduzieren« (Bieling \& Steinhilber 2000b, 115), waren die mitgliedstaatlichen Zielvorstellungen, die sich mit der Währungsunion verbanden, dabei aber insgesamt sehr heterogen. So stand die deutsche Bundesregierung der Währungsunion zu Beginn eher skeptisch gegenüber, nicht zuletzt wohl auch deshalb, weil sich die Bundesbank mit der D-Mark als eine Art Ankerwährung des EWS quasi zur heimlichen EWS-Zentralbank entwickelte und so eine deutsche »Geldautorität« 
begründete. ${ }^{2}$ Die grundsätzliche >deutscheく Haltung zur Währungsunion spiegelte sich auch im Ansatz der sogenannten »Krönungstheorie« (vgl. u.a. Höing 2016, 19) wider, nach der die Währungsunion erst das Ergebnis eines längeren wirtschaftlichen Konvergenzprozesses darstellen könne; die wirtschaftliche beziehungsweise wirtschaftspolitische Integration quasi einen Grad erreicht habe, die mit einer Währungsunion gekrönt werden könne. Vertreter*innen dieser Position werden in der Literatur häufig als »Ökonomisten« bezeichnet (vgl. u.a. Tuori \& Tuori 2014, 42). Eine ähnliche Problemperzeption wie die der Bundesregierung wies auch der damalige Kommissionspräsident Jacques Delors auf, der als Lösung vorschlug, den nötigen Konvergenzprozess unter dem Dach einer gemeinsamen Währung durch eine flankierende Europäische Wirtschaftsregierung zu gestalten (vgl. Brunkhorst 2017, 58). Das unter dem Vorsitz von Delors tagende Vorbereitungskomitee blieb in seinem Abschlussbericht allerdings weit hinter diesem Anspruch ihres eigenen Vorsitzenden und somit auch hinter den umfassenderen Vorschlägen des Werner-Plans aus den 70er Jahren zurück (vgl. Mitchell 2017, 121ff.). Der 1989 vorgelegte Plan des Komitees, das von Delors und dem damaligen Bundesbankchef Pöhl dominiert wurde (vgl. Verdun 1999, 319), sah zwar neben der geldpolitischen im Geiste der Ökonomisten des Weiteren auch makroökonomische sowie fiskalische Integrationsschritte und einen weitaus längeren Zeithorizont bis zur finalen dritten Stufe der Währungsunion vor (vgl. u.a. Bontrup 2014, 11), war aber bereits im Kern maßgeblich durch die Ideen des »Monetaristen«-Lagers beeinflusst (vgl. Mitchell 2017, 121ff.). Sie argumentierten, dass eine Währungsunion über kurze Sicht quasi automatisch zur umfassenden Konvergenz der Wirtschaftspolitiken führen werde (vgl. Degryse 2012, 8; Tuori \& Tuori 2014, 42) und favorisierten demnach einen marktgesteuerten Konvergenzprozess (vgl. Degryse, Jepsen \& Pochet 2013, 11):

»Nach dem neoklassischen Modell des allgemeinen Gleichgewichts sorgen die Marktmechanismen bei entsprechend freiem Spiel für eine optimale Entwicklung der Volkswirtschaften der Eurozone. Die Monetaristen lehnen daher die Idee einer Harmonisierung der Wirtschaftspolitiken oder einer europäischen >Wirtschaftsregierung «ab. « (Degryse 2012, 8)

Dass sich schlussendlich diese »schlanke Variante« einer Währungsunion durchsetze, liegt neben der Orientierung neoliberaler Akteur*innen an das Monetaristen-Lager insbesondere in der ambivalenten deutschen Positionierung zur Währungsunion begründet. Ursprünglich beruhte sie auf einer eher ökonomistisch geprägten Sichtweise und war von einer grundlegenden Skepsis geprägt, die sich allerdings aufgrund der hohen Zustimmung anderer Mitgliedsstaaten zur Währungsunion zusehends wandelte. Die anfängliche Skepsis wurde schließlich dazu genutzt, um deutlich herauszustellen, dass Deutschland eine Gemeinschaftswährung nur dann akzeptieren würde, wenn sie sich

Begründet liegt diese Autorität darin, dass sich die EWS-Mitgliedstaaten dazu entschlossen hatten, ihre eigenen Wechselkurse an die D-Mark zu binden, wodurch sie de facto ihre politische Unabhängigkeit aufgegeben hatten (vgl. Mitchell 2017, 108). Hinzu kommt - das führt Mitchell an anderer Stelle weiter aus -, dass »[d]ie Franzosen und Italiener wussten, dass die Bundesbank effektiv die Zinsen für alle EWS-Staaten festlegte, ohne Rücksicht darauf ob sie außerhalb von Deutschland angemessen sein würden.«(Ebd., 112) 
am »deutschen Stabilitätsmodell« (Bieling \& Steinhilber 2000b, 116) orientiere. So legte die Bundesregierung einen eigenen Vertragsentwurf vor, der als Leitbild ausgeglichene Staatshaushalte und eine finanzpolitische Disziplinierung propagierte (vgl. Stützle 2014, 226). Forderungen, die von Seiten der Bundesregierung und der Bundesbank als unumstößlich deklariert wurden, sollte Deutschland das Euro-Projekt unterstützen und der Währungsunion beitreten. Vielleicht gerade wegen dieser dogmatischen Haltung der Bundesregierung überrascht es nicht, dass die französische Regierung in ihrem Vertragsentwurf weitgehend auf die deutschen Forderungen einging: »Wie dominant Deutschlands Stabilitätskultur inzwischen war, zeigte sich daran, dass sich auch Frankreichs Vertragsentwurf konzeptionell an das deutsche Bundesbankgesetz anlehnte - als vorrangiges geldpolitisches Ziel wurde die Geldwertstabilität genannt.« (Ebd., 227) Zugleich lässt sich die französische Motivation allerdings auch als Versuch interpretieren, der deutschen »Geldautorität in Europa«, die sich im Rahmen des EWS zu Beginn der 8oer Jahre herausgebildet hatte, in Form einer gemeinsamen europäischen Notenbank zu entkommen und somit »etwas Steuerung aus Deutschland zurückzunehmen«, so Mitchell (2017, 108). Weiter schreibt er: "Sobald die Franzosen begriffen hatten, dass ihre Souveränität nicht von einer europäischen Einrichtung, sondern von der Bundesbank eingeschränkt wurde, begannen sie einen schnellen Weg zu einer Europäischen Währungsunion einzuschlagen.«(Ebd., 112) Frankreich jedenfalls stellte schließlich seine eigene geldpolitische Tradition (vgl. u.a. Brunnermeier, James \& Landau 2018, 91ff.) zurück und schwenkte - unter den sich bereits zugespitzten Umständen im EWS ${ }^{3}$ - auf die stabilitätsorientierte Währungsunion ein. Statt Frankreich waren es nun Irland, Portugal, Spanien und Griechenland, die bis zum Schluss die Verhandlungen um das Euro-Projekt dazu nutzen, »weitere Finanzzusagen durchzusetzen und so Transferleistungen zum Gegenstand machten« (Stützle 2014, 225), die ihnen zur Vorbereitung auf die Währungsunion schließlich auch durch die Etablierung des Kohäsionsfonds vorübergehend gewährt wurden. Grundlagen für dauerhafte fiskalische Transfermechanismen lassen sich im Maastrichter Vertrag hingegen nicht finden. Stattdessen wird die Unabhängigkeit der EZB und die auf sgesunde öffentliche Finanzen ausgerichtete und mit der No-Bail-Out-Klausel flankierten Eigenverantwortung für die Haushaltspolitik festgeschrieben. Dass sich im Vertrag von Maastricht somit weitgehend die deutsche geld- und währungspolitische Position durchsetzen konnte, gilt es auch der neoliberalen Unterstützung hierfür zuzuschreiben. Im Kontext des »ökonomischen Anpassungsdiskurses« (s. Tabelle 3) kann das Projekt der Währungs- 
union schließlich im Sinne Neoliberaler als ein Mittel der Disziplinierung verstanden werden:

»In der Post-Maastricht-Periode vertiefte sich allgemein die Zustimmung zur Währungsunion, und auch vom Round Table wurde dieses Projekt aktiv unterstützt. Die EWS-Krise in den Jahren 1992 und 1993 machte insbesondere den Deutschen klar, daß die D-Mark-Zone keine ausreichende Stabilität gewährte. Und auch der neoliberale Flügel des Round Table zeigte sich von den Vorteilen der EWU überzeugter als zuvor, weil die EWU-Kriterien für die Wirtschafts- und Sozialpolitik der nationalen Regierungen in Europa [...] einen >heilsamen<Disziplinierungseffekt hatten.«(van Apeldoorn 2000, 207; Herv. J. G.)

In diesem Sinne wurden letztlich die haushaltspolitischen Spielräume begrenzt, die mitgliedstaatlichen Geldpolitiken von einer technokratischen Euro-Politik der EZB abgelöst und innereuropäische Transferleistungen für wirtschaftspolitische Konvergenzprogramme ausgeschlossen. All dies führt zwangsläufig und im Sinne neoliberaler Vorstellungen zu einer Politik interner Abwertung, wenn aufgrund der globalen Konkurrenz die Wettbewerbsfähigkeit einzelner Volkswirtschaften in der Währungsunion aufrechterhalten werden soll. Daher kann das Projekt der Währungsunion als Krönung der neoliberalen Umstrukturierung verstanden werden, mit der die politischen Rahmenbedingungen im EU-Staatsapparate-Ensemble entscheidend neu abgesteckt wurden (vgl. Bieling \& Steinhilber 2000b).

Zwar wurde im Vertrag von Maastricht (1992) die Einführung des Euros als Gemeinschaftswährung beschlossen, das Projekt der Währungsunion kann allerdings erst mit dem Amsterdamer Vertrag (1997) als (vorläufig) »vollendet« gelten. Die in Maastricht festgeschriebenen Konvergenzkriterien verstanden sich lediglich als Zugangsvoraussetzung (vgl. Stützle 2014, 269), aber nicht als ein dauerhaftes Instrumentarium einer geldwertstabilitäts- und wettbewerbsorientierten Geld- und Fiskalpolitik in der EWWU. Eine solche Festschreibung wurde schließlich erst mit dem im Amsterdamer Vertrag institutionalisierten Stabilitäts- und Wachstumspakt (SWP) nachgeholt und insofern die Grundsätze der stabilitätsorientierten Währungsunion noch einmal bestätigt und sogar bestärkt. Auch bei den Amsterdamer Vertragsverhandlungen trafen heterogene Verhandlungspositionen aufeinander, die bereits zu Beginn der Diskussion um die Konvergenzkriterien im Maastrichter Vertrag sichtbar waren. Insbesondere der deutschen Position eines »harten« Stabilitätspakts stand eine Gruppe von Staaten gegenüber, die größere fiskalpolitische Spielräume befürwortete. Unterstützung für strenge Regeln kam von der Europäischen Kommission, die 1996 sogar ehrgeizigere Vorschläge unterbreitete als das deutsche Finanzministerium (vgl. ebd., 278). Das Ergebnis ist bekannt: Im SWP wurde sich - analog zu den Konvergenzkriterien von Maastricht - darauf verständigt, dass die Neuverschuldung der Mitgliedstaaten nicht über $3 \%$ des BIP und die Gesamtverschulung nicht über $60 \%$ des BIP liegen solle, ${ }^{4}$ um sicherzustellen,

4 Die konkrete Ausgestaltung der Konvergenzkriterien beruht nicht, wie man vermuten könnte, auf einem Vorschlag der deutschen Bundesregierung, sondern ist - wie Mitchell (2017, 237ff.) zeigt vom französischen Präsidenten Mitterrand in den Verhandlungen eingebracht worden. Das 3 \%Kriterium entsprach dabei genau dem Niveau des französischen Defizits im Haushaltsjahr 1983 
dass die Euroländer »in wirtschaftlich normalen Zeiten einen annährend ausgeglichenen Staatshaushalt« (Gischer, Herz \& Menkhoff 2012, 399) vorweisen können. Zugleich wurde aber insbesondere von Frankreich und jenen Ländern, die sich gegen einen zu hart formulierten Stabilitätspakt einsetzten, erreicht, dass keine automatischen Sanktionen bei Nichteinhaltung der Kriterien erfolgten (vgl. Stützle 2014, 282). Auch die Ergänzung des Stabilitätspakts um eine Wachstumskomponente für Beschäftigung, der Ausbau der regionalen Kohäsionspolitik sowie die Etablierung der Euro-Gruppe als koordinierendes Gremium gehen schließlich auf diese Ländergruppe zurück (vgl. ebd.). Diese Ergänzungen verweisen im Kern noch einmal auf die grundsätzliche Interpretation oder besser gesagt Hoffnung, dass eine Gemeinschaftswährung nicht nur eine geldpolitische oder wirtschaftspolitische Maßnahme darstellt, sondern zugleich auch Impulse für die weitere Integration liefern soll. Demnach seien die politischen Folgewirkungen der Währungsunion sogar höher zu bewerten als ihre ökonomischen (vgl. Fratianni 2000, 289): »History shows that monetary union and political union go together. A common currency carries the symbolic value of unity. For many European politicians [...] monetary union was understood to be a catalyst for political union.« (Ebd.) So sollte beispielsweise die Euro-Gruppe den Startschuss zum Aufbau einer europäischen Wirtschaftsregierung markieren und den Weg zu einer politischen Union ebenen. Mit der Euro-Gruppe war deshalb auch für große Teile der europäischen Sozialdemokratie die Hoffnung verbunden, insbesondere die Beschäftigungspolitik europäisch zu koordinieren und eine europäische Sozialpolitik zu entwickeln (vgl. Stützle 2014, 285f.). Ob hierfür allerdings ein Gremium, welches sich aus den mitgliedstaatlichen Finanzminister*innen zusammensetzt, geeignet erscheint, muss wohl nicht nur in der Retrospektive stark bezweifelt werden, zumal den realwirtschaftlichen Divergenzen in der Institutionalisierung und den vertraglichen Grundlagen der EWWU insgesamt wenig Aufmerksamkeit geschenkt wurde. Auch im SWP setzte sich schließlich - wie beim Vertrag von Maastricht - »der Glaube« durch, nach dem es »durch ungehinderten Wettbewerb zu einer wirtschaftlichen Konvergenz zwischen den Staaten [käme]«, was mit Blick auf die Euro-Krise "politisch ausgesprochen naiv [war] «, wie Bontrup $(2013,179)$ es treffend beschreibt. Insgesamt verdichtete sich neben diesem naiven wirtschaftspolitischen Leitbild fiskalpolitisch, mit Stützle (2014, 293-295) gesprochen, im SWP das Leitbild des ausgeglichenen Staatshaushaltes, welches gekennzeichnet werden könne durch: (1) neoklassische Prämissen, nach denen »dem Staat und staatlicher Kreditaufnahme ein[...] störende[r] Einfluss auf den Markt « zugeschrieben werde; (2) die »Verallgemeinerung bzw. Europäisierung der deutschen Stabilitätskultur«; (3) eine »Kompromissstruktur mit Dominante [...], in der sich Deutschland und Frankreich einerseits im Rahmen des europäischen Projekts raufeinander zubewegen $<$ mussten [...]; gleichzeitig [...] die Handschrift Deutschlands bei der Konzeption des Euro deutlich zu erkennen« sei; und schließlich (4) die Zuschreibung eines quasi-verfassungsmäßigen Ziels ausgeglichener Haushalte für alle europäischen Staaten. Kurzum handelt es sich beim Stabilitäts- und Wachstums- demnach eher um einen Austeritätspakt:

(vgl. ebd., 162) und stellt eine »willkürliche Fiskalregel« (ebd., 164) dar, die » rein politisch und nicht wirtschaftlich motiviert war (ebd., 163), da Frankreich sie laut Hochrechnungen in den Folgejahren ohne größere Mühen hatte einhalten können (vgl. ebd.). 
»The eurozone embedded many [...] neoliberal ideas into the currency's sconstitution< - without providing for enough flexibility to respond to changing circumstances or revised understandings of how economies function. In belief that markets will work well if (and only if) the central bank keeps inflation low, the ECB has a single mandate - price stability - even in times of high unemployment. (Stiglitz 2018, 25; vgl. auch Hunout \& Ziltener 1999, 23)

\subsection{Vertragliche Grundlagen der EWWU und die EU-Wirtschaftsverfassung}

Die mit den beschriebenen politischen Projekten vollzogene Staatlichkeitsgenese der EU bildet sich schließlich in den Verträgen der Europäischen Union und der ihnen inhärenten Wirtschaftsverfassung ab. Demnach verpflichten sich die EU-Mitgliedstaaten im Vertrag über die Europäische Union (EUV) eine »Wirtschafts- und Währungsunion zu [errichten], deren Währung der Euro ist« (Art. 3, Abs. 4 EUV). Konkretisiert wird diese im Titel VIII des dritten Teils des Vertrags über die Arbeitsweise der Europäischen Union (AEUV). Dort heißt es in Artikel 119, Absatz 1, dass eine Wirtschaftspolitik einzuführen sei, die auf einer engen Koordinierung der mitgliedstaatlichen Wirtschaftspolitik, dem Binnenmarkt und der Festlegung gemeinsamer Ziele beruhe, die »dem Grundsatz einer offenen Marktwirtschaft mit freiem Wettbewerb verpflichtet« (Herv. J. G.) sei. Unter Berücksichtigung dieser Grundsätze und des »vorrangigen«Ziels der Preisstabilität solle eine einheitliche Geld- und Wechselkurspolitik verfolgt werden (vgl. Art. 119, Abs. 2 AEUV). Neben stabilen Preisen werden "gesunde öffentliche Finanzen und monetäre Rahmenbedingungen sowie eine tragfähige Zahlungsbilanz« als »richtungsweisende Grundsätze« (Art. 119, Abs. 3; Herv. J. G.) der Wirtschafts- und Währungspolitik definiert. Dem Grunde nach könnte man entsprechend dieser Zielvariablen auch von drei »Teilunionen« im Kontext der EWWU sprechen: Einer Wirtschaftsunion im engeren Sinne mit dem Ziel, tragfähige Zahlungsbilanzen (Handel, Kapitalverkehr, Investitionsbedingungen etc.) zu erreichen, einer Währungsunion im engeren Sinne mit der Zielsetzung stabiler Preise (Inflationsziel) und der Schaffung gesunder monetärer Rahmenbedingungen (Geldmenge, Leitzins etc.) sowie einer rudimentären Fiskalunion, die sich schließlich dem Ziel gesunder öffentlicher Finanzen verpflichtet fühlt. Alle Grundsätze sollen dabei unter Berücksichtigung der allgemeinen Zielsetzungen des Artikels 3 des EUV verfolgt werden, der unter anderem von einem »ausgewogenen Wirtschaftswachstum «, einer »in hohem Maße wettbewerbsfähige[n] soziale[n] Marktwirtschaft, die auf Vollbeschäftigung und sozialen Fortschritt abzielt « sowie der Förderung des »wirtschaftlichen, sozialen und territorialen Zusammenhalt[s] und [der; J. G.] Solidarität zwischen den Mitgliedstaaten« spricht (Art. 3, Abs. 3 EUV).

Dreh- und Angelpunkt der »wirtschaftspolitischen Koordinierung « nach Artikel 119 AEUV stellt Artikel 121 dar, in dessen ersten Absatz die Mitgliedstaaten darauf verpflichtet werden, ihre Wirtschaftspolitik als eine »Angelegenheit von gemeinsamem Interesse zu betrachten und sie entsprechend im Rat zu koordinieren. Diese »Verpflichtung zur Koordination « (Hattenberger 2012, Rn. 5) wird durch die nachfolgenden Absätze 2 bis 5 konkretisiert. Als Instrument der Koordinierung beschreibt der AEUV die »Grundzüge der Wirtschaftspolitik der Mitgliedstaaten und der Union«, für die der Rat auf 
Empfehlung der Kommission einen Entwurf zu erstellen hat, über den im Europäischen Rat zu berichten ist, der wiederum auf dieser Grundlage eine Schlussfolgerung erörtert, vor dessen Hintergrund der Rat abschließend eine »Empfehlung« verabschiedet, in der die Grundzüge dargelegt werden (vgl. Art. 121, Abs. 2 AEUV). Absatz 3 des Artikels 121 AUEV überträgt dem Rat des Weiteren die Aufgabe, die wirtschaftliche Entwicklung in den Mitgliedstaaten und in der Union ebenso wie die Vereinbarkeit der Wirtschaftspolitik mit den beschlossenen Grundzügen anhand von Kommissionsberichten zu bewerten und in regelmäßigen Abständen eine Gesamtbewertung mit dem Ziel vorzunehmen, eine enge Koordinierung der Wirtschaftspolitik und dauerhafte Konvergenz zu gewährleisten. Dieses Verfahren, das als »multilaterale Überwachung« bezeichnet wird, basiert auf von den Mitgliedstaaten zu übermittelnden Angaben zu wichtigen einzelstaatlichen Maßnahmen im Bereich der Wirtschaftspolitik (vgl. Art. 121, Abs. 3 AEUV). Bereits primärrechtlich sind in dem Verfahren der multilateralen Überwachung Möglichkeiten vorgesehen, wie bei einer etwaigen Nichtbeachtung zu verfahren ist. Soweit im Rahmen der Überwachung festgestellt wird, dass die Wirtschaftspolitik eines Mitgliedstaates nicht mit den Grundzügen vereinbar ist oder »das ordnungsgemäße Funktionieren der Wirtschafts- und Währungsunion zu gefährden droht « (Art. 121, Abs. 4 AEUV), obliegt es der Kommission seit der Vertragsrevision von Lissabon eine Verwarnung auszusprechen (vgl. Glöckler 2015, Rn. 49). In einer weiteren Eskalationsstufe kann der Rat auf Anraten der Kommission Empfehlungen an die betreffenden Mitgliedstaaten richten, die in einem weiteren Verfahrensschritt auf Vorschlag der Kommission vom Rat auch veröffentlicht werden können. Die Beschlussfassung im Rat erfolgt dabei nach den Grundsätzen der qualifizierten Mehrheit ohne Beteiligung des betreffenden Mitgliedstaates (vgl. ebd.). Weiterführende Verfahren - beispielsweise Sanktionen kennt der AEUV an dieser Stelle nicht. Die multilaterale Überwachung operiert entsprechend nach dem Grundsatz des >peer-Drucks $<$ und dem ihm implizierten san den Pranger stellen zur Einforderung der Einhaltung der gemeinsamen Wirtschaftspolitik.

Neben den Grundzügen der Wirtschaftspolitik kennt der Vertrag im Titel IX sogenannte »beschäftigungspolitische Leitlinien «, die in Einklang mit den verabschiedeten Grundzügen der Wirtschaftspolitik stehen müssen (vgl. Art. 148, Abs. 2 AEUV). Grundlage hierfür stellt die Prüfung der Beschäftigungslage in der Union anhand eines gemeinsamen Jahresberichts des Rates und der Kommission durch den Europäischen Rat dar, zu dem letzterer Schlussfolgerungen annimmt. Diese Schlussfolgerungen bilden wiederum die Grundlage für die Erstellung der beschäftigungspolitischen Leitlinien, die der Rat auf Vorschlag der Kommission nach einer Reihe von Anhörungen (Parlament, Wirtschafts- und Sozialausschuss, Ausschuss der Regionen, Beschäftigungsausschuss) festlegt und die anschließend im politischen Handeln der Mitgliedstaaten $\mathrm{zu}$ berücksichtigen sind (vgl. ebd.). Analog zum Artikel 121 sind die Mitgliedstaaten auch im Rahmen des Artikels 148 aufgefordert, dem Rat und der Kommission jährlich einen Bericht über die wichtigsten Maßnahmen zu übermitteln, die im Kontext der beschäftigungspolitischen Leitlinien zu verorten sind (vgl. Art. 148, Abs. 3 AEUV). Der Rat nimmt auf dieser Grundlage eine Prüfung der mitgliedstaatlichen Beschäftigungspolitiken vor, wobei er auf Empfehlung der Kommission Empfehlungen an die Mitgliedstaaten richten kann, wenn er dies aufgrund der Prüfungsergebnisse für angebracht erachtet (vgl. Art. 148, Abs. 4 AEUV). Anders als im Rahmen des Artikels 121 steht der Kommissi- 
on allerdings nicht das Recht zu, Verwarnungen bei Nichtbeachtung auszusprechen. Schließlich verfassen der Rat und die Kommission auf Grundlage der Prüfungsergebnisse einen Jahresbericht über die Beschäftigungslage und die Umsetzung der beschäftigungspolitischen Leitlinien für den Europäischen Rat (vgl. Art. 148, Abs. 5 AEUV). ${ }^{5}$

Die gemeinsame Währungspolitik im Rahmen der Währungsunion wird federführend vom Europäischen System der Zentralbanken (ESZB) mit der EZB an der Spitze verantwortet und unterstützt »ohne Beeinträchtigung des Zieles der Preisstabilität [...] die allgemeine Wirtschaftspolitik in der Union « (Art. 127, Abs. 1 AEUV). Zu den Aufgaben des ESZB zählen die Geldpolitik, Devisengeschäfte, die Verwaltung offizieller Währungsreserven und die Förderung des reibungslosen Funktionierens der Zahlungssysteme (vgl. Art. 127, Abs. 2 AEUV). Weiterhin hat das ESZB »zur reibungslosen Durchführung der von den zuständigen Behörden auf dem Gebiet der Aufsicht über die Kreditinstitute und der Stabilität des Finanzsystems ergriffenen Maßnahmen bei[zutragen].« (Art. 127, Abs. 5 AEUV) Zugleich darf der Rat der EZB durch einstimmigen Beschluss in einer Verordnung »besondere Aufgaben im Zusammenhang mit der Aufsicht über Kreditinstitute und sonstige Finanzinstitute mit Ausnahme von Versicherungsunternehmen « (Art. 127, Abs. 6 AEUV) übertragen. Dabei agiert sowohl die EZB als auch das gesamte ESZB unabhängig von »Weisungen von Organen, Einrichtungen oder sonstigen Stellen der Union, Regierungen der Mitgliedstaaten oder anderen Stellen « (Art. 130 AEUV).

Diese Unabhängigkeit drückt sich auch in einer der zentralen rechtlichen Kodierungen der Fiskalunion aus: Dem im Artikel 123 AEUV verbrieften Verbot monetärer Staatsfinanzierung. Demnach sind sowohl

»Überziehungs- oder andere Kreditfazilitäten bei der Europäischen Zentralbank oder den Zentralbanken der Mitgliedstaaten [...] für Organe, Einrichtungen oder sonstige Stellen der Union, Zentralregierungen, regionale oder lokale Gebietskörperschaften oder andere öffentlich-rechtliche Körperschaften, sonstige Einrichtungen des öffentlichen Rechts oder öffentliche Unternehmen der Mitgliedstaaten«

als auch »der unmittelbare Erwerb von Schuldtiteln von diesen durch die Europäische Zentralbank oder die nationalen Zentralbanken« verboten (Art. 123, Abs. 1 AEUV). Ergänzt wird dieses durch das Verbot eines »bevorrechtigten Zugang[s] zu den Finanzinstituten« (Art. 124 AEUV), das in Ergänzung zum direkten Finanzierungsverbot durch die Zentralbank (vgl. auch VO (EG) Nr. 3603/93) dazu dienen solle, »den öffentlichen Sektor bei seinen Finanzierungsgeschäften der Disziplin der Marktmechanismen zu unterwerfen« (Erw. VO (EG) Nr. 3604/93; Herv. J. G.). Allerdings impliziert Artikel 123 AEUV lediglich ein Verbot des »unmittelbaren« Erwerbs von staatlichen Schuldtiteln, wohingegen der »mittelbare« Erwerb im Rahmen von Offenmarktgeschäften (vgl. Art. 18 Pro- 
tokoll Nr. 4) unter Achtung des Umgehungsverbots monetärer Staatsfinanzierung über die Sekundärmärkte (vgl. Erw. VO (EG) Nr. 3603/93) zulässig sei. Weiterhin findet sich im Artikel 125, Absatz 1 AEUV das sogenannte »No-Bailout-Gebot «, nach dem weder die Union im Gesamten noch die Mitgliedstaaten untereinander für »die Verbindlichkeiten der Zentralregierungen, der regionalen oder lokalen Gebietskörperschaften, sonstiger Einrichtungen des öffentlichen Rechts oder öffentlicher Unternehmen von [(anderen); J.G.] Mitgliedstaaten [haften] und [...] nicht für derartige Verbindlichkeiten ein[treten].« Allerdings ermöglicht der AEUV in einer Art Notstandsartikel (Art. 122) »unter bestimmten Bedingungen einen finanziellen Beistand der Union«, wenn nämlich »ein Mitgliedstaat aufgrund von Naturkatastrophen oder außergewöhnlichen Ereignissen, die sich seiner Kontrolle entziehen, von Schwierigkeiten betroffen oder von gravierenden Schwierigkeiten ernstlich bedroht [ist].« Diesen übergeordneten Vertragsbestimmungen folgen in der >EU-Fiskalverfassung « weitere fiskalpolitische Bestimmungen.

Der leitende Grundsatz des in Artikel 126 AEUV kodierten Stabilitäts- und Wachstumspakts (SWP) lautet im Sinne der Zielvariable gesunder öffentlicher Finanzen, dass die Mitgliedstaaten übermäßige öffentliche Defizite vermeiden sollen (vgl. Art. 126, Abs. I AEUV). Die Überwachung der Entwicklung der mitgliedstaatlichen Haushaltslagen obliegt dabei der Kommission (vgl. Art. 126, Abs. 2 AEUV), wobei die Überwachung anhand zweier zentraler Kriterien, der Defizit- und der Schuldenstandsquote, erfolgen solle. Die entsprechenden Referenzwerte sind im Vertragsprotokoll Nr. 12 hinterlegt: maximal $3 \%$ des BIP (Defizitkriterium) und $60 \%$ des BIP (Schuldenstandskriterium) (vgl. Art. I Protokoll Nr. 12). Leichte Spielräume in der Bewertung bestehen, wenn trotz Referenzwertüberschreitung die Quoten rückläufig sind und sich in der Nähe des Referenzwertes befinden (vgl. Art. 126, Abs. 2 AEUV). Für den Fall, dass ein Mitgliedstaat mindestens einen der beiden Referenzwerte nicht erfüllt, erstellt die Kommission einen Bericht, wobei sie auch einen Bericht verfassen kann, »wenn sie ungeachtet der Erfüllung der Kriterien der Auffassung ist, dass in einem Mitgliedstaat die Gefahr eines übermäßigen Defizits besteht.« (Art. 126, Abs. 3 AEUV) Der sogenannte Wirtschaftsund Finanzausschuss (WFA), ein Beratungsgremium aus Vertreter"innen der Mitgliedstaaten, der Kommission und der EZB (vgl. Art. 134, Abs. 2 AEUV), gibt zum Bericht eine Stellungnahme ab (vgl. Art. 126, Abs. 4 AEUV). Vertritt die Kommission die Auffassung, dass ein übermäßiges Defizit besteht oder sich ergeben könnte, legt sie dem Mitgliedstaat eine Stellungnahme vor und unterrichtet den Rat (vgl. Art. 126, Abs. 5 AEUV). Dem Rat obliegt es anschließend darüber zu befinden, ob ein übermäßiges Defizit besteht (vgl. Art. 126, Abs. 6 AUEV). Stellt er dieses fest, »richtet er auf Empfehlung der Kommission unverzüglich Empfehlungen an den betreffenden Mitgliedstaat mit dem Ziel, dieser Lage innerhalb einer bestimmten Frist abzuhelfen.« (Art. 126, Abs. 7 AEUV) Sollten innerhalb dieser Frist keine wirksamen Maßnahmen unternommen worden sein, kann der Rat seine Empfehlungen auf Grundlage einer Kommissionsempfehlung veröffentlichen (vgl. Art. 126, Abs. 8 i. V. m. Abs. 13 AEUV). Als weitere Eskalationsstufe kann durch den Rat (auf Empfehlung der Kommission) die Inverzugsetzung festgestellt werden, soweit der betroffene Mitgliedstaat den Empfehlungen weiterhin nicht Folge leistet (vgl. Art. 126, Abs. 9 i. V. m Abs. 13 AEUV). Zugleich kann mit der Inverzugsetzung ein konkreter Zeitplan zur Berichtslegung durch den betreffenden Mitgliedstaat beschlossen werden (vgl. ebd.). Für den Fall, dass auch die Inverzugsetzung keine Ver- 
haltensänderung bewirkt, steht es dem Rat (auf Empfehlung der Kommission) offen, Sanktionsmaßnahmen (inkl. unverzinslicher Einlagen oder Geldbußen) zu verhängen (vgl. Art. 126, Abs. 11 i. V. m. Abs. 13 AEUV). Das Defizitverfahren endet erst dann, wenn der Rat die im Rahmen des Verfahrens getroffenen Beschlüsse oder Empfehlungen auf Anraten der Kommission aufhebt oder (bei vorheriger Veröffentlichung der Empfehlungen) in einer öffentlichen Erklärung auf Empfehlung der Kommission feststellt, dass kein übermäßiges Defizit mehr besteht (vgl. Art. 126, Abs. 12 i. V. m. Abs. 13 AEUV). Auch wenn das VÜD somit »de jure von politischen Kräfteverhältnissen bestimmt wird, bildet die primärrechtliche Festlegung auf ein Verbot übermäßiger Staatsdefizite einen grundsätzlichen Paradigmenwechsel im juridischen System strategischer Selektivität der Finanzpolitik« (Petzold 2018, 165), das durch Sekundärrecht in Form zweier Verordnungen (VO (EG) Nr. 1466/97 \& VO (EG) Nr. 1467/97) weiter ausgeschärft wird (s.u.).

\section{EU-Wirtschaftsverfassung}

Die sich in den dargestellten Vertragsnormen materialisierende Wirtschaftsverfassung der EU kann beispielsweise im Gegensatz zum deutschen Grundgesetz nicht durch eine generelle »Offenheit« gekennzeichnet werden (vgl. Bandilla 2017, Art. 119, Rn. 26). In ihrem Rahmen erfolgt stattdessen die Festlegung auf eine marktwirtschaftliche Organisation des Wirtschaftslebens, die in den Verträgen wahlweise als »offene Marktwirtschaft mit freiem Wettbewerb « (Art. 119, Abs. 1 AEUV) oder aber als »im hohen Maße wettbewerbsfähige soziale Marktwirtschaft « (Art. 3, Abs. 3 EUV) gekennzeichnet wird. Hinzu kommt in der Tradition der EU-Vorläuferorganisationen die von Joerges $(2012,361)$ attestierte "Abkoppelung von Wirtschafts- und Sozialverfassung «, die sich bereits mit den Römischen Verträgen von 1957 vollzogen habe. Bis heute zieht sich diese durch alle Folgeverträge. Die EWG-Wirtschaftsverfassung von 1957 sei dabei maßgeblich von ordoliberalen Vorstellungen der damaligen deutschen Delegation geprägt worden (vgl. Brunkhorst 2014a, 63). Unter der Leitung von Müller-Armack, dem geistigen Vordenker der sozialen Marktwirtschaft, setzte sich hierbei »eine wettbewerbsorientierte und planungsfeindliche Wirtschaftsverfassung gegen den heftigen Widerstand Frankreichs als Leitverfassung der neuen Gemeinschaft durch[...] « (ebd.), die zugleich "[d]as außenwirtschaftsorientierte Akkumulationsmodell der BRD, das sich seit Beginn der 1950er Jahre herausgebildet hatte, [...] nach außen hin rechtlich $a b[. .$.$] sichert [e]$.« (Petzold 2018, 106) So umfasste schon der EWG-Vertrag die bis heute konstitutiven vier »Freiheiten« (freier Personenverkehr, freier Warenverkehr, freier Kapital- und Zahlungsverkehr sowie die Dienstleistungsfreiheit), die gegenseitige Öffnung der Volkswirtschaften, Diskriminierungsverbote sowie die Verpflichtung auf ein unverfälschtes Wettbewerbssystem (vgl. Joerges 2010, 399). Allerdings sei der Liberalisierungsdruck der EWG-Wirtschaftsverfassung noch $\mathrm{zu}$ gering gewesen, "um den sozialen Integrationskompromiß, der die nationalen Sozialstaatsverfassungen schonen und die transnationalen Gerechtigkeitsverluste national ausgleichen sollte, ernsthaft zu gefährden.« (Brunkhorst 2014a, 65) Dies änderte sich allerdings schrittweise mit den skizzierten politischen Projekten neoliberaler Restrukturierung. Zudem verhalf der EuGH der Wirtschaftsverfassung in einer »lange[n] Serie marktradikaler Urteile« (Brunkhorst 2014b, 508) zum entscheidenden Durchbruch 
und verlieh ihr einen durchschlagenden Charakter. In diesen artikulierte sich die »Wirtschaftsverfassung als >reineく Marktverfassung« und manifestierte schließlich die "Aufkündigung des gemeineuropäischen Verfassungskompromisses« (Joerges 2012, 364) zwischen suprastaatlicher Wirtschafts- und mitgliedstaatlicher Sozialverfassung. Durch die Rechtsprechung des EuGH sei das europäische Vertragsrecht letztlich $\mathrm{zu}$ einem »Immunsystem der Marktwirtschaft« (Brunkhorst 2014b, 510) avanciert. Im Zuge dieser Entwicklungen habe sich schließlich auch eine Reorientierung vom Ordozum Neoliberalismus vollzogen (vgl. Brunkhorst 2014b, 401), die sich im Maastrichter Vertrag darin niederschlage, dass die Wirtschaftsverfassung an entscheidender Stelle um Elemente einer monetär-dominierten Fiskal- und Währungsverfassung ergänzt worden sei, in deren Zentrum die unabhängige Zentralbank und das vorrangige Ziel der Preisstabilität stehe (vgl. Brunnermeier, James \& Landau 2018, 121; Glöckler 2015, Rn. 15). Verstärkt wird diese monetäre Dominanz durch die restriktiven Vorgaben im Rahmen der fiskalpolitischen Verfassungskomponente. Das 1992 mit dem Vertrag von Maastricht geschaffene »Euro-Regime«, beschrieben als eine »hochspezialisierte, geldpolitisch vereinseitigte, technische Regierung aus Bankern und Richtern, deren Gesetzgebung noch im Augenblick der Entscheidung [...] mit zumeist irreversiblen und weitreichenden Folgen exekutiert wird« ist »zusammen mit dem immer schon hegemonialen Wettbewerbsrecht und der Priorität des Privateigentums zur fast unabänderlichen, nur durch einstimmigen Beschluss aller Gliedstaaten wandelbaren, substantiellen Verfassung Europas geworden [...].« (Brunkhorst 2017, 59) Diese, um monetaristische fiskal- und währungspolitische Prämissen ergänzte ordo-/neoliberale "Wirtschaftsverfassung ist bis heute die hegemoniale Verfassung Europas geblieben.« (Brunkhorst 2014a, 68) Die Arbeits- und Sozialverfassung als Komplementär im Sinne der Vorstellung eines »europäischen Sozialmodells«, das auf Dauer die unterschiedlichen Wohlfahrtsstaatsmodelle ablöse, sei hingegen "niemals mehr als eine blasse Utopie« (Joerges 2012, 364) gewesen.

\subsection{Die Akkumulationsstrategie und das Staatsprojekt der EU unter neoliberalen Vorzeichen}

Mit dem Maastrichter Vertrag ist der ordo- und neoliberal geprägten Wirtschaftsverfassung der EU zum vollständigen Durchbruch verholfen worden. In der Folge wird mit ihr die soziale Auseinandersetzung um richtige Wirtschafts- und Sozialpolitik weitgehend stillgelegt: »Die Europäischen Verträge sind auf eine bestimmte, nämlich eine neoliberale Wirtschafts- und Sozialordnung festgelegt, die im demokratischen Prozess nicht mehr zur Disposition steht.« (Fisahn 2017b, 24) War der wirtschaftsliberale Geist der Wirtschaftsverfassung zwar schon in den Verträgen der 5oer Jahre angelegt, lässt sich das Grundmuster der Integrationsprozesse der 5oer und 6oer Jahre dennoch als eine »Integrationsweise« beschreiben, »die keynesianisch-korporatistischer Staatlichkeit« (Ziltener 1999, 113) entsprochen hätte (vgl. auch Karrass 2009, 232). Von einer Integrationsweise spricht Ziltener $(1999,81)$ dann, »[w]enn hinsichtlich der Form und Funktion europäischer Staatlichkeit über eine längere Zeit ein stabiles Grundmuster zu beobachten ist«. Eine solche Zuschreibung verweist auf jene Aspekte, die sich in einem 
Staatsprojekt verdichten. Ziel der keynesianisch-korporatistischen Integrationsweise sei dabei die »Absicherung nationaler Entwicklungswege« (ebd., 122) gewesen, wobei »die europäischen Instanzen [...] den nationalen Entwicklungswegen [assistierten]. [...] Die europäische Ebene stärkte Staatlichkeit, sie stärkte den Nationalstaat, sie schwächte ihn nicht.« (Ebd., 124) In der EG herrschte eine (Quasi-)Hegemonie des Keynesianismus und Fordismus, verstanden

»als ein Akkumulationsregime, das auf der Basis eines eigenzentrierten Kreislaufes von Massenproduktion und Massenkonsumtion existierte und das durch eine Regulationsweise gesichert wurde, die im keynesianischen Wohlfahrts-National-Staat institutionell und praktisch verwirklicht worden war.« (Jessop 2001, 146)

Im Zuge der Krisen der 7oer und zu Beginn der 8oer Jahre und des Scheiterns des »ambitiöse[n] Versuch[s] einer >Keynesianisierung^der EG« (Ziltener 1999, 117) - beispielsweise in Form des Werner-Plans - habe ein Umbau hin zur wettbewerbsstaatlichen Integrationsweise begonnen (vgl. ebd., 132; 12). Im Schatten der Fordismus-Krise und der mit ihr verbunden Krise keynesianischer Erklärungsansätze (vgl. Horn 2016, 99f.) konnte sich in diesem Umbauprozess das neoliberale Hegemonieprojekt strategisch immer stärker durchsetzen (vgl. u.a. Nicoll 2012, 81 \& Petzold 2018, 135; zur Bedeutung neoliberaler Netzwerke sallgemein s.u.a. Plehwe \& Bernhard 2006). Die Forschungsgruppe `Staatsprojekt Europa identifiziert insgesamt fünf solcher Hegemonieprojekte, verstanden als heuristische Idealtypen (vgl. Buckel 2011, 642), die Strategieansätze repräsentieren, »mit denen bestimmte Kräfte auf spezifische historische Situationen rekursiv [...] reagieren « (Buckel et al. 2014, 47) und dementsprechend in die konkreten gesellschaftlichen Prozesse und Kämpfe diskursiv intervenieren. 


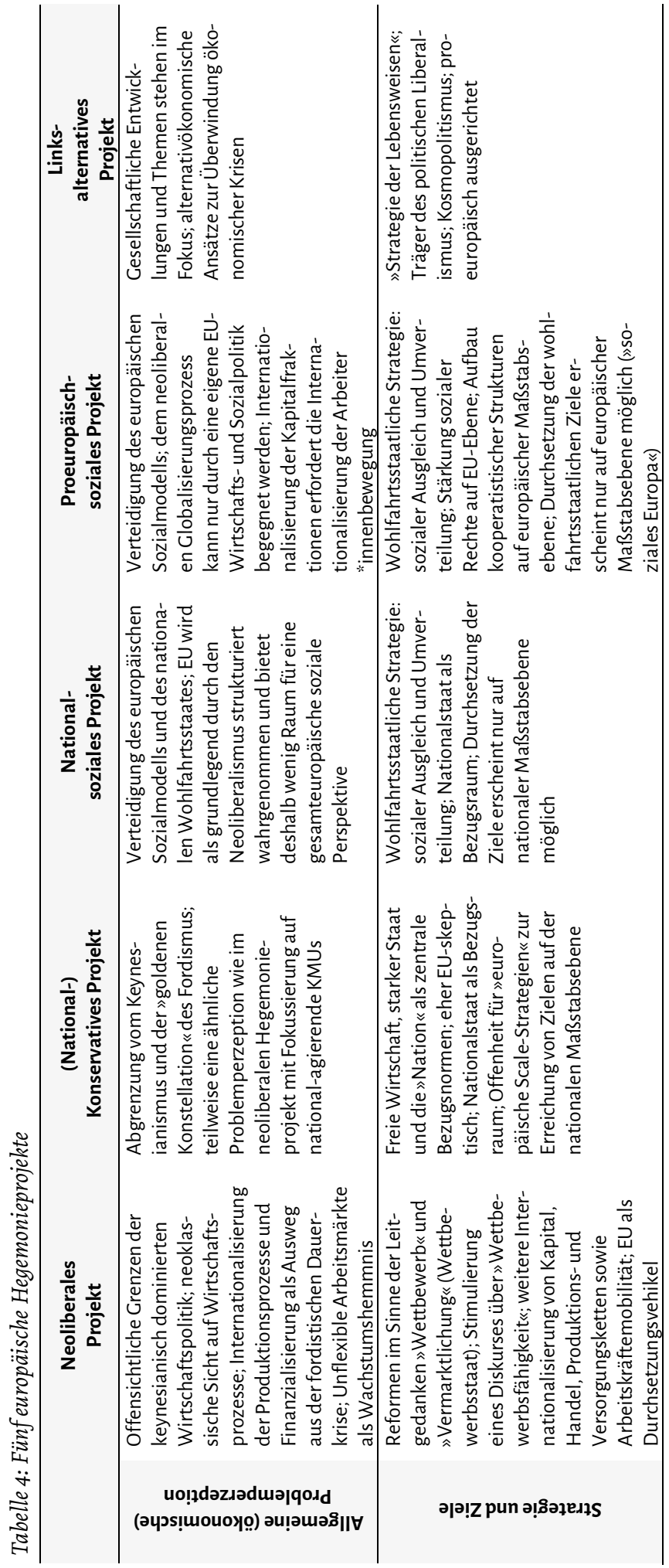




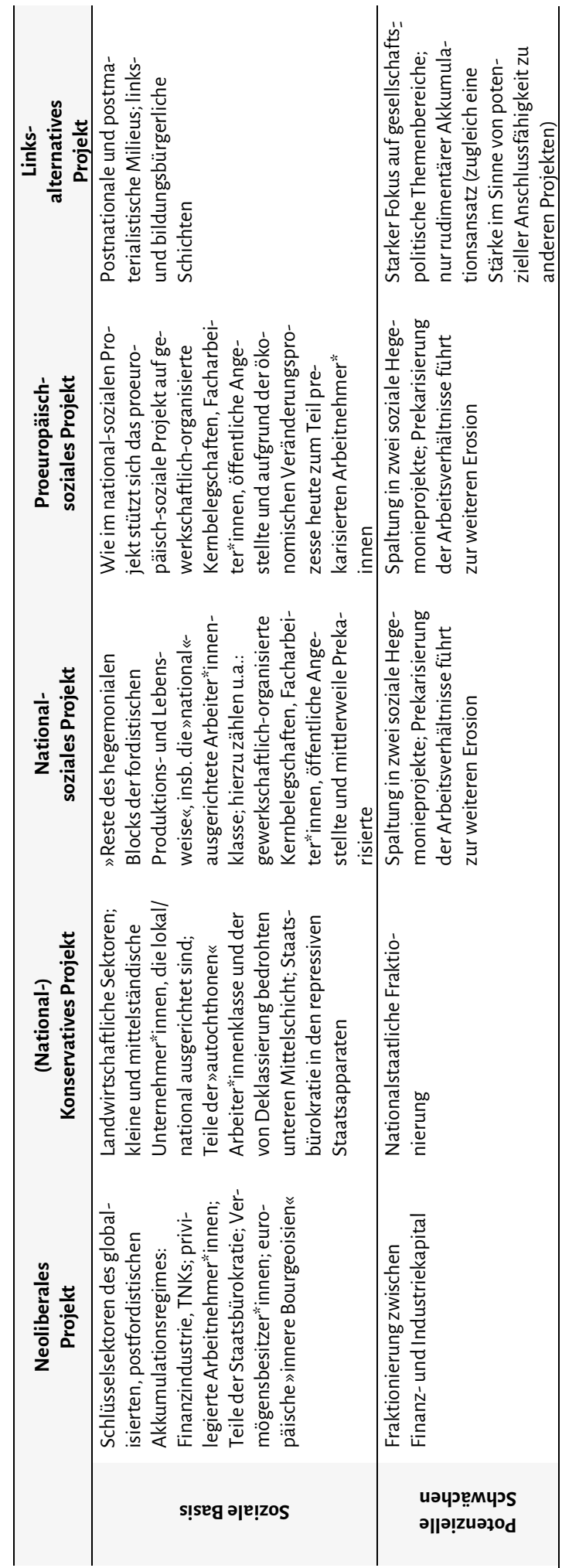




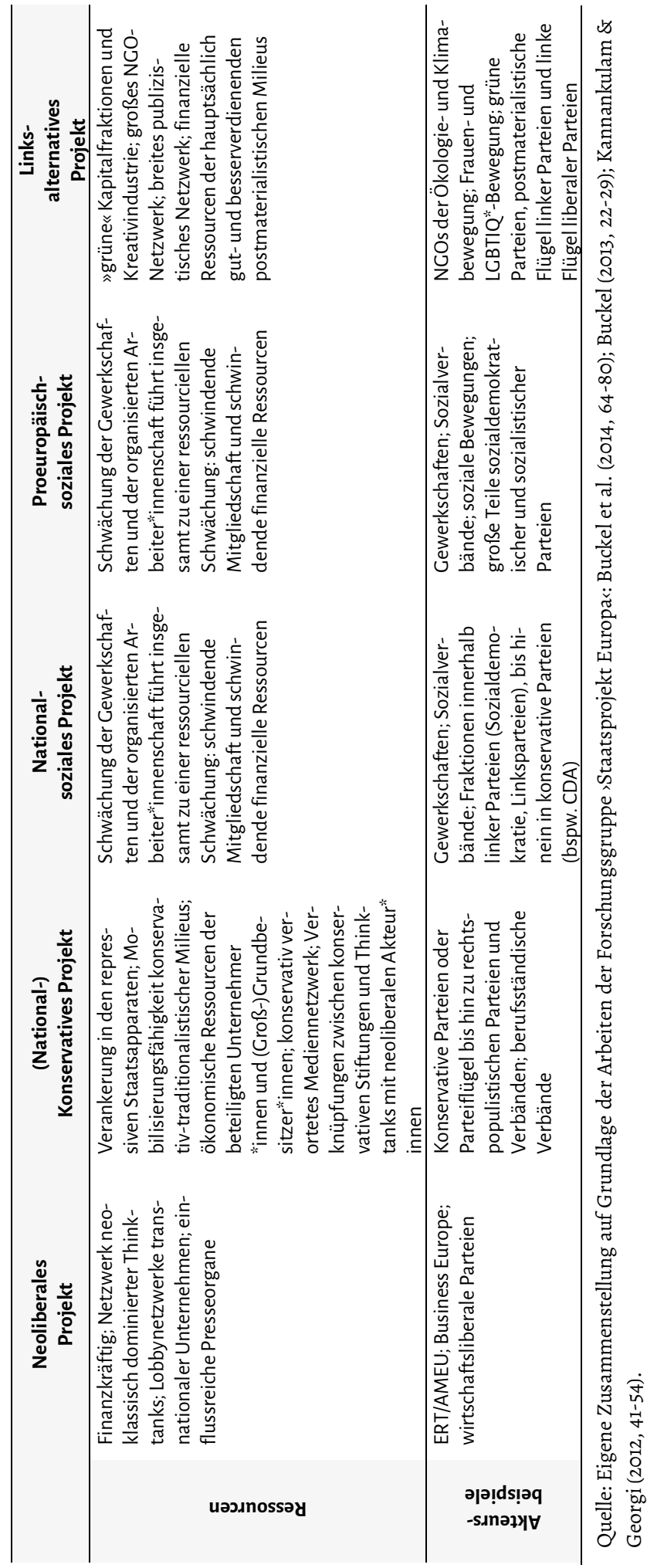


Mit den fünf beschriebenen Hegemonieprojekten wird der Anspruch verbunden, genuin europäische Kräfteverhältnisse abzubilden. Auch die mitgliedstaatlichen Staats-Zivilgesellschafts-Komplexe sind in diesem Sinne immer in unterschiedlicher Ausprägung auf sie bezogen. Allerdings muss auf Grundlage der Multiskalarität der EU-Staatlichkeit immer auch Beachtung finden, dass sich in den Mitgliedstaaten als soziale Verhältnisse - eigene Hegemonie- und Kräfteverhältnisse verdichten, die zwar in einem direkten Bezug zu den europäischen Hegemonieprojekten stehen, sich aber von Mitgliedstaat zu Mitgliedstaat unterscheiden (können). Hierauf wurde bereits im Theorieteil dieser Arbeit mit Blick auf die »integrale EU-Staatlichkeit« Bezug genommen. Insgesamt ist daher notwendig, von einem Netzwerk von Kräfteverhältnissen auszugehen, das sich multiskalar materialisiert. In diesem Sinne sollten deshalb immer auch die mitgliedstaatlichen Herrschaftsblöcke als Erklärungsvariablen auf Ebene der EU-Staatlichkeit Berücksichtigung finden, besonders da sie über die Ratsstruktur direkt auf die Politikformulierung der EU Einfluss nehmen. Dies zeigte sich nicht zuletzt auch im konkreten Ringen um die Ausgestaltung der politischen Projekte neoliberaler Strukturierung zwischen Deutschland und Frankreich, das sich aus den jeweiligen nationalen polit-ökonomischen Kräfteverhältnissen speiste. So ist der intergouvernemental ausgetragene Konflikt zwischen Deutschland und Frankreich, der sich durch alle drei politischen Projekte neoliberaler Strukturierung durchgezogen hat, auf Grundlage der Verdichtung von Kräfteverhältnissen in den mitgliedstaatlichen Staatsapparaten $\mathrm{zu}$ verstehen. Die gesamteuropäischen Kräfteverhältnisse müssen entsprechend als jeweils historisches Kompositum sowohl der transnationaleuropäischen als auch der mitgliedstaatlichen Maßstabsebene begriffen werden.

Die politischen Projekte des neoliberalen Hegemonieprojekts prägten den europäischen Integrationsprozess - wie gezeigt wurde - über viele Jahre maßgeblich, sodass es gar zum hegemonialen Projekt der europäischen Integration avancierte (vgl. u.a. Hooghe \& Marks 2008a, 165; van Apeldoorn 2009, 22 oder Bieler \& Morton 2001, 208f.). Zwischenzeitlicher Höhepunkt sei demnach die Verwirklichung des Binnenmarkt-Projektes gewesen, das regelrecht eine Euphorie ausgelöst habe (vgl. Bieling \& Steinhilber 2000a, 15), und die Stellung des neoliberalen Projekts als hegemoniales Projekt eindrücklich veranschaulichte (vgl. auch Nachtwey 2017, 81f.). Alternative Hegemonieprojekte, insbesondere jene, die zur Zeit des Fordismus eine hegemoniale Stellung einnehmen konnten, erodierten in Folge der diskursiven Verschiebungen weiter oder wurden partiell (einzelne Akteur"innen oder Fraktionen) in die hegemoniale Konstellation des Neoliberalismus eingebunden. Hegemoniefähigkeit drückt sich demnach darin aus, unterschiedliche Fraktionen eines beziehungsweise konkurrierender Hegemonieprojekte miteinander zu versöhnen, um in weite Bereiche der Gesellschaft konsensualisierend hineinwirken zu können. Exemplarisch lässt sich dies an der europäischen Sozialdemokratie illustrieren, die bis Ende der 80er/Anfang der 9oer Jahre hinein in ihrer Mehrheit einem proeuropäisch-sozialen Hegemonieprojekt mit dem Ziel eines »regulierten Kapitalismus (Hooghe \& Marks 2008a, 164) anhing und bis dato eine Stütze der keynesianisch-korporatistischen Integrationsweise (vgl. Bihr 2012, 38) darstellte, in Folge der ökonomischen Umbrüche aber ebenfalls in weiten Teilen dem neoliberalen Diskurs verfiel. Dieses Einschwenken sozialdemokratischer Akteur*innen auf einen neoliberalen Pfad zeigte sich unter anderem in den Verhandlungen um den 
Amsterdamer Vertrag. So gelang es den sozialdemokratischen Parteien, die »in dreizehn von fünfzehn Staaten regierten [...], zwar formal die Kompetenzen der EU auf die Bereiche Beschäftigung, soziale Regulierung, Frauen- und Menschenrechte sowie auf die Umweltpolitik« zu erweitern, es wurde jedoch darauf verzichtet, »die EU mit Handlungsbefugnissen auszustatten, die über eine unverbindliche Koordinierung nationaler Politik hinausging.« (Hooghe \& Marks 2008b, 199f.) Die Staatlichkeitsleitbilder der europäischen Sozialdemokratie, geprägt von den einsetzenden Diskussionen um »New Labour« und »Dritter-Weg«-Debatten, waren bereits durch den neoliberalen Diskurs um neue Steuerungsformen (bspw. normativ-geprägte Governance-Konzepte: >New Public Management $\triangleleft)$, den Niedergang des Keynesianismus und einer allgemeinen staatlichen Zurückhaltung zugunsten von Marktmechanismen geprägt.

Diese neoliberale Fokussierung setzte sich auch bei der Formulierung der sogenannten »Lissabon-Strategie« aus dem Jahre 2000 fort (vgl. u.a. Drahokoupil, van Apeldoorn \& Horn 2009, 4). Auf der Regierungskonferenz von Lissabon stellten sozialdemokratische Parteien nach den vielen Wahlerfolgen in den 1990er Jahren weiterhin die Mehrzahl der mitgliedstaatlichen Vertreter*innen. ${ }^{6}$ Dennoch wurde mit der Lissabon-Strategie eine politische Agenda für die Europäische Union beschlossen, welche im Nachgang zu den politischen Projekten neoliberaler Restrukturierung den eingeschlagenen Weg fortschrieb und die Europäische Union »zum wettbewerbsfähigsten und dynamischsten wissensbasierten Wirtschaftsraum in der Welt« (Europäischer Rat [ER] 2000) entwickeln sollte, wofür es durchaus auch Unterstützung aus Gewerkschaftskreisen gab (vgl. van Apeldoorn 2014, 194). Die Lissabon-Strategie stellte ein neuartiges Politikinstrument dar, welches im Zuge der Maastrichter Vertragsrevision von Anhänger*innen weitreichender fiskalischer und sozialpolitischer Integrationsschritte gewünscht und schließlich durchgesetzt wurde (vgl. Hacker 2017, 19). Allein hieraus generierte sich bereits eine Art sinstrumentelle Unterstützung für die neue Strategie. Zugleich lassen sich aber auch auf inhaltlicher Ebene seit dem Binnenmarktprojekt Tendenzen identifizieren, die darauf hinweisen, dass Teile der Arbeitnehmer*innen und ihrer gewerkschaftlichen Interessenvertretungen (insbesondere aus den exportorientierten Industriesektoren) ebenfalls stark in den neoliberalen Diskurs eingeschrieben sind (vgl. Bieling 2001b, 99 \& Dusse 2019, 301). Weiterhin lässt sich generell die partielle Anschlussfähigkeit des proeuropäisch-sozialen an das neoliberale Hegemonieprojekt anführen, soweit forcierte Maßnahmen eine Stärkung europäischer Interventionsräume in der Sozialpolitik offerieren (vgl. van Apeldoorn 2009, 29). In diesem Sinne wies die Lissabon-Strategie in Ansätzen gar den Charakter eines Quasi-Klassenkompromisses auf. Allerdings konstatiert van Apeldoorn (2014, 194; Herv. J. G): »[A]lthough Lisbon and its hegemonic formula of competitiveness with social cohesion [...] initially had succeeded in bringing together both European transnational capital and organized labour, it was never a real class compromise."An anderer Stelle konkretisiert er: »[...] at the heart of Lisbon we find an articulation of neoliberal competitiveness with concerns of the transnational social democratic

6 Die Dominanz sozialdemokratischer Staats- und Regierungschefs im Europäischen Rat nahm seitdem sukzessive ab. Die sozialdemokratische Vorherrschaft wich der Dominanz konservativer Poltiker*innen (vgl. Degryse, Jepsen \& Pochet 2013, 14). 
project in ways that effectively subordinate the latter to the former. (van Apeldoorn 2009, 29; Herv. J. G.) Demnach gelang es mit der Lissabon-Strategie, eine Akkumulationsstrategie zu formulieren, in der sich abermals die Vormachtstellung des neoliberalen Hegemonieprojekts und seiner Konsensualisierungsfähigkeit zeigte.

Mit der Durchsetzung der drei politischen Projekte neoliberaler Restrukturierung, ihrer vertraglichen Absicherung sowie der zu Beginn des neuen Jahrtausends formulierten Akkumulationsstrategie gelang es den Akteur*innen des neoliberalen Hegemonieprojekts somit zugleich die Staatlichkeit der EU maßgeblich im Sinne ihres Staatsprojekts zu gestalten beziehungsweise weiter umzugestalten. Dies äußert sich strukturell auch darin, dass sich »eine neue Hierarchie zwischen den unterschiedlichen Staatsapparaten und Institutionen auf europäischer und nationaler Ebene und eine neue skalare Struktur« (Wissel 2017, 270) herausbildete. Zugleich hat sich diese Hierarchie »Zuungunsten der Apparate verschoben, die mit den gesellschaftlichen Kompromissen des Fordismus verbunden waren (zum Beispiel Arbeits- und Sozialministerien).«(Wissel 2012, 10)

In diesen Verschiebungen drückt sich nicht zuletzt auch die inhaltliche Stoßrichtung des neoliberalen Hegemonieprojekts aus, indem der EU-Staatlichkeit ein Telos eingeschrieben wird, der auf einen weltmarktorientierten Akkumulationsansatz fokussiert, in dessen Zentrum die Doktrin der Wettbewerbsfähigkeit steht (Lissabon-Strategie) und sich regulatorisch im Leitbild der wettbewerbsstaatlichen Integrationsweise niederschlägt. Übersetzt in die EU-Verträgeverfassung bedeutet dies die Entkoppelung der Wirtschafts- von der Sozialverfassung und die Einschränkung diskretionärer Entscheidungsmöglichkeiten demokratischer Politik. Anders gesagt, bildet sich hier ein Staatsverständnis heraus, das auf der neoliberalen Sachzwangslogik (vgl. Karrass 2008; 2009) von Austerität und Wettbewerbsfähigkeit gründet und demnach auf einem Zurückdrängen staatlichen Interventionismus basiert.

Dieses der EU eingeschriebene Staatsprojekt konkurriere dabei aber zugleich mit den unterschiedlichen mitgliedstaatlichen Staatsprojekten (vgl. Wissel 2012, 10). Zudem unterliege das Verhältnis der genuinen EU- und der mitgliedstaatlichen Apparate zueinander einem permanenten Aushandlungsprozess, »weil es noch keinen stabilen hegemonialen Konsens über die Hierarchie der räumlichen Bezugsebenen gibt.« (Ebd.) Im Vergleich zu den Regulationsmodi des fordistischen Nationalstaats zeige sich für die EU-Staatlichkeit und ihrem Staatsapparate-Ensemble insofern,

»dass noch kein europäisches Staatsprojekt existiert, das mit den tradierten nationalen Staatsprojekten vergleichbar wäre [...]. Das bedeutet, dass die Fähigkeit des europäischen Staatsapparate-Ensembles, gesellschaftliche Kohäsion herzustellen, nur schwach ausgeprägt ist« (Buckel 2013, 42; Herv. J. G.; vgl. Buckel 2017, 36).

Demnach könne die »organisatorische Kohärenz und Anordnung« bisher »weniger durch seine - selbst noch umkämpfte - formale Struktur sichergestellt werden«, als dass sie vielmehr das Ergebnis eines hegemonialen Projekts sei (Wissel 2010, 81). Insofern unterliegt die EU der Fragilität einer strukturellen Fluidität. Zwar habe ein Suchprozess nach einem umfassend kohärenzstiftenden Staatsprojekt für die Europäische Union eingesetzt, der bisher aber fragil erscheine und in Krisenzei- 
ten mit besonderen Herausforderungen konfrontiert sei, die gar ein Scheitern des Suchprozesses nicht ausschließen könne (vgl. Buckel 2013, 42).

Das hegemoniale Staatsprojekt am Vorabend der Euro-Krise ist in diesem Sinne als ein Projekt zur Staatlichkeits-Genese zu verstehen, welches »das Terrain und die Regeln der Auseinandersetzung sowie die institutionelle Struktur, in der die Auseinandersetzungen stattfinden, erst schaffen [muss]. (Wissel 2015, 28) Es ist nur im rudimentären Sinne als ein Projekt der Staatlichkeits-Reproduktion zu begreifen, das sich bereits vollumfänglich »auf die institutionelle Struktur und die Materialität der Apparate stützen« (ebd.) könnte. Die Übergänge zwischen beiden Modi sind allerdings fließend. Ist im Namen eines Staatsprojektes eine (wenn auch in Teilen fragile) Struktur entstanden, kann diese einhergehend mit der notwendigen zivilgesellschaftlichen Absicherung auch in Ansätzen die Staatlichkeitsreproduktion anleiten. Dies gelang dem neoliberalen Hegemonieprojekt bis zum Ausbruch der transatlantischen Finanzkrise 2007. Mit der einsetzenden diskursiven Infragestellung des Neoliberalismus und schließlich mit der sich in der Euro-Krise ausdrückenden Funktionskrise der neoliberalen EWWU wird die Fragilität des EU-Staatsprojektes allerdings deutlich hervortreten und den Kampf zwischen konkurrierenden Hegemonieprojekten in der EU neu entfachen. 



\section{Die Euro-Krise als Funktionskrise der neoliberalen EWWU}

Die Euro-Krise lässt sich nach Priewe $(2017,5)$ als »die Gesamtheit der Probleme« begreifen, »die mit der Gemeinschaftswährung selbst und der Ausgestaltung der Währungsunion verbunden « ist und sich schließlich in den Entwicklungen der »kritischen Jahre 2010 - 2014 niedergeschlagen« habe. (vgl. auch Grözinger 2015a, 209) Sie ist demnach eine endogene Krise der Europäischen Wirtschafts- und Währungsunion in ihrer neoliberalen Anlage des Maastrichter Vertrags und lässt sich in Teilen aus ihrer eigenen, fehlgeleiteten Institutionalisierung heraus erklären. Dass diese fehlgeleitete Institutionalisierung oder Funktionskrise zutage treten konnte, liegt an ihrer Einbettung in die globale Krise des finanzmarktdominierten Kapitalismus seit 2007. Die hierdurch einsetzende ökonomische Krisenkaskade der Jahre bis 2009 legte schließlich jene Funktionsdefizite offen, die sich spätestens ab 2010 unter dem Dach der Euro-Krise zu einer genuinen Krise der EWWU und der EU-Staatlichkeit verdichteten. Die Euro-Krise ist insofern keine rein ökonomische Krise, sondern im Kern auch eine politische Krise, die durch eine eigene politische Krisenkaskade gekennzeichnet ist. Diese Genealogie der sich gegenseitig verschärfenden und in der Euro-Krise kumulierenden Krisenphänomene soll im Folgenden nachgezeichnet werden, um anhand der Versuche zu ihrer Bewältigung und dem durch sie induzierten Staatlichkeitsausbau die Transformation der EU-Staatlichkeit zu beschreiben.

\subsection{Die transatlantische Finanzmarktkrise als Ausgangspunkt}

Seinen Ausgangspunkt nahm der ökonomische Krisenzyklus im August 2007, als die Geschäftstätigkeit auf dem Interbankenmarkt, auf dem sich Banken gegenseitig Geld leihen und der im modernen Bankensystem eine Schlüsselrolle einnehme, fast vollständig zum Erliegen kam (vgl. Evans 2011, 98). Die immer deutlicher zu Tage tretende Finanzmarktkrise fand ihren ersten weithin sichtbaren Höhepunkt im Zusammenbruch der Investmentbank Lehman Brothers am 15.09.2008. Sie zog allerdings nicht über Nacht herein und eruptierte mit der Pleite der US-Investmentbank, sondern verwies 
auf tiefergehende, strukturelle Problemlagen des globalen, finanzmarktdominierten Akkumulationsregimes (vgl. u.a. Demirović \& Sablowski 2011; vgl. grundsätzlich Stockhammer 2008). Ausdruck fand dies in einer "Aufblähung der unproduktiven Verschuldung «, wie Zinn $(2013,53)$ es umschreibt. Im Mittelpunkt stand hierbei eine großzügige Versorgung mit Geld durch niedrige Zinsen (vgl. u.a. Altvater 2009, 13), mit der in den USA insbesondere kreditfinanziertes Wohneigentum geschaffen wurde. Das neoliberale Programm der »Home Ownership-Society« (Ronald 2008) basierte dabei auf sogenannten Subprime-Krediten, mit denen auch Bevölkerungsschichten in den Genuss von Immobilien- und hypothekenbasierten Konsumkrediten gelangten, die nur wenig Solvenz vorweisen konnten. Triebkraft hierbei war, dass »nicht genügend solvente Schuldner [...] das überreichlich vorhandene Vermögen der Reichen absorbieren konnten." (Bontrup 2013, 151) Abgesichert wurden diese Kredite durch sogenannte Securitization-Strategien (Verbriefung und Ausfallversicherungen), einer zentralen Komponente im System der finanzmarktdominierten Akkumulation und seiner Innovationen (u.a. Verbriefung und Zweckgesellschaften in Offshore-Finanzzentren; vgl. Altvater 2009, 12). Durch die weit verbreitete Praxis hypothekenbasierter Wertpapiere (sog. mortgage-backed securities (MBS) als eine spezifische Form von asset-backed securities (ABS)), können Finanzdienstleister hierbei durch das Schnüren sabgesicherter Kreditbündel kurzfristig ihre Liquidität erhöhen, indem sie die eigentlich erst für die Zukunft avisierten Renditen der Ursprungskredite bereits über den Weiterverkauf der Bündel sofort realisieren (vgl. Horn 2016, 106). Dem Platzen der Immobilienblase und ihrer Subprime-Kredite in den USA folgte aufgrund der Securitization-Praktiken und ihrem exponierten Einsatz ein schnelles Übergreifen der Krise auf das gesamte Finanzsystem.

Es zeigte sich hierbei, dass nicht nur US-amerikanische Finanzinstitute von der als Subprime-Krise bezeichneten Krisenkonstellation zu Beginn der weltweiten Finanzkrise betroffen waren, sondern insbesondere auch europäische Bankhäuser an den scheinbar lukrativen Geschäften in Nordamerika teilhaben wollten. Subprime-Kredite stellten aber nur eine Form der neuen lukrativen Finanzmarktprodukte dar, die nach der Liberalisierung der Finanzmärkte seit den 1980er und 9oer Jahren entstanden waren. Im Schoße der Profitabilitätskrise des Fordismus entwickelte sich im Namen der neoliberalen Trias der Deregulierung, Liberalisierung und Privatisierung eine in »vieler Hinsicht« geänderte »Entwicklungsweise des Kapitalismus« (Demirović \& Sablowski 2011, 80; vgl. auch Stockhammer 2008, 184). Die sogenannte Finanzialisierung weiter gesellschaftlicher Funktionsbereiche, verstanden als ein »Prozess von Verschiebungen [...], durch den Unternehmen, Haushalte und der Staat materiell, institutionell und diskursiv stärker an die Entwicklung der Kapitalmärkte gebunden werden « (Heires \& Nölke 2011, 42; vgl. auch Heires \& Nölke 2014; Stockhammer 2008), ist hierbei ein entscheidendes strategisches Moment, das die kapitalistischen Strukturveränderungen hin zum finanzmarktdominierten Akkumulationsregime kennzeichnete. Nachtwey $(2017,59)$ bezeichnet sie als »ein totalisierendes Moment der Gegenwartsökonomie«.

Das Platzen der Heilsversprechen des finanzmarktdominierten Kapitalismus, der zum Großteil auf »Wholesale Funding «, der kurzfristigen Aufnahme von Geldmitteln anderer Banken und Finanzinstitute am Geldmarkt, beruhte, führte, als die entsprechenden Aktiva aufgrund von Neubewertungen der zugrundeliegenden Immobilien vor 
dem Hintergrund eines Überangebots am US-Immobilienmarkt massiv an Wert verloren, rasch zu einer Kettenreaktion. Zuvorderst brachte sie hoch spekulativ agierende Institute und später fast ausnahmslos den gesamten Bankensektor in Bedrängnis. Milliardenschwere Abschreibungen waren die Folge. Einige Institute gerieten in eine solche Schieflage, dass Staaten eingriffen, um sie vor dem Zusammenbruch zu retten. >Too big to faik lautete das Schlagwort der Stunde; nicht nur in den USA sondern auch in Europa.

Inzwischen griff die Krise der finanzgetriebenen Wertschöpfung nicht nur auf den gesamten Bankensektor, sondern auch auf die Realökonomie über. Die Verquickungen zwischen Banken und Finanzintermediären mit der realwirtschaftlichen Wertschöpfung - also »[d]ie Beziehung zwischen dem industriellen Kapitel und dem Finanzkapitel« (Demirović \& Sablowski 2011, 82) - waren im Zeitalter der Finanzialisierung zu groß:

»Durch die Deregulierung und Liberalisierung des Bankensektors und der Finanzmärkte wurden nicht nur neue Möglichkeiten für spekulative Transaktionen gefordert und zahlreiche neue Anlagemöglichkeiten geschaffen, vielmehr haben sich die Eigentumsverhältnisse selbst verändert. Institutionelle Kapitalanleger wie Investmentfonds, Pensionsfonds und Versicherungen spielen eine erheblich größere Rolle als Vermittler zwischen den Sparern und Geldvermögensbesitzern auf der einen Seite und den industriellen Unternehmen auf der anderen Seite.« (Ebd., 82f.; vgl. auch Stockhammer 2008, 184; Durand \& Keucheyan 2015, 137)

Diese neue Qualität der Verbindungslinien zwischen industriellem und Finanzkapital (vgl. Demirović \& Sablowski 2011, 82), ausgedrückt im `Shareholder Value<-Konzept, war eine weitere Triebkraft, welche die Finanzmarktkrise zu einer allgemeinen Wirtschaftskrise auswachsen ließ, in deren Folge wiederum Staaten mit milliardenschweren Konjunktur- und Beschäftigungsprogrammen intervenierten. Verschärfend kam für die Eurozone hinzu, dass ihr Vorkrisenwachstum besonders abhängig war vom globalen Handel (vgl. Evans 2011, 100), die Exportnachfrage allerdings aufgrund der weltweiten Krisenauswirkungen und »verschärft durch einen Kollaps der Handelskredite« (ebd.; Übers. J. G.) einbrach. In dieser Konstellation drückt sich nicht zuletzt auch die Weltmarktfixierung der EU - angelegt in der Lissabon-Strategie - aus, die in Folge der weltweiten Konjunktureintrübung negativ auf sie zurückfiel.

Dass die Krise ab 2007 in Europa dabei weitläufig als eine US-amerikanische Finanzmarktkrise angesehen wurde, stellt eine erste gängige, aber zugleich auch fehlgeleitete, Krisenerzählungen dar (vgl. Horn 2016, 107). »Das verbriefte Hypothekengeschäft der Vereinigten Staaten war von Anfang an konzipiert worden, um ausländisches Kapital in die amerikanischen Finanzmärkte zu locken; und ausländische Banken zögerten nicht, diese Gelegenheit beim Schopf zu packen.« (Tooze 2018, 90f.) Gerade europäische Institute taten sich besonders hervor, was die Aufschlüsselung der globalen Bankforderungen zeigt. Innerhalb dieser stellten die »europäischen Forderungen an die Vereinigten Staaten [...] die größte Verknüpfung im System« (ebd., 96) dar. Europa stand somit im Zentrum der globalisierten Finanzmärkte (vgl. ebd., 97). Dass infolgedessen das erste Rettungspaket für europäische Banken 2008 auf die Initiative der US-amerikanischen Zentralbank zurückging, ist bis heute ein kaum diskutiertes Kri- 
senkapitel (vgl. ebd., 17): „Die US-Notenbank führte eine wahrhaft spektakuläre Neuerung ein. In letzter Minute übernahm sie die Rolle des Liquiditätsbeschaffers für das globale Bankensystem. Sie lieferte allen Bittstellern [...] Dollars, gleich, ob es eine amerikanische Bank war oder nicht. (Ebd., 19) Weiterhin bot sie ausländischen Zentralbanken Devisen-Tauschgeschäfte (sogenannte Swaps) an, bei denen die EZB »die Führung übernahm« und die Fed schließlich »Billionen Dollar in das europäische Bankenwesen [pumpte].«(Ebd.) Genaugenommen hatte die EZB bis August 2010 Swaps im Nennwert von über acht Billionen Dollar in ihrer Bilanz zu verbuchen (vgl. ebd., 252). Die Fed war somit zum "global lender of last resort « (ebd., 253) aufgestiegen. Es waren demnach 2007 und 2008 »keineswegs zwei separate amerikanische und europäische Krisen, sondern ein gigantischer Sturm im dollarbasierten nordatlantischen Finanzsystem « am Werk, so Tooze $(2018,256)$, der vor diesem Hintergrund von einer »transatlantischen Finanzkrise« spricht.

\subsection{Von der transatlantischen Finanzmarkt- zur europäischen Bankenkrise}

Wie die transatlantische Finanzkrise verdeutlichte, waren das europäische Bankensystem und die europäischen Finanzmärkte durch eine exponierte Stellung im globalen Kapitalverkehr und ein überaus starkes Engagement auf den sogenannten Eurodollarmärkten ${ }^{1}$ gekennzeichnet. Hinzu kommt nicht zuletzt auch eine finanzmarktfreundliche Regulierung (»Unterregulierung«), die den europäischen Finanzakteur"innen große Spielräume bot (vgl. Horn 2016, 126). Aufgrund der zentralen Stellung auf dem transatlantischen und internationalen Kapitalmarkt verwundert es nicht, dass im August 2007 europäische Banken aufgrund der Neubewertungen im US-amerikanischen Immobilien- und Hypothekenmarkt ein massives Liquiditätsproblem zu verzeichnen hatten. Das Misstrauen der Banken untereinander wuchs in Folge der erhöhten Ausfallrisiken, sodass der Interbanken-Markt (Wholesale-Funding) fast vollständig zum Erliegen kam (vgl. Evans 2011; s.o.). Die hierin ausgedrückte >Vertrauenskrise im Bankensektor ist eine bis zum heutigen Tage wichtige Grundlage, um einen Teil der EZB-Geldpolitik (bspw. Negativzins auf die Einlagenfazilität) während und nach der Hochphase der Euro-Krise zu verstehen.

Hinzu kamen hausgemachte ökonomische Krisen in der Eurozone. So drohten in Europa im Jahr 2007/08 wie in den USA ebenfalls zwei Immobilienblasen zu platzen. Das irische und stärker noch das spanische Wirtschaftswachstum im ersten Jahrzehnt nach der Euro-Einführung waren insbesondere auf einen Bau- und Immobilienboom zurückzuführen. Die Banken und ihre Kunden in beiden Ländern profitierten dabei von der einheitlichen Geldpolitik der EZB, die dazu führte, dass die Zinsen in der Eurozone sich auf einem einheitlichen, niedrigen Niveau einpendelten; getreu dem Motto »one

1 Eurodollarmärkte (wahlweise auch nur als Euromärkte bezeichnet) sind »internationale Märkte für finanzielle Transaktionen, die in einer Währung getätigt werden, die nicht Landeswährung ist« (Poppitz \& Stephan 2018). 
size fits all« des ehemaligen EZB-Chefökonoms Ottmar Issing (2005), der in einer Rede aus dem Jahr 2005 anmerkte: »To the question whether a single one-size monetary policy could fit all parties involved - be they national entities, social partners or economic actors - my answer was: ১One size must fit alk.« (Herv. J. G.) Einen Anspruch, den die Euro-Krise eindrücklich widerlegen sollte. Vielmehr führte die Zinskonvergenz zu Anreizen, die den Immobilienboom in Südeuropa und auch in Irland weiter anheizten. In Irland steht das Platzen der Immobilienblase in einem direkten Zusammenhang mit der künstlichen Aufblähung des Finanzsektors infolge politischer Deregulierung (inkl. Unternehmenssteuersenkungen), die Irland zu einem Offshore-Zentrum innerhalb der Eurozone werden ließ (vgl. Financial Stability Forum 2000²). Dies zeigt sich nicht zuletzt in der Bilanzsumme der in Irland registrierten Banken - zu denen auch viele Niederlassungen kontinentaleuropäischer Banken zählten -, die sich zwischenzeitlich auf bis zu 700 Prozent des irischen BIP beliefen (vgl. Tooze 2018, 219). Nachdem sich die Krise im irischen Bankensektor immer weiter zuspitzte, garantierte der irische Staat schließlich im September 2008 in einem historisch geradezu einmaligen Akt im Alleingang »nicht nur die Einlagen, sondern auch sämtliche Verbindlichkeiten von sechs großen irischen Banken für die folgenden zwei Jahre in voller Höhe« (ebd.). Die Folge hieraus war erwartungsgemäß eine hohe Belastung des irischen Staatshaushalts, die ein zentrales Bindeglied zwischen der Bankenkrise und der einsetzenden Euro-Krise darstellte (vgl. ebd., 220).

Anders als in Irland, dessen Banken- und Immobilienkrise direkt mit der transatlantischen Finanzkrise verknüpft war, schien es, als ob Spanien hiervon nur marginal betroffen wäre (vgl. López \& Rodríguez 2011, 126). Allerdings gab es erste Anzeichen dafür, dass auch in Spanien ein Platzen der Immobilienblase kurz bevorstand: Etwa eine Million unverkaufte Häuser waren auf dem Markt, die private Verschuldung stieg und erste Immobilienfirmen gerieten ins Straucheln, was wiederum die regional-organisierten Sparkassen (Cajas) ${ }^{3}$ in Bedrängnis brachte, die als Hauptfinanzierer der Immobilienblase fungierten (vgl. ebd.). Im Oktober 2008 lancierte die Regierung in Madrid ein erstes Rettungspaket für die Cajas in Höhe von 50 Milliarden Euro (vgl. ebd.) und schuf schließlich im Juni 2009 einen Bankenrettungsfonds in Höhe von 99 Milliarden Euro (vgl. ebd., 127). Den Problemlagen der Sparkassen wurde politisch außerdem dadurch begegnet, dass sie zu größeren Instituten fusioniert wurden. Einer dieser Sparkassenzusammenschlüsse war das 2010 gegründete Institut >Bankia<; jene Bank, welche schließlich 2012 verstaatlicht und unter Zuhilfenahme von Mitteln aus den späteren Rettungsfonds rekapitalisiert werden musste.

Diese beiden kurzen, holzschnittartig dargestellten Krisenbeispiele verdeutlichen, dass die schließlich ab 2009 einsetzende Euro-Krise zu Beginn durch nationale Krisenpfade und eine mitgliedstaatliche Bewältigungspolitik geprägt war und demnach eher das Bild einer Krise in der Eurozone stützt (vgl. Rodrigues 2014, 175f.). Dass dieser Eindruck aber weniger aufgrund ökonomischer Analysen angebracht erscheint, sondern

2 Neben Irland weist das Financial Stability Forum im Jahr 2000 in der Eurozone auch Luxemburg, Malta und Zypern als OFCs (Offshore Financial Centre) aus.

3 Die spanischen »Cajas « sind aufgrund ihrer Organisationsform nicht mit den deutschen »Sparkassen« gleichzusetzen. 
vielmehr ein Ergebnis politischer Fehldiagnosen und (Nicht-)Handelns darstellt (vgl. Dijsselbloem 2019, 30), trübt eine solche Krisenerzählung. Im Kern beruht sie auf der Weigerung, die wahre europäische Dimension der Bankenkrise(n) (in) der EU/Eurozone anzuerkennen. Die weitreichenden Verknüpfungen der Finanzmärkte und der europäischen Banken untereinander hätte es bereits 2008 gerechtfertigt, eine gemeinsame europäische Anti-Krisenreaktion anzustreben. Der politisch ausverhandelte Lösungsansatz der EU im Oktober 2008 sah allerdings anders aus: »Obwohl bei dem Treffen [der Staats- und Regierungschefs; J. G.] [...] eine riesige, schlagzeilenträchtige Summe für Bankengarantien herauskam, reichte es nicht für einen europäischen Plan. Es konnte keine Vereinbarung über eine gemeinsame europäische Reaktion erreicht werden.« (Tooze 2018, 228) Weiter schreibt Tooze: »Merkels Veto gab den Ausschlag. Es sollte drei lange Jahre dauern, bis ein gemeinsamer europäischer Bailout-Plan wieder auf die Tagesordnung kommen würde.« (Ebd.) Die Mitgliedstaaten waren jedenfalls vorerst weiter auf sich gestellt, um auf die scheinbar nationalen (Banken-)Krisen zu reagieren, die doch eigentlich eine europäische, transatlantisch-gerahmte Krise war. Die Möglichkeit, die Krise als eine europäische aufzufassen und sie entsprechend auch als eine Krise der institutionellen Konstruktion der EWWU zu begreifen, wurde 2008 jedenfalls nicht ergriffen. Ein solcher Schritt, der die Anerkennung einer Krise der Eurozone (vgl. Rodrigues 2014, 175f.) vorausgesetzt hätte, vollzog sich letztlich erst im Frühjahr 2010.

Die Folgen der verordneten mitgliedstaatlichen Alleingänge bei der Lösung der Finanz- und Bankenkrise zeigten sich bereits wenige Zeit später. Das Ergebnis der Bankenrettungen veröffentliche die Europäische Kommission (2012g) im Dezember 2012 in ihrem »Beihilfeanzeiger«. Sie schlüsselte auf, dass im Zeitraum 2008 bis 2011 in der EU insgesamt 1,6 Billionen Euro staatlicher Beihilfen an Banken ausgegeben worden seien; Evans $(2011,99)$ geht gar von 2,1 Billionen Euro aus. Dabei entfielen laut Kommissionsangaben alleine auf das UK 19\%, auf Irland $16 \%$ und auf Deutschland ebenfalls $16 \%$ (gesamt: $51 \%$; vgl. KOM 2012g). ${ }^{4}$ Zwar bestand der größte Teil (67\%) der 1,6 Billionen Euro lediglich aus Garantien, dennoch belasteten nicht zuletzt bereits vorgenommene und künftig noch zu leistende direkte Rettungsaktionen im Bankenund Finanzsektor die mitgliedstaatlichen Haushalte außerordentlich. Hinzu kam der durch die Finanz- und Bankenkrise ausgelöste Einbruch der Wirtschaftsleistung was schon aufgrund der gängigen Berechnungsformel automatisch die Staatsdefizite erhöhte. Automatische Stabilisatoren, zu denen unter anderem erhöhte Sozialausgaben aufgrund krisenbedingt steigender Arbeitslosigkeit gehören, lösten einen weiteren Druck auf die mitgliedstaatlichen Haushalte aus (vgl. Constâncio 2014, 251). Schließlich versuchten die EU-Staaten, der Krise in guter keynesianischer Tradition mit (europäisch `koordinierten $`$ Konjunkturprogrammen und sogenanntem defecit-spending $\mathrm{zu}$ begegnen. Bibow \& Flassbeck $(2018,18)$ sprechen von einem »keynesianischen Moment « der EU-Wirtschaftspolitik, der auf einer Art konzertierten Aktion der G20 beruhte und die staatlichen Defizite zwar weiter erhöhte, zugleich aber auch dem gängigen neoklassischen Wirtschaftsparadigma unterstellte, nicht geeignet zu sein, 
die Krise überwinden zu können. Das Krisenmanagement in der Phase der transatlantischen Finanzmarkt- und der europäischen Bankenkrise im Zeitraum 2007 bis 2009 war jedenfalls

»durch eine schrittweise Ausweitung staatlicher Interventionskapazitäten zur Abschwächung der Wirtschaftskrise und zur Beruhigung der Wertpapier- und Kreditmärkte geprägt. Die supranational-europäischen Aktivitäten beschränkten sich darauf, die nationalen Bankenrettungsprogramme und Konjunkturpakete zu koordinieren, mit einer pragmatisch-liquiditätssichernden Celdpolitik zu begleiten und im Kontext der Re-Regulierungs-Diskussion auf europäischer und globaler Ebene, so z.B. in der G-20, recht ambitionierte Ziele zu verkünden.« (Bieling 2013b, 53f.)

So entstand zeitweise gar »der Eindruck, als könnte der marktliberale Charakter der europäischen Wirtschaftsverfassung überwunden oder zumindest transformiert werden.« (Ebd., 54)

\subsection{Von der europäischen Banken- zur staatlichen Refinanzierungskrise}

Als »Hinterlassenschaft« (Deutschmann 2015, 89) stieg durch die Finanz-, Banken- und Wirtschaftskrise überall in der EU die Staatsverschuldung. Im Jahr 2009 befanden sich 20 der 27 EU-Mitgliedstaaten auf Grundlage der Bestimmungen aus dem Stabilitätsund Wachstumspakts in einem >Verfahren bei einem übermäßigen Defizit< (VÜD) (s. auch Tabelle 34 im Anhang). Dennoch schien es, als wäre der Turnaround der Krise bereits geschafft. Jedenfalls diskutierten die mitgliedstaatlichen Regierungen im (Europäischen) Rat im Herbst 2009 über eine »Ausstiegsstrategie« aus den »zur Bewältigung der Wirtschafts- und Finanzkrise ergriffenen Maßnahmen « (ECOFIN 2009, 2), die bereits im Frühjahr 2009 unter der Maßgabe einer »Mäßigung und Rückbildung staatsinterventionistischer Maßnahmen« (Babic 2019, 122) vom einflussreichen ERT eingefordert wurde. Just in dieser Situation offenbarte der griechische Finanzminister seinen Kolleg*innen der Euro-Gruppe, dass Griechenland die Defizitzahlen fürs laufende Jahr erneut zu korrigieren habe. Wie eingangs bereits angeführt, lag das prognostizierte griechische Defizit fürs Jahr 2009 schließlich bei 12 bis 13\% des BIP - am Ende sollten es $15,4 \%$ sein - und somit vier bis fünf Mal höher, als es die SWP-Kriterien erlaubten. Mit der Ankündigung Griechenlands begann letztlich eine neuerliche

»Eskalation, die ihr vorläufiges Ende ein halbes Jahr später im April 2010 fand, als auf den Finanzmärkten für griechische Staatsanleihen Zinsen von über 20 Prozent aufgerufen wurden. Damit war Griechenland der Sache nach kein Kreditnehmer mehr und musste aus der normalen fiskalischen Finanzierung aussteigen, [...]. (Polster 2014, 66)

Die staatliche Refinanzierungskrise (vgl. Reef 2018, 42) und, da nicht nur griechische Staatspapiere zunehmend in den Fokus der Marktakteur*innen rückten, mit ihr die Euro-Krise waren geboren. Waren es die Staaten, die zuerst systemrelevante Banken retteten und mit Konjunkturprogrammen die Wirtschaft zu stabilisieren versuchten, gerieten sie durch ihr aktives Handeln und ihre Eingriffe in die Märkte nun wiederum ins Visier der gerade Geretteten. Die zu zahlenden Risikoaufschläge stiegen auch 
für irische, spanische, portugiesische und italienische Staatsanleihen kontinuierlich an (s. Abbildung 3). Dieses plötzliche Ansteigen der Refinanzierungskosten einiger Euro-Mitgliedstaaten basierte nicht zuletzt auf einer der Eurozone zugeschriebenen Funktionslogik. So lautete die Annahme der Finanzmarktakteur*innen vor der Krise, dass in einer Währungsunion trotz vertraglichem No-Bail-Out-Gebot und dem Verbot monetärer Staatsfinanzierung durch die Zentralbank dennoch eine gemeinsame Bürgschaft aller Mitgliedstaaten für die gemeinsame Währung bestehe (vgl. bspw. Schnabl \& Zemanek 2011, 636). Anders ausgedrückt:

»Bei einer Währungsunion wird aus einer multifaktoriellen eine monofaktorielle Beeinflussung des Anleihezinses, Inflationsrate und Wechselkursrisiko entfallen nämlich. Der einzige Faktor [...] ist die Bonität [...] der einzelnen Staaten. Wenn nun weiter angenommen wird, dass die Währungsunion [...] eine Vertrauensgemeinschaft ist, jedenfalls kein offener Club mit beliebiger Mitgliedschaftsaufnahme und Austritten, ergibt sich ein starkes Argument für eine Pendellierung des Zinses für die einzelnen Staaten auf ein einheitliches Niveau.« (Polster 2014, 52)

Genau solch eine Pendellierung hatte in der Eurozone eingesetzt, weshalb sich die Zinsen für Staatsanleihen in der Vorkrisenzeit auf dem Niveau des niedrigsten Zinses angeglichen hatten. Die steigende Schuldenlast sowie die fehlende Solidarität im Denken der No-Bail-Out-Klausel der EU-Verträge führte deshalb im Laufe der Refinanzierungskrise zu einem rasanten Anstieg der Risikoaufschläge für einige Euro-Länder.

Abbildung 3: Renditen ausgewählter Staatsanleihen mit 10-jähriger Laufzeit (2008-2018)

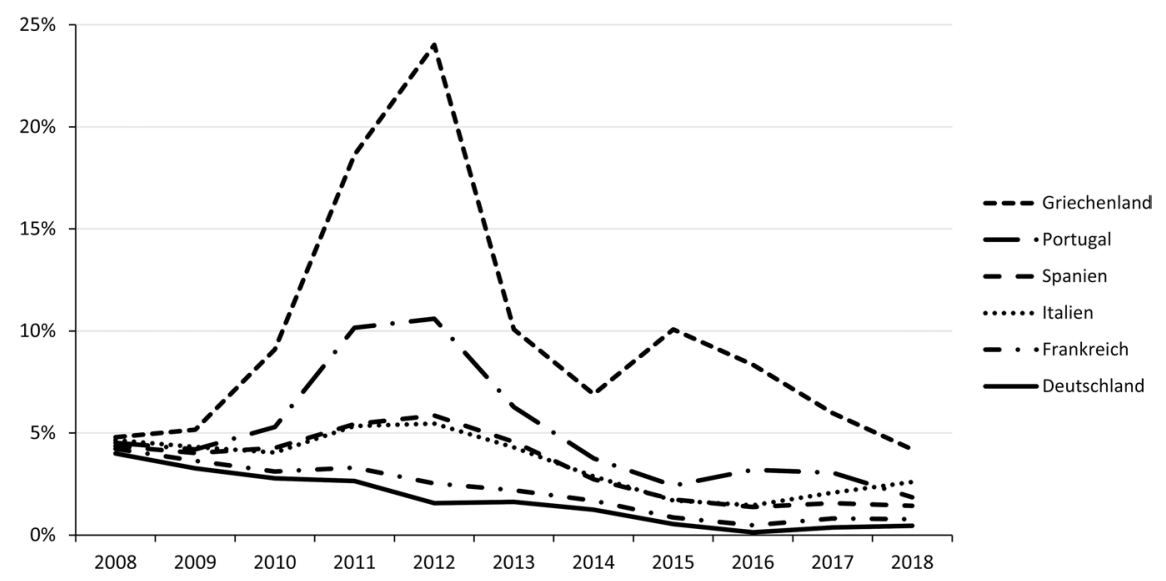

Quelle: de.statista.com

Die Marktakteur*innen bewerteten einerseits die Bonität der Schuldner neu und - wichtiger noch - revidierten ihre implizierte Annahme, nach der die Eurozone zugleich auch eine Vertrauens- oder gar Haftungsgemeinschaft darstelle. Die veränderte Einschätzung führte dazu, dass neben Griechenland im Laufe der Euro-Krise auch Portugal und Irland zur Refinanzierung ihrer Staatshaushalte auf Kredite der anderen 
Euro-Länder angewiesen waren, um letztlich einen Staatsbankrott zu vermeiden, und dass der Druck der Märkte auf Spanien und Italien zeitweise ein bedrohliches Ausmaß annahm.

Dieser Druck auf die Refinanzierungskonditionen nicht nur Griechenlands sondern insbesondere auch auf die Vor-Krisen-Musterschüler Irland und Spanien (hohes Wachstum und niedrige Staatsverschuldung) deutete auf eine Eurozonen-weite Dimension der Krisenerscheinungen hin. Das Beispiel der Zinspendellierung zur Refinanzierung von Staatsschulden verweist somit bereits auf einen systemischen Zusammenhang der Volkswirtschaften in einer gemeinsamen Währungsunion. Hinzu kommen weitere Funktionsbereiche und -logiken, in denen retrospektiv dysfunktionale Entwicklungen im ersten Jahrzehnt der Gemeinschaftswährung identifiziert werden können, die vor der Krise noch durch positive Wirtschaftszahlen in der Euro-Zone über Jahre nicht als solche identifiziert, mindestens aber nicht thematisiert wurden. Zusammengenommen lässt sich das erste Jahrzehnt der EWWU als ein ökonomischer Divergenzprozess qualifizieren, der - angebotsökonomisch verkürzt - in einer Krise der Wettbewerbsfähigkeit mündete. Ausdruck findet dies in den unterschiedlichen Wettbewerbspositionen der Eurozonen-Volkswirtschaften und in makroökonomischen Ungleichgewichten innerhalb der EWWU. Dieser Divergenzprozess und die Ungleichgewichte zwischen den Euroländern lassen schließlich im Zusammenspiel mit der Refinanzierungskrise eine Krise der EWWU - oder kurz: die Euro-Krise - erwachsen, die »sich zum erheblichen Teil durch die Fehlkonstruktion des Maastrichter Vertrages« (Zinn 2013, 55) erklären lässt. Die ökonomische Krisenkaskade seit 2007 offenbarte nicht weniger als eine Reihe von Funktionsdefiziten, die sich gegenseitig zu einer umfassenden Krise des Euro-Regimes und der gesamten EU-Staatlichkeit potenzierten, die "zu einem großen Teil auf politischen Fehlern« (Bontrup 2013, 177f.; Herv. i. O.) basierte, »die bei der Einführung der Europäischen Wirtschaftsunion (>Binnenmarkt '92く) und der Etablierung der `Europäischen Währungsunion` (Euro-Einführung) gemacht worden sind.«(Ebd.)

\subsection{Die Euro- als EWWU-Funktionskrise}

Unter anderem am Beispiel der sich nivellierenden Refinanzierungskosten für Staatsschulden wurde das Feld widersprüchlicher institutioneller Konstruktionen angedeutet, die durch die Etablierung der Wirtschafts- und Währungsunion auf die mitgliedstaatliche Politikgestaltung einwirken und in der Euro-Krise deutlich als Fehlkonstruktionen oder »Designfehler (De Grauwe 2013) zu Tage traten (vgl. auch Bibow \& Flassbeck 2018, 12). Dabei identifiziert Enderlein $(2016,43 f$.) das grundlegende Problem, nach dem die Eurozone ein heterogener Währungsraum geblieben sei, in der sich die Hoffnung auf Konvergenz (real wie zyklisch) nicht eingestellt habe und des Weiteren keine effektiven Anpassungsmechanismen etabliert worden seien, mit denen man den Divergenzen hätte entgegenwirken können: »Die gemeinsame Währung wurde eingeführt. Es wurde aber kein Institutionenrahmen geschaffen, der die Entstehung eines homogenen Wirtschaftsraums fördern konnte.« (Ebd., 43) So sei ein >riesiger Wirtschafts- und Währungsraum geschaffen worden, »dem aber die Instrumente für eine gemeinsame 
Wirtschaftspolitik fehlen«, so Habermas (2011b, 64; vgl. auch Fisahn 2017a, 99). Statt durch die EWWU Konvergenz zu schaffen - wie es die Monetaristen versprachen verstärkten sich deshalb gar noch die ökonomischen Divergenzen im Euroraum in den Jahren bis zum Krisenausbruch, wie unter anderem anhand der Geldpolitik der EZB verdeutlicht werden kann:

»Da die EZB ihre Zinsentscheidungen nicht von den wirtschaftlichen Entwicklungen der einzelnen Mitgliedsländer abhängig macht, sondern den Euro-Raum als aggregierte Gesamtgröße behandelt, kann die Celdpolitik für die einzelnen Länder zeitweilig zu restriktiv oder auch zu lax ausfallen« (Enderlein 2010, 8);

oder in Anlehnung an den oben angeführten Worten Issings: »one size fits none« (Enderlein 2016, 45). Demnach führte die vereinheitlichte Zins- und Geldpolitik der mit Unabhängigkeit ausgestatteten Zentralbank zu sich verschärfenden wirtschaftlichen Divergenzen innerhalb der Eurozone, die sich beispielsweise in auseinanderdriftenden Wettbewerbspositionen, Ungleichgewichten in den Handelsbilanzen und Auslandsvermögenspositionen (vgl. Bibow \& Flassbeck 2018, 14) oder letztlich auch in Ungleichgewichten in den inneuropäischen Kapitalverflechtungen (vgl. Heine \& Sablowski 2015) widerspiegeln. Ohne die einheitliche Geldpolitik wäre - wie schon dargelegt - auch die Blasenbildung im spanischen Immobiliensektor nicht im gegebenen Ausmaß möglich gewesen. Die Geldpolitik begünstigte schließlich eine exzessive private Kreditausweitung (vgl. bspw. De Grauwe 2013, 12). Die Konstruktionsmängel der EWWU verschlimmerten »die endogenen Dynamiken konjunktureller Auf- und Abschwünge, die weiterhin auf der nationalen Ebene wirkten« (ebd., 6; Übers. J. G.; vgl. auch Dullien 2014, 15). Weiter schreibt De Grauwe $(2013,6)$, dass es die Währungsunion nicht geschafft habe, diese in unionsweite Dynamiken zu übersetzen. Verschärfend kommt hinzu, dass es den Mitgliedern der Währungsunion nicht mehr möglich ist, durch äußere Währungsanpassungen auf die geschilderten Fehlentwicklungen zu reagieren. Eine Strategie, die in Zeiten eigenständiger Währungen häufig zur wirtschaftspolitischen Stabilisierung nutzbar gemacht wurde. Instrumente, die somit vor der Währungsunion - mit gewissen Einschränkungen ${ }^{5}$ - im Kontext eigenständiger Fiskal- und Geldpolitik auf mitgliedstaatlicher Ebene noch Wirkung entfalten konnten, wurden somit in der Eurozone eliminiert, ohne ein kompensierendes Instrumentarium auf Ebene der Währungsunion zu etablieren (vgl. ebd.; Stiglitz 2018, xv; Ehnts 2016, 200). Dies schien seitens neoliberaler Akteur*innen durchaus gewünscht (vgl. Stockhammer 2016, 374), führte letztlich aber dazu, dass der Euro »für die Länder der Eurozone [...] eine Fremdwährung [ist], die sie nicht durch eine Zentralbank erzeugen können, sondern in Konkurrenz mit privaten Investoren auf den Finanzmärkten beschaffen müssen.« (Ehnts 2016, 200) Die Mitgliedstaaten waren in der akuten Krisensituation daher »nackt< und >zerbrechlich«, letztlich »unfähig« der Krise zu begegnen (De Grauwe 2013, 6; Übers.

$5 \quad$ Im Rahmen des Bretton-Woods- und des Europäischen Währungssystems waren Währungsanpassungen aufgrund der Koppelung an den US-Dollar bzw. der Festlegung von sogenannten Korridoren de facto nur in einem begrenzten Maße möglich. Im Unterschied zur Währungsunion blieb die Möglichkeit zur Währungsanpassung allerdings bestehen und wurde auch mehrfach angewendet. 
J. G.). Statt äußerer Währungsanpassung blieb im bestehenden EWWU-Rahmen dementsprechend auf mitgliedstaatlicher Ebene nur die Strategie »interner Abwertung « mit zugleich fragwürdigen sozialpolitischen Implikationen (vgl. Bibow \& Flassbeck 2018, 10; Heinen \& Sablowski 2015, 581). Somit erwies sich »die europäische Zentralbankpolitik [...] als Desintegrationsfaktor, als das Gegenteil dessen, was die politischen Konstrukteure des Systems sich vorgestellt hatten " (Zinn 2013, 55) und infolge der fehlenden politischen Flankierung als Konstruktionsfehler (vgl. Bieling 2013a, 98).

Im Zusammenspiel mit der einheitlichen Geldpolitik ist außerdem der sogenannte reale Wechselkurseffekt von den neoliberalen Konstrukteur*innen der EWWU schlicht überschätzt worden:

»Normalerweise entsteht in einem Land, das ein deutlich höheres Wachstum als der Rest des Währungsraums verzeichnet, auch eine höhere Inflation. Wenn der reale Wechselkurskanal funktioniert, dann werden Länder mit einer hohen Inflation letztendlich an Wettbewerbsfähigkeit verlieren. [...] Ein Rückgang der Nachfrage wird dann Wachstum und Inflation zurück auf den Durchschnitt des Euroraums bringen.« (Enderlein 2016, 47)

So jedenfalls die Theorie. In der Praxis zeigt sich hingegen, dass der europäische Binnenmarkt insgesamt zu wenig integriert sei, um über den realen Wechselkurs eine Anpassung zu erreichen (vgl. ebd.). Dies äußert sich nicht zuletzt in den ungleichen Leistungsbilanzen (starke Defizite in Teilen Südeuropas, hohe Überschüsse in Deutschland; vgl. Neubäumer 2011, 829), die sich seit dem Bestehen der Währungsunion immer weiter zuspitzten (vgl. Horn 2016, 116). Der hohen Mobilität von Kapital stehe die weitaus höhere Immobilität von Waren und insbesondere Dienstleistungen gegenüber, sodass nach Enderlein $(2016,47)$ überhaupt kein direkter Wettbewerb stattfinde. Ein ähnliches Bild lässt sich für die Arbeitnehmer"innen-Mobilität innerhalb des Binnenmarktes konstatieren (vgl. Enderlein 2010, 9), welche in neoklassischer Lesart ein Ausgleichsfaktor wäre (skeptisch u.a. Rühmann 2009, 185f.; kritisch Bibow \& Flassbeck 2018, 210), in ihrem geringen realen Umfang aber die Ungleichgewichte ebenfalls nicht abmildern konnte.

Hinzu kommen weitere makroökonomische Indikatoren, die im ersten Jahrzehnt der Gemeinschaftswährung statt eines Konvergenz- das Vorliegen eines Divergenzprozesses nahelegen. Flassbeck \& Lapavitsas (2015a, 2) verweisen hierbei auf die auseinandergehenden Lohnstückkosten, durch die in ihren Augen der fundamentale Defekt der EWWU sichtbar werde. Sie vertreten eine Krisenerzählung, in deren Zentrum die deutsche Politik gewollter Lohnzurückhaltung als Quelle der Euro-Krise steht (vgl. ebd., 22-38). Der Kern der Argumentation lautet dabei, dass »Deutschland [...] gegen die fundamentalste Regel in einer Währungsunion verstoßen [hat], nämlich die Notwendigkeit, sich mit der Lohnpolitik an das gemeinsam beschlossene Inflationsziel anzupassen« (Bibow \& Flassbeck 2018, 22). Diese Strategie führte zu hohen Leistungsbilanzüberschüssen Deutschlands, die allerdings in einem Binnenmarkt mit angeschlossener Währungsunion nicht losgelöst von ihrer Wirkung auf das gesamte EWWU-Ensemble betrachtet werden können.

Makroökonomische Ungleichgewichte - teilweise bereits aus der Zeit vor der Gemeinschaftswährung - konnten sich so im Schatten oder unter dem Deckmantel der 
mit dem Maastrichter Vertrag geschaffenen Institutionalisierung potenzieren. Vorerst sogar weitgehend unbemerkt. So schrieb noch im Jahr 2006 der mehrfach angeführte Enderlein (2006, 1133), dass der Euro erfolgreich eingeführt worden sei und zu einer der führenden Währungen gehöre: "This has led to the observation that EMU should be seen as a factor of stability in the European project.« (Ebd.; vgl. bspw. auch Hallerberg 2011, 127) Ein Trugschluss, wenn man sich die in der Krise zu Tage geförderten strukturellen Defizite der EWWU vor Augen führt. Fiskalische Ausgleichsmechanismen innerhalb der Eurozone, die geholfen hätten, die wirtschaftlichen Ungleichgewichte ebenso wie die ungleiche Einkommens- und Vermögensverteilung (vgl. Horn \& van Treeck 2011, 19) abzumildern, waren jedenfalls in der Maastricht-Logik nicht vorgesehen. Stattdessen findet sich in den Verträgen das No-Bail-Out-Gebot und die gemeinsame Wirtschaftspolitik wird lediglich >koordiniert`, weshalb sie in Bezug auf die Währungsunion als Gesamtgröße weitgehend unterkomplex bleibt. So kommt auch Busch $(2016,14) \mathrm{zu}$ dem Schluss, dass in der Euro-Krise »massive Funktionsdefizite« der Wirtschafts- und Währungsunion sichtbar wurden:

»Eine gemeinsame Währung einzuführen, ohne gleichzeitig die Politische sowie die Soziale Union zu vollenden und ohne parallel eine Europäische Wirtschaftsregierung zu installieren, war schon mit dem Inkrafttreten des Maastrichter Vertrags [...] als Fehlkonstruktion zu erkennen.«(Ebd., 14; vgl. auch Busch \& Hirschel 2012, 81)

In der Gesamtschau erscheint es daher aufgrund des institutionalisierten Rahmens der EWWU, der »zum Teil im vollen Bewusstsein der handelnden Akteure [...] mit Konstruktionsfehlern in die Welt gesetzt wurde« (Fisahn 2017a, 99), notwendig, die EuroKrise als Funktionskrise der neoliberalen EWWU zu beschreiben. Diese beruht auf einem vertraglich-institutionalisierten Arrangement einer unzureichenden Geldpolitik (one-sizefits-none-Problem, Fremdwährungsproblematik, vertragliche EZB-Limitierungen), einer unzureichenden Wirtschaftspolitik (nicht-optimaler Währungsraum, makroökonomische Ungleichgewichte, ausschließlich Koordinierung unter Ausschluss der Lohnpolitik), einer unzureichenden Fiskalpolitik (Mangel an Ausgleichsmechanismen bei asymmetrischen Schocks (finanzielle Ressourcentransfers), restriktive Fiskalregeln, keine Haftungsgemeinschaft; mangelhafte Koordinierung) und wesentlich auch einer unzureichenden politischen Verantwortlichkeit (Eigenverantwortlichkeit, kein exekutives Zentrum, kein Budget, geringe demokratische Flankierung; fehlende makro-prudenzielle Aufsicht über den Finanzsektor), was die Suche nach Krisenlösungen auf Grundlage des Status quo erschwert. Die Euro-Krise lässt sich - wenn man die von ihr aufgedeckten Fehlkonstruktionen ernst nimmt - demnach aufgrund ihrer vertraglichen Grundlagen und der in ihnen festgeschriebenen Restriktionen nicht vollständig im bestehenden Rahmen auflösen und besitzt somit das Potenzial, eine tiefgreifende politische Krisenkaskade anzustoßen, als deren erster Baustein eine entsprechende Funktionskrise definiert wurde. In den Worten Balibars (2018, 81): »Die Wirtschaftskrise hat sich [...] in eine politische Krise verwandelt - sogar in eine Krise der Institution des Politischen in Europa.« 


\section{Strategische Suchprozesse und neoliberale Rückeroberungen}

In der durch die transatlantische Finanz- und europäische Bankenkrise dominierten Krisenphase sei der Eindruck entstanden, »als könnte der marktliberale Charakter der europäischen Wirtschaftsverfassung überwunden oder zumindest transformiert werden«, so Bieling (2013b, 53f.). Ausdruck findet dies unter anderem durch den ausgeweiteten staatlichen Interventionismus, der die Politik zur Bewältigung der Finanz- und Bankenkrise und der sich anschließenden allgemeinen Wirtschaftskrise prägte (Bankenrettungen, Konjunkturprogramme, Re-Regulierungsbemühungen der G20 etc.). Die Infragestellung des Neoliberalismus und seines neoklassischen und angebotsökonomischen Ökonomieverständnisses ist dabei insgesamt ein früh sichtbares Krisenphänomen (vgl. u.a. Demirović 2009, 23; Brand 2011, 45; Bieling 2009b, 41; Horn 2016, 101). So rief beispielsweise der Spiegel (31.05.2009) bereits das "Ende des Neoliberalismus« aus und sprach von einer einsetzenden »Konterrevolution im Klassenkampf«. Aber nicht nur kritische Wissenschaftler*innen und Journalist*innen fragten nach dem Ende des Neoliberalismus, sondern selbst in konservativ-neoliberalen Feuilletons wurde andiskutiert, ob sich der Neoliberalismus mit der Krise erledigt habe (vgl. Oberndorfer 2012a, 49f.). Die Finanz- und Bankenkrise schien die Vorherrschaft neoliberaler Wirtschaftsparadigmen und ihrer allgemein-politischen Leitbilder zu durchbrechen. Der »Krisenkeynesianismus« (Decker \& Sablowski 2017, 23ff.) jener Zeit spricht hierfür eigene Bände. Der grundsätzliche Dissens zwischen neoklassischer und keynesianischer Ökonomik wurde nicht nur in der Wirtschaftswissenschaft oder unter staatlichen Akteur*innen ausgetragen, sondern fand einen Resonanzboden in zivilgesellschaftlichen Diskursen (vgl. Horn 2016, 102). Im Konkreten wird hierbei um Formen des staatlichen Interventionismus miteinander gerungen (vgl. bspw. Brand 2009c, 96; Bieling 2009b). In den gesellschaftlichen Diskursen schien es, »als würde eine neue, sozial und ökologisch orientierte Konzeption des Staatsinterventionismus an Zustimmung gewinnen« (Bieling 2009a, 53). Die Vertreter*innen einer solchen Konzeption konnten

»überzeugend darlegen, dass die Finanzblase durch die wirtschaftsliberale Strategie, genauer: durch die Liberalisierung und Deregulierung der Wirtschaftsbeziehungen, die Genese eines `Kasino-Kapitalismus`, die Demontage des öffentlichen Sektors und 
die enorme Ungleichverteilung des gesellschaftlichen Reichtums erst ermöglicht worden war« (ebd.).

Der neoliberale Gegenpol >marktliberaler Orthodoxie` wirkte demgegenüber aufgrund der Erfahrungen der transatlantischen Finanzkrise in den gesellschaftlichen Diskursen marginalisiert - ihre Akteur*innen wurden von der Krise kalt erwischt und waren im ersten Moment »sprachlos« (ebd.). Ebenso erschien »das neoliberale Vertrauen in die Selbstheilungskräfte des Marktes erschüttert und die damit verbundene Ideologie gesellschaftspolitisch erledigt« (Brand 2009c, 96). Verschärfend kamen die einsetzenden Krisenphänomene der Euro-Krise hinzu, die als Funktionskrise der neoliberalen EWWU das neoliberale Hegemonieprojekt weiter unter Druck setzte. Es schien, als komme "[d]ie hegemoniale Phase des Neoliberalismus [...] nun auch im imperialen Zentrum an ihr Ende« (Oberndorfer 2012a, 51).

Die ökonomische und politische Krisenkaskade stellte vor diesem Hintergrund eine besondere strategische Herausforderung der Akteur"innen des neoliberalen Hegemonieprojekts dar und eröffnete ein Möglichkeitsfenster für alternative Projekte im Ringen um Hegemonie. Es sind die aus den Krisen erwachsenen Suchprozesse nach einer Krisenbewältigungsstrategie, die letztlich auch Veränderungen in den Hegemonieverhältnissen markieren. Die >Infragestellung des Neoliberalismus $<$ ist dabei diskursiv eng mit den beiden sozialen Hegemonieprojekten (vgl. Kapitel 4) verbunden, wobei das proeuropäisch-soziale Hegemonieprojekt in jener Zeit eine besondere Anschlussfähigkeit aufwies (vgl. Bieling 2009a, 53). Für dieses Projekt stellte die aus der transatlantischen Finanz- und der europäischen Bankenkrise erwachsene Euro-Krise nicht weniger als »eine historische Gelegenheit [...] dar« (Buckel et al. 2012, 38), um selbst eine hegemoniale Stellung einzunehmen. Die Akteur*innen des proeuropäisch-sozialen Hegemonieprojekts stehen hierbei für den Ausbau interventionistischer Politikarrangements, die sich am Leitbild des sozialen Europas orientieren, und standen der ab 2009/2010 zunehmend aufkommenden Fokussierung auf die Thematik der Staatsschulden oppositionell gegenüber (vgl. bspw. Busch et al. 2017). Als Reaktion auf die sich zuspitzenden Refinanzierungskonditionen schlugen sie unter anderem Instrumente zur Schuldenvergemeinschaftung (bspw. Eurobonds oder Schuldentilgungsfonds) und den Aufbau einer Fiskalkapazität für die Eurozone/die EU vor (vgl. Buckel et al. 2012, 39), um hierüber nicht zuletzt auch die sozialen Krisenfolgen, die bereits im Laufe der transatlantischen Finanzmarkt- und der europäischen Bankenkrisen sichtbar wurden, abzumildern und neue Wachstumsimpulse zu setzen. Die Argumentation des proeuropäischsozialen Projekts basierte dabei auf der Annahme, dass >das eigentliche Problem<, das in der Krise sichtbar werde, »in einer ungleichen Entwicklung Europas« (ebd., 38) - also dem diagnostizierten Divergenzprozess - bestünde. Insofern greifen die Akteur*innen des proeuropäisch-sozialen Hegemonieprojekts auch die Diagnose einer Funktionskrise der neoliberalen EWWU zentral auf und formulierten ausgehend hiervon Ansätze zur Krisenbewältigung. Im Kanon mit eingeforderten Umverteilungspolitiken (vgl. ebd.) stehen sie dabei wirtschaftspolitisch für eine starke (Re-)Regulierung der (Finanz-)Märkte - wie sie im Laufe der Finanzkrise von der G2o andiskutiert wurde - und votieren beispielsweise für eine europäische Arbeitsmarktpolitik, die sich insbesondere in einer stärkeren Lohnkoordinierung niederschlagen solle, um die krisenverschärfende 
Lohnsenkungsspirale angebotsökonomischer Politiken zu beenden (vgl. u.a. Flassbeck \& Lapavitsas 2015b; Busch \& Hirschel 2012). Grundsätzlich gilt für das Hegemonieprojekt, dass es

»infolge der neoliberalen Umbaumaßnahmen des europäischen Sozialmodells als Strategie auf mehr Europäisierung [setzt] und [...] von Teilen der europäischen Cewerkschaften, der sozialdemokratischen Parteien, der Arbeitnehmerflügel innerhalb bürgerlicher Parteien und deren `organische Intellektuelle (europäische Föderalisten) wie bspw. ]ürgen Habermas getragen [wird].«(Kannankulam 2013, 24)

Hierbei verfügt das proeuropäisch-soziale Projekt

»über ein eigenes, durch einen klaren Bruch von allen anderen Projekten abgegrenztes, hegemoniefähiges Projekt, das allerdings aufgrund der ökonomischen und institutionellen Schwächung seiner Akteur_innen nicht in gleicher Weise schlagkräftig ist wie die neoliberalen Akteure.«(Buckel et al. 2012, 40)

Überdies bestehen Anknüpfungspunkte zwischen dem proeuropäisch-sozialen und dem linksliberal-alternativen Hegemonieprojekt, wenn es beispielsweise um ein Werben um spolitische Lösungen<, verstanden als Integrationsvertiefung im Sinne eines (Kapazitäts-)Ausbaus der EU-Staatlichkeit, geht. So fordern linksliberal-alternative Akteur*innen Schritte zur weiteren Föderalisierung der EU (vgl. ebd., 40f.), wobei allerdings

»[d]ie fehlende ökonomische Kompetenz dieses Projekts [...] seine zentrale Schwäche [ist], da ein föderales Europa in der Krise nur dann eine Chance auf Realisierung hat, wenn es zugleich eine überzeugende Antwort auf die Fakten schaffenden Strategien der europäischen neoliberalen Eliten hat.« (Ebd., 41)

Die neoliberalen Eliten aber wiederum waren seit der aufkommenden Krisenkaskade seit 2007 selber uneins über die notwendigen Schritte zur Krisenbewältigung. Es offenbarte sich schließlich beim neoliberalen Hegemonieprojekt aufgrund eines »Auseinanderdriftens verschiedener, zum Teil unvereinbarer Strategien « im Inneren des Projekts nicht weniger als die Auflösung als ein einheitliches Hegemonieprojekt, so Buckel et al. $(2012,31)$. Es lassen sich demnach unterschiedliche strategische Suchprozesse im neoliberalen Hegemonieprojekt identifizieren, die sich anhand dreier divergierender strategischer Verortungen explizieren lassen. Eine moderat-neoliberale Fraktion ${ }^{1}$ vertritt hierbei eine in den Ansätzen dem proeuropäisch-sozialen Hegemonieprojekt ähnliche Positionierung in Bezug auf die (Re-)Regulierung der Märkte und den >moderaten A Ausbau europäischer Interventionskapazitäten, einschließlich des Aufbaus fiskalischer Komponenten (vgl. ebd.; Georgi \& Kannankulam 2012, 11). Der moderat-neoliberalen Fraktion lassen sich jene gesellschaftlichen Kräfte zuordnen,

»die u.a. durch jene Flügel innerhalb sozialdemokratischer und grüner Parteien repräsentiert werden, die weiterhin auf einer markt-orientierten, letztlich neoliberalen

1 Buckel et al. (2012, 31f.) sprechen in diesem Kontext von einer »proeuropäisch-neoliberalen Strategie«; Georgi \& Kannankulam $(2012,11 ; 2015)$ von der »neoliberalen Reregulierungs-Fraktion«. 
Grundlage operieren wollen, aber auf dieser Crundlage zu einer weitergehenden Reregulation bereit sind als andere Fraktionen des neoliberalen Hegemonieprojekts.« (Georgi \& Kannankulam 2012, 11).

Neben diesen moderaten Kräften innerhalb des neoliberalen Hegemonieprojekts, die sich klar einer proeuropäischen Orientierung zuschreiben lassen und zugleich auf die gesellschaftlichen Diskurse in Zeiten der Finanzkrise in ihren strategischen Verortungen Bezug nahmen, findet sich eine weitere, proeuropäisch ausgerichtete Fraktion, die allerdings weitaus stärker zu einem >Autoritarismus neigt. Eine »autoritär-neoliberale Strategie verfolgen vor allem die deutsche Exportindustrie sowie die Transnationalen Konzerne, die im European Round Table of Industrialists und Businesseurope organisiert sind." (Ebd.; vgl. Babic 2019; Konecny 2012; Herv. J. G.) Die Strategie dieser Akteur*innen

»gründet sich auf eine Rationalität, welche die EU-Integration seit Jahrzehnten vorantreibt: Europäischer Binnenmarkt als Absatzmarkt und Block in der Weltkonkurrenz; gemeinsame Währung zur Ausschaltung von Währungsschwankungen und Handelsförderung; EU-vermittelte Strukturreformen.« (Ceorgi \& Kannankulam 2012, 10)

Als dritte Fraktionierung innerhalb des neoliberalen Hegemonieprojekts lassen sich Akteur"innen beschreiben, die sich einer national-orthodox-neoliberalen Strategie zuordnen. Eine solche auf das nationale Scale fokussierte Strategie zeichnet "sich im Wesentlichen durch eine radikale Ablehnung proeuropäischer Krisenlösungen aus.« (Buckel et al. 2012, 34). Akteur*innen dieser neoliberalen Strömung sind dabei insbesondere in den sogenannten Zentrumsstaaten beziehungsweise den nördlichen Euroländern präsent (vgl. ebd.; Georgi \& Kannankulam 2012, 9). Ähnlich wie im Falle der moderat-neoliberalen Strategie, in der Anknüpfungspunkte zum proeuropäisch-sozialen Hegemonieprojekt angelegt sind, finden sich in der orthodox-neoliberalen Strömung Verbindungslinien zum national-konservativen Hegemonieprojekt, das zu Beginn der transatlantischen Finanzkrise ähnlich wie das neoliberale Hegemonieprojekt "massiv in die Krise geraten« (Buckel et al. 2012, 37) war. Grundlage hierfür war ebenso wie beim nationalsozialen Hegemonieprojekt, dass die aufkommenden Krisenerscheinungen aufgrund ihrer europäischen (Banken- und Euro-Krise) beziehungsweise transatlantischen/globalen Reichweite (Finanzkrise) im ersten Moment eine Problemlösung auf übergeordneten Ebenen evozierten, die die Formulierung anschlussfähiger Strategien im Rahmen dieser beiden, auf die mitgliedstaatliche Ebene fokussierenden, Hegemonieprojekte erschwerte.

\subsection{Die Umdeutung zur Staatsschuldenkrise als erstes strategisch-diskursives Moment neoliberaler Rückeroberung}

Die ersten Reaktionen auf die Fiskalproblematiken in Griechenland im Herbst 2009 bestanden auf europäischer Seite aus der öffentlichen Beschwörung der griechischen Eigenverantwortung zur Lösung der Refinanzierungsprobleme und einem immer stärker aufgebauten Druck gegenüber Griechenland, »seine Angelegenheiten in Ordnung 
$\mathrm{zu}$ bringen. Man erklärte Griechenland unmissverständlich, dass man es nicht retten würde«, so der spätere Vorsitzende der Euro-Gruppe Dijsselbloem $(2019,54)$. Nach der unterlassenen gemeinsamen Anstrengung im Kontext der europäischen Bankenkrise(n) 2008 schien es, als dass auch im Jahre 2009 die Mitgliedstaaten der EU beziehungsweise der Eurozone erneut nicht bereit waren, gemeinsam-europäisch, dieses Mal gegen die zunehmenden Spekulationen gegenüber Griechenland, zu intervenieren. Zwar ließ der Europäische Rat im Frühjahr 2010 verlautbaren, die griechische Regierung in ihren Anstrengungen zu unterstützen (vgl. ER 2010c); konkrete Maßnahmen sollten allerdings erst dann folgen, wenn die Finanzstabilität des »Euroraums als Ganzes« (ebd.; Übers. J. G.) in Gefahr geriete. Dieser Fall trat schneller ein als erhofft; bereits im März 2010 verständigten sich die Staats- und Regierungschefs der Eurozone (»Euro-Gipfel«) auf koordinierte bilaterale Darlehen für Griechenland (vgl. Euro-Gipfel 2010b, 1). Der März 2010 markiert retrospektiv somit den point of no return der Euro-Krise. Griechenland musste schließlich im April 2010 die in Aussicht gestellten bilateralen Darlehen (das sogenannte »Griechenland-Paket«) der anderen Euroländer in Anspruch nehmen, um dem Staatsbankrott und einem möglichen Herausbrechen aus der Währungsunion $\mathrm{zu}$ entgehen. Einher ging diese Inanspruchnahme mit der Verpflichtung auf einen harten Reform- und Sparkurs, festgelegt in einem Memorandum of Understanding (MoU), der nicht nur die »Griechenland-Rettung« sondern auch die Kreditprogramme für weitere Euro-Staaten bis heute maßgeblich prägt. Das Motto lautete »Solidarität gegen Austerität « (Hufeld 2011). Grundlage für die strikte austeritäre Konditionalisierung der Hilfskredite stellte die zuvor vollzogene >Umdeutung der Refinanzierungszur Staatsschuldenkrise dar: "Schob man die Verantwortung für die Krise zunächst auf die Finanzmärkte, wurde danach - nahezu übergangslos - die sverantwortungslose Fiskalpolitik bestimmter Mitgliedsländer als vermeintliche Krisenursache identifiziert « (Bibow \& Flassbeck 2018, 9). Die Staatsschuldenkrise wurde schließlich »zum Synonym für die Euro-Krise« (Neubäumer 2011, 827), und es sei »der Eindruck entstanden, dass die derzeitigen Schwierigkeiten an den Finanzmärkten das Ergebnis einer unsolideren Fiskalpolitik im Euroraum sind.«(Ebd.) Das Narrativ der Staatsschuldenkrise lautet:

»There was essentially nothing wrong with the initial design of EMU, and the crisis resulted mostly from the fact that several peripheral countries did not respect that design - in particular the fiscal rules of the Stability and Crowth Pact-which generated the sovereign debt crisis. (Constâncio 2014, 251)

Diesem Narrativ und seiner Schuldzuweisung an die mitgliedstaatlichen Fiskalpolitiken folgend, wählten die Euro-Mitgliedstaaten anstelle einer gemeinsamen Bürgschaft für ihre Schulden - und somit auch derer Griechenlands - einen Bewältigungspfad, der die Problemlösung zuvorderst bei ihnen selbst verortete. Hätten sie hingegen

»die Schulden Griechenlands zu den Schulden der gesamten EU erklärt, wäre auf den Finanzmärkten sofort Ruhe eingekehrt. Damit wäre Zeit gewonnen worden, um eine Antwort auf die strukturellen Probleme sowohl der Weltwirtschaft als auch der europäischen Ökonomien zu finden.«(Vogel 2013, 23; vgl. auch Polster 2014, 68)

Mit der Verschiebung des Krisenfokus auf die zunehmenden Refinanzierungsprobleme und der hierdurch einsetzenden Euro-Krise ab Herbst 2009 bot sich den neolibe- 
ralen Akteur*innen im Kampf um die Diskurshoheit somit die Möglichkeit für einen, letztlich erfolgreichen, Rückeroberungsversuch (vgl. auch Payandeh 2009, 88). Mit Bekanntgabe des griechischen Defizits eröffnete sich die strategische Chance, ein neues Krisenkapitel aufzuschlagen und den Kriseninterventionismus á la Keynes und der Desavouierung des Neoliberalismus etwas entgegenzusetzen. In der Umdeutung der staatlichen Refinanzierungs- zur Staatsschuldenkrise verdichtete sich dabei ein europäisches Kräfteverhältnis, das geprägt war von einer »impliziten Allianz« autoritär- und orthodox-neoliberaler Kräfte und dem

»vor allem in Deutschland verankerten ordo-konservativen Bündnis [...]. Dieses Bündnis umfasste einerseits die national-konservativen Hegemonieprojekte in Deutschland und anderen Zentrumsstaaten, mithin jene gesellschaftlichen Kräfte, die einem stark vertieften europäischen Integrationsprozess skeptisch bis ablehnend gegenüberstanden [...].« (Georgi \& Kannankulam 2015, 354; vgl. dies. 2012, 9)

Diesem reaktionären Bündnis gelang es am Ausgangspunkt der Euro-Krise, eine Diskursverschiebung als einen ersten von drei diskursiv-strategischen Rückeroberungsmomenten $\mathrm{zu}$ initiieren, die sich auch in den ersten Reaktionen auf die fiskalischen Probleme Griechenlands in den >offiziellen EUSA-Reaktionen niederschlugen und die angeblich unverhältnismäßigen Fiskalpolitiken einzelner Mitgliedstaaten ins Zentrum des politischen Aktionismus rückte. Schuldenpolitik sei letztlich »zu einer moralischen Frage gemacht« (Blyth 2014, 37) worden und Austerität daher »die Strafe, die schmerzhafte Rückkehr zur Tugend nach der unmoralischen Party« (ebd.), die nicht nur die Phase der aufkommenden Euro-Krise (Herbst 2009 bis Frühjahr 2010) maßgeblich prägen sollte. »Die Idee der Austerität « sei dabei durchaus »intuitiv und attraktiv«, so Blyth $(2014,30)$ und »lässt sich in einem Satz zusammenfassen: Schulden können nicht die Lösung für Schulden sein.« (Ebd.) Austeritätspolitik trägt überdies aber auch weitreichende wirtschaftspolitische Implikationen in sich. Sie

»ist eine Art Deflationierung, wobei die Wirtschaft durch eine Senkung von Löhnen, Preisen und öffentlichen Ausgaben wettbewerbsfähiger gemacht wird. Erreicht wird dieses Ziel (angeblich) am besten, indem man das Budget, die Schulden und die Defizite des Staatshaushalts reduziert. Dies soll bei den Unternehmen für Zuversicht sorgen, da der Staat einerseits die privaten Investoren nicht mit seinen eigenen Schuldtiteln vom Kapitalmarkt verdrängt und andererseits die ohnehin schon >zu hohen Staatsschulden nicht weiter erhöht werden.« (Ebd., 24)

Geradezu froh schienen marktliberale Kommentator*innen deshalb darüber, dass die Akteur*innen des Finanzkapitals, die zuvor selber noch in einer tiefen (Glaubwürdigkeits-)Krise steckten, nun eine (Vertrauens-)Krise staatlicher Schuldenbedienung heraufbeschwören konnten: „Dies ist die `Zinskeule des Finanzmarktes`, lobte die Frankfurter Allgemeine Zeitung. >Nur diese eine Sprache versteht die Politik wirklich, nur diese zwingst sie zur Reaktion< (FAZ, 16.8.2011), das heißt zum Schuldenabbau«. (Kaufmann \& Stützle 2016, 53)

Es war schließlich das »ideologische Interesse« (Mitchel 2017, 340) beziehungsweise die »rein ideologisch motivierte Dichtung « (Bibow \& Flassbeck 2018, 20) der neoliberalen Akteur*innen der autoritär- und orthodox-neoliberalen Fraktionen, die auf ein 
weites Netzwerk von Thinktanks zurückgreifen konnten (vgl. bspw. Plehwe, Neujeffski \& Krämer 2018), aus den Refinanzierungsproblemen Griechenlands eine Staatsschuldenkrise zu konstruieren, auf deren Grundlage schließlich eine Art Rehabilitierung des Neoliberalismus angestrebt wurde. Die Akteur"innen national-konservativer Hegemonieprojekte boten sich hier, unter anderem aufgrund ihrer Fokussierung auf den mitgliedstaatlichen Scale (`Eigenverantwortung`) und ihrer Ablehnung weitreichender europäischer Krisenlösungen (`No-Bail-Out-Gebot`), als geeignete Durchsetzungsgehilfen geradezu an und halfen somit dem neoliberalen Projekt zurück in die erste Reihe europäischer Politik.

Aufgrund der hohen Krisen(folge)kosten gerieten im Sog des neuen Narratives der Staatsschuldenkrise und der hierdurch propagierten Unterlassung, mit der neues Öl ins Krisenfeuer gegossen wurde und letztlich die implizite Annahme einer Haftungsgemeinschaft in der Eurozone revidieren sollte, schnell auch Irland und Spanien unter den Verdacht einer unsoliden Haushaltsführung, obwohl sie vor dem Einsetzen der Krisendynamik noch als Länder mit einer vorbildlichen Haushaltspolitik galten. Portugal und Italien, die bereits vor der Euro-Krise hohe Schuldenstandsquoten (60\%Kriterium) aufwiesen, folgten rasch. Die »Maastricht-Sünder« der Vorkrisenjahre (insbesondere Deutschland und Frankreich, die das 3\%-Defizitkriterium mehrfach nicht einhielten) überstanden die Krise trotz ebenfalls steigender Schuldenstände (Bankenrettungs- und Konjunkturpakete) hingegen mit nur moderaten Blessuren. Die einseitige Ursachenforschung mit Fokus auf die staatliche Verschuldung erscheint demnach und vor dem Hintergrund der attestierten EWWU-Funktionsdefizite als wesentlich zu kurz gegriffen. Nicht zuletzt deshalb wurde dem in der Umdeutung zur Staatsschuldenkrise ausgedrückten, ersten strategisch-diskursiven Moment neoliberaler Rückeroberung durch eine Überstilisierung der aufkommenden Reformagenda nicht nur zur >Rettung des Euros, sondern der gesamten EU im Sinne einer Art EU-Staatlichkeitsräson und der hierdurch vermittelten Krisenlegitimität ein zweites strategisch-diskursives Moment neoliberaler Rückeroberung zur Seite gestellt.

\subsection{Der exzeptionelle Charakter der Krise und das Rettungsdispositiv als zweites strategisch-diskursives Moment neoliberaler Rückeroberung}

Die Konsequenzen aus der anfänglichen Unterlassung von weitergehenden europäischen Maßnahmen zur Unterstützung Griechenlands vor dem Hintergrund der Diagnose einer Staatsschuldenkrise sowie der heraufbeschworenen Eigenverantwortung der griechischen Regierung 2009/10 zeigten sich bereits schnell und in aller Deutlichkeit. Einerseits konnte die begrenzte Hilfe für ein Land (bilaterales Griechenlandpaket) nicht die Probleme in den weiteren von der Refinanzierungskrise betroffenen Staaten lösen, zum anderen reichten die gemachten Zusagen nicht einmal aus, um den akuten Druck der Finanzmärkte auf Griechenland nachhaltig zu lindern: »Dieser Schritt hat die Finanzmärkte nicht beeindruckt. Eine Woche später kehrte die Panik zurück und es wurde deutlich, dass weitere Maßnahmen erforderlich waren.« (Dijsselbloem 2019, 59) Schließlich mussten auch die Staats- und Regierungschefs einsehen, dass es eines systematischeren Ansatzes bedurfte, um der sich immer weiter verschärfenden 
Krise Herr zu werden (vgl. Van Rompuy 2011, 6). Kurz nachdem sich der Euro-Gipfel auf seiner Tagung im März 2010 auf koordinierte bilaterale Darlehen für Griechenland einigte, die laut Selbstbeschreibung die »Grundsätze der Verantwortung und der Solidarität wider[spiegeln], die das Herz der Währungsunion bilden« (Euro-Gipfel 2010a, 1; Herv. J. G.), beschlossen die Staats- und Regierungschefs der Euro-Staaten »[a]ngesichts von immer stärkeren Marktverwerfungen und auf eindringliches Anraten des damaligen EZB-Präsidenten Jean-Claude Trichet, der eine Systemkrise befürchtet « (Kunstein \& Wessels 2011, 314; Herv. J. G.), deshalb bereits im Mai die Schaffung des sogenannten Euro-Rettungsschirms (vgl. Euro-Gruppe 2010a, 2). Ratspräsident Van Rompuy $(2011,6)$ beschreibt den entscheidenden Euro-Gipfel - der bis heute keine unionsvertragliche Grundlage besitzt - dabei als einen großen politischen Erfolg und versucht in sehr pathetischen Worten das genutzte informelle Verfahren zu legitimieren, das in der Krise noch so häufig herangezogen werden sollte: »[T]he special summit of the sixteen heads of state or government of the eurozone [...] unexpectedly became one of those decisive dinners which seem to be the secret of the Union's success. « Es war eine Zeit - es werden im Laufe der Krise weitere folgen -, in der »weitreichende Entscheidungen oft sehr schnell getroffen werden [mussten], manchmal über Nacht « (Juncker et al. 2015b, 19), wie im späteren Fünf-Präsidenten-Bericht durchaus selbstkritisch aufgearbeitet wird. Der Rat der Finanzminister*innen (ECOFIN) einigte sich wenige Tage später - im Rahmen der formalen EU-Verfahrenswege - auf die finalen Details des Rettungsschirms, der zum einen auf der Verordnung (EU) Nr. 407/2010 zur Einführung des Europäischen Finanzstabilisierungsmechanismus (EFSM) und zum anderen auf einer Zweckgesellschaft nach Luxemburger Recht außerhalb der Unionsverträge - der Europäischen Finanzstabilisieriungsfazilität (EFSF) - basierte (vgl. ECOFIN 2010a). Gemeinsam kamen beide Einrichtungen auf ein Darlehnsvolumen von bis zu 500 Milliarden Euro (EFSM: 60 Mrd. €, EFSF: 440 Mrd. €). Der erste Rettungsschirm, der explizit nur eine vorübergehende Maßnahme im Ausnahmezustand der akuten Euro-Krise sein sollte, durfte Mitgliedstaaten, die sich in Refinanzierungsproblemen befanden, bis zum 30.06.2013 Finanzhilfen zur Verfügung stellen (vgl. Art. 11, Abs. 2 EFSF Rahmenvertrag [EFSF-V]), die schließlich neben Griechenland auch Irland und Portugal aus dem EFSF unter den Bedingungen eines fiskal- und wirtschaftspolitischen Sanierungsprogramms (Memoranden) gewährt wurden. Flankiert wurde der temporäre Rettungsschirm im Jahr 2010 durch ein erstes EZB-Programm zum Aufkauf von Staatsschuldentiteln am Sekundärmarkt (Securities Markets Programme; SMP), das allerdings aufgrund seiner Limitierungen noch nicht den Effekt hatte wie das spätere OMT-Programm (Outright Monetary Transaction Programme; 2012), das maßgeblich zur Beruhigung der Refinanzierungskrise beitragen konnte (ausführlich s.u.). Mit der Entscheidung, eine erste systemische, wenn auch zeitlich befristete, Bewältigungsmaßnahme in Form des zuvor im EWWU-Arrangement nicht vorgesehenen - temporären Rettungsschirms zu vollziehen, schien es, als ob die Euro-Krise in all ihren Dimensionen und insbesondere ihrer Tiefe und potenziellen Folgen für die Zukunft der EWWU im Laufe des Jahres 2010 auch im Inneren des EU-Staatsapparate-Ensembles angekommen war. Dass sich eine solche Einsicht langsam durchsetzen konnte, lag an den immer deutlicher sichtbar werdenden Friktionen innerhalb der Währungsunion, deren Zusammenbruch aufgrund der sich fortwährend verschärfenden Refinanzierungskonditionen und be- 
fürchteter Staatsbankrotte zusehends offensiver in Politik und Öffentlichkeit diskutiert wurde (vgl. u.a. Dijsselbloem 2019, 55). Die Euro-Krise gefährdete in diesem Sinne den Fortbestand der neoliberalen EWWU, deren Rettung nun zum Gegenstand eines zweiten strategisch-diskursiven Moments neoliberaler Rückeroberung wurde. >Wer von der Krise spricht, will zum Handeln anregen<, so lautete eine eingangs getroffene Feststellung (vgl. Kapitel 2.6). Dies ist auch in der Euro-Krise nicht anders, besonders wenn die Krise durch anfängliche Unterlassung selber noch weiter befeuert wird. Letztlich dient auch hier die Krisenchiffre dem Evozieren eines Handlungsdrucks. Durch die Betonung der >Notwendigkeit politischer Entscheidungen in Krisenzeiten (vgl. Salomon 2013, 97) wird insofern geradezu beiläufig ein krisenbedingter Ausnahmezustand konstruiert, in dem letztlich der attestierte Handlungsdruck und vermittelt durch Krisenlegitimität getroffene Maßnahmen gestützt werden sollen. Kennzeichen eines Ausnahmezustands sind demnach, dass für eine bestimmte Zeitspanne die normalen demokratischen Verfahren, teilweise gar Grundrechte außer Kraft gesetzt werden können und Exekutivapparate zusätzliche Befugnisse »mit dem Ziel der Wiederherstellung der vorherigen Ordnung« (Brachthäuser \& Haffner 2017, 22) okkupieren. Verstärkt durch die eigene Materialität und den in ihr angelegten strategischen Selektivitäten des EU-StaatsapparateEnsembles ergibt sich demnach eine exekutive Fokussierung auf notwendig erscheinende politische Stützungsmaßnahmen zur Perpetuierung des neoliberalen Vor-KrisenCharakters der EWWU durch die Akteur*innen im neoliberalen Hegemonieprojekt und insbesondere ihrer proeuropäischen Fraktionen. Die >Euro-Rettung ${ }^{2}{ }^{2}$ wurde dabei zum diskursiven Dispositiv der sich verdichtenden Reformagenda. Denn letztlich würde, »wenn die Euro-Zone nicht überlebt«, auch die »Europäische Union nicht überleben«, so Ratspräsident Van Rompuy (zit.n. Zeit, 17.11.2010) oder noch drastischer: »scheitert der Euro, dann scheitert Europa«, wie Bundeskanzlerin Merkel $(2010,4126)$ bereits in der Diskussion um den befristeten Rettungsschirm verlautbaren ließ. Die aufkommende Reformagenda zur Bewältigung der Euro-Krise wurde in diesem Sinne mit einer spezifischen Legitimität auszustatten versucht, die auf einer herrschenden »Notstandsmentalität« (Rödl 2012, 5) beruhe. Es ist der Charakter des Exzeptionellen, der die Euro-Krise auszeichne und letztlich eine Art EU-Staatlichkeitsräson einfordere, um sowohl den Fortbestand der Währungsunion als auch das gesamte europäische Integrationsprojekt nicht zu gefährden. Die Euro-Krise wird in diesem Dispositiv letztlich zu einer umfassenden "Existenzkrise« (Schneider 2012, 326; Bieling 2013b, 89; 2019, 294) der EU stilisiert (vgl. bspw. auch Decker 2011, 303; Verdun 2013, 30; für die politischen Deutungsmuster in Deutschland siehe auch Oppermann 2014 oder Diermann, Staub \& Müller 2015), vor deren Hintergrund schließlich alles getan werde müsse, um die EWWU (in ihrer neoliberalen Anlage der Maastrichter Verträge) zu bewahren (s. bspw. auch die Anzeigenkampagne zur Euro-Rettung deutscher und französischer Konzernchefs; vgl. SZ, 20.06.2011). 


\section{3 "Europe 2020 « und die Wettbewerbsfähigkeitsdoktrin als drittes strategisch-diskursives Moment neoliberaler Rückeroberung}

Nachdem sich am Ausgangspunkt der Euro-Krise in der Umdeutung zur Staatsschuldenkrise und im Rettungsdispositiv eine implizite Allianz aus der eher proeuropäisch ausgerichteten autoritären und der national-orthodoxen Fraktion des neoliberalen Hegemonieprojekts mit Akteur*innen des national-konservativen Hegemonieprojekts zu verdichteten begonnen hatte, stand diese als Folge der von ihr provozierten Krisenzuspitzung allerdings bereits im Laufe des Jahres 2010 zunehmend unter Druck. Die ersten Krisenbewältigungsmaßnahmen, die entweder aufgrund ihrer proklamierten Einmaligkeit (erstes Griechenlandpaket) oder aber ihrer zeitlichen Befristung (Europäische Finanzstabilisierungsfazilität, EFSF) von Beginn an limitiert worden waren, und der in ihnen ausgedrückte Aktionismus der ersten Stunde reichten nicht aus, um schnell eine Beruhigung der Krisensituation zu erreichen. Der Bewältigungsansatz des reaktionären Bündnisses stellte zudem in sich eine fragile Kompromissstruktur dar, in der zwar einerseits europäische >Hilfe geleistet wurde, was die national-ausgerichteten Akteur*innen anfänglich zu verhindern suchten (`Eigenverantwortlichkeit`), allerdings nur zeitlich begrenzt und nicht in Form einer dauerhaften Infrastruktur zur Krisenbewältigung, um andererseits die Grundfesten der EWWU (>No-Bail-Out<, nationale Verantwortung für die Wirtschaftspolitik) nicht infrage zu stellen. Vor diesem Hintergrund gelang es in einem dritten strategisch-diskursiven Moment, auch die moderatneoliberalen Akteur*innen stärker auf die künftigen Maßnahmen zur Krisenbewältigung zu verpflichten. Konkreter Gegenstand hierfür stellte die parallel zur einsetzenden Euro-Krise im Zeitraum Herbst 2009 bis Frühjahr 2010 diskutierte und schließlich im Sommer 2010 beschlossene Europe-2020-Strategie dar.

Die Problembeschreibung der Kommissionsmitteilung, in der die Europe-2020Strategie skizziert wird, ähnelt dabei jener der Lissabon-Strategie aus dem Jahre 2000. So seien die strukturellen Schwächen Europas »offensichtlich« (KOM 2010c, 8f.): Das durchschnittliche Wachstum liege hinter den Wachstumsraten in anderen Weltregionen, was auf ein zunehmendes Produktivitätsgefälle zurückgeführt werde; die Beschäftigungsquoten von Frauen und insbesondere älteren Arbeitnehmer*innen liege ebenfalls hinter jenen der Vergleichsregionen und zugleich würden weniger Arbeitsstunden geleistet; die Alterung verstärke sich und werde die Sozialsysteme zusätzlich belasten. Weiterhin würden die globalen Probleme zunehmen, mit der die Europäische Union konfrontiert sei (vgl. ebd., 9): zunehmender Druck aufgrund des Wettbewerbs zwischen entwickelten und Schwellenländern; Instabilität des internationalen Finanzsystems; Klimawandel und Rohstofflage. Letztlich müsse >Europa< handeln, »um den Niedergang entgegenzutreten« (ebd.). Insofern stehe die EU vor einer Entscheidung:

»Entweder stellen wir uns gemeinsam der unmittelbaren Herausforderung des wirtschaftlichen Aufschwungs und auch den längerfristigen Problemen (Clobalisierung, Ressourcenknappheit, Alterung), damit wir die jüngsten Verluste ausgleichen, unsere Wettbewerbsfähigkeit zurückgewinnen, unsere Produktivität steigern und längerfristig dem Wohlstand in der Union den Weg bereiten (>nachhaltiger Aufschwung»).« (Ebd., 10; Herv. J. G.) 
Oder - so malt die Kommission den negativen Ausblick - könnten

»wir [...] mit langsamen und weitgehend unkoordinierten Reformen weiter[machen] und riskieren dauerhafte Wohlstandeinbußen, ein schleppendes Wirtschaftswachstum ('Schleppender Aufschwung`) mit der möglichen Folge hoher Arbeitslosenzahlen, sozialer Spannungen und relativer Bedeutungslosigkeit Europas auf der Weltbühne (’verlorenes Jahrzehnt`).«(Ebd., 10)

Wie nah die Kommission mit einem solchen Negativszenario der tatsächlichen Krisenund Nach-Krisen-Realität in der EU kommen würde, haben wohl zu Beginn des Jahres 2010 die Wenigsten erahnt; sollte doch gerade die Politik zur Krisenbewältigung den »Beginn einer neuen Wirtschaftsform « (ebd., 12) markieren, in dessen Mittelpunkt die Europe-2020-Strategie stehe, »mit der die EU in eine intelligente, nachhaltige und integrative Wirtschaft umgewandelt werden kann, die durch ein hohes Beschäftigungsund Produktivitätsniveau sowie einen starken sozialen Zusammenhalt geprägt ist.« (Ebd.) Zu diesem Dreiklang der Wachstumsparadigmen definiert die Strategie jeweilige Kernziele, deren Erreichung durch sogenannte EU-Leitinitiativen unterstützt werden soll (vgl. ebd.). Weiterhin propagiert sie eine Vertiefung des Binnenmarktes (vgl. ebd., 24f.), eine wachstumsfördernde Investitionspolitik durch eine Mobilisierung von Finanzmitteln im Rahmen der Kohäsionspolitik, des EU-Haushalts aber auch durch Mobilisierung privaten Kapitals (Public-Private-Partnerships) (vgl. ebd., 26f.) sowie eine intensivere Handelspolitik, die auf einen besseren Marktzugang setze und ein exportorientiertes Wachstumsmodell repräsentiert (vgl. ebd., 27f.). Zugleich verweist die Kommission darauf, dass die Überwindung der aktuellen Krise der erste Schritt auf dem Weg zur Zielerreichung der Strategie darstelle, wobei sie darauf hinweist, dass »hohe Schulden der öffentlichen Hand [...] nicht auf unbeschränkte Zeit durchgehalten werden [können].«(Ebd., 28) Sie plädiert deshalb für eine schrittweise Rücknahme der während der Finanz- und Wirtschaftskrise initiierten, keynesianisch inspirierten Konjunktur- und Beschäftigungsprogramme (vgl. ebd., 29) und macht deutlich, dass künftig der Haushaltskonsolidierung mehr Aufmerksamkeit geschenkt werden müsse, weshalb sie »die Durchführung mittel- bis längerfristiger Reformen zur Förderung der Nachhaltigkeit öffentlicher Haushalte und zur Stärkung des Wachstumspotenzials« (ebd., 30) anmahnt. Weiterhin verweist die Kommission auf die Notwendigkeit einer stärkeren Politik-Koordinierung innerhalb der EWWU, deren Herausforderungen sie insbesondere in der »fehlende[n] Nachhaltigkeit der öffentlichen Finanzen und des potenziellen Wachstums, aber auch [in der; J. G.] destabilisierenden Wirkung von Ungleichgewichten und Unterschieden in der Wettbewerbsfähigkeit« (ebd., 31) verortet. Entsprechend müsse die künftige politische Koordinierung

»einen Rahmen für eine weiterreichende und umfassendere Überwachung der EuroLänder [einschließen]: neben der Stärkung der Haushaltdisziplin sollten makroökonomische Ungleichgewichte und die Entwicklung der Wettbewerbsfähigkeit integraler Bestandteil der wirtschaftlichen Überwachung sein u.a. um eine Anpassungspolitik zu erleichtern« (ebd., 31; Herv. J. G.).

Auf der letzten Ratstagung des Jahres 2009 befassten sich erstmals auch die Staats- und Regierungschefs mit einer Lissabon-Nachfolgestrategie. In den Schlussfolgerungen des 
Europäischen Rates $(2009,7)$ heißt es, dass bis zur Frühjahrstagung die Elemente einer neuen Strategie festzulegen seien und geprüft werden solle,

»wie die langfristige Tragfähigkeit der öffentlichen Finanzen bei gleichzeitiger Wahrung von Investitionen und Sozialschutz sichergestellt werden kann, wie integrative und effiziente Arbeitsmärkte geschaffen werden können, wie der Binnenmarkt weiter ausgebaut werden kann und wie die wechselseiti [g; ]. G.] en Vorteile von Außenhandel und Öffnung in vollem Umfang genutzt werden können.«

Die Fragestellungen des Europäischen Rates verweisen somit bereits auf die schlussendliche inhaltliche Ausrichtung der Europe-2020-Strategie, die sich auch an der positiven Zuschreibung an die Lissabon-Strategie messen lassen muss, in der ihr ein »Nutzen für die Festlegung eines Rahmes zur Verbesserung der Wettbewerbsfähigkeit und zur Förderung von Strukturreformen« (ebd., 7) attestiert werde (vgl. auch KOM 2010l). Diese positive Bewertung in den weiteren Diskussionen zentral aufgreifend, verorteten die Staats- und Regierungschefs den Diskurs um die Europe-2020-Strategie im Unterschied zur Kommission noch einmal wesentlich stärker unter einer Doktrin der Wettbewerbsfähigkeit. Deutlich wird dies an der zentralen Feststellung, dass »[u]nsere Bemühungen [...] zielgerichteter sein [müssen], um die Wettbewerbsfähigkeit, die Produktivität, das Wachstumspotenzial und die Wirtschaftskonvergenz in Europa zu steigern « (ER 2010a, 2). Mit diesem Satz werden alle weiterführenden Inhalte der Strategie eingeleitet. Zudem definiert der Europäische Rat die Produktivitätsentwicklung in Verbindung mit der Verbesserung der Wettbewerbsfähigkeit, der Finanzmarktstabilität und makroökonomischen Entwicklungen als einen wesentlichen Fortschrittsindikator (vgl. ebd., 4), wobei sich die EU »auf die dringlichen Herausforderungen im Bereich Wettbewerbsfähigkeit und Zahlungsbilanzentwicklung konzentrieren [muss].« (Ebd., 5) Der von der Kommission vorgeschlagene Dreiklang der Wachstumsparadigmen (intelligent, nachhaltig, integrativ) wurde auf der März-Ratstagung bestätigt, zudem konnte man sich für drei der fünf Kernziele auf konkrete Zielwerte verständigen. So wurde die Zielsetzung einer Beschäftigungsquote von $75 \%$ im Jahre 2020 ebenso vereinbart wie auch die Zielmarke eines Investitionsvolumens von $3 \%$ am BIP für Forschung und Entwicklung und die von der Kommission vorgeschlagenen Zielwerte im Umwelt- und Energiebereich (vgl. ebd., 2). Keine Einigkeit konnte hingegen in Bezug auf die Zielmargen für die Bereiche Bildung und Armutsbekämpfung erreicht werden. Diese wurde erst auf der Junitagung des Europäischen Rates erzielt. Dabei lautete der Kompromiss für den Bildungsbereich, dass die von der Kommission im Kern vorgeschlagenen Ziele (Senkung der Schulabbrecherquote auf unter $10 \%$; Steigerung der 30 bis 34-Järhigen mit Hochschulabschluss auf mindestens $40 \%$ ) zwar bestätigt, zugleich aber mit der Protokollnotiz ausgestattet wurden, nach der es den einzelnen Mitgliedstaaten obliege, quantitative Ziele im Bildungsbereich festzulegen und zu verwirklichen (vgl. ER 2010b, 12). Die Zielsetzung im Bereich der Armutsbekämpfung wurde im Vergleich zum Kommissionsvorschlag gar noch einmal abgeschwächt, indem nicht mehr konkret von der Reduzierung der Anzahl der unter den mitgliedstaatlichen Armutsgrenzen lebenden Personen gesprochen wurde, sondern »die soziale Eingliederung [...] insbesondere durch die Vermeidung der Armut gefördert werden [soll], wobei angestrebt wird, mindestens 20 Millionen Menschen vor dem Risiko der Armut und der Aus- 
grenzung zu bewahren.« (Ebd.) Diese Abschwächung der ursprünglichen Zielsetzung wird zusätzlich durch eine Protokollnotiz unterstrichen, in der die adressierte Bevölkerungsgruppe

»als die Anzahl der Personen definiert [wird], die nach drei Indikatoren (Armutsrisiko, materielle Deprivation, Erwerbslosenhaushalt) von Armut und Ausgrenzung bedroht sind, wobei es den Mitgliedstaaten freigestellt ist, ihre nationalen Ziele auf der Crundlage der am besten geeigneten Indikatoren und unter Berücksichtigung ihrer nationalen Cegebenheiten und Prioritäten festzulegen.«(Ebd.)

Die ursprünglich von der Kommission angedachte sozialpolitische Flankierung in Form einer konzertierten Armutsbekämpfungskomponente innerhalb der neuen Strategie wurde mit diesem Kompromiss zugunsten der wettbewerbsorientierten Indikatoren weitgehend geschliffen.

Zur Umsetzung der Strategie verweist die Kommission in ihrer Mitteilung auf den vorhandenen Koordinierungsrahmen der Verträge, in dem einerseits ein thematischer Ansatz (in Form der Leitinitiativen) sowie eine zielgerichtete Überwachung der einzelnen Länder verfolgt werden solle (vgl. KOM 2010c, 31). Vorgesehen sei, die Berichtslegung und Bewertung im Rahmen der Strategie mit jenen des Stabilitäts- und Wachstumspakts zu verknüpfen, auch wenn beide Bereiche weiterhin als eigenständig anzusehen sind (vgl. ebd., 32). Diese Verknüpfung verweist auf die Etablierung des Europäischen Semesters als neuen, ganzheitlichen Koordinationsrahmen (ausführlich s.u.). Zugleich sollen in den Rahmen der Europe-2020-Strategie auch die in den Verträgen kodierten Instrumente der »Grundzüge der Wirtschaftspolitik « und der »beschäftigungspolitischen Leitlinien« integriert werden (vgl. ebd., 32). Die neue Strategie stellt daher die Klammer für alle weiteren Instrumente und Verfahren des wirtschaftspolitischen Regierens dar.

Die »[u]neingeschränkte Verantwortung des Europäischen Rates«, wie es die Kommission (2010c, 33) umschreibt, wird derweil durch das neue Koordinierungsverfahren nicht in Abrede gestellt, sondern ergänzt diese. So schreibt sich der Europäische Rat (2010a, 4) in der Schlussfolgerung der März-Ratstagung selber die Aufgabe zu, jährlich auf Grundlage der Überwachung durch die Kommission eine Gesamtbewertung der Strategie vorzunehmen und regelmäßig Aussprachen über die Zielsetzungen der Strategie abzuhalten. Die Überwachung der Kommission bezieht sich indes auf die Verankerung der Ziele der Europe-2020-Strategie in der mitgliedstaatlichen Politikgestaltung, die sich in spezifischen mitgliedstaatlichen Zielsetzungen mit Bezug zu den Kernzielen der Strategie abbilden und in den mitgliedstaatlichen Reformprogrammen dargelegt werden sollen (vgl. ebd., 3). Der »effiziente Überwachungsmechanismus«, den sich der Europäische Rat vorstellt, soll auf einer »bessere[n] Nutzung der in Artikel 121 des Vertrags (AEUV) vorgesehenen Instrumente« (ebd., 5) basieren. Insofern verweist die neue Strategie auf die 2009 in Kraft getretenen Vertragsänderungen, in denen der Kommission »eine stärkere Rolle bei der Koordinierung und Überwachung der nationalen Wirtschaftspolitiken« (Becker 2011, 77; vgl. u.a. auch Hattenberger 2012) zufällt, die für die Umsetzung der Europe-2020-Strategie wie auch für die später durch die Krisenbewältigungspolitik ausgebaute Wirtschafts- und Fiskalregierung von besonderer Bedeutung ist. 
Die Implementierung der Europe-2020-Strategie erfolgte schließlich auf Grundlage der Artikel 121 (Grundzüge der Wirtschaftspolitik) und 148 (beschäftigungspolitische Leitlinien) des AEUV. Erstmals wurden hierbei die zeitlichen Abläufe beider Artikel synchronisiert und die Grundzüge der Wirtschaftspolitik sowie die beschäftigungspolitischen Leitlinien zusammen als »integrierte Leitlinien für Wirtschafts- und Beschäftigungspolitik« bezeichnet, die der Europäische Rat auf seiner Juni-Tagung billigte (vgl. ER 2010b, 3) und die

»die Grundlage für alle länderspezifischen Empfehlungen sein [werden], die der Rat gegebenenfalls an die Mitgliedstaaten richtet. Diese Empfehlungen müssen uneingeschränkt mit den einschlägigen Bestimmungen des Vertrags und den EU-Vorschriften im Einklang stehen und die Zuständigkeiten der Mitgliedstaaten, zum Beispiel in Bereichen wie Bildung, unberührt lassen.«(ER 2010b, 3)

Die zehn integrierten Leitlinien, die der Rat am 13. Juli (Leitlinien 1 bis 6 als »Empfehlung über Grundzüge der Wirtschaftspolitik«; Empfehlung 2010/410/EU) sowie am 21. Oktober 2010 (Leitlinien 7 bis 10 als »Beschluss über Leitlinien für beschäftigungspolitische Maßnahmen der Mitgliedstaaten«; Beschluss 2010/707/EU) annahm, komplementierten somit die Implementierung der Europe-2020-Strategie im Jahre 2010.

Tabelle 5: Integrierte wirtschafts- und beschäftigungspolitische Leitlinien 2010

\begin{tabular}{|l|}
\hline Leitlinie 1: Cewährleistung der Qualität und langfristigen Tragfähigkeit der öffentlichen Finanzen \\
\hline Leitlinie 2: Beseitigung makroökonomischer Ungleichgewichte \\
\hline Leitlinie 3: Abbau von Ungleichgewichten im Euro-Währungsgebiet \\
\hline $\begin{array}{l}\text { Leitlinie 4: Optimierung der Forschungs- und Entwicklungs- sowie der Innovationsförderung, Stärkung } \\
\text { des Wissensdreiecks und Freisetzung des Potenzials der digitalen Wirtschaft }\end{array}$ \\
\hline Leitlinie 5: Verbesserung der Ressourceneffizienz und Abbau der Treibhausgase \\
\hline $\begin{array}{l}\text { Leitlinie 6: Verbesserung der Rahmenbedingungen für Unternehmen und Verbraucher und Moderni- } \\
\text { sierung und Weiterentwicklung der industriellen Basis, um das reibungslose Funktionieren des Binnen- } \\
\text { marktes sicherzustellen }\end{array}$ \\
\hline $\begin{array}{l}\text { Leitlinie 7: Erhöhung der Erwerbsbeteiligung von Frauen und Männern, Abbau der strukturellen Ar- } \\
\text { beitslosigkeit und Förderung der Arbeitsplatzqualität }\end{array}$ \\
\hline $\begin{array}{l}\text { Leitlinie 8: Heranbildung von Arbeitskräften, deren Qualifikation den Anforderungen des Arbeits- } \\
\text { markts entsprechen, und Förderung des lebenslangen Lernens }\end{array}$ \\
\hline $\begin{array}{l}\text { Leitlinie 9: Steigerung der Qualität und Leistungsfähigkeit des allgemeinen und beruflichen Bildungs- } \\
\text { wesens auf allen Ebenen und Verbesserung des Zugangs zur Hochschulbildung oder zu einer gleich- } \\
\text { wertigen Bildung }\end{array}$ \\
\hline \begin{tabular}{l} 
Leitlinie 10: Förderung der sozialen Eingliederung und Bekämpfung der Armut \\
\hline
\end{tabular} \\
\hline
\end{tabular}

Quelle: Empfehlung 2010/410/EU \& Beschluss 2010/707/EU

Durch die Zielvariable eines »integrativen« Wachstums wird mit der Europe-2020Strategie auch eine sozialpolitische Komponente in die ökonomische Gesamtstrategie der Union einzuflechten versucht, was von vielen Kommentator*innen im Vergleich zur Lissabon-Strategie als Fortschritt betrachtet wird (vgl. bspw. Zeitlin \& Vanharcke 2018, 155; Pereira 2011, 2 oder Sommer 2010, 6). Allerdings fällt die Reichweite der 
sozialpolitischen Säule nur sehr überschaubar aus. Statt einer proaktiven Armutsbekämpfung bleibt als einziger Faktor die vereinbarte Armutsvermeidung, wobei allerdings keine einheitlichen Indikatoren zur Messung etwaiger Fortschritte vereinbart werden konnte. Bereits im März 2014 wies die Kommission darauf hin, dass die hier intendierte Zielsetzung bis 2020 sehr wahrscheinlich nicht erreicht werden wird; ganz im Gegenteil habe sich der Anteil derjenigen Menschen, die von Armut und sozialer Ausgrenzung bedroht sind, gar noch weiter erhöht (vgl. KOM 2014a, 16; s. auch Leschke, Theodoropoulou \& Watt 2014). Neben der Zielsetzung im Bereich der Armutsvermeidung findet sich die vereinbarte Zielmarke einer erhöhten Erwerbsquote, die ebenso sozialpolitische Implikationen in sich trägt, allerdings nicht zwangsläufig dazu führen muss, zur Bekämpfung von Armutsrisiken beizutragen. Dies liegt daran, dass keine qualitativen Merkmale für eine erhöhte Erwerbsbeteiligung festgelegt werden. Vielmehr schreiben die Europe-2020-Strategie und ganz explizit die integrierten Leitlinien den bereits in der Lissabon-Strategie enthaltenen Flexicurity-Ansatz fort (vgl. Dusse 2019, 88; für die historische Genese der Europäischen Beschäftigungspolitik vgl. ebd., 76ff.), der sich aus einer aktivierenden Arbeitsmarktpolitik bei gleichzeitiger Flexibilisierung der »Arbeitsmärkte« speist (vgl. Beschluss 2010/707/EU, Leitlinie 7) und letztlich besser als eine Form der "Sozialdisziplinierung (Dusse 2019, 290) zu fassen ist. Demnach schlägt beispielsweise der Ausbau des Niedriglohnsektors für die Zielerreichung im gleichen Maße zu Buche wie die Schaffung gut bezahlter, tarifgebundener Arbeitsplätze, auch wenn die integrierte Leitlinie 7 kritisch auf solche Tendenzen eingeht. Der damalige DGB-Vorsitzende Sommer $(2010,6)$ mahnte dennoch an, dass in der Europe2020-Strategie Ziele wie »Gute Arbeit« oder »Vollbeschäftigung« fehlten. Das in der Europe-2020-Strategie propagierte gesellschaftliche Teilhabemuster lässt sich insofern auf die Marktteilnahme als Arbeitnehmer*innen reduzieren. Auch die bildungspolitischen Zielvereinbarungen erhellen dieses negative Bild nicht. Zwar ist die Reduzierung der Schulabbrecherquote ein wichtiges und erstrebenswertes Ziel, jedoch bleiben aber bildungspolitische Maßnahmen häufig auf eine rein-ökonomistische Verwertungslogik begrenzt, wie der Blick in die integrierten Leitlinien offenbart, in denen es heißt, dass das »Qualifikationsniveau der Erwerbsbevölkerung « anzuheben sei, »um sie so in die Lage zu versetzen, auf die sich rasch wandelnden Erfordernisse moderner Arbeitsmärkte [...] zu reagieren.«(Beschluss 2010/707/EU, Leitlinie 9) Auch das Paradigma des »lebenslangen Lernens« (vgl. ebd., Leitlinie 8) spricht hierfür Bände (vgl. Spilker 2013).

Weiterhin führt die Europe-2020-Strategie den Strukturreformenkonsens der Lissabon-Strategie fort (vgl. u.a. KOM 2012l). Grundvoraussetzungen für ein intelligentes, nachhaltiges und integratives Wachstum seien demnach das Bekenntnis zur weiteren Deregulierung und der Ausbau des Binnenmarktes (vgl. Empfehlung 2010/410/EU, Leitlinie 6). Plastisch wird der Ansatz zum Beispiel bei den avisierten Ausgaben für Forschung und Entwicklung. So schreibt die Europe-2020-Strategie zwar eine Zielmarge von $3 \%$ des BIP für den Bereich Forschung und Entwicklung vor (vgl. ebd., Leitlinie 4), allerdings bei gleichzeitiger Unterordnung der Strategie unter einer allgemeinen und verstärkten Haushaltsdisziplin (vgl. ebd., Leitlinie 1), weshalb möglichst private Investor*innen entsprechende Ausgabenlücken schließen sollten (vgl. ebd., Leitlinie 4). Die Rückbindung staatlichen Handelns an eine austeritätspolitische Richtschnur spielt insofern bereits in der Europe-2020-Strategie als Vorbote der 
kriseninduzierten Reformmaßnahmen und vor dem Hintergrund der Umdeutung zur Staatsschuldenkrise eine herausragende Rolle. Nach Peter Becker (2011, 87) hat sich in der Europe-2020- im Vergleich zur Lissabon-Strategie dabei die Anordnung von Fiskal- und Wachstumspolitik sogar diametral verändert:

»Waren die Konsolidierungsziele der Lissabon-Strategie [...] noch ein wichtiges Mittel zur Förderung von Wachstum und Beschäftigung, so hat sich diese Ziel-Mittel-Relation bei der >Europa 2020<-Strategie umgekehrt. [...] Bei der >Europa 2020<-Strategie tritt die Wachstumsorientierung in den Dienst der Austeritätspolitik des europäischen Stabilitäts- und Wachstumspaktes.«

Sie ordnet sich demnach einem einseitigen Austeritätsdogma unter.

Rhode $(2010,11)$ konstatiert ebenso wie Hacker \& van Treck $(2010,7 f$.) des Weiteren eine angebots- und weltmarktorientierte Ausrichtung der Europe-2020-Strategie. Die hiermit verbundenen wirtschaftspolitischen Ordnungsvorstellungen weisen einen starken Bezug zu Globalisierungstrends und der Rolle der EU in einer globalisierten Weltwirtschaft mit offenen Marktwirtschaften auf. Propagiert wird ein Ansatz, der den weltweiten Wettbewerb unter anderem in einer ausgebauten EU-Handelspolitik adressieren soll (externe Wachstumsstrategie). »Global Europe« (KOM 2006), die 2005 im Zuge der Refokussierung der Lissabon-Strategie formulierte handelspolitische Agenda und Selbstzuschreibung der Europäischen Union, eingebettet in die Zielvorstellung, den »wettbewerbsfähigsten Raum der Welt« zu schaffen, findet hier eine implizite Bestätigung. Dies zeigt sich auch in den Bemühungen der EU um neue Freihandelsabkommen in den vergangenen Jahren (u.a. TTIP, CETA, TISA oder EPAs).

Somit wurde bereits zu Beginn des Jahres 2010 mit Europe 2020 und zeitgleich zur Umdeutung zur Staatsschuldenkrise und der sich anschließenden Such- und Verdichtungsprozesse einer Reformagenda zur Bewältigung der Euro-Krise eine wirtschaftspolitische Strategie auf Unionsebene beschlossen, die eine überaus deutliche neoliberale Handschrift trägt. Die Europe-2020-Strategie und die mit ihr verknüpften integrierten Leitlinien der wirtschaftspolitischen Koordinierung ordnen hierbei die wirtschaftliche Erholung dem Primat der vorrangingen Haushaltskonsolidierung unter und tragen insofern bereits den Geist der Austerität in sich. Die hierdurch vorgenommene Begrenzung nachfrageorientierter Politikansätze und staatlicher Einflussmöglichkeiten ins Wirtschaftsgeschehen wird in der Strategie durch eine Fokussierung auf angebotsökonomische Instrumente auszugleichen versucht. Im Mittelpunkt der Strategie stehen demnach Ansätze der Flexibilisierung von Arbeitsmärkten, die Vertiefung des Binnenmarktes oder eine expansive Freihandelspolitik. Die Europe-2020-Strategie stellt daher eine Kontinuität zur herrschenden hegemonialen Konstellation in der Europäischen Union vor dem Krisenausbruch her, indem sie die Paradigmen und Dogmen der neoliberalen Akkumulationsstrategie vor der Euro-Krise restauriert. Mit Europe 2020 liegt nicht weniger als ein neoliberal geprägter, angebotsökonomisch eingefärbter und im Dienste des Austeritätsdogmas stehender Masterplan bereit, auf dem in allen weiteren Maßnahmen der reaktiven Krisenbewältigungspolitik Bezug genommen wird, egal ob suprastaatlich oder intergouvernemental lanciert. In diesen Masterplan schrieben sich letztlich alle neoliberalen Kräfte ein, weshalb er als weiteres strategisches Moment den Weg für den reaktiven Staatlichkeitsausbau in der Euro-Krise bereitete. Das Schlüssel- 
narrativ stellt hierbei die als fehlend angemahnte Wettbewerbsfähigkeit dar, wie bereits in der Entstehungsphase der EWWU und bei der Formulierung der Lissabon-Strategie im Jahr 2000 (vgl. van Apeldoorn 2000, 208-213).

Damals war der Diskurs um »Wettbewerbsfähigkeit« entscheidend von neoliberalen Akteur*innen, insbesondere dem European Round Table of Industrialists (ERT), initiiert, geprägt und in die Diskussion um die Wirtschafts- und Währungsunion eingeflochten worden. In Zeiten der hegemonialen Stellung des neoliberalen Hegemonieprojekts avancierte die Doktrin der Wettbewerbsfähigkeit so bereits zu einem zentralen Leitbild europäischer Politik, mit dem »die Absicherung der Wirtschafts- und Währungsunion im Einklang mit den Erfordernissen außenwirtschaftlicher Wettbewerbsfähigkeit propagiert (Ebner 2012, 232) wurde. In Analogie hierzu sei es demnach »der Mangel an Wettbewerbsfähigkeit der südeuropäischen Länder und Frankreichs« (Sinn 2014, 1; Übers. J. G.), der sich in der Euro-Krise gezeigt habe und dem man nun begegnen müsse. Die Lösung für dieses Problem ist für Marktliberale wie HansWerner Sinn daher klar: »Austerität im Süden« (ebd.; Übers. J. G.). Wie bereits in den 1990er und 2000er Jahren spielten auch im Jahr 2010 wirtschaftliche Interessenlagen einzelner Kapitalfraktionen eine besondere Rolle bei der neuerlichen Durchsetzung der Wettbewerbsfähigkeitsdoktrin. So veröffentlichte der ERT (2010) im Frühjahr 2010 seine >Vision für ein wettbewerbsfähiges Europa<, die im ersten Halbjahr 2009 von der ERT Competitiveness Working Group erarbeitet wurde und in vielen Bereichen große Ähnlichkeiten mit der Europe-2020-Strategie und den integrierten Leitlinien erkennen lässt. Und auch Business Europe (2010), der europäische Dachverband der Industrieverbände, griff in die Debatte ein und fasste mit ihrer Madrider Erklärung vom Juni 2010 einen Beschluss, in dem die globale Wettbewerbsfähigkeit als Schlüssel zur Krisenüberwindung in Europa definiert wurde (vgl. auch Konecny 2012, 382f.). Dass diese beiden Verbände durchaus einen exklusiven Zugriff auf europäische Entscheidungsträger*innen genießen und somit auch die europäische Agenda entscheidend mitgestalten können, zeigte sich nicht zuletzt an dem Treffen von ERT-Vertretern (sic!) mit Kanzlerin Merkel, Präsident Hollande und Kommissionspräsident Barroso am 18. März 2013 im Berliner Kanzleramt. Dieses Treffen stand unter der Überschrift Europas Wettbewerbsfähigkeit, Wachstum und Beschäftigung wiederherzustellen (vgl. ERT 2013) und bot den Kapitalvertretern (sic!) nicht zum ersten Mal einen exklusiven Zugriff auf zwei der damaligen Schlüsselfiguren im Europäischen Rat, die deutschen Bundeskanzlerin und den französischen Präsidenten. Es gelang durch »einen forcierten europäischen Wettbewerbsfähigkeitsdiskurs [...], die antagonistischen Interessen innerhalb des europäischen Machtblocks auch in der Krise zusammenzuhalten«, so Heinrich \& Jessop (2013, 26; Herv. J. G.). Gerade hieran zeigt sich die besondere strategische Bedeutung der Europe-2020-Strategie. Der Diskurs um Wettbewerbsfähigkeit ist dabei gerade auch deshalb so anschlussfähig, da hierunter sehr unterschiedliche Dinge verstanden werden können. In der Summe trägt dies aber zugleich mit dazu bei, dass ein hegemonialer Diskurs entsteht, in den sich unterschiedliche, nicht nur neoliberale, Akteur*innen einweben lassen. Die Gegenseite eines neoklassisch-monetaristischen Verständnisses von Wettbewerbsfähigkeit fokussiert in diesem Sinne zwar meist andere Wettbewerbsfähigkeitsindikatoren, stellt aber dennoch nicht in Frage, dass ihre Verbesserung auch als Exit-Strategie aus den ökonomischen Krisen durchaus 
berechtigt erscheint. So sprechen beispielsweise Bibow \& Flassbeck $(2018,36)$ - unter Wahrung kritischer Distanz - von einer »durchaus richtigen Einsicht«, nach der »die stark ungleichgewichtigen Wettbewerbspositionen innerhalb der Währungsunion $\mathrm{zu}$ einem Gleichgewicht zurückfinden müssen.« Warnungen, nach denen mit der Fokussierung auf Wettbewerbsfähigkeit im Kern aber »ein fehlgeleiteter wirtschaftspolitischer Orientierungspunkt « (Feigl \& Zuckerstätter 2013, 110) gesetzt wird »und sich die gängige Wettbewerbs-Erzählung bei näherer Betrachtung ökonomisch als wenig plausibel herausstellt« (ebd.), werden im allgemeinen - angebotsökonomisch vereinseitigten - Wettbewerbsdiskurs aber nur wenig Gehör geschenkt. Grundsätzlich lässt sich am Paradigma der Wettbewerbsfähigkeit kritisieren, dass es als Konzept unbrauchbar sei, »da Unternehmen und keine Nationen in einem wirtschaftlichen Wettbewerb stehen. Eine Übertragung auf Volkswirtschaften - die insbesondere nicht vom Markt verschwinden können - ergäbe wenig Sinn«, so Feigl und Zuckerstätter $(2013,109)$ im Anschluss an Krugman. Hiermit verbunden ergibt sich ein wirtschaftspolitischer Irrglaube, der sich auf einer Exportfixierung gründet. Einer obsessiven Exportfixierung liegt dabei ein ähnlicher Analogiekurzschluss zugrunde, wie bereits in der allgemeinen Kritik vorgebracht: die Übertragung eines »einzelwirtschaftlichen Kalküls« auf »ganze Volkswirtschaften« (ebd., 112). Entsprechend rücken - wie auch in der Euro-Krise $\mathrm{zu}$ beobachten - die volkswirtschaftlichen Leistungsbilanzen in den Mittelpunkt der Betrachtung und dienen als Gradmesser für Wettbewerbsfähigkeit (Das Motto lautet dann wahlweise sje höher der Überschuss, desto besser die Wettbewerbsfähigkeit oder >je höher das Defizit, desto schlechter die Wettbewerbsfähigkeit`). In aller Kürze lässt sich hieran kritisieren, dass ein dauerhafter und für den Euroraum als aggregierte Gesamtgröße betrachteter Leistungsbilanzüberschuss ökonomisch gesehen eine Utopie darstellt: Über kurz oder lang müssen sich Defizite und Überschüsse die Waage halten, ansonsten liefe eine Volkswirtschaft Gefahr, dass die Verbindlichkeiten (die Überschüsse stellen nichts anderes dar) durch die Schuldner (Defizitländer) irgendwann nicht mehr bedient werden können; ein Zahlungsausfall inklusive ihrer wirtschaftlichen Folgeerscheinungen wäre das wohl potenziell schlechteste Ergebnis einer so gelagerten Wirtschaftspolitik. Mindestens aber wäre eine Wertbereinigung über Wechselkursanpassungen gegenüber dem Euro eine andere Form der notwendigen Pendellierung im Sinne des gesamtwirtschaftlichen Gleichgewichts. Dauerhafte Überschüsse führen entsprechend zu systemischen Ungleichgewichten, die das >Funktionieren der Volkswirtschaften im Euroraum insgesamt bedrohen. Diesem sexternen zur Seite zu stellen: So sind Leistungsbilanzüberschüsse "zunächst nichts anderes als ein sonst wenig populärer Konsum- oder Investitionsverzicht im Inland gemessen an den Produktions- und Einkommensmöglichkeiten« (ebd., 125). Dies verdeutlicht, dass der Leistungsbilanz als Wettbewerbsfähigkeits-Indikator somit immer auch Aspekte des Klassenkampfes innewohnen. So beschreibt Angela Wigger $(2015,120)$ zutreffend, dass Wettbewerb im Kapitalismus immer als eine soziale Beziehung zu begreifen ist, die den klassischen Antagonismus in sich trägt: »competition [...] pits not only capital against capital, but also capital against labour, and in the presence of a reserve army of unemployed, labour against labour.« So werden im Verständnis der Verfechter*innen einer angebotsökonomisch-dominierten Wettbewerbsfähigkeitsdoktrin schnell 
die Arbeitsmärkte und insbesondere die Lohnniveaus zum Ausgangspunkt der als notwendig angemahnten Steigerung der Wettbewerbsfähigkeit, egal ob in Defizitoder Überschussländern. Auch in der Europe-2020-Strategie und den integrierten Leitlinien lässt sich ein solcher Politikansatz identifizieren, der sich durch die gesamte reaktive Krisenbewältigungspolitik (abzulesen bspw. in den Memoranda und den länderspezifischen Empfehlungen; ausführlich s.u.) zieht.

Durch Europe 2020, die integrierten Leitlinien, die ihnen implizierte Doktrin der Wettbewerbsfähigkeit, inklusive dem von Europäischen Rat und Kommission beschriebenen Strukturreformenkonsens, und nicht zuletzt die Unterordnung unter eine austeritätsdogmatische Richtschnur war somit bereits am Ausgangspunkt der Euro-Krise ein ganzheitlicher Politikrahmen implementiert worden, der die Akkumulationsstrategie der EU grundständig erneuert. Fortentwickelt durch die späteren Maßnahmen der Krisenbewältigungspolitik wird diese dabei sogar wirkmächtiger als zuvor die Lissabon-Strategie in die Herrschaftspraxen der EUSA eingeflochten. Schließlich stehe die restaurierte Akkumulationsstrategie auch ganz offiziell im Dienste der Krisenbewältigung:

»Die Wiederherstellung der makroökonomischen Stabilität und die Zurückführung der öffentlichen Finanzen auf einen nachhaltigen Pfad sind Crundvoraussetzungen für Wachstum und Beschäftigung. [...] Strukturreformen sind entscheidend für einen starken und nachhaltigen Aufschwung und für die Sicherung der Nachhaltigkeit unserer Sozialmodelle. [...] Die EU braucht eine neue, auf eine verstärkte Koordinierung der Wirtschaftspolitiken gestützte Strategie, um mehr Wachstum und Arbeitsplätze zu schaffen. [...] Unsere Bemühungen müssen zielgerichteter sein, um die Wettbewerbsfähigkeit, die Produktivität, das Wachstumspotenzial und die Wirtschaftskonvergenz Europas zu steigern« (ER 2010a, 1f.; Herv. J. G.).

In der Europe-2020-Strategie verdichtete sich letztlich ein Kräfteverhältnis, das deutlich von neoliberalen Kräften (in ihren unterschiedlichen Fraktionierungen) dominiert wird. War die Einbindung national-konservativer Akteur"innen in die Formulierung von Europe 2020 zwar nicht gebrochen - dies findet beispielsweise Ausdruck in der Abschwächung der sozialpolitischen Zielsetzungen (vgl. Kapitel 6.3) -, vollzog sich durch die Stimulierung eines übergeordneten und weithin anschlussfähigen Wettbewerbsfähigkeitsdiskurses, des antizipierten Ausbau des Koordinierungsrahmens (Europäisches Semester) und der europäischen Leitinitiativen doch zugleich auch eine stärkere Orientierung der autoritären Fraktion auf die proeuropäischen und moderat-orientierten Kräfte im neoliberalen Hegemonieprojekt. 



\section{Reaktiver Staatlichkeitsausbau in der Euro-Krise}

Mit der im März 2010 im Europäischen Rat getroffenen Entscheidung zu den bilateralen Hilfskrediten für Griechenland begann innerhalb des EU-Staatsapparate-Ensembles langsam ein Prozess der intensiveren Krisenauseinandersetzung. Hierbei bahnte sich im Laufe des Frühjahrs 2010, spätestens mit den Beschlüssen zum Aufbau der befristeten Rettungsschirme (EFSF \& EFSM), immer deutlicher eine Phase des reaktiven Staatlichkeitsausbaus an. Als Reaktion auf den durch die aufkommende Euro-Krise ausgelösten und somit scheinbar von außen auf das EU-Staatsapparate-Ensemble einwirkenden Impuls weisen diese Ausbauaktivitäten dabei zwar einerseits einen responsiven Charakter auf. Andererseits wohnt ihnen im Sinne des sich mit der Euro-Krise eröffnenden politischen Möglichkeitsfensters aber unterdessen auch ein initiativer Geist inne. Dementsprechend verkörpern die >reaktiven Maßnahmen zum Ausbau der EU-Staatlichkeit zugleich auch ein starkes raktives Moment. Dieses deutete sich bereits in den beschriebenen strategisch-diskursiven Rückeroberungsversuchen neoliberaler Akteur*innen an und wird auch im weiteren Verlauf der Euro-Krise und der Politik zu ihrer Bewältigung an vielen Stellen sichtbar. Neben einem >offiziellen Krisennarrativ steht hierbei am Ausgangspunkt der Phase des reaktiven Staatlichkeitsausbaus eine sich in einer Reihe leitbildprägender Berichte, Mitteilungen und Reflexionspapieren verdichtende Reformagenda der EUSA. Diese wird schließlich drei Konstitutionalisierungsprozesse des reaktiven Staatlichkeitsausbaus anleiten, mit denen die Staatlichkeit der Europäischen Union qualitativ fortentwickelt wird.

\subsection{Das EUSA-Krisennarrativ und die sich verdichtende Reformagenda des reaktiven EU-Staatlichkeitsausbaus}

Vor dem Hintergrund der drei diskursiv-strategischen Rückeroberungsversuche des neoliberalen Hegemonieprojekts - ausgedrückt im Austeritätsdogma (Staatsschuldenkrise), der Wettbewerbsfähigkeitsdoktrin (Europe 2020) und dem aufkommenden Rettungsdispositiv - verdichtete sich in den EUSA ein Krisennarrativ, das gestützt auf strategischen Selektivitäten der zuvor hegemonialen Phase des Neoliberalismus besondere Anschlussfähigkeiten $\mathrm{zu}$ diesen diskursiven Deutungskämpfen aufwies. 
Der Euro-Gipfel im Frühjahr 2010 gab hierbei den Startschuss für einen politischen Prozess, an dessen Ende eine Reformagenda des reaktiven Staatlichkeitsausbaus stehen wird. Die handlungsleitende Problemperzeption basierte dabei auch auf einer Analyse des bisherigen EWWU-Staatlichkeitsarrangements, dem es auf Grundlage des bestehenden EWWU-Regelwerks nicht gelungen sei, die mitgliedstaatliche Verschuldungsproblematik zu verhindern. Insofern sei es neben der Haushaltskonsolidierung auf mitgliedstaatlicher Ebene weiterhin nötig, das bestehende Rahmenwerk zur Sicherstellung Tragfähiger öffentlicher Finanzen zu stärken und zu vervollständigen, wie der Euro-Gipfel (2010b, 2) schlussfolgerte. Weiter heißt es: »[W]e commit to promote a strong coordination of economic policies in Europe« (ebd.). Konkret wird hierunter die stärkere Überwachung ökonomischer und fiskalischer Risiken und eine Stärkung präventiver Instrumente zu ihrer Vermeidung, inklusive dem Verfahren bei einem übermäßigen Defizit, verstanden (vgl. ebd.). Die Funktionskrise schien - wenn auch inhaltlich vereinseitigt - in Brüssel angekommen. Infolgedessen ersuchten der Euro-Gipfel (2010b, 2) und der Europäische Rat (2010a, 6) seinen Präsidenten,

»in Zusammenarbeit mit der Kommission eine Task Force aus Vertretern der Mitgliedstaaten ${ }^{1}$, des turnusmäßig wechselnden Vorsitzes und der EZB einzusetzen, die dem Rat noch vor Jahresende die Maßnahmen unterbreiten soll, die erforderlich sind, um das Ziel eines verbesserten Krisenbewältigungsrahmens und einer besseren Haushaltsdisziplin zu erreichen, wobei alle Möglichkeiten zur Stärkung des Rechtsrahmens sondiert werden sollten.«

Gleichzeitig gaben die Staats- und Regierungschefs der Kommission den Auftrag, bis Juni 2010 Vorschläge für eine verstärkte wirtschaftspolitische Koordinierung innerhalb der Eurozone zu erarbeiten (vgl. ebd., 5). Durch die doppelte Beauftragung einerseits der Kommission, andererseits der einzurichtenden Präsidenten-Arbeitsgruppe setzte der Europäische Rat ungewollt »eine Art Wettlauf« (Schwarzer 2012, 19) in Gang, der zugleich noch einmal einen krisenbezogenen Ausnahmezustand zu markieren hilft und den zeitlich betrachtet die Kommission für sich entscheiden konnte. Sie legte am 12 . Mai eine Mitteilung zur Reform des fiskal- und wirtschaftspolitischen Regierens in der EU vor (vgl. KOM 2010a), die sie in einer zweiten Mitteilung vom 30. Juni weiter konkretisierte (vgl. KOM 2010b). Die eingesetzte Arbeitsgruppe, auch als Task-Force bezeichnet, legte - nach der Präsentation von Zwischenergebnissen im Juni (vgl. ER 2010b, 4f.) - ihren Abschlussbericht am 21. Oktober (vgl. ER 2010f) parallel zur Entschließung des Europäischen Parlaments ([EP] 2010c) mit Vorschlägen zur Verbesserung der >Economic Governance < vor. Zuvor hatte bereits im Juni die EZB (2010a) ein entsprechendes Maßnahmenpapier zur Krisenbewältigung vorgelegt. 
Tabelle 6: Übersicht zentraler leitbildpolitischer Dokumente aus dem Jahr 2010

\begin{tabular}{|l|c|c|}
\hline Dokument & Organ & Datum \\
\hline Verstärkung der wirtschaftspolitischen Koordinierung & Kommission & Mai 2010 \\
\hline $\begin{array}{l}\text { Stärkung der wirtschaftspolitischen Koordinierung für Stabilität, } \\
\text { Wachstum und Beschäftigung - Instrumente für bessere wirt- } \\
\text { schaftspolitische Steuerung der EU }\end{array}$ & Kommission & Juni 2010 \\
\hline Reinforcing Economic Covernance in the Euro Area & EZB & Juni 2010 \\
\hline $\begin{array}{l}\text { Abschlussbericht der Arbeitsgruppe (»Task-Force«) } \\
\text { Empfehlungen an die Kommission zur Verbesserung der Economic } \\
\begin{array}{l}\text { Governance und des Stabilitätsrahmens in der Union, vor allem im } \\
\text { Euroraum }\end{array}\end{array}$ & Parlament & Oktober 2010 \\
\hline
\end{tabular}

Quelle: Eigene Zusammenstellung

Im Lichte der leitbildpolitischen EUSA-Dokumente verdichtete sich schließlich innerhalb des EU-Staatsapparate-Ensembles ein im Kern breit geteiltes Krisennarrativ, das auf drei zentralen Problembeschreibungen beruhte. Neben fehlgeleiteter Haushaltspolitiken (Umdeutung zur Staatsschuldenkrise) werden als weitere Ursache die divergierenden Wettbewerbspositionen der Eurozonen-Volkswirtschaften beschrieben (Wettbewerbsfähigkeitsdiskurs) und es wird darauf verwiesen, dass der institutionelle Rahmen der EWWU nicht in der Lage gewesen sei, diesen Fehlentwicklungen im ausreichenden Maße zu begegnen (Governancekrise als light-Version der EWWU-Funktionskrise). Anders ausgedrückt: Grundlegende Regeln und Grundsätze seien nicht eingehalten worden, zugleich aber hätten sich die »[d]ie bestehenden Überwachungsverfahren [...] als nicht umfassend genug erwiesen.« (KOM 2010a, 2) Diese Ineffektivität der derzeitigen Governancearrangements gepaart mit »vor der Krise aufgelaufenen haushaltspolitischen und sonstigen makroökonomischen Ungleichgewichten« (ebd.) stellten somit den Nährboden der Euro-Krise dar. Am Beispiel Griechenlands führt die Kommission aus, dass »die außergewöhnliche Kombination aus laxer Haushaltspolitik, unzureichender Reaktion auf wachsende Ungleichgewichte, strukturelle Schwächen und falsche Statistikmeldungen eine noch nie dagewesene staatliche Schuldenkrise ausgelöst « (ebd., 4) habe. Hinzu käme, dass die pendellierten Zinsen sowohl für den Staats- als auch für den Privatsektor zu »Fehlallokation von Ressourcen für oftmals wenig produktive Zwecke« und »in einigen Mitgliedstaaten zu einem auf Dauer nicht tragbaren Konsumniveau« (ebd., 4) geführt habe.

Die Situation in Griechenland stellt für das Krisennarrativ der EUSA an vielen Stellen ein Schlüsselereignis dar. Auch für den deutschen Finanzminister ist Griechenland das Beispiel, an dem das grundsätzliche Reformbedürfnis sichtbar werde. In seinem Beitrag zur Task-Force heißt es:

»The crisis in Greece has brutally exposed three weaknesses in European Monetary Union. First, the Stability and Growth Pact in its current form has clearly not provided the tools we need to prevent adverse fiscal developments. Second, the existing system of economic surveillance has failed to identify and tackle structural imbalances and 
competitive weaknesses in euro area Member States. Third, it has become apparent that the Monetary Union is ill equipped to deal with the extreme scenario of sovereign liquidity and solvency crisis.« (Bundesministerium für Finanzen [BMF] 2010, 2)

Diese Problembeschreibung Schäubles ist es, die auch den Task-Force-Abschlussbericht am Ende prägen wird, der in seiner Selbstbeschreibung einen »Quantensprung im Hinblick auf eine wirksamere wirtschaftspolitische Steuerung in der EU und im EuroWährungsgebiet « (ER 2010f, Rn. 2) erreichen solle und hierzu fünf Maßnahmenpakete vorschlägt, durch die der Euro-Krise begegnet werden müsse. Diese sind überschrieben als »Wege zu mehr Finanzdisziplin«, »Ausweitung der wirtschaftspolitischen Überwachung«, »Vertiefung und Ausweitung der Koordinierung«, »solider Rahmen für das Krisenmanagement « sowie » Stärkung der Institutionen im Hinblick auf eine wirksamere wirtschaftspolitische Steuerung« (ER 2010f).

Der Maßnahmenstrang zur Finanzdisziplin weist im Bericht den größten Umfang auf. Durch die einzelnen Maßnahmen solle »[v]erstärktes Augenmerk auf die langfristige Tragfähigkeit der öffentlichen Finanzen« (ebd., 7), eine »Verbesserung der Einhaltung der Bestimmungen« (ebd., 8) und eine »Verstärkung der nationalen Haushaltsregeln und haushaltspolitischen Rahmen« (ebd., 13) sowie eine »[b]essere Qualität statistische[r] Daten« (ebd., 14) erreicht werden. Die langfristige Tragfähigkeit der öffentlichen Finanzen solle durch ein gestärktes Schuldenstandskriterium sichergestellt werden (vgl. ebd., Rn. 6-12). Hierzu solle einem Mitgliedstaat künftig im präventiven Arm des SWP bei einer Verschuldung über $60 \%$ des BIP »eine schnellere Anpassung im Hinblick auf das Erreichen der mittelfristigen Ziele vorgeschrieben werden.« (Ebd., Rn. 9) Auch bei der Einstellung eines VÜD solle das Schuldenstandskriterium künftig Beachtung finden, weshalb es nicht mehr ausreiche, lediglich das Defizit unter $3 \%$ des BIP zu senken (vgl. ebd., Rn. 10). Zur Verbesserung der SWP-Einhaltung schlägt die Task-Force »strengere Durchführungsmechanismen« (ebd., Rn. 13) vor, die insbesondere auf einem »breitere[n] Spektrum von Sanktionen und Maßnahmen, sowohl finanzieller Art als auch auf das Ansehen zielende bzw. politische Maßnahmen« (ebd., Rn. 14), basiert. Zu diesen politischen Maßnahmen zählen, dass im präventiven Arm neue Empfehlungen und Berichterstattungsanforderungen aufgenommen und der Europäische Rat notfalls bei Nichteinhaltung des SWP ins Arrangement einbezogen werden sollte (vgl. ebd., Rn. 16). Durch eine insgesamt stärkere Überwachung seitens der Kommission (inkl. sog. Überwachungsmissionen) könne - so die Task-Force - die Einhaltung ebenfalls erhöht werden (vgl. ebd.). Die »neue[n] finanzielle[n] Durchsetzungsmaßnahmen« basieren auf dem Ansatz, dass Sanktionen möglichst früher greifen sollten als im bisherigen Rahmen. So wird vorgeschlagen, dass auch im präventiven SWP-Arm Sanktionen verhängt werden sollten, »wenn ein Mitgliedstaat selbst bei einem Defizit von unter $3 \%$ erheblich von dem im SWP vorgesehen Anpassungspfad abweicht und die Abweichung nicht korrigiert.« (Ebd., Rn. 20) Hinzu kämen Verschärfungen im Sanktionsregimes des korrektiven Arms (vgl. ebd., Rn. 22) und eine stärker automatisch ablaufende "Beschlussfassung mit umgekehrter Mehrheit« (ebd., Rn. 24). Zum Ausbau nationaler Haushaltsregeln schlägt die Arbeitsgruppe vor, Mindestanforderungen zu definieren und deren Umsetzung im Rahmen der Konvergenz- und Stabilitätsprogramme zu bewerten (vgl. ebd., Rn. 27-30). 
Zur »Beseitigung der makroökonomischen Ungleichgewichte und der Unterschiede in der Wettbewerbsfähigkeit « (ebd., Rn. 33) sei nach Meinung der Task-Force ein neuer Überwachungsmechanismus erforderlich. Dieser solle auf zwei Stufen basieren. In der ersten Stufe würden jährliche Bewertungen der Reform-, Stabilitäts- und Konvergenzprogramme vorgenommen sowie ein Warnmechanismus etabliert, auf dessen Basis indikatorengestützt eine Analyse durchgeführt werden solle (vgl. ebd., Rn. 35). Diese Analysen sollen anschließend Eingang in >länderspezifische Empfehlungen finden (vgl. ebd.). Außerdem solle die Kommission die Möglichkeit erhalten, »Frühwarnungen« abzugeben (vgl. ebd., Rn. 37). Daneben sei in der zweiten Stufe ein Durchsetzungsrahmen zu etablieren, »der eine korrektive Phase« umfasse, die ausgelöst werden solle, wenn »übermäßige Ungleichgewichte« festgestellt werden (ebd.). Dieser Mechanismus solle ebenfalls mit Sanktionen ausgestattet werden (vgl. ebd., Rn. 41).

Die Vertiefung der Koordination könne nach den Vorschlägen im Rahmen des Europäischen Semesters erfolgen. Bereits in der Europe-2020-Strategie vorgesehen, solle der Semester-Zyklus »alle Elemente der makroökonomischen Überwachung abdecken, einschließlich der Maßnahmen zur Sicherstellung von Finanzdisziplin und makroökonomischer Stabilität sowie zur Wachstumsförderung im Einklang mit der Strategie Europa 2020.« (Ebd., Rn. 43) Auf dem »Weg zu einem soliden Rahmen für die Krisenbewältigungspolitik« schlägt die Task-Force mittelfristig vor, »einen glaubwürdigen Krisenbewältigungsrahmen für das Euro-Währungsgebiet zu schaffen, mit dem finanzielle Schwierigkeiten bewältigt werden können und deren Übergreifen verhindert werden kann.« (Ebd., 48) Dieser Rahmen ist als eine Fortführung und Weiterentwicklung des EFSM und der EFSF gedacht, die bereits zum Zeitpunkt des Berichts implementiert waren.

Schließlich empfiehlt die Arbeitsgruppe zur institutionellen Stärkung der EWWU auf Ebene der Mitgliedstaaten »die Nutzung oder Einrichtung öffentlicher Institutionen oder Gremien, die unabhängige Analysen, Bewertungen und Prognosen zur innerstaatlichen Haushaltspolitik erstellen « (ebd., Rn. 53), und auf suprastaatlicher Ebene die Stärkung der Kommission in Bezug auf ihre »Rolle und [...] Unabhängigkeit [...] im Bereich der haushalts- und wirtschaftspolitischen Steuerung« (ebd., Rn. 54).

Insgesamt und im Vergleich zu späteren Berichten, Mitteilungen oder Weißbüchern wird deutlich, dass der Abschlussbericht der Task-Force noch stark im bis dato bestehenden Rahmen der EWWU verbleibt. »[A]lle Empfehlungen der Arbeitsgruppe« zielen letztlich darauf, »sämtliche Möglichkeiten, die das Sekundärrecht der EU innerhalb des bestehenden Rechtsrahmens der Union bietet, so umfassend wie möglich zu nutzen.« (Ebd., Rn. 4) Hierbei werde bereits die Billigung des Berichts durch den Europäischen Rat »Zu einer Stärkung der wirtschaftspolitischen Steuerung in der EU und im Euro-Währungsgebiet beitragen« (ebd., Rn. 55), so die Arbeitsgruppe. Er werde demnach einen »notwendigen Impuls für eine Vertiefung der Wirtschafts- als auch der Währungsunion geben.« (Ebd.) In der Gesamtschau weist der Task-Force-Bericht hierbei allerdings eher auf einen krisengetriebenen Ad-hoc-Vertiefungsmodus hin, der sich »angesichts der Dringlichkeit« (ebd., Rn. 4) insbesondere am Status quo orientiert und nur an wenigen Stellen über einen solchen Krisenbearbeitungsmodus hinausweist. Nicht zuletzt findet sich - im Unterschied zu späteren Papieren - an keiner Stelle das 
Wort »Vollendung« (oder ein Komplementärbegriff), vielmehr benennt der Bericht einzelne Maßnahmen zur >Verbesserung` des Bestehenden (vgl. ebd., Rn. 55).

Bevor die Task-Force dem Europäischen Rat seinen Abschlussbericht vorlegte, präsentierte zuvor bereits die Kommission in einer Mitteilung ein von ihr als »Dreisäulenkonzept«(KOM 2010a, 3) bezeichnetes Maßnahmenpaket. Die Ausführungen der Kommission zum »Dreisäulenkonzept « (s. Tabelle 7) und jenen des Task-Force-Berichts weisen dabei insgesamt deutlich sichtbare Parallelen auf und orientieren sich an den zentralen Schlagwörtern der >Haushaltsdisziplin<, >Wettbewerbsfähigkeit<, >Überwachung und >Koordinierung/Steuerung/Governance (kurz: des Regierens). Sowohl der TaskForce-Bericht als auch die Kommissionsmitteilungen werden schließlich die konkrete Reformagenda der Bewältigungspolitik maßgeblich prägen, der sich im Grundsatz auch die EZB und das Parlament anschließen werden, deren Problembeschreibungen an einigen Stellen aber über jene der Kommission und der Task-Force hinausweisen.

\section{Tabelle 7: »Dreisäulenkonzept« der Europäischen Kommission}

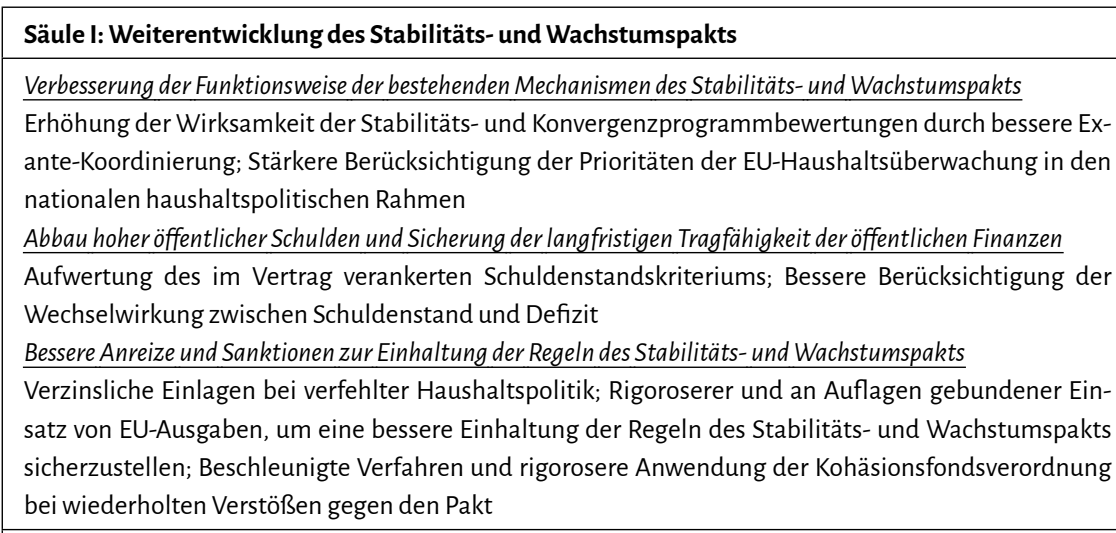

\section{Säule II: Überwachungsmechanismen}

Stärkung und Ausweitung der Überwachung makroökonomischer Entwicklungen im Euroraum

Basierend auf Europa 2020 Schaffung eines Rahmens für eine verstärkte und erweiterte makroökonomische Überwachung von Mitgliedstaaten des Euroraums auf der Grundlage einer Verordnung nach Artikel 136 AEUV; Entwicklung eines Anzeigers von Indikatoren zur Festlegung von Alarmschwellen für starke Ungleichgewichte; Formulierung länderspezifischer Empfehlungen; Rückgriff auf formale Rechtsakte des Rates mit Abstimmung in der Euroraum-Konfiguration

\section{Säule III: Europäisches Semester}

Ein»Europäisches Semester « für eine besser integrierte Ex-ante-Koordinierung der Haushaltspolitik

Abstimmung der Vorlagen der SKP und NRP und der Cespräche darüber mit dem Ziel, sich einen Eindruck von der wirtschaftlichen Gesamtlage zu verschaffen und die zeitliche Abstimmung mit den nationalen Haushaltszyklen zu verbessern; Cewährleistung wirksamer und rechtzeitiger politischer Empfehlungen vom Europäischen Rat auf der Crundlage der Bewertung der Kommission; Wirksamere integrierte Überwachung unter Nutzung aller Vorteile des »Peer-Review«

Anmerkung: Die jeweiligen Zusammenfassungen in den transparenten Zellen entsprechen dem Wortlaut der Kommissionsmitteilung.

Quelle: KOM 2010a 
Mit dem Beschluss ihres Papiers zur EWWU-Reform legte die Zentralbank nach eigenen Aussagen in Abgrenzungen zu den Kommissionsmitteilungen »a more ambitious approach « (EZB 2010a, 4) vor, der sich allerdings innerhalb der Task-Force nicht durchsetzen konnte. Dies führte dazu, dass sich EZB-Präsident Trichet nicht allen Teilen des Task-Force-Berichts anschließen mochte, was offiziell Eingang in den Bericht fand (vgl. ER 2010f, 24). An anderer Stelle heißt es: »Der EZB-Rat ist [...] der Ansicht, dass der Bericht der Arbeitsgruppe [...] nicht den Quantensprung für das Euro-Währungsgebiet darstellt, den der EZB-Rat gefordert hat.« (EZB 2011a, 2) Die >Hardliner*innen Zentralbank wichen in einigen Punkten entschieden von den Positionen der Vertreter*innen im (Europäischen) Rat und der Kommission ab. Die Perspektive der EZB generiert sich hierbei aus ihrer institutionellen Unabhängigkeit, die die Zentralbank in ihren Vorschlägen auf die EWWU als Gesamtkonstrukt übertragen möchte. Unabhängigkeit als Vor- und Leitbild einer Wirtschafts- und Fiskalregierung bedeutet eine noch technokratischere EWWU, die auf unabhängiger Überwachung, kriterien- und indikatorengestützten Bewertungen sowie sanktionierenden Automatismen beruht und dabei ungestört von politischen Einflüssen agiert. Konkret wird vorgeschlagen, dass das Verfahren bei einem übermäßigen Defizit künftig automatisch in Gang gesetzt werden sollte, sobald die Referenzwerte überschritten werden, und Sanktionen ebenfalls automatisch greifen sollten, wenn die »compliance« der Mitgliedstaaten im Verfahren nicht gegeben sei (vgl. EZB 2010a, 5f.). Zudem ist der Ausbau der Sanktionsmöglichkeiten Teil des EZB-Vorschlags (vgl. ebd., 7). Begleitet werden sollten diese Maßnahmen durch erweiterte Befugnisse für Eurostat (Statistisches Amt der Europäischen Union), die die Qualität der Statistiken prüfen solle, sowie eine Stärkung der Kommission (und insbesondere des für Währungsfragen zuständigen Kommissionsmitglieds), deren Empfehlungen durch veränderte Abstimmungsregeln (umgekehrte Mehrheitserfordernisse) ebenfalls von politischer Einflussnahme durch den Rat befreit werden solle (vgl. ebd., 6). Weiterhin wird eine eigene Fiskalagentur vorgeschlagen, die nach Ansicht der EZB die fiskalpolitische Überwachung unabhängiger als Rat und Kommission gewährleisten könne (vgl. ebd., 7f.). Im Kontext makroökonomischer Ungleichgewichte präferiert die EZB ebenfalls eine ausgebaute Überwachung, die grundsätzlich nicht im Widerspruch zu den Vorschlägen der Kommission oder der Task-Force steht, dabei aber sehr viel stärker kriterial ausgestaltet wäre, indem die EZB-eigenen Indikatoren für Wettbewerbsfähigkeit in den Mittelpunkt der Überwachung gestellt würden (vgl. ebd., 9). Auch eine mechanischere Auslegung der Indikatoren nach einem Ampelsystem ist Bestandteil des EZB-Vorschlags (vgl. ebd.). In Bezug auf einen Krisenmanagementrahmen befürwortet die EZB ebenso wie die anderen Akteur*innen die Etablierung eines Mechanismus zur Unterstützung von Euro-Staaten, der im akuten Krisenfall als >Finanzunterstützung der letzten Instanz` ausgelöst werden könne (vgl. ebd., 11). Dabei ist die größte Sorge der EZB, dass ein entsprechender Mechanismus zu einem unliebsamen Verhalten führen könne: »The absolute precondition to the establishment of a crisis management institution is the need to remove the moral hazard - which is implicit in any ex ante rescue mechanism.« (Ebd., 11) Entsprechend plädiert die EZB für >restriktive und sstarke Konditionalitäten` als Bedingung für die Gewährung finanzieller Unterstützung (vgl. ebd., 11f.). Untermauert werden solle dies nach Meinung der Zentralbanker*innen durch die Möglichkeit, Sanktionen zu verhängen, wenn eine Nichteinhaltung 
der Konditionalitäten attestiert werde. Die Bandbreite der vorgeschlagenen Sanktionsmaßnahmen reicht von einer verstärkten Revision seitens der Kommission, der EZB und der Euro-Gruppe über die Aussetzung von Mittelflüssen aus den Strukturfonds oder von Stimmrechten im Rat bis zur Einsetzung eines sogenannten »Enforcement Officers« (ebd., 13), der notfalls durch die Eurogruppe ernannt werden und mit einem Verlust der fiskalischen Souveränität des betroffenen Mitgliedstaats einhergehen sollte. Die EZB offenbart mit letztgenanntem Vorschlag sehr eindrücklich, wie weit sie zu gehen bereit wäre, indem sie politische Institutionen in ihren Rechten zu beschneiden versucht. De facto bedeutet der Vorschlag nichts anderes als die Aussetzung der Demokratie im betreffenden Euro-Staat. Zwar kennt der spätere Vertrag zur Etablierung des permanenten Rettungsschirms keine eigenen Sanktionsartikel oder gar explizit die Rolle eines »Enforcement Officers«, dennoch übernimmt die sogenannte Troika in Ansätzen genau eine solche Funktion (ausführlich s.u.).

Im Gegensatz zur EZB klingen die Vorschläge des Europäischen Parlamentes wohlwollender und weniger ideologisch aufgeladen. Zwar teilt auch das EP die Sichtweise, nach der »die derzeitigen Regeln des Stabilitäts- und Wachstumspakts [...] begleitet von einer mangelnden Anwendung nicht ausgereicht haben, um eine solide Finanzpolitik und eine breiter angelegte makroökonomische Politik zu gewährleisten « (EP 2010c, Rn. Q; vgl. auch EP 2010e), zugleich übt die große Mehrheit der Abgeordneten ${ }^{2}$ aber auch Kritik an einer zu strikten fiskalpolitischen Fokussierung zur Bewältigung der Euro-Krise. So stelle es für überschuldete Staaten zwar eine Notwendigkeit dar, ihre öffentlichen Finanzen wieder in ein Gleichgewicht zu bringen, jedoch reiche dies nicht aus, um die Probleme wirtschaftlicher Ungleichgewichte zwischen den Eurostaaten zu lösen (vgl. EP 2010c, Rn. R). Insgesamt spiegelt sich in der Entschließung ein überfraktioneller Kompromiss wider, der zwar auf der Forderung einer strikten Einhaltung der mittelfristigen Haushaltsziele des SWP aufbaut (vgl. ebd., Rn. X), zugleich aber darauf hinweist, dass die SWP-Ziele mit Verpflichtungen in Bezug auf die Ausgabenziele für Forschung und Entwicklung, Umwelt, Bildung und die Armutsbeseitigung vereinbar sein müssten (vgl. ebd., Rn. AT). Dies lässt sich als Warnung vor einer rein austeritären Krisenbewältigungspolitik verstehen. In diesem Zusammenhang antizipiert das Parlament bereits, »dass die Haushaltskonsolidierung wahrscheinlich zum Nachteil der öffentlichen Dienstleistungen und des sozialen Schutzes« (ebd., Rn. V) erfolgen werde. Auch die Vermeidung einer prozyklischen Haushaltspolitik (vgl. ebd., Anlage, Empfehlung 2) wird in der Entschließung betont, weshalb nicht zuletzt »der Prozess des Abbaus langfristiger Defizite mit anderen, die Wirtschaft stimulierenden Anstrengungen kombiniert werden muss« (ebd., Rn. AB). Neben diesen allgemeinen Verortungen enthält die Entschließung acht politikfeldspezifische Empfehlungen mit jeweils sehr umfangreichen Maßnahmenpaketen (vgl. ebd., Anlage). Das Parlament greift in diesen viele Aspekte auf, die auch in den Kommissionsmitteilungen und dem Task-Force-Bericht enthalten sind, weist aber an vielen Stellen auch über diese hinaus. So präsentierte das

2 Insgesamt stimmten 468 Abgeordnete für die Entschließung, 61 waren dagegen und 45 enthielten sich der Stimme: Die Fraktionen ALDE, EFD, PPE, S\&D sowie die Grünen stimmten mehrheitlich (S\&D gar einstimmig) für die Entschließung. Lediglich die Fraktion GUE/NGL lehnte die Entschließung einstimmig ab (vgl. EP 2010b, 198f.). 
Parlament in seinen Empfehlungen von 2010 bereits die Idee eines Europäischen Währungsfonds (EWF) (vgl. ebd.), die erst im Jahr 2017 Eingang in das sogenannte Nikolauspaket der Kommission finden sollte. Ähnlich gestaltet es sich mit der angemahnten Euro-Außenvertretung (vgl. ebd.), die erst 2015 in einem Legislativvorschlag aufgegriffen wurde.

Dem Grundsatz nach verbleibt dennoch auch die Krisenanalyse des Europäischen Parlaments im Rahmen des von der Task-Force und der Kommission präsentierten Narratives, auch wenn das EP partiell über dieses hinausgeht und ein tiefergehendes Krisenverständnis andeutet. Dies ist sicherlich dem Kompromisscharakter der Entschließung geschuldet, der im Laufe der Euro-Krise auch an anderer Stelle zu Tage tritt. Die groß-Große Koalition im Parlament des Jahres 2010 stand somit jedenfalls am Ausgangspunkt der anstehenden Reformvorhaben zusammen, was sich allerdings im Kontext der konkreten Gesetzgebungsverfahren noch ändern sollte.

\section{Die Reformagenda des reaktiven EU-Staatlichkeitsausbaus im Überblick}

Bereits vor dem finalen Beschluss des Task-Force-Berichtes durch den Europäischen Rat legte die Kommission auf Grundlage ihrer Mitteilungen im September 2010 ein Bündel von sechs Legislativvorschlägen (vgl. KOM 2010d-i) vor, die später als Six-Pack bezeichnet wurden. Das sekundärrechtliche Reformpaket adressiert zwei inhaltliche Kernanliegen. Einerseits wird mit ihm die Reform des Stabilitäts- und Wachstumspakts angestrebt (vgl. KOM 2010d-f \& 2010h), andererseits wird in Anlehnung an die fiskalpolitische Überwachung des SWP ein im Grundsatz ähnliches Verfahren bei makroökonomischen Ungleichgewichten vorgeschlagen (vgl. KOM 2010 \& $\& 2010 \mathrm{i}$ ). Zielsetzung der Reformen sei die Schaffung eines »verbesserte[n] Rahmens für die wirtschaftspolitische Steuerung«, der sich

»auf mehrere miteinander verknüpfte und ineinandergreifende Politiken für nachhaltiges Wachstum und Beschäftigung stützen [sollte], insbesondere eine Unionsstrategie für Wachstum und Beschäftigung, wobei besonderer Wert auf den Ausbau und die Stärkung des Binnenmarktes, die Förderung des internationalen Handels und der Wettbewerbsfähigkeit, ein Europäisches Semester für die verstärkte Koordinierung der Wirtschafts- und Haushaltspolitik, einen wirksamen Rahmen zur Vermeidung und Korrektur übermäßiger Staatsdefizite (Stabilitäts- und Wachstumspakt), einen soliden Rahmen zur Vermeidung und Korrektur makroökonomischer Ungleichgewichte, Mindestanforderungen an die nationalen Haushaltsrahmen sowie eine Regulierung und Überwachung der Finanzmärkte einschließlich der Aufsicht auf Makroebene durch den Europäischen Ausschuss für Systemrisiken zu legen ist. « (Erw. 4 VO (EU) Nr. 1173/2011; Erw. 9 VO (EU) Nr. 1175/2011; Erw. 4 VO (EU) Nr. 1176/2011; vgl. Erw. 1 VO (EU) Nr. 1174/2011; Erw. 6 VO (EU) Nr. 1177/2011)

Die finale Beschlussfassung über die Six-Pack-Reformen erfolgte schließlich nach zähen Verhandlungen zwischen Kommission, Rat und Parlament im November 2011: 
Tabelle 8: Gesetzgebungsakte des Six-Packs

\begin{tabular}{|l|c|c|}
\hline Dokument & Organ & Beschluss \\
\hline $\begin{array}{l}\text { Verordnung (EU) Nr.1173/2011 überdie wirksame Durchsetzung der } \\
\text { haushaltspolitischen Überwachung im Euro-Währungsgebiet }\end{array}$ & $\begin{array}{c}\text { Parlament \& } \\
\text { Rat der EU }\end{array}$ & November 2011 \\
\hline $\begin{array}{l}\text { Verordnung (EU) Nr. 1174/2011 über Durchsetzungsmaßnahmen } \\
\text { zur Korrektur übermäßiger makroökonomischer Ungleichgewichte } \\
\text { im Euro-Währungsgebiet }\end{array}$ & $\begin{array}{c}\text { Parlament \& } \\
\text { Rat der EU }\end{array}$ & November 2011 \\
\hline $\begin{array}{l}\text { Verordnung (EU) Nr. 1175/2011 über den Ausbau der haushaltspoli- } \\
\text { tischen Überwachung und der Überwachung und Koordinierung der } \\
\text { Wirtschaftspolitiken }\end{array}$ & $\begin{array}{c}\text { Parlament \& } \\
\text { Rat der EU }\end{array}$ & November 2011 \\
\hline $\begin{array}{l}\text { Verordnung (EU) Nr. 1176/2011 über die Vermeidung und Korrektur } \\
\text { makroökonomischer Ungleichgewichte }\end{array}$ & Parlament \& \\
\hline $\begin{array}{l}\text { Verordnung (EU) Nr. 1177/2011 über die Beschleunigung und Klä- } \\
\text { rung des Verfahrens bei einem übermäßigen Defizit }\end{array}$ & Ravember 2011 \\
\hline $\begin{array}{l}\text { Richtlinie 2011/85/EU über die Anforderungen an die haushaltspoli- } \\
\text { tischen Rahmen der Mitgliedstaaten }\end{array}$ & Rat der EU & November 2011 \\
\hline
\end{tabular}

Quelle: Eigene Zusammenstellung

Mit den Reformen des Six-Packs ist insgesamt ein neuer Koordinationszyklus geschaffen worden, der den SWP qualitativ fortentwickelt. Die hierdurch vollzogene Konsolidierung der in der EU-Wirtschaftsverfassung verankerten Stabilitätsunion ist eng mit dem Ausbau wirtschaftspolitischen Regierens verbunden, in dessen Rahmen künftig weiterführende makroökonomische Indikatoren in die suprastaatliche Überwachung mit einbezogen werden.

Der Vorlage der Six-Pack-Legislativvorschläge durch die Kommission im Herbst 2010 ging bereits die Beschlussfassung der Europe-2020-Strategie im ersten Halbjahr des Jahres voraus (vgl. KOM 2010c). Losgelöst von den ökonomischen und politischen Krisen seit 2007 stand der turnusgemäße Beschluss der offiziell als »Unionsstrategie für Wachstum und Beschäftigung« bezeichneten Strategie auf der Tagesordnung, die die im Jahr 2000 beschlossene Lissabon-Strategie ersetzen sollte. Mit Europe 2020 ist zugleich ein Beitrag zur Überwindung der aktuellen Krisen verbunden, indem mit ihr nicht weniger als der »Beginn einer neuen Wirtschaftsform« (ebd., 12) markiert werde, »mit der die EU in eine intelligente, nachhaltige und integrative Wirtschaft umgewandelt werden kann, die durch ein hohes Beschäftigungs- und Produktivitätsniveau sowie einen starken sozialen Zusammenhalt geprägt ist.« (Ebd.) Bereits in der Diskussion um die Europe-2020-Strategie lancierte die Kommission die Etablierung eines neuen Koordinations- und Überwachungszyklus im Rahmen des wirtschaftspolitischen Regierens, der später auch in die Mitteilungen aus dem Mai und Juni sowie den TaskForce-Bericht Eingang fand. Unter dem Dach des Europäischen Semesters sollen dabei künftig »die verschiedenen Bereiche der wirtschaftspolitischen Koordinierung zusammengeführt und die Ex-ante-Koordinierung der Wirtschaftspolitik verbessert werden.« (KOM 2010b, 13) Unter die Ex-ante-Koordinierung fällt auch der Vorschlag, nach dem ein Mitgliedstaat erst eine endgültige Haushaltsentscheidung für das jeweils folgende Jahr treffen kann, wenn »im Rahmen des `Europäischen Semesters $\triangleleft$ mit Hilfe politischer 
Leitlinien die Komplementarität der einzelstaatlichen wirtschaftspolitischen Pläne auf europäischer Ebene sichergestellt werden.«(Ebd.) Die Wirksamkeit des Verfahrens solle über eine stärker integrierte Überwachung seitens der Kommission gewährleistet werden (vgl. ebd.). Eingebettet in die Diskussion um die Reformagenda im Kontext der Krisenbewältigung stellt die Einführung des Europäischen Semesters im Herbst 2010 den Ausgangspunkt für alle weiteren Reformmaßnahmen an der vertragsbasierten Wirtschafts- und Fiskalverfassung der EU dar. Da das Semester in weiten Teilen auf der Synchronisation bereits bestehender Verfahren des Wirtschaftsregierens nach Artikel 121 AEUV beruht, sah die Kommission anfänglich auch keine Notwendigkeit, den neuen Koordinations- und Überwachungszyklus sekundärrechtlich zu verankern, was später auf Druck des Parlaments nachgeholt wurde. Die Kommission ersuchte vorerst lediglich den ECOFIN-Rat, das neue Verfahren zu genehmigen (vgl. ebd., 15). Was dieser mit der Annahme des durch den Wirtschafts- und Finanzausschuss erarbeiten "Verhaltenscodex $\aleph^{3}$ am 7. September 2010 auch tat (vgl. ECOFIN 2010b). Das Europäische Semester konnte somit bereits in 2011 zur Anwendung kommen, ohne dass die weiteren wirtschafts- und fiskalpolitischen Reformen bereits vollzogen worden wären. Die inhaltlichen Zielsetzungen der Europe-2020-Strategie wurden schließlich im Juli und Oktober in Form der sintegrierten Leitlinien< (Grundzüge der Wirtschaftspolitik \& beschäftigungspolitische Leitlinien; vgl. Art. 121 \& Art. 148 AEUV), die es bei der Formulierung der jährlichen Stabilitäts- und Konvergenzprogramme (SKP) sowie der Nationalen Reformprogramme (NRP) von den Mitgliedstaaten zu berücksichtigen gilt, final bestätigt. 
Tabelle 9: Zentrale Dokumente zur Europe-2020-Strategie

\begin{tabular}{|c|c|c|}
\hline Dokument & Organ & Datum \\
\hline Bewertung der Lissabon-Strategie & Kommission & Februar 2010 \\
\hline $\begin{array}{l}\text { EU } 2020 \text { - Nachbereitung des informellen Treffens des Europäischen } \\
\text { Rates }\end{array}$ & Parlament & Februar 2010 \\
\hline $\begin{array}{l}\text { Europa } 2020 \text { - Eine Strategie für intelligentes, nachhaltiges und inte- } \\
\text { gratives Wachstum }\end{array}$ & Kommission & März 2010 \\
\hline Schlussfolgerungen der März-Tagung 2010 & $\begin{array}{l}\text { Europäischer } \\
\text { Rat }\end{array}$ & März 2010 \\
\hline $\begin{array}{l}\text { Stärkung der wirtschaftspolitischen Koordinierung für Stabilität, } \\
\text { Wachstum und Beschäftigung-Instrumente für bessere wirtschafts- } \\
\text { politische Steuerung derEU }\end{array}$ & Kommission & Juni 2010 \\
\hline Schlussfolgerungen der Juni-Tagung 2010 & $\begin{array}{l}\text { Europäischer } \\
\text { Rat }\end{array}$ & Juni 2010 \\
\hline Empfehlung 2010/410/EU über die Grundzüge der Wirtschaftspolitik & Rat der EU & Juli 2010 \\
\hline $\begin{array}{l}\text { Beschluss 2010/707/EU über Leitlinien für beschäftigungspolitische } \\
\text { Maßnahmen der Mitgliedstaaten }\end{array}$ & Rat der EU & Oktober 2010 \\
\hline
\end{tabular}

Quelle: Eigene Zusammenstellung

Nach der Implementierung des befristeten Rettungsschirms in Form der EFSF und des EFSM (s.o.) kamen die Staats- und Regierungschefs auf Grundlage des Task-ForceBerichts (vgl. ER 2010f, 4) Ende Oktober des Jahres 2010 darin überein, »einen ständigen Krisenmechanismus zur Wahrung der Finanzstabilität des Euro-Währungsgebiets insgesamt « einzurichten und ersuchten »den Präsidenten des Europäischen Rates, mit den Mitgliedern des Europäischen Rates Konsultationen über eine begrenzte Vertragsänderung zu führen, die hierzu erforderlich sei, wobei Artikel 125 AEUV (Nichtbeistandsklausel/»no bail out«-Klausel) nicht geändert« (ER 2010d, 2) werden solle. Wurde der befristete Rettungsschirm noch mit Rückbezug auf den >Notstandsartikek 122, Absatz zwei AEUV legitimiert, bedurfte ein dauerhafter EU-Stabilitätsmechanismus einer anderen Vertragsgrundlage, die bis dato allerdings nicht vorhanden war. Mit der Schlussfolgerung des Europäischen Rates galt es daher, parallel an der vertraglichen Grundlage für einen solchen Stabilitätsmechanismus sowie seiner inhaltlichen Ausgestaltung zu arbeiten. Bereits am 28. November 2010 einigte sich die Euro-Gruppe auf die inhaltlichen Kernelemente des Europäischen Stabilitätsmechanismus (ESM), die vom Europäischen Rat auf seiner Dezember-Tagung offiziell nachvollzogen wurden (vgl. ER 2010e). Der Gründungsvertrag trat schließlich im Herbst 2012 in Kraft und der ESM nahm zum Jahresbeginn 2013 seine Arbeit auf. Der ESM umfasst ein maximales Darlehensvolumen von 700 Milliarden Euro, das Euro-Staaten im Krisenfalle in Form von konditionalisierten Krediten zur Verfügung gestellt werden kann. 
Tabelle 10: Dokumente zum Europäischen Stabilitätsmechanismus

\begin{tabular}{|l|c|c|}
\hline Dokument & Organ & Datum \\
\hline Beschluss 2011/199/EU zur Ergänzung von Art.136 AEUV & Europäischer Rat & März 2011 \\
\hline ESM-Vertrag & $\begin{array}{c}\text { Euro-Gruppe \& } \\
\text { Euro-Cipfel }\end{array}$ & September 2012 \\
\hline
\end{tabular}

Quelle: Eigene Zusammenstellung

Parallel zu den Grundsatzentscheidungen zum ESM traten im Oktober 2010 vier Verordnungen in Kraft, die noch im Kontext der transatlantischen Finanzkrise angestoßen wurden und das Europäische System der Finanzmarktaufsicht (ESFS; European System of Financial Supervision) schufen. Dieses umfasst neben drei eigenständigen Aufsichtsbehörden den sogenannten Ausschuss für Systemrisiken (ESRB; European Systemic Risk Board), angesiedelt bei der EZB. Diese ersten Schritte hin zu einer stärker integrierten Währungsunion im Bereich der Finanzaufsicht waren allerdings noch sehr zögerlich vollzogen worden, da insbesondere Deutschland und das Vereinigte Königreich gegenüber einer Europäisierung der bis dahin mitgliedstaatlichen Aufsichtsbefugnisse Bedenken hatten (vgl. Schäfer 2016).

Tabelle 11: Gesetzgebungsakte zur Etablierung der EFSF

\begin{tabular}{|l|c|c|}
\hline Dokument & Organ & Beschluss \\
\hline $\begin{array}{l}\text { Verordnung (EU) Nr. 1092/2010 über die Finanzaufsicht } \\
\text { der Europäischen Union auf Makroebene und zur Errich- } \\
\text { tung eines Europäischen Ausschusses für Systemrisiken }\end{array}$ & $\begin{array}{c}\text { Parlament \& } \\
\text { Rat der EU }\end{array}$ & November 2010 \\
\hline $\begin{array}{l}\text { Verordnung (EU) Nr.1093/2010 zur Errichtung einer Euro- } \\
\text { päischen Aufsichtsbehörde (Europäische Bankenaufsichts- } \\
\text { behörde) }\end{array}$ & Parlament \& & November 2010 \\
\hline $\begin{array}{l}\text { Verordnung (EU) Nr. 1094/2010 zur Errichtung einer Eu- } \\
\text { ropäischen Aufsichtsbehörde (Europäische Aufsichtsbehör- } \\
\text { de für das Versicherungswesen und die betriebliche Alters- } \\
\text { versorgung) }\end{array}$ & Parlament \& & Nat der EU \\
\hline $\begin{array}{l}\text { Verordnung (EU) Nr. 1095/2010 zur Errichtung einer Eu- } \\
\text { ropäischen Aufsichtsbehörde (Europäische Wertpapier-und } \\
\text { Marktaufsichtsbehörde) }\end{array}$ & Parlament \& \\
\hline
\end{tabular}

Quelle: Eigene Zusammenstellung

Neben den sekundärrechtlichen Aktivitäten zur Reform des fiskal- und wirtschaftspolitischen Regierens (Six-Pack), die von der Kommission angestoßen wurden, ließ es sich der Europäische Rat nicht nehmen, durch intergouvernementale Parallelaktionen selber in den Reformprozess einzugreifen. In einer Schlussfolgerung des Euro-Gipfels (2010b, 2) heißt es hierzu: »We consider that the European Council must improve the economic governance of the European Union and we propose to increase its role in economic coordination."(Vgl. auch ER 2010a) Erstes Produkt der Parallelaktivitäten der Staats- und Regierungschefs war der Euro-Plus-Pakt aus dem Jahre 2011, der auf der Erklärung des Euro-Gipfels vom Dezember 2010 beruhte, in der man sich unter 
anderem darauf verständigte, die fiskalpolitische Disziplin zu wahren und wachstumsfördernde Strukturreformen zu beschleunigen (vgl. ER 2010e, 11). Hierzu erarbeiteten die Staats- und Regierungschefs der Eurozone einen Maßnahmenkatalog zur stärkeren Koordinierung der Wirtschaftspolitik, den sie am 11. März 2011 als »Pakt für den Euro« finalisierten und zur Beschlussfassung an die Märztagung des Europäischen Rates weiterleiteten (vgl. Euro-Gipfel 2011a). Die Tagung des Europäischen Rates vom 24./25. März 2011 bettete den nun »Euro-Plus-Pakt « getauften Katalog des Euro-Gipfels in die weiteren Maßnahmenstränge der Krisenbewältigungspolitik ein, indem er

»die wirtschaftliche Säule der WWU weiter stärken und zu einer wirtschaftspolitischen Koordinierung von neuer Qualität führen [wird], die das Ziel hat, die Wettbewerbsfähigkeit zu verbessern und damit ein größeres Maß an Konvergenz zur Stärkung unserer sozialen Marktwirtschaft zu erreichen.«(ER 2011a, 5)

Mit dem Pakt gingen die beigetretenen Mitgliedstaaten (Eurozone plus Bulgarien, Dänemark, Lettland, Litauen, Polen und Rumänien) die Verpflichtung ein, jeweils »ein Paket konkreter Maßnahmen anzukündigen, die innerhalb der kommenden zwölf Monate durchzuführen sind « (Ebd.) und sich dabei an den Indikatoren und Grundsätzen des Euro-Plus-Paktes - insbesondere die Erhöhung der Wettbewerbsfähigkeit -zu orientieren haben.

Der Euro-Plus-Pakt ist durch seine Anlage als »Pakt« formal gesehen lediglich als Absichtserklärung zu werten, die nach Georg Feigl als eine Art der »Selbstvergewisserung ${ }^{4} \mathrm{zu}$ verstehen ist. Der Pakt kommt »als Bestandteil der Schlussfolgerungen des Europäischen Rates [am ehesten] einer Entschließung im Sinne einer Art selbst auferlegter rechtsnormativer Verpflichtungen nahe." (Weber 2013, 380) In Folge der geringen Reichweite des Pakts als »bloßes gentlemen's agreement (Obwexer 2012, 228) hatte er nur einen sehr geringen Einfluss in Bezug auf die Transformationen und den Ausbau der EU-Staatlichkeit. Wie ernst der Pakt schließlich selbst durch die Mitgliedstaaten genommen wurde, zeigt sich in einer Reihe von Schlussfolgerungen des Europäischen Rates: Auch wenn die teilnehmenden Mitgliedstaaten über 100 Einzelmaßnahmen ankündigten (ER 2011d), mussten sie sich doch mehrfach gegenseitig auffordern, bei künftigen Verpflichtungen »einen umfassenderen Geltungsbereich«, »einen konkreteren Ansatz« oder »ein ehrgeizigeres Vorgehen« (ER 2011b, 3f.) zu gewährleisten. Man sicherte sich schließlich gegenseitig zu, »im nächsten Jahr ehrgeiziger und präziser formulierte Verpflichtungen einzugehen« (ebd., 1), was allerdings ebenfalls nicht den gewünschten Erfolg zeigte (vgl. ER 2012b, 4). Retrospektiv kommt das kommissionseigene European Political Strategy Center (EPSC) deshalb 2015 auch zu dem Schluss, dass der Pakt nur eine geringe Durchsetzungskraft besaß und es ihm gegenüber an politischer Verantwortlichkeit gefehlt habe (vgl. KOM 2015j, 1).

Die Unverbindlichkeit des Euro-Plus-Paktes regte bereits im weiteren Verlauf des Jahres $2011 \mathrm{zu}$ Überlegungen an, auch »die Möglichkeit von begrenzten Vertragsänderungen zu sondieren.« (ER 2011f, 5) Insbesondere die deutsche Bundesregierung und Kanzlerin Merkel, die bereits den Euro-Plus-Pakt maßgeblich lancierte (vgl. FischerLescano \& Kommer 2011, 12), favorisierten einen solchen Schritt (vgl. Schäfer 2013, 118); 
war doch die auf Freiwilligkeit basierende Konditionalisierung á la Euro-Plus-Pakt augenscheinlich wenig erfolgreich. Der Euro-Gipfel (2011c, 10) folgte dieser Einschätzung und bekräftigte, dass der Fokus weiterhin darauf liege, die Konvergenz im Euro-Raum $\mathrm{zu}$ verbessern, die fiskalische Disziplin zu stärken und die Wirtschaftsunion zu erweitern, wobei auch die Möglichkeit >limitierter Vertragsveränderungen` sondiert werden solle. Am 6. Dezember 2011 legte der Ratspräsident ein Papier vor, in dem er »weitere bedeutsame Schritte hin zu einer wahren >Finanzunion « skizzierte, worunter er »eine erheblich engere Koordinierung der Wirtschaftspolitik und ein größeres Maß an Überwachung und Disziplin bei der Durchführung der nationalen Politik« (Van Rompuy 2012, 78) verstand. Dazu bedürfe es »weiterer Schritte in Richtung Integration hin zu einem >neuen Finanzpakt «.«(Ebd., 79) Technisch könnte dies über eine Revision des den EU-Verträgen angehängten Protokolls Nr. 12 erfolgen. Hierfür sei zwar ein einstimmiger Beschluss notwendig und das Europäische Parlament und die Zentralbank wären anzuhören, jedoch sei keine Ratifizierung auf nationaler Ebene erforderlich, was eine rasche Umsetzung ermögliche (vgl. ebd., 79). Möglich sei aber auch eine Vertragsänderung (entweder parallel oder aber später), bei der weitreichendere Änderungen möglich wären, zugleich aber ein umfangreicher Ratifizierungsprozess durchlaufen werden müsse (vgl. ebd.). Die am 9. Dezember 2011 folgende Ratstagung brachte indes nach zähen Verhandlungen keine Einigung unter den 27 Mitgliedstaaten. Eine Protokoll- oder gar Vertragsänderung scheiterte aber letztlich am Widerstand des Vereinigten Königreichs. ${ }^{5}$ In einem Statement der Staats- und Regierungschefs der Eurozone heißt es hierzu: »Considering the absence of unanimity among the EU Member States, they decided to adopt [...] an international agreement to be signed in March or at an earlier date. The objective remains to incorporate these provisions into the treaties of the Union as soon as possible« (Euro-Gipfel 2011d; Herv. J. G.). Die Verhandlungen um die genaue Ausgestaltung für den zwischenstaatlichen Vertrag, der den Titel Vertrag über Stabilität, Koordinierung und Steuerung (SKS-V) erhalten sollte, waren bis Ende Januar 2012 abgeschlossen, sodass die Unterzeichnung durch die Vertragsparteien im März erfolgen konnte (vgl. Euro-Gipfel 2012a, 1); in Kraft trat der Vertrag im Januar 2013. Neben einer stärkeren Koordinierung der mitgliedstaatlichen Wirtschaftspolitiken - in Form des Euro-Gipfels - ist der SKS-Vertrag insbesondere durch eine weitere Verschärfung fiskalpolitischer Vorschriften gekennzeichnet, die aufgrund der Sekundärrechtsakte zwar überflüssig erscheinen, partiell aber die Fiskalziele des SWP weiter verschärfen (strukturelles Defizit) und insbesondere durch die eingegangenen Verpflichtungen die auf EU-Sekundärrecht basierenden Normierungen des SWP zusätzlich durch eine Art `Schuldenbremse < beziehungsweise sautomatischen Korrekturmechanismus im mitgliedstaatlichen (Verfassungs-)Recht absichern sollen. des EU-Vertrages der 27 Mitgliedsstaaten scheiterte vor allem am Widerstand Croßbritanniens, erklärte der französische Präsident Nicolas Sarkozy nach elfstündigen Beratungen am frühen Freitagmorgen in Brüssel. Der britische Premierminister David Cameron verweigerte die Zustimmung zur EU-Vertragsänderung, weil er kein Vetorecht bei der Finanzmarktregulierung durchsetzen konnte. Dabei habe er >tollpatschig < verhandelt, sagte ein EU-Diplomat. >Nicht Europa ist gespalten, die Briten haben gespalten<, erklärte die litauische Präsidentin Dalia Grybauskaite. Cameron sagte dagegen, Großbritannien verliere nun nicht an Einfluss in der EU.« (EURACTIV, 09.12.2011) 
Tabelle 12: Parallele Krisenbewältigungsmaßnahmen des Europäischen Rates

\begin{tabular}{|l|c|c|}
\hline Dokument & Organ & Datum \\
\hline Euro-Plus-Pakt & $\begin{array}{c}\text { Europäischer } \\
\text { Rat }\end{array}$ & März 2011 \\
\hline $\begin{array}{l}\text { Vertrag über Stabilität, Koordinierung und Steuerung in der } \\
\text { Wirtschafts- und Währungsunion (SKS-Vertrag) }\end{array}$ & $\begin{array}{c}\text { Europäischer } \\
\text { Rat }\end{array}$ & März 2012 \\
\hline
\end{tabular}

Quelle: Eigene Zusammenstellung

»Obwohl die rasche und genaue Durchführung der `Sixpack«-Vorschläge ein ehrgeiziges Unterfangen ist, müssen wir noch weiter gehen«, schreibt die Kommission (2011b, 7) in einer Mitteilung im Oktober 2011 parallel zu den einsetzenden Diskussionen um den SKS-Vertrag. Einen Monat nach dieser Ankündigung und zeitgleich zu den letzten Abstimmungsrunden im Gesetzgebungsverfahren für das Six-Pack unterbreitete die Kommission daher zwei weitere Verordnungsvorschläge zum Ausbau des fiskal- und wirtschaftspolitischen Regierens im Euro-Raum (KOM 2011d; KOM 2011e), die später als »second economic governance package « oder kurz Two-Pack bezeichnet wurden. Bereits am 30. November führte der Rat hierzu einen ersten Gedankenaustausch (vgl. ECOFIN 2011d, 6). Dennoch bedurftet es über anderthalbjähriger Verhandlungen bevor das Paket im Mai 2013 von Rat und Parlament final beschlossen werden konnte. Beide Verordnungen zielen ausschließlich auf die Länder der Eurozone. Die Verordnung (EU) Nr. 473/2013 stellt eine weitere Ergänzung des SWP um Bestimmungen zur Überwachung und Bewertung der mitgliedstaatlichen Haushaltsplanungen und der Korrektur übermäßiger Defizite dar, wohingegen die Verordnung (EU) Nr. 472/2013 insbesondere den Ausbau wirtschafts- und haushaltspolitischer Überwachung jener Mitgliedstaaten zum Ziel hat, die von gravierenden finanziellen Schwierigkeiten betroffen oder bedroht sind. Letztere Verordnung setzt sowohl am SWP als auch am Verfahren bei makroökonomischen Ungleichgewichten an, weist aber über sie hinaus und deutet durch die Bezugnahme auf den außerunionsvertraglichen ESM einen gewissen Wendepunkt in der bis dato reaktiven Krisenbewältigungspolitik an, indem Verbindungslinien zwischen diesem und dem Unionsrecht geschaffen werden.

Tabelle 13: Gesetzgebungsakte des Two-Packs

\begin{tabular}{|l|c|c|}
\hline Dokument & Organ & Beschluss \\
\hline $\begin{array}{l}\text { Verordnung (EU) Nr. 472/2013 über den Ausbau der wirtschafts- } \\
\text { und haushaltspolitischen Überwachung von Mitgliedstaaten im } \\
\text { Euro-Währungsgebiet, die von gravierenden Schwierigkeiten in Be- } \\
\text { zug aufihre finanzielle Stabilität betroffen oder bedroht sind }\end{array}$ & $\begin{array}{c}\text { Parlament \& } \\
\text { Rat der EU }\end{array}$ & \\
\hline $\begin{array}{l}\text { Verordnung (EU) Nr. 473/2013 über gemeinsame Bestimmungen } \\
\text { für die Überwachung und Bewertung der Übersichten über die } \\
\text { Haushaltsplanung und fürdie Cewährleistung der Korrektur über- } \\
\text { mäßigerDefizite der Mitgliedstaaten im Euro-Währungsgebiet }\end{array}$ & Parlament \& & Mai der EU 2013 \\
\hline
\end{tabular}

Quelle: Eigene Zusammenstellung 
Trotz der bis dato bereits getroffenen beziehungsweise angekündigten Maßnahmen zur Bewältigung der Euro-Krise begann das Jahr 2012 mit einer erneuten Krisenzuspitzung. Nachdem nach Griechenland auch Irland (2010) und Portugal (2011) Hilfskredite erhielten, war Griechenland im Frühjahr 2012 auf ein weiteres Hilfspaket angewiesen; es folgte ein Hilfspaket zur Refinanzierung des Bankensektors in Spanien und auch Zypern stellte im Frühsommer 2012 offiziell einen Antrag auf Hilfskredite, der schließlich 2013 durch den ESM bewilligt wurde. In der sich zuspitzenden Gemengelage war es schließlich im Sommer 2012 EZB-Präsident Draghi, der mit seiner »whatever it takes«Rede für eine nachhaltige Beruhigung auf den Märkten für Staatsschuldentitel sorgte. In seiner Rede kündigte er nicht weniger an, als notfalls unbegrenzt staatliche Schuldtitel von Euro-Staaten auf dem Sekundärmarkt aufzukaufen, um den Euro zu retten (vgl. Draghi 2012). Dieser Ankündigung folgte im September 2012 offiziell das »Outright Monetary Transactions«-Programm (OMT) der EZB. Anders als noch 2010, als die EZB mit dem Securities Markets Programme (SMP) ebenfalls in den Sekundärmarkt interveniert hatte, unterliegt das OMT-Programm allerdings keiner Limitierung und konnte so zur maßgeblichen Abschwächung der Krisensymptome (Refinanzierungszinsen der Krisenstaaten) beitragen.

Tabelle 14: Unkonventionelle Krisenbewältigungsmaßnahmen der EZB

\begin{tabular}{|l|c|}
\hline Maßnahme & Datum \\
\hline Securities Markets Programme (SMP) & Mai 2010 \\
\hline Outright Monetary Transactions Programme (OMT) & September 2012 \\
\hline
\end{tabular}

Quelle: Eigene Zusammenstellung

Diese beiden Programme im Rahmen einer unkonventionellen Geldpolitik, die nicht unkritisiert blieben (Verdacht der monetären Staatsfinanzierung), lancierte die EZB im Rahmen ihrer Offenmarktpolitik durch sogenannte längerfristige Refinanzierungsgeschäfte (LTRO; Longer-Term-Refinancing-Operations), die insbesondere einen Beitrag zur Rekapitalisierung angeschlagener Banken im Euroraum leisten sollten (vgl. EZB 2011d). Weiterhin verfügt das Eurosystem (EZB plus die mitgliedstaatlichen Zentralbanken) mit den sogenannten Notfall-Liquiditätshilfen (ELA; Emergency Liquidity Assistance) über ein Instrument, mit dem auf akute Liquiditätsengpässe von Finanzinstituten reagiert werden kann. Obwohl die Durchführung entsprechender Hilfsaktionen zwar den mitgliedstaatlichen Zentralbanken obliegt, gilt schließlich ein Koordinierungsgebot durch die EZB. Ab einer bestimmten Höhe bedarf es sogar der expliziten Zustimmung durch die EZB-Gremien (vgl. EZB 2017). ELA sind im Laufe der Banken- und der anschließenden Euro-Krise häufig zur Anwendung gebracht worden, weshalb sie nicht zuletzt auch ein wichtiges Druckmittel der EZB gegenüber den Mitgliedstaaten darstellen. Bekannt ist, dass die EZB sowohl auf Irland als auch auf Griechenland politisch einwirkt hatte, indem angedroht wurde keine ELAs mehr zu genehmigen. Die ELAs können somit zwar einerseits krisenlindernd, andererseits - wenn gewollt - aber auch krisenverschärfend wirken.

Mit den Krisenzuspitzungen in Spanien und Zypern geriet im Laufe des Jahres 2012 die europäische Bankenkrise der Jahre 2007/2008 wieder stärker zurück ins Bewusst- 
sein. Als Bindeglied zwischen den krisenbedingten Zentralbankaktivitäten, der Diskussionen um die (Re-)Regulierung der Finanzmärkte und Bemühungen zur Abmilderung des häufig als `Teufelskreis` beschriebenen systemischen Zusammenhang zwischen Staaten und Banken ${ }^{6}$ wurden deshalb weitere Maßnahmen zum Aufbau einer Bankenunion lanciert. Im September 2012 legte die Kommission (2012i) hierzu einen »Fahrplan« vor, mit dem sie zugleich legislative Vorschläge zum Aufbau einer einheitlichen Bankenaufsicht (SSM; Single Supervisory Mechanism) unterbreitete (vgl. KOM 2012j \& 2012k), die schließlich im Oktober 2013 final beschlossen wurden. Kernbestandteil des SSM stellt die Übertragung der Makroaufsicht über Banken in der EU auf die EZB dar. Auch der sogenannte Vier-Präsidenten-Bericht, der dem Europäischen Rat im Dezember 2012 durch Ratspräsident Van Rompuy vorgelegt wurde (ER 2012a), forderte im Einklang mit dem Kommissions-Fahrplan einen »integrierten Finanzrahmen«, der neben einem einheitlichen Aufsichts- auch einen einheitlichen Abwicklungsmechanismus für Banken und Finanzinstitute umfassen sollte (vgl. Van Rompuy et al. 2012, 5ff.). Die legislativen Vorschläge zum einheitlichen Abwicklungsmechanismus (SRM; Single Resolution Mechanism), der auch einen Abwicklungsfonds (SRF; Single Resolution Fund) für Banken vorsah, legte die Kommission im Laufe des Jahres 2013 vor; 2014 wurden sie beschlossen, auch wenn der Abwicklungsmechanismus und -fonds bis heute ihre Arbeit noch nicht vollumfänglich aufgenommen haben.

Tabelle 15: Gesetzgebungsakte zur Bankenunion

\begin{tabular}{|l|c|c|}
\hline Dokument & Organ & Beschluss \\
\hline $\begin{array}{l}\text { Verordnung (EU) Nr.1022/2013 zur Änderung der Verordnung (EU) } \\
\text { Nr.1093/2011 zur Einrichtung einer Europäischen Aufsichtsbehör- } \\
\text { de (Europäische Bankenaufsichtsbehörde) hinsichtlich der Übertra- } \\
\text { gung besonderer Aufgaben aufdie Europäische Zentralbankgemäß } \\
\text { der Verordnung (EU) Nr.1024/2013 }\end{array}$ & $\begin{array}{c}\text { Parlament \& } \\
\text { Rat der EU }\end{array}$ & Oktober 2013 \\
\hline $\begin{array}{l}\text { Verordnung (EU) Nr. 1024/2013 zur Übertragung besonderer Auf- } \\
\text { gaben im Zusammenhang mit der Aufsicht über Kreditinstitute auf } \\
\text { die Europäische Zentralbank }\end{array}$ & Rat der EU & Oktober 2013 \\
\hline $\begin{array}{l}\text { Richtlinie 2014/49/EU über Einlagensicherungssysteme (»Einlagen- } \\
\text { sicherungsrichtlinie«) }\end{array}$ & Parlament \& & April 2014 \\
\hline $\begin{array}{l}\text { Richtlinie 2014/59/EU zur Festlegung eines Rahmens für die Sanie- } \\
\text { rung und Abwicklung von Kreditinstituten und Wertpapierfirmen } \\
\text { (»Abwicklungsrichtlinie«) }\end{array}$ & Parlament \& \\
\hline $\begin{array}{l}\text { Verordnung (EU) Nr. 806/2014 zur Festlegung einheitlicher Vor- } \\
\text { schriften und eines einheitlichen Verfahrens für die Abwicklung von } \\
\text { Kreditinstituten und bestimmten Wertpapierfirmen im Rahmen ei- } \\
\text { nes einheitlichen Abwicklungsmechanismus und eines einheitlichen } \\
\text { Abwicklungsfonds }\end{array}$ & Parlament \& \\
Rat der EU & Mai 2014 \\
\hline Juli 2014 \\
\end{tabular}

Quelle: Eigene Zusammenstellung

6 Der auch als Staaten-Banken-Nexus bekannte Teufelskreis »beschreibt die enge Wechselwirkung zwischen der wirtschaftlichen Stabilität von Staaten sowie der Liquidität und Solvenz von Banken. [...] Beim >Staaten-Banken-Nexus handelt es sich [...] um einen Risikoverbund zwischen Staaten und Banken mit selbstverstärkender Wirkung.«(Waschbusch 2020) 
Ergänzt werden diese institutionellen Bausteine um ein umfassendes Regelwerk für den Finanz- und Bankensektor, das zum Teil bereits auf während der transatlantischen Finanzmarktkrise in der G20 vereinbarten (Re-)Regulierungsbemühungen (Stichwort: Basel III) basierte (vgl. KOM 2010m). Gerade aufgrund der Fülle an detaillierten Regulierungen - zusammengenommen als Single Rulebook bezeichnet - soll die Bankenunion lediglich in der angekündigten limitierten Betrachtungsweise Gegenstand dieser Arbeit sein. Auch wenn die Aufstellung eines einheitlichen Regelwerks zusammengenommen bereits ein weithin sichtbarer Akt des EU-Staatlichkeitsausbaus im Sinne der Durchsetzung einer einheitlichen Sichtweise (Monopolisierung) darstellt, kann es in dieser Arbeit nicht geleistet werden, die Bankenunion in voller Gänze einzubeziehen. Einzelne Aspekte werden aber nachrichtlich dargestellt, wenn sie besondere Verbindungslinien zu den zuvor skizzierten Reformmaßnahmen aufweisen.

Tabelle 16: Gesetzgebungsakte zur Umsetzung von >Basel IIK

\begin{tabular}{|l|c|c|}
\hline Dokument & Organ & Beschluss \\
\hline $\begin{array}{l}\text { Verordnung (EU) Nr.575/2013 über Aufsichtsanforderungen an Kre- } \\
\text { ditinstitute und Wertpapierfirmen }\end{array}$ & $\begin{array}{c}\text { Parlament \& } \\
\text { Rat der EU }\end{array}$ & Juni 2013 \\
\hline $\begin{array}{l}\text { Richtlinie 2013/36/EU über den Zugang zur Tätigkeit von Kreditin- } \\
\text { stituten und die Beaufsichtigung von Kreditinstituten und Wertpa- } \\
\text { pierfirmen (»Eigenkapitalrichtlinie«) }\end{array}$ & $\begin{array}{c}\text { Parlament \& } \\
\text { Rat der EU }\end{array}$ & Juni 2013 \\
\hline
\end{tabular}

Quelle: Eigene Zusammenstellung

\section{Drei Konstitutionalisierungsprozesse des reaktiven EU-Staatlichkeitsausbaus}

Auf Grundlage der an dieser Stelle nur einführend skizzierten Reformmaßnahmen lassen sich drei Konstitutionalisierungsprozesse des reaktiven Staatlichkeitsausbaus beschreiben, die es im Folgenden genauer zu analysieren und darzustellen gilt. Hierbei wird durch die Etablierung des auf Dauer gestellten ESM sowie seiner flankierenden Maßnahmen - erstens - eine außerunionsvertragliche Notstandsverfassung der Eurozone etabliert, auf die auch in künftigen Krisensituationen zurückgegriffen werden kann. Geprägt ist diese durch ein autoritär-intergouvernementales Staatlichkeitsarrangement, das aufgrund seiner außerunionsvertraglichen Grundlage der eigentlichen EUStaatlichkeit vorgelagert scheint und demnach den politischen Prozessen innerhalb der formalen EUSA-Strukturen partiell entzogen wird, auch wenn sich innerhalb des Arrangements einzelner EUSA funktional als »Hilfsagenturen« bedient wird.

Weiterhin ist - zweitens - mit der Krisenbewältigungspolitik die Fortentwicklung der vertragsbasierten EU-Wirtschafts- und Fiskalverfassung verbunden, die sich auf Grundlage der EU-Verträge verortet. Die neue Qualität des vertragsbasierten fiskal- und wirtschaftspolitischen Regierens wird teilweise durch mitgliedstaatliches (Verfassungs-)Recht abzusichern versucht (SKS-Vertrag). Ein Ergebnis der Fortentwicklung der Wirtschafts- und Fiskalverfassung stellt die gestärkte Stellung der Kommission im EU-Staatsapparate-Ensemble dar, die immer stärker die zentrale Rolle innerhalb der Europäischen Wirtschaftsregierung einnimmt. Dabei orientiert sich der Ausbau wirtschafts- und fiskalpolitischer Staatlichkeitsmodi einerseits am Leitbild der konso- 
lidierten Stabilitätsunion, die andererseits einen leitbildlichen Komplementär in Form einer erweiterten Überwachungsunion erhält.

Schließlich stellt - drittens - eine weitere Komponente des reaktiven Staatlichkeitsausbaus die Etablierung einer (impliziten) Finanzstabilisierungsverfassung dar, in deren Mittelpunkt die Europäische Zentralbank steht. Neben der legislativbasierten Kompetenzaufwertung der EZB im Rahmen ihrer neuen Aufsichtsfunktionen für den Finanzmarkt muss im Rahmen dieser neuen Verfassungskomponente schließlich insgesamt die neue Rolle der EZB einer Bewertung unterzogen werden. So zeigt sich an unterschiedlichen Stellen der Krisenbewältigungspolitik ebenso wie in den politischen Prozessen $\mathrm{zu}$ ihrer Implementierung, dass die EZB - weitestgehend - im Verborgenem ihre Stellung innerhalb des EU-Staatsapparate-Ensembles ausbauen konnte und mittlerweile nicht nur bewiesen hat, dass sie die Rolle als Lender of Last Resort (LOLR) bereit ist anzunehmen, sondern zugleich als zusätzlicher Repressionsapparat gegenüber Mitgliedstaaten agiert.

\title{
7.2 Implementierung einer außerunionsvertraglichen Notstandsverfassung
}

Im EWWU-Notstandsartikel 122 des AEUV heißt es im Absatz 2:

\begin{abstract}
»Ist ein Mitgliedstaat aufgrund von Naturkatastrophen oder außergewöhnlichen Ereignissen, die sich seiner Kontrolle entziehen, von Schwierigkeiten betroffen oder von gravierenden Schwierigkeiten ernstlich bedroht, so kann der Rat auf Vorschlag der Kommission beschließen, dem betreffenden Mitgliedstaat unter bestimmten Bedingungen einen finanziellen Beistand der Union zu gewähren. Der Präsident des Rates unterrichtet das Europäische Parlament über den Beschluss. «(Herv. J. G.)
\end{abstract}

Auf dieser vertraglichen Grundlage basierten die ersten Maßnahmen zur Abmilderung der akuten Refinanzierungskrise in Form der Euro-Rettungsschirme EFSF und EFSM (vgl. Erw. 1 VO (EU) Nr. 407/2010). Dabei definiert die EFSM-Verordnung, dass die in Artikel 122 benannten Schwierigkeiten auch »durch eine ernsthafte Verschlechterung der internationalen Wirtschafts- und Finanzlage verursacht werden [können]« (Erw. 2 VO (EU) Nr. 407/2010), was in gewisser Weise eine erweiterte Auslegung des Vertragsartikels darstellt, der explizit lediglich auf Naturkatastrophen und sehr vage »außergewöhnliche Ereignisse« verweist. Trotz dieser weiten Auslegung des Artikels deutet er im Kern doch darauf hin, dass die Unionsverträge vor dem Hintergrund des NoBail-Out-Gebots (Art. 125 AEUV) lediglich begrenzte Möglichkeiten bieten, um EuroMitgliedstaaten >unter bestimmten Bedingungen finanziell zu unterstützen. Entsprechend waren die EUSA in ihren Rettungsschirm-Begründungen auch damit beschäftigt, die aktuell einbrechenden Ereignisse als unvorhersehbar zu qualifizieren: So habe beispielsweise die Finanzkrise $\mathrm{zu}$ »einer gravierenden Verschlechterung der Kreditkonditionen geführt, die darüber hinausgeht, was sich durch wirtschaftliche Fundamentaldaten erklären ließe« (Erw. 4 VO (EU) Nr. 407/2010; vgl. auch Erw. 3). Weiterhin seien die Mitgliedstaaten von dieser »außergewöhnlichen Situation« überrascht worden, »die sich der Kontrolle der Mitgliedstaaten entzieht.« (Erw. 5 VO (EU) Nr. 407/2010; 
vgl. auch Präambel, Abs. 2 EFSF-V) Diese Beschreibungen stehen durchaus in einem gewissen Widerspruch zur Hinwendung auf die angeblich unverhältnismäßigen Haushaltspolitiken, die häufig in den offiziellen EUSA-Dokumenten ins Zentrum der Auseinandersetzungen gerückt werden; sie verweisen aber im Kern auch auf die Herausstellung von Krisenlegitimität als Begründungszusammenhang für den Staatlichkeitsausbau im krisenbedingten Ausnahmezustand.

Dass die Limitierungen der EU-Verträge bereits im Kontext des ersten Rettungsschirms sichtbar wurden, zeigt sich letztlich auch daran, dass die stärkere der beiden Säulen außerhalb des Unionsrechts geschaffen wurde. Die EFSF als eine Zweckgesellschaft nach Luxemburger Recht steht dabei Vorbild für den später auf Dauer angelegten ESM. Sollte demnach ein dauerhafter »Krisen-Mechanismus « etabliert werden, bedurfte es der Änderung der EU-Verträge, wie schlussendlich mit der Ergänzung des Absatzes 3 des Artikels 136 AEUV auch vollzogen:

»Die Mitgliedstaaten, deren Währung der Euro ist, können einen Stabilitätsmechanismus einrichten, der aktiviert wird, wenn dies unabdingbar ist, um die Stabilität des Euro-Währungsgebiets insgesamt zu wahren. Die Gewährung aller erforderlichen Finanzhilfen im Rahmen des Mechanismus wird strengen Auflagen unterliegen.« (Art. 136, Abs. 3 AEUV)

Diese Vertragsergänzung auf Grundlage des vereinfachten Vertragsänderungsverfahrens nach Artikel 48 AEUV wurde im März 2011 vom Europäischen Rat final beschlossen (Beschluss 2011/199/EU) und machte den Weg für den ESM, als Kern der auf Dauer angelegten außerunionsvertraglichen Notstandsverfassung, frei. Die neue Notstandsverfassung basiert auf der Annahme, dass die Etablierung eines Krisenmechanismus zur »Wahrung der Finanzstabilität« unerlässlich sei (ER 2010d, 2). Die Euro-Krise verdeutlichte somit, dass es in einer Währungsunion mit einer vereinheitlichten Geldpolitik aber weiterhin eigenverantwortlicher Fiskalpolitiken in Ausnahmesituationen weiterer stabilisierender Maßnahmen bedürfe, als bis dahin vertraglich fixiert wurde. Zur Anwendung kommen solle der neue Krisenmechanismus bei einem »Risiko für die Stabilität des Euro-Währungsgebiets insgesamt« (ER 2010e, Rn. 1), wobei die Gewährung von Hilfskrediten an »äußerst strikte Auflagen« (ER 2010d, 2) geknüpft werde. Die aufgebauten ESM-Strukturen stellen in der angestammten Struktur der EWWU demnach eine »Ultima Ratio« dar, weshalb zugleich Vorkehrungen zu treffen seien, um einen »moral hazard« zu vermeiden (vgl. EZB 2011b, Rn. 2).

\section{Normierungen der außerunionsvertraglichen Notstandsverfassung}

Der ESM wird aktiviert, wenn »ernsthafte Risiken für die Finanzstabilität der Mitgliedstaaten, deren Währung der Euro ist, die Finanzstabilität des gesamten EuroWährungsgebiets gefährden« (Erw. 6 ESM-V; Herv. J. G.). Grundprinzip des ESM ist, dass er, »wie der IWF, einem ESM-Mitgliedstaat Stabilitätshilfe gewähren [wird], wenn dessen regulärer Zugang zur Finanzierung über den Markt beeinträchtigt zu werden droht.« (Erw. 16 ESM-V) Prioritäres Ziel ist »die Bekämpfung der Ansteckungsgefahren« (Erw. 3 ESM-V) zwischen den Mitgliedstaaten der Eurozone. Wobei gelten solle, dass 
»die strikte Einhaltung des Rahmens der Europäischen Union, der integrierten makroökonomischen Überwachung, insbesondere des Stabilitäts- und Wachstumspakts, des Rahmens für makroökonomische Ungleichgewicht und der Vorschriften für die wirtschaftspolitische Steuerung der Europäischen Union [...] die erste Verteidigungslinie gegen Vertrauenskrisen bleiben [sollte]« (Erw. 4 ESM-V).

Im Sinne dieses Erwägungsgrundes bleibt also der ESM auf solche Situationen beschränkt, in denen trotz des - parallel ausgebauten - EU-Fiskal- und Überwachungsrahmens (s.u.) Refinanzierungsprobleme auftreten. Er ist somit ein Instrument für Krisenzeiten und aufgrund seiner strikten Konditionalitäten zugleich eine Drohkulisse gegenüber den Mitgliedstaaten in >Normalzeiten`, mit deren Arrangements der ESM direkt verknüpft wird. So solle beispielsweise der SKS-Vertrag (ausführlich s.u.), dessen Ausarbeitung der Euro-Gipfel (2011d) vom Dezember 2011 beschlossen hatte,

»dazu beitragen, eine enge Koordinierung der Wirtschaftspolitik im Euro-Währungsgebiet zu entwickeln, um eine dauerhafte, gesunde und stabile Verwaltung der öffentlichen Finanzen zu gewährleisten und so eine der Hauptursachen der finanziellen Instabilität anzugehen. Der vorliegende [ESM-]Vertrag und der [SKS-Vertrag; ].G.] ergänzen sich gegenseitig bei der Verstärkung der haushaltspolitischen Verantwortlichkeit und der Solidarität innerhalb der Wirtschafts- und Währungsunion.« (Erw. 5 ESM-V)

Die Verknüpfung des SKS-Vertrags mit dem Stabilitätsmechanismus reicht allerdings über die bloße Beschreibungsebene hinaus. So wird vereinbart, »dass die Gewährung von Finanzhilfen im Rahmen neuer Programme durch den ESM ab dem 1. März 2013 von der Ratifizierung des [SKS-Vertrags; J. G.] durch das betreffende ESM-Mitglied abhängt« (Erw. 5 ESM-V).

Die Gewährung von ESM-Krediten kann in unterschiedlicher Weise erfolgen: Klassischerweise werden sie durch das (normale) ESM-Darlehen für Mitgliedstaaten, die sich in einer akuten Refinanzierungskrise befinden (vgl. Art. 16 ESM-V), oder einer »vorsorglichen ESM-Kreditlinie« gewährt, um den Eintritt akuter Refinanzierungskrisen zu vermeiden (vgl. Art. 14 ESM-V). Hinzu kommt, dass der ESM »Darlehen zum Zwecke der Rekapitalisierung von Finanzinstituten« vergeben kann (vgl. Art. 15 ESM-V). Ein solches Darlehen stellt ein Instrument dar, welches direkt privat akkumuliertes Ausfallrisiko, vermittelt über den entsprechenden Mitgliedstaat, sozialisiert, wie im Falle Spaniens auch während der Euro-Krise angewendet. Außerhalb dieser drei Finanzhilfeinstrumente kennt der ESM zwei weitere Formen der Hilfestellung: Die »Primärmarkt-« (Art. 17 ESM-V) und die »Sekundärmarkt-Unterstützungsfazilität« (Art. 18 ESM-V).

Als Voraussetzung für die Auszahlung von Stabilitätshilfen gilt der Abschluss eines Memorandums of Understanding. Ein Instrument, das bereits beim temporären Rettungsschirm und dem bilateralen Griechenlandpaket zur Anwendung kam. In den Memoranden werden »die Haushaltsdisziplin und wirtschafspolitischen Leitlinien der jeweiligen Staaten« (Präambel, Abs. 2 EFSF-V) geregelt. Im entsprechenden Artikel des ESM-Vertrags heißt es:

»Wird ein Beschluss [zur Cewährung von Stabilitätshilfe; ]. G.] angenommen, so überträgt der Gouverneursrat der Europäischen Kommission die Aufgabe, - im Benehmen mit der EZB und nach Möglichkeit zusammen mit dem IWF - mit dem betreffenden 
ESM-Mitglied ein Memorandum of Understanding ( $>\mathrm{MoU} \iota)$ auszuhandeln, in dem die mit der Finanzhilfefazilität verbundenen Auflagen im Einzelnen ausgeführt werden. Der Inhalt des MoU spiegelt den Schweregrad der zu behebenden Schwachpunkte und das gewählte Finanzhilfeinstrument wider.«(Art. 13, Abs. 2 ESM-V)

Äquivalent hierzu wird im Rahmen des EFSM von »wirtschaftliche[m] und finanzielle[m] Sanierungsprogramm« (Art. 3, Abs. I VO (EU) Nr. 407/2010) gesprochen. Mit den Memoranden ist somit ein neues Herrschaftsinstrument entstanden, über das einzelne EUSA bis weit in die mitgliedstaatliche Politikgestaltung Einfluss nehmen und die als weithin sichtbarer Ausdruck einer ausgebauten EU-Staatlichkeit gelten können (ausführlich s.u.).

\section{Institutionalisierungen und Verfahren der außerunionsvertraglichen Notstandsverfassung}

Der ESM wurde, wie bereits zuvor die EFSF, außerhalb des Unionsrechts in Form eines zwischenstaatlichen Vertrags der Euro-Mitgliedstaaten geschaffen. Es findet mit ihm somit eine Externalisierung von Krisenbewältigungs- und Stabilisierungsfunktionen auf Einrichtungen außerhalb des angestammten EU-Institutionengefüges statt. Dies wurde nicht zuletzt durch die EZB (2011b, Rn. 8) und das Europäische Parlament (2011a, Rn. 14; vgl. auch 2013f, Rn. 4) kritisiert, die beide einen »Mechanismus der Union« (EZB 2011b, Rn. 8) bevorzugt hätten. Allerdings lehnen sie die Implementierung eines gemeinsamen Krisenbewältigungsrahmens nicht grundsätzlich ab. So heißt es in der Entschließung des Parlaments, dass ein Stabilitätsmechanismus ein »wichtiger Bestandteil eines Gesamtpakets von Maßnahmen ist, die dazu dienen sollen, einen neuen Rahmen festzulegen, um die Haushaltsdisziplin und die Koordinierung der Wirtschafts- und Finanzpolitik der Mitgliedstaaten zu verstärken« (EP 2011a, Rn. 3; vgl. auch 2010a, Rn. 3).

Durch die Externalisierung der Stabilisierungsfunktion auf eine durch Völkerrecht etablierte Institution außerhalb der EU-Verträgeverfassung ergibt sich eine ganz eigene Form der Institutionalisierung, die letztlich im Aufbau neuer Koordinations- und Entscheidungsgremien mündet. So erhält der ESM mit dem Gouverneursrat ein Gremium, das für alle Entscheidungen letztverantwortlich ist. Laut Artikel 5 des ESM-Vertrags stellt dieser de facto die Euro-Gruppe dar, die durch den ESM somit zum exekutiven Zentrum der außervertraglichen Notstandsverfassung avanciert (vgl. auch Abels 2018, 401f.). Dabei bedient sich der Gouverneursrat der Kommission und der EZB als Hilfsagenturen, die die Aushandlung der Memoranden betreuen (vgl. Art. 13, Abs. 3 ESM-V) sowie nach Gewährung einer Finanzhilfe die wirtschaftspolitischen Auflagen gemeinsam mit dem IWF zu überwachen haben (vgl. Art. 13, Abs. 7 ESM-V). Zusammengenommen bilden die drei genannten Staatsapparate die sogenannte Troika (später: >die Institutionen ). Während die Kommission durch die Exekutierung der Gouverneursratsbeschlüsse, aber auch als der Beschlussfassung vorgelagertes Koordinierungs- und Vorbereitungsgremium eine Stärkung erfährt, bleibt das Europäische Parlament hingegen außen vor. Dies war im Übrigen bereits beim sekundärrechtlichen EFSM der Fall, der direkten Einfluss auf den EU-Haushalt hatte. In einer Entschließung geißelte das EP (2010a) dieses Vorgehen: Es »stellt fest, dass das Europäische Parlament trotz der möglicherweise erheblichen Auswirkungen dieses Mechanismus auf den EU-Haushalt 
nicht in die Beschlussfassung einbezogen wird«. Auch im Rahmen des ESM bleibt dem Parlament abermals nur die Funktion eines kommentierenden Beobachters. Hingegen erfährt die EZB im ESM-Arrangement eine Aufwertung. Durch den Schleier der »Unabhängigkeit« der Zentralbank, quasi als eine Art ausführende Behörde, wird so einerseits die Herrschaftsausübung durch den ESM im Rahmen der neuen Notstandsverfassung scheinbar technokratisiert beziehungsweise expertisiert, andererseits führt dies aufgrund der ihr zugedachten Aufgaben (u.a. bei der Aushandlung der Memoranden) zu einer Politisierung der EZB-Aktivitäten. Die Zentralbank und ihre Gremien werden im EUSA-Gefüge durch die neue Verfassungskomponente gestärkt. Hinzu kommt der Einbezug des IWF (als ein internationaler Staatsapparat) in die Architektur des Euro-Rettungsschirms. Hieran wird die Dialektik der technokratischen Expertokratie deutlich, denn schlussendlich werden politische Entscheidungsfindungen von den offiziellen EU-Gremien - unter Beibehaltung der formalen Zuständigkeiten und finalen Beschlussfassungskompetenzen - in nur scheinbar unpolitische Apparate aus- beziehungsweise vorgelagert. Einer expliziten, begründeten Stellungnahme zum Einbezug der EZB und des IWF bleibt der ESM-V und auch der Europäische Rat in seinen Beschlüssen schuldig. Eine überzeugende Hypothese Morisse-Schilbachs $(2011,35)$ für den IWF-Einbezug verweist auf das Misstrauen der deutschen Bundesregierung gegenüber dem Institutionensetting der EWWU, dem nicht zugetraut worden sei, die Probleme zufriedenstellend zu lösen; in anderen Worten: »the institutional setting of EMU is perceived as too weak to serve German interests. « Ähnlich argumentiert Pilz $(2016,32)$, der die Beteiligung des IWF im Umstand geschuldet sieht, »dass die Europäische Union weder über die notwendige Erfahrung im Umgang mit Staatsschuldenkrisen noch über die Glaubwürdigkeit zur Durchsetzung der Sanierungsprogramme verfügt.« Zugleich konstatiert er, dass durch die IWF-Einbindung politische und kulturelle Divergenzen innerhalb der Eurozone ausgeblendet werden könnten und der IWF frei sei von politischen Opportunitäten, die es beispielsweise bei den Verhandlungen innerhalb des Rates zu berücksichtigen gelte (vgl. ebd., 32f.). Nicht zuletzt bietet Tooze $(2018,28)$ die Erklärung, dass es insbesondere die USA gewesen wären, die aus Angst vor der Inkompetenz der EU darauf drängten, den IWF in die Rettungsprogramme und deren Strukturen einzubinden.

Die ESM-Abstimmungsregeln sehen vor, dass die Gewährung von Finanzhilfen, einschließlich der in dem Memorandum of Understanding [...] festgelegten wirtschaftspolitischen Auflagen sowie der Wahl der Instrumente und Festlegung der Finanzierungsbedingungen« (Art. 5, Abs. 6f ESM-V), im gegenseitigen Einvernehmen erfolgen. Eine Abweichung hiervon beschloss der Euro-Gipfel im Dezember 2011:

»[T] he mutual agreement rule will be replaced by a qualified majority of $85 \%$ in case the Commission and the ECB conclude that an urgent decision related to financial assistance is needed when the financial and economic sustainability of the euro area is threatened.«(Euro-Cipfel 2011d; vgl. Art. 4, Abs. 4 ESM-V)

Aufgrund der Stimmenverteilung im Gouverneursrat, die sich anhand der durch einen Euro-Mitgliedstaat gehaltenen ESM-Anteile auf Grundlage des durch ihn eingelegten Stammkapitals errechnet, haben somit drei Mitgliedstaaten (Deutschland, Frankreich und Italien) in einem Dringlichkeitsverfahren eine alleinige Sperrminorität. Auch wenn 
der Gouverneursrat seine Entscheidungen meist im Modus der Einstimmigkeit fasst, definiert der ESM-Vertag in Artikel 5, Absatz 7 einige Bereiche, in denen lediglich eine qualifizierte Mehrheit von $80 \%$ erreicht sein muss. Eingedenk dessen, können somit Deutschland und Frankreich als echte »ESM-Vetomächte« gelten, da ihre Stammanteile jeweils über $20 \%$ liegen. Anders ausgedrückt: Gegen Deutschland oder Frankreich kann innerhalb der ESM-Struktur nicht agiert werden. Somit schreibt der Stabilitätsmechanismus zugleich die Dominanz einzelner mitgliedstaatlicher Regierungen und folglich einen intergouvernementalen Charakter in die Notstandsverfassung ein. Diese Stärkung der mitgliedstaatlichen Exekutiven manifestiert sich auch in der weitestgehend fehlenden parlamentarischen Beteiligung:

»Einige Mitglieder der Eurozone sichern parlamentarische Rechte, indem sie Regierungen verpflichten, vor Abstimmungen in den Entscheidungsgremien des ESM eine parlamentarische Zustimmung einzuholen. [...] [Allerdings] ist diese Praxis [...] nicht weit verbreitet. Zustimmungsrechte finden sich nur in Deutschland, Österreich und Estland sowie teilweise in den Niederlanden und Luxemburg.« (Rittberger \& Winzen 2015, 436)

Zurecht ist somit aus Perspektive der mitgliedstaatlichen Parlamente von einem »Zentralisierungsschub« (ebd., 430) zu sprechen (vgl. auch Pilz 2016, 106ff.). Der gewählte Terminus des autoritär-intergouvernementalen Gläubigerregimes verdeutlicht dies in besonderer Weise. Hinzu kommt, dass sich bei der Gewährung von Stabilitätshilfen die Staats- und Regierungschefs - die formal lediglich vermittelt über den SKS-Vertrag in die neue Notstandsverfassung eingebunden sind - immer wieder selber eingeschaltet haben, indem sie im Europäischen Rat »sämtliche Bail-Out-Entscheidungen, bis auf die Zypern betreffende, persönlich abschließend verhandelt « (Puetter 2015, 414) haben. ${ }^{7} \mathrm{Au}$ toritär erscheint dieses Gläubigerregime insbesondere aufgrund der politischen Praxis im Kontext der neuen Notstandsverfassung und ihrem neuen starken Herrschaftsinstrument der Memoranden.

Der Fall Zypern weist hierbei eine besonders kritische Informalisierung der Verfahren auf, die Ratspräsident Van Rompuy (2014, 8f.) nachträglich wie folgt beschreibt: »Manche Tagungen des Europäischen Rates zeichnen sich dadurch aus, dass sie nicht stattgefunden haben. [...] Besorgt vertrauten die Staats- und Regierungschefs die Angelegenheiten ihren Finanzministern an. Als die Turbulenzen im März 2013 ausbrachen, handelten die Minister [...] mit der zyprischen Regierung ein Rettungspaket über 10 Milliarden EUR aus. Das Parlament in Nikosia lehnte die Bedingungen der Vereinbarung [...] wenige Tage später ab, was einen politischen Stillstand und Unsicherheit auslöste. Als Krisenmaßnahme innerhalb weniger Stunden eine Tagung des Europäischen Rates zu Zypern einzuberufen, wollte ich vermeiden. In ständigem Kontakt mit anderen Mitgliedern habe ich in Brüssel ein Treffen mit dem neuen zyprischen Präsidenten [...], den Präsidenten der Kommission, der Europäischen Zentralbank und der Euro-Gruppe sowie der Geschäftsführenden Direktorin des Internationalen Währungsfonds veranstaltet. In dieser Zusammensetzung haben wir nach eintägigen heiklen Cesprächen am Sonntag, den 24. März kurz vor Mitternacht eine Einigung erzielt.« 


\section{Herrschaftspraxen des autoritär-intergouvernementalen Gläubigerregimes}

Die Gewährung von Rettungsschirmkrediten erfolgt auf Grundlage strenger Konditionalitäten, die festgehalten sind in einem Memorandum of Understanding zwischen dem kreditnehmenden Euro-Mitglied und den Gläubigerstaaten, vertreten durch die sogenannte Troika aus Kommission, EZB und IWF. Die inhaltliche Reichweite der Memoranden reicht allerdings weit über fiskalpolitische Empfehlungen und Vereinbarungen hinaus, wie ein exemplarischer Blick auf die durchgeführten Programme im Kontext der Euro-Krise verdeutlicht. Folgende >Hilfsprogramme bis 2018 unter den Bedingungen eines Memorandums bereitgestellt:

Tabelle 17: Hilfskredite (2010-18): Höhe, Empfänger \& Gläubiger

\begin{tabular}{|c|c|c|c|c|c|}
\hline $\begin{array}{l}\text { Programm \& } \\
\text { Laufzeit }\end{array}$ & Bilateral & EFSM & EFSF & ESM & IWF \\
\hline $\begin{array}{l}\text { Griechenland I } \\
(2010-13)\end{array}$ & 80 Mrd. $€^{1)}$ & - & - & - & 30 Mrd. € \\
\hline $\begin{array}{l}\text { Irland } \\
(2010-13)\end{array}$ & 4,8 Mrd. $€^{2)}$ & 22,5 Mrd. € & 17,7 Mrd. $€$ & - & 22,5 Mrd. $€$ \\
\hline $\begin{array}{l}\text { Portugal } \\
(2011-14)\end{array}$ & - & 26 Mrd. $€$ & 26 Mrd. $€$ & - & 26 Mrd. $€$ \\
\hline $\begin{array}{l}\text { Griechenland II } \\
(2012-14)\end{array}$ & - & - & 144,5 Mrd. $€$ & - & 19,1 Mrd.€ \\
\hline $\begin{array}{l}\text { Spanien } \\
(2012-14)^{3)}\end{array}$ & - & - & - & 100 Mrd. $€$ & - \\
\hline $\begin{array}{l}\text { Zypern } \\
(2013-16)\end{array}$ & - & - & - & 9 Mrd. $€$ & 1 Mrd. $€$ \\
\hline $\begin{array}{l}\text { Griechenland III } \\
(2015-18)\end{array}$ & - & - & - & 86 Mrd. $€$ & - \\
\hline \multicolumn{6}{|c|}{$\begin{array}{l}\text { 1) }=\text { Aufgebracht von den Euro-Mitgliedstaaten (außer Slowakei sowie den späteren »Programmlän- } \\
\text { dern« Irland und Portugal) } \\
\text { 2) = Vereinigtes Königreich: 3,8 Mrd. €; Schweden: 0,6 Mrd. €; Dänemark: O,4 Mrd. € } \\
\text { 3) = Im Falle Spaniens handelt es sich um ein Programm zur direkten Rekapitalisierung von Finanzin- } \\
\text { stituten, weshalb sich die an Spanien gerichteten Auflagen von jenen der anderen Programmländer } \\
\text { qualitativ unterscheiden. }\end{array}$} \\
\hline
\end{tabular}

Quelle: Eigene Zusammenstellung auf Grundlage der zugänglichen Daten auf den Internetseiten der Kommission

Ein Blick auf das erste Programm für Griechenland (2010) zeigt, welche Interventionstiefe ein Memorandum als zentrales Herrschaftsinstrument der außerunionsvertraglichen Notstandsverfassung annehmen kann (vgl. KOM 2010j): Neben Ausgabenkürzungen im griechischen Staatshaushalt sowie eine Reihe von Steuererhöhungen in den unterschiedlichsten Feldern, spielen insbesondere Strukturreformen im MoU eine entscheidende Rolle. Angefangen bei der Förderung der Wettbewerbsfähigkeit und im Sinne angebotsökonomischer Paradigmen bei den Regulierungen des Arbeitsmarktes und der Lohnfindung (inkl. verordneter Renten- und Lohnkürzungen) bis hin zu detaillierten Vorgaben zur Reformierung der öffentlichen Verwaltung (vgl. auch Hoffmann \& 
Krajewski 2012, 7ff.). Nach Ansicht der Prüfer*innen des Europäischen Rechnungshofes ([EuRH] 2017, Rn. IV) betrafen die Auflagen letztlich "praktisch alle Aufgaben des griechischen Staates« (Herv. J. G.). Dabei beschloss Griechenland allein auf Grundlage des dritten Memorandums über 450 Einzelmaßnahmen (vgl. Euro-Gruppe 2018c). Mit dem Instrument der Memoranden wird insofern ein allumfassender Politikansatz verfolgt, in dem grundsätzlich kein Politikfeld außer Acht gelassen wird. Dabei stehen die verabredeten Maßnahmen an vielen Stellen auch in direkter Konkurrenz zur Unionspolitik, wie das Europäische Parlament (2014a \& 2014b) in zwei Entschließungen aus dem Jahr 2014 herausstellte, die man in ihrer Diktion als eine Art >Abrechnungく mit der Troika und den Memoranden verstehen kann. So weist das Parlament darauf hin,

»dass die in den MoU enthaltenen Empfehlungen der Modernisierungspolitik zuwider laufen, wie sie in der Lissabon-Strategie und der Europa-2020-Strategie formuliert wurde; [es] bedauert ferner, dass Mitgliedstaaten mit Vereinbarung (MoU) von jeglicher Berichterstattung des Europäischen Semesters, einschließlich der Berichterstattung im Rahmen der Ziele bezüglich der Bekämpfung von Armut und sozialer Ausgrenzung, ausgenommen sind«(EP 2014a, Rn. 31).

Es findet somit eine Isolierung und Immunisierung der Herrschaftsmodi der außerunionsvertraglichen Notstandsverfassung vom eigentlichen politischen Handeln im Rahmen des unionsvertraglichen EU-Staatsapparate-Ensembles statt. Notfalls werden dabei die Auflagen und Anforderungen des Gläubigerregimes mit entsprechendem Druck durchzusetzen versucht. So beispielsweise auch 2011, als der damalige griechische Premierminister ein Referendum über die Memorandum-Auflagen der Troika ankündigte. Fände ein solches Referendum wirklich statt, so Merkel und Sarkozy, sei es aus ihrer Perspektive keines über die konkreten Auflagen, sondern über den Verbleib Griechenlands in der Währungsunion: »Sollten die Griechen mit Nein zum Memorandum stimmen, müssten sie die Gemeinschaftswährung aufgeben. Bis dies geklärt sei, werde dem Land die nächste, dringend benötigte Kreditrate vorenthalten." (Vogel 2013, 62) Eine solche Form der Erpressung unter Androhung eines `Grexits` - die bei Papandreou noch Wirkung zeigte - wurde schließlich auch 2015 gegenüber der SYRIZA-Regierung angewendet, die sich ihr allerdings (vorerst) entzog und dennoch ein Referendum durchführte, an dessen Ende zwar kleinere Konzessionen gegenüber Griechenland, allerdings kein generelles Abrücken von den Troika-Auflagen stand. Deutlich wird hieran, dass das autoritär-intergouvernementale Gläubigerregime nicht vor Einschüchterung und Erpressung zurückschreckt und überdies durch ihre Hilfsagentur der Troika bis weit in die Hoheitsrechte von Mitgliedstaaten einwirken kann. Ähnlichkeiten zu dem von der EZB vorgeschlagenen »Executive Officer« (s.o.) kommen wohl nicht von ungefähr.

In diesem Sinne sind mit der Memoranden-Politik auch sgewollte Konsequenzen verbunden, die nicht nur direkt auf die Programmländer, sondern auf alle Eurostaaten wirken. So haben sich implizit alle Euro-Mitgliedstaaten dem in der außerunionsvertraglichen Notstandsverfassung angelegten Politikansätzen unterzuordnen, um quasi vorbeugend nicht selber in die Fänge des ESM und der Troika zu geraten. Insofern wirken die Memoranden auf zwei Ebenen, entweder direkt gegenüber den sogenannten Programmländern und indirekt - unterstützt durch die Änderungen am europäischen Sekundärrecht - gegenüber allen Ländern der Währungsunion. Die Herrschaftspra- 
xis, nach der die Programmländer zu »Maßnahmestaaten« (Kritidis 2014) oder »EUProtektoraten « (Kielmansegg 2015, 90) degradiert wurden, stellt demnach ein statuiertes Exempel der tonangebenden Akteur*innen im neuen Gläubigerregime der Eurozone dar. Dies zeigt sich beispielsweise auch in der Verfügungsgewalt über die sogenannten Hilfskredite, die in den Händen der Gläubiger verbleiben. Die Gelder werden im Falle Griechenlands beispielsweise statt an die Regierung auf ein Treuhandkonto beziehungsweise seit 2012 auf ein Sperrkonto überwiesen (vgl. Vogel 2013, 51 \& 56): „Über das dort eingezahlte Geld kann Athen nicht verfügen, es dient ausschließlich zur Zahlung von Zinsen und Tilgungen bei den privaten Gläubigern.« (Ebd., 56) Insofern verwundert es nicht, dass die Hilfskredite am Ende zum Großteil bei großen europäischen Banken, Versicherungen und Fondsgesellschaften (hauptsächlich in Deutschland und Frankreich) landeten, die im Besitz griechischer Staatspapiere waren (vgl. Lindner 2013, 7). Durch diese Kontomodelle wird die griechische Regierung aber letztlich zusätzlich auf die ausgehandelten Bedingungen der Programme verpflichtet, die inhaltlich im Sinne des gängigen EUSA-Krisennarrativs eine austeritäre Schocktherapie mit dem Ziel durchzusetzen suchte, durch Ausgabenkürzungen die Staatsfinanzen zu konsolidieren und mit Strukturreformen die Wettbewerbsfähigkeit zu verbessern (interne Abwertung). Das Europäische Parlament kommt in seiner Entschließung von 2014 hierbei letztlich zu dem Schluss, »dass sich Erwartungen, durch interne Abwertung an Wettbewerbsfähigkeit zu gewinnen und so wieder Wachstum und Beschäftigung zu schaffen, nicht bewahrheiten haben« (EP 2014b, Rn. 6; Herv. J. G.). Stattdessen »bedauert« es,

»dass die umgesetzten Maßnahmen der Ungleichheit der Einkommensverteilung kurzfristig hat ansteigen lassen; weist darauf hin, dass diese Ungleichheiten in den vier [Programm-]Ländern überdurchschnittlich zugenommen haben; stellt fest, dass Kürzungen der Sozialleistungen und der sozialen Dienstleistungen und die steigende Arbeitslosigkeit, die durch in den Programmen vorgesehene Maßnahmen in Bezug auf die makroökonomische Lage hervorgerufen wird, sowie Lohnkürzungen die Armut vergrößern« (EP 2014a, Rn. 34; vgl. auch EP 2014b)

Dabei beginnt nach Ansicht von Bibow \& Flassbeck $(2018,36) »[d]$ ie Idee der internen Abwertung [...] mit der durchaus richtigen Einsicht, dass die stark ungleichgewichtigen Wettbewerbspositionen innerhalb der Währungsunion zu einem Gleichgewicht zurückfinden müssen." Dass die Herstellung des Gleichgewichts allerdings als eine Aufgabe der gesamten Eurozone zu betrachten und demnach nicht einseitig durch die Programmländer zu leisten sei (vgl. ebd., 36f.), gehört aber ebenso zu dieser richtigen Einsicht. In den konkreten Praxen konnte diese allerdings keine Relevanz entfalten. Vielmehr werde Lohnkostensenkung zum alleinigen Allheilmittel der Abwertungsstrategie, die sich im »von Keynes aufgedeckte[m] klassische[n] Trugschluss der Komposition« ausdrücke, nach dem »Lohnkürzungen [...] die Lösung für Arbeitslosigkeit und niedriges Wachstum [seien]." (Mitchell 2017, 370) Nach Bibow \& Flassbeck $(2018,39)$ sei diese Art der Anpassungspolitik und mit ihr die Herstellung eines Gleichgewichts »fulminant gescheitert«:

»Stattdessen wurde das externe Gleichgewicht nur scheinbar erreicht, das interne Cleichgewicht dagegen noch nachhaltiger gestört. Wenn die Eurokrisenländer 
heute nahezu ausgeglichene Leistungsbilanzsalden aufweisen, so ist dies in erster Linie Resultat der Tatsache, dass die Einkommen am Boden liegen und auch die Importe entsprechend geschrumpft sind. Von dem angestrebten internen Cleichgewicht - Vollbeschäftigung, ausgeglichener Staatshaushalt und sinkende staatliche Schuldenquote - bleiben die Eurokrisenländer bis heute weit entfernt. Denn die Lohnsenkungspolitik hat die Krise verschärft, statt sie überwinden zu helfen.« (Ebd.)

Die Auswirkungen der Troika- und Programm-Politik fassen Flassbeck \& Lapavitsas (2015a, 87f.) für Griechenland sehr anschaulich zusammen:

»At the end of 2014, Greek CDP had contracted by more than 25 percent since the global crisis truly burst out in 2008, and by 22 percent since the introduction of the bailouts in 2010. Unemployment had exploded to 27.5 percent in 2013, representing 750,000 lost jobs since the intervention by the troika, two thirds of which were [...] in construction, manufacturing, and trade and retail. Industrial output had collapsed by roughly 35 percent since 2007 , a decline that has occurred from an already low base reflecting the sustained de-industrialisation of Greece since the early 1980s. Wages, finally, declined by 27 percent in 2010-2014 contributing to a collapse of disposable incomes. The social impact of these developments has been simply devastating, with mass poverty emerging again in the country.« (Vgl. u.a. auch Karamessini 2014)

\section{Außerunionsvertragliche Notstands- und die EU-Verträgeverfassung}

Die Implementierung der außerunionsvertraglichen Notstandsverfassung in der dargestellten Form eines völkerrechtlichen Vertrags zwischen den Mitgliedstaaten der Eurozone eröffnet weitreichende Fragen in Bezug auf die Auslegung des bestehen Vertragsrahmens der EU und der in ihr kodierten Wirtschafts- und Fiskalverfassung, die letztlich auch durch den Europäischen Gerichtshof juristisch zu bewerten waren.

Am 13. April 2012 erhob der irische Parlamentarier Thomas Pringle vor dem irischen High Court Klage gegen die Einrichtung des permanenten Stabilitätsmechanismus. Gegenstand dieser waren einerseits die rechtmäßige Anwendung des vereinfachten Vertragsänderungsverfahrens nach Artikel 48 AEUV sowie andererseits die Ratifizierung des ESM-Vertrags, der nach Argumentation der Klagebegründung Verbote und Beschränkungen der Vorschriften des AEUV in Bezug auf die Wirtschafts- und Währungspolitik unterliefe (vgl. EuGH 2012, Rn. 24f.). Nachdem das irische Gericht die Klage in vollem Umfang abwies, reichte Pringle Berufung ein, in deren Folge der irische Supreme Court dem EuGH Fragen zur Vorabentscheidung vorlegte. Die Luxemburger Richter*innen hatten dabei zu klären, ob der Beschluss des Europäischen Rates zur Änderung des AUEV gültig sei und zweitens, ob die Euro-Mitgliedsstaaten aufgrund der unionsvertraglichen Bestimmungen überhaupt berechtigt gewesen wären, einen zwischenstaatlichen ESM-Vertrag zu unterzeichnen und zu ratifizieren. Das Gericht urteilte hierzu, dass die »Prüfung nichts ergeben hat, was die Gültigkeit des Beschlusses 2011/199 berühren könnte.«(Ebd., Rn. 76) Dies leitete der EuGH daraus ab, dass der Stabilitätsmechanismus nach seiner Ansicht zum Bereich der Wirtschaftspolitik gehöre (vgl. ebd., Rn. 60) und insofern - im Sinne des AEUV - einen Beitrag zur engeren Koordinierung und Überwachung der Wirtschafts- und Haushaltspolitik darstelle (vgl. ebd., Rn. 59). Der EuGH folgte damit nicht der Lesart, nach der es sich beim ESM 
um eine währungspolitische Maßnahme handele (vgl. ebd., Nr. 63 \& 95), welche in die ausschließliche Zuständigkeit der Union fiele und somit den intergouvernementalen Aktivitäten entzogen gewesen wäre. Letztlich hielt der Gerichtshof fest, dass

»auch wenn [...] die Stabilität des Euro-Währungsgebiets Auswirkungen auf die Stabilität der in diesem Gebiet verwendeten Währung haben mag, [...] eine wirtschaftspolitische Maßnahme nicht allein deshalb einer währungspolitischen Maßnahme gleichgestellt werden [kann], weil sie mittelbare Auswirkungen auf die Stabilität des Euro haben kann.«(Ebd., Rn. 56)

Somit seien in der Auslegung des EuGH die Mitgliedstaaten befugt gewesen, einen zwischenstaatlichen Stabilitätsmechanismus einzurichten (vgl. ebd., Rn. 68), wenngleich sie sich »jedoch bei der Ausübung ihrer Zuständigkeiten [...] nicht über die Beachtung des Unionsrechts hinwegsetzen [dürfen]« (ebd., Rn. 69). Zugleich stellte der EuGH fest, dass der Union durch die Änderung keine neuen Zuständigkeiten übertragen werde (vgl. ebd., Rn. 73). So spreche aus Sicht des EuGH auch eine Aufgabenausführung durch Unions-Organe im Rahmen des ESM nicht gegen die Rechtmäßigkeit des Beschlusses und des Beschlusstextes zur Vertragsänderung (vgl. ebd., Rn. 74 \& 154-177). Die neu geschaffene vertragliche Grundlage für die Einrichtung eines permanenten Rettungsbeziehungsweise Stabilitätsmechanismus wird somit in der Rechtsprechung des EuGH bestätigt. Allerdings ergeben sich aus den dargestellten >Anforderungen < des EuGH weiterführende Konsequenzen, wie Andreas Fischer-Lescano (2014) in einem Gutachten herausarbeitete. Er bewertet dabei die Aktivitäten der Kommission und der EZB im Rahmen der außerunionsvertraglichen als im Widerspruch zu den kompetenzrechtlichen Anforderungen des Unions-Primärrechts stehend, deren verpflichtende Einhaltung nicht nur in Artikel 13, Absatz 3 des ESM-Vertrags angelegt ist (s.o.), sondern auch durch den EuGH nochmals gesondert bestätigt wurde:

»Die MoU sehen umfangreiche Maßnahmen auf den Gebieten Bildung, Beschäftigung, Gesundheit und Sozialpolitik vor. Nach dem EuCH müssen die durch den ESMV übertragenen Funktionen den Aufgaben aus dem Unionsrecht entsprechen. Das sei dann der Fall, wenn im Einklang mit Art. 282 Abs. 2 AEUV die allgemeine Wirtschaftspolitik der Union unterstützt werde. [...] Dieser Kompetenztitel ist aber nicht schrankenlos. Die Union kann über die Regelung der >Wirtschaftskoordinierung` keine Detailregulierungen in der Cesundheits-, Beschäftigungs-, Sozial- und Bildungspolitik vornehmen. Die Kompetenz zur Wirtschaftskoordinierung ist durch das Subsidiaritätsgebot des Art. 5 Abs. 3 EUV und das Prinzip der begrenzten Einzelermächtigung beschränkt.« (Ebd., 19)

Nicht zuletzt auch aufgrund zweier erfolgreicher Klagen gegen einige Austeritätsmaßnahmen vor dem portugiesischen Verfassungsgericht (vgl. FAZ, 31.08.2013), sehen Kommer \& Fischer-Lescano $(2014,76)$ deshalb auch Klagemöglichkeiten vor dem EuGH, deren Erfolgsaussichten sie aber erfahrungsbasiert ${ }^{8}$ zugleich eher gering einschätzen (vgl. ebd., 79).

8 Im Zusammenhang mit Klagen gegen einzelne Memoranden-Auflagen erklärte sich der EuCH (2013; 2014) in zwei Fällen für nicht zuständig. 
Weiterhin nahm der EuGH auch Stellung zu zwei zentralen Normen des AEUV, die im Rahmen des Krisen(bewältigungs)diskurses an unterschiedlichen Stellen kontrovers betrachtet wurden: der Nichtbeistandsgrundsatz (Art. 125 AEUV) sowie das Verbot monetärer Staatsfinanzierung (Art. 123 AEUV). Der ESM-Vertrag stehe mit beiden Normen im Einklang, wie der EuGH feststellte. In Bezug auf den Artikel 123 AUEV urteilte der EuGH, dass dieser zum einen speziell die EZB und die Zentralbanken der Mitgliedstaaten adressiere, hingegen nicht die Mitgliedstaaten selber, wenn diese anderen Mitgliedstaaten finanziellen Beistand leisteten (vgl. ebd., Rn. 125), zumal sie im Falle des ESM nur mittelbar tätig seien (vgl. ebd., Rn. 126). Als Zweck des in Art. 125 AEUV festgeschriebenen Verbotes definierte der EuGH,

»dass die Mitgliedstaaten bei ihrer Verschuldung der Marktlogik unterworfen bleiben, was ihnen einen Anreiz geben soll, Haushaltsdisziplin zu wahren. Die Einhaltung einer solchen Disziplin trägt auf Unionsebene zur Verwirklichung eines übergeordneten Ziels bei, und zwar dem der Aufrechterhaltung der finanziellen Stabilität der Unionswährung.«(Ebd., Rn. 135)

Zumal das Gericht festhält, dass der ESM nicht als Bürge für Schulden der Mitgliedstaaten auftrete (vgl. ebd., Rn. 138). Somit »ist die Aktivierung einer Finanzhilfe aufgrund eines Stabilitätsmechanismus wie des ESM nur dann mit Art. 125 AEUV vereinbar, wenn sie für die Wahrung der Finanzstabilität des gesamten Euro-Währungsgebietes unabdingbar ist und strengen Auflagen unterliegt.«(Ebd., Rn. 136) Der EuGH unterstrich insofern auch die Voraussetzung harter Konditionalitäten und Auflagen für die Gewährung von Finanzhilfen aus dem ESM. Denn nur, wenn die geknüpften Auflagen geeignet seien, einen Mitgliedstaat »zu einer soliden Haushaltspolitik zu bewegen«, »verbietet es Art. 125 AUEV nicht, dass ein oder mehrere Mitgliedstaaten einem Mitgliedstaat, der für seine eigenen Verbindlichkeiten gegenüber seinen Gläubigern haftbar bleibt, eine Finanzhilfe gewähren« (ebd., Rn. 137).

Auch das Bundesverfassungsgericht (BVerfG) hatte sich mit ähnlichen Fragestellungen wie der irische Supreme Court und der EuGH auseinanderzusetzen. Die Karlsruher Richter*innen urteilten bereits zwei Monate vor dem EuGH ebenfalls, dass der ESM prinzipiell mit den europäischen Verträgen vereinbar sowie grundgesetzkonform sei (vgl. BVerfG 2012), weshalb sie eine einstweilige Anordnung gegen die Ratifizierung des ESM-V ablehnte. Auch in Bezug auf den Haftungsausschluss und die monetäre Staatsfinanzierung vertraten das BVerfG und der EuGH eine ähnliche Argumentationslinie (vgl. insb. ebd., Rn. 129 \& 174), die schließlich auch im abschließenden BVerfG-Urteils (2014b) bestätigt wurde.

In dieser Lesart stellen der ESM und die außerunionsvertragliche Notstandsverfassung demnach keinen Bruch mit der EWWU in der mit Maastricht begründeten Anlage einer Stabilitätsunion dar. So sieht es auch Höing $(2016,25)$, wenn er schreibt, dass der ESM »auch in einer regelbasierten Stabilitätsunion einen wichtigen Platz ein[nimmt]« und insofern nicht als ein Einstieg in eine Transferunion bewertet werden könne. Vielmehr müsse der ESM »als Versuch betrachtet werden, durch die von ihm gesetzten Konditionalitäten die Wettbewerbsfähigkeit von Programmstaaten zu erhöhen, ohne gleichzeitig einen wirklichen finanziellen Lastenausgleich vorzunehmen.« (Ebd.) Dennoch wird in der juridischen und politikwissenschaftlichen Einordnung der Rechtspre- 
chungen kontrovers darüber gestritten, inwiefern die Vertragsauslegung im Widerspruch zum Gehalt des vertraglich fixierten No-Bailout-Gebots - und damit der Ankernorm der Stabilitätsunion - steht. So zeichnen Tuori \& Tuori $(2014,123)$ ein konträres Bild:

»In our mind, the premise should be clear enough: if EU law prohibits Member States a certain action, the prohibition extends to Member States acting both individually and in concert, through intergovernmental agreements, whether under private or international law. The prohibition also covers intergovernmental facilities, established by Member States, regardless of whether these possess a distinct legal subjectivity or not.«

In diesem Sinne bewerten sie die Rettungsschirmmaßnahmen als nicht vereinbar mit dem EU-Vertragsrahmen. Durch die Krise sei somit »beiläufig außer Kraft gesetzt, was die Währungsunion sich selbst bei ihrer Gründung als fundamentale conditio sine qua non vorgegeben hatte", wie Kielmansegg $(2015,99$; Herv. i. O.) es auffasst. Anders und im Lichte der Urteile einleuchtender - urteilen Weiß \& Haberkamm (2013, 99), dass »durch die strengen Auflagen [...] sehr wohl dem eigentlichen Sinn von Art. 125 I AEUV [...] Rechnung getragen wird, unter Umständen sogar besser als durch einen mittels dieser Norm erzwungenen Staatsbankrott.« Schließlich gelte es, in diesem Sinne zu fragen, wer schlussendlich die Insolvenz einzelner Euro-Staaten zu >bezahlen hätte. Die Verstrickungen innerhalb des europäischen Banken- und Finanzsystems deuten darauf hin, dass insbesondere die institutionellen Gläubiger des europäischen Nordens für etwaige Staatsinsolvenzen im europäischen Süden massive Kreditausfälle und Abschreibungen hätten verzeichnen müssen, wie sich nicht zuletzt auch beim sogenannten »Haircut« im Frühjahr 2012 zeigte (Schuldenschnitt privater Gläubiger), bei dem beispielsweise deutsche Institute mit etwa 20 Milliarden Euro beteiligt waren (vgl. Meyer 2018, 407). Im Sinne simplifizierender Kostenkalkulationen könnte man behaupten, dass die finanziellen Auswirkungen der Rettungsschirmpolitik das geringere Übel im Vergleich zu Insolvenzen von Euro-Mitgliedstaaten darstellten. Infolgedessen erfuhr das No-Bailout-Gebot eine erneuerte, weite Auslegung:

»Nach der Lesart des EuCH verbietet Art. 125 Abs. 1 AEUV nur finanzielle Hilfe dergestalt, dass der ESM als Schuldner an die Stelle des Empfängerstaates in die mit den Cläubigern bestehende Schuldverhältnisse tritt. Hierbei scheint es keine Bedeutung zu haben, was mit dem Geld, das dem Empfängerstaat zur Verfügung gestellt wird, geschieht. Ob es den Cläubigern indirekt wieder zufließt, ist irrelevant. Wichtig ist bloß, dass dies nicht direkt [...] passiert. [...] Kurzum: Nach dieser Lesart ist ein direkter Bailout zwar verboten, ein indirekter Bailout aber erlaubt.«(Palmstorfer 2013, 220)

Die zuvor »enge, restriktive Auslegung« (Hilpold 2014, 38) des Artikels 125 erfährt schließlich im Rahmen der Rechtsprechung durch die vorgelegte Zweckbestimmung des No-Bailout-Gebots eine Ausschärfung:

»In Übereinstimmung mit dem BVerfC betont der EuGH, dass der Zweck der No-BailOut-Klausel darin liegt, eine solide Haushaltspolitik der Mitgliedstaaten sicherzustellen. Die Norm verbietet einen finanziellen Beistand, der den Anreiz mindert, eine so- 
lide Haushaltpolitik zu verfolgen. Mit Art. 125 AEUV vereinbar ist ein finanzieller Beistand in der Folge nur dann, wenn er für die Wahrung der Finanzstabilität des gesamten Euro-Währungsgebiets unabdingbar ist, der Empfängerstaat haftbar bleibt und die mit der Finanzhilfe verbundenen Auflagen ihn zu solider Haushaltspolitik zu bewegen geeignet erscheinen.«(Calliess 2013, 104)

Demnach stellen die Rettungsschirme keinen Bruch mit dem Leitbild einer auf Stabilität ausgerichteten Wirtschafts- und Währungsunion dar, sondern sind ganz im Gegenteil darauf ausgelegt, durch das erweiterte Instrumentarium der außerunionsvertraglichen Notstandsverfassung dieses in krisenbedingten Ausnahmezuständen effektiv in Form konditionalisierender Kredite und der Memoranden zu exekutieren.

\subsection{Fortentwicklung der vertragsbasierten Wirtschafts- und Fiskalverfassung}

Im Zentrum der Fortentwicklung der vertragsbasierten EU-Wirtschafts- und Fiskalverfassung stehen mit den sekundärrechtlichen Reformpaketen der Kommission und den intergouvernementalen Parallelaktionen des Europäischen Rates zwei auf den ersten Blick konkurrierende Maßnahmenstränge der Krisenbewältigungspolitik. Die Aktivitäten der EUSA zum Staatlichkeitsausbau zielen dabei insgesamt auf eine Konsolidierung der Stabilitätsunion, die um eine reffektivereく Überwachungsunion ergänzt wird. Hinzu kommt das Europäische Semester als neuer Koordinationszyklus des wirtschafts- und fiskalpolitischen Regierens in der EU, in dessen Rahmen die zuvor genannten Unionen ihre Wirkung entfalten. Die konkurrierenden Ausbauaktivitäten weisen dabei aufgrund ihrer qualitativ-unterschiedlichen Entstehungskontexte zwar einerseits auf interinstitutionelle Konflikte und Dynamiken der Euro-Krise hin, sie werden sich allerdings andererseits in ko-produktive Staatlichkeitsakte zur Fortentwicklung der Wirtschafts- und Fiskalverfassung auflösen.

\section{Das Europäische Semester als neuer Koordinationsrahmen}

Bereits Ende 2010 hielt das sogenannte Europäische Semester als Bestandteil der neuen Unionsstrategie für Wachstum und Beschäftigung (Europe 2020) Einzug in die Verfahren fiskal- und wirtschaftspolitischen Regierens. Das Semester, angelegt als >Exante-Koordinierung‘, sollte die Komplementarität der mitgliedstaatlichen Wirtschaftspolitiken mit den Zielen der Unionsstrategie sicherstellen. Die Kommission (2010a, 10) bezeichnet diesen Ansatz als »integrierte Koordinierung der Wirtschaftspolitik in der EU«. Zugleich wird im Semester die inhaltliche Verknüpfung zwischen Wirtschaftsund Fiskalpolitik propagiert, indem angestrebt sei, die »Bewertung der Haushalts- und Strukturpolitik der EU-Mitgliedstaaten zu synchronisieren.« (Ebd.) Es gehe demnach auch um eine »umfassende makroökonomische Überwachung «, deren Ergebnisse sich in der »Formulierung haushaltspolitischer Empfehlungen« (ebd.) niederschlagen sollten. Die Kommission spricht deshalb auch von einem »integrierte[n] Überwachungszyklus« (Herv. J. G.), der es ermögliche, »echte Leitlinien zu formulieren, die der europäischen Dimension Rechnung tragen und in die nationale Entscheidungsfindung einflie- 
ßen könnten.« (Ebd.) Auch wenn die Kommission noch vorsichtig im Konjunktiv verbleibt, lässt sich bereits an dieser Stelle die grundsätzliche Zielsetzung herausstellen, welche die Kommission mit dem Europäischen Semester verfolgt: die Stärkung ihrer Direktivkraft gegenüber den mitgliedstaatlichen Staatsapparaten. So beabsichtigt sie im Rahmen des Semesters, jeweils zu Beginn des Jahres eine »Analyse [...] der wichtigsten wirtschafspolitischen Herausforderungen der EU und des Euroraums « (später als Jahreswachstumsbericht bezeichnet) vorzulegen, die »strategische Hinweise « für die Mitgliedstaaten enthalten solle, welche wiederum in die Erstellung der mitgliedstaatlichen Stabilitäts- und Konvergenzprogramme (SKP) und der Nationalen Reformprogramme (NRP) ${ }^{9}$ einfließen sollten (vgl. ebd., 11), zu deren Einreichung die Mitgliedstaaten laut Artikel 121 AEUV vertraglich verpflichtet sind.

Das Semester decke nicht weniger als »alle Elemente wirtschaftspolitischer Überwachung ab[...], einschließlich der Strategien zur Sicherstellung der Haushaltsdisziplin und makroökonomischer Stabilität sowie zur Wachstumsförderung im Einklang mit der Strategie Europa 2020.« (KOM 2010b, 13; Herv. J. G.) Die Kommission gibt mit dieser Beschreibung bereits einen guten Ausblick auf jene Reformen des wirtschafts- und fiskalpolitischen Regierens, die sie im Anschluss an die Etablierung des Semesters mit dem Six-Pack anzustoßen suchte. Der Fokus liegt - zusammengefasst - auf einer Haushaltsdisziplinierung, die durch eine umfängliche Überwachung sichergestellt werden solle und sich an den Prämissen makroökonomischer Stabilität und Wachstumsförderung im Sinne der Europe-2020-Strategie orientiere. Dreh- und Angelpunkt bleibt hierbei die mitgliedstaatliche Fiskalpolitik, auch wenn die Kommission in ihrer JuniMitteilung von 2010 ihre Vorgehensweise vorsichtiger als zuvor formuliert: »Selbstverständlich wird nicht darauf abgestellt, dass die Mitgliedstaaten umfassende Haushaltspläne vorlegen müssen, die zunächst von der EU ıvalidiert` werden müssen, bevor sie dem jeweiligen nationalen Parlament präsentiert werden.« (Ebd., 13) Da das Semester auf der Neuanordnung bereits bestehender Verfahren beruhte, ersuchte die Kommission den Rat lediglich um Genehmigung der neuen Zeitabläufe, die im sogenannten SWP->Verhaltenskodex ${ }^{10}{ }^{0}$ festgehalten werden (vgl. ebd., 15). Der ECOFIN-Rat kam diesem Ersuch nach und ließ anschließend durch den Wirtschafts- und Finanzausschuss (WFA) den Verhaltenscodex anpassen, den er am 7. September 2010 ebenfalls beschloss (vgl. ECOFIN 2010b). Mit der Annahme des geänderten Verhaltenscodex war bereits vor den eigentlichen Reformvorhaben des Six-Packs ein grundsätzlich veränderter Koordinationsrahmen unter der Bezeichnung "Europäisches Semester « geschaffen worden, der ohne sekundärrechtliche Verankerung für das Jahr 2011 Anwendung finden sollte. Das Jahr 2011 war dabei eine Art Testballon für das Semester, das bis zu den Six-Pack-Beschlüssen, in denen es auf Druck des Parlaments schließlich doch auch sekundärrechtlich verankert wurde (vgl. EP 2011e, 8; 2011g, 18f.), auf der angedeuteten Hilfskonstruktion (AEUV \& technischer Kodex) beruhte.

9 Stabilitätsprogramme sind durch Mitgliedstaaten des Euro-Währungsgebiets und Konvergenzprogramme durch Mitgliedstaaten, deren Währung nicht der Euro ist, vorzulegen. 
»Die Theorie dieses Ansatzes könnte überzeugen, werden doch die beiden Dimensionen der Wirtschaftspolitik (Finanz- und Strukturpolitik) im europäischen Semester zusammengefasst auf EU-Ebene debattiert «, so Enderlein $(2011,40)$ in einer ersten Einschätzung zum neuen Koordinationsverfahren. Allerdings bezweifelt er, dass dies in der Praxis gelingen werde (vgl. ebd.). Kritisch hingegen lässt sich anfügen, dass bereits die zeitliche Anlage des Zyklus unter der Prämisse der »ex-ante-Koordinierung« der europäischen Staatlichkeitsebene einen ausgebauten Einfluss auf die Ausgestaltung der mitgliedstaatlichen Haushaltspolitik sichert (vgl. bspw. Klatzer \& Schlager 2011, 65). Hufeld $(2013,206)$ sieht dementsprechend das »historische Königsrecht « der mitgliedstaatlichen Parlamente unter Druck geraten, auch wenn er zugleich darauf verweist, dass das Europäische Semester »einer zwingenden Integrationslogik« entspräche. Zeitlin \& Vanhercke $(2018,150 f$.) identifizieren im Kern drei Kritiken am neuen Koordinationsverfahren und seiner inhaltlichen Fokussierung: erstens die Unterordnung sozialer Zielsetzungen unter übergeordnete Wirtschaftsziele; zweitens die Dominanz wirtschaftspolitischer Akteur*innen gegenüber solchen aus dem Feld der Sozial- und Arbeitsmarktpolitik und drittens die Schaffung eines zentralisierten Mechanismus der Union zur Implementierung von Strukturreformen in den Mitgliedstaaten. Guth (2013, 39) bringt schließlich den dem Semester innewohnenden Geist auf den Punkt. Es bedeute

»eine Verlagerung von Kompetenzen in Richtung Exekutive: die nationale Exekutive legt der europäischen Exekutive (Kommission) ihren Budgetentwurf vor, der von dieser begutachtet wird. Die Kommission legt ihre Einschätzung dann dem Rat vor [...], also aller nationaler Exekutiven der EU. Erst nach dem Zusammenspiel dieser exekutivischen Dreifaltigkeit wird der jeweilige Budgetentwurf dem nationalen Parlament der einzigen direkt demokratisch legitimierten Institution - zur Abstimmung vorgelegt. (Herv. J. G.)

Es ist diese Funktionslogik des Semesters, vor der die weiteren Reformen des Six- und Two-Packs schließlich ihre volle Wirkung entfalten.

Die Six-Pack-Gesetzgebungsakte beginnen dabei durchaus selbstreflektiert und in Teilen gar selbstkritisch, wird doch anerkannt, dass man aus dem ersten Jahrzehnt des Bestehens der EWWU »Erfahrungen« gewonnen habe (vgl. Erw. I RL 2011/85/EU; Erw. 3 VO (EU) Nr. 1173/2011; Erw. 4 VO (EU) Nr. 1174/2011 \& VO (EU) Nr. 1177/2011; Erw. 8 VO (EU) Nr. 1175/2011), es als »Notwendigkeit« erachte, »Lehren [...] zu ziehen« (Erw. 2 VO (EU) Nr. 1176/2011) und dabei sogar anerkennt, »Fehler« (Erw. 3 VO (EU) Nr. 1173/2011; Erw. 4 VO (EU) Nr. 1174/2011 \& VO (EU) Nr. 1177/2011; Erw. 8 VO (EU) Nr. 1175/2011) gemacht zu haben. Wenn man allerdings nachzuvollziehen versucht, wer die Fehler zu verantworten hat, wird wie bei der Verdichtung des offiziellen EUSA-Krisennarrativs abermals auf die notwendige Eigenverantwortung der Mitgliedstaaten bei der Beachtung der gemeinsamen Regeln sowie den fehlenden "soliden Rahmen[s] auf Unionsebene zur Überwachung der nationalen Wirtschaftspolitiken« (ebd.) rekurriert. Die Fehler sind demnach einerseits auf Seiten der Mitgliedstaaten zu verorten, die ihre Verantwortung nicht im ausreichenden Maße wahrgenommen hätten, um den vertraglich-vereinbarten Rahmen einzuhalten und andererseits auf Unionsebene zu verzeichnen, welche schließlich das Instrumentarium gefehlt habe, um die Einhaltung des Rah- 
mens zufriedenstellend überwachen zu können und gegebenenfalls korrigierend einzugreifen. Im Prinzip ist es diese EUSA-eigene Zuschreibung einer Funktionskrise der EWWU, die die einzelnen Maßnahmen des Six- und Two-Packs prägen: die Ausschärfung des Regelwerks zur `Stärkung« mitgliedstaatlicher Eigenverantwortung sowie die Stärkung und der Ausbau suprastaatlicher Überwachungs-, Kontroll- und Sanktionsmechanismen bei ungewünschtem Verhalten im Sinne der wirtschafts- und fiskalpolitischen Verfassungs-Normen.

\section{Die Konsolidierung der Stabilitätsunion und der Ausbau der EU-Fiskalregierung}

Die sekundärrechtlichen Bestimmungen des mit dem Amsterdamer Vertrag etablierten Stabilitäts- und Wachstumspakts finden sich in den beiden Verordnungen (EG) Nr. 1466/97 über den Ausbau der haushaltspolitischen Überwachung und der Überwachung und Koordinierung der Wirtschaftspolitiken (präventive Komponente) sowie Nr. 1467/97 über die Beschleunigung und Klärung des Verfahrens bei einem übermäßigen Defizit (korrektive Komponente). Im Rahmen des Six-Packs erfährt erstere durch die Verordnung (EU) Nr. 1175/2011 und zweitere durch die Verordnung (EU) Nr. 1177/2011 eine erneute Abänderung, nachdem bereits 2005 an den Ursprungsverordnungen, als den Kernverordnungen der »Stabilitätsunion«, Änderungen vorgenommen wurden.

Mit den krisenbedingten SWP-Reformen werde hierbei angestrebt, dass die Mitgliedstaaten »erhebliche Konsolidierungsanstrengungen unternehmen« und »insbesondere ihren Schuldenstand verringern« (KOM 2010d, 2). Demnach sei »[e]ine Stärkung des Pakts [...] in zweierlei Hinsicht von Bedeutung: erstens, um die Glaubwürdigkeit des vereinbarten koordinierten Ausstiegs aus den Konjunkturprogrammen zu erhöhen, und zweitens, um die Wiederholung von Fehlern aus der Vergangenheit zu vermeiden.« (Ebd.) Die Stärkung des SWP solle nach Ansicht der Kommission (2o10d, 2) dadurch erreicht werden, dass »seine Bestimmungen unter Berücksichtigung der nicht zuletzt anlässlich der Krise gesammelten Erfahrungen verbesser[t]« (spätere VO (EU) Nr. 1175/2011 \& VO (EU) Nr. 1177/2011) und »wirksamere Durchsetzungsmöglichkeiten vor[ge]sehen « würden (spätere VO (EU) Nr. 1173/2011), schließlich solle er »durch Bestimmungen $\mathrm{zu}$ den nationalen Haushaltsregelnd ergänz[t] « werden (spätere RL 2011/85/EU).

Grundsätzlich beruhe der SWP dabei

»auf dem Ziel einer gesunden öffentlichen Finanzlage als Mittel zur Verbesserung der Voraussetzungen für Preisstabilität und ein kräftiges, tragfähiges Wachstum, das auf einem stabilen Finanzsystem fußt, was zur Verwirklichung der Ziele der Union für nachhaltiges Wachstum und Beschäftigung beiträgt. « (Erw. 3 VO (EU) Nr. 1175/2011; vgl. Erw. 3 VO (EU) Nr. 1177/2011)

In diesem Sinne müssen die Mitgliedstaaten in der präventiven SWP-Komponente

»ein mittelfristiges Haushaltsziel erreichen und halten und zu diesem Zweck Stabilitäts- und Konvergenzprogramme vorlegen. Dieser präventiven Komponente würden strengere Überwachungsmaßnahmen zugute kommen, um sicherzustellen, dass die Mitgliedstaaten mit dem haushaltspolitischen Koordinierungsrahmen der 
Union übereinstimmen und ihn halten.« (Erw. 4 VO (EU) Nr. 1175/2011; vgl. Erw. 18 VO (EU) Nr. 1173/2011)

Hinzu kommt die korrektive Komponente, die weithin als > Defizitverfahren < bekannt ist und einsetzt, wenn die Defizit- und Schuldenstandskriterien nicht den vorgeschriebenen Zielmarken entsprechen. Trotzdem das Defizitverfahren auch in Vor-Krisenzeiten zur Anwendung kam, konnte es die Euro-Krise und ihre nach offizieller Lesart fiskalischen Ursachen nicht verhindern. Der »offizielle« Schluss hieraus lautet:

»Da auf Regeln beruhende haushaltspolitische Rahmen in den Mitgliedstaaten der Stärkung der nationalen Eigenverantwortung für die Haushaltsregeln der Union und der Haushaltsdisziplin erwiesenermaßen förderlich sind, muss sich die verstärkte haushaltspolitische Überwachung in der Union in erster Linie auf strenge länderspezifische numerische Haushaltsregeln stützen, die mit den Haushaltszielen der Union in Einklang stehen. Die strengen numerischen Haushaltsregeln sollten genaue Zielvorgaben sowie Mechanismen für eine wirksame und zeitnahe Überwachung erhalten. Diese Regeln sollten auf verlässlichen unabhängigen Analysen beruhen, die von unabhängigen Einrichtungen oder von solchen Einrichtungen vorgenommen werden, deren funktionelle Eigenständigkeit gegenüber den Haushaltsbehörden der Mitgliedstaaten gegeben ist. Im Übrigen hat die Erfahrung gezeigt, dass numerische Haushaltsregeln nur wirksam sind, wenn ihre Missachtung Konsequenzen nach sich zieht, wobei der Preis auch der bloße Ansehensverlust sein kann.« (Erw. 16 RL 2011/85/EU; Herv. J. G.)

Aus dieser Zuschreibung werden vier Dinge deutlich: So wird wieder einmal die Betonung der mitgliedstaatlichen Eigenverantwortung hervorgehoben, die sich an dem Prinzip der »Haushaltsdisziplin« $\mathrm{zu}$ orientieren habe; zweitens bestehe der Bedarf $\mathrm{zu}$ einer ausgeweiteten Überwachung der gesetzten Haushaltsregeln, die notfalls durch den Verweis auf mögliche Konsequenzen und den zu erwartenden Ansehensverlust durchgesetzt werden müssten und sich dabei drittens an einer Bandbreite technischer Normierungen der Haushaltspolitik zu orientieren hätten, die durch unabhängige Einrichtungen überprüfbar sein sollten. Wobei viertens unterschwellig die Ineffektivität des bisherigen SWP mitschwingt, der scheinbar nach seiner Reformierung im Jahre 2005 (VO (EG) Nr. 1055/2005 und VO (EG) Nr. 1056/2005) nicht die nötige Kraft entfalte, um das mit ihm beabsichtigte Ziel zu erreichen.

Der Neufassung des SWP im Jahre 2005 ging die Nichteinhaltung des Defizitkriteriums seitens Deutschlands und Frankreichs zu Beginn der $2000 e r$ Jahre voraus. Aufgrund einer später durch den EuGH bestätigten Ratsentscheidung (vgl. Petzold 2018, 174) führten diese Verletzungen allerdings nicht zu einem förmlichen Verfahren bei einem übermäßigen Defizit (VÜD). Der damalige Kommissionspräsident Romano Prodi äußerte 2002 deutliche Worte in Bezug auf die SWP-Regelungen, die er als »starr « und »dumm « bezeichnete (FAZ, 17.10.2002) und die im Lichte der Euro-Krise aus der Zeit gefallen scheinen. Mit der 2005 beschlossenen Reform wurden deshalb zwar die grundsätzlichen Zielsetzungen des Pakts beibehalten, zugleich aber »eine Reihe von Tatbeständen aufgezählt, mit denen die Mitgliedsstaaten in Zukunft Überschreitungen rechtfertigen können.«(Kromphardt 2005, 688; vgl. auch Mitchell 2017, 303) Weiterhin wurde »empfohlen, den Kurs der Haushaltskonsolidierung von der Konjunkturlage abhängig zu ma- 
chen.« (Kromphardt 2005, 688) Kromphardt $(2005,693)$ bewertet die Reform letztlich positiv, da sie "zu einer sinnvolleren Ausgestaltung des Europäischen Stabilitäts- und Wachstumspaktes geführt [hat]«. So seien die betroffenen Mitgliedstaaten nicht gezwungen, »kurzfristig unerreichbare oder wohlfahrtsmindernde Ziele anzustreben.« (Ebd.) Allerdings hält er ebenso fest, dass der SWP »jedoch um eine klare und umsetzbare Verpflichtung auf eine mittelfristige Konsolidierungsstrategie« hätte ergänzt werden müssen, »um die auf Dauer unumgängliche Stabilisierung der Zinslastquote zu erreichen.« (Ebd.) Genau in eine solche Richtung zielt schließlich eine der 2011 vorgenommenen Änderung am SWP.

Den eigentlichen Reformen an den SWP-Verordnungen ist die Richtlinie 2011/85/EU vorangestellt, in der Anforderungen an die haushaltspolitischen Rahmen der Mitgliedstaaten festgelegt werden. Sie ist im Sinne einer technischen und methodischen Vereinheitlichung der mitgliedstaatlichen haushaltspolitischen Prozesse zu verstehen. So werden unter anderem Regelungen getroffen, die auf ein gemeinsames Verständnis zielen, beispielsweise in Form einheitlicher Anforderungen für Statistiken (vgl. Kap. II RL 2011/85/EU). Neben den Bemühungen um eine umfassende Transparenz im Bereich der öffentlichen Finanzen (vgl. Kap. IV RL 2011/85/EU) ist insbesondere die Forderung nach einem mehrjährigen, mittelfristigen Haushaltsrahmen mit einem Planungshorizont von mindestens drei Jahren von Bedeutung (vgl. Art. 9 RL 2011/85/EU), der auch in den weiteren Legislativakten eine Rolle spielt. Erst im Rahmen der mittelfristigen Haushaltsplanung werden auch die Korrekturmechanismen des präventiven und korrektiven Arms des SWP vollends verständlich. In diesem Sinne ist die Richtlinie als Akt der Vereinheitlichung unter von der EU gesetzten Standards zu verstehen. Weiterhin fordert die Richtlinie auf nationaler Ebene »Regelungen für eine unabhängige Überwachung und Durchführung von Analysen zur Erhöhung der Transparenz einzelner Elemente des Haushaltsprozesses « (Art. 2 RL 2011/85/EU), die beispielsweise durch Rechnungshöfe geleistet werden könnten. Erstaunlich sind an der Richtlinie insgesamt aber weniger die inhaltlichen Bestimmungen als vielmehr die Tatsache, dass ein vergleichbarer Rahmen für die mitgliedstaatlichen Prozesse der Haushaltserstellung bis zur Euro-Krise nicht oder nur in einem sehr rudimentären Ausmaß vorhanden schienen. Dass eine solche Richtlinie erst zehn Jahre nach Einführung der Gemeinschaftswährung beschlossen wurde, mag noch einmal unterstreichen, dass die Konstruktionsmängel nicht nur inhaltlicher Natur sind, sondern auch auf technischer Ebene sichtbar werden. Im Sinne der Herausbildung von Staatlichkeit als Monopolisierungs- und Konzentrationsprozess und unter Hinweis auf Bourdieus Terminus der Benennungsmacht deutet aber bereits diese eher technisch ausgerichtete Richtlinie auf einen Ausbau der EU-Staatlichkeit hin, der sich in den drei SWP-Reformverordnungen fortsetzen wird.

Die präventive Komponente des SWP wurde mit der Verordnung (EU) Nr. 1175/2011 in drei zentralen Bereichen erweitert. Hierzu zählen neben neuen haushaltspolitischen Kriterien (insb. das sog. mittelfristige Haushaltsziel: `Medium Term Objective‘; MTO) des Weiteren Anforderungen an die mitgliedstaatliche Berichtslegung und die hieran anschließende Prüfung und Überwachung durch die suprastaatlichen Apparate. All dies mit dem Ziel, 
»dass die EU-Mitgliedstaaten in guten Zeiten eine vorsichtige Finanzpolitik betreiben, um die für schlechte Zeiten notwendigen Polster zu bilden. Um der bisherigen Selbstzufriedenheit in Zeiten günstiger Konjunktur ein Ende zu setzen, wird sich die Überwachung der öffentlichen Finanzen auf das neue Konzept einer vorsichtigen Haushaltspolitik stützen, das eine Annäherung an das mittelfristige Ziel sicherstellen dürfte.« (KOM 2010k, 2; Herv. J. G.)

Im Zentrum des präventiven Arms des SWP steht das mittelfristige Haushaltsziel der Mitgliedstaaten, welches zwar »von der Anforderung eines nahezu ausgeglichenen oder einen Überschuss aufweisenden Haushalts abweichen« könne, für Euro-Mitgliedsstaaten und WKM-II-Mitglieder allerdings »innerhalb einer konkreten Spanne, die konjunkturbereinigt und ohne Anrechnung einmaliger und befristeter Maßnahmen zwischen $-1 \%$ des BIP und einem ausgeglichenen oder einen Überschuss aufweisenden Haushalt « (Art. 2 a VO (EG) Nr. 1466/97 i. d. F. VO (EU) Nr. 1175/2011) liegen solle. Die kriteriale Normierung des mittelfristigen Haushaltsziels verbleibt damit auf dem Stand der $2005 \mathrm{er}$ Reform (vgl. VO (EU) Nr. 1055/2005), wobei sowohl 2005 als auch 2011 Erwähnung findet, dass der »Notwendigkeit von öffentlichen Investitionen Rechnung getragen« werden solle und Abweichungen für den Fall möglich sind, dass "strukturelle Reformen« durchgeführt werden (Art. 2 a VO (EG) Nr. 1466/97 i. d. F. VO (EU) Nr. 1175/2011). Neu ist, dass das mittelfristige Haushaltsziel alle drei Jahre zu überprüfen sei (vgl. ebd.). Die eigentliche Verschärfung des präventiven SWP-Arms wird allerdings anhand der Anforderungen zur Erreichung des mittelfristigen Haushaltsziels deutlich. Hierbei haben Rat und Kommission zu prüfen,

»ob der betreffende Mitgliedstaat eine zur Erreichung dieses mittelfristigen Haushaltsziels angemessene jährliche Verbesserung eines konjunkturbereinigten Haushaltssaldos ohne Anrechnung einmaliger und sonstiger befristeter Maßnahmen verfolgt, wobei ein Richtwert von 0,5\% des BIP zugrunde gelegt wird.«(Art. 5, Abs. 1 (1) VO (EG) Nr. 1466/97 i. d. F. VO (EU) Nr. 1175/2011)

Die Verschärfung setzt nun bei jenen Mitgliedstaaten an, deren Schuldenstand über $60 \%$ des BIP liegt oder jenen »mit ausgeprägten Risiken hinsichtlich der Tragfähigkeit ihrer Gesamtschulen « (ebd.). Hier prüfen Rat und Kommission, ob die fiskalischen Verbesserungen »über $0,5 \%$ des BIP hinausgehen« (ebd.). Zugleich gelten folgende Bedingungen, die bei der Bewertung des Anpassungspfades zu berücksichtigen sind: (a) für Länder, die das mittelfristige Haushaltsziel erreicht haben, gilt, dass das jährliche Ausgabenwachstum nicht über der mittelfristigen Referenzrate des potenziellen BIPWachstums hinausgehen darf, es sei denn, es wird durch Maßnahmen auf der Einnahmenseite ausgeglichen; (b) für Länder, die das mittelfristige Haushaltsziel noch nicht erreicht haben, gilt einerseits, dass das Ausgabenwachstum unterhalb der mittelfristigen Referenzrate liegen muss und (c) andererseits, dass jede »diskretionäre Senkung der Staatseinnahmen entweder durch Ausgabenkürzungen oder durch eine diskretionäre Erhöhung anderer Staatseinnahmen« ausgeglichen werden müssen (vgl. ebd.). Daneben wird in Artikel 6, Absatz 3 definiert, wann von einer »erheblichen Abweichung« 
ausgegangen wird. Beim strukturellen Haushaltssaldo ${ }^{11}$ gilt, dass eine solche vorliegt, wenn diese »in einem Jahr mindestens $0,5 \%$ des BIP oder in zwei aufeinanderfolgenden Jahren im Durchschnitt mindestens $0,25 \%$ des BIP jährlich beträgt« (lit. a). Bei der Beurteilung der Ausgabenentwicklung gilt eine Abweichung als erheblich, wenn sie »eine Gesamtauswirkung auf den Haushaltssaldo von mindestens 0,5\% des BIP in einem Jahr oder kumulativ in zwei aufeinanderfolgenden Jahren hat « (lit. b). Ausnahmetatbestände ermöglichen aber auch weiterhin prinzipiell eine Abweichung von den festgeschriebenen Normierungen. Neben den bereits oben angesprochenen Investitionstätigkeiten und der Umsetzung von Strukturreformen findet sich auch im erneuerten SWP weiterhin eine Blaupause für die Nichteinhaltung. So kann

»[b]ei einem außergewöhnlichen Ereignis, das sich der Kontrolle des betreffenden Mitgliedstaats entzieht und erhebliche Auswirkungen auf die Lage der öffentlichen Finanzen hat, oder bei einem schweren Konjunkturabschwung im Euro-Währungsgebiet oder in der Union insgesamt [...] den Mitgliedstaaten gestattet werden, vorübergehend von dem Anpassungspfad [...] abzuweichen, vorausgesetzt, dies gefährdet nicht die mittelfristige Tragfähigkeit der öffentlichen Finanzen.«(Ebd.)

Der präventive Arm des SWP enthält somit immer noch Bestände einer antizyklischen Fiskalpolitik, die in einer gewissen Konkurrenz zum eigentlichen Austeritätsdogma des SWP stehen. Auch die Richtlinie 2011/85/EU gibt in Erwägungsgrund 18 letztlich die fiskalpolitische Leitlinie aus, nach der »[d]ie Mitgliedstaaten [...] eine prozyklische Finanzpolitik vermeiden und in Zeiten guter wirtschaftlicher Entwicklung ihre Haushaltskonsolidierungsanstrengungen verstärken [sollten].« Nicht nur der Blick auf die Maßnahmen in den sogenannten Programmländern offenbart vor diesem rechtlichen Hintergrund einen Widerspruch mit der konkreten Herrschaftspraxis in der Euro-Krise.

Auf Ebene der mitgliedstaatlichen Berichtslegung finden sich im reformierten SWP weitergehende Anforderungen an die Stabilitäts- und Konvergenzprogramme, die von Seiten der Mitgliedstaaten zu beachten sind. Beide Programme sollen künftig auf der »Tragfähigkeit der öffentlichen Finanzen« (Art. 3, Abs. 1 \& Art. 7, Abs. 1 VO (EG) Nr. 1466/97 i. d. F. VO (EU) Nr. 1175/2011) gründen. Ausgeführt werden in der neuen Fassung des SWP auch, welche Informationen in den Programmen enthalten sein müssen, beispielsweise solche über »implizite Verbindlichkeiten im Zusammenhang mit der Bevölkerungsalterung« (Art. 3, Abs. 2, lit. aa VO (EG) Nr. 1466/97 i. d. F. VO (EU) Nr. 1175/2011), die Vereinbarkeit mit den Grundzügen der Wirtschaftspolitik und nationaler Reformprogramme (lit. ab) sowie die ausführliche Darstellung der Hauptannahmen für die wirtschaftliche Entwicklung (lit. b). Festgeschrieben wird, dass die Programme auf dem »wahrscheinlichsten makrobudgetären [...] oder einem vorsichtigeren Szenario basieren« (Art. 3, Abs. 2a VO (EG) Nr. 1466/97 i. d. F. VO (EU) Nr. 1175/2011) sollten. Zugleich ist offenzulegen, wie die Programme im Rahmen der mitgliedstaatlichen Verfahren der Haushaltspolitik eingebunden sind, hierbei ist insbesondere die Rolle der Parlamente zu beschreiben (vgl. Art. 3, Abs. 4 VO (EG) Nr. 1466/97 i. d. F. VO (EU) Nr. 1175/2011).

11 Das strukturelle Haushaltssaldo drückt das um Sonder- und konjunkturelle Effekte bereinigte Haushaltsergebnis aus. 
Im Kontext der Prüfung und Überwachung im präventiven SWP-Arm wird mit dem Six-Pack schließlich ein Ausbau der entsprechenden Infrastrukturen betrieben. Auf die Prüfung der mittelfristigen Haushaltsziele durch Rat und Kommission wurde dabei schon hingewiesen. Bei der Neustrukturierung der mitgliedstaatlichen Überwachung fällt aber bereits hier auf, dass der Rat einen Teil seiner Befugnisse zugunsten der Kommission abgeben musste. So prüfte bis 2011 offiziell alleine der Rat die Anpassungspfade der Mitgliedstaaten auf das mittelfristige Haushaltsziel. Mit der nun in Kraft getretenen Änderung zeichnet auch die Kommission hierfür Verantwortung. Zudem wird die »multilaterale Überwachung « nicht mehr nur - wie auch noch 2005 - ausschließlich auf Seiten des Rates verortet, sondern auch die Kommission im entsprechenden Artikel 1 der Verordnung als Akteurin benannt. Die gewachsene Rolle der Kommission wird weiterhin deutlich, wenn man sich die Detailänderungen in weiteren Artikeln der SWPVerordnung anschaut. Demnach sind Rat und Kommission beispielsweise gemeinsam für die Prüfung der Stabilitäts- und Konvergenzprogramme verantwortlich (vgl. Art. 5, Abs. 1 (2) \& Art. 9, Abs. 2 VO (EG) Nr. 1466/97 i. d. F. VO (EU) Nr. 1175/2011). Auch die detaillierten Zuständigkeiten im Rahmen der multilateralen Überwachung sprechen für eine Kompetenzverschiebung durch die SWP-Reform. Im Rahmen der multilateralen Überwachung bilden die Programmbewertungen der Kommission und des Wirtschafts- und Finanzausschusses die Grundlage für das gesamte Verfahren. Neu ist, dass die Kommission in den veränderten Strukturen des SWP Verwarnungen im Kontext der Vermeidung übermäßiger Defizite an Mitgliedstaaten ausgibt (vgl. Art. 6, Abs. 2 \& Art. 10, Abs. 2 VO (EG) Nr. 1466/97 i. d. F. VO (EU) Nr. 1175/2011), die zuvor noch in die Beschlusszuständigkeit des Rates fiel. Der SWP wird somit bereits zu einem frühen Zeitpunkt im Verfahren zur Vermeidung beziehungsweise späteren Korrektur übermäßiger Defizite unabhängiger von den im Rat vertretenen mitgliedstaatlichen Regierungen. Allerdings verbleibt die Kompetenz zur Beschlussfassung von Empfehlungen über erforderliche (Korrektur-)Maßnahmen im Kompetenzbereich des Rates, der sie auf Empfehlung der Kommission an Mitgliedstaaten richten kann (vgl. ebd.). Geschieht dies, ist der adressierte Mitgliedstaat aufgefordert, einen Bericht »über die auf die Empfehlung hin ergriffenen Maßnahmen« (ebd.) abzugeben. Erweisen sich die im Bericht dargelegten Maßnahmen als nicht ausreichend, empfiehlt die Kommission dem Rat, »unverzüglich« mit qualifizierter Mehrheit einen Beschluss zu fassen, in dem festgestellt wird, »dass keine wirksamen Maßnahmen ergriffen wurden« (ebd.). Dies kann einhergehen mit einer weiteren Empfehlung an den entsprechenden Mitgliedstaat, in der weitere Maßnahmen eingefordert werden. In gewisser Weise zeigt dieses Verfahren viele Parallelen zum bisher gültigem (de-facto wie de-jure) auf. Das Verfahren spiegelt somit eine geteilte Kompetenzordnung und Ko-Produktion zwischen Rat und Kommission wider. Neu im Verfahren ist die letzte Stufe im Überwachungszyklus. Für den Fall, dass der Rat keinen Beschluss fasst, der feststellt, dass keine ausreichenden Maßnahmen seitens des Mitgliedstaates unternommen wurden, obliegt es der Kommission, bei fortbestehender Nichtbeachtung der an den Mitgliedstaat gerichteten Maßnahmenempfehlungen, dem Rat neuerlich eine Beschlussempfehlung vorzulegen. An dieser Stelle greift dann ein neues Abstimmungsprozedere, bei dem der Rat innerhalb von zehn Tagen nach Annahme der Empfehlung durch die Kommission diese mit 
einfacher Mehrheit ablehnen muss (reversed qualified majority voting; RQMV), ansonsten gilt sie als vom Rat angenommen (vgl. ebd.).

Mit der Reform der präventiven SWP-Komponente wurde, wie bereits angeführt, auch das Europäische Semester als jährlicher »Zyklus der Politiküberwachung und -koordinierung « (Erw. 14 VO (EU) Nr. 1175/2011), in dessen Rahmen »auf der nationalen Ebene stärker Eigenverantwortung für den Stabilitäts- und Wachstumspakt übernommen« (Erw. 15 VO (EU) Nr. 1175/2011) werden soll, vom reinen Agreement ins Sekundärrecht überführt. Wobei es den Gesetzgeber*innen wichtig erschien, noch einmal darauf hinzuweisen, dass

»die nationalen Parlamente umfassend in das Europäische Semester und die Erstellung der Stabilitätsprogramme, der Konvergenzprogramme sowie der nationalen Reformprogramme eingebunden werden [sollten], um die Transparenz der sowie die Eigenverantwortung und die Rechenschaftspflicht für die getroffenen Entscheidungen zu steigern.« (Erw. 16 VO (EU) Nr. 1175/2011)

Nach Einfügung des Artikels 2-a, Absatz 3 in die SWP-Verordnung (EG) Nr. 1466/97 nimmt die Kommission unter den neuen Vorgaben eine Bewertung der durch die Mitgliedstaaten einzureichenden Programme (Stabilitätsprogramm, Konvergenzprogramm, nationales Reformprogramm) vor, auf deren Grundlage der Rat entsprechende Leitlinien an die Mitgliedstaaten richtet, die gebührend zu berücksichtigen sind, »ehe sie die wesentlichen Beschlüsse über die nationalen Haushalte für die kommenden Jahre fassen.«Wird ein Mitgliedstaat den an ihn gerichteten Leitlinien nicht gerecht, sind neben den Instrumenten neuerlicher "Empfehlungen « und "Verwarnungen« seitens der Kommission auch Sanktionsmaßnahmen möglich, die auf Grundlage der SWP-Verordnung (EG) Nr. 1467/97 (i. d. F. VO (EU) Nr. 1177/2011) sowie der Verordnung (EU) Nr. 1176/2011 (Vermeidung makroökonomischer Ungleichgewichte) vom Rat verhängt werden können (s.u.).

Dabei ist es das »Verdienst « des Europäischen Parlaments, dass das Semester überhaupt eine sekundärrechtliche Verankerung erfahren hat (vgl. EP 2011f; vgl. auch Hallerberg, Marzinotto \& Wolff 2012). Der Verordnungsvorschlag der Kommission (KOM 2010h) war noch ohne die entsprechenden Artikel ausgekommen. Dabei hatte sich das Parlament bereits in seiner allgemeinen Entschließung zur »Verbesserung der Economic Governance und des Stabilitätsrahmens in der Union« vom Oktober 2010 deutlich für die Einführung eines Europäischen Semesters ausgesprochen,

»um mögliche Spill-over-Effekte nationaler haushaltspolitischer Maßnahmen sowie die frühzeitige Ermittlung übermäßiger Haushaltsdefizite anzugehen und die Kohärenz zwischen Maßnahmen im Rahmen der integrierten Leitlinien auf nationaler und auf Unionsebene sowie die Verwirklichung der quantitativen und qualitativen Zielvorgaben, z.B. Wachstum und Beschäftigung, zu gewährleisten, was einen wirklichen und rechtzeitigen Beitrag aller betroffenen Parteien, einschließlich der nationalen Parlamente und des Europäischen Parlaments, sowie die Konsultation mit den Sozialpartnern ermöglichen würde [...] (EP 2010c, Anlage, Empfehlung 2).

Insbesondere der letztgenannte Aspekt, die Einbindung des EP, der mitgliedstaatlichen Parlamente sowie der Sozialpartner, wird in der Empfehlung an anderer Stelle noch- 
mals wiederholt und ist auch im Kontrast zur tatsächlichen Implementierung der neuen Verfahren von Bedeutung. Mit der Verankerung des Semesters in den Sekundärrechtsakten verbanden die EP-Berichterstatter*innen ${ }^{12}$ nicht nur eine stärkere parlamentarische Beteiligung, sondern zugleich auch eine stärkere Verbindlichkeit des Verfahrens:

»Cesteigerte Eigenverantwortung, Transparenz, Peer Review und Beeinträchtigung des nationalen Ansehens (Regeln einhalten bzw. deren Nichteinhaltung erläutern (`comply or explain`)) über das `Europäische Semester sowie die Anreize und Sanktionen dieser im Zusammenhang stehenden Verfahren sollten eine stärkere Angleichung an die und Einhaltung der EU-Regeln durch die Mitgliedstaaten gewährleisten« (EP 2011g, 18f.),

wie es in einem der Parlamentsberichte vom April 2011 heißt. Insgesamt wird bereits an dieser Stelle ein generelles Handlungsmuster des Parlaments im Kontext der Krisenbewältigungspolitik deutlich, das sich in den weiteren Diskussionen noch expliziter zeigen wird: Das EP kritisiert die verbindlichere Ausgestaltung von suprastaatlichen Koordinierungs-, Überwachungs- und Sanktionsverfahren unter Zuhilfenahme einer gestärkten Europäischen Kommission nur sehr selten; vielmehr unterstützt sie einen solchen Ansatz auch dann, wenn es selber nicht in die entsprechenden Verfahren eingebunden ist. In diesem Handlungsansatz ließe sich die Strategie vermuten, nach welcher der Ausbau des suprastaatlichen Kompetenzrahmens - auch bei einseitiger Stärkung der Kommission - unterstützt wird, um später eine nachholende Parlamentarisierung anzustreben. Ausgangspunkt für eine solche Strategie, die sicherlich auf die Erfahrungswerte bei der Fortentwicklung parlamentarischer Beteiligungsrechte im Kontext früherer EU-Vertragsrevisionen zurückgreift (vgl. Hofmann \& Wessels 2009, 83), könnte hierbei der sogenannte »wirtschaftliche Dialog« (Art. 14 VO (EU) Nr. 1176/2011) darstellen, dessen Ergänzung das Parlament in den Six-Pack-Verhandlungen erreichen konnte (vgl. EP 2011b). Im Rahmen des Dialogs tritt das Parlament in einen regelmäßigen Austausch mit Vertreter*innen der Kommission, des Rates und auch der EZB über die europäische Wirtschaftspolitik. Allerdings erwachsen hierdurch keine weitreichenderen, formalen Mitsprache- oder gar Entscheidungsrechte. Angelegt als ein Kontrollund Diskussionsrahmen, bietet er lediglich die Möglichkeit, Ansichten und Meinungen zu äußern, deren Einfluss auf die konkrete Ausgestaltung daher ausschließlich informell wirken kann.

Die mit der Verordnung (EU) Nr. 1177/2011 im Rahmen der korrektiven SWPKomponente vorgenommenen Reformen zielen insbesondere auf zwei zentrale Bereiche, wobei der Ausbau der Prüfungs- und Überwachungsinfrastruktur eindeutig im Fokus der Reformbemühungen steht. Daneben findet des Weiteren eine Ausschärfung kriterialer Haushaltsnormierungen statt.

Mit der Reform der korrektiven Komponente des SWP wird hierbei erstmalig eine numerische Normierung der notwendigen Anpassung in Bezug auf einen rückläufigen Schuldenstand definiert, solange der Referenzwert von $60 \%$ des BIP überschritten ist.

12 Da es sich beim Six-Pack formal um sechs legislative Einzelmaßnahmen handelt, fungierten im Europäischen Parlament entsprechend unterschiedliche Berichterstatter ${ }^{*}$ innen für jeweils einen der Vorschläge. 
Mit dem neuen Absatz 1-a des Artikels 2 werden die Staatsschulden als »hinreichend rückläufig« bewertet, wenn sie sich »in den letzten drei Jahren durchschnittlich um ein Zwanzigstel verringert « haben (VO (EG) Nr. 1467/97 i. d. F. VO (EU) Nr. 1177/2011). Somit wird ein Interpretationsspielraum im SWP (vgl. Kromphardt 2005) geschlossen und ein künftig einzuhaltender Anpassungspfad verbindlich skizziert.

Das reformierte Prüfungs- und Überwachungsverfahren im Rahmen der korrektiven SWP-Komponente orientiert sich im Großen und Ganzen an den bereits vorhandenen Strukturen vorm Six-Pack. So legt die Kommission dem Rat eine Stellungnahme vor, wenn aus ihrer Sicht ein übermäßiges Defizit vorliegt. Die Entscheidung hierüber obliegt weiterhin dem Rat, der auch entsprechende Empfehlungen an den betroffenen Mitgliedstaat richtet, in denen ihm sechs Monate Zeit für Korrekturmaßnahmen eingeräumt werden (vgl. Art. 3 VO (EG) Nr. 1467/97 i. d. F. VO (EU) Nr. 1177/2011). Neu ist aber, dass »wenn der Ernst der Lage es erfordert [...], die Frist für wirksame Maßnahmen drei Monate betragen [kann]«(Art. 3, Abs. 4 VO (EG) Nr. 1467/97 i. d. F. VO (EU) Nr. 1177/2011), auch wenn das rekodifizierte Verfahren weiterhin einen Aufschub beim Eintritt »unerwartete[r] nachteilige[r] wirtschaftliche[r] Ereignisse« (Art. 3, Abs. 5 VO (EG) Nr. 1467/97 i. d. F. VO (EU) Nr. 1177/2011) ermöglicht. Ist eine entsprechende Empfehlung des Rates an einen Mitgliedstaat erlassen, so ist dieser aufgefordert, seine Maßnahmen in Form eines Berichts offenzulegen (vgl. Art. 3, Abs. 4a VO (EG) Nr. 1467/97 i. d. F. VO (EU) Nr. 1177/2011). Dieser wird wiederum durch den Rat abschließend bewertet. Wenn der Rat hierbei zu der Auffassung gelangt, dass keine ausreichenden Maßnahmen durch den Mitgliedstaat zur Reduktion des Defizits beschlossen wurden, wird dem Europäischen Rat hierüber ein Bericht vorgelegt (vgl. Art. 4 VO (EG) Nr. 1467/97 i. d. F. VO (EU) Nr. 1177/2011). Dies ist ein Novum im SWP. Erstmals wird der Europäische Rat direkt in die Überwachungsstrukturen mit eingebunden, was primärrechtlich nicht vorgesehen ist und deshalb Fragen in Bezug auf die Vertragskonformität eröffnet (vgl. Hattenberger 2012, Rn. 45).

Weiterhin kann der ECOFIN-Rat innerhalb einer Frist von zwei Monaten nach Beschlussfassung darüber, dass keine ausreichenden Maßnahmen ergriffen wurden, die Inverzugsetzung über Maßnahmen zum Defizitabbau beschließen. Dieses Verfahren ist zwar nicht neu, die sprachliche Kodifizierung allerdings wurde erweitert:

»In der Inverzugsetzung ersucht der Rat den Mitgliedstaat, jährliche Haushaltsziele zu erfüllen, die auf der Crundlage der die Empfehlung untermauernden Prognose mit einer als Richtwert dienenden jährlichen Mindestverbesserung des konjunkturbereinigten Saldos ohne Anrechnung einmaliger und befristeter Maßnahmen von mindestens 0,5\% des BIP vereinbar sind, um die Korrektur des übermäßigen Defizits innerhalb der in der Inverzugsetzung gesetzten Frist zu gewährleisten. Der Rat gibt zudem Maßnahmen an, die der Erfüllung dieser Ziele förderlich sind.« (Art. 5, Abs. 1 VO (EG) Nr. 1467/97 i. d. F. VO (EU) Nr. 1177/2011; Herv. J. G.)

Die Kommission überwacht - wie bisher - die Maßnahmen in Kooperation mit dem Rat. Hierfür steht der Kommission mit der Reform des SWP allerdings ein neues Instrument zur Verfügung, die sogenannten Überwachungsmissionen. Neben dem Bekenntnis zur Gewährleistung eines ständigen Dialoges zwischen Kommission und mitgliedstaatlichen Behörden sowie Besuchen der Kommission zur »Prüfung der aktuellen Wirt- 
schaftslage [...] und zur Ermittlung möglicher Risiken oder Probleme« bietet der neue Artikel 10-a der Verordnung (EG) Nr. 1467/97 (i. d. F. VO (EU) Nr. 1177/2011) die Möglichkeit einer »verstärkte[n] Überwachung zum Zweck der Beobachtung vor Ort«, wobei die Kommission dem Rat hierüber Bericht erstattet, der seitens der Kommission auch veröffentlicht werden kann. Im Rahmen des Verfahrens bei einem übermäßigen Defizit ist zudem als letztmögliches Instrument weiterhin die Verhängung von Sanktionen durch den Rat möglich. Die Höhe und Zusammensetzung der Sanktionen verbleibt im bisherigen Rahmen, wobei die verhängten Geldbußen seit der 2011er Reform nicht mehr in den Haushalt der EU, sondern an den ESM fließen (vgl. Art. 16 VO (EG) Nr. 1467/97 i. d. F. VO (EU) Nr. 1177/2011).

Zusätzlich zu den Änderungen am Stabilitäts- und Wachstumspakt, der für alle EUMitgliedstaaten Gültigkeit besitzt, wurden mit der Verordnung (EU) Nr. 1173/2011 gestützt auf Artikel 136 AEUV für Mitgliedstaaten des Euro-Währungsgebiets zusätzliche Maßnahmen zur "wirksamen Durchsetzung der haushaltspolitischen Überwachung« verabschiedet, da sie

»ein besonderes Interesse daran [haben], bzw. [...] eine besondere Verantwortung dafür [tragen], eine Wirtschaftspolitik zu verfolgen, durch die das ordnungsgemäße Funktionieren der Wirtschafts- und Währungsunion gefördert wird, und Maßnahmen zu vermeiden, durch die dieses Funktionieren gefährdet wird.« (Erw. 1 VO (EU) Nr. 1173/2011)

Im Konkreten verschärft die Verordnung die Sanktionsmöglichkeiten gegenüber den Euro-Mitgliedstaaten im Rahmen beider SWP-Komponenten. Beginnend im korrektiven Arm ergibt sich in Bezug auf die oben angeführten Sanktionen ein verändertes Verfahren für Euro-Länder. Durch die Einführung des sogenannten reversed qualified majority voting (RQMV) wird es erleichtert, entsprechende Sanktionen zu verhängen. So kann die Kommission Sanktionen empfehlen, die als beschlossen gelten, wenn der Rat sie nicht binnen zehn Tagen mit qualifizierter Mehrheit ablehnt (vgl. Art. 6 VO (EU) Nr. 1173/2011). Der betreffende Mitgliedstaat ist hierbei nicht stimmberechtigt (vgl. Art. 12 VO (EU) Nr. 1173/2011). In der juristischen Literatur wird das neue RQMV-Abstimmungsverfahren dabei häufig auf Grundlage der geltenden EUVerträge als nicht rechtskonform bewertet (vgl. u.a. Häde 2016, Art. 121, Rn. 23), weshalb Oberndorfer $(2015,195)$ letztlich auch vor dem Hintergrund der weiteren Verschärfungen des SWP eine ordentliche Vertragsrevision für nötig gehalten hätte. Dies gilt letztlich insbesondere für die Verordnung (EU) Nr. 1173/2011, die einen neuen SWP-Durchsetzungsmechanismus für Eurostaaten begründet, mit dem der bisherige Kompetenzrahmen der EU-Verträge überschritten werde (vgl. u.a. Hattenberger 2012, Rn. 46). Diese Überschreitung leite sich nicht zuletzt aufgrund zwei neuer Sanktionsformate gegenüber Euro-Mitgliedstaaten her, die bereits im Rahmen der präventiven SWP-Komponente aufgefordert werden können, eine verzinsliche Einlage bei der Kommission zu hinterlegen. Die Kommission kann die Verhängung einer verzinslichen Einlage empfehlen, sobald der Rat eine Empfehlung in Folge einer Abweichung vom Anpassungspfad auf das mittelfristige Haushaltsziel ausgesprochen hat, deren Höhe maximal 0,2 \% des BIP betragen darf (vgl. Art. 4 VO (EU) Nr. 1173/2011). Auch hier gilt das umgekehrte Abstimmungsprozedere wie bei der Verhängung von Geldbußen. 
Zugleich eröffnet die Verordnung (EU) Nr. 1173/2011 die Möglichkeit, im Rahmen des korrektiven Arms des SWP bereits nach Feststellung eines übermäßigen Defizits eine Sanktionierung durch eine unverzinsliche Einlage zu verhängen (vgl. Art. 5 VO (EU) Nr. 1173/2011). Anders als bei einer verhängten Geldbuße, die erst später im Verfahren bei einem übermäßigen Defizit verhängt werden kann, ist diese Form der Sanktionierung bereits am Ausgangspunkt des Verfahrens vorgesehen. Auch hier gilt, wie bei der verzinslichen Einlage in der präventiven SWP-Komponente, das skizzierte Abstimmungsverfahren und die maximale Höhe von $0,2 \%$ des BIP. Neu geschaffen ist des Weiteren die Möglichkeit, Sanktionen bei Manipulation von Statistiken zu verhängen. So kann »der Rat, der auf Empfehlung der Kommission tätig wird, [...] beschließen, gegen einen Mitgliedstaat, der Daten über Defizite und Schulden [...] absichtlich oder aufgrund schwerwiegender Nachlässigkeit falsch darstellt, eine Geldbuße zu verhängen.« (Art. 8, Abs. I VO (EU) Nr. 1173/2011) Weiter heißt es, dass »[d]ie Geldbußen nach Absatz 1 [...] wirksam, abschreckend und - in Bezug auf Art, Schwere und Dauer der Verfälschung der Darstellung - verhältnismäßig sein [müssen].« (Art. 8, Abs. 2 VO (EU) Nr. 1173/2011)

Neben dem Ausbau von Sanktionsmöglichkeiten gegenüber den Euro-Mitgliedsstaaten forcierte die Kommission mit zwei weiteren Verordnungsvorschlägen, die später als Two-Pack bezeichnet wurden, den weiteren Ausbau des fiskalpolitischen Regierens in der Eurozone. Laut Kommission (2013c, 6) zeigten sich dabei im Laufe des Jahres 2011 die Abhängigkeiten zwischen den Euro-Mitgliedstaaten immer deutlicher. Trotz der mit dem Six-Pack angestoßenen Reformdiskussionen schwächte sich die Krise nicht merklich ab. Stattdessen waren mit Irland und Portugal zwei weitere Eurostaaten auf Hilfskredite angewiesen und Griechenland stand kurz vor einem zweiten Hilfspakt. Vor diesem Hintergrund habe die Kommission den Gesetzgebern zwei weitere Legislativakte vorgeschlagen, mit denen die Vervollständigung des Europäischen Semesters durch verstärkte Überwachung und Koordinierung und weitere Ergänzungen des SWP beabsichtigt wurden (vgl. Erw. 9 VO (EU) Nr. 473/2013). Das verstärkte Überwachungsverfahren solle dabei »zu besseren haushalts- und wirtschaftspolitischen Ergebnissen, makrofinanzieller Stabilität und Wirtschaftskonvergenz beitragen« (Ebd.). Ansatzpunkt stellt abermals die Haushaltspolitik dar, die anhand eines gemeinsamen Haushaltszeitplans ausgerichtet und noch stärker synchronisiert werden soll (vgl. Erw. 12 VO (EU) Nr. 473/2013). Allerdings werde den Mitgliedstaaten mit der Verordnung ausdrücklich »keine zusätzlichen Anforderungen oder Verpflichtungen in Bezug auf länderspezifische numerische Haushaltsregeln auferlegt.«(Erw. 18 VO (EU) Nr. 473/2013) Als gänzlich neues Instrument werden mit der Verordnung sogenannte Wirtschaftspartnerschaftsprogramme geschaffen, die auf den bekannten Reform- und Stabilitätsprogrammen des SWP aufbauen und in denen Mitgliedstaaten, die sich in einem Defizitverfahren befinden, »die politischen Maßnahmen und die Strukturreformen im Einzelnen« (Erw. 28 VO (EU) Nr. 473/2013) aufführen müssen, mit denen sie schließlich auch eine fiskalische Konsolidierung erreichen möchten.

Die zusätzlichen Regelungen zur Synchronisation der mitgliedstaatlichen Haushaltsplanungen basieren auf drei Aspekten, die künftig durch die Euro-Mitgliedstaaten zu beachten sind. Demnach ist erstens auf die zeitliche Synchronisation hinzuweisen, nach der spätestens bis zum 30. April eines Jahres die mittelfristige Haushaltsplanung vorzu- 
legen und spätestens zum 15. Oktober der Haushaltsplan des Folgejahres zu veröffentlichen ist, bevor der endgültige Haushaltsbeschluss zum 31. Dezember zu erfolgen hat (vgl. Art. 4 VO (EU) Nr. 473/2013). Im Sinne inhaltlicher Kohärenz und Synchronisation der Koordinierungs-Verfahren sind die Mitgliedstaaten zweitens dazu angehalten, ihre (mittelfristige) Finanz- und Haushaltsplanung mit den im SWP vorgesehenen Stabilitätsprogrammen in Einklang zu bringen und die mittelfristige Planung zeitgleich mit dem Stabilitäts- und dem nationalen Reformprogramm vorzulegen (vgl. Art. 4, Abs. I VO (EU) Nr. 473/2013). Als dritter, ebenfalls inhaltlicher Aspekt, sind die Eurostaaten dazu aufgefordert, in ihrer Finanzplanung sowie im nationalen Reformprogramm aufzuzeigen, wie ihre Planungen im Einklang mit den Zielen der Strategie der Union für Wachstum und Beschäftigung stehen (vgl. ebd.). Somit werden die Mitgliedstaaten durch die Verordnung (EU) Nr. 473/2013 auch noch einmal auf die Zielvorgaben der Europe-2020-Strategie eingeschworen. Neben diesen Regelungen ist des Weiteren vorgesehen, dass die mitgliedstaatlichen Planungen durch "unabhängige Einrichtungen« auf der mitgliedstaatlichen Ebene geprüft werden, die die Einhaltung der genannten Verordnung sowie der in anderen Rechtsakten hinterlegten Verfahren und Regelungen bewerten (vgl. Art. 5 VO (EU) Nr. 473/2013). In diesem Sinne wird an dieser Stelle eine erhöhte Verbindlichkeit der Verfahrensregeln hergestellt, die zuvor hauptsächlich in der Richtlinie 2011/85/EU hinterlegt waren und demnach in der Hierarchie der EUSekundärrechtsakte nur einen geringeren Stellenwert einnahmen.

Weitreichender als die technischen Verfahren zur synchronisierten Aufstellung der mitgliedstaatlichen Haushaltspläne erscheint hingegen der weitere Ausbau des Überwachungsverfahrens und der hierin angelegten weiteren Verschärfung der Überwachung durch suprastaatliche Apparate, die in Kapitel 4 der Verordnung kodifiziert wird. Neben weiter ausdifferenzierten Anforderungen an die einzureichenden Unterlagen (vgl. Art. 6 VO (EU) Nr. 473/2013) stellt die Bewertung der Haushaltsplanungen, wie sie Artikel 7 der Verordnung (EU) Nr. 473/2013 vorsieht, abermals eine Stärkung der Kommission dar. Sie gibt bis zum 30. November eine Stellungnahme zu den eingereichten Übersichten der avisierten mitgliedstaatlichen Haushaltsplanungen ab (vgl. Art. 7, Abs. 1 VO (EU) Nr. 473/2013). Sie kann - in Ausnahmefällen - allerdings bereits binnen einer Woche einen Mitgliedstaat auffordern, eine überarbeitete Haushaltsübersicht einzureichen, wenn sie »einen besonders schwerwiegenden Verstoß gegen die im Stabilitäts- und Wachstumspakt festgelegten haushaltspolitischen Verpflichtungen feststell« (Art. 7, Abs. 2 VO (EU) Nr. 473/2013). ${ }^{13}$ Die Stellungnahmen der Kommission werden anschließend der Euro-Gruppe vorgestellt, auf gesonderten Antrag ist dies auch im Europäischen Parlament oder in mitgliedstaatlichen Parlamenten möglich (vgl. Art. 7, Abs. 3 VO (EU) Nr. 473/2013). Neben der Bewertung der mitgliedstaatlichen Haushaltsübersichten zieht die Kommission hieraus zugleich eine Bewertung der Haushaltslage für die Euro-Zone im Gesamten. Hierbei kann sie Maßnahmen vorschlagen, »die auf eine stärkere Koordinierung der Haushaltspolitik und der makroökonomischen Strategie auf der Ebene des Euro-Währungsgebiets ausgerichtet sind.« (Art. 7, Abs. 4 VO (EU) Nr. 473/2013) Die Euro-Gruppe erörtert schließlich alle Stellungnahmen der Kommission (vgl. Art. 7, Abs. 
5 VO (EU) Nr. 473/2013). Außerdem gehen die Euroländer mit der Verordnung die Verpflichtung ein, die Kommission und die Euro-Gruppe künftig »im Voraus und rechtzeitig« (Art. 8 VO (EU) Nr. 473/2013) über die Emission von Schuldtiteln zu unterrichten.

Sobald im Sinne des SWP ein übermäßiges Defizit festgestellt wird, findet mit der Verordnung (EU) Nr. 473/2013 für Euro-Mitgliedstaaten zudem ein ausgebauter Rahmen zur Korrektur der attestierten übermäßigen Defizite Anwendung, der unter dem Schlagwort der Wirtschaftspartnerschaftsprogramme firmiert. Interessanterweise fehlte dieses neue Instrument im Kommissionsvorschlag vom November 2011 noch gänzlich (vgl. KOM 2011e). Erst im Laufe des informellen Trilogs wurden die Wirtschaftspartnerschaftsprogramme in den Verordnungstext aufgenommen, wobei die Initiative hierfür auf die Staats- und Regierungschefs der Eurozone zurückgeht. Im Zusammenhang mit dem fiskalpolitischen Pakt des SKS-Vertrags formulierten sie im Dezember 2011 einen der späteren Umsetzung entsprechenden Vorschlag (vgl. Euro-Gipfel 2011d, 3), der neben der Berücksichtigung im Two-Pack zugleich auch in den SKS-Vertrag Eingang fand (vgl. Art. 5 SKS-V). Als neues Instrument bündelt es einerseits die notwendigen Maßnahmen, die sich aus den SWP-Verordnungen ergeben (vgl. Art. 9, Abs. 3 VO (EU) Nr. 473/2013) weist aber andererseits qualitativ über die bisherigen Instrumente hinaus. Wird laut SWP-Verordnung vom Mitgliedstaat mit festgestelltem Defizit lediglich ein Bericht über zu treffende Gegenmaßnahmen eingefordert (vgl. Art.3, Abs. 4a VO (EG) Nr. 1467/97 i. d. F. VO (EU) Nr. 1177/2011), beschreibt die neue Verordnung (EU) Nr. 473/2013 das nun geforderte Wirtschaftspartnerschaftsprogramm eines Mitgliedstaats als

»Weiterentwicklung seines nationalen Reformprogramms und seines Stabilitätsprogramms, [in dem] die politischen Maßnahmen und strukturelle Reformen dargelegt werden, die erforderlich sind, um eine wirkliche und dauerhafte Korrektur des übermäßigen Defizits sicherzustellen, und das den Empfehlungen des Rates über die Umsetzung der integrierten Leitlinien für die Wirtschafts- und Beschäftigungspolitik des betroffenen Mitgliedstaats umfassend Rechnung trägt.«(Art. 9, Abs. 1 VO (EU) Nr. 473/2013)

Dabei sollen - so heißt es in der Verordnung weiter - »eine Reihe spezifischer Prioritäten ermittelt und ausgewählt [werden], die darauf ausgerichtet sind, die Wettbewerbsfähigkeit zu stärken, ein dauerhaft nachhaltiges Wachstum zu fördern und strukturelle Schwächen des betroffenen Mitgliedstaats in Angriff zu nehmen« (Art. 9, Abs. 2 VO (EU) Nr. 473/2013), wobei jene Prioritäten im Einklang mit der Europe-2020-Strategie $\mathrm{zu}$ stehen haben und zugleich anzuzeigen ist, wie Reformen ggf. auch über externe Finanzierungsmöglichkeiten (bspw. die Europäische Investitionsbank) gegenfinanziert werden können. Weiterhin kann der Korrekturmaßnahmenplan, der im Verfahren bei makroökonomischen Ungleichgewichten eingefordert wird (s.u.), in die Erarbeitung des Wirtschaftspartnerschaftsprogramms einbezogen werden (vgl. Art. 9, Abs. 5 VO (EU) Nr. 473/2013). Schließlich gehe es um eine Art ganzheitliche Betrachtung, bei der »haushaltspolitische Maßnahmen möglicherweise nicht ausreichen, um eine dauerhafte Korrektur des übermäßigen Defizits zu bewirken« (Erw. 28 VO (EU) Nr. 473/2013). Kommission und Rat überwachen gemeinsam die Durchführung des Programms (vgl. Art. 9, Abs. 6 VO (EU) Nr. 473/2013). Zudem kann der Rat auf Vorschlag der Kommis- 
sion in der Beschlussphase Stellungnahmen zum vorgelegten Programm abgeben (vgl. Art. 9, Abs. 4 VO (EU) Nr. 473/2013). Deutlich wird, dass mit dem Instrument der Wirtschaftspartnerschaftsprogramme eine Light-Version der aus der außerunionsvertraglichen Notstandsverfassung bekannten Memoranden beziehungsweise makroökonomischen Anpassungsprogramme geschaffen wurde, mit der auf eine striktere Konditionalität gezielt wird. Zwar gibt es im Defizitverfahren keine klassische Gegenleistung in Form von Krediten oder Darlehen, allerdings sind die geforderten Programm-Pflichten einzuhalten, um der Auslösung der möglichen Sanktionsmechanismen, die letztlich durch das Six-Pack insbesondere für die Eurozone verschärft wurden, vorzubeugen.

Auch die weiteren Berichtspflichten werden mit dem Two-Pack ausgebaut. So ist ein Mitgliedstaat, der Gegenstand eines Defizitverfahrens ist, aufgefordert, fortlaufend (halbjährlich) der Kommission und dem Wirtschafts- und Finanzausschuss eine umfassende Bewertung des Haushaltsverzugs vorzulegen und hierbei auch Eventualverbindlichkeiten zu berücksichtigen (vgl. Art. 10, Abs. 2-4 VO (EU) Nr. 473/2013), wobei »[d]er Kommission [...] die Befugnis übertragen [wird] [...], zur Festlegung des Inhalts der in diesem Absatz genannten regelmäßigen Berichterstattung delegierte Rechtsakte zu erlassen.« (Art. 10, Abs. 3 VO (EU) Nr. 473/2013; vgl. Art. 14 VO (EU) Nr. 473/2013) (4) $^{14}$ Sollte der Rat gar eine Inverzugsetzung (s.o.) beschließen, wird der Berichtsintervall verkürzt und der Mitgliedstaat ist angehalten, quartalsweise einen entsprechenden Bericht zu erstatten (vgl. Art. 10, Abs. 5 VO (EU) Nr. 473/2013). Eurostat prüft hierbei die Qualität der vorgelegten Daten (vgl. Art. 10, Abs. 6 VO (EU) Nr. 473/2013). Für den Fall, dass die Kommission die Gefahr sieht, dass die Korrekturfrist nicht eingehalten wird, richtet sie eine Empfehlung an den betreffenden Mitgliedstaat, in dem er aufgefordert wird, die im »Beschluss über die Inverzugsetzung vorgesehenen Maßnahmen vollständig umzusetzen oder andere Maßnahmen zur Korrektur seines übermäßigen Defizits zu ergreifen, oder beides.« (Art. 11, Abs. 2 VO (EU) Nr. 473/2013) Über den Umgang mit einer solchen Empfehlung ist wiederum vom Mitgliedstaat Bericht zu erstatten (vgl. Art. 11, Abs. 3 VO (EU) Nr. 473/2013). Dabei findet das skizzierte Verfahren im Kontext der Wirtschaftspartnerschaftsprogramme ebenso wie die ausgebaute Überwachung nur Anwendung, wenn die Mitgliedstaaten nicht zugleich Gegenstand eines makroökonomischen Anpassungsprogramms auf Grundlage der außerunionsvertraglichen Notstandsverfassung sind (vgl. Art. 13 VO (EU) Nr. 473/2013). In einem solchen Falle greift schließlich die zweite Two-Pack-Verordnung, auf die im weiteren Verlauf der Arbeit näher eingegangen wird.

\section{Die ausgebaute fiskalpolitische Überwachung als EU-Staatlichkeitspraxis}

Im Rahmen der fiskalpolitischen Überwachung lassen sich grundsätzlich (und für alle EU-Mitgliedstaaten) drei Eskalationsstufen unterscheiden, die in der Eurozone teilweise in einer verschärften Form exekutiert werden (können). Das Verfahren bei einem übermäßigen Defizit stellt die höchste dieser Stufen dar, in der auf Vorschlag der Kommission durch den Rat Empfehlungen an die Mitgliedstaaten gerichtet werden

14 Zum Zwecke der Berichtslegung hat die Kommission am 27. Juni 2013 eine Verordnung erlassen, in der die Übersichtsvorlagen zu den einzelnen Punkten der Berichtsverpflichtungen aufgeführt sind (DelVO (EU) Nr. 877/2013). 
und Euro-Staaten zugleich aufgefordert sind ein Wirtschaftspartnerschaftsprogramm (Light-Memorandum) vorzulegen. Zuvor kann die Kommission bereits entsprechende Berichte formulieren, wenn sie aufgrund ihrer Bewertung nicht zugleich auch die Einleitung eines formalen Verfahrens vorschlägt. Daneben ist im Six-Pack mit dem MTO als Kriterium des präventiven SWP-Arms ein neues Verfahren bei signifikanter Abweichung vom Anpassungspfad auf das mittelfristige Haushaltsziel etabliert worden. Eine Übersicht aller Verfahren seit 2009 ist in Tabelle 34 im Anhang hinterlegt.

Für die Mitgliedstaaten der Eurozone besteht seit der Two-Pack-Reform zudem ein intensiveres Überwachungsverfahren als für die übrigen EU-Mitgliedstaaten. Erfolgt die fiskalpolitische Überwachung der Nicht-Eurostaaten voranging auf Grundlage der jährlichen Konvergenzprogramme sowie der zwei Mal jährlich einzureichenden »Maastricht-Meldungen ${ }^{15}$, sind die Eurostaaten zusätzlich aufgefordert, jeweils im Herbst eines Jahres der Kommission die wichtigsten Parameter ihrer Haushaltsplanentwürfe des folgenden Jahres zur Prüfung vorzulegen. Die Kommission prüft ihrerseits die Entwürfe und bewertet ihre scompliance mit den Anforderungen des SWP. Im Rahmen des Prüfungszyklus kann die Kommission an Mitgliedstaaten Rückfragen richten oder sie auffordern, Konkretisierungen zu den Plänen einzureichen. Hiervon macht die Kommission auch Gebrauch, wie ein Blick in die entsprechenden Mitteilungen über die Gesamtbewertung (vgl. KOM 2018e; 2017r; 2016g; 2015l; 2014c) sowie auf die Website der Kommission (o.J. e) verrät, auf der entsprechende Schriftverkehre teilweise dokumentiert werden.

Tabelle 18: Prüfungsergebnisse der Haushaltsplanentwürfe der Euroländer (Haushaltsjahre 2015-19)

\begin{tabular}{|c|c|c|c|c|}
\hline $\begin{array}{l}\text { Haushalts- } \\
\text { jahr }\end{array}$ & Erfüllt & $\begin{array}{l}\text { Weitestgehend } \\
\text { erfüllt }\end{array}$ & $\begin{array}{c}\text { Risiko der } \\
\text { Nichterfüllung }\end{array}$ & $\begin{array}{l}\text { Besonders } \\
\text { schwerer } \\
\text { Verstoß }\end{array}$ \\
\hline 2015 & DE, IE, LU, NL, SK & $\mathrm{EE}, \mathrm{FI}, \mathrm{LV}, \mathrm{SI}$ & $\begin{array}{c}\text { AT, BE, ES, FR, IT, } \\
\text { MT, PT }\end{array}$ & - \\
\hline 2016 & DE, EE, LU, NL, SK & $\begin{array}{c}\mathrm{BE}, \mathrm{FI}, \mathrm{FR}, \mathrm{IE}, \mathrm{LV}, \\
\mathrm{MT}, \mathrm{SI}\end{array}$ & AT, ES, IT, LT & - \\
\hline 2017 & DE, EE, LU, NL, SK & AT, FR, IE, LV, MT & $\begin{array}{c}\text { BE, CY, ES, FI, IT, LT, } \\
\text { SI, PT }\end{array}$ & - \\
\hline 2018 & $\begin{array}{c}\mathrm{DE}, \mathrm{FI}, \mathrm{LT}, \mathrm{LU}, \mathrm{LV}, \\
\mathrm{NL}\end{array}$ & $\begin{array}{c}\mathrm{CY}, \mathrm{EE}, \mathrm{ES}, \mathrm{IE}, \mathrm{MT} \text {, } \\
\text { SK }\end{array}$ & AT, BE, FR, IT, PT, SI & - \\
\hline 2019 & $\begin{array}{l}\text { AT, CY, DE, FI, IE, } \\
\text { EL, LT, LU, MT, NL }\end{array}$ & EE, LV, SK & BE, ES, FR, PT, SI & IT \\
\hline \multicolumn{5}{|c|}{$\begin{array}{l}\text { AT - Österreich; BE-Belgien; CY - Zypern; DE-Deutschland; EE-Estland; EL-Criechenland; ES- } \\
\text { Spanien; FI - Finnland; FR - Frankreich; IE-Irland; IT - Italien; LT - Litauen; LU - Luxemburg; LV - } \\
\text { Lettland; MT - Malta; NL - Niederlande; PT - Portugal; SI-Slowenien; SK-Slowakei }\end{array}$} \\
\hline
\end{tabular}

Quelle: Eigene Zusammenstellung auf Grundlage von KOM (2018e; 2017r; 2016g; 2015l; 2014c) 
Im verschärften haushaltspolitischen Überwachungsverfahren des Europäischen Semesters stellt das Attestieren von besonders schweren Verstößen gegen die fiskalischen Anforderungen des konsolidierten SWP eine neue, dem VÜD vorgelagerte, Eskalationsstufe für die Eurostaaten dar. Dieser Fall trat bisher allerdings erst einmal ein: So hat die Kommission die italienischen Haushaltspläne für das Jahr 2019 zurückgewiesen und Italien zu Korrekturen aufgefordert (vgl. KOM 2018a). Erst nachdem Italien im Dezember 2018 die projektierte Neuverschuldung von 2,4\% auf 2,04\% im Budgetplan reduzierte, beschloss die Kommission kein Defizitverfahren einzuleiten (vgl. taz, 19.12.2018). Hätte es keine Einigung gegeben, wäre die Einleitung eines VÜD die Folge gewesen.

Auch wenn die Verfahren bei einem übermäßigen Defizit seit 2010/11 rückläufig sind (vgl. Tabelle 34 im Anhang) und 2019 mit Spanien das letzte Land das Verfahren verlassen hat (Beschluss (EU) 2019/1001), zeigt der Blick auf die fiskalpolitische Überwachungsinfrastruktur, dass die Kommission neben dem eigentlichen Defizitverfahren auch ihre weiteren Möglichkeiten zur Einflussnahme nutzt. Dies insbesondere auch vor dem Hintergrund, dass die Ergebnisse der Überwachung und die Bewertungen der mitgliedstaatlichen Fiskalpolitiken Eingang in die länderspezifischen Empfehlungen, als eines der wichtigsten suprastaatlichen Herrschaftsinstrumente, finden (s.u.).

\section{Die erweiterte Wirtschaftsregierung - Makroökonomische Überwachung}

Nach Ansicht der Kommission (2010g, 3) gelte es, künftig makroökonomische Ungleichgewichte »zusammen mit finanzpolitischen Aspekten und wachstumsfördernden Reformen im Rahmen von Europa 2020« zu betrachten. Während in der Mitteilung vom Juni 2010 in diesem Zusammenhang bereits von einem entsprechenden, indikatorgestützten Warnmechanismus die Rede war, wird dieser erst mit den konkreten Legislativvorschlägen des Six-Packs richtig greifbar. Kern des künftigen »Mechanismus zur Vermeidung und Korrektur makroökonomischer Ungleichgewichte« ist das sogenannte »Excessive Imbalance Procedure« (EIP), welches nach Meinung der Kommission »eine vollkommen neue Komponente im Verfahren der wirtschaftspolitischen Überwachung« darstelle und »die regelmäßige Bewertung von Ungleichgewichtsrisiken [umfasst], einschließlich eines Warnmechanismus, kombiniert mit Regeln, die bei nachteiligen makroökonomischen Ungleichgewichten über die Haushaltspolitik hinaus Korrekturmaßnahmen ermöglichen.« (Ebd., 4) Bestandteil des Warnmechanismus ist ein sogenanntes Scoreboard, bei dem für einzelne Indikatoren jeweils Warnschwellen festgelegt werden. Dabei sollen die zu definierenden Werte »als Richtgrößen für die Bewertung gesehen, jedoch nicht mechanisch ausgelegt werden« (ebd.). Sie werden deshalb durch eine »ökonomische Beurteilung « und »länderspezifischen Sachverstand « ergänzt (vgl. ebd.). Dem EIP als einzuleitender Mechanismus des `korrektiven Arms $\measuredangle$ bei einem festgestellten übermäßigen Ungleichgewicht ist das vorgelagerte und auf ein Gesamtmonitoring ausgerichtete MIP (Macroeconomic Imbalance Procedure), als Teil des 'präventiven Arms`, voranzustellen, das dem gesamten Mechanismus seinen Namen verleiht. Innerhalb des MIP-Rahmens beabsichtige die Kommission jährlich eine Liste der Mitgliedstaaten zu erstellen, bei denen sie die Gefahr eines Ungleichgewichts vermute, und die im Anschluss hieran »frühzeitig« im Rat und der Euro-Gruppe er- 
örtert werden solle (vgl. ebd., 5). Hieran könne sich eine »eingehende Überprüfung« etwaiger Ungleichgewichte anschließen, die zugleich »eine ausführliche Analyse der ursächlichen Probleme« (ebd.) beinhalte. Nach Vorschlag der Kommission würden die Ungleichgewichte anhand einer dreistufigen Skalierung klassifiziert: Werden sie als »unproblematisch« befunden, folgen keine weiteren Schritte; werden sie hingegen als problematisch angesehen, empfiehlt die Kommission dem Rat, »die nötigen präventiven Empfehlungen an den betreffenden Mitgliedstaat zu richten«; auf einer dritten Stufe können »schwere« Ungleichgewichte attestiert werden, »die das ordnungsgemäße Funktionieren der Wirtschafts- und Währungsunion zu gefährden drohen« (ebd.). Wird ein solcher Fall diagnostiziert, solle der Rat auf Empfehlung der Kommission den entsprechenden Mitgliedstaat auffordern können, »innerhalb einer bestimmten Frist Korrekturmaßnahmen zu ergreifen und seine beabsichtigte Politik in einem Korrekturmaßnahmenplan dazulegen.« (Ebd., 6) Diese Ungleichgewichtsstufe löse somit das EIP aus, innerhalb dessen die betreffenden Mitgliedstaaten unter »erhöhtem Gruppendruck« (ebd.) stünden und innerhalb bestimmter (flexibler) Fristen Maßnahmenpläne vorzulegen hätten, die durch die Kommission und den Rat zu bewerten seien. Erst wenn der Rat beschließt, dass der betreffende Mitgliedstaat »angemessene Maßnahmen ergriffen hat, ruht das Verfahren.«(Ebd.) Bis zu diesem Punkt solle der Mechanismus alle EU-Mitgliedstaaten einbeziehen. Für Euro-Mitgliedstaaten hingegen würde ein zusätzlicher Durchsetzungsmechanismus etabliert, der dann greife, wenn im Rahmen des EIP keine ausreichenden Gegenmaßnahmen attestiert und Empfehlungen des Rates nicht umgesetzt würden. In einem solchen Fall könnten Sanktionen in Form von jährlichen und deshalb nicht zwangsläufig einmaligen Geldbußen (0,1\% des Vorjahres-BIP) verhängt werden (vgl. ebd., 7). Nach Überzeugung der Kommission hätten Euro-Staaten »[d]urch die jährliche Geldbuße [...] auch dann noch den nötigen Anreiz, die Empfehlungen umzusetzen bzw. einen ausreichenden Korrekturmaßnahmenplan zu erstellen, wenn die erste Geldbuße schon entrichtet wurde.« (Ebd.) Sanktionsbeschlüsse sollten in der ECOFIN-Ratsformation unter Nichtbeteiligung der Nicht-Eurostaaten, also de facto der Euro-Gruppe, getroffen werden.

Das gerade skizzierte und in der Kommissionsmitteilung aus dem Frühjahr 2010 präsentierte Verfahren mündete schließlich in den beiden Verordnungen zum Ausbau der makoökonomischen Überwachung (VO (EU) Nr. 1174/2011 \& VO (EU) Nr. 1176/2011). Das grundsätzliche Ziel der beiden Verordnungen wird dabei noch einmal in den Erwägungsgründen 6 (VO (EU) Nr. 1174/2011) beziehungsweise 7 (VO (EU) Nr. 1176/2011) zusammengefasst:

»Insbesondere sollte die Überwachung der Wirtschaftspolitik der Mitgliedstaaten über die haushaltspolitische Überwachung hinaus um einen detaillierten und formalisierten Rahmen erweitert werden, um übermäßige makroökonomische Ungleichgewichte zu vermeiden und die betroffenen Mitgliedstaaten bei der Aufstellung von Korrekturplänen zu unterstützen, bevor sich Divergenzen verfestigen und die wirtschaftlichen und finanziellen Entwicklungen dauerhaft in eine äußerst nachteilige Richtung gehen. Diese Erweiterung der Überwachung der Wirtschaftspolitik sollte parallel zu einer Vertiefung der haushaltspolitischen Überwachung erfolgen.«(Herv. J. G.) 
Um »detaillierte Regeln für die Erkennung makroökonomischer Ungleichgewichte« (Art. 1, Abs. 1 VO (EU) Nr. 1176/2011) festzulegen, definiert die Verordnung (EU) Nr. 1176/2011 in Artikel 2, Absatz 1 Ungleichgewichte als »alle Trends, die zu makroökonomischen Entwicklungen führen, die sich nachteilig auf das ordnungsgemäße Funktionieren der Wirtschaft eines Mitgliedstaats oder der Wirtschafts- und Währungsunion oder der Union insgesamt auswirken oder potenziell auswirken können.« Übermäßige Ungleichgewichte sind demzufolge »schwere Ungleichgewichte, einschließlich Ungleichgewichte oder Risiken, die das ordnungsgemäße Funktionieren der Wirtschafts- und Währungsunion gefährden. (Art. 2, Abs. 2 VO (EU) Nr. 1176/2011) Diese Definitionen verweisen im Kern auf einen umfassenden Einbezug von potenziellen Indikatoren, welche es innerhalb der ausgebauten Überwachungsinfrastruktur $\mathrm{zu}$ berücksichtigen gelte. Zur Erkennung möglicher Ungleichgewichte wird der bereits skizzierte Warnmechanismus eingerichtet, der von der Kommission verantwortet wird und der über die multilaterale Überwachung nach Artikel 121 des AEUV in die Rats-Struktur eingebunden ist. Grundlage ist hierbei der jährliche Bericht der Kommission, der Aufschluss darüber geben soll, ob Ungleichgewichte vorhanden sind (vgl. Art. 3 VO (EU) Nr. 1176/2011). Methodisch basiert der Bericht auf dem bereits angekündigten Scoreboard (ausführlich s.u.), bei dem allerdings keine »Schlussfolgerungen [...] durch eine mechanische Auslegung der Indikatoren [...] gezogen [werden].« (Art. 3, Abs. 2 VO (EU) Nr. 1176/2011) Auch wenn die Detailausgestaltung des Scoreboards in Verantwortung der Kommission gelegt wurde (vgl. Art. 4, Abs. 6 VO (EU) Nr. 1176/2011), gibt die Verordnung einen Rahmen vor, indem Indikatoren zur Bewertung interner Ungleichgewichte (öffentliche und private Verschuldung, Entwicklung auf den Finanz- und Anlagemärkten (einschließlich Wohnungsmarkt), Kreditströme des privaten Sektors, Arbeitslosigkeit; vgl. Art. 4, Abs. 3a VO (EU) Nr. 1176/2011) und externer Ungleichgewichte (Leistungsbilanz- und Nettoinvestitionsposition, realer effektiver Wechselkurs, Anteil an Exportmärkten, Veränderungen der Preisund Kostenentwicklung, nichtpreisgebundene Wettbewerbsfähigkeit unter Berücksichtigung verschiedener Komponenten der Produktivität; vgl. Art. 4, Abs. 3b VO (EU) Nr. 1176/2011) definiert werden. Zugleich solle besondere Aufmerksamkeit auf realwirtschafte Entwicklungen (Wirtschaftswachstum, Beschäftigungsstand, Arbeitslosigkeit, nominale und reale Konvergenz, Produktivitätsentwicklung, Investitionen, sektorale Entwicklungen, das BIP und die Leistungsbilanzentwicklung; vgl. Art. 4, Abs. 4 VO (EU) Nr. 1176/2011) gelegt werden. Wirtschaftspolitisch verorten sich die Verordnungen innerhalb des Rahmens der Europe-2020-Strategie. So solle einerseits »die Wahl der Indikatoren und Schwellenwerte [...] der Förderung der Wettbewerbsfähigkeit in der Union dienlich sein « (Art. 4, Abs. 4 VO (EU) Nr. 1176/2011). Andererseits wird konstatiert, dass »die Bewertung von Mitgliedstaaten, die hohe Leistungsbilanzdefizite aufweisen [...], sich von der Bewertung der Mitgliedstaaten, die hohe Leistungsbilanzüberschüsse anhäufen, unterscheiden [kann].« (Art. 3, Abs. 2 VO (EU) Nr. 1176/2011) Hierdurch wird ein Akkumulationsansatz herausgestellt, der auf eine stark exportorientierte Wettbewerbsposition auf dem Weltmarkt zielt, wie er in Europe 2020 angelegt ist.

Anschließend an die Beratungen des jährlichen Kommissionsberichts im Rat kann die Kommission »unter gebührender Berücksichtigung« der Ratserörterungen »eine eingehende Überprüfung für jeden Mitgliedstaat durch[führen], der nach ihrer Auf- 
fassung von Ungleichgewichten betroffen oder bedroht sein könnte.« (Art. 5, Abs. I VO (EU) Nr. 1176/2011) »Im Falle von unerwarteten, bedeutsamen wirtschaftlichen Entwicklungen« (Art. 5, Abs. I VO (EU) Nr. 1176/2011) kann die Kommission aber auch ohne vorherige Ratskonsultation eine solche durchführen. Hieran wird deutlich, dass in potenziellen Krisenzeiten der Kommission die Aufgabe zufällt, eine möglichst schnelle und umfassende Analyse der makroökonomischen Kontextvariablen vorzunehmen. Dabei ist insgesamt zu prüfen, ob ein entsprechender Mitgliedstaat letztlich wirklich von Ungleichgewichten betroffen ist (vgl. Art. 5, Abs. 2 VO (EU) Nr. 1176/2011), wenn die Indikatoren des Scoreboards hierauf im Vorfeld hingewiesen hätten. Zugleich ist zu prüfen, ob die entsprechenden Ungleichgewichte als übermäßige zu bewerten sind (vgl. Art. 5 Abs., 2 VO (EU) Nr. 1176/2011). Die Kommission erlangt hierdurch eine Deutungshoheit über die makroökonomischen Bedingungen der Mitgliedstaaten, da sie den »Ursprung der entdeckten Ungleichgewichte [prüft]« und zugleich die »im Zusammenhang mit der Strategie der Union für Wachstum und Arbeitsplätze relevanten Entwicklungen analysiert.« (Art. 5, Abs. 2 VO (EU) Nr. 1176/2011) Insofern bewertet die Kommission vor dem Hintergrund der Europe-2020-Strategie die wirtschaftlichen (Wettbewerbs-)Positionen der Mitgliedstaaten. Soweit die Kommission zur Einschätzung gelangt, dass Ungleichgewichte bestehen, informiert sie die weiteren Institutionen (Parlament, Rat und Euro-Gruppe) hierüber und schlägt dem Rat eine Empfehlung an den betreffenden Mitgliedstaat vor (vgl. Art. 6 VO (EU) Nr. 1176/2011). Das bis hierhin skizzierte Verfahren orientiert sich an der oben dargestellten zweiten Stufe des MIP. Sobald allerdings übermäßige Ungleichgewichte konstatiert werden, schließt sich als Prozedere der Stufe drei das »Verfahren bei einem übermäßigen Ungleichgewicht« (Kap. III VO (EU) Nr. 1176/2011) und somit der >korrektive Arm` an. Demnach kann der Rat auf Empfehlung der Kommission feststellen, dass ein übermäßiges Ungleichgewicht besteht (vgl. Art. 7, Abs. 2 VO (EU) Nr. 1176/2011), was zugleich die Aufforderung an den betreffenden Mitgliedstaat impliziert, einen Korrekturmaßnahmenplan (inkl. Zeitplan) vorzulegen, mit dem den Ungleichgewichten begegnet werden solle (vgl. Art. 8, Abs. 1 VO (EU) Nr. 1176/2011). Auf der Grundlage des Korrekturmaßnahmenplans wird von Seiten der Kommission ein Bericht erstellt, auf dessen Grundlage wiederum der Rat die vom betroffenen Mitgliedstaat vorgelegten Maßnahmen bewertet und, soweit die Maßnahmen nach Ansicht des Rates ausreichend erscheinen, einen Überwachungszeitplan festlegt (vgl. Art. 8, Abs. 2 VO (EU) Nr. 1176/2011). Kommt der Rat auf Grundlage des Kommissionsberichts zur Einschätzung, dass der betreffende Mitgliedstaat keine ausreichenden Absichtserklärungen und Maßnahmenpakete vorgelegt hat, wird mit Frist von zwei Monaten ein überarbeiteter Korrekturmaßnahmenplan eingefordert (vgl. Art. 8, Abs. 3 VO (EU) Nr. 1176/2011). Zugleich werden sowohl die Maßnahmenpläne als auch die Kommissionsberichte und die Ratsempfehlungen veröffentlicht (vgl. Art. 8, Abs. 4 VO (EU) Nr. 1176/2011), um dem an anderen Stellen formulierten Anspruch eines erhöhten Gruppendrucks Genüge zu tun. Insgesamt kommt bei der Überwachung und der Bewertung der Korrekturmaßnahmen der Kommission eine entscheidende Rolle zu. Die Kommission legt dem Rat nach Artikel 9, Absatz 3 regelmäßig Fortschrittsberichte vor. Zusätzlich kann die Kommission »in dem betreffenden Mitgliedstaat Missionen zur verstärkten Überwachung durchführen, um die Durchführung des Korrekturmaß- 
nahmenplans zu überwachen, und zwar in Absprache mit der EZB [...].«(Art. 9, Abs. 3 VO (EU) Nr. 1176/2011; vgl. auch Kap. IV VO (EU) Nr. 1176/2011)

Die gestärkte Rolle der Kommission spiegelt sich letztlich auch im RQMVAbstimmungsverfahren im Rat wider. Zwar fasst der Rat weiterhin auf Empfehlung der Kommission den Beschluss, in dem die Nichteinhaltung festgestellt wird (inkl. eines Beschlusses über neue Fristen zur Durchführung der Korrekturmaßnahmen), die Empfehlung der Kommission gilt allerdings vom Rat angenommen, »sofern er nicht innerhalb von zehn Tagen nach ihrer Annahme durch die Kommission mit qualifizierter Mehrheit beschließt, die Empfehlung abzulehnen." (Art. 10, Abs. 4 VO (EU) Nr. 1176/2011) Stehen die getroffenen Maßnahmen des betroffenen Mitgliedstaates im Einklang mit dem von der Kommission erwarteten Fortschritt, ruht das gesamte Verfahren (vgl. Art. 10, Abs. 5 VO (EU) Nr. 1176/2011) und kann auf Grundlage einer Empfehlung der Kommission durch den Rat aufgehoben werden, »sobald er zu der Auffassung gelangt, dass in dem betreffenden Mitgliedstaat keine übermäßigen Ungleichgewichte [...] mehr bestehen.« (Art. 11 VO (EU) Nr. 1176/2011)

Wie bereits beschrieben, findet die Verordnung über die Vermeidung und Korrektur makroökonomischer Ungleichgewichte (VO (EU) Nr. 1176/2011) für alle EU-Mitglieder Anwendung, somit auch für jene Mitgliedstaaten, deren Währung nicht der Euro ist. Im Unterschied zu diesen Mitgliedstaaten kennt das Verfahren bei einem übermäßigen makroökonomischen Ungleichgewicht für Eurostaaten weitere Durchsetzungs- und Sanktionsmaßnahmen (VO (EU) 1174/2011). So wird eine verzinsliche Einlage auferlegt, wenn aufgrund der Nichteinhaltung des Korrekturmaßnahmenplans eine Empfehlung durch die Kommission ergeht (vgl. Art. 3, Abs. 1 VO (EU) Nr. 1174/2011). Die nächste Stufe der Sanktionierung kann durch Beschluss des Rates nach vorheriger Empfehlung der Kommission eingeleitet werden, wenn vom Rat zweimal ein unzureichender Korrekturmaßnahmenplan attestiert (vgl. Art. 3, Abs. 2a VO (EU) Nr. 1174/2011) oder aber zweimal die Nichteinhaltung der empfohlenen Korrekturmaßnahmen festgestellt wird (vgl. Art. 3, Abs. 2 b VO (EU) Nr. 1174/2011). In beiden Fällen wird statt einer verzinslichen Einlage eine jährliche Geldbuße in Höhe von 0,1\% des Vorjahres-BIP (vgl. Art. 3, Abs. 5 VO (EU) Nr. 1174/2011) fällig. Die Verhängung der Geldbußen erfolgt ebenfalls nach dem RQMV-Prinzip (vgl. Art. 3, Abs. 3 VO (EU) Nr. 1174/2011), wobei die Kommission laut Verordnung dazu angehalten ist, binnen 20 Tagen eine entsprechende Empfehlung zur Verhängung der Sanktionen an den Rat zu richten, soweit die genannten Kriterien erfüllt sind (vgl. Art. 3, Abs. 4 VO (EU) Nr. 1174/2011). Ausnahmen beziehungsweise verringerte Sanktionshöhen können aufgrund »außergewöhnlicher wirtschaftlicher Umstände oder auf begründeten Antrag des betreffenden Mitgliedstaats« (Art. 3, Abs. 6 VO (EU) Nr. 1174/2011) gewährt werden. Zugleich wird die verzinsliche Einlage beziehungsweise die Geldbuße zeitanteilig zurückgezahlt, sobald innerhalb des betreffenden Jahres Korrekturmaßnahmen ergriffen wurden und dies durch entsprechende Empfehlungen und Beschlüsse der Kommission beziehungsweise des Rates festgestellt wird (vgl. Art. 3, Abs. 7 VO (EU) Nr. 1174/2011). Dabei ist durchaus umstritten, ob auch an dieser Stelle eine nicht durch die EU-Verträge gedeckte Ausweitung des Sanktionsregimes vollzogen wurde. Kern der Kritik ist, dass »Art. 121 und Art. 136 Abs.1 [...] zwar eine Vorabkoordinierung zulassen [mögen]; neue Sanktionen jedoch nicht. Dasselbe gilt für die hier erneut vorgesehene Annahmefiktion eines Ratsbeschlusses« (Häde 
2016, Art. 121, Rn. 23) durch das RQMV-Verfahren. (Vgl. auch Höpner \& Rödl 2012, 222; Obwexer 2012, 226)

\section{Die ausgebaute wirtschaftspolitische Überwachung als EU-Staatlichkeitspraxis}

Neben dem Ausbau der fiskalpolitischen Überwachung ist mit dem Six-Pack wie dargestellt die wirtschaftspolitische Überwachungskomponente massiv ausgeweitet worden. Im sogenannten MIP steht das eigens entwickelte Scoreboard im Mittelpunkt der Überwachung, wobei es der Kommission oblag, das Scoreboard in Eigenregie zu entwickeln. Insofern materialisiert sich mit dem Scoreboard eine in Anlehnung an Bourdieu (2016, 23ff.) zu konstatierende Benennungsmacht der Kommission, zumal im "Zeitalter der Quantifizierung« die Benennungsmacht gerade »über Zahlen, Grafiken und Rangtabellen« (Mau 2017, 188), wie im Scoreboard angelegt, wirkt. Das Scoreboard stellt insofern einen wichtigen Bezug zum kriseninduzierten Staatlichkeitsausbau dar, zumal es in seinen Normierungen politisch gewollte Selektivitäten aufweist.

In der am 8. November 2011 veröffentlichten Version des Scoreboards (Working Paper) werden vier Prinzipien beschrieben, auf denen das Scoreboard beruhe: Erstens solle es auf die relevantesten Dimensionen makroökonomischer Ungleichgewichte und den Verlust an Wettbewerbsfähigkeit fokussieren, zweitens reliable Warninstrumente zur Identifizierung von schädlichen Ungleichgewichten in einem führen Stadium bieten, drittens eine wichtige Informations- und Kommunikationsfunktion erfüllen und schließlich auf einer hohen statistischen Qualität basieren (vgl. KOM 2011c, 2f.). Auf Grundlage dieser Prämissen präsentierte die Kommission eine Liste von zehn Indikatoren, die angefangen beim Leistungsbilanzsaldo über Lohnstückkosten und den (privaten und öffentlichen) Schuldenständen bis zur Arbeitslosenquote reichte (vgl. ebd., 3). Der am 8. November 2011 tagende ECOFIN-Rat beriet über das im Working Paper skizzierte Scoreboard. In seiner Schlussfolgerung forderte er die Kommission auf, es möglichst zeitnah zu veröffentlichen (was am selben Tag auch geschah), und billigte somit indirekt die vorgeschlagene Ausgestaltung (vgl. ECOFIN 2011c, 2). Allerdings betonte der Rat in seiner Schlussfolgerung zugleich, dass

»neben den im Kommissionvorschlag wiedergegebenen Indikatoren zusätzliche Indikatoren erforderlich sind, die die Kommission bei der ökonomischen Auslegung des Scoreboards berücksichtigen sollte, einschließlich Indikatoren für Entwicklungen bei den verschiedenen Komponenten der Produktivität und Indikatoren für den Finanzsektor.«(Ebd., 3)

Er erteilte der Kommission den Auftrag, bis 2012 einen zusätzlichen Indikator im $\mathrm{Zu}$ sammenhang mit dem Finanzsektor vorzulegen (vgl. ebd., 4). Außerdem wies er noch einmal in aller Deutlichkeit darauf hin, »dass das Über- bzw. Unterschreiten eines oder mehrerer indikativer Schwellenwerte nicht zwangsläufig zu weiteren Schritten im Verfahren bei einem übermäßigen Ungleichgewicht führen muss.« (Ebd., 3) Hierdurch wird der mechanische, quasi technisch-automatische Charakter seitens des Rates zu begrenzen versucht, was im Umkehrschluss allerdings auch zur Ausweitung von Ermessensspielräumen der Kommission beiträgt. Hierfür spricht auch, dass im im Vergleich zum ersten Kommissionsvorschlag bei den Indikatoren des Scoreboards mittlerweile nicht mehr von »Richt-« (vgl. KOM 2010i), sondern nur noch von »Schwellenwerten« ge- 
sprochen wird. In der Schlussfolgerung des Rates heißt es weiter: »Eine ökonomische Bewertung sollte stets parallel zur Veröffentlichung des Scoreboards erfolgen und dafür sorgen, dass sämtliche Informationen, unabhängig davon, ob sie aus dem Scoreboard stammen oder nicht, im Zusammenhang gesehen und Teil einer umfassenden Analyse werden.« (ECOFIN 2011c, 3) Wie der Rat schien auch das Europäische Parlament, das am 15. Dezember eine Entschließung zum Scoreboard-Entwurf beschloss (vgl. EP 2011d), gewisse Vorbehalte gehabt zu haben, wenngleich dem Parlament daran gelegen war, dass »der Rahmen für die makroökonomische Überwachung so bald wie möglich funktionsfähig ist.« (Ebd., Rn. 2) Die Kritik an der Kommission wird allerdings sehr deutlich formuliert: So stellte das Europäische Parlament fest, »dass die Kommission nicht alle Elemente berücksichtigt hat, die in Artikel 4 der Verordnung (EU) Nr. 1176/2011 für die ökonomische Auslegung des Scoreboards angeführt sind«; weshalb es die Kommission aufforderte, »allen diesen Elemente bei der ökonomischen Auslegung des Scoreboards Rechnung zu tragen, insbesondere in Bezug auf die Arbeitslosigkeit, die Motoren der Produktivität und die Rolle der Energie« (ebd., Rn. 7). Auch methodisch äußerte das Parlament gewisse Vorbehalte, wenn es festhält, »dass die Kommission in ihrem Arbeitsdokument auf die >verfügbare wirtschaftswissenschaftliche Fachliteratur verweist, ohne jedoch auch nur eine einzige spezifische Referenz anzugeben« (ebd., Rn. 9.). Das EP forderte die Kommission daher weiterhin auf, »ihren methodologischen Ansatz einschließlich der verschiedenen geprüften Optionen genauer zu erläutern sowie eine umfassende Bibliografie zur Untermauerung des Scoreboards anzugeben« (ebd., Rn. 9). Diesem Wunsch kam die Kommission im Februar 2012 nach (vgl. KOM 2012d; vgl. auch KOM 2016d). Ein Blick auf die Anzahl der angeführten Referenzen (37, von denen sechs auf interne Papiere der Kommission oder Eurostat verweisen) spricht allerdings nur für eine überschaubare Validität und zugleich politische Selektivität des Verfahrens. Auch der Europäische Rechnungshof kritisierte in einem Sonderbericht das Scoreboard auf methodischer Ebene. Die Prüfer*innen des Rechnungshofes konstatierten, dass die Ausgestaltung des Scoreboards für die frühzeitige Feststellung von makroökonomischen Ungleichgewichten ungeeignet sei, da es auf zwei Jahre alten Daten beruhe und zahlreiche Indikatoren leitende Durchschnittswerte oder Bestandsvariablen seien, anhand derer die Berücksichtigung aktueller Entwicklungen nur langsam erfolge (vgl. EuRH 2018a, 53f.).

Auf Grundlage stattgefundener Fachgespräche legte die Kommission (2012b) schließlich im November 2012 den vom Rat und vom Parlament eingeforderten Finanzmarktindikator vor, der die Verbindlichkeiten des Finanzsektors mit in die Bewertung makroökonomischer Ungleichgewichte einbezieht. Nach dieser - eher widerwillig vollzogenen (vgl. ebd., 3) - Ergänzung blieb das Scoreboard bis zum Jahr 2015 unverändert. Die Kommission ging insofern nicht weiter auf die vom Parlament geäußerte Kritik ein. Dies bewog das EP zu einer Entschließung, in der es in aller Deutlichkeit festhält, dass es »nicht länger hinnehmen [wird], dass die notwendige Änderung der Kultur im Hinblick auf die vollständige Anerkennung der Rolle des Parlaments bei der wirtschaftspolitischen Steuerung in den Dienststellen der Kommission immer noch andauert« (EP 2013g, Rn. 7). Stein des konkreten Anstoßes war, dass die Kommission vor Einführung des neuen Indikators 2012 keine Konsultation mit dem Parlament vornahm, Arbeitsgruppen des Rates hingegen einbezogen hatte (vgl. 
ebd., Rn. 4). Erst im September 2015 ging die Kommission explizit auf die anhaltende Kritik aus dem Europäischen Parlament ein und schlug vor, das Scoreboard um drei beschäftigungspolitische Indikatoren zu ergänzen (vgl. KOM 2015f). Neben der bereits seit 2011 enthaltenen Arbeitslosenquote werden seit dem Semester 2016 auch die Erwerbsquote sowie die Quoten für Langzeit- und Jugendarbeitslosigkeit einbezogen (s. die letzten drei Indikatoren in Tabelle 19). Somit ergibt sich seit dem Jahr 2016 ein Set von insgesamt 14 Indikatoren:

Tabelle 19: Indikatoren und Schwellenwerte des Scoreboards

\begin{tabular}{|c|c|c|c|}
\hline \multirow{2}{*}{$\begin{array}{l}\text { Indikator } \\
\text { Leistungsbilanzsaldo }\end{array}$} & \multirow{2}{*}{$\begin{array}{c}\text { Einheit } \\
\text { 3-Jahresdurschnitt in \% } \\
\text { des BIP }\end{array}$} & \multicolumn{2}{|c|}{$\begin{array}{c}\text { obere | untere } \\
\text { Schwellenwerte }\end{array}$} \\
\hline & & $6 \%$ & $-4 \%$ \\
\hline Nettoauslandsvermögensstatus & in $\%$ des BIP & l & $-35 \%$ \\
\hline Realer effektiver Wechselkurs & $\begin{array}{l}\text { 3-Jahresveränderung in \% in } \\
\text { Abhängigkeit zu ausgewählten } \\
\text { Handelspartnern }\end{array}$ & $\begin{array}{c}5 \%(€) \\
11 \%(\$)\end{array}$ & $\begin{array}{l}-5 \%(€) \\
-11 \%(\$)\end{array}$ \\
\hline Exportmarktanteil & $\begin{array}{l}\text { 5-Jahresveränderung an den } \\
\text { weltweiten Exporten in \% }\end{array}$ & l & $-6 \%$ \\
\hline Nominale Lohnstückkosten & 3-Jahresveränderung in \% & $\begin{array}{r}9 \%(€) \\
12 \%(\$)\end{array}$ & 1 \\
\hline Hauspreisindex & $\begin{array}{l}\text { Veränderungen zum Vorjahr } \\
\text { in } \%\end{array}$ & \multicolumn{2}{|c|}{$6 \%$} \\
\hline Kreditfluss des privaten Sektors & in $\%$ des BIP & $14 \%$ & I \\
\hline Schuldenstand des privaten Sektors & in $\%$ des BIP & $133 \%$ & l \\
\hline Öffentlicher Schuldenstand & in $\%$ des BIP & $60 \%$ & l \\
\hline Arbeitslosenquote & 3-Jahresdurchschnitt & $10 \%$ & I \\
\hline Verbindlichkeiten des Finanzsektors & $\begin{array}{l}\text { Veränderungen zum Vorjahr } \\
\text { in } \%\end{array}$ & $16,5 \%$ & I \\
\hline Erwerbsquote & $\begin{array}{l}\text { 3-Jahresveränderung in \% der } \\
\text { Cesamtbevölkerung im Alter } \\
\text { von } 15 \text { bis } 64\end{array}$ & I & $-0,2 \%$ \\
\hline Langzeitarbeitslosenquote & $\begin{array}{l}\text { 3-Jahresveränderung in \% der } \\
\text { Erwerbsbevölkerung im Alter } \\
\text { von } 15 \text { bis } 74\end{array}$ & $0,5 \%$ & I \\
\hline Jugendarbeitslosenquote & $\begin{array}{l}\text { 3-Jahresveränderung in \% der } \\
\text { Erwerbsbevölkerung im Alter } \\
\text { von } 15 \text { bis } 24\end{array}$ & $2 \%$ & I \\
\hline \multicolumn{4}{|c|}{$\begin{array}{l}\text { Legende: } \\
(€)=\text { Schwellenwert hat Gültigkeit für Euro Mitgliedstaaten } \\
(\$)=\text { Schwellenwert hat Gültigkeit für Mitgliestaaten, deren Währung nicht der Euro ist } \\
\text { Anmerkungen: Neben den Scoreboard-Indikatoren nutzt die Kommission im Rahmen ihrer } \\
\text { Bewertung weitere »Hilfsindikatoren« (auxilary indicators). Die Liste besteht aus weiteren } 28 \text { Indi- } \\
\text { katoren (vgl. Eurostat o.J.). }\end{array}$} \\
\hline
\end{tabular}


Der Glaube an eine marktbasierte Angleichung der im gemeinsamen Währungsraum verbundenen differierenden Ökonomien ist mit der Euro-Krise deutlich widerlegt worden. Das genannte Scoreboard ließe sich zwar als ein Ansatz zur Behebung einer der benannten Fehlkonstruktionen interpretieren, ist in seiner Ausgestaltung allerdings höchstens als ein unvollkommener, vielmehr als ein »einseitiger "(Watt 2013, 23; vgl. u.a. auch Feigl 2015, 76) Ansatz zu qualifizieren. Ein Beispiel: »Wenn man keine Währungsunion will, die auch eine Transferunion ist, kann es in der EWU«, so Bibow \& Flassbeck (2018, 104), »keine Länder mit notorischen Leistungsbilanzüberschüssen und andere mit ewigen Defiziten geben."Das Scoreboard hingegen setzt andere Parameter, wie die Schwellenwerte für die Leistungsbilanzsalden exemplarisch zeigen (s. Tabelle 19). Die Bewertung der beiden Autoren fällt daher in aller Deutlichkeit aus:

»Die Europäische Kommission hat ihren gemeinschaftlichen Auftrag krass missachtet. Ihr wirtschaftspolitisches Mandat betriff das Wohl der Union insgesamt. Sie hätte die notwendige Symmetrie der Anpassungspolitik also einfordern müssen, statt als Handlanger des Berliner Finanzministeriums zu agieren. Das sogenannte $>$ Macroeconomic Imbalance Procedure ist schon in der Konzeption ein asymmetrischer Witz. Eine wirksame Anwendung findet sich nicht einmal bei deutschen Überschüssen von fast neun Prozent des BIP. Man darf doch nicht glauben, den Bestand der EWU allein durch Heuchelei sichern zu können.«(Ebd., 105)

Trotz dieser Selektivität bildet das Scoreboard den Ausgangspunkt für die weiteren wirtschaftspolitischen Bewertungs- und Überwachungsverfahren seitens der Kommission. Nach Verordnung (EU) Nr. 1176/2011 führt sie eingehende Überprüfungen jener Länder durch, bei denen sie die Auffassung vertritt, dass Ungleichgewichte vorliegen. Wie die Tabelle 35 (hinterlegt im Anhang) verdeutlicht, wurden seit Einführung dieses Verfahrens jedes Jahr bis zu 19 Mitgliedstaaten eingehender in Bezug auf mögliche Ungleichgewichte im Sinne des scoreboardinhärenten wettbewerbsorientierten Gleichgewichtsparadigmas untersucht. Betrachtet man dabei jene Staaten, die seit der Einführung des Verfahrens ununterbrochen einer eingehenden Überprüfung unterzogen wurden, so findet man derer fünf (Bulgarien, Frankreich, Italien, Spanien und Schweden). Zieht man jene Staaten hinzu, die sich in einem makroökonomischen Anpassungsprogramm auf Basis der außerunionsvertraglichen Notstandsverfassung befunden haben und deshalb während der Programmlaufzeit nicht Bestandteil des Semesters waren, sondern durch die »Troika« überwacht wurden, erhöht sich diese Zahl um weitere vier Länder (Irland, Portugal, Zypern, Griechenland) auf insgesamt neun Mitgliedstaaten. Nach dem EU-Beitritt stellt Kroatien das zehnte Land dar, das seit 2014 ununterbrochen einer eingehenden Überprüfung unterzogen wird. Diese Zahlen verdeutlichen, dass die Berichtstätigkeit der Kommission in Bezug auf die wirtschaftspolitische Überwachung mit der Einführung des MIP einen deutlich wahrnehmbaren Umfang angenommen hat. Allerdings verweist die bloße Quantität der eingehenden Überprüfungen (insgesamt 115 im Zeitraum 2012-2019; ohne Programmländer) noch nicht auf das wirkliche Vorhandensein von Ungleichgewichten. Vielmehr nutzt die Kommission das Scoreboard, um Vermutungen über potenzielle Ungleichgewichte zu äußern, die anschließend eingehender überprüft werden. Entsprechend ergibt sich ein differenzierteres Bild tatsächlich attestierter makroökonomischer Ungleichgewichte für die Jahre 2012 bis 2019. 
Auffällig ist aber auch hier, dass der Anteil der Mitgliedstaaten, denen makroökonomische Ungleichgewichte attestiert werden, durchgehend bei deutlich über einem Drittel, in der Spitze (2015) gar annähernd bei zwei Dritteln (ohne Berücksichtigung der Programmländer Griechenland und Zypern) lag. Noch höher fällt der Anteil bei isolierter Betrachtung der Eurozone aus: Bis einschließlich 2017 waren hier mindestens die Hälfte der Euro-Mitgliedstaaten von makroökonomischen Ungleichgewichten betroffen (ebenfalls ohne Berücksichtigung der Programmländer). Bezieht man die Programmländer mit ein, auch wenn sie nicht in den formalen MIP-Rahmen fallen, trübt sich das Bild weiter. Ebenso bei Bereinigung der Daten um die erst später beigetretenen Euro-Mitglieder Lettland und Litauen, denen seit ihrem Beitritt zum Euro im Rahmen der makroökonomischen Überwachung noch keine Ungleichgewichte attestiert wurden. Die anhaltend hohen Ungleichgewichte innerhalb der Eurozone sprechen dafür, dass sich bis heute die gesamtwirtschaftliche Lage nicht einmal im Sinne des neoklassisch und angebotsökonomisch inspirierten Indikatorensets und Analysetools der Kommission hat merklich verbessern können; von alternativen wirtschaftsparadigmatischen Ansätzen zur Bewertung der wirtschaftlichen Gesamtlage in der Eurozone an dieser Stelle einmal ganz zu schweigen. Vielmehr scheint es, als dass der aufgrund der Fehlkonstruktion der ursprünglichen EWWU vorgenommene Ausbau der wirtschaftspolitischen Überwachung insgesamt nicht zu einer deutlichen Abmilderung der ökonomischen Divergenzen geführt hat. Trotzdem hat die Kommission das geschaffene Instrumentarium bis dato noch nicht vollumfänglich zur Anwendung gebracht. So wurde bisher beispielsweise noch kein formales Verfahren bei übermäßigen Ungleichgewichten (EIP) gegen einen Mitgliedstaat eingeleitet (vgl. Zoppè 2018, 10; Kritik hieran äußert der Europäische Rechnungshof (2018a, 37)). Dennoch zeigt sich durch den Blick auf die eingehenden Überprüfungen, dass die Kommission von den etablierten Prüf- und Analysekompetenzen in einem Umfang Gebrauch macht, der dafür spricht, dass sie ihrer neuen Rolle als Hüterin der konsolidierten Stabilitäts- und Überwachungsunion durchaus gerecht zu werden beabsichtigt und zugleich ihre Einflussmöglichkeiten gegenüber den Mitgliedstaaten zu nutzen sucht. Mittel der Wahl sind hierbei vornehmlich die länderspezifischen Empfehlungen, die auf Grundlage der makroökonomischen wie auch der fiskalpolitischen Überwachung von Seiten der Kommission erstellt und formal vom Rat verabschiedet werden. Der gewählte Ansatz entspricht demnach eher einer >Good-CopStrategie , bei der durch seichtere Herrschaftsformen die notwendige >compliance mit den suprastaatlichen Vorgaben herzustellen versucht wird. 


\section{Länderspezifische Empfehlungen als Herrschafts- und Interventionsinstrument}

Tabelle 20: Länderspezifische Empfehlungen (CSR) im Rahmen der Europäischen Semester 2012-19

\begin{tabular}{|c|c|c|c|c|c|c|c|}
\hline \multirow{2}{*}{ Jahr } & \multirow{2}{*}{$\begin{array}{c}\text { CSR } \\
\text { gesamt }\end{array}$} & \multicolumn{4}{|c|}{ CSRs nach Bereichen } & \multirow{2}{*}{ MS } & \multirow{2}{*}{ 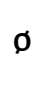 } \\
\hline & & SWP \& 2020 & MIP \& 2020 & SWP\&MIP & Exkl.2020 & & \\
\hline 2012 & 138 & 18 & 31 & 5 & 84 & 23 & 6,0 \\
\hline 2013 & 141 & 18 & 50 & 6 & 67 & 23 & 6,1 \\
\hline 2014 & 157 & 19 & 58 & 8 & 72 & 26 & 6,0 \\
\hline 2015 & 102 & 11 & 48 & 10 & 33 & 26 & 3,9 \\
\hline 2016 & 89 & 13 & 36 & 9 & 31 & 27 & 3,3 \\
\hline 2017 & 78 & 12 & 27 & 8 & 31 & 27 & 2,9 \\
\hline 2018 & 73 & 11 & 27 & 5 & 30 & 27 & 2,7 \\
\hline 2019 & 96 & 9 & 35 & 5 & 48 & 28 & 3,4 \\
\hline
\end{tabular}

Anmerkungen: Folgende Mitgliedstaaten (MS) sind aufgrund von makroökonomischen Anpassungsprogrammen nicht am Europäischen Semester der angegebenen Jahre beteiligt: Irland (2012 \& 2013), Griechenland (2012-18), Zypern (2013-15), Portugal (2012 \& 2013), Rumänien (2012). Kroatien ist nach seinem EU-Beitritt erstmals 2014 am Europäischen Semester beteiligt.

Quelle: Eigene Zusammenstellung auf Grundlage von Angerer, Hagelstam \& Ciucci (2019)

Die an die Mitgliedstaaten gerichteten länderspezifischen Empfehlungen (country-specific recommendations; CSR) speisen sich im integrierten Rahmen des Europäischen Semesters insgesamt aus drei Quellen: dem SWP, dem MIP sowie den integrierten Leitlinien zur Umsetzung der Europe-2020-Strategie. Einige Empfehlungen werden des Weiteren auf der gemeinsamen Grundlage von SWP und MIP ausgesprochen. Die tabellarische Übersicht verdeutlicht dabei, dass die Empfehlungen seit dem Semester 2015 merklich abgenommen haben. Wurden zuvor im Durchschnitt pro Mitgliedstaat je sechs Empfehlungen ausgesprochen, hat sich deren Anzahl im Semester 2018 um mehr als die Hälfte reduziert; erst mit dem Semester 2019 stieg die Anzahl der Empfehlungen wieder. Insgesamt speist sich dieser Befund einerseits aus der Abnahme der eingehenden Überprüfungen und der tendenziell leicht abnehmenden Anzahl attestierter Ungleichgewichte (s. Tabelle $35 \mathrm{im}$ Anhang), andererseits verweist dieser Befund aber auch auf veränderte Praxen im Europäischen Semester, wie sie durch die neue Juncker-Kommission ab 2015 forciert wurden. Auf das sogenannte Streamlining des Europäischen Semesters später genauer eingehend, soll an dieser Stelle kurz der Einfluss der länderspezifischen Empfehlungen auf die mitgliedstaatliche Politikgestaltung reflektiert werden. Zurückgegriffen werden kann hierbei auf vorhandene politikwissenschaftliche Analysen und offizielle Bewertungen der Kommission und des Europäischen Parlaments.

In ihrer Analyse der Semester 2011 bis 2014 haben Darvas \& Leandro $(2015,14)$ herausgestellt, dass die Bereitschaft zur Umsetzung der länderspezifischen Empfehlungen im von ihnen untersuchten Zeitraum abgenommen habe. Sie errechneten hierfür einen Reformimplementationsindex (vgl. ebd., 10), der anzeigt, dass die Umsetzungsquote 
von $40 \%$ im Jahr 2011 auf $29 \%$ im Jahr 2014 sank. Zugleich zeigt der Index, dass die Eurostaaten eine leicht höhere Bereitschaft zur Umsetzung aufwiesen (31 \% gegenüber $23 \%$ in 2014; vgl. ebd., 15). Außerdem konnten sie aufzeigen, dass die Umsetzungswahrscheinlichkeit im Zusammenhang mit der Quelle der Empfehlung steht: Wurden im Durchschnitt der Semester 2012 bis 2014 lediglich $29 \%$ der integrierten Leitlinien (Europe 2020) umgesetzt, waren es bei MIP-Empfehlungen $32 \%$ und bei Empfehlungen im Rahmen des SWP gar 44 \% (vgl. ebd.). Eine Auswertung Zoppès $(2018,12)$ zu den Empfehlungen im Rahmen des MIP zeigt ebenfalls, dass ihre Umsetzung im Zeitraum 2012 bis 2017 rückläufig ist, wobei die vollständige Umsetzung einzelner MIP-Empfehlungen bereits seit Beginn des neuen Verfahrens auf einem niedrigen Niveau verharrte:

Tabelle 21: Umsetzung der länderspezifischen Empfehlungen, basierend auf dem MIP (2012-17)

\begin{tabular}{|l|c|c|c|c|c|c|}
\hline & $\mathbf{2 0 1 2}$ & $\mathbf{2 0 1 3}$ & $\mathbf{2 0 1 4}$ & $\mathbf{2 0 1 5}$ & $\mathbf{2 0 1 6}$ & $\mathbf{2 0 1 7}$ \\
\hline Umsetzung oder erheblicher Fortschritt & $6 \%$ & $5 \%$ & $5 \%$ & $7 \%$ & $2 \%$ & $0 \%$ \\
\hline Einiger Fortschritt & $\mathbf{7 8} \%$ & $43 \%$ & $\mathbf{5 2} \%$ & $\mathbf{4 7} \%$ & $40 \%$ & $37 \%$ \\
\hline Geringer oder kein Fortschritt & $17 \%$ & $\mathbf{5 2} \%$ & $44 \%$ & $46 \%$ & $\mathbf{5 8} \%$ & $\mathbf{6 3} \%$ \\
\hline
\end{tabular}

Quelle: Zoppè $(2018,15)$

Weiterhin bestehen länderbezogene Unterschiede in der Umsetzung der Empfehlungen, welche Efstathiou \& Wolff $(2018,5)$, die wie Darvas \& Leandro eine Indizierung verwenden, in einer weiteren Analyse herausgearbeitet haben:

Tabelle 22: Durchschnittlicher Implementationsscore, nach Ländern (2013-17)

\begin{tabular}{|c|c|c|c|c|c|}
\hline \multicolumn{2}{|c|}{ Sore $<33 \%$} & \multicolumn{2}{|c|}{ Score $33-50 \%$} & \multicolumn{2}{|c|}{ Score $>50 \%$} \\
\hline Luxemburg $(€)$ & $23 \%$ & Rumänien & $33 \%$ & UK & $51 \%$ \\
\hline Deutschland $(€)$ & $29 \%$ & Belgien $(€)$ & $37 \%$ & Finnland $(€)$ & $53 \%$ \\
\hline Slowakei $(€)$ & $29 \%$ & Frankreich (€) & $37 \%$ & & \\
\hline Ungarn & $29 \%$ & Niederlande $(€)$ & $37 \%$ & & \\
\hline Bulgarien & $30 \%$ & Dänemark & $38 \%$ & & \\
\hline Kroatien & $31 \%$ & Portugal $(€)$ & $39 \%$ & & \\
\hline Schweden & $31 \%$ & Italien $(€)$ & $40 \%$ & & \\
\hline Zypern (€) & $31 \%$ & Lettland $(€)$ & $40 \%$ & & \\
\hline Österreich (€) & $32 \%$ & Litauen $(€)$ & $40 \%$ & & \\
\hline Polen & $32 \%$ & Estland $(€)$ & $42 \%$ & & \\
\hline \multirow[t]{4}{*}{ Tschechien } & $32 \%$ & Irland $(€)$ & $43 \%$ & & \\
\hline & & Spanien $(€)$ & $44 \%$ & & \\
\hline & & Malta $(€)$ & $46 \%$ & & \\
\hline & & Slowenien $(€)$ & $48 \%$ & & \\
\hline \multicolumn{6}{|c|}{$\begin{array}{l}\text { Anmerkung: „Subparts related to fiscal policy in terms of SCP targets are excluded.« } \\
\text { Legende: }(€)=\text { Euro-Mitgliedstaaten }\end{array}$} \\
\hline
\end{tabular}

Quelle: Efstathiou \& Wolff $(2018,5)$ 
Insgesamt verdeutlichen die präsentierten Befunde ein eher durchwachsenes Bild der Durchschlagskraft der länderspezifischen Empfehlungen als suprastaatliches Herrschafts- und Interventionsinstrument. Auch der Europäische Rechnungshof kritisierte in einem Sonderbericht die mangelnde Umsetzung beziehungsweise den mangelnden Fortschritt der Mitgliedstaaten beim Abbau makoökonomischer Ungleichgewichte (vgl. EuRH 2018a, 23), wobei er der Kommission in puncto Überwachung der CSR-Umsetzung insgesamt einen »guten Standard« attestierte (vgl. ebd., 22). Im Unterschied zur jahresbezogenen Bewertung der Umsetzung von länderspezifischen Empfehlungen propagiert die Kommission ihrerseits einen mehrjährigen Bewertungsmaßstab, durch den sie Fortschritte auch rückwirkend in ihren Kennzahlen abzubilden versucht: »Bei der mehrjährigen Bewertung wird beurteilt, wie die Empfehlungen ab dem Zeitpunkt, zu dem sie erstmals ausgesprochen wurden, bis zur vorliegenden Mitteilung [...] umgesetzt wurden«, so die Kommission (2018d, 4). In ihrer Mitteilung $\mathrm{zu}$ den länderspezifischen Empfehlungen des Europäischen Semesters 2018 weist die Kommission demnach Implementationswerte auf, die im Vergleich zu den zuvor präsentierten Befunden für eine höhere Umsetzungsbereitschaft sprächen: So seien $9 \%$ der Empfehlungen vollständig umgesetzt und bei $17 \%$ wesentliche sowie bei weiteren $44 \%$ einige Fortschritte erreicht worden (vgl. ebd.). Lediglich bei $25 \%$ seien nur begrenzte und bei $5 \%$ keine Fortschritte erzielt worden (vgl. ebd.).

Auch wenn alle bis hierhin dargestellten Bewertungen aufgrund methodischer Unterschiede nur in Ansätzen miteinander vergleichbar sind, so sind doch zusammenfassend folgende Feststellungen in Bezug auf die länderspezifischen Empfehlungen zu treffen: Zum ersten lässt sich attestieren, dass die Anzahl der länderspezifischen Empfehlungen seit Implementierung des Europäischen Semesters rückläufig sind und sie insgesamt eine nach Art der Empfehlung (SWP, MIP, Europe 2020) unterschiedlich stark ausgeprägte Bindekraft aufweisen. Trotzdem sollte den Empfehlungen - zweitens - eine direkte Wirkungsmacht zugeschrieben werden. Auch wenn Empfehlungen nicht innerhalb eines Referenzjahres umgesetzt werden, muss dies im Umkehrschluss nicht zwangsläufig bedeuten, dass sie keinen Einfluss auf die konkrete Politikgestaltung eines Mitgliedstaats nehmen konnten. Dies verdeutlicht die von der Kommission vorgenommene Mehrjahresperspektive. Drittens bleibt zu konstatieren, dass abseits der konkreten Umsetzung, respektive der Umsetzungsdauer, die diskursive Kraft der länderspezifischen Empfehlungen nicht unterschätzt werden sollte. Als Instrument zur Benennung von Ansätzen der Politikgestaltung, inklusive einer ex- wie impliziten Reformagenda, weisen die Empfehlungen einen gewissen inkrementellen Charakter auf, der in den bisher angeführten Untersuchungen nicht explizit untersucht wurde. Hierfür spricht die Beobachtung, dass in vielen der dargestellten Indizes die Kategorie »einige Fortschritte« ein insgesamt häufig auftretendes Ausprägungsmerkmal darstellt. Insofern lässt sich mit Blick auf die längerfristigen Folgewirkungen festhalten, dass die länderspezifischen Empfehlungen ein durchaus wirkmächtiges Herrschaftsinstrument darstellen können. Sie bleiben deshalb auch in der wissenschaftlichen Diskussion nicht unkritisiert. Insbesondere die Tiefe des Instruments steht dabei häufig im Zentrum. So werden mit den CSRs nicht nur fiskalische oder wirtschaftspolitische Empfehlungen ausgesprochen, sondern auch sozial- oder bildungspolitische Politiken zum Gegenstand gemacht. Die CSR greifen damit weit in die Kernkompetenzen und Verant- 
wortlichkeiten der Mitgliedstaaten ein. So analysiert Stefan Clauwaert seit dem ersten Semester für das European Trade Union Institut (ETUI) den Umfang sozial- und arbeitsmarktpolitischer Empfehlungen an die Mitgliedstaaten, deren Anteil seit dem Semester 2015 durchgehend über die Hälfte der ausgesprochenen Empfehlungen ausmacht:

Tabelle 23: Anzahl sozial- und arbeitsmarktpolitischer CSRs in den Europäischen Semestern 2012-19

\begin{tabular}{|c|c|c|c|}
\hline Semester & Alle CSRs & Anzahl »Social CSRs» & Anteil \\
\hline 2012 & 138 & 61 & $44,2 \%$ \\
\hline 2013 & 141 & 57 & $40,4 \%$ \\
\hline 2014 & 157 & 74 & $47,1 \%$ \\
\hline 2015 & 102 & 51 & $50,0 \%$ \\
\hline 2016 & 89 & 48 & $53,9 \%$ \\
\hline 2017 & 78 & 46 & $59,0 \%$ \\
\hline 2018 & 73 & 46 & $63,0 \%$ \\
\hline 2019 & 96 & 53 & $55,2 \%$ \\
\hline
\end{tabular}

Anmerkung: Sozialpolitische Empfehlungen werden anhand eines Sets aus acht unterschiedlichen Kategorien identifiziert: »1) wages (including wage indexation and the reform of wage-setting systems); 2) employment protection legislation (EPL);3) labour market participation (and that of different groups of workers, for example women and older workers); 4) youth employment (including the Youth Guarantee, facilitating the transition from education to work, reducing early school-leaving etc.); 5) pensions (including general pension reforms and reform of the (early) retirement age); 6) social protection/assistance (including demands for better coverage and better quality social security and assistance systems/benefits); 7) child poverty (including more child support and more and better childcare facilities); and 8) >tax< (mainly consisting of a request to shift the tax burden away from labour, or >broadening the tax base $<$ as the Commission calls it).«(Clauwaert 2018, 7f.)

Quelle: Clauwaert (2019; 2018 \& 2017)

Es gilt wiederum, dass auf Grundlage der bloßen Anzahl der Empfehlungen kein Rückschluss auf die inhaltliche Reichweite der einzelnen Empfehlungen möglich ist. Allerdings identifiziert beispielsweise Sonja Bekker (2018) in ihrer Untersuchung den Flexicurity-Ansatz als das den sozial- und arbeitsmarktpolitischen Empfehlungen innewohnende Schlüsselkonzept der Kommission. Sie konstatiert, dass trotz massiver Kritik von Seiten der Wissenschaft und insbesondere auch der Gewerkschaften (vgl. ebd., 176; differenzierter: Dusse 2019, 92ff. \& $300 f f$.) der Flexicurity-Ansatz eine Art Wiederbelebung erfahren habe (vgl. Bekker 2018, 181; vgl. auch Dusse 2009, 93f.). Die Kommission selbst macht hieraus auch keinen Hehl. In ihrer Mitteilung »Einen arbeitsplatzintensiven Aufschwung gestalten« erklärte sie bereits 2012, dass der Flexicurity-Ansatz weiterhin »eine tragende Säule für den Aufbau dynamischer Arbeitsmärkte« (KOM 2012e, 10) sein werde, wie sich nicht zuletzt auch in den integrierten Leitlinien der Europe2020-Strategie zeigt (s.o.). In einem weiteren Staff Working Document wird die von der Kommission durchaus wahrgenommene Kritik am Flexicurity-Ansatz (vgl. KOM 2012h, 1) nicht weiter reflektiert. Stattdessen heißt es: 
»[T] he experience of recent years has confirmed flexicurity as a framework and a tool to understand and implement employment policy-making and to identify good and bad practices. It continues to be a useful concept within the employment agenda, supporting Europe's effort to build open, dynamic and inclusive labour markets.« (Ebd., 21)

Der in der Europe-2020-Strategie angelegte angebotsökonomische Umbau der Arbeitsmärkte findet sich somit folglich auch in den länderspezifischen Empfehlungen wieder. Entsprechend stecken somit auch die länderspezifischen Empfehlungen einen Rahmen ab, der eine Politik im Sinne neoklassischer und angebotsökonomischer Paradigmen vorgibt und sich am fiskalischen Austeritätsprimat ausrichtet. In diesem Sinne wirken somit auch die sozial- und arbeitsmarktpolitischen Empfehlungen, wie die Empfehlungen an Belgien im Semester 2012 exemplarisch zeigen:

»So erhält Belgien nicht weniger als neun Empfehlungen im sozialen Bereich, wodurch es [...] zu den Ländern gehört, die am stärksten von der EU unter Druck gesetzt werden. Und das, obwohl die klassischen Indikatoren belegen, dass Belgien der Krise besser trotzte als die meisten anderen Mitgliedstaaten.« (Degryse 2012, 80)

Weiter führt Degryse aus: »Manchen Stimmen zufolge gehe es dabei weniger um eine fundierte Auswertung der Fakten, sondern um einen ideologischen Krieg, bei dem die eigentlichen Sachlagen, Wirtschaftsleistungen und spezifischen Probleme keinerlei Berücksichtigung finden.« (Ebd.) Ob diese frühe Bewertung der Wirkungsweise des Europäischen Semesters und insbesondere der in ihr angelegten länderspezifischen Empfehlungen auch im Lichte der dargestellten Wirkungsmacht und Reichweite der Verfahren über die Jahre hinweg aufrechterhalten werden kann, gelte es in weiteren Analysen zu prüfen. Die Darstellung an dieser Stelle sollte indes deutlich machen, welche Extreme die länderspezifischen Empfehlungen annehmen können, um hierdurch zugleich künftige Nutzungsmöglichkeiten durch die EUSA im Sinne kriseninduzierter Staatlichkeitstransformationen antizipieren zu können.

\section{Schuldenbremse, Austeritätsmechanismus \& Euro-Gipfel - Der SKS-Vertrag}

Neben den sekundärrechtlichen Reformen lancierte der Europäische Rat in seiner intergouvernementalen Nebenagenda weitere Reformschritte, schließlich könnten, so Ratspräsident Van Rompuy (vgl. ER 2011e, 1), die aktuellen Probleme, mit denen die Eurozone konfrontiert sei, nur auf der höchsten Ebene gelöst werden. Nachdem allerdings die ersten Versuche des Europäischen Rates in Form des Euro-Plus-Paktes nur mäßige Erfolge zeigten (s.o.), wurde nach einer verbindlicheren Implementierungsform gesucht. Als eine Vertragsrevision zur Stärkung der fiskalpolitischen Vorgaben und eines erweiterten Rahmens zur Verbesserung der Wettbewerbsfähigkeit insbesondere am Widerstand des Vereinigten Königsreichs scheiterte, brach die Koalition der Willigen - wie bereits bei den Rettungsschirmen - abermals aus dem EU-Rechtsrahmen aus und implementierte mit dem »Vertrag über Stabilität, Koordinierung und Steuerung in der Wirtschafts- und Währungsunion« (SKS-V) einen zwischenstaatlichen Vertrag, der sich dem gängigen Krisennarrativ verpflichtet fühlte und in diesem Sinne weitere Reformen am fiskal- und wirtschaftspolitischen Rahmen der EWWU vollzog. Die Kern- 
anforderungen zur konkreten Ausgestaltung des SKS-Vertrags gab der Euro-Gipfel im Oktober 2011 den mitgliedstaatlichen Verhandlungsführer*innen bereits mit auf den Weg: Implementierung einer Regel - vorzugsweise mit Verfassungsrang - für ausgeglichene Haushalte auf Ebene der Mitgliedstaaten, Verstärkung des mitgliedstaatlichen fiskalpolitischen Regelwerks bzgl. der Anforderungen für den Haushaltsrahmen (über die RL 2011/85/EU hinaus), Aufforderung an die mitgliedstaatlichen Parlamente die auf EU-Ebene beschlossenen Empfehlungen in die wirtschafts- und haushaltspolitische Planung einzubeziehen, Mitteilungspflichten über größere fiskalische oder wirtschaftspolitische Reformvorhaben der Mitgliedstaaten, Vereinbarung über ein konzertiertes Abstimmungsverhalten im Rat in Bezug auf die Kommissionsempfehlungen im Rahmen des SWP (vgl. Euro-Gipfel 2011c, Rn. 26). Alle fünf Anforderungen finden sich schließlich in unterschiedlichem Umfang im späteren Vertrag wieder. Zugleich beschloss der Euro-Gipfel in einem separaten Papier zehn Maßnahmen zur Verbesserung der Governance im Euro-Raum (vgl. ebd., Anlage I), die ebenfalls in ihren wichtigsten Passagen in den SKS-Vertrag überführt wurden und in deren Folge dem Euro-Gipfel überhaupt erst eine »rechtliche« Basis verliehen wurde. Zugleich statteten die Staatsund Regierungschefs ihre Vorhaben mit jenem Pathos aus, der diesen Legitimität zu geben versuchte. So ließ Ratspräsident Van Rompuy nach dem Euro-Gipfel verlautbaren: »We do not want to repeat some of the errors from the recent past. In taking today's decisions, we lay the foundations for our future. All Members of the Euro Summit are determined to follow this path.« (ER 2011c, 2) Der schließlich im Januar 2013 in Kraft tretende Vertrag umfasst drei Handlungsfelder, die allesamt der »Erreichung der Ziele der Europäischen Union für nachhaltiges Wachstum, Beschäftigung, Wettbewerbsfähigkeit und sozialen Zusammenhalt «(Art. 1, Abs. 2 SKS-V) dienen sollen: Förderung der Haushaltsdisziplin, verstärkte Koordinierung der Wirtschaftspolitik und die Verbesserung der Steuerung des Euro-Währungsgebiets (vgl. ebd.).

Der fiskalpolitische Pakt als Kern des SKS-Vertrags umfasst die Verpflichtungen zu einem ausgeglichenen oder einem Überschuss aufweisenden Haushalt sowie die »rasche« Sicherstellung einer Annäherung auf das jeweilige länderspezifische Haushaltsziel (vgl. Art. 3, Abs. 1a \& Ib SKS-V). Beides Verpflichtungen, die bereits im Rahmen des reformierten SWP vereinbart wurden. Neu ist hingegen eine Verschärfung für jene Mitgliedstaaten, deren Schuldenstand über $60 \%$ des BIP liegt: Der Haushalt dieser Länder gilt als ausgeglichen, wenn das strukturelle Defizit maximal 0,5\% des BIP entspricht (vgl. Art. 3, Abs. Ib SKS-V), liegt das Defizit »erheblich« unter $60 \%$, darf ein strukturelles Defizit von $1 \%$ ausgewiesen werden (vgl. Art. 3, Abs. Id SKS-V). Lediglich der zuletzt genannte Richtwert entspricht dem reformiertem Sekundärrecht. »Der Fiskalvertrag ist damit für Mitgliedstaaten mit hoher Schuldenstandsquote oder Risiken in Bezug auf die Tragfähigkeit ihrer öffentlichen Finanzen strenger als der europäische Stabilitäts- und Wachstumspakt «, wie das Bundesfinanzministerium (2018) auf seiner Internetseite zusammenfasst. Wie der SWP kennt auch der SKS-Vertrag außergewöhnliche Umstände, die zu einer Abweichung der dargestellten Regelungen führen können, wobei trotzdem die mittelfristige Tragfähigkeit der öffentlichen Finanzen gewahrt bleiben muss (vgl. Art. 3, Abs. 3b SKS-V). Bei Abweichungen vom mittelfristigen Haushaltsziel beziehungsweise dem Anpassungspfad dorthin wird ein Korrekturmechanismus ausgelöst, der auf EU-Ebene bereits im SWP angelegt ist. Neu ist die 
Verpflichtung der teilnehmenden Mitgliedstaaten, auf mitgliedstaatlicher Ebene zusätzlich einen eigenständigen Korrekturmechanismus einzurichten (vgl. Art. 3, Abs. 2 SKS-V), der auf gemeinsamen Grundsätzen beruhen solle, die von der Kommission im Juni 2012 in einer Mitteilung vorgelegt wurden (vgl. KOM 2012f, 3). Weiterhin gehen die SKS-Vertragsparteien mit Absatz 2 des Vertragsartikels 3 die wohl wichtigste Vereinbarung ein, indem sie sich verpflichten, die genannten fiskalpolitischen Bestimmungen dauerhaft in mitgliedstaatliches Recht - vorzugsweise mit Verfassungsrang - zu überführen.

Die eingegangenen Verpflichtungen der Mitgliedstaaten sollen ein Jahr nach Inkrafttreten des Vertrags seitens der Kommission überprüft werden und bei Nichteinhaltung eines Mitgliedstaats der Gerichtshof mit der Angelegenheit betraut werden (vgl. Art. 8, Abs. 1 SKS-V). Zugleich können bei Nichtimplementierung der Fiskalregeln und des Korrekturmechanismus oder Nichtberücksichtigung einer potenziellen EuGH-Entscheidung finanzielle Sanktionen seitens der Kommission verhängt werden (vgl. Art. 8, Abs. 2 SKS-V). In Artikel 4 des SKS-Vertrags wird außerdem noch einmal die im reformierten SWP hinterlegte Regelung bestätigt, nach der der Schuldenstand jährlich um mindestens ein Zwanzigstel zu reduzieren sei, wenn er über dem Maastrichtwert von $60 \%$ liegt. Artikel 5 schreibt die Formulierung von Wirtschaftspartnerschaftsprogrammen vor, wenn ein Verfahren bei einem übermäßigen Defizit anhängig ist, welches durch die Kommission und den Rat überwacht wird. Für die EuroMitgliedsstaaten ist dieser Punkt parallel durch das Two-Pack auch sekundärrechtlich implementiert worden, für die teilnehmenden Nicht-Euro-Mitglieder stellt er hingegen eine wichtige Neuerung dar. Ebenso gestaltet es sich mit der Vorankündigung bei der Ausgabe für Staatsschuldentitel (vgl. Art. 6 SKS-V), die ebenso Bestandteil des TwoPacks ist. Hinzu kommt schließlich die nicht unwichtige Selbstverpflichtung der EuroMitgliedstaaten

»zur Unterstützung der Vorschläge oder Empfehlungen der Europäischen Kommission, in denen diese die Auffassung vertritt, dass ein Mitgliedstaat der Europäischen Union, dessen Währung der Euro ist, im Rahmen eines Verfahrens bei einem übermäßigen Defizit gegen das Defizit-Kriterium verstößt. Diese Verpflichtung entfällt, wenn zwischen den Vertragsparteien, deren Währung der Euro ist, feststeht, dass eine analog zu den einschlägigen Bestimmungen der Verträge, auf denen die Europäische Union beruht, unter Auslassung des Standpunkts der betroffenen Vertragspartei ermittelte qualifizierte Mehrheit von ihnen gegen den vorgeschlagenen oder empfohlenen Beschluss ist.«(Art. 7 SKS-V)

Hierdurch soll eine möglichst automatische Einleitung des Defizitverfahrens sichergestellt werden, weshalb die EZB (2011a, 3) bereits während der Six-Pack-Diskussion eine entsprechende Selbstverpflichtung als »unverzichtbares Element für das reibungslose Funktionieren der wirtschaftspolitischen Steuerung der EU« erfolgreich anmahnte. So erklärten die Finanzminister*innen schon im Juli 2011, dass der Rat »[b]ei seinen Entscheidungen bezüglich der Schritte im Rahmen des Stabilitäts- und Wachstumspaktes [...] voraussichtlich die Empfehlungen der Kommission befolgen oder seinen Standpunkt schriftlich erläutern [wird].«(ECOFIN 2011b, 4) Insofern ist die Selbstverpflichtung im SKS-Vertrag nicht gänzlich neu, auch wenn sie in Vertragsform eine 
andere Wirkmacht aufweist. Neu und weitrechender als das bis dato kodierte SWPSekundärrecht ist hingegen der zweite Satz dieses Artikels. Er führt über den Umweg eines zwischenstaatlichen Vertrags neue Mehrheitsanforderungen im Falle der Einleitung eines Defizitverfahrens für Euro-Mitgliedstaaten ein. Juristisch ist eine solche Vertragsbestimmung von besonderem Interesse, da sie in unionsvertragsbasierte Verfahrensabläufe eingreift und eine Umkodierung vornimmt, die primärrechtlich nicht vorgesehen ist.

Im Kontext wirtschaftspolitischer Koordinierung und Konvergenz verfolgen die Vertragsparteien das Ziel »Wettbewerbsfähigkeit und Beschäftigung zu fördern, weiter zur langfristigen Tragfähigkeit der öffentlichen Finanzen beizutragen und die Finanzstabilität zu stärken« (Art. 9 SKS-V). Hierzu leiten sie »in allen für das reibungslose Funktionieren des Euro-Währungsgebiets wesentlichen Bereichen die notwendigen Schritte und Maßnahmen ein.« (Ebd.) In diesem Sinne seien die Vertragsparteien bereit, von den in den Verträgen hinterlegten Möglichkeiten (bspw. Art. 136 AEUV zum Erlass von Rechtsakten zum reibungslosen Funktionieren des Euro-Währungsgebiets oder die Methode der Verstärkten Zusammenarbeit) »aktiven Gebrauch zu machen.« (Art. 10 SKS-V) Zugleich enthält der Vertrag die Verpflichtung, sich vorab gegenseitig von größeren wirtschaftspolitischen Reformen zu unterrichten und diese gemeinsam zu erörtern (vgl. Art. I1 SKS-V). Insgesamt fällt auf, dass die hier getroffenen Vereinbarungen eine unübersehbare Ähnlichkeit mit den Verpflichtungen aus dem 'gescheiterten Euro-Plus-Pakt aufweisen. So ist die in Artikel 9 hinterlegte Zielsetzung sogar im Wortlaut identisch.

Der Abschnitt zur Steuerung des Euro-Währungsgebiets umfasst die rechtliche Kodifizierung der Arbeitsregelungen für den Euro-Gipfel, der als neues Steuerungszentrum des Euro-Währungsgebiets fungieren solle. Demnach kommen die Staats- und Regierungschefs der Eurozone unter Beteiligung der Präsident"innen der Kommission und der Zentralbank »informell «u Tagungen des Euro-Gipfels zusammen, wobei dem Gipfel ein*e eigene*r Präsident*in vorsitzt, die*der analog zur*zum Ratspräsident*in zu bestimmen ist (vgl. Art. 12, Abs. I SKS-V). Der Gipfel tritt bei Bedarf, jedoch mindestens zweimal jährlich zusammen (vgl. Art. 12, Abs. 2 SKS-V). Auch die Beteiligung der NichtEuro-Staaten findet Berücksichtigung, soweit sie den Vertrag ratifiziert haben und die zu behandelnden Fragestellungen des Euro-Gipfels die Themen Wettbewerbsfähigkeit, Änderungen an der allgemeinen Architektur des Euroraums oder Fragen bezüglich der Durchführung des SKS-Vertrags betreffen (vgl. Art. 12, Abs. 3 SKS-V). Inhaltlich wird die Tagung durch die Euro-Gruppe vorbereitet (vgl. Art. 12, Abs. 4 SKS-V) und die*der Präsident" in des Europäischen Parlaments kann zu den Gipfeln eingeladen werden (vgl. Art. 12, Abs. 5 SKS-V). Weiterhin ist die*der Gipfelpräsident*in aufgefordert, dem Parlament nach jeder Tagung einen Bericht vorzulegen (vgl. ebd.) und alle Mitgliedstaaten über die Vorbereitung und die Ergebnisse zu unterrichten (vgl. Art. 12, Abs. 6 SKS-V). Schließlich werden in Artikel 13 das Europäische Parlament und die mitgliedstaatlichen Parlamente aufgefordert, in Form einer gemeinsamen Konferenz über »die Haushaltspolitik und andere von diesem Vertrag erfasste Angelegenheiten zu diskutieren. « Auf Druck des Europäischen Parlamentes, das Delegierte zu den Vertragsverhandlungen entsandte, die allerdings nicht an der konkreten Ausgestaltung des Vertragstextes mit- 
wirken durften (vgl. Fabbrini 2015, 305), wurde zugleich noch ein interessanter finaler Artikel in den Vertrag aufgenommen, der besagt, dass

»[b]innen höchstens fünf Jahren ab dem Inkrafttreten dieses Vertrages [...] auf der Grundlage einer Bewertung der Erfahrungen mit der Umsetzung des Vertrags gemäß dem Vertrag über die Europäische Union und dem Vertrag über die Arbeitsweise der Europäischen Union die notwendigen Schritte mit dem Ziel unternommen [werden], den Inhalt dieses Vertrags in den Rechtsrahmen der Europäischen Union zu überführen.« (Art. 16 SKS-V; vgl. EP 2012f, 4.)

Nachdem der SKS-Vertrag am 1. Januar 2013 in Kraft trat (vgl. Art. 14, Abs. 2 SKS-V), ist diese Frist allerdings ohne eine entsprechende Überführung in den Unionsrechtsrahmen am 31. Dezember 2017 verstrichen.

Der SKS-Vertrag wurde schließlich von 25 der damaligen 27 EU-Mitgliedstaaten unterzeichnet. Das Vereinigte Königreich und Tschechien schlossen sich dem Vertrag nicht an, Kroatien ratifizierte ihn nach dem Beitritt zur EU im Jahre 2013 ebenfalls nicht. Alle übrigen EU-Mitgliedstaaten sind Vertragsparteien, wenngleich mit unterschiedlicher Reichweite: So haben alle Unterzeichnerstaaten Vertragstitel V (Steuerung des Euro-Währungsgebiets) ratifiziert, der ihnen die partielle Teilnahme an den Tagungen des Euro-Gipfels garantiert (vgl. de Finance 2016, 7). Am Titel IV (wirtschaftspolitische Koordinierung und Konvergenz) beteiligten sich allerdings nur Bulgarien und Dänemark (vgl. ebd.). Die beiden zuletzt genannten und Rumänien sind zugleich die einzigen Nicht-Euroländer, die sich dem fiskalpolitischen Pakt (Titel III) des Vertrags angeschlossen haben (vgl. ebd.). Gerade die Beteiligung dieser drei Mitgliedstaaten am Fiskalpakt ist besonders interessant, da die im SKS-Vertrag benannten fiskalpolitischen Restriktionen (abgesehen von der in der öffentlichen Diskussion häufig als »Schuldenbremse« bezeichneten verfassungsrechtlichen Verankerung der vereinbarten fiskalpolitischen Regelungen und des automatischen Korrekturmechanismus) für die Nicht-Euro-Staaten eine besondere Verschärfung des SWP darstellt. Für EuroMitgliedstaaten sind die numerischen Verschärfungen hingegen weitestgehend bereits zuvor oder aber parallel in Form des Six- und des Two-Packs - letzteres findet ausschließlich Anwendung für die Eurozone - sekundärrechtlich verankert worden. Trotz dieser weitgehenden Doppelung bewertet die Kommission in einem Occasional Paper den SKS-Vertrag als einen positiven Beitrag zur Vervollständigung des SWP: »The TSCG complements the SGP by committing the signatories to mirror key elements of the SGP, in particular of its preventive arm, in national law and by making further steps in the surveillance and coordination of budgetary policies.«(KOM 2013d, 18) Dennoch hätte es auch die Kommission (2017n, 3) vorgezogen, sich auf den Rechtsrahmen der Union zu stützen, statt einen »zwischenstaatlichen Ansatz als Notlösung« zu wählen. Letzteres sieht das Europäische Parlament ähnlich, das in einem gemeinsamen Entschließungsantrag von PPE, S\&D, ALDE und Grünen das Ansinnen eines zwischenstaatlichen Vertrags scharf kritisiert. So bezweifeln es die benannten Fraktionen, "dass ein solches zwischenstaatliches Abkommen notwendig ist, da die meisten der darin genannten zentralen Ziele besser und wirksamer durch Maßnahmen im Rahmen des EU-Rechts verwirklicht werden können« (EP 2012f, Rn. 1), stattdessen seien sie »fest davon überzeugt, dass sich die Währungsunion nur durch Anwendung der Gemeinschaftsmethode 
zu einer echten Wirtschafts- und Steuerunion entwickeln kann« (ebd., Rn. 3). Auch inhaltlich lässt das Parlament den Vertrag nicht unkritisiert. So vertreten die genannten Fraktionen

»die Auffassung, dass Haushaltsdisziplin zwar die Voraussetzung für ein tragfähiges Wachstum ist, dass sie allein aber keinen wirtschaftlichen Aufschwung herbeiführen wird, und dass von dem Abkommen die klare Botschaft ausgehen muss, dass die europäischen Staats- und Regierungschefs an beiden Fronten [(Stabilität \& Wachstum);

J. G.] mit der gleichen Entschiedenheit handeln werden« (ebd., Rn. 5).

Mit dieser Einschätzung antizipiert das Parlament bereits die Diskussionen, die der sozialistische Kandidat für die französischen Präsidentschaftswahlen, Hollande, 2012 im Kontext des SKS-Vertrags angestoßen hat und die in der flankierenden Beschlussfassung des sogenannten >Pakts für Wachstum und Beschäftigung`mündete, der allerdings ähnlich wie der Euro-Plus-Pakt im Grunde nur wenig Einfluss auf die konkrete Politikgestaltung nehmen konnte (vgl. KOM 2013e). Konkret fordern die Parlamentarier*innen der "großen Koalition« aus Sozialist"innen, Grünen, Liberalen und Konservativen, dass das Abkommen auch Vorschläge für einen Tilgungsfonds, zu projektspezifischen Anleihen, zur Finanztransaktionssteuer und einen Fahrplan für Stabilitätsanleihen (Eurobonds) enthalten sollte (vgl. EP 2012f, Rn. 5). Nicht zuletzt wird in der Entschließung an die Kommission appelliert, ihrer Rolle als Hüterin der Verträge gerecht $\mathrm{zu}$ werden (vgl. ebd., Rn. 8) und sich das Recht vorzubehalten, "möglicherweise alle zur Verfügung stehenden politischen und rechtlichen Möglichkeiten zur Verteidigung des EU-Rechts und der Rolle der EU-Organe zu nutzen, vor allem, wenn Teile des endgültigen Abkommens nicht mit dem EU-Recht vereinbar sind« (ebd., Rn. 7). Von dieser Drohung wurde bisher zwar kein Gebrauch gemacht, doch unterstreicht sie nochmals die vom Parlament durchgesetzte Vertragsklausel, nach der die Inhalte des Vertrags innerhalb von fünf Jahren in den Unionsrechtsrahmen zu überführen sind.

Die Überprüfung, ob die fiskalpolitischen Zielsetzungen des Vertrags in die mitgliedstaatlichen Rechtsrahmen überführt wurden, schreibt der Vertrag der Kommission zu, die im Februar 2017 eine Bestandsaufnahme des Fiskalpakts (vgl. KOM 2017n) sowie einen Bericht zur mitgliedstaatlichen Implementierung (vgl. KOM 2017p) vorlegte. Darin heißt es, dass »[a]lle Vertragsparteien [...] aufgrund der Anforderungen des fiskalpolitischen Pakts, in Verbindung mit den Rechtsvorschriften der Union, ihre nationalen haushaltspolitischen Rahmen erheblich angepasst [haben].« (KOM 2017n, 4) Die Kommission (2017p, 3) bescheinigt allen Vertragsparteien die Konformität der mitgliedstaatlichen Bestimmungen mit denen des SKS-Vertrags. Allerdings zeigen die konkreten Umsetzungen eine unterschiedliche Tiefe der verankerten mitgliedstaatlichen Regelungen. Lediglich elf der 22 Vertragsparteien des fiskalpolitischen Pakts haben Regelungen mit »Verfassungsrang oder als besonderes Rechtsinstrument mit höherem Status als das Haushaltsrecht« (ebd., 4) erlassen und nur vier dieser Länder haben entsprechende Regelungen in ihre Verfassung aufgenommen (Deutschland, Spanien, Italien und Slowenien). Im Falle Griechenlands und Luxemburgs bedurfte es gar der Zusicherung, Sonderbestimmungen zu erlassen, »die sie der Kommission angekündigt haben und die ihrer eigenen Einschätzung nach erforderlich sind, um das nationale Recht mit dem Fiskalpakt in Einklang zu bringen.« (Ebd., 5) Abseits der unterschiedlichen 
Formen der mitgliedstaatlichen Implementierung steht die inhaltliche Ausgestaltung der mitgliedstaatlichen Gesetzestexte mit den vorgegebenen numerischen Haushaltsregeln des Paktes im Einklang, wobei die Mehrzahl der Länder (19 von 22) einen direkten Bezug zu den sekundärrechtlichen Bestimmungen des SWP herstellen ${ }^{16}$. Drei Länder haben gar striktere Untergrenzen für das strukturelle Defizit implementiert: Estland ( $0,0 \%)$, Spanien (0,०\%) und Österreich (-0,45 \%) (vgl. ebd.). Die Ausgestaltung der mitgliedstaatlichen Korrekturmechanismen (vgl. ebd., 7f.) sowie der unabhängigen Überwachungsinstitutionen (vgl. ebd., 9ff.) fällt insgesamt sehr unterschiedlich aus, auch wenn die Kommission allen Ländern die Vertragskonformität bescheinigt. Interessant erscheint, dass in 19 der 22 Fälle der Mechanismus per Definition »automatisch« ausgelöst wird: So gilt für Österreich, Deutschland, Dänemark, Spanien und Litauen, dass die Haushaltspläne unabhängig von Abweichungen der Vorjahre immer entsprechend dem mittelfristigen Haushaltsziel vorgelegt und verabschiedet werden müssen (»Regel des ausgeglichenen Haushalts im strikten Sinne«; ebd.). Für insgesamt 14 weitere Staaten gilt, dass der Korrekturmechanismus ausgelöst wird, wenn im Rahmen der sekundärrechtlichen SWP-Verordnungen »eine erhebliche Abweichung« vom Haushaltsziel festgestellt wird (vgl. ebd.). Die Auslösung obliegt in solchen Fällen demnach nicht der mitgliedstaatlichen sondern der suprastaatlichen Politikebene. Lediglich in drei Ländern (Belgien, Bulgarien und Frankreich) wird die Auslösung des Mechanismus in die Hände der >unabhängigen Überwachungsinstitutionen< gelegt (vgl. ebd.). Spannend erscheint auch, dass in elf der 22 Vertragsstaaten ${ }^{17}$ »ein direkter Zusammenhang geschaffen [wird] zwischen den Empfehlungen der Unionsorgane im Rahmen des SWP und den Haushaltsvorschriften, die im Plan für Abhilfemaßnahmen hinsichtlich des Umfangs und zeitlichen Rahmens der Korrektur zu beachten sind.« (Ebd.) Die beiden letztgenannten Punkte sind insbesondere deshalb hervorzuheben, weil sie neue Zugriffsrechte der suprastaatlichen Staatsapparate auf die mitgliedstaatlichen Haushaltspolitiken in den betreffenden Mitgliedstaaten ermöglichen.

Auch in der wissenschaftlichen Diskussion und Bewertung des SKS-Vertrags stellt der automatische Korrekturmechanismus einen wichtigen Bezugspunkt dar. Oberndorfer (2012b, 178) bezeichnet ihn beispielsweise als "Austeritätsmechanismus«, der eine große Bandbreite von Austeritätsmaßnahmen ermögliche, zumal der Korrekturmechanismus über das mit der RL 2011/85/EU geschaffene Sekundärrecht hinausgehe (vgl. bspw. Antpöhler 2012, 384). Dies zeigt auch die mitgliedstaatliche Umsetzung der Vorgabe zur Einrichtung der automatischen Korrekturmechanismen, die teilweise die Zugriffsrechte der suprastaatlichen Staatsapparate stärkt. Dabei lässt sich insgesamt festhalten, dass der Fiskalpakt »wirtschaftspolitisch die verschärfte Fortschreibung der neoliberalen Theorie, die glaubt, sich mit einer Austeritätspolitik [...] aus der Krise befreien zu können« (Bontrup 2013, 182), darstellt. Ähnlich bewertet auch Radice (2014, 318) den Vertrag: »[T]he TSCG has been widely and rightly interpreted as signaling a

16 Diese Form schließt ein, dass bei einer Änderung des Unionsrechts etwaige neue Zielvorgaben direkt im mitgliedstaatlichen Rechtsrahmen verankert sind.

17 Bulgarien, Estland, Griechenland, Irland, Lettland, Malta, Niederlande, Rumänien, Slowakei, Slowenien und Zypern. 
commitment to austerity for many years to come, and this in turn has helped to galvanise opposition in politics, the media and the street across Europe.« Neben dem Austeritätsmechanismus sind die Normierungen des SKS-Vertrags insgesamt als »weitestgehend redundant « (Antpöhler 2012, 391) zu bezeichnen, wobei allerdings die Frage von Relevanz ist, ob der SKS-Vertrag mit dem Unionsrechts vereinbar ist oder nicht. Antpöhler $(2012,391)$ vertritt hierbei die These, dass der SKS-Vertrag europarechtskonform sei. Anders sehen es Fischer-Lescano \& Oberndorfer $(2013,14)$ : „Der Eingriff in die primärrechtlich geregelte Fiskalordnung der Europäischen Union durch völkerrechtliches Nebenunionsrecht ist aus der Perspektive des Unionsrechts rechtswidrig." Mit Bezug auf die Pringle-Entscheidung des EuGH (s.o.) halten die beiden Autoren fest, dass

»ein unionsrechtliches Zustimmungsverfahren ${ }^{18}$ zu einer völkerrechtlichen Aufgabenübertragung nur dann entbehrlich [ist], wenn (1) durch das völkervertragliche Vorgehen keine Verfälschung unionaler Befugnisse eintritt, wenn also insbesondere (2) die völkervertraglichen zu den unionsrechtlichen Aufgaben in einem Entsprechungsverhältnis stehen und wenn (3) den EU-Organen durch den Völkerrechtsvertrag skeine Entscheidungsbefugnisse im eigentlichen Sinn< eingeräumt werden.«(Ebd.)

Da alle drei Bedingungen im Falle des SKS-Vertrags nicht zuträfen, sei der Vertrag aufgrund seines Implementationsprozederes letztlich als rechtswidrig zu bezeichnen. Ein weiteres Beispiel für die fragwürdige Europarechtskonformität stellt der Artikel 7 des SKS-Vertrags dar, nach dem die Unterzeichnerstaaten sich verpflichten, im Rat die Empfehlungen der Kommission im Rahmen des SWP unverändert mitzutragen. Bei einer so formulierten Zusammenfassung des Kerngehalts des Artikels könnte der Eindruck bestehen, dass der Artikel 7 lediglich »als politische Absichtserklärung ohne rechtliche Bindungswirkung eingestuft werden «(Ortmann 2015, 540) könne. Allerdings, darauf weist Ortmann $(2015,541)$ hin,

»schränkt die völkerrechtliche Abstimmungsregel in Art. 7 VSKS nicht nur den im Kompetenzbereich der Mitglied- bzw. Euro-Staaten verbleibenden Entscheidungsspielraum ihres Vertreters im Rat ein, sondern verändert für den Kreis der EuroStaaten unter Umgehung der vom Unionsrecht in Art. 48 EUV vorgesehen Verfahren zur Änderung des Primärrechts die sich aus Art. 126 XIII iVm Art. 238 III Buchst. A AEUV folgenden Mehrheitserfordernisse für die Ablehnung eines Ratsbeschlusses im Defizitverfahren.«

So besagen die Unionsverträge, dass bei der Beschlussfassung über Defizitverfahren die qualifizierte Mehrheit (55\% der Mitgliedstaaten und $65 \%$ der Bevölkerung) erreicht werden müsse. Artikel 7 des SKS-Vertrags kodiert nun allerdings, dass nur in solchen Fällen der Beschluss als nicht erreicht gilt, wenn eine qualifizierte Mehrheit gegen die Annahme des Kommissionsvorschlags votiere. In Zahlen ausgedrückt bedeutet dies, dass vorher die Sperrminorität gegen die Einleitung eines Verfahrens bei $>45 \%$ der

Die Argumentation Fischer-Lescanos \& Oberndorfers basiert auf der Annahme, dass aufgrund der vorgenommenen tiefen Eingriffe des SKS-Vertrags in den Rechtsrahmen der Europäischen Union ein ordentliches Vertragsänderungsverfahren nötig gewesen wäre, das unter anderem die Beteiligung des Europäischen Parlamentes vorgesehen hätte. 
Mitgliedstaaten und $>35 \%$ der Bevölkerung lag und nun mindestens $55 \%$ der Mitgliedstaaten mit mindestens $65 \%$ der Bevölkerung gegen ein solches Verfahren stimmen müssten. Insofern überlagert Artikel 7 »die primärrechtlichen Mehrheitsvorgaben für die Ablehnung von Beschlüssen im Defizitverfahren« (ebd., 540), er

»führt auf völkervertraglicher Ebene das sumgekehrte Abstimmungsverfahren ein. Die Umkehrung des Erfordernisses der qualifizierten Mehrheit führt zu einer Einschränkung der Erfolgschance von politischen Interessen, die jenseits des Fiskalvertrags liegen, aber durch das europäische Primärrecht geschützt sind. Das Abstimmungsverhalten wird durch den Mechanismus des Art. 7 SKSV deshalb einseitig an fiskalische Rationalität gebunden«,

wie Fischer-Lescano \& Oberndorfer $(2013,12)$ es zusammenfassen.

In seiner Anlage und vor dem Hintergrund seiner fiskalischen Rationalität spiegele der SKS-Vertrag deutlich die maßgebliche Handschrift der deutschen Bundesregierung wider (vgl. Petzold 2018, 263), deren Durchsetzungsfähigkeit Schäfer $(2013,118)$ darin erkennt, dass der Vertrag »außerhalb des rechtlichen Fundaments der Europäischen Union ohne Zustimmung durch das Vereinigte Königreich « durchgesetzt werden konnte. Weiterhin hält er fest, dass »vieles [...] für die Betrachtung des Fiskalvertrags als Produkt deutscher Präferenzen [spricht] « (ebd., 120), auch wenn zugleich »die erfolgreiche Verhandlungsführung Frankreichs [ersichtlich]« (ebd.) werde. So habe Frankreich beispielsweise verhindern können, dass der Gerichtshof überprüft, ob das Defizit- und das Schuldenstandskriterium eingehalten und dass der Kommission ein weitreichenderes Klagerecht eingeräumt wird (vgl. ebd., 119f.). Des Weiteren ging der im SKS-Vertrag kodifizierte Euro-Gipfel auf die Initiative des damaligen französischen Präsidenten Sarkozy zurück.

Auch wenn der SKS-Vertrag insgesamt einige Redundanzen mit bereits zuvor oder parallel sekundärrechtlich verankerten Instrumenten aufweist, lässt sich zusammenfassend festhalten, dass er in einigen Bereichen über diese hinausweist und nicht unwichtige weitere Verschiebungen im rechtlichen Rahmen des Stabilitätsund Wachstumspakts durchsetzt. Neben den mitgliedstaatlichen Fiskalrestriktionen (bei einem Schuldenstand über $60 \%$ des BIP) zählen hierzu die mitgliedstaatlichen Korrekturmechanismen (Austeritätsmechanismus oder auch »Schuldenbremse«) und nicht zuletzt die Verschärfung der negativen Mehrheitserfordernisse im Defizitverfahren (Art. 7 SKS-V). Dass dabei die Rechtskonformität mit dem Unionsrecht stark strapaziert und zurecht darauf hingewiesen wird, dass sie nicht erreicht ist, gelten die entsprechenden Passagen des Vertrags dennoch solange, bis ihm durch eine juristische Entscheidung des EuGH eine mögliche fehlende Konformität attestiert wird. So sieht jedenfalls Ortmann $(2015,544)$ die Möglichkeit, dass wenn »die völkerrechtliche Abstimmungsregel [...] angewendet werden [sollte], [...] ein Mitgliedstaat den Beschluss, der ihm gegenüber nach Maßgabe des Art. 7 VSKS erlassen wurde, gem. Art. 263 AEUV im Wege einer Nichtigkeitsklage vor dem EuGH anfechten [könnte].« Der SKS-Vertrag sei als Notlösung in der Tat >unglücklich‘, so Calliess $(2015,43)$ und verweist somit noch einmal eindringlich auf die schwache legitimatorische Basis des SKS-Vertrags, als Bestandteil eines europäischen Notstandsrechts der Euro-Krise. So juristisch fragwürdig der Vertrag deshalb auch bleibt, umso klarer ist sein Inhalt. Als parallelvertraglich- 
fixierter Bestandteil der EU-Verträgeverfassung schwört er letztlich auf die neoliberale Austeritäts- und Wettbewerbsfähigkeitsagenda ein.

\section{Die Synchronisierung von Wirtschaftsregierung \& Notstandsverfassung}

Mit der Verordnung »über den Ausbau der wirtschafts- und haushaltspolitischen Überwachung von Mitgliedstaaten im Euro-Währungsgebiet, die von gravierenden Schwierigkeiten in Bezug auf ihre finanzielle Stabilität betroffen oder bedroht sind«, legte die Kommission im Rahmen des Two-Packs eine weitere Verordnung vor, mit der sie die Überwachungsinfrastruktur in der Eurozone auszuweiten suchte. Im Unterschied $\mathrm{zu}$ den vorangegangenen Legislativakten des Six-Packs und der ersten Two-Pack-Verordnung (EU) Nr. 473/2013 adressiert die zweite Two-Pack-Verordnung (EU) Nr. 472/2013 allerdings keine zusätzlichen Überwachungstätigkeiten in >Normalzeiten<, sondern greift erst dann, wenn »schwere finanzielle Schwierigkeiten« (Erw. 5 VO (EU) Nr. 472/2013) attestiert wurden, in deren Folge eine verstärkte Überwachung (vgl. Art. 2 \& 3 VO (EU) Nr. 472/2013) ausgelöst wird. Neben diesem Ausbau der SWPÜberwachungsinfrastruktur wird mit der Verordnung zugleich das Ziel formuliert, »[e]ine uneingeschränkte Kohärenz zwischen dem im AEUV dargelegten multilateralen Überwachungsrahmen der Union und den unter Umständen mit einer Finanzhilfe verbundenen politischen Auflagen [...] im Unionsrecht« (Erw. 3 VO (EU) Nr. 472/2013) zu verankern. Dies bedeutet im Klartext, dass die geschaffenen außervertraglichen Zweckgesellschaften und Institutionen der Notstandsverfassung (EFSF \& ESM) durch die Verordnung sekundärrechtlich in den Rahmen des EU-Wirtschafts- und Fiskalregierens eingeflochten werden, wobei allerdings die formalen Verfahren innerhalb der Rettungsschirme unangetastet bleiben (vgl. Erw. 12 VO (EU) Nr. 472/2013). Die sekundärrechtliche Flankierung der Rettungsschirme deutet insofern eine interessante Wandlung an. Dabei kodiert die Verordnung einerseits Regelungen für Mitgliedstaaten, die finanzielle Hilfen aus den Rettungsschirmen erhalten, für die eine »verstärkte« Überwachung gelten soll (vgl. Erw. 5 VO (EU) Nr. 472/2013). Andererseits werden zugleich die mit den Rettungsschirmen erprobten Herrschaftsmechanismen, wie sie insbesondere in den Memoranden zum Ausdruck kommen, in Form makroökonomischer Anpassungsprogramme als sekundärrechtliches Äquivalent im Rechtsrahmen der Union etabliert. Insofern findet mit der Verordnung (EU) Nr. 472/2013 eine Verschränkung der intergouvernementalen mit den suprastaatlichen Reformmaßnahmen der reaktiven Krisenbewältigungspolitik statt.

Konkret benennt die Verordnung zwei Fälle, in denen eine verstärkte Überwachung eingeleitet wird. Demnach umfasst ihr Adressatenkreis einerseits jene Mitgliedstaaten, die Finanzhilfen ersuchen oder erhalten, sowie andererseits Mitgliedstaaten, die von "gravierenden Schwierigkeiten in Bezug auf ihre finanzielle Stabilität oder die Tragfähigkeit ihrer öffentlichen Finanzen betroffen oder bedroht sind [...].« (Art. 1, Abs. I VO (EU) Nr. 472/2013; vgl. auch Art. 2, Abs. 3 VO (EU) Nr. 472/2013) Dabei obliegt es der Kommission, einen solchen Fall gravierender Schwierigkeiten festzustellen (vgl. Art. 2, Abs. 1 VO (EU) Nr. 472/2013). Als Bewertungsgrundlage dienen das MIP-Scoreboard, gegebenenfalls sich hieraus ergebene eingehende Überprüfungen sowie umfassende Bewertungen der Kreditaufnahmekonditionen, des Tilgungsprofils, der Robustheit des Haus- 
haltsrahmens, die langfristige Tragfähigkeit der öffentlichen Finanzen, die Bedeutung der Schuldenlast und schlussendlich die Gefahr eines Übergreifens schwerer Spannungen im Finanzsektor auf die Haushaltsposition des betreffenden Mitgliedstaats (vgl. Art. 2, Abs. 1 VO (EU) Nr. 472/2013). Der Einbezug des Rates im Prozess der Beschlussfassung über die Anwendung einer verstärkten Überwachung ist in der Verordnung nicht vorgesehen. Im Einklang mit dem SWP ist ein Mitgliedstaat, der unter verstärkter Überwachung steht, aufgefordert,

»nach Abstimmung und in Zusammenarbeit mit der Kommission, die in Verbindung mit der EZB, den Europäischen Aufsichtsbehörden, dem ESRB und gegebenenfalls dem IWF handelt, Maßnahmen [zu ergreifen], mit denen die Ursachen bzw. potenziellen Ursachen der Schwierigkeiten behoben werden sollen.« (Art. 3, Abs. 1 VO (EU) Nr. 472/2013)

Zugleich gelten für den Mitgliedstaat uneingeschränkt die Berichtspflichten nach der Verordnung auch für den Fall, dass kein übermäßiges Defizit vorliegt (vgl. Art. 3, Abs. 2 VO (EU) Nr. 472/2013). Außerdem werden federführend von der EZB in Zusammenarbeit mit dem Ausschuss für Systemrisiken (ESRB; s.u.) und anderen europäischen Aufsichtsbehörden Analysen, Stresstests und Bewertungen für den Finanzsektor eines Mitgliedstaates vorgenommen (vgl. Art. 3, Abs. 3 VO (EU) Nr. 472/2013). Weiterhin können die genannten Institutionen zusammen mit der Kommission und gegebenenfalls mit dem IWF regelmäßige Überprüfungsmissionen vornehmen (vgl. Art. 3, Abs. 4 VO (EU) Nr. 472/2013). Wenn die Kommission im Anschluss an eine Überprüfungsmission

»zu dem Schluss kommt, dass weitere Maßnahmen erforderlich sind und die finanzielle und wirtschaftliche Lage des Mitgliedstaats erhebliche nachteilige Auswirkungen auf die finanzielle Stabilität des Euro-Währungsgebiets oder eines seiner Mitgliedstaaten hat, kann der Rat dem betroffenen Mitgliedstaat auf Vorschlag der Kommission mit qualifizierter Mehrheit empfehlen, vorsorgliche Korrekturmaßnahmen zu ergreifen oder einen Entwurfeines makroökonomischen Anpassungsprogramms zu erarbeiten. (Art. 3, Abs. 7 VO (EU) Nr. 472/2013; Herv. J. G.)

Neben der verstärkten Überwachung wird mit der Verordnung des Weiteren ein Verfahren etabliert, das bei künftigen Hilfsgesuchen durch die Eurostaaten einzuhalten ist. Demnach ist ein Mitgliedstaat verpflichtet, den Vorsitzenden der Arbeitsgruppe »Euro-Gruppe«, den Wirtschafts- und Währungskommissar sowie den EZB-Präsidenten unverzüglich in Kenntnis zu setzen, sobald ein Finanzhilfeersuch beabsichtigt wird. Erst nach einer von der Kommission vorgelegten Bewertung berät die Arbeitsgruppe »Euro-Gruppe« hierüber und prüft, ob innerhalb des Rahmens »der bestehenden Finanzierungsinstrumente der Union oder des Euro-Währungsgebiets« Möglichkeiten bestehen, bevor der betroffene Mitgliedstaat sich an die potenziellen Kreditgeber - die Rettungsschirme beziehungsweise den IWF - wendet (Art. 5 VO (EU) Nr. 472/2013). Das hiermit verbundene Verfahren lässt den Schluss zu, dass hierüber eine geschlossene Informationskette sichergestellt und zugleich mitgliedstaatliche >Alleingänge ausgeschlossen werden sollen. Insbesondere was die Beantragung von Finanzhilfen beim IWF betrifft, könnte diese Vermutung nahe liegen. Des Weiteren nimmt Artikel 6 der Verordnung die in den Rettungsschirmen vorgesehenen Be- 
wertungsketten vorweg, indem vorgeschrieben wird, dass sobald ein Ersuch eines Mitgliedstaates an einen der Rettungsschirme ergeht, »die Kommission im Benehmen mit der EZB und nach Möglichkeit mit dem IWF die Tragfähigkeit der öffentlichen Verschuldung des betreffenden Mitgliedstaats und seinen vorhandenen oder potenziellen Finanzierungsbedarf [bewertet].« (Art. 6 VO (EU) Nr. 472/2013) Bereits in den Gründungsverträgen des ESM beziehungsweise der EFSF ist ein solches Verfahren angelegt, das nun in den Rechtsrahmen der Union eingebunden und der eigentlichen Bewertung durch die Organe des Rettungsschirms vorweggenommen wird.

Ähnlich gestaltet es sich auch beim anschließenden Artikel 7, in dem die Regelungen zum makroökonomischen Anpassungsprogramm festgehalten sind. Dort heißt es in Absatz 1:

»Ersucht ein Mitgliedstaat einen oder mehrere andere Mitgliedstaaten oder Drittländer, den EFSM, den ESM, den EFSF oder den IWF um Finanzhilfe ${ }^{19}$, erarbeitet er in Übereinstimmung mit der Kommission, die im Benehmen mit der EZB und gegebenenfalls mit dem IWF handelt, einen Entwurf eines makroökonomischen Anpassungsprogramms, das sich auf die Wirtschaftspartnerschaftsprogramme gemäß der Verordnung (EU) Nr. 473/2013 stützt sowie diese ersetzt und auch jährliche Haushaltsziele enthält.«

Anschießend muss der Rat das makroökonomische Anpassungsprogramm - auf Vorschlag der Kommission - billigen, ${ }^{20}$ wobei die Kommission sicherzustellen hat, "dass das von der Kommission im Namen des ESM oder der EFSF unterzeichnete Memorandum of Understanding in vollem Einklang mit dem vom Rat gebilligten makroökonomischen Anpassungsprogramm steht.« (Art. 7, Abs. 2 VO (EU) Nr. 472/2013; Herv. J. G.) Im Umkehrschluss bedeutet eine solche Konditionalität, dass die Memoranden durch die parallele Erarbeitung eines makroökonomischen Anpassungsprogramms auf sekundärrechtlicher Grundlage des Two-Packs selbst eine Art rechtliche Legalisierung erfahren. Die Kommission ist nach dem Beschluss über die entsprechenden Programme und Vereinbarungen wiederum Hauptakteurin der Überwachung, die sie »im Benehmen mit der EZB und gegebenenfalls mit dem IWF (Art. 7, Abs. 4 VO (EU) Nr. 472/2013) ausführt. Bemerkt sei zudem, dass hier die viel kritisierte Troika durch die Verordnung (EU) Nr. 472/2013 quasi in das EU-Sekundärrecht überführt wurde, auch wenn weder der Name »Troika« noch der Euphemismus »die Institutionen« direkt genannt werden. Weiter heißt es im besagten Artikel, dass der Rat auf Vorschlag der Kommission die Feststellung treffen kann, dass ein Mitgliedstaat seine Verpflichtungen aus dem makroökonomischen Anpassungsprogramm nicht erfüllt, ${ }^{21}$ woraufhin der betreffende Mitgliedstaat wiederum im Benehmen mit der oben genannten »Troika« (insb. der

19 Vorsorgliche Finanzhilfen oder solche zur Rekapitalisierung von Finanzinstituten fallen nicht unter diese Bestimmung (vgl. Art. 7, Abs. 12 VO (EU) Nr. 472/2013).

20 Abstimmungsberechtigt im Rat sind lediglich Mitgliedstaaten des Euro ohne Berücksichtigung der Stimmen des die Abstimmung betreffenden Mitgliedstaats, wobei eine qualifizierte Mehrheit erreicht werden muss (vgl. Art. 15 VO (EU) Nr. 472/2013).

21 Wobei es zu berücksichtigen gilt, dass »hinreichende Mittel für grundlegende Politikbereiche, wie Bildung und Gesundheit, bereitgestellt werden müssen.«(Art. 7, Abs. 7 VO (EU) Nr. 472/2013) 
Kommission) Maßnahmen ergreift, »um die Märkte zu stabilisieren und seinen Finanzsektor funktionsfähig zu erhalten.« (Art. 7, Abs. 7 VO (EU) Nr. 472/2013) Für den Fall, dass die Umsetzung des Anpassungsprogramms aufgrund ungenügender Verwaltungskapazitäten oder anderer erheblicher Probleme ins Stocken gerät, besteht zudem die Möglichkeit, die Kommission um »technische Hilfe« zu ersuchen (vgl. Art. 7, Abs. 8 VO (EU) Nr. 472/2013). Entsprechende Expert*innengruppen, zusammengesetzt aus Mitarbeiter*innen der Kommission, einzelner Mitgliedstaaten, anderer EU- oder »einschlägige[r] internationale[r] Institutionen «, können durch die Kommission zusammengestellt und in den betreffenden Mitgliedsstaat entsandt werden (vgl. ebd.). Zugleich kann »[d]ie technische Unterstützung [...] die Einsetzung eines im betreffenden Land ansässigen Vertreters sowie von Unterstützungspersonal beinhalten, die die Behörden in Fragen der Durchführung des Programms beraten.« (Ebd.) Übersetzt bedeutet dies, dass durch die Verordnung die Möglichkeit geschaffen wird, einen »europäischen Statthalter« - die Ähnlichkeit zum EZB-Vorschlag des »Enforcement Officers" ist augenscheinlich - einzusetzen, der die Einhaltung des makroökonomischen Anpassungsprogramms vor Ort überwacht. Zugleich steht der Rückkehr zur »SWP-Normalität« nach erfolgreicher Umsetzung des makroökonomischen Anpassungsprogramms eine weitere Hürde im Weg: Erst wenn 75 \% der aus den Rettungsschirmen erhaltenen Finanzhilfen zurückgezahlt wurden, erlischt die oben dargestellte verstärkte Überwachung eines Mitgliedstaats, allerdings auch nur dann, wenn die Kommission keine Verlängerung aufgrund anhaltender Finanzinstabilität oder in Sorge um die Tragfähigkeit der öffentlichen Finanzen beim Rat beantragt hat, der innerhalb von zehn Tagen im RQMVVerfahren einen entsprechenden Kommissionsantrag zurückweisen muss, um die verstärkte Überwachung zu beenden (vgl. Art. 14, Abs. I VO (EU) Nr. 472/2013). Auch kann die Kommission nach Abschluss des Anpassungsprogramms, bei anhaltender verstärkter Überwachung, Empfehlungen zu weiteren Korrekturmaßnahmen erlassen, die im RQMV-Beschlussverfahren als vom Rat angenommen gelten, falls dieser jene Empfehlungen nicht binnen zehn Tage ablehnt (vgl. Art. 14, Abs. 4 VO (EU) Nr. 472/2013).

Insgesamt bildet der geschaffene Rahmen der makroökonomischen Anpassungsprogramme im Sinne der dargestellten Verordnung (EU) Nr. 472/2013 und der hiermit verbundenen beziehungsweise ihr vorausgehenden verstärkten Überwachung das einflussreichste Instrumentarium unter den neu geschaffenen sekundärrechtlichen Regelungen und stellt somit die höchste Eskalationsstufe des Kriseninterventionismus im ordentlichen EU-Vertragsrahmen dar, dem zugleich alle anderen Instrumente der weiteren Sixund Two-Pack-Verordnungen nachgeordnet sind (vgl. Art 10-13 VO (EU) Nr. 472/2013).

\subsection{Aufbau einer (impliziten) Finanzstabilisierungsverfassung}

Neben der Implementierung einer außerunionsvertraglichen Notstandsverfassung und der Fortentwicklung der vertragsbasierten Fiskal- und Wirtschaftsverfassung lässt sich im Rahmen der reaktiven Krisenbewältigungspolitik ein dritter Konstitutionalisierungsprozess identifizieren, der sich im Aufbau einer (impliziten) Finanzstabilisierungsverfassung ausdrückt. Im Zentrum dieser neuen - an vielen Stellen ungeschriebenen und deshalb auch impliziten - Finanzstabilisierungsverfas- 
sung steht die Europäische Zentralbank. Die EZB stellte bereits vor der Euro-Krise in der Architektur der Währungsunion einen weithin sichtbaren Ausdruck der EUStaatlichkeit dar, schließlich obliegt ihr die ausschließliche Verantwortung für die Geldpolitik im gesamten Euroraum. Als EUSA besonderer Art agiert sie aufgrund ihrer vertraglichen Ausgestaltung vordergründig weitgehend unabhängig von den politischen Prozessen der anderen Apparate des EU-Staatsapparate-Ensembles. Neben den eingangs angeführten Kernnormen der EU-Wirtschaftsverfassung (insbesondere die Preisstabilität) umfasst die Zielvorgaben der Zentralbankpolitik dabei laut den Verträgen auch das Verbot monetärer Staatsfinanzierung, das die EZB im Unterschied zu anderen Zentralbanken (bspw. Kanada; vgl. Ehnts 2016, 94) vor dem Zugriff der Mitgliedstaaten oder auch der Union zur Finanzierung ihrer Defizite schützen und die Staaten stattdessen der sogenannten Marktdisziplin unterwerfen soll. Der Eurozone fehlt in diesem Sinne in Bezug auf die letztinstanzliche Liquiditätsversorgung der Euro-Mitgliedstaaten der sogenannte Lender of Last Resort (LOLR; Kreditgeber letzter Instanz), dessen Funktion in anderen Währungen meist die jeweilige Zentralbank übernimmt. Das Fehlen eines LOLR wird häufig als eine Fehlkonstruktion der EWWU beschrieben (vgl. Illing \& König 2014; De Grauwe 2011 \& 2013; De Grauwe \& Ji 2015), die es im Lichte der reaktiven Krisenbewältigungspolitik der EZB neu zu bewerten gilt. So bleibt zu klären, ob die EZB auf Grundlage der Programme zum Kauf von Staatschuldentiteln (SMP \& OMT) letztlich zum vermissten LOLR für die Eurozone geworden ist. Weiterhin gilt es, nicht nur vor dem Hintergrund der EZB-Beteiligung an der Troika die Frage zu klären, inwiefern die EZB in der Euro-Krise den >offiziellen Pfad eines unabhängig-technokratischen Staatsapparats verlassen hat. Anzeichen für Akte der Selbstermächtigung, in denen die Zentralbank gegenüber einzelnen Mitgliedstaaten in einer hoch-politischen Art und Weise intervenierte, sprechen jedenfalls dafür, insgesamt von einer Politisierung der EZB auszugehen, die letztlich auch formal durch Kompetenzübertragungen im Rahmen des Ausschusses für Systemrisiken und der Bankenaufsicht untermauert werden.

\section{Kreditgeber letzter Instanz? - Die Programme der EZB}

Seit dem Ausbruch der Finanz- und in ihrer Folge der realwirtschaftlichen Krise beruhte das Agieren der Zentralbanker*innen auf einer so bezeichneten >lockeren Geldpolitik , deren Umsetzung im konventionellen Sinne zuvorderst über das Instrument des Leitzinses erfolgt. Durch eine entsprechende Zinssenkung soll hierbei die Liquiditätsversorgung der Wirtschaft sichergestellt und somit ein wirtschaftlicher Stimulus erzeugt werden (๖billiges Geld ). Lag der Leitzins vor Ausbruch der Finanzkrise im Juli 2008 noch bei 4,25\%, wurde er in mehreren Schritten bis Mai 2009 auf 1,0\% gesenkt (vgl. Statista 2020a). Vor der Verschärfung der Finanz- und Bankenkrise zur Eurokrise lag er entsprechend schon auf einem niedrigen Niveau. Nach einem kurzen Intermezzo in 2011 (April: 1,25 \%; Juli: 1,5\%; November: 1,25\%; Dezember: 1,0 \%) wurde der Leitzins ab Juli 2012 schrittweise gar auf $0,0 \%$ abgesenkt (vgl. ebd.). Auf diesem Niveau verbleibt er seit März 2016 und wird nach der neuerlichen Ankündigung der EZB im Jahr 2019 auch sehr wahrscheinlich über das Jahr 2020 hinaus auf diesem historisch einmaligen Niveau verbleiben. Neben der Leitzinspolitik bietet sich der Zentralbank im 
Rahmen ihrer Offenmarktpolitik zugleich eine Politik quantitativer Lockerung (quantitative easing) an, bei der über den Aufkauf von Wertpapierbeständen (bspw. Staatsanleihen) die sich im Umlauf befindliche Geldmenge erhöht wird. Auch hiervon hat die EZB im Laufe der Euro-Krise Gebrauch gemacht, wenngleich erst dann von einer Maßnahme quantitativer Lockerung zu sprechen ist, wenn nicht zugleich sogenannte Sterilisationsmaßnahmen durchgeführt werden, die als begleitende (bzw. zeitversetzt einsetzende) Maßnahmen die Geldmenge wieder zu beschränken versuchen, um hierdurch die Inflationsgefahr zu minimieren. Werden Sterilisationsmaßnahmen durchgeführt, wird von credit easing gesprochen. Neben den mit den beschriebenen Maßnahmen beabsichtigen Stimuli für die Wirtschaft, die mittelbar auf die Preisstabilität einwirken, können sie zugleich Einfluss auf die Refinanzierungskonditionen von Staatsschulden geltend machen. Mit dem 2015 aufgelegten EAPP (expanded asset-purchase programme) wendet die EZB derzeit beispielsweise eine Politik quantitativer Lockerung an. Ein Teilprogramm des EAPP ist das PSPP (public sector purchase programme; Beschluss (EU) 2015/774) zum Aufkauf von Staatsschuldentiteln auf dem Sekundärmarkt, das anders als beim SMP und dem OMT-Programm nicht durch begleitende Maßnahmen sterilisiert wird (vgl. Sikora 2019, 140). Zudem ist es im Unterschied zu den beiden Programmen aus 2010 und 2012 nur mittelbar als eine Krisenbewältigungsmaßnahme anzusehen, da es sich nicht ausschließlich auf Staaten in einem makroökonomischen Anpassungsprogramm bezieht, sondern in allen Euro-Staaten entsprechende Aufkäufe durch die mitgliedstaatlichen Zentralbanken vorsieht, die durch die EZB koordiniert werden (vgl. Beschluss (EU) 2015/774). Insgesamt können sich die programmbasierten Eingriffe der EZB im Rahmen ihrer Geldpolitik, egal ob als direkte Reaktion auf die Refinanzierungskrise (SMP/OMT) oder im Rahmen ihrer allgemeinen Geldpolitik (PSPP), positiv auf die Refinanzierungskonditionen der Euro-Staaten auswirken, wie anschließend näher ausgeführt werden soll. Das SMP und das OMT-Programm, als Bestandteile reaktiver Krisenbewältigungspolitik, trugen dabei - mit dem Ziel, die Währungsunion $\mathrm{zu}$ stabilisieren - auch eine politische Handschrift der EZB. Letztlich habe sich gezeigt, so Tokarski $(2016,8)$, »dass Geldpolitik ohne stabile Finanzmärkte nicht effektiv funktionieren kann«, was die EZB dazu gezwungen habe, auch auf den Märkten für Staatsverschuldungstitel aktiv zur Stabilisierung beizutragen.

Das erste Programm zur Intervention der EZB in den Markt für Staatsverschuldungstitel wurde im Mai 2010 unter dem Namen Securities Markets Programme (SMP) lanciert (Beschluss 2010/281/EU). Das Programm, welches bis September 2012 angewendet wurde, sah vor, Staatsanleihen jener Länder auf dem Sekundärmarkt aufzukaufen, die unter dem Druck der Finanzmärkte standen, wobei die Maßnahme explizit neutral auf die Geldmenge wirken sollte (vgl. EZB 2010c, 24). Ziel der Intervention war die Stabilisierung der Zinsen auf dem Sekundärmarkt, die indirekt auf die Zinssätze bei der Emission neuer Staatsschuldtitel auf dem Primärmarkt einwirkt. Im Bulletin der EZB heißt es hierzu: »A key consideration behind the setting-up of the SMP was the inability of certain financial market segments to absorb transaction without much effect on prices« (ebd.). Mit der Maßnahme ist ein Markteingriff verbunden, der aufgrund der zugespitzten Ereignisse im Mai 2010 aus Sicht der Zentralbank notwendig erschien, auch wenn die akuten Problemlagen bereits einen früheren Eingriff der EZB gerechtfertigt hätten. Solange in Brüssel jedoch die Verhandlungen um das erste Hilfs- 
paket für Griechenland geführt wurden, sah man sich in Frankfurt nicht veranlasst, in diese Auseinandersetzung durch eigene Maßnahmen zu intervenieren. Die politische Intervention der EZB bestand gerade darin, erst zu dem Zeitpunkt aktiv zu werden, als die Eurostaaten ihrerseits in Vorleistung getreten waren. So kündigte die EZB beispielsweise einen Tag nach der Einigung auf das bilaterale Griechenlandpaket an, dem griechischen Bankensektor auf Grundlage geänderter Sicherheitsregeln weiterhin Liquidität zu gewähren (vgl. Tokarski 2016, 20). Auch das SMP wurde erst öffentlich vorgestellt, als sich die Brüsseler Politik auf die Etablierung der EFSF und des EFSM geeinigt hatte:

»Am 9. Mai 2010 beschloss der EZB-Rat, Staatsanleihen solcher Länder aufzukaufen, die unter dem Druck der Finanzmärkte standen [...]. Diese Entscheidung hielt die EZB jedoch vor den EU-Finanzministern geheim, die in den frühen Morgenstunden des Folgetages vorübergehende Finanzhilfe-Mechanismen beschlossen.«(Ebd.)

Die EZB verweist mir ihrem Verhalten auf eigene Konditionalitäten, die zu erfüllen sind, bevor sie ihrerseits Maßnahmen einleitet.

Nach der Lancierung des SMP erreichte der Bestand an aufgekauften Papieren mit rund 220 Mrd. $€$ im Juni 2012 seinen Höchststand und das Portfolio bestand aus griechischen, italienischen, spanischen, portugiesischen und irischen Staatsanleihen (vgl. Statista 2020b). Wurde zwar in der wissenschaftlichen wie öffentlichen Diskussion ausführlich über die juristische Tragweite und Vertragskonformität des Programms diskutiert, wird doch der Aufkauf von Staatsanleihen auf dem Sekundärmarkt inhaltlich meist als positiver Beitrag zur Bekämpfung der Spekulation gegen einzelne EuroStaaten gesehen. Die Kritik der Befürworter*innen bezieht sich daher hauptsächlich auf die zu zögerliche und zu späte Intervention. So etwa De Grauwe (2015, 207): »Probably the worst decision was made by the ECB early on in the crisis, when it decides not to take on the responsibility of systematically providing liquidity in the government bond markets of the Eurozone.« Und auch Mitchell $(2017,37)$ moniert, dass die EZB umgehend ein Programm hätte auflegen können: »Wenn das SMP 2008 statt 2010 eingeführt worden wäre, und ohne die daran geknüpften Bedingungen von Sparmaßnahmen, wäre alles ganz anders gekommen.« Allerdings spitzten sich trotz des SMPs die Krisenerscheinungen im Laufe des Jahres 2012 erneuert zu. Es waren insbesondere Problemlagen im spanischen Bankensektor, die immer noch befürchtete Verschärfung der Krise in Italien sowie die noch nicht abgeschlossenen Verhandlungen um einen permanenten Rettungsschirm, die auf den Finanzmärkten weiterhin für den Anstieg der Refinanzierungskonditionen einzelner Euro-Länder sorgten. Deters $(2014,263)$ führt eine Reihe weiterer »schlechter Nachrichten« an, die den Frühsommer 2012 prägten:

»Moody's had cut the outlook of its triple-A rating for the EFSF. Spanish bond yields had crossed the magical line of seven per cent, and also Italy's re-financing costs had again been steadily increasing [...]. Moreover, speculation about >Grexit< [...] surged since it became obvious that Greece would hardly be able to implement the conditionalities that it had accepted in return for the second bail-out package.«

In diesem Kontext war es der Nachfolger Trichets im Amt des EZB-Präsidenten, der mit seiner historischen »What-ever-it-takes«-Rede ein neues Kapitel der Zen- 
tralbankintervention öffnete. Nach Draghis Ankündigung beschloss der EZB-Rat im August 2012 das OMT-Programm (Outright Monetary Transaction), mit dem wie im SMP-Vorgängerprogramm notfalls Staatsanleihen von Eurostaaten mit Refinanzierungsproblemen auf dem Sekundärmarkt aufgekauft werden sollten. In Draghis Rede war hierbei die unbegrenzte Höhe möglicher Ankäufe durch die EZB angelegt. Allerdings beinhaltet das OMT-Programm Konditionalitäten, die es zu erfüllen gilt, bevor die EZB das Programm aktiviert. Wichtigste Voraussetzung hierbei ist, dass sich der betreffende Eurostaat in einem Anpassungsprogramm des Rettungsschirms befindet (vgl. EZB 2012b). Das OMT-Programm weist insofern formalere Konditionalitäten als das SMP auf, das noch durch informelle Konditionalitäten (Briefe des EZB-Präsidenten an betroffene Staaten) geprägt war.

Interessant erscheint die Irrationalität der zu beobachtenden Folgen der bloßen Ankündigung des späteren OMT-Programms (August 2012) im Juni 2012:

»Obwohl das OMT-Programm seither nie angewendet wurde und zum Zeitpunkt von Draghis Rede gar nicht ausgearbeitet war, zudem seitens der Bundesbank und zahlreicher konservativer Ökonom_innen und von ihnen beeinflussten Jurist_innen verfassungsrechtliche Zweifel an der Rechtmäßigkeit bestanden, gingen die Zinsaufschläge sofort zurück.« (Priewe 2017, 14)

Priewes Fazit lautet deshalb, »dass die EZB in dieser kritischen Situation die Eskalation der Krise in der Eurozone zu einer existenziellen Krise des Euro verhindert hat." (Ebd.) Und auch Flassbeck \& Lapavitsas $(2015 a, 5)$ halten fest, dass die Draghi-Rede das Währungssystem 2012 stabilisierte, die Finanzmärkte beruhigte und somit einen Raum für stabilisierend wirkende wirtschaftspolitische Maßnahmen geboten hätte. So wichtig der Schritt der EZB im Jahre 2012 deshalb im Sinne des Fortbestands der EWWU zu werten ist, bleibt dennoch auch hier die Frage zu stellen, weshalb eine entsprechende beherzte Ankündigung vergleichbar mit der von Draghi nicht bereits unter Trichet vorgenommen wurde? Die Antwort hierauf lässt sich wohl einerseits im EWWU-Leitbild der EZB finden, die statt politischer Interventionen seit jeher technokratische Arrangements präferiert, die regel- und kriteriengebunden sowie quasi-automatisch wirken und dabei zugleich jeglichen >moral hazard vermeiden sollen. Andererseits besteht ein weiterer Grund sicherlich darin, dass der dauerhafte Stabilitätsmechanismus zum damaligen Zeitpunkt noch nicht abschließend implementiert war, der auf politischer Seite die entsprechenden Hilfskonditionen in Form makroökonomischer Anpassungsprogramme hätte ausverhandeln können und somit als politischer LOLR-Arm für EuroStaaten fungiert hätte.

Insgesamt lässt sich das OMT-Programm als ein EZB-eigener Stabilisierungsmechanismus bei Refinanzierungskrisen qualifizieren, der in akuten Krisensituationen auch künftig einen Beitrag zur Stabilisierung leisten kann. Nach De Grauwe \& Ji (2015) ist die EZB durch das OMT-Programm zum bis dato vermissten Lender of Last Resort für die Euro-Staaten geworden, wenngleich die Einschränkung gemacht werden sollte, dass eine Charakterisierung als konditionalisierender Kreditgeber letzter Instanz, der diese Aufgabe zugleich gemeinsam mit dem ESM ausfüllt, sicherlich hinreichender erscheint. Unvollständig und fragil bleibt diese LOLR-Konstruktion allerdings, da einerseits »die Effektivität der EZB durch den fehlenden fiskalischen Rückhalt, der die Risi- 
ken aus ihrer Funktion als Lender of Last Resort ebenso übernimmt wie aus der Abwicklung von Banken« (Illing \& König 2014, 552), auch weiterhin stark beeinträchtigt ist und andererseits der ESM, »[u]m [...] als Lender of Last Resort für Staaten wirksam agieren zu können, [...] Zugang zu Krediten der Europäischen Zentralbank erhalten [müsste].« (Ebd., 554) Insofern weist die sich als Staatlichkeitstransformation darstellende Erweiterung des Zentralbankhandelns an dieser Stelle auf fortbestehende Konstruktionsmängel hin, die schlussendlich im Fehlen einer genuinen Fiskalunion auf Ebene der EU kumulieren.

Bis heute bleibt außerdem umstritten, inwiefern die EZB-Ankaufprogramme durch die EU-Verträge gedeckt sind und dem Verbot monetärer Staatsfinanzierung widersprächen. Häde (2016, Art. 123, Rn. 13) fasst die beiden gegensätzlichen Positionen zu dieser Frage wie folgt zusammen: Es gebe demnach Stimmen,

»die die Staatsanleihekäufe der EZB generell für unzulässig halten, weil es sich um wirtschaftspolitische Maßnahmen und verbotene Staatsfinanzierung handele und damit um eine Umgehung des Art. 123. >Die Stabilisierung der Finanzsysteme sei nicht Aufgabe der EZB. [... Sie] treten [...] für eine enge Begrenzung des Mandats der EZB ein. Deren Begründung, sie werde tätig, wenn das erforderlich sei, um den geldpolitischen Transmissionsmechanismus freizusetzen, wird ebenfalls abgelehnt. Die Rechtfertigung der Unabhängigkeit der EZB erlösche, sobald sie aus ihrem begrenzten geldpolitischen Aufgabenkreis heraustrete.«

Dem stehe die Meinung gegenüber,

»die der EZB nicht zuletzt wegen ihrer Unabhängigkeit einen weiten Einschätzungsspielraum zubilligt und deshalb Staatsanleihekäufe der Zentralbanken am Sekundärmarkt grundsätzlich akzeptiert. Auch die Deutsche Bundesbank habe dieses Instrument früher gelegentlich genutzt. Nach dieser Ansicht ist die Argumentation der EZB mit dem geldpolitischen Transmissionsmechanismus tragfähig oder zumindest im Rahmen des der Zentralbank zugebilligten Spielraums schlüssig.« (Ebd., Art. 123, Rn. 14)

Diese unterschiedlichen Argumentationen lassen sich interessanterweise auch beim Bundesverfassungsgericht und dem Europäischen Gerichtshof finden. Hierbei tendiert letzterer zur zweiten und das Bundesverfassungsgericht zur ersten Argumentation. Das wird insbesondere im Beschluss des BVerfG (2014a) vom 14. Januar 2014 deutlich, mit welchem es dem EuGH Fragen zur Vorabentscheidung vorlag. Die Karlsruher befragten die Luxemburger Richter"innen dahingehend, ob der OMT-Beschluss des EZBRates mit dem AEUV vereinbar sei. Weiterhin sollten sie klären, ob die EZB bei Betrachtung der wirtschafts- und nicht geldpolitischen OMT-Konditionalitäten (Anpassungsprogramme), der OMT-Selektivität (nur Krisenländer), der Parallelität zu anderen Maßnahmen (Rettungsschirme) und des unbegrenzten Volumens des OMT, seiner möglichen Qualifizierung als monetäre Haushaltsfinanzierung sowie des hiermit verbundenen Eingriffs der EZB in die Marktpreisbildung und Marktlogik für Staatsanleihen ihr Mandat überschritten habe. Vorbehaltlich der EuGH-Entscheidung gab das BVerfG hierzu bereits eine eigene Einschätzung ab. So sei nach Meinung der Bundesverfassungsrichter*innen der OMT-Beschluss des EZB-Rates 
»mit Art. 119 und Art. 127 Abs. 1 und Abs. 2 AEUV und Art. 17ff. ESZB-Satzung unvereinbar, weil er über das in den genannten Vorschriften geregelte Mandat der Europäischen Zentralbank hinausgeht und in die Zuständigkeiten der Mitgliedstaaten für die Wirtschaftspolitik übergreift (1.). Er erscheint ferner mit dem in Art. 123 AEUV verankerten Verbot monetärer Haushaltsfinanzierung unvereinbar (2.). An beidem dürfte die Berufung der Europäischen Zentralbank auf eine sStörung des geldpolitischen Transmissionsmechanismus « nichts ändern (3.). Demgemäß hätten die Anträge voraussichtlich Erfolg.«(BVerfC 2014a, Rn. 55)

$\mathrm{Zu}$ einer anderen Einschätzung kam hingegen der EuGH in seinem Urteil vom 16. Juni 2015. Dort heißt es:

»Art. 119 AEUV, Art. 123 Abs. 1 AEUV und Art. 127 Abs. 1 und 2 AEUV sowie die Art. 17 bis 24 des Protokolls (Nr. 4) über die Satzung des Europäischen Systems der Zentralbanken und der Europäischen Zentralbank sind dahin auszulegen, dass sie das Europäische System der Zentralbanken (ESZB) dazu ermächtigen, ein Programm für den Ankauf von Staatsanleihen an den Sekundärmärkten wie dasjenige zu beschließen, das in der Pressemitteilung angekündigt wurde, die im Protokoll der 340. Sitzung des Rates der Europäischen Zentralbank (EZB) am 5. und 6. September 2012 genannt ist." (EuCH 2015, Rn. 128)

Der Gerichtshof verweist in seinem Urteil auf die bereits im Rahmen des Pringle-Urteils entwickelte Argumentation, nach der im AEUV keine "genaue Definition der Währungspolitik« (ebd., Rn. 42) enthalten sei und eine währungspolitische Maßnahme nicht allein deshalb einer wirtschaftspolitischen Maßnahme gleichgestellt werden könne, nur weil sie mittelbare Auswirkungen auf die Stabilität des Euro-Währungsgebietes habe (vgl. ebd., Rn. 52). Der Gerichtshof urteilte daher, dass das OMT-Programm als währungspolitische Maßnahme zu bewerten sei (vgl. ebd., Rn. 56), wobei gerade die vom BVerfG kritisierte Verquickung des OMT-Programms mit den Rettungsschirmen und ihren makroökonomischen Konditionalitäten nach Ansicht des EuGH vermeide, dass die »beschlossenen währungspolitischen Maßnahmen der Wirksamkeit der von den Mitgliedstaaten verfolgten Wirtschaftspolitik zuwiderlaufen.« (Ebd., Rn. 60) Auch bei der Frage, ob es sich beim OMT-Programm um eine mögliche monetäre Haushaltsfinanzierung handeln könnte, vertritt der EuGH eine andere Auffassung als das BVerfG. Nach seiner Auffassung könne das OMT-Programm nicht mit einer finanziellen Unterstützungsleistung für einen Mitgliedstaat gleichgestellt werden (vgl. ebd., Rn. 103), zumal der EuGH darauf verweist, dass die Geldpolitik der EZB fortlaufend durch die Zinspolitik und die gesetzten Refinanzierungskonditionen für Banken indirekt auch auf die Refinanzierungsbedingungen der Mitgliedstaaten einwirke (vgl. ebd., Rn. 110). Hier sei das OMT-Programm in der Auslegung des EuGH nicht von anderen währungs- und geldpolitischen Maßnahmen zu unterscheiden. In seinem abschließenden Urteil vom Juni 2016 urteilt das BVerfG deshalb auf Grundlage der Vorabentscheidung des EuGH, dass die den Inhalt des OMT betreffenden Verfassungsbeschwerden unzulässig seien. Allerdings seien jene Verfassungsbeschwerden zulässig, die »sich gegen das Unterlassen der Bundesregierung richten, gegen den Grundsatzbeschluss des Rates der Europäischen Zentralbank über das OMT-Programm vom 6. September 2012 vorzugehen« 
(BVerfG 2016, Rn. 76). So erachtete das Gericht die von den Antragsstellern vorgebrachte Argumentation, nach der es sich bei dem Programm um eine Kompetenzüberschreitung der EZB handle, insofern für plausibel, dass sie eine »hinreichende Bedingung für eine Aktivierung der Integrationsverantwortung der Bundesregierung (ebd., Rn. 79ff.) sehe. Zugleich sei die Verfassungsbeschwerde auch insoweit zulässig, »als sie eine verfassungswidrige Untätigkeit der Bundesregierung im Hinblick auf eine mögliche Beeinträchtigung der haushaltspolitischen Gesamtverantwortung des Bundestages rügt.« (Ebd., 94) Mit dem abschließenden Urteilsspruch des Bundesverfassungsgerichts wird deutlich, dass die Richter*innen in Karlsruhe dem Urteil des EuGH nicht vorbehaltlos folgen wollten. Sie erkennen zwar die Konformität des OMT-Programms mit dem Unionsrecht an, rügen aber auf Grundlage der Vorgaben des Grundgesetzes zugleich die Rolle der Bundesregierung, die nach Auffassung des Gerichts direkt die Fragen hätte zur Klärung bringen müssen, die nun - drei, beziehungsweise vier Jahre nach dem Beschluss des OMT-Programms - im Rahmen der Verfassungsbeschwerden Dritter behandelt wurden. Durch dieses Urteil räumt das BVerfG dementsprechend die vorgebrachten rechtlichen Zweifel trotz Urteilsspruch des EuGH nicht vollumfänglich aus. Es unterstreicht allerdings im Sinne der kriseninduzierten Transformationsprozesse der EU-Staatlichkeit, dass auch im Kontext des Zentralbankinterventionismus eine Neuauslegung der EU-Verträge stattfand, in der, wie bereits mit dem Pringle-Urteil deutlich wurde, ein Wandel von einer dogmatischen zu einer pragmatischen Vertragsauslegung angelegt ist. ${ }^{22}$

22 Dieser pragmatischeren Vertragsauslegung setze das Bundesverfassungsgericht allerdings mit seinem neuerlichen Urteil zum PSPP vorläufig ein Ende. Im Aufsehen erregenden Urteil vom 5. Mai 2020 qualifizierten die Karlsruher Richter*innen das Programm aus dem Jahr 2015 trotz der durch das EuCH (2018) attestierten Vertragskonformität vorerst als eine Kompetenzüberschreitung seitens der EZB (vgl. BVerfC 2020, Rn. 116). Insbesondere kritisierte das BVerfC (2020, Rn. 133) die nicht ausreichende Abwägung der wirtschaftspolitischen Auswirkungen des PSPP und widersprach insofern auch der seit dem Pringle-Urteil bekannten Kernargumentation des EuCH, nach der man eine währungspolitische Maßnahme nicht automatisch als wirtschaftspolitische Maßnahme, die in den Kompetenzbereich der Mitgliedstaaten fiele, qualifizieren könne, nur weil sie Einfluss auf die Wirtschaftspolitik habe. Das »komplexe Urteil« (Fisahn 2020, 87) des Bundesverfassungsgerichts forderte deshalb von der EZB »Argumente für ihr bisheriges Agieren nachzuliefern«, bevor über die Rechtmäßigkeit des Ankaufs durch die EZB abschließend entschieden werden könne. Bundesregierung und Bundestag wurden vom BVerfG (2020, Rn. 232) daher beauftragt, auf eine entsprechende Verhältnismäßigkeitsprüfung durch die EZB hinzuwirken. Zugleich wurde der Bundesbank untersagt, »nach einer für die Abstimmung im ESZB notwendigen Übergangsfrist von höchstens drei Monaten an der Umsetzung und Vollzug des Beschlusses (EU) 2015/774 sowie der hierauf folgenden Beschlüsse [...] mitzuwirken, [...], wenn nicht der EZB-Rat in einem neuen Beschluss nachvollziehbar darlegt, dass die mit dem PSPP angestrebten währungspolitischen Ziele nicht außer Verhältnis zu den damit verbundenen wirtschafts- und fiskalpolitischen Auswirkungen stehen. (Ebd., Rn. 235) Die langfristige Wirkung des Urteilsspruchs des BVerfC, mit dem sich das Gericht erstmals offen gegen eine EuCH-Entscheidung wandte, auf künftige Maßnahmen der EZB und den gesamten Integrationsprozess gilt es weiter zu beobachten. Schließlich lege das Urteil laut Fisahn $(2020,92)$ nicht weniger als das zentrale Problem der EU offen: »Die Verträge passen nicht mehr auf die aktuelle wirtschaftspolitische Situation. Und das betrifft nicht nur die Krisenphänomene, sondern auch notwendige Umstrukturierungen der Wirtschaft, um den ökonomischen Herausforderungen durch Digitalisierung und Klimakrise gerecht zu werden.« 


\section{Die "politische Zentralbank - Konditionalitäten und Selbstermächtigung}

Das Selbstbild der EZB ist von der Vorstellung geprägt, als >unabhängige< Institution nach technischen Maßstäben ihre durch die Verträge gesetzten Zielkriterien zu erreichen und insofern sunpolitisch $\mathrm{zu}$ agieren. Das Erbe der Deutschen Bundesbank, das in der formalen EZB-Unabhängigkeit zum Ausdruck gebracht wird, war eine der grundsätzlichen Bedingungen seitens der deutschen Bundesregierung für die EuroEinführung. Allerdings verweist Majone (2012, 14) auf einen zentralen Unterschied, der die Qualität der »Unabhängigkeit« zwischen Bundesbank und Europäischer Zentralbank in einem etwas anderen Licht erscheinen lässt:

»Despite frequently repeated assertions that the Bundesbank has served as the model for the European Central Bank, the differences between the two institutions are much more significant than the similarities. The main difference may be expressed by saying that the German central bank was not only politically independent, but also socially embedded; while the ECB enjoys, on paper, ever greater independence than its German counterpart, but in fact its performance is compromised by the fact that it has to operate in a political and social vacuum.»

Sein Fazit lautet deshalb, dass die EZB uneingebettet sei, da ihr beispielsweise keine genuine europäische Regierung gegenüberstehe (vgl. ebd., 14). Zugleich verweist diese Diagnose noch einmal auf die bereits andiskutierte Problematik einer in Teilen weiterhin fragmentierten EU-Zivilgesellschaft, die im Sinne Gramscianischer Kategorien der EZB einen entsprechenden Resonanzraum bieten könnte. Folglich agiert die EZB in einem Staatsapparate-Ensemble, das weder ein klares exekutives Zentrum noch eine vollumfängliche zivilgesellschaftliche Rückgebundenheit aufweist. Ihr Agieren ist dabei deutlich von politischer Natur, wie die ganz zu Beginn dargestellten Reformvorschläge offenbaren, die nicht einmal vor einen Eingriff in die Grundfesten demokratischer Verfassungsstaaten zurückschrecken (s. »Executive Officer«).

Darauf, dass es ganz grundsätzlich betrachtet eine unpolitische Zentralbank schon aufgrund der Wirkungen ihres Handelns nicht geben kann, weist Stiglitz $(2018,161)$ hin: »There are winners and losers in most economic policies. In making their decisions, policymakers in the ECB have to make judgments with distributional consequences. These are not merely technocratic issues, like the best design of a bridge.« (Herv. i. O.) Hinzu kommt, dass bereits der Rückgriff auf die in den Verträgen kodierten Zielkriterien und die EU-Wirtschaftsverfassung einen politischen Rahmen absteckt, innerhalb dessen die EZB mit ihrem konkreten Handeln tagtäglich Entscheidungen trifft, welche die Verwirklichung einer den Verträgen eingeschriebenen Politik darstellt. Vereinfacht gesagt: Jedes vertragsbasierte Agieren der EZB reproduziert den politisch gesetzten Rahmen und ist somit per se politisch und bedarf insofern einer eigenen Rechtfertigung, wenn sie demokratischen Maßstäben genügen möchte. Die EZB ist Durchsetzungsgehilfin der in den Verträgen festgeschriebenen Fiskal- und Wirtschaftsverfassung. Somit ist auch die EZB »seit Jahren Partei, die eine bestimmte wirtschaftspolitische Richtung mit einer selbstgewissen Brutalität durchsetzt.« (Grözinger 2015b, 37) Ein Bild, das sich in der Euro-Krise geradezu aufdrängt, in der die EZB als ein wirkmächtiger politischer Repressionsapparat agierte, wie anhand dreier markanter Beispiele nachfolgend illustriert werden soll. 
Bekannt ist, dass die EZB im Verborgenen auf den unterschiedlichen Maßstabsebenen auf verantwortliche Politiker*innen einwirkt(e). Dass solche Interventionen aufgrund ihres meist informellen Charakters nur schwierig zu systematisieren sind, liegt auf der Hand, wenngleich im Kontext der Euro-Krise mehrere Briefe dokumentiert sind, welche die Einflussnahme der Zentralbank und ihr Druckpotential verdeutlichen. Der erste bekannte Briefwechsel fand Ende des Jahres 2010 zwischen dem EZB-Präsidenten Trichet und dem damaligen irischen Finanzminister Lenihan statt. Irland war nach Griechenland der zweite Eurostaat, der in eine bedrohliche Schieflage geriet. Bereits während der Finanzkrise 2008 war der irische Bankensektor aufgrund der weitreichenden Verflechtungen mit den internationalen Finanzmärkten in Folge niedriger Regulierungsstandards in große Bedrängnis geraten. Das irisches Bankenrettungspaket der Jahre 2008/09 umfasste nicht weniger als 614 Milliarden Euro, was annährend $230 \%$ des damaligen irischen BIP entsprach (vgl. Woll 2011, 21). Auch wenn die direkten Finanzhilfen für die Banken nur etwa $4 \%$ des BIP ausmachten (vgl. ebd., 22), geriet Irland in der Folge in massive fiskalpolitische Problemlagen, die durch die realwirtschaftlichen Verwerfungen und die Immobilien- in Folge der Finanzund Bankenkrise weiter verschärft wurden. Die irische Bankenkrise war zum Zeitpunkt des Briefwechsels nicht überwunden, vielmehr sah sich die irische Zentralbank gezwungen, irischen Kreditinstituten sogenannte ELA (Emergency Liquidity Assistance) zur Verfügung zu stellen. Durch dieses Instrument können mitgliedstaatliche Zentralbanken Kreditinstituten Notfallkredite gewähren. Allerding handeln die Zentralbanken hierbei nicht autonom, sondern im Verbund aller Zentralbanken des Eurosystems, deren Fäden bei der EZB zusammenlaufen, die das gesamte Verfahren überwacht. Die ELAs der irischen Notenbank waren zugleich der thematische Ausgangspunkt für den Briefwechsel zwischen Frankfurt und Dublin. ${ }^{23}$ Am 15. Oktober 2010 schrieb Trichet an den irischen Finanzminister: »[T] he current large provisions of liquidity by the Eurosystem and the Central Bank of Ireland to entities such as Anglo Irish Bank should not be taken for granted as a long-term solution." (EZB 2010d, 2) Weiterhin geht Trichet auf die von der irischen Regierung angekündigte Vier-Jahres-Strategie ein und stellt hierzu Anforderungen, wenn die EZB weiterhin die ELA-Praxis der irischen Zentralbank stützen solle:

»I trust that the four-year strategy will target a fiscal deficit of below $3 \%$ in 2014 and a decline in the public debt-to-GDP ratio from 2012/13 onward, based on cautious real growth forecasts, as well as a strong structural reform programme. Future decisions by the Governing Council of the ECB regarding the terms of liquidity provisions to Irish banks will thus need to take into account appropriate progress in the areas of fiscal consolidation, structural reforms and financial sector restructuring.«(Ebd., 2)

In seinem Antwortschreiben unterstreicht der irische Finanzminister die eigenen Bemühungen zur Erreichung fiskalischer Nachhaltigkeit (vgl. Department of Finance 2010a, 2). Zudem beschreibt er, dass aufgrund von Spekulationen auf den Märkten, ausgelöst durch die politischen Debatten über die Konditionen für Hilfsgelder aus der

23 Die Briefe unterlagen der Geheimhaltung und wurden erst 2014, nachdem bereits »Cerüchte«über eine direkte Einflussnahme seitens der EZB kursierten, zugänglich gemacht. 
EFSF (bspw. auch die mögliche Privatgläubigerbeteiligung in Form eines sogenannten »Haircuts«), die neuerlich verschlechterten Refinanzierungskonditionen Irlands auch aufgrund dieser externen Effekte entstanden wären (vgl. ebd.). Lenihan ersucht Trichet, dies zu berücksichtigen und bittet darum, dass die EZB weiterhin ihren Einfluss geltend macht, um die Märkte zu beruhigen (vgl. ebd., 2). In seinem auf den 19. November 2010 datierten Brief geht Jean-Claude Trichet hingegen nicht auf die vorgetragene Argumentation Lenihans ein, stattdessen unterstreicht er noch einmal den Ausnahmecharakter der ELA und drückt seine Sorge über die hohen Summen aus, die bereits über die ELA an die irischen Banken geflossen seien (vgl. EZB 2010b, 2). Er stellt daher klar: »It is the position of the Governing Council that it is only if we receive in writing a commitment from the Irish Government vis-à-vis the Eurosystem on the four following points that we can authorise further provisions of ELA to Irish financial institutions « (ebd., 1). Die genannten vier Konditionen sind: (1) ein offizielles Gesuch der irischen Regierung um Finanzhilfen; dem Gesuch soll (2) eine Vereinbarung über die fiskalische Konsolidierung, Strukturreformen und die Restrukturierung des Finanzsektors folgen; (3) ein Plan zur Rekapitalisierung des irischen Bankensektors, der aus den bereitgestellten Hilfsgeldern finanziert werden solle; (4) die Zusicherung der vollen Rückzahlung der bereits gewährten ELA-Mittel (vgl. ebd., If.). Bereits zwei Tage später meldete Lenihan nach Frankfurt, die vier Forderungen zu akzeptieren und informierte darüber, dass die irische Regierung ein entsprechendes Finanzhilfegesuch an die Euro-Mitgliedstaaten gerichtet habe (vgl. Department of Finance 2010b). Die EZB machte demnach im Falle Irlands unter Androhung, die ELA-Kredite $\mathrm{zu}$ suspendieren, Einfluss geltend und drängte Irland in die Arme der Troika, mit der die genauen Konditionen - unter Beteiligung der EZB - für die Gewährung von Finanzhilfen festzulegen waren.

Die politischen Verstrickungen, welche die EZB dabei im Kontext der Euro-Krise in Kauf nahm, zeigen sich dabei besonders gut an ihrer Eingebundenheit in die Troika. Das bereits in den Briefen an Irland plastisch gewordene politische Agieren der Zentralbanker*innen wird mit der Beteiligung an der Troika noch einen entscheidenden Schritt erweitert, da sie nicht nur informelle Absprachen trifft, sondern in Vertretung für die Mitgliedstaaten der Eurozone formale Konditionen aushandelt. De facto wird die EZB somit in die Formulierung wirtschafts- und fiskalpolitischer Leitlinien einbezogen, wofür sie kein vertragsbasierendes Mandat besitzt. Es scheint nahezu so, als sei die Beteiligung der EZB an der Troika gar ein Zugeständnis der mitgliedstaatlichen Regierungen an die Zentralbank. Verfügt doch gerade die EZB über wirksame Druckmittel, um Krisenstaaten ein Programm aufzuzwingen, wie das Beispiel Irland zeigte. Ein weiteres, sehr plastisches Beispiel für eine solche Praxis fällt bereits nicht mehr in die hier darzustellende Zeitspanne reaktiver Krisenbewältigungspolitik, verdeutlicht aber sehr eindringlich den von den Mitgliedstaaten und der Kommission tolerierten Aktivismus der EZB. Nachdem Griechenland bereits 2010 im Rahmen der Verhandlungen über das erste Hilfspaket die Machtposition der EZB kennenlernte, ließ sie diese Griechenland nach der Wahl SYRIZAs abermals spüren. So hat die EZB im Februar 2015 die Ausnahmeregelung rückgängig gemacht, nach der sie griechische Staatsanleihen trotz ihres niedrigen Ratings als Sicherheit für die Refinanzierung griechischer Banken akzeptierte (s.o.). Nach Schneider $(2017 \mathrm{~b}, 116)$ argumentierte die EZB hierbei ex- 
plizit politisch, indem sie verlautbaren ließ, dass sie unter den neuen Umständen nicht davon ausgehe, dass das Troika-Programm erfolgreich zu Ende geführt werden könne. Erst als die SYRIZA-geführte Regierung den Bedingungen des dritten Memorandums zustimmte (s.u.), nahm der Druck der EZB auf Griechenland wieder ab. Die EZB spielt in der Architektur der Troika somit eine herausragende und machtvolle Rolle, die unter legitimatorischen Betrachtungen eine Reihe kritischer Fragen aufwirft.

Ein weiteres Beispiel für das Handeln der EZB ist erneuert schriftlich fixiert und weist Ähnlichkeiten zum irischen Fall auf. So sendete Trichet zusammen mit dem jeweiligen Präsidenten der mitgliedstaatlichen Zentralbank am 5. August 2011 einen Brief an den italienischen Ministerpräsidenten Silvio Berlusconi und den spanischen Ministerpräsidenten José Luis Rodríguez Zapatero. Hintergrund der Briefe war die weitere Zuspitzung der Refinanzierungsbedingungen beider Staaten und infolgedessen der mögliche Ankauf italienischer und spanischer Staatsschuldentitel auf dem Sekundärmarkt im Rahmen des damaligen SMP. Wenn auch nicht explizit in den Briefen benannt, weisen sie darauf hin, dass mit ihnen die Konditionalitäten formuliert sind, auf deren Grundlage eine entsprechende Intervention der Zentralbank erfolge. Jedenfalls begann die EZB erst nach Erhalt von (Reform-)Zusagen mit dem Ankauf italienischer und spanischer Staatsanleihen (vgl. Tokarski 2016, 26). Im Falle Spaniens forderte die EZB neben fiskalpolitischen Zusagen auch Arbeitsmarkt- und Produktmarktreformen (vgl. EZB 2011c). Das Schreiben von Trichet und Draghi, dem damaligen Zentralbankchef Italiens, das anders als der Brief an Zapatero bis heute nicht offiziell veröffentlicht wurde (er wurde aber bereits 2011 geleakt: Corriere Della Sera, 29.09.2011), sah als eine Konditionalität ebenfalls fiskalpolitische Zusagen vor. Zugleich sollten in Italien Verwaltungsreformen angestoßen sowie arbeits- und wirtschaftspolitische Reformmaßnahmen umgesetzt werden. Entscheidend ist auch hier: Die Briefe gehen inhaltlich weit über das Zentralbankmandat der EU-Verträge hinaus. Insgesamt stehen die Briefe ebenso wie die Beteiligung der EZB an der Troika für eine Selbstermächtigung der EZB als politischem EUSA. In letzter Konsequenz kann die EZB dabei sogar als der eigentliche Souverän der Eurozone gelten (vgl. Guérot 2013, 6), der durch seine Entscheidungen und unter Umgehung der demokratischen Verfahrensabläufe ganze Länder zu einer »richtigen« Politik zwingen kann.

\section{Die EZB als Nutznießerin der europäisierten Bankenaufsicht}

Die Kommission präsentierte im Mai 2009 - noch vor der Verdichtung der Finanz- zur Euro-Krise - in ihrer Mitteilung zur Europäischen Finanzaufsicht folgende Eingangsanalyse:

»Die Finanzkrise hat erhebliche Schwachstellen bei der Einzel- und der Systemaufsicht offengelegt. Mit den bestehenden Aufsichtsregelungen konnte die Krise weder verhindert noch gesteuert oder beigelegt werden. Die nationalen Aufsichtsmodelle können mit der Integration und der Verknüpfung der heutigen Finanzmärkte mit vielen grenzübergreifend tätigen Finanzinstituten nicht länger Schritt halten. Auch hat die Krise gezeigt, dass es in hohem Maße an Zusammenarbeit, Koordinierung, Kohärenz und gegenseitigem Vertrauen zwischen den nationalen Aufsichtsbehörden fehlt.« (KOM 2009, 2) 
Ihre Schlussfolgerung hieraus lautete, dass ein »neuer Aufsichtsrahmen« zu etablieren sei, der auf zwei Säulen beruhe (vgl. ebd., 3): Zum einen sei ein »Europäischer Rat für Systemrisiken« (später als »Ausschuss für Systemrisiken« bezeichnet) zu schaffen, »der die potenziellen Risiken für die Finanzmarktstabilität, die sich aus makroökonomischen Entwicklungen und aus Entwicklungen innerhalb des Finanzsystems insgesamt ergeben, überwachen und bewerten soll (`Aufsicht auf Makroebene`). (Ebd.) Zum anderen solle ein »Europäisches Finanzaufsichtssystem« (ESFS) etabliert werden,

»bei dem die nationalen Finanzaufsichtsbehörden in einem Netzverbund zusammenarbeiten und sich gemeinsam mit den neuen Europäischen Finanzaufsichtsbehörden darum bemühen sollen, die finanzielle Solidität einzelner Unternehmen des Finanzdienstleistungssektor zu erhalten und die Empfänger von Finanzdienstleistungen zu schützen (`Aufsicht auf Mikroebene`).«(Ebd.)

Mit der Mitteilung der Kommission war ein erster Schritt hin zum Aufbau der Europäischen Finanzaufsicht und -überwachung für alle EU-Mitgliedstaaten eingeschlagen, der bis dato lediglich aus einer verstärkten Koordinierung - >Netzverbund - statt im Aufbau schlagkräftiger neuer Staatsapparate bestand. Auch die Frage einer gemeinsamen Haftung für die Stabilität des Finanzsektors stand nicht im Fokus der Bemühungen des Jahres 2009: »Aber Europas Hauptproblem war nicht das Fehlen einer fiskalischen Brandschutzordnung. Sein Problem war das Fehlen einer Finanzfeuerwehr«, wie Tooze $(2018,132)$ die eigentliche Herausforderung beschreibt. Diskussionen über eine wirkliche Finanzfeuerwehr gelangten erst später auf die Agenda. Neben den Rettungsschirmen (als ein Part der Feuerwehr), kam als zweiter Löschzug ein gemeinsamer Abwicklungsfonds im Kontext der sogenannten Bankenunion auf das politische Tableau. Trotz der Reichweiteneinschränkungen der 2009er Reformen gilt es, sie in gebotener Kürze etwas genauer zu beleuchten. Schließlich bilden sie die Grundlage für die im Laufe des Jahres 2014 beschlossenen Legislativmaßnahmen und getätigten Absichtserklärungen zum Aufbau der sogenannten Bankenunion.

Mit der Verordnung (EU) Nr. 1092/2010 wurde dabei im November 2010 der Europäische Ausschuss für Systemrisiken (ESRB; European Systemic Risk Board) geschaffen, dessen Aufgabe darin bestehe, »in normalen Zeiten die Systemrisiken zu überwachen und zu bewerten, um die Gefahr des Ausfallrisikos von Systemkomponenten für das System zu begrenzen und die Widerstandfähigkeit des Finanzsystems gegen Schocks zu stärken.«(Erw. 10 VO (EU) Nr. 1092/2010) Hierzu erhält der ESRB mit einem Verwaltungsrat, einem Lenkungsausschuss, einem eigenen Sekretariat, einem beratenden Fachausschuss und schließlich einem beratenden Wissenschaftlichen Ausschuss eine sehr umfassende Institutionalisierung (vgl. Art. 4, Abs. I VO (EU) Nr. 1092/2010). Eng verknüpft ist der ESRB dabei mit der EZB, deren Präsident zugleich dem ESRB vorsitzt (vgl. Art. 5, Abs. 1 VO (EU) Nr. 1092/2010); im Verwaltungsrat sind weiterhin die Präsident*innen der mitgliedstaatlichen Zentralbanken vertreten (vgl. Art. 6, Abs. $1 \mathrm{~b}$ VO (EU) Nr. 1092/2010). Da »die Marktteilnehmer [...] wertvolle Beiträge zum Verständnis der Entwicklungen liefern [können], die das Finanzsystem beeinflussen«, solle der ESRB weiterhin "privatwirtschaftliche Akteure, darunter Vertreter des Finanzsektors, [und] Verbraucherverbände [...] konsultieren und ihnen angemessene Gelegenheit zur Stellungnahme geben.« (Erw. 29 VO (EU) Nr. 1092/2010) 
Neben der »Erhebung und dem Austausch von Informationen« (Art. 15 VO (EU) Nr. 1092/2010) bekommt der ESRB bei Feststellung signifikanter Risiken das Recht zugesprochen, »Warnungen und gegebenenfalls Empfehlungen für Empfehlungen heraus[zugeben; J. G.], gegebenenfalls auch für Gesetzgebungsvorhaben.« (Art. 16, Abs. 1 VO (EU) Nr. 1092/2010) Dabei obliegt es dem ESRB, selbstständig die Umsetzung dieser Empfehlungen zu überwachen (vgl. Art. 17 VO (EU) Nr. 1092/2010). Sowohl über die Warnungen und Empfehlungen wie auch über die Nichteinhaltung wird dem Rat Bericht erstattet (vgl. ebd.). Der durch den ESRB ausgehende Umsetzungsdruck auf die Empfehlungsempfänger wird dadurch erhöht, dass der ESRB beschließen kann, seine Warnungen und Empfehlungen zu veröffentlichen (vgl. Art. 18, Abs. I VO (EU) Nr. 1092/2010). Der ESRB stellt somit einen wichtigen Schritt zur Zentralisierung der Makroaufsicht über den Finanzsektor auf suprastaatlicher Ebene dar. Er nimmt dabei nicht nur die Form eines klassischen Beratungsgremiums an, sondern kann durch seine Anlage und Institutionalisierung gar als ein neuer EU-Staatsapparat gelten.

Ergänzt wird diese gestärkte Form der Makroaufsicht durch die eher netzwerklich angelegte Mikroaufsicht. Auch in ihrem Kontext werden zwar neue »Behörden« geschaffen, deren Reichweite bleibt allerdings hinter der des ESRB zurück. Verordnung (EU) Nr. 1093/2010 schafft die Europäische Bankenaufsichtsbehörde (EBA; European Banking Authority), Verordnung (EU) Nr. 1094/2010 die Europäische Aufsichtsbehörde für das Versicherungswesen und die betriebliche Altersversorgung (EIOPA; European Insurance and Occupational Pensions Authority) und schließlich Verordnung Nr. 1095/2010 die Europäische Wertpapier- und Marktaufsichtsbehörde (ESMA; European Securities and Markets Authority). Zusammengenommen bilden sie das Europäische System der Finanzaufsicht (ESFS; European System of Financial Supervision), bei dem »es sich um ein integriertes Netz nationaler Aufsichtsbehörden der Union handeln [sollte], in dem die laufende Beaufsichtigung auf nationaler Ebene verbleibt. (Erw. 9 VO (EU) Nr. 1093/2010; Erw. 8 (EU) Nr. 1094/2010; Erw. 8 (EU) Nr. 1095/2010) Zugleich wird ihm die Aufgabe zuteil »eine größere Harmonisierung und kohärente Anwendung von Vorschriften für die Finanzinstitute und -märkte in der Union« (ebd.) zu erreichen. Die neue Struktur der Aufsichtsbehörden für den Finanzsektor zielt somit insgesamt auf eine Vereinheitlichung von Standards, die es auf Ebene der Mitgliedstaaten umzusetzen gilt und die durch entsprechende Rechtsakte der Unionsorgane erlassen werden können. In diesem Sinne werden die Aufsichtsbehörden nicht wie der ESRB direkt tätig, sondern verbleiben in den bestehenden Beschlussfassungsarrangements des EU-Staatsapparate-Ensembles.

Nachdem im Jahr 2010 das ESFS eingerichtet wurde, spitzte sich in der Zwischenzeit die Krise in der Eurozone zur Euro-Krise weiter zu. Als nun die Legislativakte im Kontext der wirtschafts- und fiskalpolitischen Reformen (Six-Pack) abschließend verhandelt und beschlossen waren, widmeten sich die EUSA zunehmend dem Thema Bankenunion. Auf der Juni-Tagung 2012 des Euro-Gipfels fassten die Staats- und Regierungschefs der Eurozone den Beschluss,

»dass es von ausschlaggebender Bedeutung ist, den Teufelskreis zwischen Banken und Staatsanleihen zu durchbrechen. Die Kommission wird in Kürze [...] Vorschläge für einen einheitlichen Aufsichtsmechanismus unterbreiten. Wir ersuchen den 
Rat, diese Vorschläge dringlich bis Ende 2012 zu prüfen. Sobald unter Einbeziehung der EZB ein wirksamer einheitlicher Aufsichtsmechanismus für Banken des EuroWährungsgebiets eingerichtet worden ist, hätte der ESM nach einem ordentlichen Beschluss die Möglichkeit, Banken direkt zu rekapitalisieren.«(Euro-Cipfel 2012b, 1)

Der Europäische Rat teilte dieses Ansinnen (vgl. ER 2012c, Rn. 4), eingebunden in die Arbeiten des Ratspräsidenten an einem weiteren Bericht »Auf dem Weg zu einer echten Wirtschafts- und Währungsunion « (ausführlich s.u.), an dem auch die Präsidenten der Kommission, der EZB und der Euro-Gruppe beteiligt waren (Vier-Präsidenten-Bericht). Der Bericht lag schließlich im Dezember 2012 vor. Zuvor veröffentlichte die Kommission bereits im September ihren »Fahrplan für eine Bankenunion«, in dem sie eine

»Bankenunion [...] fordert, die den Bankensektor auf ein solideres Fundament stellen und wieder Vertrauen in den Euro schaffen soll. Die Verlagerung der Bankenaufsicht auf die europäische Ebene ist ein Kernbestandteil dieses Prozesses, der in der Folge mit anderen Schritten wie der Einführung eines gemeinsamen Einlagensicherungssystems und eines integrierten Bankenkrisenmanagements kombiniert werden muss. (KOM 2012i, 2; Herv. J. G.)

Zeitgleich mit ihrer Mitteilung präsentierte die Kommission zwei konkrete Legislativvorschläge, die schließlich in den beiden Verordnungen (EU) Nr. 1022/2013 zur Änderung der EBA-Verordnung hinsichtlich der Übertragung von Aufgaben auf die EZB sowie (EU) Nr. 1024/2013 zur Übertragung besonderer Aufgaben im Zusammenhang mit der Aufsicht über Kreditinstitute auf die EZB mündeten. Der hierdurch entstandene Aufsichtsrahmen, der offiziell als SSM (Single Supervisory Mechanism) bezeichnet wird, zentralisiert schließlich die Bankenaufsicht in der Eurozone bei der Zentralbank in Frankfurt. Erstere der beiden Verordnungen kann dabei als Kohärenzverordnung des neuen SSM angesehen werden, in der die Zuständigkeiten zwischen der EZB und der EBA geregelt werden. So solle die EBA »ihre Rolle und all ihre derzeitigen Befugnisse und Aufgaben beibehalten: Sie sollte weiterhin das einheitliche Regelwerk für alle Mitgliedstaaten entwickeln, zu dessen einheitlicher Anwendung beitragen und die Konvergenz der Aufsichtspraktiken unionsweit verbessern. «(Erw. 4 VO (EU) Nr. 1022/2013) Zugleich wird die EZB als neuer Zentralsupervisor der Eurozone in den EBA-Strukturen den nationalen Aufsichtsbehörden gleichgestellt: »[D]ie EBA [sollte] ihre Aufgaben in Bezug auf die EZB in gleichem Maße wahrnehmen können wie in Bezug auf andere zuständige Behörden«, heißt es hierzu in der Verordnung (EU) Nr. 1022/2013 im Erwägungsgrund 12.

Der eigentliche - und juristisch abermals nicht unumstrittene (vgl. Tridimas 2019, $45^{24}$ ) - Kompetenztransfer findet hingegen durch die zweite Verordnung statt, mit der nach dem Anspruch der Kommission (2012j, 4) nicht weniger beabsichtigt war als der »EZB zentrale Aufsichtsaufgaben hinsichtlich aller Kreditinstitute [...], die in den teilnehmenden Mitgliedstaaten niedergelassen sind, unabhängig von ihrem Geschäftsmodell

24 »The SSM Regulation grants the ECB more extensive prudential powers than the reticent wording of Article 127(2) TFEU appears to allow. [...] In the case of the SSM, there is a risk of overreach in terms of institutional empowerment. « 
und ihrer Größe« (Herv. J. G.) zu übertragen, wobei die mitgliedstaatlichen Aufsichtsbehörden »als integraler Bestandteil des einheitlichen Aufsichtsmechanismus auch hinsichtlich der auf die EZB übertragenen Aufgaben die meisten laufenden Prüfungen und weitere für die Vorbereitung und Umsetzung von Rechtsakten der EZB erforderlichen Aufsichtstätigkeiten vornehmen.«(Ebd., 5) Zugleich verblieben alle nicht explizit auf die EZB übertragenen Aufgaben ebenfalls weiterhin durch die mitgliedstaatlichen Aufsichtsbehörden (vgl. ebd.). Diese auf den ersten Blick einfach erscheinende Aufteilung der Befugnisse zwischen der supra- und der mitgliedsstaatlichen Ebene wurde hingegen nicht verwirklicht. Stattdessen wird mit dem SSM ein weitverzweigtes Netz aus Zuständigkeiten und Zuarbeiten gesponnen, das aufgrund der Verhandlungsposition der deutschen Bundesregierung (vgl. Schäfer 2016, 967) lediglich in der Spitze in der direkten Aufsicht von derzeit 115 sogenannter »bedeutender « Institute mündete (vgl. EZB 2021). Somit werden »[i]nnerhalb des SSM [...] die jeweiligen Aufsichtsbefugnisse auf Grundlage der Bedeutung der in den Geltungsbereich des SSM fallenden Unternehmen zwischen der EZB und den [National Competent Authorities] aufgeteilt«, wie es in der von der EZB erlassenen SSM-Rahmenverordnung (EU) Nr. 468/2014 in Erwägungsgrund 5 heißt. Erst wenn der Gesamtwert der Aktiva die Marke von 30 Milliarden Euro übersteigt, die Aktiva eines Instituts mehr als $20 \%$ des BIP des beheimatenden Mitgliedstaats überschreitet oder eine mitgliedstaatliche Behörde »ein [...] Institut als bedeutend für die betreffende Volkswirtschaft betrachtet« (Art. 6, Abs. 4 VO (EU) Nr. 1024/2013), fällt die vollumfängliche Aufsichtsfunktion der EZB zu. Den mitgliedstaatlichen Behörden werden allerdings auch in einem solchen Fall weiterhin Aufgaben zuteil und sie sind zugleich im sogenannten "gemeinsamen Aufsichtsteam « vertreten, das für jedes einzelne Institut zusammengestellt wird (vgl. Art. 3 VO (EU) Nr. 468/2014). Unbeschadet dessen »übt die EZB die ihr [...] übertragenen Aufgaben in Bezug auf die drei bedeutendsten Kreditinstitute in jedem teilnehmenden Mitgliedstaat aus.« (Art. 6, Abs. 4 VO (EU) Nr. 1024/2013) Alle Regelungen und Kompetenzverteilungen in diesem Paradebeispiel verflochtener Staatlichkeit können an dieser Stelle allerdings aufgrund des Regulierungsumfangs $\mathrm{s}^{25}$ nicht dargestellt werden.

Im Kanon mit den Akten der Selbstermächtigung und der Politisierung der EZB im Rahmen ihrer Beteiligung an der Troika komplettieren die komprimierten Darstellungen zur Aufgaben- und Kompetenzausweitung der Zentralbank im Rahmen der Bankenunion insgesamt die Tendenz des kriseninduzierten Staatlichkeitsausbaus in Form einer (impliziten) Finanzsstabilisierungsverfassung mit der EZB im Zentrum. Mit ihrem neuen Aufgabenumfang avancierte die EZB dabei zu einem »multitasker« (Breuss 2017, 201) und nimmt beinahe schon die Form einer zweiten Kommission an.

25 Der SSM steht im direkten Bezug zu zwei weiteren Legislativakten des Jahres 2013. So wird in der Verordnung (EU) Nr. 575/2013 in nicht weniger als 521 Artikeln die »Aufsichtsanforderungen an Kreditinstitute und Wertpapierfirmen « und in Richtlinie 2013/36/EU in immerhin 165 Artikeln der »Zugang zur Tätigkeit von Kreditinstituten und die Beaufsichtigung von Kreditinstituten und Wertpapierfirmen« geregelt. 


\subsection{Die ausgebaute EU-Interventionsstaatlichkeit und ihr Herrschaftsmodus der (Selbst-)Disziplinierung}

Die drei beschriebenen Konstitutionalisierungsprozesse des reaktiven Staatlichkeitsausbaus in der Euro-Krise verweisen zusammengenommen auf die Stärkung der Interventionskapazitäten des EU-Staatsapparate-Ensembles. Sie begründen einen neuen Normalzustand und werden auch künftige krisenbedingte Ausnahmezustände prägen. Die verfassungsbezogenen Szenarien des neuen Normal- und krisenbedingten Ausnahmezustands unterliegen in ihrem Interventionismus gewissen Variationen in Tiefe und Tragweite, welche die ausgebaute Interventionsstaatlichkeit der EU als ein Kontinuum wirken lässt. Dabei stellt unter den Reproduktionsbedingungen kapitalistischer Gesellschaften jede Form von Staatlichkeit zugleich auch eine Form der Interventionsstaatlichkeit dar (vgl. Buckel \& Martin 2019, 248). Allein aus dieser Grundkonstante jedweder Herrschaftsakte des Staates oder äquivalenter Staatlichkeitsformen ließe sich auch bei der Europäischen Union ein entsprechender Staatlichkeitsinterventionismus beschreiben. Allerdings erfolgt eine solche Qualifizierung an dieser Stelle insbesondere aufgrund der konkreten, transformierten Herrschaftspraxen der durch die Euro-Krise ausgebauten EU-Staatlichkeit, die sich deutlich in der Stärkung ihrer Interventionskapazitäten zeigt (vgl. insbesondere Schulten \& Müller 2013, die in Bezug auf die `Economic Governance explizit von einem »neuen europäischen Interventionismus« sprechen; vgl. auch Puetter 2015, 407). Demnach lässt sich vor dem Hintergrund der drei Konstitutionalisierungsprozesse des reaktiven Staatlichkeitsausbaus insgesamt eine Entwicklungstendenz beschreiben, die im Sinne der theoretischen Vorüberlegungen $\mathrm{zu}$ einer Konzentration von Interventionsbefugnissen auf EU-Ebene beigetragen hat. Diese zeigen sich schließlich in einer Monopolisierung symbolischer Gewaltsamkeit, an deren Spitze die EUSA-eigene Benennungs- und Durchsetzungsmacht einer (verfassungs-)rechtlich-festgeschriebenen richtigen Politik steht, die einen Herrschaftsmodus der (Selbst-)Disziplinierung begründet. Innerhalb der drei beschriebenen Verfassungsbestände der vertragsbasierten Fiskal- und Wirtschaftsverfassung, der (impliziten) Finanzstabilisierungsverfassung und der außerunionsvertraglichen Notstandsverfassung tritt die EU-Interventionsstaatlichkeit jeweils sowohl im neuen Normal- als auch im (künftigen) Ausnahmezustand deutlich hervor.

Bereits im >neuen Normalzustand - als eine Beschreibungsfolie für die alltägliche Herrschaftsausübung durch die EUSA - ist mit den Reformprozessen der Krisenbewältigungspolitik der ausgebaute Koordinationszyklus des Europäischen Semesters wirksam, welcher in der Selbstbeschreibung auch als >integrierter Überwachungszyklus bezeichnet wird. Durch die Formulierung ihrer Jahreswachstumsberichte nimmt in diesem neuen Setting die Kommission bereits früh Einfluss auf die Formulierung der mitgliedstaatlichen Stabilitäts- und Konvergenz- sowie ihrer Nationalen Reformprogramme, bei denen die Mitgliedstaaten auf die Analysen und Prognosen der Kommission Bezug zu nehmen haben. Der Kommission obliegt bereits am Anfang des Zyklus die Setzung eines Rahmens, auf den sich die Mitgliedstaaten zu beziehen haben. Durch ihre Beurteilungskompetenzen fällt der Kommission zudem die Aufgabe zu, eine Bewertung der entsprechenden Programme zu vollziehen. Besonders deutlich wird dies beim neuen integrierten Haushaltszyklus, der ebenfalls Bestandteil des Semesters ist, 
und bei dem die Kommission nach deren Prüfung sogar Haushaltsentwürfe von EuroMitgliedstaaten zurückweisen kann (siehe Italien 2018). Auf die Grundsatzkritik, nach der dieser neue Rahmen das »historische Königsrecht (Hufeld 2013, 206), also das Budgetrecht, der mitgliedstaatlichen Parlamente untergräbt, wurde hierbei schon hingewiesen (vgl. u.a. auch Brachthäuser \& Haffner 2017, 23, Schwan 2017, 156 oder Crum 2018).

Dem Grunde nach wurde auf der neuen koordinativen Grundlage mit den weiteren kriseninduzierten Reformmaßnahmen die bereits mit dem Vertrag von Maastricht angelegte Stabilitätsunion in ihren neoliberalen Grundfesten perpetuiert, indem die Formen des fiskalpolitischen Regierens auf suprastaatlicher Ebene gestärkt und die Regelgebundenheit der Fiskalpolitik - als Vorgaben an die Mitgliedstaaten - insgesamt ausgebaut wurden. Das Schlagwort einer solchen restriktiven Fiskalpolitik lautet »Haushaltsdisziplin«. Die Vereinheitlichung, Synchronisation und suprastaatliche Zentralisierung unter dem Dach des Europäischen Semesters, die nach der Kodierung im Six-Pack durch Ergänzungen im Two-Pack weiter ausgebaut und noch stärker formalisiert wurden, bietet laut Kommission einen erweiterten Rahmen zur Formulierung europäischer Leitlinien, die in die Entscheidungsfindung auf Ebene der Mitgliedstaaten einfließen sollen. Neben diesem Synchronisationsprozess, der politische Empfehlungen der EUSA an die Mitgliedstaaten beinhaltet, wurden im Rahmen des SWP die numerischen Haushaltsregeln - also: die Durchsetzung einer einheitlichen Sichtweise - verschärft und ausgebaut. Im präventiven Arm des SWP sind die Mitgliedstaaten dabei angehalten, ihre öffentlichen Finanzen am jeweiligen mittelfristigen Haushaltsziel (MTO) auszurichten. Das mittelfristige Haushaltsziel ist mit den kriseninduzierten Reformen zu einem harten Kriterium geworden, dessen Einhaltung künftig durch die Kommission überwacht wird. An dieser Stelle gibt der Rat seine Befugnisse gar in Gänze an die Kommission ab, die ohne eine entsprechende Ratskonsultation Verwarnungen aussprechen kann, wenn ein Mitgliedstaat den Anpassungspfad auf das mittelfristige Haushaltsziel nicht einhält. Zugleich sind mit der Neuregelung weitere Auflagen verbunden, selbst wenn das mittelfristige Haushaltsziel erreicht ist. So kennt der durch das Six-Pack reformierte SWP eine Begrenzung des Ausgabenwachstums und schreibt vor, dass diskretionäre Einnahmesenkungen nur durch gleichzeitige Ausgabenkürzungen möglich sein dürfen. Eine weitere Verschärfung basiert auf der gestärkten Bedeutung des Schuldenstandskriteriums. Demnach ist zum Abbau öffentlicher Verschuldungen über $60 \%$ des BIP künftig ein spezifischer Anpassungspfad einzuhalten, nach dem der Schuldenstand jährlich mindestens um ein Zwanzigstel abzubauen ist. Mit den beschriebenen kriterialen Neujustierungen des SWP gehen zugleich Einschränkungen der haushaltspolitischen Autonomie der Mitgliedstaaten einher, oder anders ausgedrückt, haben sie »zu eine[m] haushaltspolitischen Souveränitätsverlust [...] geführt.« (Hillebrand 2017, 5)

Um sicherzustellen, dass die Mitgliedstaaten ihren Verpflichtungen nachkommen, wurde der Ausbau des SWP-eigenen Überwachungs- und Sanktionsregimes vorangetrieben und zugleich durch den SKS-Vertrag auf Basis des Völkerrechts - Everson \& Joerges $(2014,200)$ sprechen von einem »Ersatzunionsrecht - abzusichern versucht (vgl. auch Petzold 2018, 260). Mit ihm findet eine weitere Konstitutionalisierung der restriktiven Haushaltspolitik statt, die man mit Petzold $(2018,265)$ als einen »interskalar verketteten Konstitutionalismus der Austerität« begreifen kann. So hält der SKS-Vertrag 
die Unterzeichnerstaaten an, bei einer Schuldenstandsquote über $60 \%$ des BIP striktere Defizitgrenzen einzuhalten als im SWP hinterlegt, einen Austeritätsmechanismus (wahlweise auch »automatischer Korrekturmechanismus« oder »Schuldenbremse«) auf Ebene der Mitgliedstaaten zu implementieren und künftig im Rat Defizitverfahren nicht mehr zu verhindern, soweit sie von der Kommission vorgeschlagen werden.

Im Bereich des wirtschaftspolitischen Regierens basiert der neue Interventionsrahmen insbesondere auf dem Verfahren bei makroökonomischen Ungleichgewichten (MIP). Im Zentrum steht dabei das neue Scoreboard, mit dem ein Instrument geschaffen wurde, das Benchmarks für einzelne Bereiche und Indikatoren setzt, deren Einhaltung durch die Kommission überwacht wird. Im Rahmen ihrer Bewertungen und gegebenenfalls »eingehender Überprüfungen« von Mitgliedstaaten obliegt der Kommission dabei das Attestieren von Ungleichgewichten, die je nach Schwere zur Einleitung eines EIPs, also einem Verfahren bei übermäßigen Ungleichgewichten, führen kann. Alle Analysen und Bewertungen, welche die Kommission im Rahmen des MIP anfertigt, fließen schließlich in die Formulierung der länderspezifischen Empfehlungen ein, dem wichtigsten Interventionsinstrument in Normalzeiten. Die inhaltliche Bandbreite der Empfehlungen reicht dabei allerdings, wie gezeigt wurde, weit über den Bereich der Wirtschafts- und Fiskalpolitik hinaus und kann demnach fast alle Politikbereiche umfassen, egal ob der EU hierbei eine vertragliche Zuständigkeit zufällt oder nicht.

Mit den beiden Verfahren bei einem übermäßigen Defizit (VÜD) und einem übermäßigen makroökonomischen Ungleichgewicht (EIP) ist zudem bereits die nächste Stufe des ausgebauten Interventionsrahmens angedeutet worden, die bei einer Abweichung von den fiskal- und wirtschaftspolitischen Zielvariablen des SWP und des MIP einsetzt. In ihr tritt der EU-Interventionismus noch deutlicher zu Tage. So sind Mitgliedstaaten nach Auslösung des EIP aufgefordert, einen Korrekturmaßnahmenplan einzureichen, der durch die Kommission und den Rat zu bewerten ist und dabei durch diese auch als unzureichend zurückgewiesen werden kann. Dies gilt auch für das VÜD, bei dem Eurostaaten neuerdings ein sogenanntes Wirtschaftspartnerschaftsprogramm vorzulegen haben, das die betroffenen Mitgliedstaaten nicht nur auf fiskalische Anpassungsmaßnahmen sondern auch auf weitergehende Strukturreformen verpflichten soll und eine unübersehbare Ähnlichkeit zu den Memoranden des Ausnahmezustandes aufweist. Hinzu kommt die Möglichkeit, dass die Kommission in den betroffenen Mitgliedstaaten Überwachungsmissionen durchführen kann, um die Einhaltung der Programme zu kontrollieren, zu deren Einhaltung zugleich die Sanktionsmöglichkeiten ausgebaut wurden. Bereits früh in den entsprechenden Verfahren kann die Kommission hierbei selbstständig Verwarnungen aussprechen, die durch entsprechende Sanktionsbeschlüsse, an denen der Rat beteiligt ist, untermauert werden können. Aufgrund der umgekehrten Mehrheitserfordernisse (RQMV) wird es dem Rat allerdings nicht nur erschwert, Änderungen an den von der Kommission vorgelegten Bewertungen und Empfehlungen vorzunehmen, sondern auch Sanktionen zurückzuweisen. Abgesichert wird dies auch im völkerrechtlichen SKS-Vertrag, in dem die Mitgliedstaaten zusichern, den Empfehlungen der Kommission Folge zu leisten. Anders als für Nicht-Eurostaaten basiert das gesamte Sanktionssystem für die Eurozone auf dem neuen RQMV-Verfahren. Die Verordnung (EU) Nr. 1173/2011 etabliert dabei einen umfassenden SWP- und MIPDurchsetzungsmechanismus des fiskal- und wirtschaftspolitischen Regierens in der Eu- 
rozone, in dem nicht nur neue Mehrheitserfordernisse gelten, sondern der insgesamt durch die Ausweitung des Sanktionsregimes geprägt ist. So können im konsolidierten SWP bereits im korrektiven Arm Sanktionen verhängt werden, um die >compliance des betroffenen Mitgliedstaats mit den Regeln sicherzustellen.

Neben dem ausgebauten Interventionsrahmen im Kontext der vertragsbasierten Fiskal- und Wirtschaftsverfassung, von dem insbesondere die Kommission profitiert, stellt sich mit der (impliziten) Finanzstabilisierungsverfassung auch der Funktionsund Interventionsrahmen der EZB im sneuen Normalzustand erweitert dar. Im Sinne einer Finanzstabilisierungsagentur obliegt es der Zentralbank, durch die Übertragung der Aufsichtsfunktion für Banken und ihre institutionelle Verknüpfung mit dem Ausschuss für Systemrisiken (ESRB), eine ausgeweitete Überwachung der Finanzmärkte in der Eurozone sicherzustellen. Der Ausschuss kann dabei sogar Verwarnungen und Empfehlungen ausgeben, die formal unter Zustimmungsvorbehalt des Rates stehen. Daneben hat die EZB in der Euro-Krise bewiesen, dass sie auch für die Euro-Staaten in Ansätzen - die LOLR-Funktion übernimmt und notfalls durch ihre Programme auf den Märkten für Staatsverschuldungstitel interveniert. Hierin ist bereits die Überleitung vom neuen Normal- zu einem potenziellen Ausnahmezustand angelegt, in dem die EZB auf Grundlage ihrer impliziten Stabilisierungsverfassung verstärkt auch intervenierend gegenüber Mitgliedstaaten auftritt. In ihrer neuen Funktion als LOLR für die Eurostaaten agiert sie konditionalisierend gegenüber Mitgliedstaaten, die sich in (potenziellen) Refinanzierungsschwierigkeiten befinden. Ihr Instrumentarium umfasst dabei neben den Programmen im Kontext von Stützungsmaßnahmen auf den Märkten für staatliche Refinanzierungstitel bei Schwierigkeiten in den mitgliedstaatlichen Bankenund Finanzsektoren unter anderem die sogenannten Notfalliquiditätshilfen (ELA). Der EZB fällt somit eine besondere Scharnierfunktion in der ausgebauten EU-Staatlichkeit zu. Sie besitzt einerseits das nötige Instrumentarium, um refinanzierungs- und finanzmarktbezogenen Schwierigkeiten zu begegnen und somit Krisen zu verhindern. In dieser Funktion obliegt ihr es aber andererseits zugleich, durch Verweigerung entsprechender Maßnahmen die Zuspitzung zu einer akuten Krise zu befördern. Tritt diese letztlich ein, wandelt sich zugleich das Verfassungsszenario zum krisenbedingten Ausnahmezustand, in den schließlich die außerunionsvertragliche Notstandsverfassung einsetzt und die höchste Eskalationsstufe des Staatlichkeitsinterventionismus der EU darstellt, in der nicht zuletzt auch reguläre Politikprozesse auf Grundlage der EU-Verträge suspendiert werden.

In diesem Falle kommt der Interventionsrahmen des autoritär-intergouvernementalen Gläubigerregimes des ESM zur Anwendung, in dessen Zentrum der ESM-Gouverneursrat (de facto die Euro-Gruppe) und mit ihm die Troika als dessen Durchsetzungsbehörde steht. Im Rahmen der Troika erfahren auch reguläre EUSA eine Kompetenzausweitung. Die Kommission und die EZB agieren hier als Hilfsagenturen des Gläubigerregimes. Sie sind maßgeblich an der Aushandlung und der Überwachung der Memoranden, dem Herrschafts- und Interventionsinstrument des neuen Regimes und der in ihnen enthaltenen Konditionalitäten beteiligt. Mit ihnen wird im ausgerufenen Ausnahmezustand der Notstandsverfassung weit in die mitliedstaatliche Politikgestaltung eingegriffen und so beiläufig de facto die Demokratie auf Ebene der Mitgliedstaaten suspendiert. Dieser autoritäre Charakter ist eines der bestimmenden Momente der neuen Notstands- 
verfassung, der sich nicht auch zuletzt im Umgang mit den gewählten Regierungsvertreter*innen zeigt, die eher als Bittsteller*innen statt als Partner*innen angesehen werden. Durch die Externalisierung des Krisenbewältigungsmechanismus erscheinen die Interventions- und Herrschaftsarrangements der Notstandsverfassung der eigentlichen EU-Staatlichkeit in gewisser Weise vorgelagert. Allerdings wurden die getroffenen völkerrechtlichen Reformmaßnahmen zum Aufbau des ESM durch entsprechende Sekundärrechtsakte ergänzt, mit denen die Notstandsverfassung letztlich unionsrechtlich flankiert wurde. Mit dem Two-Pack wird in diesen Sinne das Verfahren zur Beantragung und Gewährung von Stabilitätshilfen aus dem ESM in einen Entsprechungsrahmen auf Grundlage der EU-Verträge gegossen, indem beispielsweise analog zur Ausformulierung der Memoranden ein entsprechendes makroökonomisches Anpassungsprogramm von dem betreffenden Mitgliedstaat eingefordert wird. Hinzu kommt die mit dem Two-Pack implementierte sverstärkte Überwachung<, die analog zu den Aufgabenzuweisungen an die Troika zu verstehen ist, überdies aber bereits wesentlich früher wenn die Kommission schwerwiegende Ungleichgewichte und fiskalische Beeinträchtigungen feststellt - durch die Kommission im Alleingang ausgelöst werden kann. Im krisenbasierten Ausnahmezustand ist die maximale Interventionstiefe erreicht. Im Gegenzug für Hilfskredite wird den EUSA letztlich ein Interventionismus gewährt, der die betroffenen Mitgliedstaaten eher zu Befehlsempfängern und nur noch teil-souveränen Gliedstaaten der EU degradiert.

Das autoritär-intergouvernementale Gläubigerregime der außerunionsvertraglichen Notstandsverfassung markiert in seiner Interventionstiefe und seinem Disziplinierungscharakter einen im Anschluss an Poulantzas (2002) zu bezeichnenden »autoritären Etatismus« (vgl. auch Kannankulam 2013; 2017; Sandbeck \& Schneider 2013). Im konkreten Anwendungsfall der neuen EU-Verfassungskomponente umfasst dieser die Stärkung der Exekutive durch weitestgehende Nichtbeteiligung der Legislative, das Schwinden der Rechtsstaatlichkeit, der Bedeutungsverlust von Parteien und eine Verlagerung der Entscheidungsfindung in parallele Machtzentren (vgl. Oberndorfer 2017, 77). Auf den ESM als Kern der neuen Notstandsverfassung treffen letztlich all diese Qualifizierungen zu: Bereits bei der Implementierung des ESM fanden in einer Reihe von Mitgliedstaaten abweichende parlamentarische Beschlussfassungsverfahren Anwendung (vgl. Maatsch 2015, 16f.); hinzu kommt, dass lediglich in Deutschland, Österreich, Estland und mit Abstrichen in den Niederlanden ein parlamentarisches Zustimmungsrecht im Vorfeld von Abstimmungen in den ESMEntscheidungsgremien implementiert wurde (vgl. Rittberger \& Winzen 2015, 436) und "weniger als die Hälfte der Eurozonen-Parlamente nennenswerte Informationsrechte genießt.« (Ebd., 437) Die mitgliedstaatlichen Exekutiven stehen demnach im Zentrum der Notstandsverfassung, wobei eine Externalisierung der Entscheidungsfindung in den ESM-Gouverneursrat stattfindet (>parallele Machtzentren`). Eine solche Externalisierung ist auch in der Troika angelegt, deren Gebundenheit an das Unionsrecht bereits Gegenstand kritischer Betrachtung war (vgl. Kap. 7.2), die die Frage aufwarf, ob hier ein >Vertragsbruch vorliegt (`Rechtsstaatlichkeit`). Der Bedeutungsverlust von Parteien und ihrer Funktion, "gesellschaftliche Interessen in die Produktion von Hegemonie ein[zu]speisen« (Oberndorfer 2017, 77) äußert sich schließlich in den verordneten Programmen ( $>$ Memoranden $\triangleleft)$, die durch die Mitgliedstaaten zu akzeptieren 
sind; Nachverhandlungen werden schlicht nicht geduldet (»we don't change our policy according to elections ${ }^{26}$ ). Ein ähnlich autoritärer-disziplinierender Charakter ist auch in der (impliziten) Finanzstabilisierungsverfassung der EZB angelegt, die sich im Besonderen einer autoritär-neoliberalen Krisenbewältigungsstrategie verpflichtet fühlte, wie einerseits die EZB-Reformvorschläge im Rahmen der Task-Force-Diskussion (>Leitbild einer technokratischen EWWU<) und andererseits ihr konkretes Agieren als konditionalisierender LOLR zeigte.

Durchaus etwas differenzierter gestaltet sich die Situation im Rahmen des Konstitutionalisierungsprozesses, der auf die Fortentwicklung der EU-Wirtschafts- und Fiskalverfassung zielte. Zwar lassen sich auch hier deutlich autoritäre Elemente erkennen (bspw. im SKS-Vertrag), zugleich bleiben aber die formalen Diskussions- und Beschlussfassungswege weitgehend unangetastet (Six- und Two-Pack). Dennoch stützte sich auch der Prozess zur Fortentwicklung der vertragsbasierten EU-Wirtschaftsund Fiskalverfassung weitgehend auf einem Handlungsmuster koproduktiver Exekutivstaatlichkeit im Herrschaftsmodus der (Selbst-)Disziplinierung, das sich letztlich in der Stärkung der Trias aus Europäischen Rat, Europäischer Kommission und Europäischer Zentralbank innerhalb des ausgebauten Verfassungsrahmens manifestiert. Aufgrund des exekutiven Primats oder, mit Habermas (2011a, 48) gesagt, "postdemokratischen Exekutivföderalismus« und der Materialität der einzelnen Exekutivapparate, die weitgehend geprägt ist von der vormals hegemonialen Phase des neoliberalen Hegemonieprojekts, bleibt es deshalb meist bei einer Zurückweisung und daher nur sehr rudimentären Berücksichtigung alternativer Politikansätze (strategische Selektivitäten; s. bspw. die Diskussion um Eurobonds), worin bereits ein Merkmal nicht-hegemonialer Staatlichkeits(re)produktion angedeutet wird (ausführlich s.u.).

Der Disziplinierungscharakter der konkreten Herrschaftspraxen auf Grundlage der ausgebauten EU-Interventionsstaatlichkeit wurde anhand der konkreten Interventionsinstrumente und ihrer Herrschaftspraxen vor dem Hintergrund der drei beschriebenen Konstitutionalisierungsprozesse des reaktiven Staatlichkeitsausbaus, die man zusammengenommen mit Bieling (2013a \& 2013b) als »Krisenkonstitutionalismus« oder mit Oberndorfer (2013 \& 2012a) als »autoritären Konstitutionalismus« bezeichnen könnte, herauszustellen versucht. Die drei Konstitutionalisierungsprozesse stehen demnach in der historischen Genese der EU-Staatlichkeit in einer Kontinuitätslinie mit dem von Gill (1998) beschriebenen »neuen Konstitutionalismus«, der darauf gezielt habe,

»die markt- und wettbewerbsorientierten Reorganisationsprozesse rechtlich und institutionell abzusichern, den Modernisierungs- und Anpassungsdruck auf die nationalen Entwicklungsmodelle [...] zu erhöhen, und die europäischen Vorgaben zugleich einer zukünftigen demokratischen Kontrolle und Gestaltung zu entziehen.«(Bieling 2013a, 97)

Seine strategische Bedeutung bestehe demnach darin, die Macht des Kapitals langfristig durch politische und rechtliche Mechanismen zu verankern, die nur schwer ver-

26 Dies ließ Kommissionsvizepräsident Jyrki Katainen nach der WahI SYRIZAs im Januar 2015 verlautbaren (zitiert nach Featherstone 2016, 56). 
änderlich seien (vgl. Gill 2000, 44). Neben der Begrenzung der demokratischen Einflussnahme auf die politische Ökonomie zählen für Gill $(2000,44)$ rechtliche und quasi-rechtliche Übereinkünfte oder die Institutionalisierung von Standards zum Maßnahmenkatalog des neuen Konstitutionalismus. Er ist »demzufolge ein Versuch, den Staat, die Zivilgesellschaft und die Akkumulationsmuster neu zu gestalten.« (Ebd., 25; vgl. ders. 2003, 65f.) Innerhalb dieses Versuchs identifiziert er den disziplinierenden Neoliberalismus als ideologisches und ökonomisches Programm, welches die Integrationsprozesse kennzeichne, sich zunehmend von einer klassischen politischen Artikulation in Form hegemonialer Auseinandersetzungen löse und stattdessen durch eine Politik der Vorherrschaft und der Disziplinierung charakterisiert werden könne (vgl. Gill 2000., 41; vgl. Bohle 2012, 168f.). Die Konstitutionalisierungsprozesse des reaktiven Staatlichkeitsausbaus führen diesen Weg in intensivierter Weise fort, indem sie den Interventionsrahmen der EU-Staatlichkeit ausbauen und die Staatlichkeitspraxen im Herrschaftsmodus der (Selbst-)Disziplinierung, die je nach Interventionsinstrument in Tiefe und Reichweite variieren, stärken: 


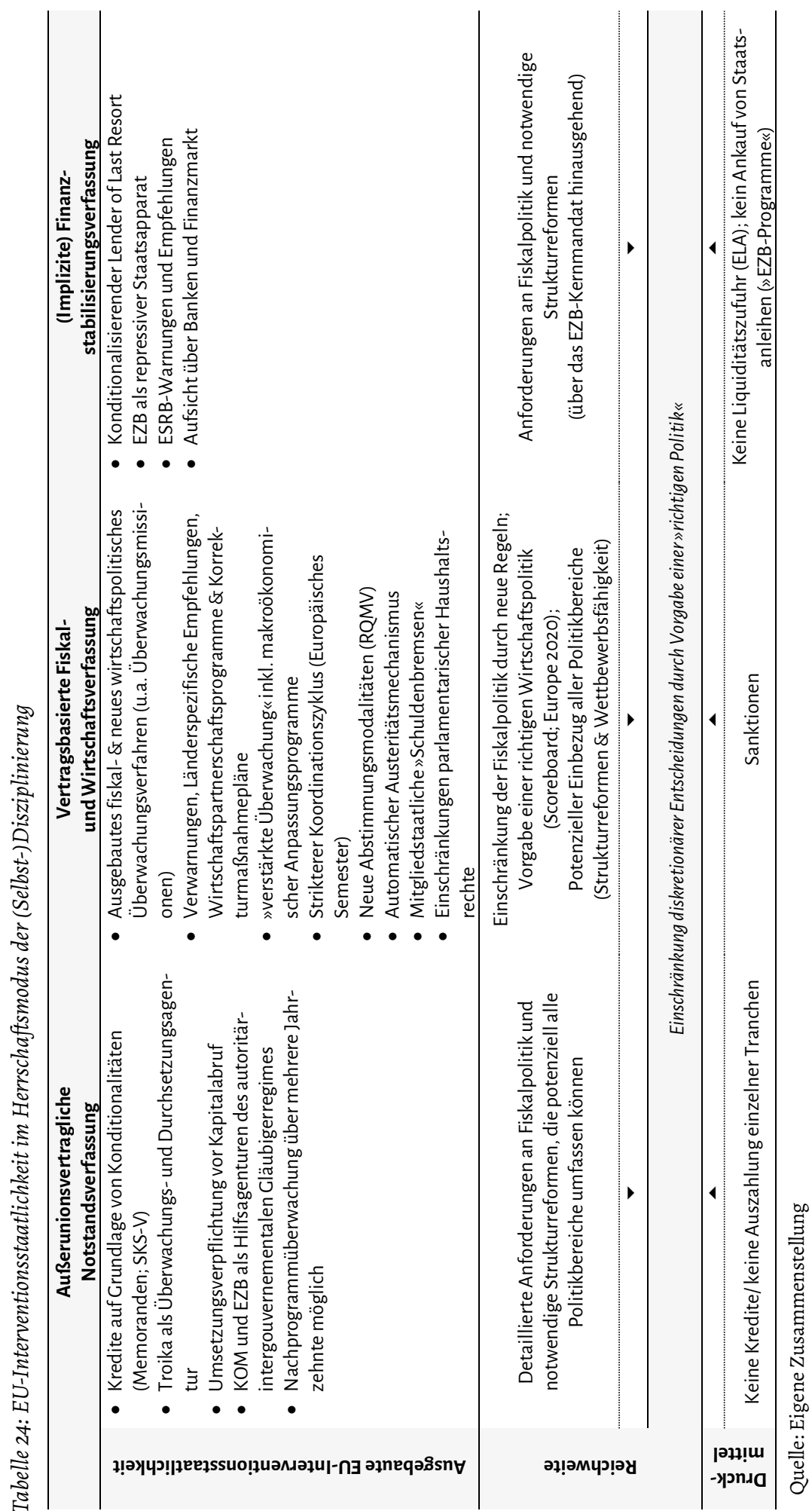


All diese Interventionsmöglichkeiten und -instrumente dienen letztlich dem gemeinsamen Ziel, eine (verfassungs-)rechtlich-festgeschriebene richtige Politik gegenüber den Mitgliedstaaten durchzusetzen, die sich aus den Kernnormen der EU-Verträge, der sich in den Reformmaßnahmen materialisierenden Konstitutionalisierungsprozessen und letztlich den strategischen Zielsetzungen der EU (Europe 2020) speist. Dabei unterwerfen sich die Mitgliedstaaten in der ersten Stufe quasi freiwillig der »richtigen Politik«; wollen sie schließlich verhindern, letztlich der höchsten Interventionsstufe im Rahmen der außerunionsvertraglichen Notstandsverfassung ausgesetzt zu sein.

$\mathrm{Zu}$ Beginn dieser Arbeit wurde in der Darstellung der EU-Staatlichkeitsgenese vor der Euro-Krise (Kapitel 4) herausgestellt, wie sich in den Integrationsschritten hin zur EWWU eine EU-Wirtschaftsverfassung materialisiert hat, die im Kern von ordo- und neoliberalen Prämissen und Zielnormen geprägt ist. Auf diesem Verfassungsbestand bauen die beschriebenen Transformationsprozesse im Kontext des reaktiven Staatlichkeitsausbaus in Zeiten der Euro-Krise auf und entwickelten ihn im Rahmen der drei beschriebenen Konstitutionalisierungsprozesse im Sinne einer serlaubten Ordnungspolitik (vgl. Altvater 1981, 13) qualitativ fort. So zielen die Reformen am SWP auf eine weitere Einschränkung diskretionärer Fiskalpolitiken zur Vermeidung einer >nicht erlaubten Prozesspolitik^(vgl. ebd.) der im Maastrichter Vertrag vollzogenen Hinwendung auf eine Stabilitätsunion, in deren Zentrum die Idee ausgeglichener Haushalte steht (vgl. Stützle 2014). Diese Fokussierung wird mit den kriseninduzierten Reformen perpetuiert und führte schließlich zu einer noch restriktiveren Fiskalpolitik, die man mit Petzold $(2018,13)$ auch als eine Form »normalisierter Austerität« bezeichnen könnte, bei der »[d]ie Disziplinierung der öffentlichen Haushalte [...] schon präventiv an[setzt], bevor es >zu spät< und die Notwendigkeit zum Sparen entstanden ist.« Letztlich wird so ein Fiskalregime, »also ein historisch-geographisch besonderes, temporär stabilisiertes System strategischer Selektivität« begründet, »durch das bestimmte (finanz-)politische Strategien in einen >organischen Zusammenhang gebracht und dadurch im Verhältnis $\mathrm{zu}$ anderen systematisch privilegiert werden.« (ebd., 69) Auch den wirtschaftspolitischen Zielvorstellungen der Verträge wird mit den Reformmaßnahmen Rechnung getragen. Sie erfahren infolgedessen eine weitere Ausschärfung, auf deren Grundlage das neue Regime makroökonomischer Überwachung fußt und auf dem Scoreboard mit seinen Selektivitäten basiert. Mit den beschriebenen neuen Herrschaftsarrangements der EU-Interventionsstaatlichkeit ist insofern letztlich die Formulierung einer »richtigen Politik« verbunden, die als Ausdruck eines symbolischen Gewaltmonopols gelten kann. Die Vorgaben dieser richtigen Politik werden anschließend in einen Schleier der Technokratisierung und Managerialisierung (»Scoreboard«, »Benchmarks«, »Indikatoren«, »Schwellenwerte«) gehüllt und Politik somit als quasi `unpolitische - oder gar alternativlose - Angelegenheit dargestellt, die von Expert*innen zu gestalten ist, getreu dem Motto des ehemaligen britischen Premierministers Tony Blair, nach dem es keine linke oder rechte, sondern nur gute oder schlechte Wirtschaftspolitik gebe (vgl. Neues Deutschland, 20.03.2002). Die europäische Wirtschafts- und Währungsordnung vor und wesentlich stärker noch nach den kriseninduzierten Transformations- und Ausbauprozessen steht paradigmatisch für einen solchen Ansatz einer quasi sakrosankten, weil angeblich richtigen Politik (vgl. u.a. Fisahn 2017b). Diese wird zum einzigen Referenzpunkt und die politisch Verantwortlichen werden zu Gelingens- und Durch- 
setzungsagent*innen einer institutionalisierten Sachzwanglogik, wie sie Anne Karrass (2008; 2009) als charakteristisch für das neoliberale Staatsverständnis in Bezug auf die EU herausgearbeitet hat (vgl. u.a. auch Aglietta 2004, 102ff.).

In einem solchen Sinne kann auch von Euro-Heteronomien gesprochen werden, welche die Abhängigkeit und Fremdbestimmtheit charakterisieren, die innerhalb der EU und insbesondere in der EWWU an vielen Stellen auf die mitgliedstaatlichen StaatZivilgesellschafts-Komplexe einwirken (vgl. bspw. Feigl 2015). Zur Verschleierung dieser Heteronomien wird von verantwortlicher Seite gerne die "Eigenverantwortung « der Mitgliedstaaten beschworen. Der vermeintliche Widerspruch zwischen der suggerierten Entscheidungsautonomie und den institutionalisierten Heteronomien entpuppt sich hierbei aber als reiner Euphemismus. Unter dem Deckmantel der Eigenverantwortung versteckt sich vielmehr ein Durchsetzungsvehikel der richtigen Politik, bei dem autonome Entscheidungsbefugnisse suggeriert werden, die in der Realität allerdings nicht auffindbar sind. Die Formulierung der >richtigen Politik erfolgt dabei insbesondere auch über die sogenannte Unionsstrategie für Wachstum und Beschäftigung, die sich die Europäische Union seit 2000 für einen Zehnjahreszeitraum gibt. Die ausgebaute Infrastruktur der kriseninduzierten Reformprozesse bezieht sich an vielen Stellen auf die Europe-2020-Strategie und stattet sie somit zugleich mit entsprechenden Interventionskapazitäten aus, die ihrer Vorgängerin, der Lissabon-Strategie, noch verwehrt blieben. War bereits in der Lissabon-Strategie ein Strukturreformenkonsens und die Fixierung auf eine exportorientierte Wettbewerbsfähigkeitsdoktrin (wettbewerbsfähigster und dynamischter Wirtschaftsraum der Welt) enthalten (vgl. u.a. ER 2009, 7), wird diese schließlich in der Europe-2020-Strategie fortgesetzt und gar - vor dem Hintergrund der EU-Verträge und der ihr eingeschriebenen Zielvorstellung einer im hohen Maße wettbewerbsfähigen Marktwirtschaft (vgl. Art. 3 EUV) - noch weiter radikalisiert. Durch die Europe-2020-Strategie, die integrierten Leitlinien, die ihnen implizierte Doktrin der Wettbewerbsfähigkeit und nicht zuletzt der Unterordnung unter das Austeritätsdogma war somit bereits am Ausgangspunkt des reaktiven Staatlichkeitsausbaus in der Euro-Krise ein ganzheitlicher Politikrahmen implementiert worden, der die Verfassungsnormen der EU-Verträge in eine konkrete »richtige Politik« übersetzt. Diese prägt auf Grundlage der durch die Krisenbewältigungspolitik ausgebauten Interventionsstaatlichkeit die konkreten Herrschaftspraxen des EU-Staatsapparate-Ensembles wirkmächtiger als zuvor, die letztlich den Herrschaftsmodus der (Selbst-)Disziplinierung begründen; getreu dem Motto des damaligen Währungskommissars Olli Rehn, der nach den finalen Six-Pack-Beschlüssen im November 2011 sagte:

»And I expect the Member States to play by the rules from now on, so that we do not have to face a similar crisis never again. Countries living beyond their means, the lack of economic reforms in the context of open markets, the building up of financial bubbles... The price we have paid is high, too high, and it should prevent us from falling again in the same traps.«(KOM 2011f) 


\subsection{Die fortschreitende Hegemoniekrise in der Phase des reaktiven EU-Staatlichkeitsausbaus}

In der Phase des reaktiven Staatlichkeitsausbaus wurde anhand der beschriebenen drei Konstitutionalisierungsprozesse der Herrschaftsmodus der (Selbst-)Disziplinierung, vermittelt durch die Vorgabe einer (verfassungs-)rechtlich-festgeschriebenen richtigen Politik, fortentwickelt, der auf eine Traditionslinie der EU-Staatlichkeitsgenese unter neoliberaler Hegemonie verweist (vgl. Kapitel 4). In den gesellschaftlichen Aushandlungsprozessen zur Suche nach einer geeigneten Strategie zur Bewältigung der Euro-Krise verdichtete sich dabei am Ausgangspunkt der Euro-Krise ein europäisches Kräfteverhältnis, das von einer impliziten Allianz aus neoliberalen Kräften - in Form der proeuropäisch-autoritären und der national-orthodoxen Fraktion im neoliberalen Hegemonieprojekt - mit Kräften aus den national-konservativen Hegemonieprojekten, insbesondere der Zentrumsstaaten, dominiert war (vgl. Georgi \& Kannankulam 2015). Es gelang diesen Akteur*innen, durch drei strategisch-diskursive Momente (Staatsschuldenkrise, Wettbewerbsfähigkeitsdiskurs \& Rettungsdispositiv; vgl. Kapitel 6) eine Krisenbewältigungsstrategie in die EUSA einzuschreiben (vgl. Kapitel 7.1), die sich deutlich als autoritär und neoliberal charakterisieren lässt (vgl. insb. Kapitel 7.5). Kernelemente hierbei sind, wie gezeigt werden konnte, ein auf Disziplinierung zielender Neoliberalismus, autoritäre Formen des Etatismus, der Hang zu einem Modus koproduktiver Exekutivstaatlichkeit und letztlich fehlende ökonomische Zugeständnisse gegenüber Subalternen als auch eine ausbleibende demokratische Vermittlung der Herrschaftsausübung. Die autoritär-neoliberale Schlagseite der ausgebauten EUInterventionsstaatlichkeit ergibt sich weiterhin vor dem multiskalaren Hintergrund der Kräfteverhältnisse in der EU. Es sind demnach gerade die Euro-Staaten des Nordens, die aufgrund ihrer ökonomischen Dominanz und ihrer Nichtbetroffenheit von der Refinanzierungskrise ein Kräfteungleichgewicht zwischen den unterschiedlichen mitgliedstaatlichen Staats-Zivilgesellschafts-Komplexen der Eurozone und somit auch auf Ebene der EU-Staatlichkeit erzeugten. Ausdruck findet dies in der Einbindung der national-konservativen Hegemonieprojekte der Zentrumsstaaten in die Rettungsallianz, die vehement für die Begrenzung europäischer Krisenlösungen eintraten und denen gegenüber deutlich wahrnehmbare Konzessionen gemacht wurden.

Solche Konzessionen wurden im Laufe der Krise auch gegenüber proeuropäisch-sozialen Akteur*innen notwendig, die aufgrund ihrer Einseitigkeit immer deutlicher und vehementer in Opposition zu einer im Kern autoritär-neoliberalen Krisenbewältigungspolitik standen (vgl. bspw. Georgi \& Kannankulam 2015). Dies zeigte sich letztlich auch in der Diskussion um den SKS-Vertrag, der eine Konzession in Gestalt des lancierten >Pakts für Wachstum und Beschäftigung` (vgl. ER 2012c) erforderte, der sich allerdings in seiner Reichweite und Stoßrichtung am Ende stärker der Europe-2020-Strategie verpflichtet fühlte als den mit ihm zu Beginn der Diskussion erhofften sozialpolitischen Flankierung der austeritären Krisenbewältigungspolitik. Der Spiegel (27.06.2012) sprach daher folgerichtig von einem »Mogelpack« und das EP (2012b) forderte bereits wenige Monate später mit ihrem Vorschlag eines »Pakts für soziale Investitionen« ebenfalls ein stärkeres Zeichen ein. Auch die 2013 in Reaktion auf die horrende Jugendarbeitslosigkeit als Folge der Krise und ihrer austeritären Bewältigungsstrategie lancierte 
Jugendgarantie lässt sich in diesem Sinne als ein Zugeständnis verstehen (vgl. Empfehlung des Rates 2013/C 120/01) und fördert zugleich immer deutlicher auch eine Reorientierung der autoritär-neoliberalen Kräfte auf moderat-neoliberale Akteur"innen zutage. Die autoritär-neoliberal dominierte Krisenbewältigungspolitik der Phase des reaktiven Staatlichkeitsausbaus bleibt in diesem Sinne umstritten und "gesellschaftlich wie intergouvernemental umkämpft« (Bieling 2013a, 93). Der reaktive Staatlichkeitsausbau in der Hochphase der Euro-Krise ist dementsprechend nicht hegemonial verankert, sondern verweist auf einen Modus nicht-hegemonialer Staatlichkeits(re)produktion im Zustand einer perpetuierten Hegemoniekrise in der Europäischen Union.

War bereits im Kontext der transatlantischen Finanzkrise die Infragestellung des Neoliberalismus angelegt, konnte sich trotz der erfolgreichen Rückeroberungsversuche durch neoliberale Akteur"innen aufgrund der autoritären Vermittlung ihrer Krisenbewältigungspolitik kein neuerlicher Zustand neoliberaler Hegemonie herauskristallisieren. Vielmehr zeigte sich in der EU eine verschärfte Legitimationskrise - als konkrete Ausdrucksform einer Hegemoniekrise (vgl. Kap. 2.5) -, die sich neben der Tendenz zur autoritären Krisenbearbeitung insbesondere in der »relative[n] und absolute[n] Verelendung der Bevölkerung und den relativen Niedergang in ihren grundlegen Reproduktionsweisen und Lebensumständen « (Solty \& Gill 2013, 85) zeige. Diese Verelendung lässt sich nicht nur an der großen (Jugend-)Arbeitslosigkeit fast überall in Europa sondern auch in den Troika-Programmen gegenüber den Programmländern ablesen (vgl. Heimberger 2015), die unter anderem auf Lohnsenkungen, Rentenkürzungen und den Rückbau sozialer Daseinsfürsorge zielte und »die materielle Grundlage der Demokratie europaweit [...] erodieren« (Wöhl 2016, 43) ließ. Letztlich erfolgten die >Rettungs<-Maßnahmen auf »Kosten der Lohnabhängigen« (Sablowski, Schneider \& Syrovatka 2018, 362ff.): Zunahme befristeter Beschäftigung und Leiharbeit, Abnahme der Tarifbindung, Reallohnverluste und Senkung der Lohnquote (vgl. auch Busch et al. 2012). Die verordnete Austeritätspolitik hat durch ihre Wirkungen letztlich gar die Krise im Süden Europas weiter verschärft (vgl. Engler \& Klein 2017; Heimberger 2016) und so beiläufig auch die materielle Voraussetzung im Sinne nötiger ökonomischer Zugeständnisse für eine mögliche Konsolidierung neoliberaler Hegemonie weiter erodieren lassen:

»Die Mehrheit der betroffenen Bevölkerungen ist klar gegen diese Art der Restrukturierung, sowohl was das undemokratische autoritär-technokratische Vorgehen der Troika angeht, als auch den Versuch, die Prämissen der bisherigen sozialstaatlichen Klassenkompromisse durch die Wettbewerbsanforderungen der Economic Governance zu ersetzen.«(Kompsopoulos 2017, 43)

Dabei wirkt der neue EU-Interventionismus, wie gezeigt wurde, nicht nur in seiner höchsten Eskalationsstufe im Rahmen der außerunionsvertraglichen Notstandsverfassung gegenüber den Mitgliedstaaten mit Refinanzierungsproblemen, sondern vermittelt sich auch in den Praxen der fortentwickelten EU-Wirtschafts- und Fiskalverfassung (inkl. Europe 2020) und schließt somit alle Mitgliedstaaten der EU ein. Das Ergebnis hiervon ist nach zehn Jahren Euro-Krise ein EU-weit 'verlorenes Jahrzehnt<, das sich unter anderem in unverändert hohen Einkommensungleichgewichten zeigt (vgl. Dauderstädt 2020; 2015). Aufgrund der Wucht, mit der die EUSA letztlich aber insbesondere 
in den Krisenländern >direkt intervenierte, und eines fehlenden demokratischen Interessensausgleichs (vgl. Wöhl 2016, 46) führten die "[g]esellschaftliche[n] Abstiegs- und Prekarisierungsprozesse, die mit dem autoritär-neoliberalen europäischen Krisenmanagement einhergingen, [...] insbesondere in Süd- und Osteuropa zu einer integrationsskeptischen Politisierung der EU« (Huke \& Wigger 2019, 212). Insofern tritt als weiterer Indikator »[e]ine Krise der Repräsentation und politischen Massenintegration « (Solty \& Gill 2013, 86; vgl. auch Armingeon, Guthmann \& Weisstanner 2015) hinzu. Hierbei ist insbesondere eine Schwächung der Integrationswirkung der traditionellen Großparteien $\mathrm{zu}$ verstehen, die sich unter anderem in einer europaweiten Krise der Sozialdemokratie (vgl. u.a. PROKLA 196) und dem Aufstieg populistischer, radikaler, extremistischer und teilweise neo-faschistischer Parteien am rechten Rand konservativer oder christdemokratischer Volksparteien zeigt (bspw. Goldene Morgenröte in Griechenland, Vox in Spanien, AfD in Deutschland, Lega Nord in Italien oder Rassemblement National in Frankreich). Fast überall in Europa ist der Verlauf der Euro-Krise mit solchen Wandlungsprozessen in den Parteiensystemen verbunden, die auch den Aufstieg neuer linker Parteien begünstigte (bspw. SYRIZA in Griechenland und Podemos in Spanien). Letztlich ist es allerdings die Multiskalarität der zivilgesellschaftlichen Vermittlungsformen, in der sich eine Ungleichzeitigkeit von Verschiebungen in den Kräfte- und Hegemonieverhältnissen ausdrückt, die einen umfassenden Bruch mit dem Neoliberalismus scheitern lässt.

Während sich in den südeuropäischen Krisenländern (für Spanien s. bspw. Huke 2016) demgemäß bereits früh durch entsprechende neue Protestkulturen, soziale Bewegungen aber auch durch Verschiebungen in den politischen Apparaten in Folge von Regierungsabwahlen und dem Aufstieg neuer Parteien (vgl. Kouki \& Fernandez Gonzalez 2016) Anzeichen einer umfassenden Hegemoniekrise zeigten, finden sich beispielsweise in Frankreich erst solche Ansätze, als in Folge der starken Verflechtungen mit den südeuropäischen Volkswirtschaften auch die französische Ökonomie ins Schwanken geriet (vgl. Oberndorfer 2016a, 569f.). Die französische Politik zur Krisenbewältigung setzte schließlich auch in Frankreich eine Massenmobilisierung in Gange (Stichwort: Arbeitsgesetz), die mit zu einer weiteren Erosion des tradierten Parteiensystems beitrug und in einer "weitreichenden Krise der Repräsentation« (Lindner 2017, 275; vgl. auch Amable \& Palombarini 2018) mündete, aus der nicht zuletzt der Front National gestärkt hervorging. Für Deutschland hingegen, das hält Demirović (2011b, 75f.) fest, hatte sich in Folge der Weltwirtschaftskrise vorerst keine umfassende Krisenkonstellation herauskristallisiert, die darauf schließen ließe, dass eine Ideologie- oder Hegemoniekrise vorläge. Auch die in Deutschland weit verbreitete "Staatsschuldensemantik « und der hierdurch gestützte »Austeritätsdiskurs« hat dies auf dem Höhepunkt der Euro-Krise noch einmal eindrücklich bestätigt. Auch wenn sich seit der ersten Diagnose Demirovićs in Deutschland mittlerweile die Kräfte- und Hegemonieverhältnisse einerseits durch die Radikalisierung von Akteur*innen am rechten Rand des national-konservativen Hegemonieprojekts und andererseits durch die Mobilisierung austeritätskritischer Kräfte, wie das Beispiel der Blockupy-Proteste zeigte (vgl. Mullis 2015), nicht zuletzt insbesondere im Kontext der Auseinandersetzung um die Euro-Krisenbewältigungspolitik wahrnehmbar gewandelt haben, bleibt es dennoch richtig, darauf hinzuweisen, dass die krisenbedingte Mobilisierungsfähigkeit in Deutschland im Vergleich zu anderen Re- 
gionen und Mitgliedstaaten der EU geringer ausfiel. Die »zeitlichen und inhaltlichen Divergenzen zwischen den Konflikten in den Überschuss- und den Defizitländern« erschwerten insofern insgesamt »die Herausbildung einer europäischen Protestbewegung« (Bieling, Haas \& Lux 2013, 244). Bieling, Haas \& Lux (2013, 244) sprechen zurecht von einer fragmentierten Konfliktdynamik im Euroraum, welche die Krisenkonstellation in der Europäischen Union kennzeichne. Gleichzeitig bleibt aber auch Oberndorfers (2016b, 569) Hinweis richtig, dass sich »die Hegemoniekrise der neoliberalen Integrationsweise in den Mitgliedstaaten zwar ungleichzeitig aber kombiniert entwickelt« habe. Die Nicht-Herausbildung einer europäischen Protestbewegung, die Ausdruck einer zivilgesellschaftlichen Krisenbearbeitung auf Ebene der EU-Staatlichkeit wäre, basiert schließlich auch auf unterschiedlichen Orientierungs- und Ausgangspunkten für die einsetzenden Protestdynamiken (vgl. Bieling, Haas \& Lux 2013, 241ff.). Dies äußert sich unter anderem in institutionellen Eigenarten und organisationspolitischen Traditionen beispielsweise in den europäischen Gewerkschaften, eine wichtige Akteursgruppe im Feld sozialer Proteste. Diese erschweren gemeinsame gewerkschaftliche Krisenproteste wie sie noch im Jahr 2012 kurzzeitig in Südeuropa zu beobachten waren (vgl. Hofmann 2018).

Die ungleichzeitige, wenn auch aufeinander bezogene Krise neoliberaler Hegemonie stellt sich demnach als eine fragmentierte Hegemoniekrise dar (vgl. Martin \& Wissel 2015). Steht auf der einen Seite der Medaille eine solch fragmentierte Krise der Hegemonie, lassen sich auf der anderen Seite Restbestände der vormals hegemonialen Konstellation vor der Krise identifizieren. Fragmentierte Hegemonie sei insofern »dadurch charakterisiert, dass in sozialer Perspektive nur einzelne subalterne gesellschaftliche Gruppen und Klassenfraktionen hegemonial eingebunden werden « und »ökonomische Zugeständnisse [...] nur selektiv [erfolgen].« (Ebd., 228) Sie stelle eine »hybride Herrschaftsform « dar, deren »Hybridität [...] sich sowohl in der Amalgamierung von hegemonialen mit nichthegemonialen Herrschaftsmechanismen als auch im Fortbestehen von Elementen vorhergehender hegemonialer Konstellationen niederschlagen [kann].« (Ebd., 229) Fragmentierte Hegemonie als Resultat der Euro-Krise äußert sich entsprechend in der andiskutierten und zunehmenden »innere[n] Fragmentierung in den Mitgliedstaaten und zwischen diesen« (ebd., 233), vor deren Hintergrund letztlich der kriseninduzierte EU-Staatlichkeitsausbau stattgefunden hat. Dabei deutet die Hybridität der nicht-hegemonialen Staatlichkeits(re)produktion in der jetzigen Konstellation darauf hin, dass es an einem hegemonialen Projekt mangele. Ohne dieses und einer ihr eingeschriebenen stragfähigen Gesellschaftsversion sei die derzeitige Krisenkonstellation allerdings nicht überwindbar (vgl. Buckel 2017, 36). Fragmentierte Hegemonie repräsentiert letztlich den von Gramsci beschriebenen Zustand eines Interregnums, in dem

»die herrschende Klasse den Konsens verloren hat, das heißt nicht mehr sührend dern einzig sherrschend ist, Inhaberin der reinen Zwangsgewalt, bedeutet das gerade, daß die großen Massen sich von den traditionellen Ideologien entfernt haben, nicht mehr an das glauben, woran sie zuvor glaubten usw. Die Krise besteht gerade in der Tatsache, daß das Alte stirbt und das Neue nicht zur Welt kommen kann [...].«(Gramsci 1991-2002, 354) 


\section{Parlamentarische Vermittlungsformen nicht-hegemonialer Staatlichkeits(re)produktion}

Die Hybridität der nicht-hegemonialen Staatlichkeits(re)produktion wird zudem parlamentarisch vermittelt, da sich gesellschaftliche Kräfteverhältnisse letztlich auch in parlamentarischen Repräsentationszusammenhängen verdichten. Bei der Herausbildung des EUSA-Krisennarrativs zeigte sich hierbei noch, dass sich das Europäische Parlament grundsätzlich hinter den exekutiven Deutungsmustern vereinen konnte. In einer als überfraktionelle Kompromissformel bezeichneten Entschließung stellten sich die Parlamentarier"innen 2010 somit prinzipiell hinter die Task-Force und die Kommission, griffen aber schon in diesem frühen Krisenstadium über diese hinaus und offerierten ein umfassenderes Integrationsprogramm, das sich insbesondere bereits an einem Ausbau der Fiskalunion orientierte. Nicht nur innerhalb der Politikempfehlungen vom Oktober 2010, sondern insbesondere auch im Sonderbericht zur >Finanz-, Wirtschaftsund Sozialkrise aus dem Juli 2011 deutet das Parlament ein fiskalpolitisches Reformprogramm an, dem allerdings - vor allem durch den (Europäischen) Rat - nur wenig Aufmerksamkeit geschenkt wurde. Im genannten Bericht vertritt das Europäische Parlament die Auffassung,

»dass die Vertiefung der wirtschaftlichen Integration Europas für die Sicherung der Stabilität der Eurozone sowie der Union insgesamt unerlässlich ist, was weitere Entwicklungen erfordert in Bezug auf die Vertretung der Eurozone nach außen, die Abstimmung mit qualifizierter Mehrheit über die Körperschaftssteuer, Maßnahmen zur Bekämpfung von Steuerhinterziehung und Steuerumgehung, mögliche gegenseitige Ausgabe von staatlichen Schuldtiteln und Eurobonds zur Förderung der Haushaltsdisziplin, die Kreditaufnahmekapazität der EU, ein besseres Gleichgewicht zwischen Wirtschafts-und Sozialpolitik, Eigenmittel für den EU-Haushalt sowie die Rolle der nationalen Parlamente und des Europäischen Parlaments« (EP 2011c, Rn. 102; Herv. J. G.)

Mit diesen Vorschlägen griffen die Parlamentarier"innen dabei auch bereits späteren Initiativen speziell der Kommission vorweg. Die eingeforderte Außenvertretung für die Eurozone (vgl. ebd., Rn. 27) sowie ein Eurozonensitz im Exekutivdirektorium des IWF (vgl. ebd., Rn. 28) zeigt, dass das EP bereits 2011 jene Forderungen formulierte, welche die Juncker-Kommission erst 2015 im Rahmen des >dritten Economic-GovernancePakets`(s.u.) in die legislativen Beratungen des Rates einbrachte. Ähnlich verhält es sich mit der Forderung nach einem europäischen Finanzminister (vgl. ebd., Rn. 12), die erst 2017 im Nikolauspaket von der Kommission aufgegriffen werden sollte. Fiskalpolitisch umfasst das EP-Leitbild die Schaffung von Eurobonds und eines nennenswerten Haushalts auf EU-Ebene. Die eingeforderten Eurobonds, die sich durch fast alle Stellungnahmen des Parlaments im Kontext der reaktiven Krisenbewältigungspolitik ziehen, würden demnach

»die Integration des Marktes für europäische staatliche Schuldtitel, geringere Kreditkosten, eine größere Liquidität, die Haushaltsdisziplin und Einhaltung des Stabilitätsund Wachstumspaktes begünstigen, koordinierte Strukturreformen fördern, die Kapitalmärkte stabiler machen und somit die Idee des Euro als weltweite sichere Anlage unterstützen können« (Ebd., Rn. 13). 
Die Kommission (2011a, 3) griff die Parlamentsforderung nach Eurobonds noch im November 2011 explizit auf und legte ihrerseits ein Grünbuch zur Einführung sogenannter Stabilitätsanleihen vor. In diesem werden durchaus differenziert verschiedene Optionen für die Schaffung gemeinsamer Anleihen diskutiert und jeweilige Vor- und Nachteile dargestellt. Insgesamt deutet sich dabei im Grünbuch eine positive Grundhaltung der Kommission gegenüber Stabilitätsanleihen an, mit denen ein Beitrag zur Krisenbewältigung und zur Verhinderung künftiger Krisen erreicht, die finanzielle Stabilität der Eurozone und die Markteffizienz gesteigert, eine Unterstützung der EZB-Geldpolitik geleistet und letztlich die Rolle des Euros im globalen Finanzsystem gestärkt werden könne (vgl. ebd., 5ff.). Zugleich verweist die Kommission aber auch auf eine Reihe von Voraussetzungen, an denen gearbeitet werden müsste, um Stabilitätsanleihen - egal ob in teilschuldnerischer oder gesamtschuldnerischer Haftung der Euro-Mitgliedstaaten - einführen zu können (vgl. ebd., 9ff.). In diesem Sinne sei letztlich auch der größten befürchteten Gefahr gemeinsamer Schuldtitel - dem `moral hazard - zu begegnen:

»Da sich die Emission von Stabilitätsanleihen negativ auf die Marktdisziplin auswirken könnte, wären wesentliche Änderungen des Rahmens für die wirtschaftspolitische Steuerung im Euroraum erforderlich. Zusätzliche Sicherheitsvorkehrungen zur Gewährleistung tragfähiger öffentlicher Finanzen wären vonnöten. Diese Maßnahmen müssten nicht nur auf die Haushaltsdisziplin, sondern auch auf die wirtschaftliche Wettbewerbsfähigkeit ausgerichtet sein [...].«(Ebd., 10)

Entsprechend deutete die Kommission in ihrem Grünbuch ein erweitertes Reformprogramm an, das in Tiefe und Verbindlichkeit über das Six-Pack hinausweist (vgl. ebd., 26ff.) und das letztlich als Voraussetzung einer möglichen Einführung von Stabilitätsbonds gelten kann.

Trotz Rückendeckung für das Grünbuch der Kommission durch das Europäische Parlament (2012a) lehnt die Mehrheit der mitgliedstaatlichen Regierungen Stabilitätsoder Eurobonds allerdings bis heute ab. Zwar führten sowohl der ECOFIN- (2011e) als auch der Europäische Rat (2012d) Aussprachen zum Grünbuch, allerdings gab es unter den Finanzminister*innen wie unter den Staats- und Regierungschefs »unterschiedliche Ansichten [...] zur künftigen Einführung von Eurobonds« (ebd., 2), wie Ratspräsident Van Rompuy der Presse nach der Ratstagung im Mai 2012 mitteilte. Besonders plastisch werden die polarisierenden Sichtweisen zu gemeinsamen Schuldtiteln derweil in den Äußerungen Angela Merkels, die öffentlich verlautbaren ließ, dass es keine Eurobonds geben werde, so lange sie lebe (vgl. Spiegel, 26.06.2012). Vielleicht auch deshalb liegt das im Grünbuch angekündigte >Follow-up zum mit dem Grünbuch angestoßenen Konsultationsprozess (vgl. KOM 2012a, 34) bis heute nicht vor.

Ähnlich verhielt es sich letztlich auch mit der zweiten vom Parlament vorgeschlagenen Säule notwendiger Schritte zur gestärkten Fiskalintegration, die eine Ausweitung der fiskalischen Kapazitäten auf Unionsebene vorgesehen hatte. Hierbei gelangte das EP (2011c, Rn. 99) in seinem Bericht zur >Finanz-, Wirtschafts- und Sozialkrise zu dem Schluss,

»dass die EU für die Verwirklichung der politischen Union und wirtschaftlichen Integration, die der Währungsunion entsprechen, [...] über ein ausreichendes Haushaltsvolumen 
verfügen muss, um den Euro dauerhaft zu festigen und für die Währung einen entsprechenden Haushaltsraum auf Ebene der politischen Organisation sicherzustellen, auf der sie ausgegeben wird« (Herv. J. G.).

Konkret bezieht sich das EP an dieser Stelle auf alte Berichte, die im Vorfeld der Verwirklichung der EWWU angefertigt wurden (Werner-Plan und McDougall-Bericht) und die darauf hingewiesen hätten, dass ein entsprechender Haushalt, um eine makroökonomische Steuerungswirkung entfalten zu können, 2,5 bis $10 \%$ des Bruttonationaleinkommens entsprechen sowie aus Eigenmitteln finanziert werden müsste (vgl. ebd., Rn. 100). Aber auch dieser Vorschlag der Parlamentarier*innen konnte in den kommenden Jahren nur wenig Einfluss auf die konkrete Politikgestaltung der EUSA nehmen.

Deutlich wird, dass die konkreten Vorschläge des Europäischen Parlaments über die exekutive Reformagenda am Ausgangspunkt des reaktiven EU-Staatlichkeitsausbaus hinausreichten. Sie deuten vor dem Hintergrund gesellschaftlicher Kräfteverhältnisse bereits eine Teilopposition gegenüber der offiziellen Krisenbewältigungspolitik der EUSA an, die sich auch im Gesetzgebungsprozess um die Six- und Two-Pack-Legislativakte herausstellen wird. Hierbei zeigte sich schließlich eine klassische links-rechts-Spaltung im Parlament. Bereits während der informellen Trilogverhandlungen ${ }^{27}$ zwischen Parlament, Rat und Kommission deutete sich an, dass das Parlament von seinen durch den Vertrag von Lissabon gestärkten Mitsprache- und Mitentscheidungsrechten im Bereich der Wirtschaftspolitik Gebrauch machen würde. Die Verhandlungen benötigten aufgrund der umfangreichen Änderungsvorschläge (vgl. EP 2011g; 2011h-l) und den teilweise unüberbrückbaren Positionen zwischen Parlament und Rat (vgl. u.a. EP 2011e \& 2013h) länger, als vom (Europäischen) Rat erwartet (vgl. ECOFIN 2011a, 6; ER 2011a, 9). Sie konnten erst im September 2011 mit den finalen Parlamentsbeschlüssen abgeschlossen werden. Hierbei votierten schließlich die linken Parlamentsfraktionen (S\&D, GUENGL) gegen die Verschärfung des SWP und die Etablierung eines erweiterten Sanktionsregimes für die Eurozone:

27 Als informeller Trilog wird die Verkürzung des ordentlichen EU-Gesetzgebungsverfahrens bezeichnet, bei dem statt der formalen Verfahrenswege direkt ein informeller Vermittlungsausschuss bestehend aus Europäischem Parlament, Rat und Kommission eingesetzt wird, der im formalen Verfahren eigentlich erst nach der 2. Lesung eines Gesetzgebungsvorschlags im Europäischen Parlament einberufen werden kann (formeller Trilog). Für eine allgemeine Kritik an diesem Verfahren s. bspw. Dauner \& Sohn (2015). In einer jüngsten Rechtsprechung des Cerichts der Europäischen Union (2018) wurde zudem die Intransparenz des Verfahrens kritisiert. 
Tabelle 25: Abstimmungskoalitionen im Rahmen der Six-Pack-Gesetzgebung

\begin{tabular}{|c|c|c|}
\hline Legislativakt & $\begin{array}{l}\text { Mehrheitliche } \\
\text { Zustimmung } \\
\text { durch }\end{array}$ & Ja|Nein|Enth. \\
\hline $\begin{array}{l}\text { Verordnung (EU) Nr. 1173/2011 über die wirksame Durch- } \\
\text { setzung der haushaltspolitischen Überwachung im Euro- } \\
\text { Währungsgebiet }\end{array}$ & ALDE, EPP & $352|243| 61$ \\
\hline $\begin{array}{l}\text { Verordnung (EU) Nr. 1174/2011 über Durchsetzungsmaß- } \\
\text { nahmen zur Korrektur übermäßiger makroökonomischer } \\
\text { Ungleichgewichte im Euro-Währungsgebiet }\end{array}$ & Grüne, ALDE, EPP & $395 \mid 64$ | 201 \\
\hline $\begin{array}{l}\text { Verordnung (EU) Nr. 1175/2011 über den Ausbau der haus- } \\
\text { haltspolitischen Überwachung und der Überwachung und } \\
\text { Koordinierung der Wirtschaftspolitiken }\end{array}$ & ALDE, EPP & $356|265| 35$ \\
\hline $\begin{array}{l}\text { Verordnung (EU) Nr. 1176/2011 über die Vermeidung und } \\
\text { Korrekturmakroökonomischer Ungleichgewichte }\end{array}$ & $\begin{array}{l}\text { S\&D, Grüne, ALDE, } \\
\text { EPP }\end{array}$ & $550|57| 24$ \\
\hline $\begin{array}{l}\text { Verordnung (EU) Nr. 1177/2011 über die Beschleunigung } \\
\text { und Klärung des Verfahrens bei einem übermäßigen Defizit }\end{array}$ & ALDE, EPP & $\begin{array}{c}361|270| 35 \\
\text { (Konsultation) }\end{array}$ \\
\hline $\begin{array}{l}\text { Richtlinie 2011/85/EU über die Anforderungen an die haus- } \\
\text { haltspolitischen Rahmen der Mitgliedstaaten }\end{array}$ & $\begin{array}{l}\text { Grüne, ALDE, EPP, } \\
\text { ECR }\end{array}$ & $\begin{array}{l}442|185| 40 \\
\text { (Konsultation) }\end{array}$ \\
\hline
\end{tabular}

Quelle: Eigene Zusammenstellung auf Grundlage von Cencig \& Sabani (2017)

Letztendlich wurden die Verordnungen (EU) Nr. 1175/2011 und (EU) Nr. 1177/2011, als Kernverordnungen des reformierten SWP, ebenso wie der erweitere fiskal- und wirtschaftspolitische Durchsetzungsmechanismus (VO (EU) Nr. 1173/2011) von einer liberalkonservativen Parlamentsmehrheit beschlossen. Kann sich demgegenüber die Etablierung eines Verfahrens zur Vermeidung und Korrektur makroökonomischer Ungleichgewichte (VO (EU) Nr. 1176/2011) insgesamt auf eine breitere Unterstützung auch links von ALDE und EPP stützen, wurde hingegen die Verordnung (EU) Nr. 1174/2011, die die Korrektur- und Sanktionsmaßnahmen im neuen Verfahren bei makroökonomischer Ungleichgewichte kodiert, außer von Liberalen und Konservativen nur von den Grünen mitgetragen. Einen umfassenden Austeritätspolitikkonsens oder die Vereinigung der Parlamentarier*innen hinter dem Herrschaftsmodus der (Selbst-)Disziplinierung lässt sich im Europäischen Parlament jedenfalls nicht feststellen. Dem EP kommt im Rahmen der EU-Staatlichkeit demnach die wichtige Rolle eines teiloppositionellen Mittlers $\mathrm{zu}$, der sich anhand der klassischen politischen links-rechts-Achse formiert, und insofern auch hegemonieanalytisch betrachtet eine nicht zu unterschätzende Rolle bei der Herausbildung und Sicherung einer hegemonialen Konstellation zukommt.

Auch im Rahmen des Two-Packs wird das Parlament einer solchen Zuschreibung gerecht und ist retrospektiv betrachtet maßgeblich an der diskursiven Vorbereitung der partiellen Reorientierungen der ab 2012 langsam einsetzenden Phase des inkrementellen EU-Staatlichkeitsausbaus beteiligt. In Bezug auf das Two-Pack war das Parlament bemüht, die beiden Textvorschläge umfangreich durch Änderungsanträge mitzugestalten. In den Berichten vom Mai 2012 von Jean-Paul Gauzès (EPP) zur späteren Verordnung (EU) Nr. 472/2013 finden sich derer 71 (vgl. EP 2012d) und von Elisa Ferreira (S\&D) zur späteren Verordnung (EU) Nr. 473/2013 gar 81 (vgl. EP 2012e). Insbesondere 
im Ferreira-Bericht finden sich viele weitgehende Änderungsvorschläge, die sich zum Beispiel in sehr ausführlichen Vorschlägen zur Ergänzung der entsprechenden Artikel für die Wirtschaftspartnerschaftsprogramme (vgl. ebd., 45ff.), der Einfügung von Bestimmungen zum wirtschaftspolitischen Dialog (vgl. ebd., 52), dem Vorschlag einer europäischen Schuldenbehörde (vgl. ebd., 54f.) und eines europäischen Tilgungsfonds (vgl. ebd., 43f.) sowie eines eingeforderten Fahrplans für die Lancierung von Stabilitätsbonds (vgl. ebd., 42) zeigen. Der Gauzès-Bericht hingegen ist weniger ambitioniert. So begrüßt der Berichterstatter

»im Großen und Ganzen den Vorschlag der Kommission, [...] dass Mitgliedstaaten, deren Währung der Euro ist, einer verstärkten Überwachung unterliegen, wenn sie von einer gravierenden finanziellen Schieflage betroffen oder bedroht sind. Wir sollten rasch zu einer normalen Situation zurückkehren und die anderen Mitgliedstaaten der Eurozone vor möglichen nachteiligen Auswirkungen schützen.« (EP 2012d, 47)

Die unterschiedliche Herangehensweise und der Umfang der Änderungswünsche verweisen auf die bereits bekannte Trennungslinie innerhalb des Europäischen Parlaments. Waren schon während der Six-Pack-Diskussion links-rechts Friktionen sichtbar geworden, traten diese auch bei den Two-Pack-Beratungen offen zu Tage. In einem >Background-Paper< des Parlaments heißt es:

»The stwo pack regulations took 15 months to finalise, i.e. above the 9-10 month average for economic governance and financial services legislation over the past 3 years. This delay was primarily due to a shift in the political climate from the date the rules were first proposed to when they were ultimately adopted. This change saw the left of centre become increasingly critical of the sausterity only< approach to deal with the Eurozone crisis. [...] The main bone of contention was over whether the stwo pack s should be restricted to rules for preventing excessive deficits and enforcing reforms in >programme countries or whether it should also include mechanisms for solidarity among countries and public investment leading to their economic convergence. » (EP 2013e, 5; Herv. J. G.; vgl. Ferreira-Bericht: EP 2012e)

Die Mehrheitsverhältnisse in jenem Parlament, das eigentlich seit Jahrzehnten von einer informellen »Großen Koalition« aus Sozialdemokrat*innen und Konservativen sowie partiell von der liberalen und der grünen Fraktion getragen wird, waren wie bereits beim Six-Pack auch im Jahre 2012 unklar. ${ }^{28}$ Das erste Trilog-Treffen am 11. Juli stand unter diesen Vorzeichen und offenbarte schließlich weitere Verhandlungsblockaden. Erst am 29. November schien eine Einigung in greifbarer Nähe. Für die zypriotische Ratspräsidentschaft stellte der Kompromisstext vom 29.11.2012 das am besten zu erreichende Ergebnis dar (vgl. ECOFIN 2012a, 6). Aus Sicht des Rates ist diese Bewertung sicherlich nicht von der Hand zu weisen, zeigen die entsprechenden Textsynopsen (vgl. ECOFIN 2012c \& ECOFIN 2012d) doch, dass die Verhandlungsmacht des Europäischen

28 In der 6. Legislaturperiode (2004-2009) stimmten die sozialdemokratische und die konservative Fraktion in knapp 70 \% der Fälle gemeinsam ab; in der 7. Legislaturperiode (2009-2014) erhöhte sich dieser Wert weiter, sodass bei nahezu dreiviertel der Abstimmungen beide Fraktionen gemeinsam abstimmten (vgl. Alcidi, Giovannini \& Peidrafita 2014, 59). 
Parlaments - und hier insbesondere seiner linken Fraktionen - an vielen Stellen nicht ausreichte, um substanzielle Änderungen am Two-Pack zu erreichen. Von kleineren Erfolgen abgesehen, steht diesen insbesondere die Ablehnung der im Ferreira-Bericht vorgeschlagenen Maßnahmen (Stabilitätsbonds, Tilgungsfonds und Schuldenbehörde) entgegen. Im Bericht an den ECOFIN-Rat hieß es: „Chapter 3a new in Ferreira's report, on the Establishment of a roadmap for enhanced economic policy coordination, a growth facility and a framework for enhanced debt issuance<, is out « (ECOFIN 2012b, 6). Der stattdessen ausgehandelte Formelkompromiss lautete:

»As part of the global agreement, the Commission announced that it could make a declaration on its plans to implement proposals foreseen in the Communication sa blueprint for a deep and genuine EMU < published on 28 November 2012. The European Parliament indicated that its support to the global agreement will depend on it concurring with the Commission declaration.«(Ebd., 2)

Der ECOFIN-Rat billigte am 4. Dezember den im Trilog-Verfahren erreichten Kompromiss (vgl. ECOFIN 2012e). Anders das EP: Auf Antrag sozialdemokratischer, liberaler und grüner Parlamentarier*innen wurde das Trilogverfahren Mitte Dezember aufgrund der fehlenden Kompromissbereitschaft von Rat und Kommission offiziell suspendiert:

»In negotiations, some member states then proved particulary reluctant to include any reference to setting up a debt redemption fund and the Commission was not prepared to present a proposal for one by the end of 2013. Other issues to do with using the stwo pack to promote growth and investment were also contested by member states. (EP 2013e, 5)

Erst im Februar 2013 konnte ein weiterer Kompromiss erreicht werden, dem auch das Europäische Parlament schlussendlich zustimmte. Hierbei sagte die Kommission unter anderem zu, bis Ende Juli 2013 einen Bericht vorzulegen, in dem dargestellt werden solle, wie ein Ausgleich zwischen "produktiven öffentlichen Investitionen« und dem "Ziel fiskalischer Disziplin« gestaltet werden könne (vgl. ECOFIN 2013a, 2). Weiterhin offerierte sie, in zukünftigen Dokumenten verstärkt Bezug auf die weiterführenden Vorschläge der Parlamentarier*innen zu nehmen und eine Expert*innengruppe einzurichten, die die möglichen Vorzüge, Risiken, Voraussetzungen und Hürden einer teilweisen Ersetzung der mitgliedstaatlichen Emission von Staatspapieren durch eine gemeinsame Emission analysieren und hierzu einen Bericht bis März 2014 erarbeiten solle (vgl. ebd.; vgl. auch EP 2013e, 5). Die Ratstagung vom 5. März begrüßte diese Einigung (vgl. ECOFIN 2013b), woraufhin das informelle Trilogverfahren mit der Verabschiedung des Standpunktes des Europäischen Parlaments am 12. März 2013 (vgl. EP 2013b; EP 2013c; vgl. auch ECOFIN 2013c; ECOFIN 2013d) und dem finalen Beschluss der beiden Verordnungen im ECOFIN-Rat im Mai 2013 offiziell beendet werden konnte.

Am Ende fand sich im Europäischen Parlament, trotz aller im Trilogverfahren sichtbar gewordenen Differenzen und Konflikte, eine breite Mehrheit für die beiden Legislativakte (528 Stimmen für VO (EU) Nr. 472/2013 und 526 Stimmen für VO (EU) Nr. 473/2013). Die »Two-Pack-Koalition« umfasste dabei die Mehrheit der Abgeordneten von S\&D, ALDE, EPP und den Grünen (vgl. Cencig \& Sabani 2017, 12). Dass, anders als noch 
im Six-Pack, auch große Teile der sozialdemokratischen Fraktion den Vorschlägen letztlich zustimmten, lag sicherlich nicht zuletzt auch an den von Ferreira erreichten - wenn auch im Vergleich zu den sehr umfassenden Vorschlägen überschaubaren - Änderungen und insbesondere den weiterführenden Zusicherungen seitens der Kommission. Zugleich fanden Roger, Otjes \& van der Veer $(2017,576)$ in ihrer Interview-Studie ein weiteres, taktisch motiviertes Argument für die breite Parlamentszustimmung, das im Kern auf die durchaus erfolgreiche Durchsetzung des >Rettungsdispositivs $<$ hinweist, das nach wie vor präsent scheint:

»They needed to cooperate in order to offer a unified front vis-à-vis the Council. The pro-European parties of the left and right, inside and outside of the Grand Coalition accepted the compromise in order to ensure the stability of the eurozone, a political project that is on the long-term more important to them than the short-term policy goals they were divided over.«

Augenscheinlich ist aber zugleich, dass beim Two-Pack eine noch kritischere Auseinandersetzung mit dem dominierenden Krisennarrativ der EUSA stattgefunden hatte als zuvor beim Six-Pack. Allein die Tatsache, dass durch den Ferreira-Bericht so substanzielle Änderungen an den Verordnungstexten vorgeschlagen wurden, die nicht weniger als eine an vielen Stellen grundsätzliche Revision der bis dato herrschenden Krisenbewältigungspolitik bedeutet hätte, deutet auf ein zunehmendes Spannungsverhältnis hin. Dass am Ende dieser parlamentarische Kampf um alternative Politikansätze im Kontext des Two-Packs scheiterte, zeigt allerdings ebenfalls, dass die apparatlichen Kräfteverhältnisse im EU-Staatsapparate-Ensemble es nicht gestatteten, diese schlussendlich auch durchsetzen zu können:

»Die Umkehrung der Kette von Ursache und Wirkung gewinnt derzeit mehr und mehr Anhänger im Süden Europas und sogar bei Ökonomen. Die Weltsicht aber, dass Schuldenabbau und Konsolidierung die aktuelle Wirtschaftskrise verursachten, will Barroso nicht stehen lassen. >Diese Krise mit ihren Problemen ist nicht ein Ergebnis deutscher Politik oder Fehler der EU. Sie ist Ergebnis exzessiver Ausgabenpolitik, mangelnder Wettbewerbsfähigkeit und unverantwortlichen Handelns auf den Finanzmärkten« (Welt, 04.05.2013),

stellte der Kommissionspräsident im Mai 2013 noch einmal öffentlich klar und verteidigte damit das altbekannte Austeritäts- und Wettbewerbsfähigkeitsmantra. Auch wenn das Two-Pack aufgrund der Einbindung der außerunionsvertraglichen Rettungsschirmarchitektur in den Unionsrechtsrahmen inhaltlich bereits auf eine gewisse Reflexionsbereitschaft hingeweisen hatte, verharrten Rat und Kommission trotz zunehmender Kritik demnach vorerst weiterhin gedanklich und ideologisch im Modus der reaktiven Krisenbewältigung. Für ihren autoritär-neoliberalen Krisenbewältigungsansatz genossen sie dabei zu Beginn des Jahres 2013 im Europäischen Parlament zwar auch weiterhin ausreichend Unterstützung, es stand ihnen aber eine deutlich wahrnehmbare Opposition gegenüber. Diese speiste sich aus einer Gruppe von Abgeordneten der gesellschaftlichen Linken beziehungsweise einem links-liberalen Milieu, welche die Krisenbewältigungspolitik nicht (mehr) vorbehaltlos mittragen wollte. Nicht zuletzt hierdurch deutet sich langsam aber immer sichtbarer eine einsetzende Reflexionsphase der 
234 EU-Staatlichkeit zwischen Ausbau und Stagnation

bis dato dominierenden Krisenbewältigungspolitik an. In diesem Sinne verweist der Gesetzgebungsprozess des Two-Packs letztlich auch auf den sich andeutenden Wechsel von der Phase des reaktiven zur Phase des inkrementellen Staatlichkeitsausbaus, der sich, beginnend im Sommer 2012, langsam vollzog. 


\section{Inkrementeller Staatlichkeitsausbau in der sich abschwächenden Euro-Krise}

Noch im Frühjahr 2012 schien es aufgrund einer erneuten Krisenzuspitzung - weiterhin keine Beruhigung auf den Märkten für Staatsverschuldungstitel, Verhandlungen um ein zweites Kredit- und Maßnahmenpaket für Griechenland, Zuspitzung der spanischen Bankenkrise und der aufkommende Krisenfall in Zypern - erforderlich, eine erweiterte Reformagenda zu entwickeln: »Um Wähler und Anleger zu überzeugen, war es wesentlich geworden, zu skizzieren, wo das Euro-Währungsgebiet in zehn Jahren stehen wird, und wie wir die strukturellen Schwächen, die durch die Krise deutlich wurden, zu beheben gedachten.«(Van Rompuy 2013a, 7f.; Herv. J. G.) Nicht nur die Anerkennung funktionaler Defizite sondern insbesondere auch die bereits von Beginn an und immer offensiver vorgetragene Kritik an der reaktiven Krisenbewältigung schienen an dieser Stelle in das Bewusstsein gerückt zu sein. Um der beschriebenen Aufgabe gerecht $\mathrm{zu}$ werden, beauftragten die Staats- und Regierungschefs Van Rompuy - in enger Kooperation mit den Präsidenten der Kommission, der EZB und der Euro-Gruppe - während eines informellen Abendessens mit der Ausarbeitung von Vorschlägen zur Stärkung der Währungsunion, mit dem Ziel, die EWWU auf eine neue Stufe zu heben (vgl. ER 2012d, 2; Euro-Gipfel 2011b). Die Umsetzung des durchaus ambitionierten, später als Vier-Präsidenten-Berichts bezeichneten, Reformpapieres scheiterte allerdings letztlich. Stattdessen leitete EZB-Präsident Draghi mit seiner vielbeachteten Londoner Rede im Sommer 2012 (»whatever it takes«), an der sich das oben beschriebene OMT-Programm der EZB anschloss, einen Wendepunkt in der Krisenchronologie ein, in dessen Folge die krisengetriebene Reformdynamik merklich abnahm. Die mit der Rede und dem OMT einsetzende Beruhigung auf den Märkten für Staatsanleihen wurde unterstützt durch die EuGH-Entscheidung zum Rettungsschirm. In ihr urteilten die Luxemburger Richter*innen im November 2012, dass die Einrichtung des permanenten Rettungsschirms ESM mit dem Unionsrecht vereinbar sei (vgl. EuGH 2012) und beendete hierdurch zu einem gewissen Grad die anhaltende Diskussion über die Rechtmäßigkeit einer der wichtigsten Maßnahmen der Krisenbewältigungspolitik. Parallel hierzu befanden sich die Verhandlungen zwischen Europäischem Parlament, Rat und Kommission über die finale Ausgestaltung des Two-Packs auf der Zielgeraden. 2013 verließ mit Irland das 
erste Land den Rettungsschirm. Portugal und Spanien sollten 2014 folgen. So lässt sich insgesamt ab Mitte 2012, spätestens aber seit Anfang 2013 ein schleichender Wandlungsprozess nachzeichnen, der den Politikmodus reaktiver Krisenbewältigungspolitik langsam ablösen sollte. Die akute Euro-Krise schien vorüber. Die Kommission (2013a, 3) ging für das Jahr 2014 schließlich sogar von einer leichten wirtschaftlichen Erholung aus, auch wenn diese nach ihrer Ansicht noch moderat ausfallen werde und fragil sei. Der Höhepunkt der Krise sei überschritten, so die Kommission (2013a, 3), auch wenn es noch bis 2016 dauern sollte, bis sich in allen Volkswirtschaften der Eurozone die Wirtschaft wieder erholte und nicht nur in deren Durchschnitt ein Wachstum generiert wurde (vgl. EFA 2017a, 5f.).

\subsection{Das Scheitern der erweiterten Reformagenda 2012/13}

Nach der Beauftragung durch die Staats- und Regierungschefs stellte Van Rompuy auf der Ratstagung im Juni 2012 einen ersten Bericht vor, der nach eigenen Aussagen »kein fertiger Plan sein [soll], sondern [...] vielmehr die Bausteine fest[legt] und [...] eine Arbeitsmethode vor[schlägt].«(Van Rompuy 2013b, 44) Der Bericht entwickele nicht weniger als »die Vision einer WWU im Dienste von Stabilität und anhaltendem Wohlstand«, so der Ratspräsident (ebd.). Van Rompuy präsentierte schließlich vier wesentliche Bausteine zur Erreichung dieser >Vision $<$. Möchte man sie mit Schlagworten versehen, ließe sich sagen, dass sie auf die Etablierung der Banken- und der Fiskalunion, die Stärkung der Wirtschaftsunion sowie schließlich einer politischen Union zielen. Neben die ins bisherige Bild passenden Verschärfungen von Haushaltsregeln (bspw. Genehmigungsvorbehalt gegenüber Staatsanleiheemissionen bei Überschreitung der Maastricht-Kriterien) schlägt der Ratspräsident auf »mittlere Sicht« weiterführend aber sogar gemeinsame Schuldtitel und eine gesamtschuldnerische Haftung (einschränkend: »solange ein robuster Rahmen für Haushaltsdisziplin und Wettbewerbsfähigkeit vorhanden ist«; ebd.) vor. Erstmals wurde somit eine Kernforderung alternativer Krisenbewältigungsansätze (Stichwort Eurobonds) und des Europäischen Parlaments in einem Papier des Europäischen Rats aufgegriffen. Weiter heißt es:

»Eine vollwertige Fiskalunion setzt voraus, dass auf der europäischen Ebene eine stärkere Kapazität aufgebaut wird, die zum Management der wirtschaftlichen Verflechtungen in der Lage ist, und dass letztlich im Euro-Raum eine haushaltspolitische Einrichtung, so etwas wie ein Finanzministerium, geschaffen wird.« (Ebd.; Herv. J. G.)

Beim Thema Fiskalunion ist der vorläufige Bericht in seinen Vorschlägen am weitreichendsten. Van Rompuys Ausführungen zur Wirtschafts- und politischen Union bleiben hingegen blass:

»Eine stärkere wirtschaftliche Integration ist [...] erforderlich, um die Koordinierung und die Konvergenz in verschiedenen Politikbereichen zwischen den Ländern des Euro-Raums zu fördern, Ungleichgewichte zu beheben und um Erschütterungen abzufedern und in einer globalisierten Weltwirtschaft bestehen zu können.« (Ebd.) 
Mit konkreten politischen Maßnahmen abseits bereits beschlossener werden diese Äußerungen allerdings nicht weiter untermauert. Es findet sich lediglich der Hinweis auf eine notwendige »Stärkung der politischen und der administrativen Kapazitäten von nationalen Institutionen und zur Förderung der nationalen Eigenverantwortung für Reformen« (ebd.). Im Rahmen der politischen Union bleibt schließlich lediglich das Bekenntnis, das Europäische Parlament und die mitgliedstaatlichen Parlamente in die Beschlussfassungsprozesse besser einbinden zu wollen (vgl. ebd.).

Dass Van Rompuy mit seinen Vorschlägen nicht bei allen Staats- und Regierungschefs vollen Rückhalt genoss, ${ }^{1}$ wird an den Schlussfolgerungen der Juni-Ratstagung deutlich. Darin heißt es:

»Nach einem offenen Gedankenaustausch, in dem unterschiedliche Auffassungen deutlich gemacht wurden, wurde der Präsident des Europäischen Rates gebeten, [...] einen Fahrplan mit Terminvorgaben für die Verwirklichung einer echten Wirtschafts- und Währungsunion auszuarbeiten« (ER 2012c, Rn. 4; Herv. J. G.).

Bevor Van Rompuy einen solchen Fahrplan schließlich auf der Dezembertagung den Staats- und Regierungschefs vorlegte, präsentierte er auf der Oktoberratstagung erneut einen Zwischenbericht, der "sich weitgehend auf die Ideen und Vorschläge [stützt], die bei den bilateralen Treffen mit sämtlichen EU-Mitgliedstaaten und mit dem Europäischen Parlament und seinem Präsidenten [...] vorgebracht worden sind.« (Van Rompuy 2013c, 53) Im Gegensatz zum ersten fällt der neue Zwischenbericht an einigen Stellen hinter der im Juni skizzierten »Vision« zurück. So ist statt von einem europäischen Finanzministerium nur noch von der "Schaffung einer Finanzverwaltungsfunktion mit klar abgegrenzten fiskalischen Verantwortlichkeiten« (ebd., 55) die Rede und aus der »mittleren Sicht« zum Aufbau einer umfassenderen Fiskalunion wird nun eine »Option «, die »langfristig« zu prüfen sei (vgl. ebd., 54). Diese Neudefinition des Zeithorizonts bezieht sich insbesondere auf die Schaffung einer Fiskalkapazität und die Ausgabe von gemeinsamen Schuldtiteln. Neben einer allgemeinen Funktion zur Abmilderung von Schocks, die einer solchen Fiskalkapazität - langfristig - zugedacht werden könne, wird eine weitere Funktionszuschreibung diskutiert, bei der die Fiskalkapazität dem Ziel diene könne, »strukturelle Reformen zur Verbesserung der Wettbewerbsfähigkeit und des Potenzialwachstums in Bezug auf einen integrierten wirtschaftspolitischen Rahmen [...] zu erleichtern.« (Ebd., 55) An dieser Stelle ergibt sich eine interessante Erweiterung zum Juni. Vorgeschlagen wird, Strukturreformen in Mitgliedstaaten zu fördern, wozu »die Mitgliedstaaten des Euro-Währungsgebiets mit den EU-Organen individuelle Vereinbarungen vertraglicher Natur [...] schließen« (ebd.) sollen. Erstmals findet sich somit eine Art »Light-Version« des von Merkel erstmals 2011 vorgeschlagenen >Pakts für Wettbewerbsfähigkeit in offiziellen EUSA-Dokumenten wieder, der damals nicht durchsetzbar war und im »weicheren« Euro-Plus-Pakt mündete (vgl. FAZ, 
01.03.2011). ${ }^{2}$ Der Zwischenbericht aus dem Oktober 2012 zeichnet somit eine interessante Wendung nach: War der Ausgangsbericht vom Juni noch von dem Ziel beseelt, eine Vision für die EWWU-Vertiefung zu offerieren, sind die ursprünglichen »visionären« Vorschläge nach den Konsultationen der mitgliedstaatlichen Regierungen bereits im Oktober deutlich zurückhaltender formuliert. Diese Entwicklung wird sich bis zur Vorlage des endgültigen Berichts noch weiter fortsetzen und deutet bereits eine aufkommende politische Blockade an. Statt der Zehn-Jahres-Vision verbleibt am Ende ein schmales Aktionsprogramm, das lediglich den >Wegく zu einer echten Wirtschafts- und Währungsunion skizziert.

Der finale Fahrplan gliedert sich an den inhaltlichen Parametern des ersten Zwischenberichts sowie einer dreistufigen Zeitplanung: In der ersten Stufe (2012/13) gibt er neben Fortschritten in Bezug auf die Bankenunion lediglich den Abschluss der zum damaligen Zeitpunkt bereits laufenden Gesetzgebungsmaßnahmen (Two-Pack) und die vollständige Umsetzung bereits beschlossener Maßnahmen (Six-Pack \& SKS-Vertrag) als Ziel vor (vgl. Van Rompuy et al. 2012, 4). In den Jahren 2013 und 2014 (Stufe 2) wird die

»Schaffung eines Mechanismus für eine stärkere Koordinierung, Konvergenz und Durchsetzung der strukturpolitischen Maßnahmen, der auf Vereinbarungen vertraglicher Natur zwischen den Mitgliedstaaten und den EU-Organen über die von den Ländern zugesagten politischen Maßnahmen und über deren Umsetzung beruht« (ebd.),

angestrebt. Alle weiteren Maßnahmen werden schließlich auf die Zeit »nach 2014« (Stufe 3) geschoben. Hierzu zählt auch die "Schaffung einer genau umrissenen und beschränkten Fiskalkapazität« (ebd., 5; Herv. J. G.).

»[F]erner [könnte diese Stufe] auf einem zunehmenden Maß an gemeinsamer Beschlussfassung in Bezug auf die einzelstaatlichen Haushalte und einer verstärkten Koordinierung der Wirtschaftspolitik, insbesondere in den Bereichen Besteuerung und Beschäftigung, auf der Crundlage der nationalen Beschäftigungspläne der Mitgliedstaaten aufbauen.«(Ebd.)

Die Antwort auf die Frage, was eine »echte« Wirtschafts- und Währungsunion schlussendlich auszeichne, bleibt der abschließende Bericht allerdings schuldig. Statt eine wirkliche Langfristperspektive und ein Leitbild zu präsentieren, propagiert der sogenannte >Vier-Präsidenten-Bericht< eine perpetuierte Orientierung auf eine inkrementelle Fortentwicklung des Status quo des reaktiven Staatlichkeitsausbaus in der EuroKrise. Auch wenn die vom Parlament befeuerte Debatte um eine Fiskalunion in der Diskussion der Berichte durchaus einfließen konnte, was das EP (2012c) ausdrücklich begrüßte, bleibt am Ende doch am ehesten zu konstatieren, dass diese erneut durch die Mitgliedstaaten zurückgewiesen wurde.

Die Kommission, deren Präsident bei der Erarbeitung des Fahrplans und der beiden Zwischenberichte beteiligt war, schien sich diese Blockade im Europäischen Rat zu 
Nutze zu machen, um im interinstitutionellen Kampf um die Deutungshoheit im EUStaatsapparate-Ensemble Boden gut zu machen. So jedenfalls lässt sich die Vorlage des kommissionseigenen »Konzept[s] für eine vertiefte und echte Wirtschafts- und Währungsunion« (KOM 2012a) interpretieren. In der Ende November, nur wenige Tage vor Ratstagung, auf der Van Rompuy seinen Fahrplan präsentierte, vorgelegten Mitteilung griff die Kommission die unter den vier Präsidenten diskutierten und in den Zwischenberichten konkretisierten Parameter auf, bettete sie aber überdies in ein umfassenderes Verständnis notwendig erscheinender Vertiefungsschritte ein:

»Wir brauchen eine umfassende Vision für eine vertiefte und echte WWU, die eine starke und stabile Architektur in finanzieller, steuerlicher, wirtschaftlicher und politischer Hinsicht fördern und Stabilität und Wohlstand sichern kann. In einer solchen vertieften und echten WWU sollten alle wirtschafts- und fiskalpolitischen Entscheidungen der Mitgliedstaaten Gegenstand einer umfassenden Koordinierung, Billigung und Überwachung aufeuropäischer Ebene sein. Dies sollte Besteuerung und Beschäftigung wie auch andere Politikbereiche einschließen, die für die Funktion der WWU entscheidend sind. Eine solche WWU sollte auch durch eine autonome und angemessene fiskalpolitische Kapazität untermauert werden, damit aus dem Koordinierungsprozess resultierende politische Entscheidungen wirksam unterstützt werden können. Ein entsprechender Teil der Entscheidungen hinsichtlich Einnahmen, Ausgaben und Schuldtitelemissionen sollte gemeinsamen Entscheidungen und einer gemeinsamen Durchführung auf WWU-Ebene unterliegen.«(Ebd., 13; Herv. J. G.)

Dieser »Vision« liegt eine Problembeschreibung zugrunde, nach der nicht nur die fehlende Einhaltung des SWP als Krisenursache angesehen wird, sondern auch der institutionelle Aufbau der EWWU ein Grund für den Krisenausbruch gewesen sei (vgl. ebd., 2).

Ambitionierter als der Vier-Präsidenten-Bericht möchte das Kommissionskonzept bereits innerhalb von sechs bis 18 Monaten - neben Fortschritten in Bezug auf die Bankenunion - die vollständige Umsetzung der bereits beschlossenen Reformmaßnahmen, eine rasche Einigung auf den nächsten Mehrjährigen Finanzrahmen, die Investitionstätigkeit durch eine Reinterpretation des SWP ankurbeln, die Vorabkoordinierung stärken, ein Instrument für Konvergenz und Wettbewerbsfähigkeit etablieren sowie schließlich erste Schritte hin auf eine gemeinsame Außenvertretung unternehmen.

In mittelfristiger Perspektive - 18 Monate bis fünf Jahre - spricht sich die Kommission für die weitere Verschärfung der Haushaltskontrollen im Sinne weitreichender Interventionsrechte aus, wozu aus ihrer Sicht allerdings eine Vertragsänderung notwendig erscheine (vgl. ebd., 31). Weiterhin schlägt sie eine eigene Fiskalkapazität, einen Schuldentilgungsfonds sowie Euro-Anleihen vor, die zusammengenommen in langfristiger Perspektive (mehr als fünf Jahre) zu einer »voll integrierten Fiskal- und Wirtschaftsunion« führen sollen:

»Mit der Verwirklichung einer voll integrierten Fiskal- und Wirtschaftsunion wäre die letzte Stufe der WWU erreicht. Dies würde als Endziel die Schaffung einer politischen Union mit einer geeigneten Bündelung der Hoheitsrechte mit sich bringen, die über eine ei- 
gene Fiskalkapazität in Form eines zentralen Budgets und über eigene Mechanismen verfügt, die es ihr unter bestimmten genau definierten Voraussetzungen erlauben, haushalts- und wirtschaftspolitische Entscheidungen bei ihren Mitgliedern durchzusetzen.«(Ebd., 36; Herv. J. G.)

Um der politischen Union demokratische Legitimität und ausreichende Rechenschaftspflicht zu verleihen, schlägt die Kommission Maßnahmen in Richtung auf eine stärkere Parlamentarisierung bisheriger Verfahren vor. Sie forderte beispielsweise einen stärkeren Einbezug des Europäischen Parlaments in Fragen des wirtschafts- und fiskalpolitischen Regierens, zugleich aber auch die Sicherstellung eines angemessenen Einbezugs der mitgliedstaatlichen Parlamente zur Legitimierung des mitgliedstaatlichen Handelns im (Europäischen) Rat; schließlich müsse im Einklang mit den bestehen Verfahren auch die Zusammenarbeit der Parlamente untereinander verstärkt werden (vgl. ebd., 40). Zur Erreichung einer höheren Legitimität des derzeitigen Handelns strebe die Kommission bereits kurzfristig Verfahrensänderungen an, die sich beispielsweise im Einbezug des EP in die Diskussionszusammenhänge des Europäischen Semesters darstellen sollen (vgl. ebd., 41). Für den Fall einer Vertragsänderung mit dem Ziel, eine »echte« EWWU zu schaffen, werden im Papier Maßnahmen diskutiert, die auch formal eine höhere Rechenschaftspflicht und somit Legitimität mit sich bringen könnten. So solle das Mitentscheidungsverfahren zum Regelverfahren werden (vgl. ebd., 45), zugleich sollten die integrierten Leitlinien (Grundzüge der Wirtschaftspolitik \& beschäftigungspolitische Leitlinien) ebenfalls im ordentlichen Gesetzgebungsverfahren beschlossen werden, weiterhin solle dem Parlament bei der von der Kommission vorgeschlagenen verschärften Haushaltsüberwachung ebenso Mitspracherechte eingeräumt werden (vgl. ebd., 43). Schließlich schlägt die Kommission einen eigenen EuroParlamentsausschuss vor, dem gegenüber auch die zuständigen Kommissare rechenschaftspflichtig sein könnten (vgl. ebd., 44). Neben der Parlamentarisierung der EWWU propagiert die Kommission Integrität als weitere zentrale Säule ihres Leitbilds einer politischen Union. Dies äußert sich daran, dass sie einem Eurozonen-Parlament implizit - aber deutlich - eine Absage erteilt (vgl. ebd., 40) und auch eine Stärkung der Euro-Gruppe ablehnt (vgl. ebd., 44). Aus Sicht der Kommission müsse der Rat weiterhin das Diskussions- und Entscheidungsgremium für die EWWU sein. Sie räumt zwar Möglichkeiten ein, dass auf Grundlage der verstärkten Zusammenarbeit (Art. 136 AEUV) bei einzelnen Entscheidungsfindungen nicht alle Mitgliedstaaten Stimmrecht besitzen müssten, sie verwehrt sich allerdings gegen die Externalisierung der Entscheidungsprozesse in ein Gremium, das unter Ausschluss der Nicht-Euro-Länder tagt (vgl. KOM 2012a, 44f.). Spannend erscheint weiterhin, dass neben der Parlamentarisierung und der Integrität, wenig über die in einer politischen Union auszuübenden Exekutivfunktionen gesprochen wird. Ausgeklammert wird hier zugleich die Rolle der Kommission. Lediglich an einer Stelle findet sich ein expliziter Hinweis. So wird vorgeschlagen, dass die Position des für die EWWU zuständigen Vizepräsidenten der Kommission gestärkt werden müsse (er wäre der Komplementär zum Euro-Ausschuss des EP) und dass bei der Verwirklichung einer vollumfänglichen Fiskalunion »innerhalb der Kommission so etwas wie eine WWU-Finanzverwaltung einzurichten« (ebd.) sei. Die Kommission spart an dieser Stelle offensichtlich sehr bewusst die Forderung nach einem europäischen »Fi- 
nanzministerium « aus und vermeidet somit zugleich die Verwendung von Termini, die Ähnlichkeiten zu den klassischen mitgliedstaatlichen Exekutiven aufweisen könnten.

Insgesamt lässt sich das »Konzept für eine vertiefte und echte Wirtschafts- und Währungsunion« als ein Schulterschluss zwischen Kommission und Parlament begreifen (vgl. hierzu EP 2012c). Die Fiskalunion als ein Schlüssel zur »Vollendung der EWWU« wurde schließlich von den Parlamentarier*innen mehrfach prominent gefordert. Vom Europäischen Rat in seinem Fahrplan sehr stark reduziert und zugleich auf die lange Bank geschoben, wird sie nun von der Kommission wiederum zu einem der Schlüsselbereiche für künftige Reformen erklärt. Der Schulterschluss zeigt sich nicht zuletzt auch an einem Dank für die »massive Unterstützung des Europäischen Parlaments« (ebd., 4) bei der Umsetzung der bis dato getätigten Krisenbewältigungspolitik. Zugleich zeigt der Vergleich zwischen Kommissionskonzept und dem Vier-Präsidenten-Bericht eindringlich die Rückeroberung der Agenda-Setting-Funktion seitens der Kommission, die nicht zuletzt auch in der Selbstzuschreibung mündet, nach der die Kommission sich attestiert, »bei der Krisenbewältigungspolitik eine führende Rolle übernommen« (ebd.) zu haben. Im Gegensatz zur »echten« EWWU des Vier-Präsidenten-Berichts zeichnet die Kommission allein schon aufgrund von Umfang und Zeitperspektiven wesentlich deutlicher ein Bild einer tatsächlich vertiefteren und »echten« EWWU. Dass dieser Eindruck allerdings nicht lange währte, zeigt ein Blick auf die ersten konkreten Maßnahmenvorschläge der zur Jahresmitte 2014 hin ausscheidenden Kommission um José Manuel Barroso, welche sie im Laufe des Jahres 2013 noch unterbreitete.

Auf Grundlage ihres Konzeptes schlug die Kommission drei konkrete Initiativen vor. Als kurzfristig umzusetzende Maßnahmen definierte sie unter anderem, die Vorabkoordinierung großer Reformen zu stärken und ein Instrument für Konvergenz und Wettbewerbsfähigkeit zu etablieren. Beide Maßnahmen waren nicht nur im Kommissionskonzept sondern auch im Bericht der vier Präsidenten enthalten. In der Schlussfolgerung zur Ratstagung forderten die Staats- und Regierungschefs, dass bis zur JuniTagung 2013 konkretere Schritte zu einer ausgebauten Koordinierung nationaler Reformen, die Durchführbarkeit und die Modalitäten gegenseitig vereinbarter Verträge für Wettbewerbsfähigkeit und Wachstum sowie Vorschläge für geeignete Solidaritätsmechanismen für Mitgliedstaaten, die entsprechende Verträge abschließen, erarbeitet werden sollen (vgl. ER 2012a, 4f.). Dieser Aufforderung kam die Kommission in Form zweier Mitteilungen im März 2013 nach. Im Juni legte die Kommission schließlich eine weitere Initiative vor: 
Tabelle 26: Reformvorschläge der Barroso-Kommission 2013

\begin{tabular}{|l|c|c|}
\hline \multicolumn{1}{|c|}{ Initiative } & Art & Status \\
\hline $\begin{array}{l}\text { Vorabkoordinierung wirtschaftspolitischer Reformvorha- } \\
\text { ben }\end{array}$ & Mitteilung & $\begin{array}{c}\text { Vorerst keine } \\
\text { direkten } \\
\text { Folgemaßnahmen }\end{array}$ \\
\hline Instrument für Konvergenz und Wettbewerbsfähigkeit & Mitteilung & $\begin{array}{c}\text { Vorerst keine } \\
\text { direkten } \\
\text { Folgemaßnahmen }\end{array}$ \\
\hline $\begin{array}{l}\text { Bereitstellung und Qualität von Statistiken im Rahmendes } \\
\text { MIP-Verfahrens }\end{array}$ & VO-Vorschlag & Keine Einigung \\
\hline
\end{tabular}

Quelle: Eigene Zusammenstellung

Die Überlegungen der Kommission (2013g) zum Ausbau der Vorabkoordinierung größerer wirtschaftspolitischer Reformvorhaben basierte auf der Selbstverpflichtung der Mitgliedstaaten, wirtschaftspolitische Reformvorhaben untereinander stärker zu koordinieren (vgl. Art. 11 SKS-Vertrag; vgl. auch Euro-Plus-Pakt). Auf Grundlage dieser außerunionsrechtlichen Vertragsbasis und dem im SKS-Vertrag festgeschriebenen Überführungsgebot ihrer Kerninhalte in den originären Rechtsrahmen der Union binnen fünf Jahren schlägt die Kommission ein im Europäischen Semester verortetes Verfahren zur Koordinierung wirtschaftspolitischer Reformmaßnahmen vor. Demnach obliegt es - wie bereits im SKS-Vertrag - den Mitgliedstaaten, auf eigene Initiative entsprechende Informationen über größere wirtschaftspolitische Reformen an die EUSA (hier: die Kommission und den Rat) zu übermitteln (vgl. ebd., 5). Die regelmäßig anzufertigenden nationalen Reformprogramme sind dabei für die Kommission das Medium der Wahl, auch wenn etwaige Dringlichkeitsklauseln in einer gegebenenfalls später aus der Mitteilung entstehenden Verordnung andiskutiert werden und die Kommission festhält, dass mit dem Vorschlag auch beabsichtigt sei, Regelungen zu treffen, bei denen die Kommission oder der Rat einen Mitgliedstaat zugleich dazu auffordern könne, entsprechende Reformvorhaben im Rahmen des Semesters näher zu erläutern (vgl. ebd., 5). Weiterhin schlägt die Kommission vor, die von den Mitgliedstaaten eingereichten Reformprogramme oder anderweitig angezeigte Reformvorhaben zu prüfen und eine entsprechende Stellungnahme hierzu abzugeben, die im weiteren Prozess Gegenstand der Ratsberatungen werden sollte, an deren Ende die Ergebnisse dieser Koordinationsbemühungen in die Formulierung der länderspezifischen Empfehlungen Eingang finden könnte.

Der Blick auf den skizzierten Koordinationszyklus für größere wirtschaftspolitische Reformvorhaben verdeutlicht, wie halbherzig mittlerweile - nach vier Jahren EuroKrise -Reformvorschläge für die EWWU vorbereitet und eingebracht werden: Inhaltlich würde der Kommissionsvorschlag die wirtschaftspolitische Steuerung qualitativ nicht verbessern helfen, sondern lediglich Verfahren fortschreiben, die bereits existieren. Ein Mehrwert ist in der Mitteilung insgesamt nur schwerlich erkennbar, zumal die Kommission im März 2013 noch nicht einmal eine kohärente Vorstellung davon zu haben schien, welche potenziellen Reformen überhaupt unter dem Label sgrößerer wirtschaftspolitischer Reformvorhaben` zu fassen wären. Statt klarer Kriterien 
sinniert die Kommission über mögliche »Filter«, die bei Qualifizierung als "größere wirtschaftspolitische Reform « herangezogen werden könnten. Relevant seien demnach Reformen, die in die Bereiche »Handel« und »Wettbewerbsfähigkeit« fallen und die Übertragungseffekte über die Finanzmärkte erzeugen könnten; zu guter Letzt seien aber auch »wirtschaftspolitische Erwägungen« relevant, so die Kommission (2013g, 4), worunter sie im Sinne der effektiven Durchsetzung von Strukturreformen insbesondere inländische Reformblockaden versteht, die durch den europäischen Überbau in Ansätzen umgangen werden könnten. ${ }^{3}$ Dass auf Grundlage der dargestellten Parameter dieses uninspirierten Kommissionsvorschlags das Echo der anderen Institutionen zurückhaltend ausfiel, verwundert wenig: Das Europäische Parlament »bedauert die vagen Formulierungen und die zu schwammigen Definitionen einiger der vorgeschlagenen Filter für wichtige und wirtschaftspolitische Reformen « (EP 2013d, Rn. 12) und vertritt insgesamt die Meinung, »dass die Mitteilungen nicht zur richtigen Zeit veröffentlicht wurden « (ebd., Rn. 6). Statt am vorgelegten Vorschlag zur Vorabkoordinierung weiterzuarbeiten, schlägt das Parlament vor, alternativ »einen Vorschlag zur Annahme eines Konvergenzkodex im Rahmen des EU-Semesters auf der Grundlage von EU 2020, der auch einen starken sozialen Pfeiler aufweist, vorzulegen « (ebd; vgl. auch Rn. 12; EP 2013f, Rn. 8; Herv. J. G.). Auch die Rückmeldung seitens des Rates zu beiden Mitteilungen fällt bescheiden aus. Zwar nahm der ECOFIN-Rat die Vorschläge im Mai 2013 zur Kenntnis (vgl. ECOFIN 2013e) und erörterte sie im Juli gemeinsam mit der Kommission (vgl. ECOIN 2013f, 8), doch weitere Aussprachen oder offizielle Stellungnahmen wurden nicht vorgenommen beziehungsweise abgegeben. Die im Rahmen der Juli-Ratstagung von der Kommission angekündigten weiterführenden Mitteilungen (vgl. ebd., 8) wurden ebenfalls nicht veröffentlicht. Der Kommissionsvorschlag zur Vorabkoordinierung größerer wirtschaftspolitischer Reformvorhaben versandete somit schließlich in den interinstitutionellen Mühlen der EUSA. Dieses Schicksal ereilte schließlich - trotz höherer Brisanz des Inhalts und des expliziten Rückhalts durch den Europäischen Rat (vgl. ER 2012a \& 2013) - auch die zweite März-Mitteilung der Kommission (2013f), mit der die Einführung eines Instruments für Konvergenz und Wettbewerbsfähigkeit vorgeschlagen wurde. Dieser Vorschlag stellte den Versuch der Kommission dar, Merkels Pakt für Wettbewerbsfähigkeit im Rahmen des Unionsrechts zu verwirklichen und somit trotz starker Kritik an Merkels Vorschlag (vgl. Oberndorfer 2013, 84; Feigl 2013, 90) doch noch zur Umsetzung zu führen. Das vorgeschlagene Instrument umfasst einerseits »[v]ertragliche Vereinbarungen, in denen die Maßnahmen festgelegt würden, zu deren Umsetzung sich der betreffende Mitgliedstaat verpflichtet, samt des hierfür vereinbarten Zeitrahmens. Diese Maßnahmen wären insbesondere auf die Umsetzung 
der länderspezifischen Empfehlungen gerichtet «(KOM 2013f, 3); andererseits profitierte der Mitgliedstaat von »[f]inanzielle[r] Unterstützung für die Durchführung der in der vertraglichen Vereinbarung genannten Reformen« (ebd., 3), wobei es einen moral hazard auszuschließen gelte (vgl. ebd., 4). Die Kommission sieht in ihrem Vorschlag ein »Bindeglied « zwischen den »Richtungsvorgaben« aus dem Europäischen Semester und der Durchführung von »Strukturreformen « auf mitgliedstaatlicher Ebene, der auf dem bestehenden Überwachungsrahmen der konsolidierten Stabilitätsunion aufbaue (vgl. ebd., 4). Dem Instrument liegt zusammengefasst der Gedanke zugrunde, die bereits bekannten Wirtschaftspartnerschaftsprogramme (Two-Pack) sowie die außerunionsvertragsrechtlichen Memoranden auf alle Mitgliedstaaten der Eurozone auch außerhalb krisenbezogener Ausnahmezustände anzuwenden und sie entsprechend mit finanziellen Mitteln $\mathrm{zu}$ incentivieren. Ihm ist dementsprechend zugleich der weitere Ausbau der Überwachungsfunktionen im Rahmen des wirtschaftspolitischen Regierens intendiert. Der Kommission fiele in einem solchen System die Aufgabe zu, die Reformvorhaben der Mitgliedstaaten zu bewerten und die entsprechenden Vertragsverhandlungen zu führen, bevor der Rat die Verträge billigt und sie gemeinsam mit der Kommission im Rahmen des Semesters überwacht (vgl. ebd., 6). An welchen Stellen in den bestehenden Verfahren des Wirtschaftsregierens das Instrument angesiedelt werden soll, lässt die Kommission in ihrer Mitteilung hingegen noch offen. Sie präsentiert hierzu drei Überlegungen: So sei es einerseits denkbar, dass das Instrument auf einer »freiwilligen Teilnahme« beruhe, andererseits könne es an bestehenden Komponenten der makroökonomischen Überwachung eingegliedert werden (vgl. ebd., 5). Wäre es in der präventiven Komponente verortet, bestünde im Prinzip die Notwendigkeit einer Teilnahme aller Mitgliedstaaten, wohingegen der dritte Vorschlag eine Angliederung an das Verfahren bei einem übermäßigen Ungleichgewicht vorsähe, bei dem die vertraglichen Vereinbarungen die bereits bekannten Korrekturmaßnahmepläne (s.o.) ersetzen könnten (vgl. ebd., 5). Der Blick auf die drei Gestaltungsoptionen verdeutlicht, dass auch dieser Kommissionsvorschlag nur einen geringen Mehrwert aufweist. Freiwillige Verpflichtungen gab es im Laufe der Euro-Krise zu Genüge und ob die finanziellen Anreize dazu führen, die Selbstverpflichtungen besser einzuhalten, gilt es aufgrund der nicht benannten Finanzausstattung zu bezweifeln. Andererseits wäre die Verortung im präventiven MIP-Arm ohne entscheidenden Mehrwert für das Verfahren, da mit den Korrekturmaßnahmeplänen bereits ein Durchsetzungsinstrument vorhanden ist. Lediglich die Integration in den präventiven MIP-Arm käme einem echten Ausbau von Staatlichkeit nahe, wobei auch hier kritisch zu hinterfragen wäre, ob hierdurch wirklich eine höhere compliance mit den Selbstverpflichtungen der Mitgliedstaaten und den länderspezifischen Empfehlungen der EUSA erreicht werden könnte.

Bei der Bewertung des Instruments ist das Europäische Parlament ebenso wie bei der Vorabkoordinierung skeptisch. Laut den Parlamentarier*innen sollte das Augenmerk derzeit verstärkt auf die Konvergenz gerichtet und das vorgeschlagene Instrument erst dann etabliert werden, wenn entsprechende Fortschritte bei der Überwindung sozialer Ungleichgewichte und in Richtung eines nachhaltigen Wachstums erreicht seien (vgl. EP 2013d, Rn. 18). Zugleich kritisiert das EP den Vorschlag dafür, dass in ihm »Verträge zwischen der EU und den Mitgliedstaaten vorgesehen sind « und er demnach »nicht die einheitliche europäische Rechtsordnung« (ebd., Rn. 24) achte. Der 
Europäische Rat nahm den Vorschlag der Kommission auf seiner Dezember-Tagung 2013 zwar insgesamt positiv zur Kenntnis und taufte ihn auf den Namen »Partnerschaft für Wachstum, Beschäftigung und Wettbewerbsfähigkeit« um, beauftragte aber lediglich seinen Präsidenten und die Kommission damit, weitere Vorbereitungen zu unternehmen, um im Oktober 2014 nochmals über den Vorschlag zu beraten (vgl. ER 2013, 17ff.). Dass sich allerdings die Bereitschaft zur Umsetzung zwischenzeitlich nicht erhöht hatte, zeigt sich in der Schlussfolgerung der Oktober-Ratstagung 2014, in der es zwar heißt, »dass es dringend einer zügigen Umsetzung von Maßnahmen zur Stärkung von Beschäftigung, Wachstum und Wettbewerbsfähigkeit [...] bedarf« (ER 2014b, 10), zugleich aber weder ein direkter Bezug zum Kommissions->Instrument< noch zur vom Europäischen Rat vorgeschlagenen >Partnerschaft hergestellt wird. Auch der anschließend tagende Euro-Gipfel bleibt in seiner Stellungnahme allgemein und vage:

»Die Gipfelteilnehmer waren sich darin einig, dass eine engere Koordinierung der Wirtschaftspolitik der Mitgliedstaaten von wesentlicher Bedeutung ist, um das reibungslose Funktionieren der Wirtschafts- und Währungsunion zu gewährleisten. In dieser Hinsicht riefen sie dazu auf, dass weiterhin in enger Zusammenarbeit mit der Kommission an der Entwicklung konkreter Mechanismen für eine verstärkte wirtschaftspolitische Koordinierung, Konvergenz und Solidarität gearbeitet wird. Die Gipfelteilnehmer ersuchen den Präsidenten der Kommission, in enger Zusammenarbeit dem Präsidenten des Euro-Gipfels, dem Präsidenten der Euro-Gruppe und dem Präsidenten der Europäischen Zentralbank die nächsten Schritte in Bezug auf eine besser wirtschaftspolitische Steuerung im Euro-Währungsgebiet vorzubereiten.« (Euro-Gipfel 2014)

Statt also intensiver über die konkret im Raum stehenden Vorschläge zu beraten, zog es der Euro-Gipfel vor, die vier Präsidenten erneut mit der Erarbeitung eines Perspektivpapieres zu beauftragen. Nicht nur die Vertagung konkreter Entscheidungsfindungen, sondern auch diese wiederkehrenden Neubeauftragungen von Blueprints sprechen dafür, von einer einsetzenden Erlahmung der krisenbezogenen Reformdynamik zu sprechen.

Deutlich zu Tage tritt die fast gänzlich aufgebrauchte Bereitschaft zu neuen Reformvorhaben im Zusammenhang mit dem Kommissionsvorschlag zur Verabschiedung einer Verordnung über die Bereitstellung und Qualität von Statistiken für das Verfahren bei einem makroökonomischen Ungleichgewicht. Der Verordnungsvorschlag der Kommission griff die auch im Rat geführte Diskussion über die für die Glaubwürdigkeit des MIP notwendige Qualität der Statistiken auf (vgl. KOM 2013b, 2) und skizzierte einen Rahmen, der dies sicherstellen solle. Dabei schlägt die Kommission vor, ihr - insbesondere ihrer Unterabteilung Eurostat - neue Aufgaben zuteilwerden zu lassen. Hierzu zählen unter anderem eine Qualitätsvalidierung relevanter Daten, eine Analyse der Erhebungsquellen und -verfahren sowie die Ausarbeitung und Umsetzung eines Planes für Verbesserungsmaßnehmen (vgl. ebd.). Auf Grundlage technischer Übermittlungsanforderungen (vgl. Kap. II des VO-Vorschlags in KOM 2013b) und der Erstellung von Qualitätsberichten seitens der Mitgliedstaaten (vgl. ebd., Kap. III) obläge es der Kommission, eine Qualitätsbewertung der eingereichten Statistiken vorzunehmen (vgl. ebd., Kap. IV). »Stellt die Kommission (Eurostat) Probleme fest, insbesondere im Rahmen der Qualitätsbewer- 
tung [...], so kann sie beschließen, Besuche in dem betreffenden Mitgliedstaat durchzuführen.« (Ebd., Art. 7, Abs. 1) Des Weiteren schlägt die Kommission Sanktionen in solchen Fällen vor, in denen Mitgliedstaaten absichtlich oder aufgrund schwerwiegender Nachlässigkeit Daten falsch darstellen (vgl. ebd., Art. 9). Ein entsprechender Prozess zur näheren Untersuchung durch die Kommission könnte durch den Rat eingeleitet werden, dem auch die Beschlusskompetenz über zu verhängende Geldbußen obläge. Im Rahmen der Untersuchungen in Bezug auf die Manipulation von Statistiken solle laut Verordnungsvorschlag der Kommission zugleich eine Reihe von Befugnissen zum Erlass von delegierten Rechtsakten übertragen werden, mit denen sie in ihrer Funktion als Hüterin der Stabilitätsunion weiter gestärkt würde.

In ihrer Stellungnahme zum Verordnungsvorschlag teilt die EZB (2013a) zwar generell die Auffassung, qualitativ hochwertige Statistiken bereitzustellen, kritisiert aber, dass für die MIP-Statistiken eine eigene Verordnung erlassen werden solle, statt sie in die bestehenden Regelungen und dem hiermit verbundenen System der Qualitätssicherung zu integrieren (s. VO (EG) Nr. 223/2009). Zu den potenziellen Sanktionsmaßnahmen und Überprüfungsmissionen äußern sich die Zentralbanker*innen überraschenderweise nicht. Anders das Europäische Parlament, das in erster Lesung im März 2014 einen abgeänderten Verordnungstext beschloss. Nach Vorstellungen des Parlaments sollten nicht direkt Geldbußen verhängt, sondern in einem zweistufigen Verfahren zuerst eine verzinsliche Einlage auferlegt werden, die - soweit die betroffenen Mitgliedstaat keine Abhilfemaßnahmen unternommen - in eine Geldbuße umgewandelt werden könne (vgl. EP 2014c, Abänderung 34). Zugleich ergänzte das Parlament eine Passage, nach der die Kommission verpflichtet wäre, den zuständigen Parlamentsausschuss über die Untersuchungen zu unterrichten (vgl. ebd., Abänderung 39). Neben diesen nahm das Parlament eine Reihe weiterer kleiner Änderungen am Verordnungsvorschlag an, der seitdem aber vergeblich auf eine entsprechende legislative Beratung im Rat wartet. Der Rat, der wie dargestellt, selber Initiativgeber für den Verordnungsvorschlag war, scheint mit den grundsätzlichen Parametern der bisherigen Verordnungstexte nicht einverstanden zu sein, auch wenn in den offiziellen Stellungnahmen und Protokollen der Ratstagungen keine expliziten Hinweise auf den Verlauf der Verhandlungen innerhalb des Rates zu finden sind. Allerdings wurde bereits im September 2013 - also knapp ein halbes Jahr nach Veröffentlichung durch die Kommission der Juristische Dienst des Rates um ein Gutachten zum Verordnungsvorschlag gebeten. Dieses Gutachten liegt dem Rat seit Oktober 2013 vor - wird seitdem aber unter Verschluss gehalten. ${ }^{4}$ Lediglich die Einleitung des Gutachtens wurde am 22. Februar 2019 der Öffentlichkeit zugänglich gemacht. Darin hießt es, dass der Juristische Dienst "um Stellungnahme zur Vereinbarkeit der Bestimmungen (a) zu Sanktionen und (b) zu Besuchen in Mitgliedstaaten mit der Rechtsgrundlage sowie (c) zur Achtung des Grundsatzes der Verhältnismäßigkeit ersucht« (ECOFIN 2013i, 1) worden sei. Die Klärungsanfragen verweisen insgesamt darauf, dass es Befürchtungen im Rat zu geben scheint, nach denen die der Kommission zugedachten Aufgabenausweitungen zu weitreichend ausfallen könnten. Im Begleitschreiben des Generalsekretariats zur Dokumentenfrage heißt es, dass 
»[d]ie Fragen, auf die sich die Rechtsberatung bezieht, [...] einen wichtigen Teil der Grundlage für die Beratungen [bilden] und [...] strittig [sind], da die verschiedenen Akteure in diesem Gesetzgebungsverfahren zu diesen Fragen unterschiedliche Standpunkte zum Ausdruck gebracht haben.«(Ceneralsekretariat 2019, 2)

Dass es zukünftig noch zu einer Einigung zum Verordnungsvorschlag kommen wird, sei ein weiterer Grund, die Beurteilungen des Juristischen Dienstes nicht der Öffentlichkeit zugänglich zu machen (vgl. ebd., 2). Ob es hierzu allerdings jemals kommen wird, darf aufgrund des jahrelangen Stillstands aber wohl bezweifelt werden.

Das Schicksal des letzten Verordnungsvorschlags der Barroso-Kommission zur Reformierung und Weiterentwicklung der EWWU verdeutlicht, dass die Reformdynamik der Phase der reaktiven Krisenbewältigungspolitik in Bezug auf den vertraglichen Kern der EWWU (Titel VII des dritten Teils AEUV) zur Jahresmitte 2013 vollends zum Erliegen kam. Neben der zunehmenden Fokussierung auf die Thematik der Bankenunion (auf Grundlage des Titels I des dritten Teils AEUV), auf die sich ein Großteil der Politikaktivitäten seit 2012 richteten, scheint sich auch eine interne Reformmüdigkeit aufgetan zu haben, die sich einerseits in den unambitionierten Vorschlägen der Kommission - im deutlichen Kontrast zum ambitionierten Ausgangskonzepts aus dem November 2012 und andererseits in den immer sichtbarer werdenden Blockaden innerhalb des Rates zeigen. Auch die Stellungnahme des Wirtschafts- und Finanzausschusses zu weiteren potenziellen Reformen vom Oktober 2013 verdeutlicht dies exemplarisch:

»While most Members underlined that the current areas for economic policy coordination are the right ones and the focus should be on effective implementation of the reinforced economic governance framework provided notably by the 6-pack and the 2-pack, a few Members indicated that there may be policy areas in which closer coordination and monitoring would be needed to complement existing frameworks and procedures.«(WFA 2013b, 2; Herv. J. G.)

Schlussendlich schafften es weder der Europäische Rat mit seinem scheidenden Präsidenten Van Rompuy ${ }^{5}$ noch die Kommission mit ihrem scheidenden Präsidenten Barroso, $2013 \mathrm{im}$ Anschluss an das Two-Pack eine vergleichbare Reformdynamik aufrecht $\mathrm{zu}$ erhalten, wie sie noch die Jahre 2010-2012 prägte. Der Minimalkompromiss zur Rettung der EWWU schien unter den mitgliedstaatlichen Regierungen mit der Abschwächung der akuten Krisenerscheinungen im Jahr 2013 in Bezug auf wirtschafts- und fiskalpolitische Reformvorschläge erschöpft. Die Zeit größerer, kriseninduzierter Reformmaßnahmen zum Ausbau der EU-Staatlichkeit schien vorüber; nicht zuletzt aufgrund der einsetzenden Krisenberuhigung durch das im Sommer 2012 aufgelegte OMT-Programm der EZB.

Auch unter der neuen Kommission um Jean-Claude Juncker änderte sich die Reformbereitschaft nicht grundsätzlich, allerdings gelang es dem ehemaligen Vorsitzenden der Euro-Gruppe mit einer Reihe von Maßnahmen - die zum Teil auf dem 2012er Kommissionskonzept beruhten - im Rahmen der ausgebauten EU-Staatlichkeit diese inkrementell fortzuentwickeln und hierüber schließlich weiter auszubauen. Es vollzog 
sich in der beschriebenen Zeitspanne vom Sommer 2012 bis zur Einsetzung der neuen Kommission in 2014 aus analytischer Perspektive schließlich ein Wechsel von der Phase des reaktiven hin zur Phase des inkrementellen Staatlichkeitsausbaus, der sich an der von Juncker ausgegebenen Devise »Vertiefung durch Handeln« orientieren sollte.

\section{2 "Vertiefung durch Handeln« als neue Devise}

Mit der Vorlage des sogenannten Fünf-Präsidenten-Berichts versuchte die neue Kommission um Jean-Claude Juncker die Vertiefungsdiskussion ab 2015 erneuert zu beleben. Der dem Bericht zugrundeliegende Stufenplan für künftige Reform- und Ausbaumaßnahmen gibt dabei in der ersten Stufe die Devise »Vertiefung durch Handeln« aus. Unter dieser Maxime sollten bis Juni 2017 konkrete Vertiefungsschritte unternommen werden, die »auf vorhandenen Instrumenten aufbauen und die bestehenden Verträge bestmöglich nutzen.« (Juncker et al. 2015b, 5) In der kurzfristigen Perspektive zielte der Bericht vor diesem Hintergrund auf neue Impulse für Konvergenz, Beschäftigung und Wachstum, die Einsetzung eines beratenden Europäischen Fiskalausschusses sowie einer Neugestaltung des Europäische Semesters, wodurch nicht zuletzt eine stärkere parlamentarische Kontrolle erreicht werden solle (vgl. ebd., Anhang 1). In der sich anschließenden zweiten Stufe (ab 2017) schlagen die Präsidenten die Formalisierung und Stärkung des Konvergenzprozesses, die Einrichtung einer makroökonomischen Stabilisierungsfunktion sowie die Überführung des ESM in den Unionsrechtsrahmen und die Einführung eines euroraumweiten Schatzamtes vor (vgl. ebd.). Die Verwirklichung der Stufe zwei solle bis spätestens 2025 erreicht werden, sodass an deren Ende »eine vertiefte und echte WWU - ein Hort der Stabilität und des Wohlstands für alle Bürgerinnen und Bürger der EU-Mitgliedstaaten [steht], die eine gemeinsame Währung miteinander teilen.« (Ebd., 6)

Nachdem bereits im Jahr 2012 die Kommission langsam wieder zur Hauptakteurin der EUSA-internen Leitbildproduktion wurde, kommt diese Rückeroberung des Terrains auch im Fünf-Präsidenten-Bericht zum Ausdruck. Lag die Verantwortung für die Formulierung von Aktions- und Fahrplänen zuvor noch beim Präsidenten des Europäischen Rates (Task-Force- \& Vier-Präsidenten-Bericht), entstand der nun vorgelegte Bericht unter Federführung des Kommissionspräsidenten Juncker. Dieser wurde vom Euro-Gipfel im Oktober 2014 ersucht,

»in enger Zusammenarbeit mit dem Präsidenten des Euro-Gipfels, dem Präsidenten der Euro-Gruppe und dem Präsidenten der Europäischen Zentralbank die nächsten Schritte in Bezug auf eine bessere wirtschaftspolitische Steuerung im Euro-Währungsgebiet vorzubereiten.«(Euro-Cipfel 2014; vgl. auch ER 2014C, Rn. 4)

Auf der informellen Tagung des Europäischen Rates im Februar 2015 legten die benannten vier Präsidenten den Staats- und Regierungschefs eine erste »Analytische Note« vor, die als »eine Art Standortbestimmung« (Juncker et al. 2015a, 1) dienen sollte. Die Note wirft zuerst einen Blick zurück auf die Euro-Krise, die sie als eine - teilweise parallele - Abfolge vierer Krisen beschreiben: Ausgangspunkt sei die Finanzkrise (I) gewesen, in deren Folge einige Mitgliedstaaten Bankenrettungspakete geschnürt hät- 
ten, die zugleich die Haushaltsposition verschlechtert haben. Diese negativen Auswirkungen werden auch den Konjunkturprogrammen attestiert, die in einigen Mitgliedstaaten zur Abfederung der Krisenauswirkungen lanciert wurden. Neben diesen Krisenfolgen diagnostizieren die vier Präsidenten aber zugleich die Nichteinhaltung der SWP-Regeln, die in der Gesamtschau schließlich in der Staatsverschuldungskrise (II) mündeten. Eine weitere Krise stelle in der Erzählung der fünf Präsidenten jene der zum Teil fehlenden Wettbewerbsfähigkeit dar (III), die auf einen Mangel an Strukturreformen seit der EWWU-Schaffung hindeute. Schließlich wird eine Krise der Märkte (IV) beschrieben, die sich in einer fehlenden Marktdisziplinierung der Euro-Staaten vor dem Krisenausbruch - gezeigt habe. Insofern basiert der Bericht auf dem punktuell erweiterten Krisennarrativ (Haushaltspositionen in Folge der Finanzkrise \& Schuldzuweisung an die Finanzmärkte) vom Ausgangspunkt des reaktiven Staatlichkeitsausbaus in der Euro-Krise.

Trotz der getroffenen Krisenbewältigungsmaßnahmen zeichnen die Präsidenten in ihrer Ist-Analyse ein düsteres Bild, das einen entsprechenden Handlungsdruck evozieren soll:

»Eine hohe Verschuldung, eine hohe Arbeitslosigkeit und erhebliche Hindernisse für die Entstehung flexibler Märkte schwächen das Wachstumspotenzial der Länder [...]. Eine hohe Verschuldung wirkt sich in der Regel negativ auf das Wachstum aus [...], ein langsames Wachstum und eine geringe Inflation wiederum erschweren es einem Land, seinen Schuldenstand zu verringern und auf diese Weise seine Krisenresistenz und Nachhaltigkeit zu stärken. Somit könnte es sich für einige hochverschuldete Länder des Euro-Währungsraums mit geringen Potenzialwachstumsraten als besonders schwierig erweisen, ihre Schuldenstände schnell abzubauen. Sollen Widerstandsfähigkeit gegenüber Schocks und Potenzialwachstum erhöht werden, müssen nationale Strukturreformen weiter vorangetrieben werden« (ebd., 8),

so das Fazit. Untermauert wird diese Forderung anhand dreier Beispiele: So seien laut internationalen Indikatoren die Arbeits- und Produktmärkte zu rigide und das wirtschaftliche Umfeld nicht so ausgestaltet, dass Unternehmensneugründungen begünstigt würden. Außerdem käme außer Finnland kein weiterer Euro-Staat unter die Top Ten im Weltbank-Ranking der wirtschaftsfreundlichsten Staaten (vgl. ebd.). Kurzfristig sei es deshalb wichtig, "eine in sich schlüssige Strategie umzusetzen, beruhend auf dem >magischen Dreieck aus Strukturreformen, Investitionen und Haushaltsdisziplin, und dabei wirksame Verpflichtungen zu wachstumsfördernden Strukturreformen im EuroWährungsgebiet zu erreichen.« (ebd., 9; Herv. J. G.) Die wortschöpferische Ähnlichkeit dieses neuen magischen Dreiecks zum klassischen magischen Viereck der Wirtschaftspolitik (hoher Beschäftigungsstand, stabiles Preisniveau, außenwirtschaftliches Gleichgewicht, stetiges und angemessenes Wirtschaftswachstum) scheint nicht von ungefähr. Allerdings kannte bereits das »magische« Viereck das Problem der Zielerreichung, da aufgrund der gegenseitigen Interdependenzen nicht alle Ziele im selben Maße erreichbar sind. In dieser Analogie ist auch das neue »magische« Dreieck mit Zielkonflikten behaftet, die sich beispielsweise darin äußern, dass staatliche Investitionstätigkeiten dem Ziel der Haushaltsdisziplin zuwiderlaufen können. Ebenso kann sich die Umsetzung von Strukturreformen, die unter Umständen einen monetären Ressourcenein- 
satz erfordern, negativ auf die Haushaltsbilanz auswirken. Dass sich die handelnden Akteur*innen darüber bewusst sind, zeigt sich in jenen Maßnahmen, die dem FünfPräsidenten-Bericht vorausgingen und auf eine Intensivierung der Investitionstätigkeit zielten:

Tabelle 27: Kommissionsmaßnahmen zur Intensivierung der Investitionstätigkeit (2014/15)

\begin{tabular}{|c|l|c|c|}
\hline Datum & Initiative & Art & Status \\
\hline 02.11 .2014 & Investitionsoffensive & Mitteilung & $\begin{array}{c}\text { Umsetzung in } 2015 \text { und } \\
2016\end{array}$ \\
\hline 13.01 .2015 & Fonds für strategische Investitionen & VO-Vorschlag & VO (EU) 2015/1017 \\
\hline 10.02 .2015 & Flexibilität im SWP & Mitteilung & Umsetzung in 2016 \\
\hline
\end{tabular}

Quelle: Eigene Zusammenstellung

Der neue wirtschaftspolitische Dreiklang - Juncker selbst spricht auch gerne vom »tugendhaften Dreieck (KOM 2016c, 2016e; vgl. auch KOM 2016f) - markiert zugleich ein erneutes Austarieren zwischen den beiden Polen der Schuldenproblematik und der Wettbewerbsfähigkeit zugunsten der Letzteren. Neben den angemahnten Strukturreformen auf Ebene der Mitgliedstaaten fordern die vier Präsidenten die Vertiefung des Binnenmarktes, die sich einerseits in einer höheren Arbeitnehmer*innenmobilität zeigen solle sowie im Aufbau einer Kapitalmarktunion (vgl. ebd.). Weitere Hinweise insbesondere auch eine »Vision « für die EWWU-Vollendung - zur EWWU-Vertiefung fehlen in der Februar-Note hingegen komplett.

Diese werden erst im eigentlichen Bericht (Juni 2015) präsentiert, in deren Erarbeitung auch der Präsident des Europäischen Parlamentes eingebunden war. Überraschend »ehrlich« findet hierbei die Problemdarstellung statt. So biete die EWWU

»momentan das Bild eines Hauses, an dem jahrzehntelang gebaut wurde, das aber nur teilweise fertiggestellt ist. Mitten im Sturm mussten Mauern und Dach rasch befestigt werden. Jetzt ist es höchste Zeit, die Fundamente zu verstärken und die WWU zu dem zu machen, was sie eigentlich sein sollte: ein Ort des Wohlstands, der auf einem ausgewogenen Wirtschaftswachstum und stabilen Preisen beruht, sowie auf einer wettbewerbsfähigen sozialen Marktwirtschaft, die auf Vollbeschäftigung und sozialen Fortschritt angelegt ist« (Juncker et al. 2015b, 4),

so die Vision der nun fünf Präsidenten. Weiter heißt es an anderer Stelle selbstkritisch:

»Auf dem Höhepunkt der Krise mussten weitreichende Entscheidungen oft sehr schnell getroffen werden, manchmal über Nacht. In einigen Fällen wurden zwischenstaatliche Lösungen gewählt, um Entscheidungen zu beschleunigen oder Widerstände zu überwinden. Jetzt ist es an der Zeit, unser politisches Konstrukt zu überdenken und zu konsolidieren und die nächste Stufe der Wirtschafts- und Währungsunion zu verwirklichen.«(Ebd., 19)

Hierzu greift der Bericht die bereits aus seinen Vorläuferberichten bekannten vier Unionen auf, in denen Fortschritte erzielt werden müssten: Aufbau einer echten Wirtschaftsunion, einer Banken- beziehungsweise Finanzunion, einer Fiskalunion und schließlich 
einer politischen Union (vgl. ebd., 5). Nach Jahren der Krise gehe es dabei nun nicht mehr nur um das `Überleben<, sondern vielmehr um ein >Aufblühen` der Eurozone (vgl. ebd.). Zugleich verlangt der vorgeschlagene Weg zu einer echten EWWU einen Wandel des Politikmodus. So müsse sich die EWWU

»von einem System der Regeln und Leitlinien für die nationale Wirtschaftspolitisch hin zu einem System weitgehender Souveränitätsteilung im Rahmen gemeinsamer Institutionen [wandeln], die größtenteils bereits existieren und diese Aufgabe nach und nach übernehmen können. In der Praxis würde das bedeuten, dass die Mitgliedstaaten in zunehmendem Maß gemeinsame Entscheidungen über Teile ihrer jeweiligen nationalen Haushalts- und Wirtschaftspolitik akzeptieren müssten.« (Ebd.; Herv. J. G.)

Diesen vollmundigen Ankündigungen und blumigen Umschreibungen einer EWWU, die »allen Bürgerinnen und Bürgern ein besseres Leben mit mehr Chancengerechtigkeit ermöglichen« (ebd., 2) solle, folgen aber bei der Beschreibung der konkreten kurz- wie langfristigen Maßnahmen nur wenige >Taten $\prec$. Auf Grundlage des neuen handlungsleitenden Prinzips der »Vertiefung durch Handeln«, schlagen die Präsidenten vor, dass "[wir] ausgehend vom derzeitigen Steuerungsrahmen, der weiter verstärkt werden sollte, kurzfristig unsere Bemühungen intensivieren [müssen], so dass sich alle in Europa den höchsten Leistungen und den bestehen Methoden annähern. (Ebd., 8) Dies stelle die Methode dar, um eine echte Wirtschaftsunion zu erreichen, die auf vier Säulen beruhe:

»einem euroraumweiten System von Einrichtungen zu Stärkung der Wettbewerbsfähigkeit, einer konsequenteren Durchführung der Verfahren bei makroökonomischen Ungleichgewichten, einer größeren Fokussierung auf Beschäftigung und Soziales und einer stärkeren wirtschaftspolitischen Koordinierung innerhalb eines umgestalteten Europäischen Semesters.«(Ebd.)

In der Mittel- und Langfristperspektive sollen sich diese Maßnahmen (zusammengenommen als Konvergenzprozess beschrieben) einen verbindlicheren Charakter erhalten und innerhalb des Konvergenzprozesses strenge Standards, die sich auf »Arbeitsmärkte, Wettbewerbsfähigkeit, Rahmenbedingungen für Unternehmen und öffentliche Verwaltung sowie bestimmte Aspekte der Steuerpolitik [...] konzentrieren« (ebd., 11), erreicht werden. Die avisierte Vertiefung der Fiskalunion orientiert sich am perpetuierten Leitbild verantwortungsvoller Haushaltspolitik als Chiffre für das altbekannte Austeritätsdogma (vgl. ebd., 16). Hierzu schlägt der Bericht kurzfristig (Stufe 1) vor, dass

»der bestehende Steuerungsrahmen durch die Einrichtung eines beratenden Europäischen Fiskalausschusses gestärkt werden [sollte]. Dieser neue beratende Ausschuss würde die Arbeit der nationalen Räte für Finanzpolitik, die vor dem Hintergrund der EU-Richtlinie über die Haushaltsrahmen geschaffen wurden, koordinieren und ergänzen.«(Ebd.)

Mit der Schaffung eines euroraumweiten Schatzamtes (vgl. ebd., 20) schlagen die Präsidenten zugleich eine mögliche Form der infrastrukturellen Voraussetzungen einer gemeinsamen Fiskalpolitik der Euro-Staaten vor, die sich einerseits vom Vorschlag eines Finanzministeriums (vgl. EP 2011c \& Van Rompuy 2013b) und zum anderen von der bei der Kommission verorteten Finanzverwaltung (vgl. KOM 2012a) abhebt. Langfristig 
sehen die fünf Präsidenten außerdem die Notwendigkeit einer Stabilisierungsfunktion in Form gemeinsamer Haushaltsinstrumente für die Eurozone (vgl. Juncker et al. 2015b, 18). Sie greifen damit die seit langem im Raum stehenden und zum Teil bereits in die Vorläuferberichte eingeflossenen Forderungen nach einer umfassend vergemeinschafteten Fiskalpolitik auf, fallen dabei allerdings abermals weit hinter die Forderungen insbesondere des Europäischen Parlaments (2011c) zurück. Demnach wären Leitprinzipien für eine euroraumweite Stabilisierungsfunktion, dass diese keine Dauertransfers bewirke, sie keine Anreize für eine unsolide Haushaltspolitik biete, sich dabei in den bestehenden Rahmen einfüge und kein klassisches Krisenbewältigungsinstrument (wie bspw. der ESM) sein solle (vgl. Juncker et al. 2015b, 17). Weder eine klassische Fiskalkapazität noch die Möglichkeit von gemeinsamen Staatsanleihen werden im Bericht diskutiert. Insofern fällt der Fünf-Präsidenten-Bericht sogar hinter jenen der vier Präsidenten aus dem Jahr 2012 zurück.

Ähnlich unambitioniert erscheinen die Vorschläge für die politische Union. In der ersten Umsetzungsstufe solle die »Schlüsselrolle« der Parlamente gestärkt werden; neben der Neugestaltung des Europäischen Semesters äußert sich dies allerdings abermals nur in weitestgehend informellen Verfahrensfragen (vgl. ebd., 19). Weiterhin solle in der ersten Stufe weiter an der einheitlichen Vertretung des Euro-Währungsgebiets nach außen gearbeitet sowie die zwischenstaatlichen Maßnahmen zur Krisenbewältigung schrittweise in den EU-Rechtsrahmen integriert werden, wobei die Überführung des ESM erst in der zweiten Stufe vorgesehen ist (vgl. ebd., 20). Im Unterschied zur Wahrung der Integrität, die durch die Kommission im 2012er >Konzept ‘ zum Ausdruck gebracht wurde, propagiert der Fünf-Präsidenten-Bericht als weitere Maßnahme zur Stärkung der politischen Union eine ausgebaute Steuerungsfunktion für die EuroGruppe (vgl. ebd.). So wird vorgeschlagen, kurzfristig die Funktion des Vorsitzenden aufzuwerten und ihm mehr Ressourcen zur Verfügung zu stellen, bevor in der zweiten Stufe über die Einrichtung eines ständigen, hauptamtlichen Vorsitzes zu beraten sei (vgl. ebd.). Dies würde allerdings die Asymmetrien zwischen den Mitgliedern der Währungsunion und den übrigen Mitgliedstaaten der EU weiter verschärfen und wirkt insofern für die Legitimierung und Erhöhung der Rechenschaftspflicht der EWWU auf lange Sicht wenig erfolgsversprechend.

In der Gesamtschau lässt sich demnach festhalten, dass der Fünf-PräsidentenBericht einerseits inhaltlich und in seiner Reichweite eher zurückhaltend gestaltet ist; im Vergleich zu den Vorläuferberichten sogar in Teilen hinter diese zurückfällt. Das handlungsleitende Prinzip der »Vertiefung durch Handeln« offeriert ein insgesamt wenig ambitioniertes Reformprogramm, das sich in weiten Teilen lediglich auf veränderte Praxen in bestehenden Politikarrangements beruft. Andererseits - und dies mag die Stärke des Berichts sein - umgeht er so zugleich die einsetzende Reformmüdigkeit und setzt auf eine inkrementelle Fortentwicklung der EWWU.

Der Fünf-Präsidenten-Bericht (Juni 2015) mündete schließlich im Oktober 2015 in einer ersten Kommissionsmitteilung (vgl. KOM 2015c). Eingebettet ist diese in eine Reihe konkreter Maßnahmenvorschläge, die in Anlehnung an das Six- und Two-Pack auch als drittes Economic-Governance-Paket bezeichnet werden können. Anders als bei seinen Vorgängern fällt allerdings auf, dass das Paket lediglich in einem Fall Legislativcharakter aufweist (vgl. KOM 2015g). Das erste größere Maßnahmenpaket der 
neuen Juncker-Kommission - es werden zwei weitere folgen - steht demnach exemplarisch für den prozeduralen und inkrementellen Ansatzes des Staatlichkeitsausbaus, der insbesondere auf eine Konsolidierung der Ausbautätigkeiten der Vorjahre zielt. Dieser Prozess zur Konsolidierung der EU-Interventionsstaatlichkeit fokussiert hierbei vornehmlich auf die Staatlichkeitspraxen im Kontext der vertragsbasierten Wirtschaftsund Fiskalverfassung:

Tabelle 28: Drittes Economic-Governance-Paket (Oktober/November 2015)

\begin{tabular}{|c|c|c|}
\hline Initiative & Art & Status \\
\hline $\begin{array}{l}\text { Schritte zur EWWU-Vollendung (inkl. Neugestal- } \\
\text { tung des Europäischen Semesters und Verfahrens- } \\
\text { änderungen an der wirtschaftspolitischen Steue- } \\
\text { rung) }\end{array}$ & $\begin{array}{l}\text { Einleitende } \\
\text { Mitteilung }\end{array}$ & $\begin{array}{l}\text { Weitestgehend Umsetzung in } \\
\qquad 2016^{*}\end{array}$ \\
\hline Nationale Ausschüsse für Wettbewerbsfähigkeit & $\begin{array}{l}\text { Empfehlung } \\
\text { einer } \\
\text { Ratsempfehlung }\end{array}$ & $\begin{array}{l}\text { Umsetzung als Ausschüsse für } \\
\text { Produktivität }{ }^{* *}\end{array}$ \\
\hline Fahrplan für die Außenvertretung des Euros & Mitteilung & $\begin{array}{l}\text { Lediglich kleinere } \\
\text { Veränderungen im } \\
\text { Koordinationsablauf }\end{array}$ \\
\hline Einheitliche Vertretung im IWF & $\begin{array}{l}\text { Vorschlag eines } \\
\text { Ratsbeschlusses }\end{array}$ & Bisher kein Beschluss \\
\hline Einrichtung eines Europäischen Fiskalausschusses & $\begin{array}{l}\text { Beschluss der } \\
\text { Kommission }\end{array}$ & Beschluss (EU) 2015/1937 \\
\hline $\begin{array}{l}\text { Programm zur Unterstützung von Strukturrefor- } \\
\text { men }\end{array}$ & VO-Vorschlag & VO (EU) $2017 / 825$ \\
\hline \multicolumn{3}{|c|}{$\begin{array}{l}\text { "Die Bewertung bezieht sich an dieser Stelle auf jene Aspekte (Neugestaltung des Europäischen Se- } \\
\text { mesters \& Verbesserungen an der wirtschaftspolitischen Steuerung), die nicht noch einmal gesondert } \\
\text { in einer eigenständigen Mitteilung oder einem anderweitigen Beschluss adressiert wurden. } \\
\text { vität, in: ABl. C349 vom 24.9.2016, S. 1-4. }\end{array}$} \\
\hline
\end{tabular}

Quelle: Eigene Zusammenstellung

Der mit dem Maßnahmenpaket angestoßene Konsolidierungsprozess ist dabei einerseits von einer partiellen Redefinition einzelner Aspekte der reaktiven Krisenbewältigungspolitik geprägt und adressiert überdies andererseits neue wie alte Herausforderungen im Zusammenhang mit der Euro-Krise. Mit ihm ist schließlich ein weiterer Ausbau des Interventionsrahmens verbunden, der sich im Unterschied zum reaktiven Staatlichkeitsausbau unter der Devise »Vertiefung durch Handeln« wesentlich stärker in - wenn auch nicht unwichtigen - Detailoperationalisierung statt an neuen Legislativ- oder größeren Vertragsakten abarbeiten wird und demnach mit abnehmender Krisenintensität unter geringerer Beobachtung der (medialen) Öffentlichkeit steht. Vor diesem Hintergrund sind die Ausbautätigkeiten demzufolge als inkrementell zu bezeichnen. 


\subsection{Konsolidierung des fiskalpolitischen Regierens}

Ausgangspunkt der Reflexionen im Kontext fiskalpolitischen Regierens stellte die trotz lockerer EZB-Geldpolitik weiterhin nur geringe Investitionstätigkeit dar, die zunehmend als Hemmnis für eine schnelle wirtschaftliche Erholung und einen Wirtschaftsaufschwung angesehen wurde (vgl. u.a. Baldi et al. 2014). Die zurückhaltende private Investitionstätigkeit wurde durch die öffentliche Investitionszurückhaltung in Folge der restriktiven Fiskalvorgaben weiter verstärkt (vgl. u.a. Gechert 2015). Die Kommission rief daher die Mitgliedstaaten dazu auf, Anstrengungen zu unternehmen, um die private wie die öffentliche Investitionstätigkeit auszubauen (vgl. KOM 2012a). Die Kommission schien, um dieses Ziel zu erreichen, schon 2012 bereit, nötige Feinjustierungen im Rahmen der Fiskalverfassung zur Anwendung zu bringen. So stellen laut Kommission

»[0̈]ffentliche Investitionen [...] einen der einschlägigen Faktoren dar, die es zu berücksichtigen gilt, wenn die Haushaltslage eines Mitgliedstaats im Rahmen des Berichts gemäß Artikel 126 Absatz 3 AEUV bewertet wird, der vor Einleitung eines VÜD vorzulegen ist. Seit der letzten Reform des SWP kommt den einschlägigen Faktoren wie öffentlichen Investitionen bei der Bewertung eine wesentlich höhere Bedeutung zu. Unter bestimmten Voraussetzungen kann deren Berücksichtigung dazu führen, dass auf die Eröffnung eines VÜD gegen einen Mitgliedstaat verzichtet wird.« (Ebd., 27)

Weiterhin kündigte die Kommission an, »aus[zu]loten, ob die präventive Komponente weitere Möglichkeiten bietet, Investitionsprogramme bei der Bewertung von Stabilitäts- und Konvergenzprogrammen zu berücksichtigen.« (Ebd., 28) Hierdurch eröffnete die Kommission letztlich eine Diskussion über eine weniger strikte Anwendung der Defizitregelungen des Stabilitäts- und Wachstumspakts (vgl. auch KOM 2015e). Dieser ersten, durchaus überraschenden Ankündigung im Jahr 2012 folgte allerdings schnell die Dämpfung allzu umfassender Erwartungen. So machte die Kommission unmissverständlich klar, dass zwar ein gewisser Interpretationsspielraum innerhalb des SWP nutzbar gemacht werden könne, den es allerdings nicht in dem Sinne misszuverstehen gelte, dass »[s]pezifische Bestimmungen für Investitionsvorhaben [...] mit einer >goldenen Regek gleichgesetzt werden, die eine unbefristete Ausnahmeregelung für sämtliche öffentliche Investitionen zulassen würde.« (KOM 2012a, 28) Hoffnungen auf eine wirkliche fiskalpolitische Wende weg von einem einseitigen Austeritätsansatz sollten insofern durch die Kommissionsankündigungen nicht genährt werden, zumal es noch bis zum Jahr 2016 dauerte, bis aus der Ankündigung eine veränderte Praxis resultierte (vgl. ECOFIN 2016; WFA 2015a). Diese war eingebettet in ein Set von Maßnahmen zur wirtschaftlichen Stimulierung, die von der neuen Juncker-Kommission im Herbst 2014 lanciert wurden. Ein Teil hiervon ist die sogenannte Investitionsoffensive (vgl. KOM 2014b), durch die der Investitionsflaute begegnet werden sollte.

\section{Die Investitionsoffensive}

Der Offensive vorausgegangen war Junckers Rede am 15. Juli 2014 vor dem Europäischen Parlament, in der er ankündigte: 
»Meine erste Priorität als Kommissionspräsident gilt der Stärkung der Wettbewerbsfähigkeit Europas und der Belebung der Investitionstätigkeit in Europa, um auf diese Weise neue Arbeitsplätze zu schaffen. Mein Ziel ist es, innerhalb der ersten drei Monate meines Mandats im Rahmen der Überprüfung der Europa-2020-Strategie ein ehrgeiziges Paket zur Förderung von Arbeitsplätzen, Wachstum und Investitionen zu schnüren.« (Juncker 2014, 4)

Dabei verortete sich der neue Kommissionspräsident durchaus in den langen Linien der Vorgängerkommission, indem er anmahnte, dass Wachstum nicht auf Grundlage wachsender Schuldenberge geschaffen werden könne und stattdessen vorschlug, bestehende EU-Instrumente (EIB \& Strukturfonds) für einen Investitionsimpuls zu nutzen (vgl. ebd.). Wie genau ein solcher Impuls aussehen solle, führt die Kommission in ihrer Mitteilung vom 2. November 2014 näher aus. Demnach basiert die Investitionsoffensive auf drei Komponenten:

»1.) Mobilisierung von zusätzlichen Investitionsmitteln in Höhe von mindestens 315 Mrd. EUR in den nächsten drei Jahren, um die Wirkung der öffentliche[n] Mittel zu maximieren und private Investitionen zu erschließen, 2.) gezielte Initiativen, durch die sichergestellt wird, dass diese zusätzlichen Investitionen auf die Bedürfnisse der Realwirtschaft abgestimmt sind, und 3.) Maßnahmen zur Verbesserung der Vorhersehbarkeit der regulatorischen Rahmenbedingungen und zum Abbau von Investitionshemmnissen mit dem Ziel, Europa für Investitionen attraktiver zu machen und so die Auswirkungen der Investitionsoffensive zu vervielfachen.« (KOM 2014b, 3f.)

Kernstück hierbei ist der, vom Europäischen Rat mitgetragene (vgl. ER 2014b \& 2014c), Vorschlag zur Schaffung eines neuen Fonds für strategische Investitionen, der bereits in der November-Mitteilung detailliert beschrieben (vgl. KOM 2014b) und im Januar 2015 auf Grundlage eines Verordnungsvorschlags der Kommission (2015m) weiter ausgeschärft wurde. Mit der Investitionsoffensive sei die Erwartung verbunden, »an verschiedenen Fronten gleichzeitig zu handeln und dabei sowohl auf der Angebots- als auch auf der Nachfrageseite der Wirtschaft tätig zu werden.« (KOM 2014b, 3) Die Mitgliedstaaten sollten sich hierbei von dem Grundsatz leiten lassen, dass »Mitgliedstaaten mit haushaltspolitischem Handlungsspielraum [...] mehr investieren« und »Mitgliedstaaten mit eher begrenzten haushaltspolitischen Möglichkeiten [...] investitions- und wachstumsbezogene[n] Ausgaben in ihrem Haushalt Vorrang geben [sollten] (ebd., 3). Ob eine Investitionsoffensive unter solchen Prämissen allerdings tatsächlich einen markanten Impuls setzen kann, ist eher fragwürdig. Festzuhalten gilt allerdings, dass die herausgestellte Notwendigkeit öffentlicher Investitionstätigkeit sicherlich einen wichtigen Reorientierungstatbestand darstellt. Das grundsätzliche Dilemma der verhaltenen Investitionstätigkeit in der EU, die sich in der Übertragung der Investitionsverantwortung $\mathrm{zu}$ einem Großteil auf Private zeigt, lässt sich hierdurch jedenfalls nicht lösen. Gerade die Lehren aus der Finanzkrise sollten aber deutlich gezeigt haben, dass der unterstellte positive Zusammenhang zwischen staatlichem Investitionsverzicht und privater Investitionstätigkeit nicht gegeben ist. Die Finanzkrise selbst ist das Produkt einer Überakkumulation von Kapital, das statt investiv in die Realwirtschaft zur Spekulation auf den Finanzmärkten eingesetzt wurde. Flassbeck \& Steinhardt $(2018,184)$ sprechen in die- 
sem Zusammenhang von »funktionslosen Gewinnen «, die man den privaten Akteur"innen im Goldenen Zeitalter des Neoliberalismus vor Ausbruch der globalen Finanzkrise mit dem Ziel verschafft hatte, dass diese ihre Gewinne reinvestieren, um hierüber neue Nachfrage zu schaffen. Das Ergebnis dieser Strategie sei allerdings als »katastrophal« (ebd., 184) zu bezeichnen. Nun aber, ein halbes Jahrzehnt nach dem Finanzcrash, sollen es genau jene Mechanismen richten, die mit in die Krise geführt haben, um Europa aus seinem Investitionstief zu befreien. Dass auch der öffentliche Anteil an der Investitionsoffensive lediglich ein Placebo ist, wird deutlich, wenn man den Fonds für strategische Entwicklungen genauer betrachtet. Grundlage des Fonds ist eine Garantie von 16 Milliarden Euro aus dem EU-Haushalt, die um weitere 5 Milliarden Euro von der Europäischen Investitionsbank ergänzt wird. Die Haushaltsmittel sollen langfristige Investitionen im Umfang von 240 Milliarden Euro generieren, wohingegen auf Grundlage der EIB-Garantien Finanzmittel in Höhe von 75 Milliarden Euro speziell für KMUs bereitstehen sollen. Entsprechend geht die Kommission von einem Multiplikatoreffekt von 1:15 bei den Fonds-Einlagen aus (vgl. KOM 2014b, 8). Anders als man es erwarten könnte, stellen die EU-Garantien allerdings keine neuen finanziellen Ressourcen dar. Es handelt sich lediglich um eine Umschichtung von bereits zuvor eingeplanten Finanzmitteln für die Finanzierungslinien »Horizont 2020« und »Connecting Europe«. Neu geschaffen werden mit dem Fonds hingegen zwei Instrumente zur Verbesserung des Wirtschaftsregierens. So soll die Sichtbarkeit von künftigen Investitionsvorhaben für Investor*innen über die Lancierung eines Europäischen Investitionsvorhabenportal (vgl. Art. 15 VO (EU) 2015/1017) erhöht und eine Europäische Plattform für Investitionsberatungen eingerichtet werden (vgl. Art. 14 VO (EU) 2015/1017). Ziel der Plattform sei

»Unterstützung in Form von Beratung bei der Ermittlung, Vorbereitung und Entwicklung von Investitionsvorhaben zu leisten und als zentrale technische Anlaufstelle für die Vorhabenfinanzierungsberatung in der Union zu fungieren. Eine solche Unterstützung erstreckt sich unter anderem auf eine zielgerichtete Unterstützung in Bezug auf den Einsatz technischer Hilfe bei der Vorhabenstrukturierung, die Nutzung innovativer Finanzinstrumente und dem Einsatz öffentlich-privater Partnerschaften sowie gegebenenfalls auf die Beratung zu relevanten Themen mit Bezug auf das Unionsrecht, wobei die Besonderheiten und Bedürfnisse von Mitgliedstaaten mit weniger entwickelten Finanzmärkten zu berücksichtigen sind.«(Art. 14, Abs. 1 VO (EU) 2015/1017)

Die Plattform verweist somit insgesamt auf eine Rationalität, in deren Zentrum ein als Marktakteur agierender staatlicher Investor (’governing through financial markets‘; vgl. Braun, Gabor \& Hübner 2018) im Unterschied zum Ansatz des investiven Etatismus unter keynesianischen Vorzeichen steht. Dabei solle der staatliche Investor schließlich »im Rahmen $d[$...]er Offensive verbindlich zusagen, in innovationsträchtigen Schlüsselbereichen [...] viel häufiger innovative Finanzinstrumente heranzuziehen." (KOM 2014b, 10) Die Plattform und das Investitionsinformationsportal stellen ihrerseits die konkreten Bausteine zum zweiten Ziel der sogenannten Juncker-Offensive dar, mit dem die zielgerichtete Lenkung der Finanzmittel in die Realwirtschaft beabsichtigt werde (s.o.). Schließlich sei mit der Investitionsoffensive drittens die generelle Verbesserung des Investitionsumfeldes beabsichtigt. Innerhalb dieser Komponente »wird angestrebt, für eine bessere Berechenbarkeit der Regulierung zu sorgen, europaweit 
Investitionshemmnisse abzubauen und den Binnenmarkt durch Schaffung optimaler Rahmenbedingungen für Investitionen in Europa weiter zu stärken.« (Ebd., 14) Zusammengenommen umfasst diese dritte Komponente die Fokussierung auf weitere Strukturreformen sowohl auf Ebene der Mitgliedstaaten wie auch auf EU-Ebene. Als Ziele gelten hierbei unter anderem effizientere Steuersysteme, intelligentere Regulierung und die Schaffung von verbesserten Wettbewerbsbedingungen insbesondere für KMU (vgl. ebd., 14f.). Im Sinne der dritten Zielkomponente verweist die Investitionsoffensive des ausgehenden Jahres 2014 bereits auf zwei weitere zentrale Anliegen der Juncker-Kommission: die aufkommende Binnenmarktagenda (vgl. KOM 20150) und die Bemühungen zur Schaffung einer Kapitalmarktunion (KOM 2015a \& 2015b). Die Kapitalmarktunion kann dabei als eine Art Bindeglied zwischen der Wirtschafts- und der im Aufbau befindlichen Bankenunion sowie dem EU-Binnenmarkt gelten. Sie zielt auf einen eigenständigen europäischen Finanzbinnenmarkt und dient der »Verbesserung des Zugangs zu Finanzmitteln für alle Unternehmen in ganz Europa (insbesondere KMU) und für Investitionsprojekte, etwa im Bereich Infrastruktur« (KOM 2015a, 5f.). Durch die »Ausweitung und Diversifizierung der Finanzierungsquellen« solle sie »Anleger und Unternehmen oder Projekte mit Finanzierungsbedarf [...] kostengünstiger zusammenbringen « (ebd.) und ist somit als ein Akt des market-buildings zu verstehen, der in seinen Grundfesten wiederum im Kontrast zu den Erfahrungen aus der Finanzkrise steht. Insbesondere, wenn sich die Kommission von einem Kapitalbinnenmarkt die »Neubelebung der Verbriefungsmärkte« oder die Ausweitung der Praxis von »Privatplatzierungen auf breiterer Front « erhofft (vgl. KOM 2014b, 16); kurzum: Finanzialisierung revisited! (Vgl. auch Engelen \& Glasmacher 2018) Sind zwar erste, wenn auch nur leichte, Reorientierungen erkennbar, die eine strikte Unterordnung der Fiskalpolitik unter das Austeritätsprimat hinterfragen, werden gleichzeitig deren grundsätzliche Prämissen weiterhin gestützt. Insbesondere die mitgliedstaatlichen Regierungen bleiben an dieser Stelle den bisherigen Krisennarrativen treu. In der Schlussfolgerung des ECOFIN-Rats zur Investitionsförderung wird der Zusammenhang zwischen Investitionen, (angebotsseitigen) Strukturreformen sowie der Tragfähigkeit öffentlicher Finanzen noch einmal explizit herausgestellt: Demnach betonte der Rat,

»dass - als entscheidende Voraussetzung für die Förderung von Investitionen - ein Zusammenhang mit Strukturreformen besteht und dass es gilt, investitionsfreundliche Reformen zu ermitteln, zu fördern und umzusetzen, um europaweit ein günstiges Wirtschaftsumfeld zu schaffen und dabei die länderspezifischen Empfehlungen umfassend zu nutzen« (ECOFIN 2014, 3)

Weiterhin stellt er fest, »dass entsprechend dem Stabilitäts- und Wachstumspakt tragfähige öffentliche Finanzen eine wichtige Rolle bei der Schaffung eines investitionsfreundlichen Umfelds spielen« (Ebd.).

\section{"Optimale Nutzung der im Stabilitäts- und Wachstumspakt vorgesehenen Flexibilität"}

Bereits Ende 2012 tauchten in Veröffentlichungen der Kommission erste Hinweise da$\mathrm{zu}$ auf, die strikten fiskalpolitischen Regelungen des Stabilitäts- und Wachstumspakts aufgrund ihrer negativen Auswirkungen in Bezug auf eine rasche wirtschaftliche Er- 
holung zu hinterfragen (vgl. KOM 2012a, 27f.; s.o.). Der Prozess einer partiellen Reorientierung in Bezug auf die restriktiven haushaltspolitischen Vorgaben des SWP wurde zugleich in den Debatten um die von Juncker präsentierte Investitionsoffensive noch etwas verhalten aufgegriffen, mündete dann aber schließlich im Februar 2015 in einer Kommissionsmitteilung über die »Optimale Nutzung der im Stabilitäts- und Wachstumspakt vorgesehenen Flexibilität« (KOM 2015e). Kerngedanke der Mitteilung stellt eine Präzisierung und teilweise sogar Reinterpretation der SWP-Vorgaben dar, ohne hierbei jedoch den legislativen Rahmen des Paktes zu verändern (vgl. KOM 2015e, 3; KOM 2015c, 9f.). Die Kommission führt aus, dass es kein Zufall sei,

»[d]ass der Pakt in Bezug auf die Art und Weise der Anwendung seiner Regeln sowohl im Verlauf der Zeit als auch von Land zu Land eine gewisse Flexibilität vorsieht [...]. Auch wurde Kommission und Rat bewusst innerhalb der vereinbarten Regeln ein Ermessensspielraum belassen, die Beurteilung der Solidität der öffentlichen Haushalte unter Berücksichtigung der länderspezifischen Cegebenheiten vorzunehmen, um Empfehlungen für den sinnvollsten künftigen Kurs auf die jüngsten Entwicklungen und Informationen zu stützen.«(KOM 2015e, 4)

Konkret schlägt die Kommission in der Mitteilung neue Auslegungen für die Berücksichtigung von »Investitionen«, »Strukturreformen« und »Konjunkturlagen« als »einschlägigen Faktoren« (wie es in den Verordnungen offiziell heißt ${ }^{6}$ ) auf die Bewertung der mitgliedstaatlichen Fiskalpolitiken vor. Dies bedeutet, dass zum Beispiel die Beiträge zum Fonds für strategische Investitionen bei der Haushaltsbewertung und der potentiellen Einleitung eines VÜD nicht berücksichtigt werden sollten (vgl. ebd., 8). Weiterhin offeriert die Kommission den Mitgliedstaaten, vorübergehend - bei Wahrung des $3 \%$-Defizitziels - vom mittelfristigen Haushaltsziel oder dem Anpassungspfad hierauf abzuweichen, um Investitionen zu tätigen (vgl. ebd., 10), oder wenn sie größere Strukturreformen anstrebten (vgl. ebd., 13). Auch für Mitgliedstaaten, die sich in einem VÜD befinden, will die Kommission Strukturreformen künftig stärker bei der Festlegung der Anpassungsfristen berücksichtigen (vgl. ebd., 15). Die Resonanz auf die neuen Auslegungsvorschläge der Kommission war ausgesprochen positiv. Das Europäische Parlament teilt nahezu uneingeschränkt die Ausführungen der Kommission (vgl. EP 2015a, Rn. 16ff.) und selbst der Europäische Rat hatte bereits im Juni 2014 eine Art Freifahrtsschein ausgestellt, indem er schlussfolgerte, dass

»Strukturreformen, die das Wachstum steigern und die langfristige Tragfähigkeit der öffentlichen Finanzen verbessern, [...] besondere Aufmerksamkeit gewidmet werden [sollte], auch durch eine geeignete Bewertung der fiskalischen Maßnahmen und Struk-

6 In der Verordnung (EG) Nr. 1467/97 wird allgemein darauf hingewiesen, dass konjunkturelle Abschwünge bei der Bewertung der Tragfähigkeit öffentlicher Finanzen sowie des Schuldenstandskriteriums Rechnung getragen werden solle (vgl. insb. Art. 2). In der Verordnung (EG) Nr. 1466/97 finden sich neben der konjunkturellen Bewertungskomponente (vgl. insb. Art. 5) des Weiteren in Artikel 2a Hinweise auf die notwendige Berücksichtigung öffentlicher Investitionen sowie einschlägiger Faktoren, die es bei der Umsetzung von Strukturreformen in Bezug auf ihre Auswirkungen auf die öffentlichen Finanzen zu beachten gilt. 
turreformen unter optimaler Nutzung der in den geltenden Regeln des Stabilitäts- und Wachstumspakts enthaltenen Flexibilität.«(ER 2014a, Rn. 15)

Entsprechend dieser Leitlinie prüften auch die Fachminister*innen im Rat die Kommissionvorschläge wohlwollend und beauftragten den Wirtschafts- und Finanzausschuss (WFA) mit weiteren technischen Präzisierungen (vgl. ECOFIN 2015a, 8). Nachdem der WFA (2015a) im November 2015 eine abgestimmte Position vorgelegt hatte, nahm der ECOFIN-Rat diese zur Kenntnis (vgl. ECOFIN 2015b, 14) und billigte schließlich gemeinsam mit der Beauftragung der Überarbeitung des SWP-Code-of-Conducts die neuen Auslegungsmerkmale für den Stabilitäts- und Wachstumspakt (vgl. ECOFIN 2016). In diesem Zusammenhang beschlossen die Finanzminister*innen auch die von der Kommission vorgeschlagene Detailoperationalisierung zur »Festlegung der jährlichen Haushaltsanpassungen in Richtungen auf das mittelfristige Haushaltsziel«. Hierbei handelt es sich im Prinzip um eine nicht-legislative Reform einer der zentralen Ergänzungen durch das 2011er Six-Pack am SWP. Auf der Grundlage der neuen Matrix ergeben sich dabei in "außergewöhnlich schlechten Zeiten" keine erforderlichen Anpassungen; in "guten Zeiten « hingegen sollte die Anpassung - bei einem Schuldenstand über $60 \%$ des BIP und unter der Voraussetzung eines »Wachstums über Potenzial« bei über einem $1 \%$ liegen (vgl. KOM 2015e).

Überraschend an den Änderungen ist insgesamt, dass sie eine zentrale Stoßrichtung der Six-Pack-Reformen in Ansätzen aushebeln. Waren die 2011er Reformbemühungen insbesondere von dem Ziel getragen, den SWP in seiner »quasi-automatischen « Auslegung zu stärken, wirken die 2016 beschlossenen Flexibilisierungsmaßnahmen genau in die entgegengesetzte Richtung. Dies führt zu neuen Interpretationsspielräumen der Kommission, die hierdurch in ihrer Exekutivfunktion gestärkt wird. Diesen Wandel forcierte die Kommission auch im darauffolgenden Semester 2017. In der einleitenden Mitteilung zu den länderspezifischen Empfehlungen gibt sie die Leitlinie aus, dass die

»Mitgliedstaaten, wenn sie Maßnahmen zur Erreichung der im Rahmen der präventiven Komponente des Pakts empfohlenen Haushaltskorrekturen einleiten, sowohl der Tatsache, dass die Konjunkturerholung gestützt werden muss, als auch den potenziellen Auswirkungen auf die Beschäftigung Rechnung tragen [sollten].« (KOM 2017l, 19)

In diesem Sinne sei die Kommission bereit, »bei künftigen Bewertungen in Fällen, in denen sich große Haushaltskorrekturen besonders signifikant auf das Wachstum und die Beschäftigung auswirken, ihren Ermessensspielraum zu nutzen.« (Ebd., 19) Der Europäische Rechnungshof (2018b, 13) hingegen hegt Zweifel daran, ob »[m]it den von der Kommission beschlossenen Durchführungsbestimmungen und ihren operativen Entscheidungen [...] sichergestellt [ist], dass das Hauptziel der Verordnung erreicht wird. « Der Rechnungshof empfiehlt in seinem Sonderbericht deshalb die »wichtigsten Komponenten des Rahmens [...] auf koordinierte Art und Weise« (ebd., 14) zu verschärfen und somit den neuen Ermessensspielraum der Kommission zurückzudrängen. Der kommissionseigene Beraterkreis des 2015 etablierten Europäischen Fiskalausschusses (ausführlich s.u.) hält dem entgegen: »To be clear, discretion as such is not the issue. What matters is how discretion is exercised: on the basis of economic reflections or other considerations. « (EFA 2017b, 4) Bisher blieb der Ruf der Rechnungsprüfer*innen 
jedenfalls ungehört, wenngleich es nicht auszuschließen ist, dass er im Zuge künftiger krisenhafter Verwerfungen erneut zum Ausgangspunkt neuer politischer Vorstöße werden könnte. Vorerst bleibt an dieser Stelle aber die Feststellung zu wiederholen, nach der dem SWP eine Anpassung unterzogen wurde, die sich in einer inoffiziellen Abkehr vom orthodoxen hin zu einem pragmatischeren Austeritätsverständnis äußert.

Ein solcher Wandlungsprozess deutet sich auch in jenem Streit an, der innerhalb des Ausführungsorgans des autoritär-intergouvernementalen Gläubigerregimes, der Troika, im Kontext des Phasenwechsels ausbrach. Im Mittelpunkt der Auseinandersetzung stand dabei die Frage, welchen Effekt Budgetkürzungen auf die Wirtschaftsleistung eines Landes nehmen. »By 2012 a series of IMF studies had shown negative fiscal multipliers greater than one for the periphery countries of Europe, which meant that a $1 \%$ cut in public expenditure led to a greater than $1 \%$ cut in GDP, with no offsetting confidence effects.« (Matthijs \& Blyth 2018, 119) Übersetzt bedeutet dieser Zusammenhang, dass bei einer Ausgabenkürzung um einen Euro die Wirtschaftsleistung (ausgedrückt im BIP) um mehr als einen Euro sinkt (vgl. Blyth 2014, 344), was der Annahme entgegensteht, nach der Ausgabenkürzungen positive, mindestens aber ausgleichende Effekte im Bereich der privaten Marktakteure auslösten. Auf den Punkt gebracht, bedeuten die IWF-Annahmen die Diskreditierung der bis dato getätigten reaktiven Krisenbewältigungspolitik, die nicht nur in den Programmländern ein striktes Austeritätsdiktat durchzusetzen suchte, sondern auch in Form der sekundärrechtlichen Normierungen eine strikte Fiskalpolitik protegierte. »In making this challenge [...] the ECB and EC approach to the crisis was attacked from within the Troika itself.« (Matthijs \& Blyth 2018, 119) Trotz der Reorientierungen des IWF, die auf einem längeren Reflexionsprozess seit 2008 beruhten (vgl. Ban 2015), hielt die Kommission hingegen an ihren bisherigen Annahmen in Bezug auf die fiskalischen Multiplikatoreneffekte fest (vgl. Blyth 2014, 345; vgl. auch KOM 2012c) und fand stattdessen eine andere Begründung dafür, dass sich die Effekte bis dato noch nicht wie erwartet eingestellt hätten: »The Commission argued that, in essence, while the IMF was correct, Troika policies were the right policies, but that the multipliers would have been less than one had it not been for a lot of people talking about the break-up of the euro, which made things worse." (Matthijs \& Blyth 2018, 119) Auch die OECD unterstützte später (2016) die Bewertungen des IWF in Bezug auf die negativen Auswirkungen der Austeritätspolitik (vgl. ebd., 119). Trotz des bröckelnden Blocks strikter Austeritätsbefürworter*innen bleibt die EU bis heute offiziell auf ihrem Standpunkt stehen. Matthijs \& Blyth $(2018,119)$ gelangen daher zu folgendem Fazit: »[I]f social learning [...] is going on in Europe, it should, we argue, be understood as a process where the wrong lessons seem to be constantly reaffirmed as a part of an ongoing authority contest over what the crisis means, and who gets to dictate how to respond. "Diese Zuschreibung ist im Kern zutreffend, da ein Zugeständnis an dieser Stelle zur Diskreditierung der gesamten reaktiven Krisenbewältigungspolitik führen würde. Auch die Zuspitzungen im Konflikt mit Griechenland im Jahre 2015 um weitere Hilfskredite (ausführlich s.u.) verweisen darauf, dass den EUSA im Grunde daran gelegen ist, die austeritäre Drohgebärde als Disziplinierungsmaßnahme aufrecht zu erhalten; auch wenn - und an dieser Stelle gilt es, die Feststellung Matthijs' \& Blyths zu revidieren - innerhalb der EUSA ebenfalls längst ein affirmativer Wandel in Richtung der IWF-Position stattgefunden hat. So argumentieren Bibow \& 
Flassbeck (2018, 95f.), dass ab 2013 die Sparpolitik weitgehend ausgesetzt, wenn auch nicht generell beendet worden sei (vgl. auch Hodson 2017, 127). Auch Cornillie (2017) führt beispielsweise die wirtschaftliche Erholung Spaniens seit 2015 auf das Aussetzen der Sparmaßnahmen zurück und Truger $(2018,1)$ hält fest, »[d]ass die aktuelle Krise in den Ländern der europäischen Peripherie - zumindest vorläufig - überwunden wurde, [...] ganz wesentlich mit einer lockereren Handhabung der fiskalischen Regeln zusammen[hängt]." Insgesamt zeigt sich somit, dass sich hinter der offiziellen Fassade des orthodoxen Austeritätskurses eine leichte Reorientierung vollzogen hat, die auf ein pragmatischeres Austeritätsverständnis zielt, ohne dabei allerdings die Drohgebärden der neuen Notstandsverfassung und ihres autoritär-intergouvernementalen Gläubigerregimes im Grundsatz aufzugeben.

\section{Die Etablierung des Europäischen Fiskalausschusses als neues Hilfsorgan der Kommission}

Als eine der konkreten Maßnahmen des >dritten Economic-Governance-Pakets schuf die Kommission durch den Beschluss (EU) 2015/1937 den sogenannten Europäischen Fiskalausschuss (EFA), dessen Hauptaufgabe darin bestehe,

»die Umsetzung der haushaltspolitischen Rahmenvorschriften der EU [zu] evaluieren und dabei insbesondere die horizontale Kohärenz der Beschlüsse und die Durchführung der haushaltspolitischen Überwachung sowie besonders schwere Verstöße gegen die Vorschriften [zu] berücksichtigen und [zu] prüfen, ob der jeweilige auf Ebene des Euro-Währungsgebiets und auf nationaler Ebene eingeschlagene haushaltspolitische Kurs angemessen ist. (KOM 2015c, 13; vgl. Erw. (4) \& Art. 2, Abs. 2a Beschluss (EU) 2015/1937)

In dieser Diktion trägt der Ausschuss »in beratender Funktion zur Wahrnehmung der Aufgaben der Kommission im Rahmen der multilateralen fiskalpolitischen Überwachung des Euro-Währungsgebiets im Sinne der Artikel 121, 126 und 136 AEUV bei.«(Art. 2, Abs. 1 Beschluss (EU) 2015/1937) Aufgrund seiner Größe (vier Mitglieder plus ein*e Vorsitzende" $r$ ) ist der Ausschuss als ein exklusives Beratungsgremium der Kommission, die verantwortlich für die Berufung der Mitglieder ist (vgl. Art. 3 Beschluss (EU) 2015/1937), konzipiert. Der Ausschuss übt insofern auch eine legitimatorische Funktion aus, indem er durch seine Beratungstätigkeit das politische Handeln der Kommission in gewisser Weise zu expertisieren verhilft. Dies erscheint umso wichtiger, je stärker die Kommission von ihren Ermessensspielräumen im SWP- und MIP-Rahmen Gebrauch macht. In einem solchen Sinne stützte der EFA beispielsweise auch die Reorientierungen der Kommission seit 2015 in Bezug auf die flexiblere Ausrichtung des SWP (vgl. EFA 2017a \& 2018), was sich nicht zuletzt auch in der Reaktion auf den Sonderbericht des Europäischen Rechnungshofs zeigte (s.o.).

Gleichzeitig, hierauf deuten die bisherigen Aktivitäten des EFA hin, scheint sich durch die Etablierung des Ausschusses auch die Reformdebatte weiter im Sinne der Kommission beeinflussen zu lassen (Stichwort: Meta-Governance). Auch wenn sich der Kommission ein solches Kalkül lediglich hypothetisch unterstellen ließe, fällt auf, dass der EFA in seinen bisherigen Berichten beispielsweise fortwährend die Position vertritt, dass eine zentrale Fiskalkapazität für den Euro-Raum geschaffen werden sollte (vgl. EFA 
2017a; 2017b \& 2018), wie sie nicht zuletzt auch von der Kommission selber eingefordert wurde (vgl. Vertiefungskonzept 2012, späteres Nikolauspaket 2017 \& Fiskal-TwoPack 2018; ausführlich s. u.). Man könnte entsprechend von einem klugen Schachzug der Kommission sprechen, mit dem EFA eine Institution geschaffen zu haben, die dazu beiträgt, den Diskursraum positiv in Richtung auf die Kommissionspräferenzen zu verschieben. In einem solchen Verständnis lässt sich der EFA als eine Art neu geschaffenes Hilfsorgan der Kommission und somit auch als Stärkung ihrer Exekutivrolle verstehen.

\subsection{Konsolidierung des wirtschaftspolitischen Regierens}

Bereits im Jahreswachstumsbericht für das Jahr 2014 kündigte die ausscheidende Barroso-Kommission an, dass es »[i]n Bezug auf eine Vertiefung des Prozesses des Europäischen Semesters [...] eine ganze Reihe von Bereichen [gibt], in denen weitere Verbesserungen notwendig sind, wenn die neue wirtschaftliche Steuerung durch die EU ihr volles Potenzial entfalten soll.« (KOM 2013a, 6) Die Barroso-Kommission verstand hierunter unter anderem, die mitgliedstaatliche Eigenverantwortung zu erhöhen, indem die mitgliedstaatlichen Parlamente ebenso wie die Sozialpartner"innen in die Diskussion der nationalen Reform- sowie der Stabilitäts- und Konvergenzprogramme einbezogen werden sollten (vgl. ebd., 6f.). Weiterhin forderte sie eine engere Abstimmung zwischen den Mitgliedstaaten, insbesondere bei der Vorab-Koordinierung wichtiger wirtschaftspolitischer Maßnahmen (vgl. ebd., 7), sowie letztlich eine bessere Befolgung der länderspezifischen Empfehlungen, was durch »quasi-vertragliche Vereinbarungen in Verbindung mit einer finanziellen Unterstützung« (ebd., 7) erreicht werden solle. Die beiden letztgenannten Vorschläge sind die bereits bekannten Vorhaben aus dem März 2013, die zwar nicht in ihrer vorgeschlagenen Variante verwirklicht wurden, die allerdings zusammen mit dem Jahreswachstumsbericht 2014 einen Reflexionsprozess über die Funktionsweisen des Europäischen Semesters und mit ihm der weiteren Interventionsrahmen des wirtschaftspolitischen Regierens in Gang setzten. Am Ende dieses Prozesses (2016) steht das sogenannte »Streamlining« des Semesterzyklus und des MIP sowie der Ausbau der Interventionskapazitäten im Kontext von Strukturreformen zur Erhöhung der Wettbewerbsfähigkeit.

\section{Streamlining des Europäischen Semesters und des MIP}

Das Europäische Semester weist bereits seit seinen Anfängen den Charakter eines lernenden Systems auf; kaum ein Semester gleicht dem anderen. ${ }^{7}$ Mehrfach wurden seit dem ersten Durchgang 2011 Zeitpläne, der Code-of-Conduct oder kommissionsseitige Bewertungsmaßstäbe verändert. In diesem Zusammenhang wurde bereits auf die abnehmende Zahl der länderspezifischen Empfehlungen - als wichtigstes Herrschaftsinstrument des Semesters - hingewiesen (vgl. Kapitel 7.3). Trotz dieser permanenten,

$7 \quad$ Neben der Kommission spielt bei der Verbesserung der semesterbezogenen Abläufe und Verfahren der Wirtschafts- und Fiskalausschuss eine entscheidende Rolle. Er zieht zum Ende eines Semesterzyklus jeweils Rückschlüsse (»lessons learned«) für die künftigen Zyklen (vgl. u.a. WFA 2013a; 2015b; 2016a; 2017; 2018). 
inkrementellen Fortentwicklung nehmen die fünf Präsidenten in ihrem Bericht das Europäische Semester noch einmal dezidiert in den Blick und forderten weitere "Schritte zur Straffung und Stärkung« (Juncker et al. 2015b, 10). Konkret schlägt die Kommission in ihrer Oktober-Mitteilung 2015 vor, die Euroraum-Dimension im Zyklus zu stärken. Hierzu beabsichtige sie, im Jahreswachstumsbericht »ihr Augenmerk insbesondere auf die zentralen budgetären, wirtschaftlichen und finanziellen Prioritäten für das Euro-Währungsgebiet insgesamt « (KOM 2015c, 4; Herv. J. G.) zu legen. Zugleich forderte sie die Euro-Gruppe auf, »bei der Beurteilung der Entwürfe der Übersichten über die Haushaltsplanung den haushaltspolitischen Kurs des Euro-Währungsgebiets gesondert zu erörtern.« (Ebd., 4f.) Zum Zweiten möchte die Kommission im Europäischen Semester eine stärkere Fokussierung auf die Themenbereiche »Beschäftigung « und »Soziales« erreichen. $\mathrm{Zu}$ diesem Zweck verweist sie auf die Ergänzung des Scoreboards um arbeitsmarktbezogene Indikatoren sowie auf ein neues Verfahren zur sozialen Folgeabschätzung im Rahmen von Stabilitätshilfen (wobei dieses allerdings nicht Gegenstand des Europäischen Semesters ist!). Dieses Verfahren kam erstmals vor dem dritten Griechenland-Paket zur Anwendung, indem die Kommission eine Analyse über die sozialen Folgewirkungen der Programmmaßnahmen durchführte (vgl. KOM 2015n). Gemeinsam mit der Absicht zur Lancierung der sogenannten »europäischen Säule sozialer Rechte« (ESSR) (ausführlich s.u.) und der sozialen Folgenabschätzungen bekräftigt sie schließlich noch einmal das Flexicurity-Konzept als wichtigen Bezugsrahmen für die EU-Beschäftigungspolitik im Rahmen des Europäischen Semesters (vgl. KOM 2015c, 6). Zur Stärkung des Wirtschaftsregierens möchte die Kommission des Weiteren das »Benchmarking« zur Förderung von Konvergenz ausbauen:

»Ab dem [...] Semester 2016 wird die Kommission schrittweise Benchmarks und vergleichende Untersuchungen zwischen Politik- und Themenbereichen vorschlagen. Deren Ergebnisse werden in die Diskussion der jeweiligen Ratsformation und der EuroCruppe einfließen, um so ein gemeinsames Verständnis der Herausforderungen und Cegenmaßnahmen der Politik zu fördern.«(Ebd., 7)

Zur Stärkung der länderspezifischen Empfehlungen schlug die Kommission schließlich eine gezielte Reformförderung durch EU-Fonds und die Gewährung technischer Unterstützung vor, die einen Monat später in einem separaten Verordnungsvorschlag (vgl. KOM 2015g) mündete (s.u.). Die von der Kommission vorgeschlagenen Änderungen am Europäischen Semester wurden bereits mit dem im November 2015 einsetzenden Semesterzyklus 2016 umzusetzen begonnen. Insbesondere ein neuer Zeitplan - das Semester baut nun auf zwei Stufen auf (erste Stufe von November bis Februar mit Fokus auf die europäische Komponente und zweite Stufe von Februar bis Juni mit Fokus auf die mitgliedstaatliche Komponente) - wurde hierbei zur Anwendung gebracht (vgl. KOM 2015k, 5). Dabei gehe es der Kommission auch um eine höhere Rechenschaftspflicht des Verfahrens:

»Die Kommission hat das Europäische Semester seit vergangenem Jahr erheblich gestrafft und einen vertieften Dialog mit den Mitgliedstaaten eingeführt, indem sie beispielsweise Interessenträger auf allen Ebenen schon im Vorfeld einbindet, ihre Leitlinien nach klaren Schwerpunkten ausrichtet und die Länderberichte im Februar veröf- 
fentlicht, so dass mehr Zeit für die Vorbereitung der länderspezifischen Empfehlungen bleibt.«(Ebd., 19)

Daneben erörterte die Kommission Vorschläge zur Stärkung des Verfahrens bei makroökonomischen Ungleichgewichten. Hierbei möchte sei im MIP-Rahmen ebenfalls die Eurozonen-Dimension stärken, indem sie »Erwägungen, die das gesamte EuroWährungsgebiet betreffen, [...] besser in die maßgeblichen Dokumente (den Warnmechanismusbericht und die Mitteilung über die Ergebnisse der eingehenden Überprüfungen) und Beschlüsse integriert.« (KOM 2015c, 11) Weiterhin kündigte die Kommission an, das Kategorienset des MIP, welches bereits mehrfach verändert wurde, zu konsolidieren und überdies den Rat stärker in das Monitoring jener Länder einzubeziehen, die zwar ein übermäßiges Ungleichgewicht aufweisen, für die allerdings kein EIP eingeleitet worden sei (vgl. ebd., 11). Schließlich kündigt die Kommission die Veröffentlichung eines Kompendiums an, in dem sie alle MIP-relevanten Informationen sammeln und darstellen möchte, um hierdurch die Transparenz des Verfahrens zu erhöhen (vgl. ebd., 10).

Ein Ergebnis dieser angekündigten Reflexion des MIP-Verfahrens stellte die im Frühjahr 2016 vorgenommene Reduktion der Ungleichgewichts-Kategorien dar, die mittlerweile eine sechsstufige Skala umfasste. ${ }^{8}$ Statt der sechs sollen künftig lediglich vier Schweregerade bei Ungleichgewichten unterschieden werden (vgl. KOM 2016d, 32). Um dem Eindruck entgegenzuwirken, dass das neue Kategorienset eine Schwächung der dem MIP inhärenten Überwachung der Mitgliedstaaten implizieren könne, hält die Kommission (2016d, 33) weiterhin fest: »[T]he Commission put in place in 2016 specific monitoring for all countries identified with either imbalances or excessive imbalances. Monitoring is modulated according to the severity of the challenges and depending on whether the identified imbalances are excessive or not.« Dabei sollen auch die sgestrafften länderspezifischen Empfehlungen eine höhere compliance mit dem MIP-Verfahren sicherstellen. Durch eine Reduktion der Empfehlungen und ihrer Fokussierung auf die politischen Prioritäten des Jahreswachstumsberichts erhoffte sich die Kommission, das Semester »wirksamer« und »relevanter« zu gestalten: Die Kommission

»hat dieses Jahr die Zahl der Empfehlungen weiter gesenkt und dabei den Schwerpunkt auf wichtige wirtschafts- und sozialpolitische Themen gelegt, die sie bereits in ihrem Jahreswachstumsbericht für 2016 herausgestellt hatte. Um die Eigenverantwortung der Mitgliedstaaten für den Prozess zu stärken, hat sie mehr Zeit in den Austausch mit den Mitgliedstaaten und den sonstigen Beteiligten auf allen Ebenen investiert. Ferner hat sie - im Einklang mit der vereinbarten Empfehlung für die Wirtschaftspolitik im Euro-Währungsgebiet - die Herausforderungen für das Euro-Währungsgebiet und die Interdependenz zwischen den Volkswirtschaften stärker in den Mittelpunkt gestellt.«(KOM 2016b) 
Ähnlich wie beim Prozess der Reorientierung im SWP werden auch die prozeduralen Veränderungen im Bereich des Europäischen Semesters und des MIP-Verfahrens bereitwillig mitgetragen. So begrüßt das Europäische Parlament (2016, Rn. 5)

»den von der Kommission verfolgten Ansatz, die Anzahl der Empfehlungen zu begrenzen, und ihre Bemühungen, das Semester zu optimieren, indem bei der Festlegung der politischen Ziele der nächsten 18 Monate hauptsächlich Schwerpunktthemen von makroökonomischer und sozialer Tragweite einbezogen werden« (vgl. auch EP 2015, Rn. 34).

Auch die weiteren Anpassungen fügen sich in die vom Parlament geäußerten Verbesserungswünsche ein. So wies es bereits im Juni 2015 in einer Bestandsaufnahme der wirtschaftspolitischen Steuerung auf die

»große Bedeutung von einfachen und transparenten Verfahren für die wirtschaftspolitische Steuerung hin und warnt davor, dass die derzeitige Komplexität des Rahmens, die mangelnde Umsetzung und das Fehlen der Übernahme von Verantwortung seiner Wirksamkeit und seiner Akzeptanz in den nationalen Parlamenten, den lokalen Behörden sowie bei den Sozialpartnern und den Bürgern in den Mitgliedstaaten abträglich sind «. (EP 2015, Rn. 13)

Entsprechend sind die Parlamentarier*innen »der Ansicht, dass eine vertiefte und widerstandsfähigere Wirtschafts- und Währungsunion dringend weniger Komplexität und mehr Eigenverantwortung und Transparenz anstatt eines bloßen Hinzufügens neuer Regeln zu dem bereits vorhandenen Regelwerk erfordert « (ebd., Rn. 48). Schließlich nimmt das Parlament

»zur Kenntnis, dass der Rahmen für die wirtschaftspolitische Steuerung unter Berücksichtigung der aktuellen Situation vereinfacht, besser durchgesetzt und gegebenenfalls korrigiert und vervollständigt werden muss, damit die EU und das Euro-Währungsgebiet den Herausforderungen in den Bereichen Konvergenz, nachhaltiges Wachstum, Vollbeschäftigung, Wohl der Bürger, Wettbewerbsfähigkeit, gesunde und nachhaltige öffentliche Finanzen, zukunftsorientierte dauerhafte Investitionen mit einer hohen sozial-ökonomischen Rendite und Vertrauen begegnen können« (ebd., Rn. 49).

Auch die Staats- und Regierungschefs im Europäischen Rat hatten bereits im Dezember 2015 grundsätzlich grünes Licht für die erste Stufe des Fünf-Präsidenten-Berichts gegeben (vgl. ER 2015, Rn. 14), in der auch das Streamlining des Europäischen Semesters und des MIP-Verfahrens vorgesehen war. Sie billigten schließlich auf ihrer März-Tagung 2016 den Jahreswachstumsbericht, in dem die Änderungen am Europäischen Semester beschrieben wurden (vgl. ER 2016b, Rn. 11). Auch die Änderungen im MIP wurden an keiner Stelle durch den (Europäischen) Rat infrage gestellt, vielmehr deutet sich an, dass der Rat selber der Ideengeber für die Straffung, Reduktion und Refokussierung der länderspezifischen Empfehlungen gewesen war (vgl. EuRH 2018a, 27). Lediglich der Europäische Rechnungshof kommt abermals zu der Einschätzung, dass die Änderungen dem eigentlichen Ziel des Verfahrens nicht dienlich seien. Die Rechnungsprüfer*innen kritisieren, dass »in den MIP-relevanten länderspezifischen Empfehlungen nun, 
da sie kürzer und allgemeiner formuliert sind, keine spezifische Auseinandersetzung mit den in der eingehenden Überprüfung festgestellten Ungleichgewichten [erfolgt].« (EuRH 2018a, 27) In diesem Sinne attestiert der Rechnungshof, dass das Ziel der Kommission, die Transparenz des MIP zu erhöhen, im starken Widerspruch zum »seit 2016 bestehende[n] Mangel an Zusammenhängen oder Begründungen in Bezug auf eingehende Überprüfungen und MIP-relevante länderspezifische Empfehlungen« (ebd., 32) stehe. Zwar kritisiert auch der Europäische Fiskalausschuss (2017b) in seiner Bewertung des rejustierten Verfahrens einige Aspekte, zieht im Gegensatz zum EuRH allerdings ein wohlwollenderes Fazit:

»[T] he Board believes that the 2016 implementation succeeded in avoiding on the one hand a major relaxation of the rules, potentially detrimental to the longer-run sustainability of public finances, and, on the other hand, a rigid application of the rules, which should have undermined the continuation of a still fragile recovery.« (Ebd., 1)

Insgesamt bietet die neue Zweiteilung des Semesters (europäische und mitgliedstaatliche Komponente) sicherlich Vorteile in Bezug auf die mögliche demokratische Einhegung des sintegrierten Überwachungszyklus`. Durch die von Seiten der Kommission angemahnte Einbeziehung der mitgliedstaatlichen Parlamente in der zweiten Semesterhälfte ist jedenfalls ein Möglichkeitsraum erschlossen, der die Rechenschaftspflicht des europäischen Wirtschaftsregierens stärken kann. Ob und in welchem Umfang hingegen dieser Raum schlussendlich genutzt wird, bleibt in der jetzigen Handhabe allerdings offen. Dadurch, dass die veränderten Verfahren nicht legislativ kodiert sind, bleibt es am Ende den Mitgliedstaaten überlassen, wie stark sich die parlamentarische Kontrolle ausgestaltet. Auch die stärkere Betonung der Euroraum-Dimension im Semester ist sicherlich für eine kohärente Wirtschaftspolitik innerhalb der EWWU förderlich. Allerdings gilt es auch hier, Einschränkungen zu benennen. Einerseits birgt der Eurozonenfokus die Gefahr, Politikempfehlungen zu verabschieden, die den mitgliedstaatlichen Gegebenheiten zuwiderlaufen könnten (one-size-fits-all-Problem), andererseits ist mit dem gestärkten Fokus auf das Euro-Währungsgebiet gleichzeitig eine Aufwertung der Euro-Gruppe verbunden. Es besteht somit die Gefahr, dass sich das Semester durch die Neujustierung noch stärker exklusiv auf die Euro-Mitgliedstaaten und ihr informelles Entscheidungsgremium (Euro-Gruppe) fokussiert und in dieser Folge eine EU sunterschiedlicher Geschwindigkeiten festschreibt.

Auch das Streamlining der MIP-Kategorien ist prinzipiell begrüßenswert. Die alte sechs-stufige Skala zur Bewertung von Ungleichgewichten war weder nachvollziehbar noch trennscharf. Insofern bietet die übersichtlicher gestaltete vier-stufige Skala eindeutige Vorteile, wenngleich nicht verschwiegen werden sollte, dass sich die Kommission durch die Neujustierung weitere Interpretationsspielräume erschließen konnte. Diese schlagen sich insbesondere im Ansatz des beabsichtigten Benchmarkings nieder, durch das die Kommission den wirtschaftspolitischen Diskursraum noch stärker in ihrem Sinne formen möchte. Die Nachjustierung im MIP-Verfahren stärkt demnach abermals die Kommissionsspielräume. Schwierig ist in diesem Zusammenhang die Straffung der länderspezifischen Empfehlungen zu bewerten. Einerseits nimmt zwar durch die Reduktion die Strahlkraft der einzelnen Empfehlungen zu und es wird einfacher, ihren Input auf die mitgliedstaatliche Politikgestaltung zu bewerten. Demgegenüber 
steht hingegen die allgemeiner formulierte Stoßrichtung der Empfehlungen, die wiederum die eigentliche Bewertung, ob und in welchem Umfang eine Empfehlung umgesetzt wurde, erschwert. Es bleibt daher in künftigen Untersuchungen genauer zu eruieren, wie sich die Implementationswirklichkeit der länderspezifischen Empfehlungen seit dem Streamlining im Detail entwickelt hat. Einige vorläufig-skeptische Hinweise hierzu wurden bereits im Kontext der reaktiven Krisenbewältigungspolitik angeführt.

\section{Das Programm zur Unterstützung von Strukturreformen}

Neben der fiskalpolitischen Reflexion und der Nachjustierung am Europäischen Semester sowie dem MIP legt der Fünf-Präsidenten-Bericht einen weiteren Fokus auf die altbekannte Thematik der Wettbewerbsfähigkeit. Hierzu empfehlen die fünf Präsidenten, »dass jeder Euro-Mitgliedstaat eine nationale Stelle einrichtet, die seine Leistungen und seine Strategien in Sachen Wettbewerbsfähigkeit beobachtet.« (Juncker et al. 2015b, 9) Wettbewerbsfähigkeit sei

»eine wesentliche Voraussetzung für Widerstandfähigkeit und Anpassungsfähigkeit innerhalb der Währungsunion und für die zukünftige Cewährleistung von nachhaltigem Wachstum und Konvergenz. Zur Förderung von Fortschritten bei Strukturreformen, die auf die Wettbewerbsfähigkeit abzielen, müssen die vorhandenen EU-Mechanismen für die wirtschaftspolitische Koordinierung von einer größeren nationalen Identifikation mit den Reformagenden geprägt sein. Es ist sinnvoll, unabhängiges politisches Expertenwissen auf nationaler Ebene heranzuziehen und den politischen Dialog zwischen der EU und den Mitgliedstaaten zu stärken.«(KOM 2015c, 11; Herv. J. G.)

Der Vorschlag zur Einrichtung nationaler Ausschüsse für Wettbewerbsfähigkeit (vgl. KOM 2015h) adressiert in dieser Diktion ein zentrales Problem des bisherigen Wirtschaftsregierens auf Ebene des Euro-Währungsgebiets: der auf Freiwilligkeit und Eigenverantwortlichkeit beruhende Koordinierungsansatz, der - wie der Euro-Plus-Pakt verdeutlichte - dazu führt, dass Fortschritte in Bezug auf Strukturreformen zur Erhöhung der Wettbewerbsfähigkeit bisweilen nur schleppend vollzogen werden. Durch die Schaffung nationaler Ausschüsse für Wettbewerbsfähigkeit würde eine weitere Instanz zur »Überwachung « der in den intergouvernementalen Parallelaktionen eingegangenen Selbstverpflichtungen (Euro-Plus-Pakt, Pakt für Wachstum und Beschäftigung etc.) geschaffen, die zwar weiterhin in Verantwortung der Mitgliedstaaten läge, deren Koordinationszusammenhang allerdings durch die Kommission stärker beeinflussbar wäre als bisher (vgl. Erw. 8 in KOM 2015h). Gleichzeitig findet hierüber, wie dezidiert im Eingangszitat dargestellt, eine beabsichtigte weitere »Expertisierung « und »Technokratisierung « diskretionärer Entscheidungsprozesse statt, die dadurch begründet wird, dass »eine unabhängige hochwertige wirtschaftliche Analyse der politischen Herausforderungen die Transparenz der politischen Debatte« (Erw. 6 Empfehlung des Rates vom 20. September 2016 zur Einrichtung nationaler Ausschüsse für Produktivität) zu steigern helfe. Allerdings wird die inhaltliche Zielsetzung der wissenschaftlichen Beratung zugleich vorgegeben (Stichwort: Meta-Governance). Demnach sollen die Ausschüsse »eine weitgefasste Definition von Produktivität und Wettbewerbsfähigkeit zugrunde« legen: 
»Sie sollten die langfristigen Antriebsfaktoren und Voraussetzungen für Produktivität und Wettbewerbsfähigkeit, einschließlich Innovation, berücksichtigen sowie die Fähigkeit, Investitionen, Unternehmen und Humankapital anzuziehen und sich mit Kosten- und Nichtkostenfaktoren zu befassen, die Auswirkungen auf Preise und Qualität von Waren und Dienstleistungen haben können, auch im kurzfristigen Vergleich mit globalen Wettbewerbern. (Erw. 5 Empfehlung des Rates vom 20. September 2016 zur Einrichtung nationaler Ausschüsse für Produktivität)

Verbunden mit den Analysen ist weiterhin die Förderung der Umsetzung von wettbewerbsrelevanten Reformen in den Mitgliedstaaten (vgl. I.1 Empfehlung des Rates vom 20. September 2016 zur Einrichtung nationaler Ausschüsse für Produktivität). Einen Grundgedanken solcher Reformen formuliert der Europäische Rat auf seiner FebruarTagung 2016 noch einmal explizit in seiner Erklärung zur Wettbewerbsfähigkeit, die einen starken Fokus auf »bessere Rechtssetzung« legt und dazu auffordert »überflüssige Rechtsvorschriften aufzuheben« sowie für »eine Vereinfachung der Rechtsvorschriften und eine Verringerung der Verwaltungslasten « (ER 2016a, 30) einzutreten. Allgemein gefasst geben die Staats- und Regierungschefs somit den Auftrag zur Umsetzung von Deregulierungsmaßnahmen zur Förderung der Wettbewerbsfähigkeit. Die Zusammenschau zeigt dabei, dass die altbekannte Wettbewerbsfähigkeitsdoktrin keiner inhaltlichen Revision unterzogen wurde und eine Kontinuitätslinie zur Phase der akuten EuroKrise darstellt.

Nachdem sich die Staats- und Regierungschefs grundsätzlich mit der Einrichtung nationaler Ausschüsse für Produktivität einverstanden erklärten (vgl. ER 2016c, Rn. 16), nahm der Rat im September 2016 eine entsprechende Empfehlung an die Mitgliedstaaten an. Bis die Kommission allerdings zur stärkeren Koordinierung der Wettbewerbsfähigkeitsagenda auf ein vollständiges Produktivitätsausschuss-Netzwerk zurückgreifen kann, wird noch weitere Zeit vergehen. Bis Ende 2018 hatten lediglich zehn der 19 Eurozonen-Mitgliedstaaten einen entsprechenden Ausschuss eingerichtet (vgl. KOM 2019a, 6). Laut Kommissionshomepage sind aktuell (März 2021) in 14 der 19 EuroStaaten entsprechende Ausschüsse eingerichtet. ${ }^{9}$

Neben den Wettbewerbsfähigkeits- beziehungsweise Produktivitätsausschüssen offerierte die Kommission in ihrer Mitteilung vom Oktober 2015 zur Steigerung der Wettbewerbsfähigkeit eine weitere Initiative. Im Mittelpunkt steht dabei eine »gezielte Reformförderung durch EU-Fonds und technische Unterstützung« (KOM 2015c, 7). Hierdurch beabsichtigte die Kommission die Umsetzung der länderspezifischen Empfehlungen zu verbessern, indem sie einen neuen Rechtsrahmen vorschlägt, in dem »Programme, die von europäischen Struktur- und Investitionsfonds kofinanziert werden, allen relevanten länderspezifischen Empfehlungen Rechnung tragen [müssen].« (Ebd., 7) Hierzu präsentierte die Kommission im November 2015 einen eigenständigen Verordnungsvorschlag (vgl. KOM 2015g), der in der Verordnung (EU) 2017/825 mündete.

9 Österreich, Estland, Finnland, Italien und Spanien sind der Empfehlung noch nicht nachgekommen. Überdies haben Dänemark und Ungarn als Nicht-Euroländer freiwillig Produktivitätsausschüsse eingerichtet (vgl. KOM o.J. a). 
Im direkten Zusammenhang mit dem Legislativvorschlag steht die nicht auf legislativer Grundlage basierende technische Unterstützung für Strukturreformen, welche die Kommission bereits seit 2015 allen Mitgliedstaaten anbietet. ${ }^{10}$ Zur Unterstützung der Troika und Griechenlands gründete die Kommission 2011 die sogenannte »Task Force for Greece«, später kam die »Support Group for Cyprus« hinzu. In Form dieser Verwaltungsdienste führte die Kommission eine Art Politikberatung durch, indem sie Programmstaaten bei der Umsetzung der in den Memoranden zugesagten Strukturreformen zu unterstützen versuchte. Diese Praxis zum Vorbild nehmend, überführte die Kommission den zuvor auf einzelne Staaten ausgerichteten Verwaltungsdienst in eine dauerhafte Struktur. Seit 2015 verfolgt die Kommission mit ihrem »Dienst zur Unterstützung von Strukturreformen « (Structural Reform Support Service; SRSS) das Ziel,

»allen Mitgliedstaaten bei der Ausarbeitung und effektiven Durchführung von Reformen im Zusammenhang mit den Verfahren der wirtschaftspolitischen Steuerung, insbesondere bei der Umsetzung länderspezifischer Empfehlungen, bei Maßnahmen im Rahmen des Verfahrens bei makroökonomischen Ungleichgewichten oder bei Reformen im Rahmen von Stabilitätshilfeprogrammen auf Anfrage technische Unterstützung zur Verfügung zu stellen« (KOM 2015c, 8; vgl. auch KOM 2015g, 2).

Das gängige Verfahren basiert dabei auf einem Ersuch eines Mitgliedstaats um technische Unterstützung, in deren Folge einzelne Maßnahmen eruiert und in einem »Plan für die Zusammenarbeit und Unterstützung (KOM 2017m) fixiert werden. In der Umsetzungsphase bietet die Kommission dem Mitgliedstaat »Fachkenntnisse aus ganz Europa (ebd.) und praktische Unterstützung bei der Reformumsetzung an. Bemerkenswert an der Etablierung dieser Kommissionsdienststelle ist, dass die Kommission hierüber tief in die mitgliedstaatliche Politikagenda hinein intervenieren kann, obwohl der Dienst lediglich aus einer informellen Initiative der Kommission hervorgegangen ist. Mit dem SRSS ist es der Kommission folglich gelungen, ihre Stellung im Kontext wirtschaftspolitischen Regierens weiter auszubauen. Zwar ist sie im Rahmen des SRSS lediglich beratend tätig, kann hierüber aber - wie an anderer Stelle bereits angemerkt eine nicht zu unterschätzende diskursive Kraft entwickeln, die potentiell in allen Politikbereichen wirkmächtig werden kann, wie der Blick auf bisherige Projekte verdeutlicht: So habe der Dienst zum Beispiel Malta dabei unterstützt, die Effizienz des Personalwesens in der Verwaltung zu verbessern; in Portugal sei man an der Beseitigung regulatorischer Hürden für Unternehmen beteiligt gewesen; in den baltischen Staaten habe man zur Verbesserung der Funktionsfähigkeit der Kapitalmärkte beigetragen und in Kroatien sei der SRSS sogar bei der Gestaltung neuer Lehrpläne unterstützend tätig gewesen (vgl. KOM 2017q, 3).

Mit dem 2015 vorgelegten Vorschlag für eine eigenständige Verordnung, die das bis dato »informelle« Unterstützungsangebot in das EU-Sekundärrecht einbetten sollte (vgl. KOM 2015g), gelang es der Kommission somit, einen umfassenderen Mechanismus zur Unterstützung von Strukturreformen zu verwirklichen. Das mit der Verordnung (EU)

10 Im Two-Pack ist die Möglichkeit einer stechnischen Unterstützung`lediglich für Mitgliedstaaten vorgesehen, die sich in einem makroökonomischen Anpassungsprogramm befinden. 
2017/825 über die Auflage des Programms zur Unterstützung von Strukturreformen initiierte »Programm« setzte sich dabei zum Ziel,

»die institutionellen, administrativen und wachstumsfördernden strukturellen Reformen in den Mitgliedstaaten zu fördern, indem die nationalen Behörden bei Maßnahmen zur Reform und Stärkung der Institutionen, der öffentlichen Verwaltung sowie der Bereiche Wirtschaft und Soziales als Reaktion auf wirtschaftliche und soziale Herausforderungen unterstützt werden, um insbesondere im Rahmen der wirtschaftspolitischen Steuerung Zusammenhalt, Wettbewerbsfähigkeit und Produktivität zu verbessern und ein nachhaltiges Wachstum, die Schaffung von Arbeitsplätzen und Investitionen zu unterstützen, unter anderem durch einen effizienten, wirksamen und transparenten Einsatz der Unionsfonds.« (Art. 4 VO (EU) 2017/825)

Neben dieser angekündigten Verknüpfung mit den finanziellen Unterstützungen aus den EU-Fonds ist mit dem Programm eine weitere Finanzförderlinie verbunden; insgesamt stehen für den Zeitraum 2017-2020 142,8 Millionen Euro zur Verfügung, wobei sich diese Förderung in Analogie zum bisherigen Unterstützungsangebot auf die Finanzierung von Dienstleistungen zur Begleitung von Strukturreformen (Vorbereitungs-, Implementations- und Nachbereitungsphase) bezieht. Hierunter fallen zum Beispiel Maßnahmen, die angefangen bei der Finanzierung der »Bereitstellung von Fachwissen für politische Beratung, politischen Wandel, die Erstellung von Strategien und Reformfahrplänen sowie für rechtliche, institutionelle und administrative Reformen« (Art. 6a VO (EU) 2017/825) oder die »Erhebung von Daten und Erstellung von Statistiken« (Art. 6d VO (EU) 2017/825) über die Finanzierung von Maßnahmen zur »Kommunikation und Öffentlichkeitsarbeit« (Art. 6h VO (EU) 2017/825) bis hin zum »Aufbau von IT-Kapazitäten« (Art. 6f VO (EU) 2017/825) reichen. Entsprechend lässt sich zusammenfassend sagen, dass sich die finanzielle Unterstützung auf die Förderung der Verwaltungs- und Exekutivprozesse bezieht, hingegen keine Förderung für die eigentliche Umsetzung oder die Übernahme möglicher Folgekosten von Strukturreformen vorsieht. Dass trotz der finanziellen Überschaubarkeit des Programms, was sowohl den Umfang $^{11}$ als auch die zu fördernden Maßnahmen betrifft, dennoch eine große Bereitschaft seitens der Mitgliedstaaten zur Teilnahme vorhanden scheint, verdeutlichen die Antragszahlen der letzten Jahre: So hat der Dienst laut Kommissionsangaben bis Ende 2017 in 15 Ländern mehr als 150 Projekte durchgeführt (vgl. KOM 2017q). Für das Jahr 2018 lagen insgesamt 444 Anträge aus 24 Mitgliedstaaten vor, von denen letztlich 146 ausgewählt wurden (vgl. KOM 2019c, 2). Die wichtigsten Politikbereiche waren dabei mit $24 \%$ die Finanzverwaltung und öffentliches Finanzmanagement, $23 \%$ fielen auf den Bereich Wachstum und Rahmenbedingungen für Unternehmen, $21 \%$ betrafen den Bereich Arbeitsmarkt, Bildung, Gesundheit und Sozialpolitik sowie ebenfalls $21 \%$ die Governance und öffentliche Verwaltung (vgl. ebd.). Diese Zahlen verdeutlichen, dass

11 Der überschaubare Finanzumfang soll an einer Beispielrechnung verdeutlicht werden: Stehen bei einer vierjährigen Programmlaufzeit (2017-2020) insgesamt 142,8 Millionen Euro zur Verfügung und jeder Mitgliedstaat wolle an dem Programm partizipieren, stünden je Mitgliedstaat insgesamt 5,1 (jährlich entsprechend 1,725) Millionen Euro zur Verfügung, was selbst im Verhältnis zum Umfang des Staatshaushalts kleiner Mitgliedstaaten lediglich einen geringen Beitrag darstellt. 
sich die oben attestierten Einflussmöglichkeiten der Kommission auch real bieten. Der Ansatz Compliance durch Incentivierung scheint sich, wenn an dieser Stelle auch in einem überschaubaren Umfang, jedenfalls auf den ersten Blick als durchaus vielversprechend im Sinne der EU-Wettbewerbsfähigkeitsdoktrin und ihrer Strukturreformenagenda zu erweisen. Hierfür spricht auch, dass bereits ein halbes Jahr nach dem Inkrafttreten der Verordnung die Kommission im Kontext ihres »Nikolaus-Pakets« (s.u.) mit einer vorgeschlagenen Abänderungsverordnung die Erhöhung der Finanzmittel für das Programm vorschlug (vgl. KOM 2017i), die nach positiver Beratung im Parlament und Rat im November 2018 in Kraft trat. Statt der 143,8 Millionen Euro stehen fortan bis zum Ende der Programmlaufzeit 222,8 Millionen Euro zur Verfügung (vgl. Art. 10, Abs. 1 VO (EU) 2017/825 i. d. F. VO (EU) 2018/1671), was einem Plus von nahezu $65 \%$ entspricht.

Überraschend an der Verordnung erscheint die Tatsache, dass in ihr keine explizite Einbettung in den in der Euro-Krise geschaffenen Rahmen des Wirtschaftsregierens (insbesondere dem Europäischen Semester und die multilaterale Überwachung) erfolgt. Lediglich an zwei Stellen wird eine Verknüpfung mit den Reformen des Sixund Two-Packs hergestellt, indem die Verordnung festhält, dass Unterstützungsersuche im Kontext der »Umsetzung von Programmen zur wirtschaftlichen Anpassung für Mitgliedstaaten, die im Rahmen bestehender Instrumente, insbesondere gemäß der Verordnung (EU) Nr. 472/2013 [...], finanzielle Unterstützung durch die Union erhalten« (Art. 7, Abs. 3b VO (EU) 2017/825) oder zur »Durchführung von Reformen zur Förderung des Wirtschaftswachstums im Zusammenhang mit der wirtschaftspolitischen Steuerung, insbesondere der länderspezifischen Empfehlungen im Rahmen des Europäischen Semesters [...]« (Art. 7, Abs. 3C VO (EU) 2017/825), erfolgen können. Daneben sieht Absatz $3 a$ des selben Artikels allerdings ganz allgemein die Möglichkeit vor, dass Unterstützungsersuche auch zur »Durchführung von Reformen, die Mitgliedstaaten aufeigene Initiative insbesondere zur Förderung eines nachhaltigen Wirtschaftswachstums und einer nachhaltigen Schaffung von Arbeitsplätzen ergreifen« (Herv. J. G.) eingereicht werden könnten, worunter schließlich jedwede Form von »Strukturreformen « zu verstehen wären. Grundlage für die Förderung nach der Verordnung ist, nach Antragsprüfung durch die Kommission, der zusammen von Kommission und Mitgliedstaat aufgestellte »Plan für die Zusammenarbeit und Unterstützung« (Art. 7 VO (EU) 2017/825). Sowohl der Plan als auch die eigentliche Programmdurchführung ist dabei selber - wie bereits angedeutet - kein Gegenstand von Beratungen im Rat. Er und das Parlament werden lediglich hierüber »unterrichtet« (vgl. Art. 8 VO (EU) 2017/825). Dementsprechend ist die Kommission alleinverantwortlich für die Durchführung des aufgelegten Programms, auch wenn sie dem Parlament und dem Rat jährlich einen Bericht hierüber vorlegt (vgl. Art. 16, Abs. 2 VO (EU) 2017/825). Auch die Überwachung des Programms und der Einhaltung der »Pläne« obliegt allein der Kommission (vgl. Art. 16, Abs. I VO (EU) 2017/825). Insgesamt erscheint es daher auch an dieser Stelle angemessen, von einer Stärkung der Exekutivfunktion der Kommission durch die besagte Verordnung zu sprechen.

Offensichtlich ist auch, dass die Verordnung von 2017 auffällige Ähnlichkeiten zu Merkels Wettbewerbsfähigkeits-Pakt-Idee sowie der hieraus abgeleiteten Kommissionmitteilung zur Etablierung eines »Instruments für Konvergenz und Wettbewerbsfähigkeit« aus der Barroso-Ära aufweist. Der 2013 bereits >tot< geglaubte Merkel-Vorschlag 
scheint sich trotz der eher zurückhaltenden bis ablehnenden Reaktionen auf ihre PaktIdee mit der Strukturreformen-Verordnung in reduzierter Form dennoch materialisiert zu haben. Die Charakterisierung der Verordnung als eine reduzierte Form des Pakts für Wettbewerbsfähigkeit bezieht sich darauf, dass, anders als in Merkels ursprünglicher Diktion, zwar zwischen Kommission und Mitgliedstaat ein gemeinsamer »Plan« für die Durchführung von Maßnahmen ausgehandelt wird, dieser aber keinen klassischen Vertragscharakter und entsprechend eine geringere Verbindlichkeit aufweist. Weiterhin basiert das in der Verordnung hinterlegte »Programm« auf Freiwilligkeit und stellt für die Mitgliedstaaten lediglich eine »Option« dar; dagegen ließe sich vermuten, dass Merkel mit ihrem »Pakt« einen insgesamt verbindlicheren Charakter intendiert sah (analog zum SKS-Vertrag). Auch fehlt der Verordnung die bekannte Drohkulisse der anderen SWP- und MIP-Verordnungen; in ihr sind beispielsweise keine Sanktionen vorgesehen. Zugleich ist das Programm nicht direkt im primär- und sekundärrechtlichen Rahmen des Wirtschaftsregierens verortet, was zu einer insgesamt nur geringen Einflussnahme seitens der mitgliedstaatlichen Regierungen (Rat/Europäischer Rat) führt. Schließlich ist das Programm in seiner Laufzeit begrenzt, weshalb seine Umsetzung sicherlich auch als »Testballon« interpretiert werden kann, der dazu beigetragen haben könnte, entsprechende Blockaden gegenüber den ursprünglichen Vorschlägen zu minimieren. Insgesamt ist somit statt eines intergouvernementalen Pakts oder gar zusätzlichen Vertrags ein unverbindlicheres Herrschaftsinstrument etabliert worden, das den Charakter eines »Angebots « an die Mitgliedstaaten aufweist. Dass dieses angenommen wird, verdeutlichen die präsentierten Zahlen und Beispiele. Zugleich steht aber auch die Erkenntnis, dass mit der VO (EU) 2017/825 ein schleichender, inkrementeller Prozess in Gang gesetzt wurde, um die ursprüngliche Pakt-Idee von Merkel doch noch umzusetzen. Dies deutet sich im späteren Kommissionsvorschlag zur Unterstützung von Strukturreformen (vgl. KOM 2017j) an, der Teil des Nikolaus-Pakets ist. Mit diesem weiterführenden Verordnungsvorschlag sollte das bestehende Programm ergänzt und in die Dachverordnung der EU-Fonds (vgl. VO (EU) Nr. 1303/2013) integriert und zugleich verbindlicher gestaltet werden (s.u.).

Der ursprünglich vorgeschlagene Pakt für Wettbewerbsfähigkeit verdeutlicht dabei par excellence die Wirkungsweise inkrementeller Ausbauprozesse. Seit dem Merkel erstmals im Jahr 2011 einen solchen Pakt vorschlug, war er als wirkmächtige Idee innerhalb des EU-Staatsapparate-Ensembles präsent. Viele Reformmaßnahmen der Folgejahre nahmen hierauf im- wie explizit Bezug. Auch wenn der Pakt letztlich nicht in Form einer Vereinbarung zwischen den Mitgliedstaaten geschlossen werden konnte, nahm er Einfluss auf die Transformation der EU-Staatlichkeit im Kontext der EuroKrise und leitete in unterschiedlichen Bereichen die Reformvorhaben an. Neben der eben dargestellten Implementationssäule in Form der Strukturreformen-Verordnung von 2017 zeigt sich dies exemplarisch auch am Mehrjährigen Finanzrahmen für die Jahre 2014-2020. Auf diesen nahm die Idee eines Pakts für Wettbewerbsfähigkeit über das 2013 von Barroso vorgeschlagene >Wettbewerbsfähigkeits-Instrument « und die vom Europäischen Rat vorgenommene Umetikettierung zur >Partnerschaft für Wettbewerbsfähigkeit< (s.o.) sowie der mit ihnen intendierten svertraglichen Vereinbarungen (vgl. u.a. Bundesregierung 2013, 9) letztlich entscheidenden Einfluss. Dies zeigt sich an den sogenannten »Partnerschaftsvereinbarungen«, festgeschrieben in der Dachverordnung 
der EU-Struktur- und Investitionsfonds (Kapitel II VO (EU) Nr. 1303/2013), in denen die Mitgliedstaaten offenzulegen haben, wie sie die Fondsmittel in Übereinstimmung mit der Europe-2020-Strategie, ihrer nationalen Reformprogramme sowie der länderspezifischen Empfehlungen einzusetzen beabsichtigen (vgl. Art. 15, Abs. 1a VO (EU) Nr. 1303/2013). Die Partnerschaftsvereinbarungen, die auf mitgliedstaatlicher Ebene im Dialog mit den Ländern und Kommunen, den Wirtschafts- und Sozialpartnern und Vertreter*innen der Zivilgesellschaft ausgearbeitet werden sollen (vgl. Art. 5, Abs. 1 VO (EU) Nr. 1303/2013), stehen dabei unter Genehmigungsvorbehalt der Kommission (vgl. Art. 16, Abs. 2 VO (EU) Nr. 1303/2013) und stellen daher letztlich ein durchaus starkes neues Instrument und einen weiteren Baustein des Staatlichkeitsausbaus dar. Tritt in den technischen Formulierungen des Verordnungstexts der Bezug des neuen Instruments zur Wettbewerbsfähigkeitsdoktrin zwar nicht übermäßig hervor, ist dieser dennoch durch die inhaltlichen Querbezüge zur Europe-2020-Strategie und zu den Verfahren des wirtschaftspolitischen Regierens implizit sehr deutlich erkennbar. Schließlich sei mit den Partnerschaftsvereinbarungen der Anspruch verbunden, »eine umfassende, kohärente Strategie« (KOM 2016h, 20) auf mitgliedstaatlicher Ebene zu entwickeln, in der die »Mitgliedstaaten [...] nun sehr viel deutlicher werden [müssen], was den geplanten Beitrag de[r] [...] Fonds zur Erreichung der EU-Prioritäten im Sinne der Strategie Europa 2020 [...] und der relevanten länderspezifischen Empfehlungen angeht.«(Ebd., 21) Demnach wird auch die Fondspolitik der EU - als ein weiterer Befund inkrementeller Aus- und Transformationsprozesse - dezidiert in den Dienst der Wettbewerbsfähigkeit gestellt (vgl. u.a. auch Bodirsky 2015).

Der Mehrjährige Finanzrahmen 2014-2020 und die Annahme des Programms zur Unterstützung von Strukturreformen zeigen schließlich, dass in einem inkrementellen Prozess in unterschiedlichen Politikbereichen Merkels Pakt-Idee Einfluss nehmen konnte und letztlich in reduzierter Form umgesetzt wurde. Hierdurch wird nicht nur ein weiteres Mal die Wirkmächtigkeit der Wettbewerbsfähigkeitsdoktrin unterstrichen, sondern im Besonderen auch noch einmal die Durchsetzungsfähigkeit der deutschen Bundesregierung hervorgehoben.

\subsection{Die inkrementell ausgebaute EU-Interventionsstaatlichkeit}

Die Phase des inkrementellen Staatlichkeitsausbaus ist insgesamt von der mit dem Fünf-Präsidenten-Bericht ausgegebenen Devise >Vertiefung durch Handeln` geprägt. Dies wird insbesondere im Kontext des fiskalpolitischen Regierens deutlich. Hierbei vollzog sich durch die partielle Redefinition numerischer Haushaltsregeln vor dem Hintergrund lahmender Investitionstätigkeit und ihrer negativen Auswirkungen auf die wirtschaftliche Erholung ein Wandel vom orthodoxen Austeritätsverständnis der reaktiven Krisenbewältigungspolitik hin zu einer pragmatischeren Austeritätsauslegung. Diese Nivellierung - die lediglich auf Grundlage einer veränderten Praxis und nicht aufgrund legislativer Maßnahmen vollzogen wurde - trägt insgesamt zu erweiterten Ermessenspielräumen der Kommission bei, die ihrerseits durch den Europäischen Fiskalausschuss ein neues Hilfsorgan implementiert, das die Kommission in ihrer konkreten Herrschaftsausübung unterstützt. 
Ähnlich gestaltet es sich im Kontext des wirtschaftspolitischen Regierens, wo mit dem Streamlining des Europäischen Semesters und des MIP ebenfalls die Ermessensspielräume der Kommission ausgebaut wurden. Ausgegebenes Ziel dabei war unter anderem die Durchschlagskraft der länderspezifischen Empfehlungen als das wichtigste Interventionsinstrument der EU-Staatlichkeit im verfassungsbezogenen Normalzustand zu erhöhen. Neben den Verfeinerungen und Neujustierungen der diesen zugrundeliegenden Verfahren (Europäisches Semester \& MIP) sollte hierzu auch der Mehrjährige Finanzrahmen ab 2014 und die Reform der Kohäsionspolitik (Strukturfonds) beitragen. Demgemäß werde künftig bei der Vergabe der Fördermittel auch die Umsetzung der länderspezifischen Empfehlungen stärker berücksichtigt (vgl. Becker \& Müller 2015; KOM 2012a, 22f.). Hinzu kommt mit dem Aufbau der Dienststelle und der Implementierung des Fonds zur Unterstützung von Strukturreformen ein erweiterter Interventionsrahmen zur Verbesserung der Wettbewerbsfähigkeit. Im Unterschied zu der durch den reaktiven Staatlichkeitsausbau aufgebauten Drohkulisse der Disziplinierung wurde hierbei allerdings ein - im Sinne der neoliberalen Strukturreformenagenda durchaus erfolgsversprechender - Ansatz der Incentivierung gewählt. Technische Unterstützung und Finanzmittel im Gegenzug für Strukturreformen lautet hierbei das Motto. Dieser Ansatz verleiht dem Herrschaftsmodus der (Selbst-)Disziplinierung ein freundlicheres Antlitz, auch wenn die zugrundeliegenden Prämissen der EU-Interventionsstaatlichkeit sich hierdurch nicht grundsätzlich verändern. Dies verdeutlicht nicht zuletzt auch Junckers stugendhaftes Dreieck«. Trotz gewisser Reorientierungen und leichten Redefinitionen präsentieren die inkrementellen Ausbauaktivitäten der EU-Staatlichkeit demnach auch weiterhin eine Fixierung auf die (verfassungs-)rechtlich-festgeschriebene richtige Politik. Dies wird letztlich auch an der Diskussion um die Steigerung der Wettbewerbsfähigkeit deutlich, welche die Phase des inkrementellen Staatlichkeitsausbau noch stärker prägte als die vorausgegangene Phase des reaktiven Staatlichkeitsausbaus. Sie rückt, nachdem sich die akuten Symptome der Euro-Krise im Laufe der beschriebenen Phase des inkrementellen Staatlichkeitsausbaus abschwächten, eindeutig ins Zentrum der politischen Aktivitäten der EUSA. Es ist vor diesem Hintergrund gerade der Aktivismus der Europäischen Kommission, der die Herrschafts- und Staatlichkeitspraxen in jener Phase formte und die ausgebaute EU-Interventionsstaatlichkeit um gewisse diskretionäre Elemente im Sinne der neuen Ermessensspielräume erweiterte und die Kommission immer deutlicher zur zentralen Akteurin des fiskal- und wirtschaftspolitischen Regierens in der EU hat werden lassen.

\subsection{Allianzwechsel und die Strategie der nachholenden hegemonialen Absicherung in der Phase inkrementellen Staatlichkeitsausbaus}

Vor dem Hintergrund nicht-hegemonialer Staatlichkeits(re)produktion in der Phase des reaktiven Staatlichkeitsausbaus, fragmentierter Hegemonie und einer sich verschärfenden Legitimationskrise, die sich zusammengenommen in der neoliberalen Hegemoniekrise ausdrückte (vgl. Kapitel 7.6), ist es letztlich der zunehmende Druck "gegenüber einer Krisenpolitik, die maßgeblich von in Deutschland verankerten ordokonservativen Kräften beeinflusst gewesen war« (Georgi \& Kannankulam 2015, 362), 
der im Sommer $2012 \mathrm{zu}$ einem »impliziten Allianzwechsel der autoritär-neoliberalen Fraktion« (ebd.) führte. Nachdem sich im ersten Halbjahr 2012 die Euro-Krise zunächst weiter zuspitzte, ist es dieser Allianzwechsel, der die moderat-neoliberalen Kräfte stärker in die offizielle Politikagenda einbinden sollte. Das reaktionäre Bündnis, angeführt von der proeuropäisch-autoritären Fraktion im neoliberalen Hegemonieprojekt, das die kurze Phase der mitgliedstaatlichen Eigenverantwortung und die des reaktiven Staatlichkeitsausbaus bis zum Sommer 2012 prägte, zerbrach dabei an der Frage, wie weitreichend die Maßnahmen zur Krisenbewältigung auf Ebene der EU-Staatlichkeit schlussendlich sein dürfen: möglicherweise sogar swhatever it takes`? An der vehementen Kritik national-konservativer und orthodox-neoliberaler Akteur*innen gegenüber der EZB-Ankündigung zum unbegrenzten Kauf von Staatsanaleihen auf dem Sekundärmarkt zeigte sich ihre neue oppositionelle Rolle und der implizite Allianzwechsel in aller Deutlichkeit. In Deutschland führte dies unter anderem zu einer >Radikalisierung، und >Verselbstständigung` ordo-konservativer Kräfte und mündete schließlich sogar in der Gründung der AfD (vgl. ebd., 363; Winkler 2018). Die im Sommer 2012 eingeschlagene Politik verdeutlicht in diesem Sinne letztlich auch notwendige Konzessionen seitens der autoritär-neoliberalen Fraktion gegenüber proeuropäischen Kräften, die zur Krisenlösung notfalls auch den Ausbau der Haftungsgemeinschaft bereit waren zu akzeptieren (moderat-neoliberale Fraktion) oder ihn als Krisenbewältigungsstrategie vehement vortrugen (proeuropäisch-soziales Hegemonieprojekt). Dies illustrierte nicht zuletzt bereits die parlamentarische Auseinandersetzung um das Six- und insbesondere um das Two-Pack. Schließlich war auch die seit 2012 zunehmende Diskussion um die Bankenunion insbesondere von Fragen in Bezug auf die Haftungsgemeinschaft geprägt (gemeinsame Letztsicherung und Abwicklungsfonds). Vor diesem Hintergrund vollzog sich der Allianzwechsel der autoritär-neoliberalen hin zur moderat-neoliberalen Fraktion, die dadurch gekennzeichnet sei, dass sie zwar »Troika-Memoranden, Six-Pack-Richtlinien und Fiskalpakt unterstützte«, zugleich aber »zu einer begrenzten wirtschafts- und sozialpolitischen Kurskorrektur bereit [war]«, indem sie

»die Krisenpolitik um keynesianische Elemente ergänzen [wollte], darunter Schuldenschnitt, Steuer auf Finanztransaktionen und Vermögen, Eurobonds oder Altschuldentilgungsfonds, Konjunkturpolitik durch staatliche Investitionen und höhere Löhne sowie eine expansive Geldpolitik« (Georgi \& Kannankulam 2015, 363; vgl. Buckel et al. 2012, 32).

Der implizite Allianzwechsel autoritär-neoliberaler Kräfte führte sogar dazu, dass moderat-neoliberale Akteur*innen sukzessive eine Führungsrolle innerhalb des neoliberalen Hegemonieprojekts einnehmen und den inkrementellen EU-Staatlichkeitsausbau seit 2013 maßgeblich gestalten konnten. Es war demnach die sich in der autoritär-neoliberale Krisenbewältigungsstrategie vermittelnde Hegemoniekrise, in der sich ein europäisches Kräfteverhältnis verdichtete, das in einer gewissen Distanz zum reaktiven Staatlichkeitsausbau unter autoritär-neoliberalen Vorzeichen stand und die Grundlage für die Reorientierungen im Inneren der EUSA darstellte. Will man die Wandlungsprozesse in den Kräfteverhältnissen personifizieren, ließe sich dieser letztlich auch am Wechsel an der Kommissionsspitze von Barroso zu Juncker im Jahr 2014 festmachen. Steht ersterer für die autoritär-neoliberale Krisenbewältigungsstrategie der Pha- 
se des reaktiven Staatlichkeitsausbaus, repräsentiert zweiterer einen moderat-neoliberalen Strategieansatz, der die Phase des inkrementellen Staatlichkeitsausbaus prägen sollte. Dieser Ansatz lässt sich zusammenfassend als Strategie einer nachholenden hegemonialen Absicherung des kriseninduzierten EU-Staatlichkeitsausbaus auffassen.

Grundlage einer solchen Strategie stellen die leitbildlichen Agenden des Vier- und des späteren Fünf-Präsidenten-Berichts dar, die maßgeblich vom moderat-neoliberalen Strategieansatz beeinflusst waren. In ihnen wird eine im Vergleich zur vorherigen Phase erweiterte Reformagenda sichtbar, die sich neben weiteren Vertiefungsschritten insbesondere auch in einer Reflexion der reaktiv vollzogenen Maßnahmen zur Krisenbewältigung andeutet. Es sind die angestoßenen Reflexionsprozesse, die in der Phase des inkrementellen Staatlichkeitsausbaus den Wandel vom orthodoxen zu einem pragmatischeren Austeritätsverständnis anstießen und die reaktiv ausgebaute Interventionsstaatlichkeit durch gewisse diskretionäre Elemente, beispielsweise im sgestrafften Europäischen Semester, ergänzten, die zugleich zu erweiterten Ermessensspielräumen der Europäischen Kommission führten.

Daneben versuchte die Juncker-Kommission durch das Lancieren eines sozialpolitischen Aktionsprogramms auch den Diskurs um die soziale Dimension der EU wiederzubeleben. Ende 2015 kündigte Juncker die Einführung einer sogenannten europäischen Säule sozialer Rechte (ESSR) an, zu der die Kommission (2016a) im Frühjahr 2016 einen ersten Entwurf vorlag und eine Konsultationsphase einläutete. Die Säule selbst ist als eine Antwort auf die sozialen Krisenverwerfungen zu sehen. So heißt es in einer Kommissionsmitteilung, dass

»[t]rotz jüngster Verbesserungen der wirtschaftlichen und sozialen Bedingungen in Europa [...] die Folgen der Krise des vergangenen Jahrzehnts weiter deutlich spürbar [bleiben] und [...] von Langzeit- und ]ugendarbeitslosigkeit bis zu Armutsrisiken in weiten Teilen Europas [reichen].«(KOM 2017b, 3f.; vgl. dies. 2016a, 3f.; ESSR, Präambel, Rn. 10)

An anderer Stelle wird die Kommission (2018f, 14) noch deutlicher: »[D]ie Wirtschaftsund Gesellschaftskrise des vergangenen Jahrzehnts [hatte] weitreichende Auswirkungen auf unser soziales Gefüge und stellt damit die Grundlagen unserer sozialen Marktwirtschaft infrage.« Die vorgeschlagene Säule sozialer Rechte sei deshalb nach Meinung der Kommission $(2017 b, 5)$ »nicht nur [...] ein soziales Erfordernis, sondern auch [...] eine wirtschaftliche Notwendigkeit «. Sie kann dementsprechend auch als $>$ Konzession gegenüber den >Krisenverlierer*innen interpretiert werden, um hierdurch letztlich auch der legitimatorischen Prekarität der EU-Staatlichkeit zu begegnen. Die Kommission bezieht sich dabei explizit auf die ökonomischen Divergenzen innerhalb der Eurozone, bei der die Säule beispielsweise helfen solle, durch die Schaffung effizienter und widerstandsfähiger Arbeitsmärkte zur Leistungskonvergenz zwischen den Mitgliedstaaten beizutragen (vgl. ebd.). Die Säule richte sich daher »in erster Linie« an die Euro-Mitgliedstaaten, könne jedoch von allen Mitgliedstaaten umgesetzt werden (vgl. ebd., 6). Die schlussendlich auf dem Göteborger Sozialgipfel 2017 >proklamierteく Säule umfasst neben einer Präambel insgesamt 20 soziale Rechte, angefangen vom $>$ Recht auf allgemeine und berufliche Bildung bis zum >Recht auf den Zugang zu essenziellen Dienstleistungen wie Wasser-, Sanitär- und Energieversorgung, Verkehr, Finanz- 
dienste und digitale Kommunikation<. Mit der Zusammenstellung der 20 grundlegenden sozialen Rechte sei nach Meinung der Kommission ein `Orientierungsrahmen $<$ (vgl. ebd., 8) entstanden, auf den künftig im politischen Prozess Bezug zu nehmen sei. Allerdings besitzt die ESSR selber keine eigene Rechtsverbindlichkeit, vielmehr basiert sie auf den bereits an unterschiedlichen Stellen kodierten Rechten (Verträge, Sozialcharta, Sekundärrecht), weshalb durch die Säule lediglich »die in der EU sowie im internationalen rechtlichen Besitzstand bereits bestehende[n] Rechte bestätigt und zur Berücksichtigung neuer Realitäten ergänzt [werden].« (Ebd., 7) Insofern gilt zugleich, dass die ESSR-Rechte

»für die Bürgerinnen und Bürger nicht einklagbar [sind]. Weder für die Mitgliedstaaten noch für die europäischen Institutionen existiert - ausgenommen für die wenigen Aspekte, die in den Verträgen kodifiziert sind [...] - ein über die Selbstbindung hinausgehender Zwang, die ESSR zu achten und umzusetzen.« (Hacker 2018a, 47; vgl. ders. 2018b)

Letztlich ist die ESSR als ein Versuch zu werten, der ausgebauten EU-Interventionsstaatlichkeit durch die Stimulierung eines Diskurses über das `Soziale Europa ein sozialpolitischeres Antlitz zu verleihen, um hierüber vermittelt eine Form hegemoniale Absicherung zu initiieren. In diesem Sinne könnte man gar von einem vierten strategischdiskursiven Moment neoliberaler Rückeroberung sprechen, wobei die politische Reichweite analog zum Pakt für Wachstum und Beschäftigung abermals nur überschaubar ist und die Säule daher nur symbolischen Charakter besitzt (vgl. Bsirske \& Busch 2017). Im Konkreten wird mit dem ESSR ein sozialpolitisches Scoreboard eingeführt, das künftig Bestandteil des Europäische Semesters ist und anhand dessen die Kommission »die Leistungen der EU-Mitgliedstaaten mit den Durchschnittswerten für die EU und den Euro-Raum in Beziehung [...]setzt.« (KOM 2017a, 2; vgl. auch frühere Überlegungen: KOM 2013h) Insofern leisten die ESSR und das Scoreboard sogar selber einen zusätzlichen Beitrag zum inkrementellen Ausbau der EU-Interventionsstaatlichkeit, die allerdings die in der Europe-2020-Strategie angelegte Unterordnung sozialpolitischer Zielsetzungen unter den Anforderungen der Wettbewerbsfähigkeit fortführt (vgl. Wigger \& Horn 2019; Parker \& Pye 2018) und dabei durch die ESSR und ihrem Scoreboard einen neuen Bezugspunkt für neoliberal-angebotsökonomische Politikempfehlungen seitens der Kommission schafft (gestiegene Anzahl sozial- und arbeitsmarktpolitischer CSRs; vgl. Kapitel 7.2). Aufgrund dieser ESSR-Limitierungen verbleibt der Ansatz der nachholenden hegemonialen Absicherung daher fragil.

Ähnlich gestaltet es sich mit den aufkommenden Initiativen zum Ausbau der Fiskalunion, die in ihrer moderat-neoliberalen Variante in einen übergeordneten Legitimationsdiskurs um die Zukunft der EWWU und der EU eingebunden wird: Im Sinne des neoliberalen Strukturreformenkonsens dient ein Ausbau der EU-Fiskalkapazität - insbesondere in seiner derzeit zur Diskussion gestellten, vergleichsweise limitierten Form (s. Wandlungsprozess vom Van-Rompuy-Zwischenbericht 2012 bis zum FünfPräsidenten-Bericht 2015) - letztlich nur der Durchsetzung der Wettbewerbsfähigkeitsdoktrin im Sinne der EU-Staatlichkeit eingeschriebenen >richtigen Politik (ausführlich s.u.). Eine Fiskalkapazität, wie sie sich beispielsweise proeuropäisch-soziale Akteur*innen zur Umsetzung einer genuin europäischen Wirtschaftspolitik vorstellen und die 
in diesem Sinne auch einen fiskalischen Ausgleichsmechanismus zur Verwirklichung gleicher Lebensbedingungen überall in der Union darstellen würde (vgl. bspw. Andor 2018; Koll \& Watt 2018), steht jedenfalls mit den konkreten Initiativen der Phase des inkrementellen Staatlichkeitsausbaus nicht zur Debatte. Auch die mit dem späteren Nikolauspaket (2017) erneut befeuerte Diskussion um die Fiskalunion wird in diesem Sinne voraussichtlich abermals zu einer Bestätigung der grundsätzlichen neoliberalen Einschreibungen in die EU-Staatlichkeit führen (ausführlich s. Kapitel 9). Auch dieses potenzielle, fünfte strategisch-diskursive Moment neoliberaler Rückeroberung zur Festigung und Sicherung der ausgebauten EU-Interventionsstaatlichkeit wird demnach nur eine begrenzte Wirkung in Bezug auf ihre hegemoniale Verankerung entfalten können.

Insgesamt können der Strategie einer nachholenden hegemonialen Absicherung sicherlich gewisse kleinere Erfolge zugeschrieben werden. Unter Führung moderatneoliberaler Kräfte gelang es hierbei, dem autoritären Charakter der ausgebauten EUInterventionsstaatlichkeit durch die Reorientierungen im Konsolidierungsprozess des fiskal- und wirtschaftspolitischen Regierens, dem Lancieren eines Diskurses um das Soziale Europa und letztlich auch um eine Fiskalunion einen freundlicheren Anstrich $\mathrm{zu}$ verleihen. Allerdings verbleibt die in diesem Sinne inkrementell ausgebaute EUStaatlichkeit und ihr angedeuteter potenzieller Ausbau weiterhin in einem Herrschaftsmodus der (Selbst-)Disziplinierung verfangen. Im Grunde bildet er die Materialität der ausgebauten EU-Staatlichkeit oder anders gesagt: der Ausnahmezustand wohnt dem 'neuen Normalzustand inne. Dies verdeutlicht auch der Umgang mit Griechenland 2015, der eine Art Rückfall in die Phase des reaktiven Staatlichkeitsausbaus markierte. In diesem zeigte sich, dass die neue Allianz moderat-neoliberaler und autoritär-neoliberaler Kräfte ab 2012 zwar bereit war, gewisse Konzessionen zu machen, um hierdurch die ausgebaute EU-Interventionsstaatlichkeit nachträglich $\mathrm{zu}$ `hegemonialisieren<, sie im Kern aber dennoch weitgehend autoritär-neoliberal geprägt bleibt. Ein Abrücken von den der EU-Staatlichkeit eingeschriebenen neoliberalen Prämissen stand deshalb zu keiner Zeit ernsthaft zur Disposition (vgl. Konecny 2015, 329).

Der Auseinandersetzung zwischen dem autoritär-intergouvernementalen Gläubigerregime des ESM und Griechenland war ein EU-weit beachteter Regierungswechsel im Januar 2015 vorausgegangen. Das Linksbündnis SYRIZA konnte zusammen mit der ANEL-Partei die Regierungsgeschäfte von der vorherigen ND-PASOK-DIMAR-Koalition in dem bereits seit 2010 unter Kuratel der Troika stehenden Land übernehmen. SYRIZA war nicht zuletzt aufgrund des Versprechens, die bisherige Austeritätspolitik zu beenden, ins Amt gekommen und beabsichtigte »ein gegenhegemoniales Projekt gegen den europäischen Krisenkonstitutionalismus umzusetzen« (Kompsopoulos 2018, 482). Nachdem die neue Regierung im Januar die Amtsgeschäfte übernahm, liefen bereits im Februar die Vereinbarungen des zweiten griechischen Hilfspakets aus und die TsiprasRegierung wurde mit der `harten Realität $<$ konfrontiert (vgl. Featherstone 2016, 52). Um mehr Zeit für die Verhandlungen eines dritten Hilfspakts zu erlangen, einigten sich die Euro-Gruppe und die griechische Regierung auf eine vorübergehende Verlängerung des bestehenden Programms um vier Monate (vgl. Euro-Gruppe 2015), weshalb sich SYRIZA bereits zu diesem Zeitpunkt "gezwungen sah, eine >Austeritätspolitik light zu betreiben.« (Georgi \& Kannankulam 2015, 365; vgl. Featherstone 2016, 52) Der sich anschlie- 
ßende Versuch, in den Verhandlungen um ein drittes Hilfspaket, nun »ihr gegenhegemoniales Projekt umzusetzen, stieß umgehend auf den kompromisslosen Widerstand der EU-Regierungen [...] wie auch eines Großteils der europäischen Medien.« (Kompsopoulos 2018, 480; vgl. Georgi \& Kannankulam 2015, 366f.) Im Verlauf der Auseinandersetzung zeigte sich kaum Bereitschaft auf Seite der EUSA, von der außerunionsvertraglichen Notstandsverfassung eingeschriebenen Hilfsstrategie und ihrer Konditionalitäten abzurücken; >einer gegen achtzehn<, wie Featherstone $(2016,53)$ die Verhandlungssituation auf den Punkt bringt. Nach einem Ping-Pong-Spiel zwischen Euro-Gruppe und Griechenland, das jeweils in einer Zurückweisung der Vorschläge der jeweils anderen Seite bestand, kündigte der griechische Premierminister Tsipras vor dem Hintergrund der sich zuspitzenden finanziellen Situation des griechischen Staatshaushalts (anstehende Kreditrückzahlung) im Juni 2015 ein Referendum über die zuletzt von der EuroGruppe vorgeschlagenen Parameter für ein drittes Hilfspaket an. In diesem stimmten letztlich 61,3\% gegen die Austeritätsauflagen der EUSA und stärkten somit die Position der SYRIZA-Regierung.

»Doch obwohl die zentralen Inhalte des MoU im Referendum [...] abgelehnt wurden, sah sich die Regierung Tsipras durch die rücksichtslose, einen Grexit offen in Kauf nehmende Machtpolitik der deutschen Bundesregierung gezwungen, am 13. Juli noch härterer Austerität und einem demütigenden Souveränitätsverlust zuzustimmen, «(Georgi \& Kannankulam 2015, 366)

um neue ESM-Kredite zu erhalten. Es war die von Finanzminister Schäuble lancierte Debatte um einen (zeitweisen) Grexit (vgl. Featherstone 2016, 55), die letztlich disziplinierend gegenüber der SYRIZA-Regierung wirkte, deren oberstes Ziel darin bestanden habe, Griechenland in der EU und der Eurozone zu halten: "Es wird keinen einseitigen Bruch mit Europa geben«, ließ Tsipras (zit.n. Kompsopoulos 2018, 481) bereits nach dem Wahlsieg im Januar 2015 verkünden. Auch die nach der Regierungsübernahme in kurzer Zeit vollzogene spersonelle und funktionelle Transformation« »von einer linksradikalen Kleinstpartei in eine sozialdemokratische Partei klassischen Typs (Kompsopoulos 2018,480 ) trug letztlich zu einem veränderten Auftreten gegenüber den EUSA bei. Es war somit eine Trias aus drei Gründen, die Griechenland erneut in die Arme der Troika trieb: die proeuropäische Fokussierung SYRIZAs, die ökonomischen Kräfteverhältnisse innerhalb der Eurozone, die für eine ungleiche Verhandlungsposition sorgten und letztlich die Stützung des in den Memoranden ausgedrückten disziplinierenden Herrschaftsmodus durch moderat-neoliberale Kräfte, die mittlerweile gar bereit schienen, einzelne Mitglieder aus der Währungsunion herausbrechen zu lassen, wenn sie ihren autoritär-neoliberalen Charakter offen infragestellten (vgl. Georgi \& Kannankulam 2015, 367). Das gegenhegemoniale Projekt, mit dem SYRIZA angetreten war und das bei den Akteur*innen aus dem Kontext der beiden sozialen Hegemonieprojekte große Sympathien genoss, scheiterte daher innerhalb weniger Monate und konterkarierte insofern auch die Bemühungen der moderat-neoliberalen Strategie zur hegemonialen Absicherung des reaktiven Staatlichkeitsausbaus. Vielmehr zeigte sich 2015 in aller Deutlichkeit, dass sich hinter der inkrementell fortentwickelten EU-Staatlichkeit und ihrer nun freundlicheren Fassade letztlich auch nur eine im Kern autoritär und antidemokratisch ausgerichtete Exekutivstaatlichkeit im Herrschaftsmodus der Diszi- 
plinierung verbarg. Die Botschaft hierbei ist eindeutig: Die neoliberalen Grundfesten der EWWU dürfen abseits kleinerer Zugeständnisse und Konzessionen nicht grundsätzlich hinterfragt werden. In diesem Sinne wirkt im >neuen Normalzustand ‘ der krisenbedingte Ausnahmezustand fortwährend als Drohkulisse.

Das Agieren gegenüber Griechenland und seinem alternativen Projekt führte allerdings innerhalb des national-sozialen Hegemonieprojekts zu einer wahrnehmbaren Diskussion um einen »Euro-Exit von links« (Leftxit). Organische Intellektuelle des Hegemonieprojekts wie Fritz Scharpf und Wolfgang Streeck unterstützten hierbei einen solchen Bruch mit dem Euro als linke Strategie zur Überwindung der Euro-Krise und zur Rückeroberung mitgliedstaatlicher Handlungsmöglichkeiten (vgl. Scharpf 2017a \& 2017b; Streeck 2015a; Höpner 2016). Ähnlich wie der rechts-konservative Euro-Exit á la Schäuble oder der AfD war allerdings auch der Euro-Exit von links gesellschaftlich nicht im hohen Maße anschlussfähig. Selbst in der Hochphase der Euro-Krise zeigte sich nicht nur in Griechenland (vgl. Konecny 2015, 331), sondern insgesamt in der Eurozone eine ungebrochen hohe Zustimmung weiter Teile der Bevölkerung zur Gemeinschaftswährung (vgl. Bruttel 2014; Hobolt \& Wratil 2015), deren Bestand somit nicht grundsätzlich infrage gestellt wurde. Verstärkt wurde dies diskursiv durch die schwer zu kalkulierenden Kosten eines möglichen Euro-Ausstiegs oder eines Zusammenbruchs der EWWU (vgl. Reef 2018, 45ff.; Husson 2012, 301). Eine solche Orientierung auf den Verbleib in der EWWU >nahezu um jeden Preis` wurde durch die wirtschafts-strukturellen Unsicherheiten eines Euro-Ausstiegs aufgrund der bestehenden ökonomischen Abhängigkeitsverhältnisse im europäischen Binnenmarkt weiter begünstigt (vgl. Schneider 2017a \& 2017b). Das >Rettungsdispositiv< als strategisch-diskursives Moment neoliberaler Rückeroberung hat daher auch an dieser Stelle seinen Zweck erfüllt. 


\section{Stagnierender Staatlichkeitsausbau im Anschluss an die Euro-Krise}

Im Jahr 2017 versuchte die Kommission mit der Vorlage des >Weißbuchs zur Zukunft Europas` im Zuge der Feierlichkeiten zum 60. Jahrestag der Römischen Verträge erneut die Lancierung eines Vertiefungsprozesses für die EWWU, der eine Reihe konkreter Reformvorschläge - insbesondere das sogenannte Nikolauspaket - folgten. Die vorgeschlagenen Vertiefungsmaßnahmen, beispielsweise ein*e Europäische*r Finanzminister"in oder die Weiterentwicklung des ESM zum EWF, die einen weiteren Ausbau der EU-Staatlichkeit bedeutet hätten, wurden allerdings bis zum heutigen Tage nicht umgesetzt. Auch dem 2018 vorgelegten Fiskal-Two-Pack, in dem die Kommission die Diskussion um ein eigenständiges Eurozonen-Budget aufgriff, das zuvor bereits vom französischen Präsidenten Macron in seiner vielbeachteten Europarede eingefordert wurde, blieb die Umsetzung bisher verwehrt. Es ist deshalb letztlich spätestens ab Mitte 2017 von einer Phase des stagnierenden Staatlichkeitsausbaus zu sprechen, in der trotz erkennbarer Ambitionen und der Lancierung einer Diskussion über die >Vollendung der EWWU « die Tätigkeiten zum Ausbau der EU-Staatlichkeit dennoch ins Stocken geraten. Geprägt ist diese Phase überdies durch einen historischen Einschnitt, der in gewisser Weise auch den Vertiefungs- und Ausbaudiskurs um die EU-Staatlichkeit nachhaltig verändern sollte: Mit dem Vereinigten Königreich reichte erstmals ein EU-Mitgliedstaat am 29. März 2017 - nach einem erfolgten Referendum im Jahr 2016 - offiziell ein Austrittsgesuch nach Artikel 50 AEUV ein. Infolgedessen wendete sich der Fokus der EUSA nach der aufkommenden »Krise des europäischen Migrationsregimes « ab 2015 schließlich mit der »Brexit-Krise« beständig weiter von der Euro- und somit der Funktionskrise der EWWU ab.

\subsection{Die »Zukunft Europas" und die »Vollendung der EWWU»}

Am 1. März 2017 legte die Kommission das »Weißbuch zur Zukunft Europas« vor, das in seiner Anlage nicht nur die potenzielle Weiterentwicklung der EWWU thematisierte, sondern einen allgemeinen Blick auf die Zukunft der Europäischen Union wirft. Der 
Aufbau des Weißbuchs überrascht dabei durch seinen >offenen` Charakter. So wird zu Beginn festgehalten, dass

»[a]|lzu oft [...] die Diskussion über die Zukunft Europas auf die Wahl zwischen >mehr oder >weniger r reduziert worden [ist]. Dieser Ansatz führt in die Irre und ist zu einfach gedacht. Die [im Weißbuch; ]. G.] dargelegten Möglichkeiten reichen von der Fortsetzung des Status quo über veränderte Handlungsbereiche und Prioritäten bis zum partiellen oder gemeinsamen Sprung nach vorn.«(KOM 20170, 15)

Die fünf Entwicklungsszenarien, die das Weißbuch offeriert, weisen insofern nicht auf eine alternativlose Integrationsvertiefung, sondern zugleich auch auf eine potenzielle Redefinition der EU im Gesamten, die in zwei der fünf Szenarien (Szenario (2): »Schwerpunkt Binnenmarkt « \& Szenario (4): »Weniger, aber effizienter«) gar auf einen partiellen Rückbau hinauslaufen könnte. Berechtigter Zweifel im Hinblick darauf, dass die Kommission wirklich ein Interesse an einem solchen Rückbau hätte, wird aber daran deutlich, dass die Szenarien lediglich »von bildhaftem Charakter [sind], um das Nachdenken anzuregen « (ebd.) und in ihren Ausführungen teilweise sehr überschaubar ausfallen. Die Anlage des Weißbuchs entbehrt insofern nicht einer gewissen Kommunikationsstrategie, die schließlich einen »Prozess « anstoßen möchte, »in dem Europa selbst darüber entscheidet, welchen Weg es künftig einschlagen wird.« (Ebd., 3; vgl. ebd., 26) Aus diesem Grunde skizziert das Weißbuch die »vor uns liegenden Herausforderungen und Chancen « und legt dar, "wie wir uns auf eine gemeinsame Antwort verständigen können.«(Ebd., 3) Das Weißbuch markiert in diesem Sinne zugleich die Fortführung der bereits in der Phase inkrementellen Staatlichkeitsausbaus angelegten Strategie einer nachholenden Hegemonialisierung. Dies zeigt sich unter anderem in seiner Aufmachung, in der mit einem historischen Rekurs über die Errungenschaften der Europäischen Union begonnen wird: Aus dem »Traum einer friedlichen, gemeinsamen Zukunft« (ebd., 6) erwuchs das Friedensprojekt EU, welches über 70 Jahre Frieden in Europa gesichert habe. Dieser Frieden werde durch die »Herrschaft des Rechts« gesichert und schützt somit eine »einzigartige Vielfalt an Kulturen, Ideen und Traditionen« (ebd.). Trotz dieser Errungenschaften stehe die Union in der Kritik, da sie »für viele Europäer entweder viel zu weit weg oder viel zu sehr darauf erpicht [ist], sich in ihren Alltag einzumischen.«(Ebd.) Hinzu kämen Herausforderungen wie die »Flüchtlingskrise«, »Terroranschläge«, »neue Weltmächte« oder der britische »Austritt aus der Union« (ebd.). Aber, so die Botschaft: Der bisherige Integrationsprozess sei nie frei von Krisen gewesen; und gerade die Krisen seien es gewesen, die zu neuen Integrationsschritten geführt hätten (vgl. ebd., 6f.). Neben dieser pointierten historischen Aufladung widmet sich das Weißbuch anschließend jenen Faktoren, die Europas Zukunft prägten. »In einer Welt im Wandel« werde der Anteil der EU- an der Weltbevölkerung kontinuierlich sinken, ebenso der Anteil am weltweiten BIP (vgl. ebd., 8). Militärisch stehe man aufgrund der »zunehmende[n] Militarisierung in allen Teilen der Welt« (u.a. russische Truppen an den EU-Ostgrenzen, Krieg im Nahen Osten) vor der Herausforderung, "seine Sicherheit selbst in die Hand « zu nehmen (Motto: »Eine ssanfte Macht ist nicht länger machtvoll genug, wenn Gewalt die Regeln außer Kraft zu setzen droht.«; ebd., 9). Im internationalen Handel müsse man sich weiter für einen wertebasierten Multilateralismus einsetzen und somit der Isolation und dem Protektionismus etwas entgegenstel- 
len (vgl. ebd.). Neben diesen externen gebe es weitere interne Herausforderungen, auf die Antworten zu geben seien. Hierunter fallen insbesondere die "Altlasten der Krise von der Langzeitarbeitslosigkeit bis hin zur hohen öffentlichen und privaten Verschuldung in vielen Teilen Europas« (ebd.). Die Gefahr dieser Altlasten bestehe darin, dass es »[z]um ersten Mal seit dem Zweiten Weltkrieg [...] der heutigen Jugend schlechter gehen wird als ihren Eltern.«(Ebd.) Hinzu kämen Faktoren wie die Bevölkerungsalterung und die hiermit verbundenen Herausforderungen für die sozialen Sicherungssysteme, die Digitalisierung als neuer Megatrend sowie das selbstgesteckte Ziel der Dekarbonisierung der Wirtschaft (vgl. ebd., 10). Neben diesen Herausforderungen, Trends und Zielen widmet sich die Kommission letztlich noch dem Sicherheitskomplex (vgl. ebd., 11) und greift das »Gefühl der Unsicherheit, das viele Menschen real empfinden« (ebd., 12) auf. Sie schließt damit, dass die EU derzeit zwar noch breite Unterstützung genieße, »aber nicht mehr bedingungslos« (ebd.). Die Problemlösungskompetenz der Union stehe einerseits vor der Herausforderung, dass »nicht gut genug erklärt [wird], wer was tut, und der positive Beitrag der EU zum Alltag [...] eben nur dann sichtbar [wird], wenn die Geschichte auch vor Ort erzählt wird.« (Ebd.) Andererseits klafften »die Erwartungen und die tatsächlichen Handlungsmöglichkeiten der EU, diese zu erfüllen, auseinander. (Ebd.) Auf der Grundlage dieser Problemperzeptionen und dargestellten Herausforderungen skizziert die Kommission schließlich ihre fünf Szenarien, deren Reichweite von »weniger, aber effizienter« (Szenario (4)) über »weiter wie bisher« (Szenario (1)) bis zu »vielmehr gemeinsam Handeln« (Szenario (5)) reichen. In Bezug auf die Fortentwicklung der EWWU würden sich diese Szenarien laut Kommission wie folgt darstellen: 
Tabelle 29: Szenarien des Weißbuchs und ihre potenzielle Wirkung auf die EWWU

\begin{tabular}{|c|c|}
\hline Szenario & Auswirkung auf die EWWU \\
\hline $\begin{array}{l}\text { Szenario (1): } \\
\text { »Weiter wie } \\
\text { bisher« }\end{array}$ & $\begin{array}{l}\text { „Das Funktionieren der einheitlichen Währung wird weiter verbessert, um das } \\
\text { Wachstum anzukurbeln und Schocks mit Ursprung innerhalb und außerhalb der EU } \\
\text { zuvorzukommen. Es werden weitere Schritte unternommen, um die Finanzaufsicht } \\
\text { zu straffen, die Tragfähigkeit der öffentlichen Finanzen sicherzustellen und Kapital- } \\
\text { märkte weiterzuentwickeln, die die Realwirtschaft besser finanzieren.«(Ebd., 16) }\end{array}$ \\
\hline $\begin{array}{l}\text { Szenario (2): } \\
\text { „Schwerpunkt } \\
\text { Binnenmarkt» }\end{array}$ & $\begin{array}{l}\text { „Der Euro erleichtert zwar den Handel, doch zunehmende Divergenzen und be- } \\
\text { grenzte Zusammenarbeit führen zu Anfälligkeiten. Infolgedessen werden die Inte- } \\
\text { grität der einheitlichen Währung und ihre Fähigkeit, auf eine neue Finanzkrise zu } \\
\text { reagieren, gefährdet.«(Ebd., 18) }\end{array}$ \\
\hline $\begin{array}{l}\text { Szenario (3): } \\
\text { „Wer mehr will, } \\
\text { tut mehr» }\end{array}$ & $\begin{array}{l}\text { „Eine Gruppe von Ländern aus Mitgliedern des Euro-Währungsgebiets und mögli- } \\
\text { cherweise einigen anderen Mitgliedstaaten entscheidet sich für eine deutlich en- } \\
\text { gere Zusammenarbeit vor allem in den Bereichen Steuern und Soziales. Eine stär- } \\
\text { kere Harmonisierung von Steuervorschriften und Steuersätzen bewirkt geringere } \\
\text { Rechtsbefolgungskosten und hält die Steuerhinterziehung in Crenzen. Vereinbarte } \\
\text { Sozialstandards bieten den Unternehmen Sicherheit und fördern bessere Arbeits- } \\
\text { bedingungen. Die Industrie arbeitet bei einigen hochmodernen Technologien, Pro- } \\
\text { dukten und Dienstleistungen enger zusammen und stellt gemeinsam Regeln für } \\
\text { deren Nutzung auf.« (Ebd., 20) }\end{array}$ \\
\hline $\begin{array}{l}\text { Szenario (4): } \\
\text { »Weniger, aber } \\
\text { effizienter« }\end{array}$ & $\begin{array}{l}\text { „Es werden weitere Schritte zur Konsolidierung des Euro-Währungsgebiets und zur } \\
\text { Sicherung seiner Stabilität unternommen; die EU-27 beschränkt ihre Aktivitäten in } \\
\text { manchen Bereichen der Beschäftigungs- und Sozialpolitik.«(Ebd., 23) }\end{array}$ \\
\hline $\begin{array}{l}\text { Szenario (5): } \\
\text { „Viel mehr } \\
\text { gemeinsam } \\
\text { Handeln« }\end{array}$ & $\begin{array}{l}\text { »Innerhalb des EuroWährungsgebiets, aber auch in allen anderen Mitgliedstaaten, } \\
\text { die sich anschließen wollen, werden fiskalische, soziale und steuerliche Fragen so- } \\
\text { wie die europäische Aufsicht über den Finanzdienstleistungssektor wesentlich stär- } \\
\text { ker koordiniert. Die EU stellt zusätzliche Finanzmittel zur Verfügung, um die wirt- } \\
\text { schaftliche Entwicklung anzukurbeln und auf regionaler, sektoraler und nationaler } \\
\text { Ebene auf Schocks reagieren zu können.«(Ebd., 24) }\end{array}$ \\
\hline
\end{tabular}

Quelle: KOM 20170

Insgesamt ist dem Weißbuch zu bescheinigen, dass es weniger auf die Aufstellung konkreter Reforminitiativen ausgerichtet ist, als vielmehr grob umrissene Entwicklungspfade zu skizzieren sucht, bei denen aber zugleich deutlich wird, dass trotz der Offenheit für Desintegration doch insgesamt eine Präferenz zur weiteren Integrationsvertiefung sichtbar wird. Schließlich liegt dies bereits in der grundsätzlichen Funktion eines Weißbuchs begründet, das am Anfang eines Konsultationsprozesses innerhalb des EU-Staatsapparate-Ensembles und mit der Zivilgesellschaft steht, als dessen Ergebnis sich im >Idealfalk eine konkrete, mehrheitsfähige Politikagenda verdichtet. Vor diesem Hintergrund erscheint die Kommunikations- und Diskursstrategie der Kommission offensichtlich: das Evozieren einer integrationsfreundlichen Stimmung durch Aufzeigen der Bandbreite und Komplexität aktueller Trends bei gleichzeitiger Präsentation negativer Assoziationen beim Ausbleiben weiterer Integrationsschritte oder selbst bei einer Orientierung am Status quo. Schließlich endet das Weißbuch mit der Feststellung, dass »[n] ur unser kollektiver Wille [...] Europa voranbringen« (ebd., 26) werde. 
Zwei Monate nach der Veröffentlichung des Weißbuchs legte die Kommission (2017d) mit ihrem »Reflexionspapier zur Vertiefung der Wirtschafts- und Währungsunion « ein weiteres leitbildpolitisches Papier vor, in dem sie - detaillierter als im Weißbuch - eine weitere Reformagenda für die EWWU skizzierte. Geradezu trotzig wirkt - aufgrund der bereits in der Phase des inkrementellen Staatlichkeitsausbaus offensichtlichen Blockaden - das Motto des Papiers: „Es ist an der Zeit, Pragmatismus über Dogmatismus zu stellen und Brücken zu schlagen, statt einander zu misstrauen.« (Ebd., 38) An anderer Stelle heißt es:

»Wir wissen nur zu gut, was getan werden muss. Doch Meinungsverschiedenheiten stehen dem Fortschritt häufig im Wege. Einige argumentieren, die Folgen der Krise ließen sich am besten durch größere Solidarität bewältigen, anderen beharren darauf, dass als Voraussetzung für ein weiteres Voranschreiten erst die Eigenverantwortung der Mitgliedstaaten gestärkt werden müsse. Trotz aller Anstrengungen der letzten Jahre ist die Dynamik zur weiteren Reformierung der WWU dadurch zu einem Teil verloren gegangen.« (Ebd., $5 f$.)

Zuvor schrieb die Kommission pessimistisch, dass es aufgrund der Heterogenität der Euro-Mitgliedstaaten »ein einheitliches Zukunftskonzept für die WWU oder eine sewig währende gemeinsame Sicht der besten weiteren Vorgehensweise [...] niemals geben [wird].«(Ebd., 20) Das Reflexionspapier offenbart insofern an unterschiedlichen Stellen die Problematik der bis dato ausgebliebenen Konsens- beziehungsweise Kompromissfindung unter den 19 Eurostaaten. Die von der Kommission präsentierte Ausgangslage, wonach man in Zeiten der Krise bereits viele Verbesserungen erreicht habe, die EWWU dennoch unvollständig geblieben sei, bleibt den Erzählungen der Vorläuferpapiere treu. Demnach sei die Währungskomponente gut entwickelt, die wirtschaftliche Komponente hinke hingegen hinterher. Hieraus resultiere eine nur »eingeschränkte Fähigkeit zur Unterstützung der Geldpolitik und der von den einzelnen Euro-Ländern verfolgten Wirtschaftspolitik« (ebd., 5), der man begegnen müsse. In diesem Sinne entwickelt das Reflexionspapier Ansätze eines Reformprogramms, das sich zeitlich erneut auf zwei Phasen bezieht: einer ersten Phase bis 2019 sowie einer weiteren Phase ab dem Jahr 2020, die auf eine vertiefte EWWU im Jahre 2025 abzielt. Das Reflexionspapier baut inhaltlich auf den Fünf-Präsidenten-Bericht auf (vgl. ebd., 6) und bleibt somit auch dem Ansatz treu, eher ausgewählte Initiativen zu beschreiben, als eine umfassende Vorstellung einer vollendeten EWWU zu entwickeln. Gliederungsebenen sind dem Grunde nach weiterhin die bereits bekannten vier Unionen (Wirtschafts-, Finanz/Banken-, Fiskal- und politische Union), wobei die politische Union im Reflexionspapier als solche nicht explizit benannt ist. Stattdessen wird von einer transparenteren und effektiveren Steuerung der EWWU gesprochen (vgl. u.a. ebd., 17): 
Tabelle 30: Argumente für die EWWU-Vertiefung laut Kommissionsmitteilung

\begin{tabular}{|c|c|}
\hline Union & Begründung \\
\hline $\begin{array}{c}\text { "Was spricht für weitere } \\
\text { Schritte in Richtung } \\
\text { einer } \\
\text { Wirtschaftsunion?» }\end{array}$ & $\begin{array}{l}\text { »Nach den Jahren der Krise braucht die Wirtschaft der Euro-Mitgliedstaaten } \\
\text { einen kräftigen Wachstums- und Wohlstandskurs. Damit alle Bürgerinnen } \\
\text { und Bürger sowie die Unternehmen mehr vom Euro profitieren, muss dieser } \\
\text { Kurs mit einer erneuten, nachhaltigen länderübergreifenden Konvergenz } \\
\text { einhergehen, von der er wiederum profitieren würde. Dafür sind Strukturre- } \\
\text { formen erforderlich, um die Wirtschaft zu modernisieren und besser gegen } \\
\text { Schocks zu wappnen.«(Ebd., 14) }\end{array}$ \\
\hline $\begin{array}{c}\text { » Was spricht für weitere } \\
\text { Schritte in Richtung } \\
\text { einer Finanzunion?» }\end{array}$ & $\begin{array}{l}\text { »Die Finanzstabilität im Euroraum wurde gefestigt. Dennoch bestehen wei- } \\
\text { terhin enge Verflechtungen zwischen den Banken und sihren Ländern, und } \\
\text { der Bestand an notleidenden Krediten bleibt hoch. Weitere Schritte sind er- } \\
\text { forderlich, um Risiken im Bankensektor zu vermeiden und gemeinsam zu } \\
\text { schultern und der Realwirtschaft bessere Finanzierungsmöglichkeiten auch } \\
\text { über die Kapitalmärkte zu eröffnen. Dies kann nur gelingen, wenn Banken- } \\
\text { union und Kapitalmarktunion vollendet werden.«(Ebd., 15) }\end{array}$ \\
\hline $\begin{array}{c}\text { » Was spricht für weitere } \\
\text { Schritte in Richtung } \\
\text { einer Fiskalunion?» }\end{array}$ & $\begin{array}{l}\text { »Damit die einheitliche Währung funktioniert, müssen folgende Voraus- } \\
\text { setzungen geschaffen werden: i) gesunde öffentliche Haushalte und Haus- } \\
\text { haltsspielräume, die dazu beitragen, die Wirtschaft krisenfester zu machen; } \\
\text { ii) die Ergänzung der gemeinsamen Stabilisierungsinstrumente des Euro- } \\
\text { Währungsgebiets; iii) die Verknüpfung von Marktdisziplin mit einem ge- } \\
\text { meinsamen Regelwerk, wodurch diese Regeln an Wirksamkeit gewinnen } \\
\text { und leichter verständlich und handhabbar würden.«(Ebd., 17) }\end{array}$ \\
\hline $\begin{array}{c}\text { » Was spricht für weitere } \\
\text { Schritte in Richtung } \\
\text { einer besseren } \\
\text { Steuerung der WWU?» }\end{array}$ & $\begin{array}{l}\text { „Für eine stärkere WWU bedarf es einer festeren Steuerung. Das derzeiti- } \\
\text { ge System ist ein Agglomerat vergangener Einzelentscheidungen. Darun- } \\
\text { ter leidet die Wirksamkeit der gemeinsamen Institutionen und Instrumente. } \\
\text { Die Abläufe sind komplex und intransparent. Angesichts der Notwendigkeit, } \\
\text { mehr wirtschaftliche Konvergenz zu schaffen und sich gegen künftige Er- } \\
\text { schütterungen zu wappnen, ist diese Situation nicht optimal. Eine gemein- } \\
\text { same Vorstellung davon, wie es weitergehen soll, ist für eine bessere WWU- } \\
\text { Architektur unerlässlich.«(Ebd., 19) }\end{array}$ \\
\hline
\end{tabular}

Quelle: KOM 2017d

Die im Reflexionspapier skizzierte sstärker integrierte Wirtschafts- und Fiskalunion orientiere sich am Ziel, Konvergenz zwischen den Mitgliedstaaten herzustellen (vgl. ebd., 27f.). Für den ersehnten, neuen Konvergenzprozess - insbesondere für die Eurozone - stelle der Binnenmarkt der geeignetste Rahmen dar, der weiter vertieft und gestärkt werden müsse (bspw. durch die Initiativen »digitaler Binnenmarkt«, »Energie-« und »Kapitalmarktunion«) (vgl. ebd., 28). Das Europäische Semester bleibt in den Vorstellungen der Kommission insgesamt das zentrale Instrument des fiskal- und wirtschaftspolitischen Regierens in der EWWU und somit auch des avisierten Konvergenzprozesses (vgl. ebd.). Angereichert werden solle es um soziale Aspekte, die sich in den Initiativen rund um die »europäische Säule sozialer Rechte« widerspiegeln (vgl. ebd.). Zur kurzfristigen Stärkung des Semesters (bis 2019) schlägt die Kommission des Weiteren drei Maßnahmen vor, die im Sinne des Integrationsmodus »Vertiefung durch Handeln« wiederum nur an prozessualen Stellschrauben ansetzen: So solle im Rahmen des Semesters der Dialog zwischen den unterschiedlichen Ebenen und Interessensträ- 
ger*innen gestärkt werden, was zugleich zu einer besseren Umsetzung der mitgliedstaatlichen Reformvorhaben beitragen könne. Weiterhin wolle die Kommission im Semester die Gesamtdimension des Euro-Währungsgebietes stärken und für eine engere Abstimmung zwischen dem Semester und den mehrjährig angelegten Reformprogrammen sorgen (vgl. ebd., 29). Auch die bereits im Fünf-Präsidenten-Bericht angekündigte verbindlichere Steuerung des Konvergenzprozesses bleibt in den Ausführungen eher vage. So sei eine Einbindung in das Europäische Semester angestrebt, innerhalb dessen die Einhaltung vereinbarter Standards (bspw. zu Investitionstätigkeiten, Marktliberalisierungen, Qualität öffentlicher Finanzen etc.) überwacht werden könne (vgl. ebd.). Zugleich verweist die Kommission aber darauf, dass

»[d]erartige Standards [...] jedoch nur dann für rechtsverbindlich erklärt werden [können], wenn sich ihre Einhaltung durch eine enge Verknüpfung von einschlägigen Reformen, der Verwendung von EU-Mitteln und dem [sic!] Zugriff auf eine mögliche makroökonomische Stabilisierungsfunktion stärken lässt.« (Ebd.)

Der angestrebte Konvergenzprozess, so ließe sich die Äußerung übersetzen, kann entsprechend nur dann gelingen, wenn zugleich auch eine finanzielle Incentivierung (EUMittel \& Stabilisierungsfunktion) des erwünschten Verhaltens (einschlägige Reformen) durch die EUSA ermöglicht werde. Erste Schritte seien hierzu bereits im Finanzrahmen 2014-2020 verwirklicht worden, indem bei kofinanzierten Programmen durch den betreffenden Mitgliedstaat den länderspezifischen Empfehlungen Rechnung zu tragen sei (vgl. ebd.). Langfristig könne sich die Kommission für den EU-Haushalt vorstellen, Anreize für Reformen zu erhöhen, indem ein eigener Fonds hierfür eingerichtet werde oder aber die Auszahlung bestehender Fondsmittel von der Erreichung zuvor gemachter Reformzusagen abhängig zu machen (vgl. ebd.). Allerdings verweist die Kommission auch darauf, dass der bisherige Umfang des EU-Haushalts nicht ausreiche, um den Konvergenzprozess fiskalisch zu steuern und insofern auch keine makroökonomische Stabilisierungsfunktion für die EU/den Euroraum übernehmen könne (vgl. ebd., 30). Kurzfristig sei es zwar möglich, im begrenzten Rahmen die Stabilisierungsfunktion des EU-Haushaltes beispielsweise durch eine systematischere Differenzierung der Kofinanzierungssätze zu stärken, langfristig sei aber die Einführung einer makroökonomischen Stabilisierungsfunktion für das Euro-Währungsgebiet nötig (vgl. ebd.). Wie genau eine solche Stabilisierungsfunktion aussehen könnte, lässt die Kommission analog zum Fünf-Präsidenten-Bericht - allerdings offen. Vielmehr stellt sie verschiedene Möglichkeiten dar, die sich auf unterschiedlich weit gefassten Zielsetzungen sowie unterschiedliche Finanzierungswege beziehen (vgl. ebd., 31). Ferner werden hierzu kurz drei Formate (Investitionsschutzregel, Arbeitslosenrückversicherung, Rainy-DayFonds) vorgestellt (vgl. ebd., 32). Grundsätzlich offen, aber dennoch bei der Bewertung der Umsetzungsbereitschaft skeptisch, zeigt sich die Kommission auch gegenüber einem Eurozonen-Haushalt (vgl. ebd.). Im Zusammenhang mit all diesen fiskalischen Instrumenten verweist sie noch einmal auf die technische Unterstützung bei der Umsetzung von Strukturreformen, die in der Amtszeit der Juncker-Kommission etabliert wurde, und deren Kapazitätserhöhung sie vorschlägt (vgl. ebd., 33).

In Bezug auf die Stärkung der EWWU-Architektur und der Verankerung demokratischer Rechenschaftspflichten räsoniert das Reflexionspapier eingangs über die recht- 
liche Form künftiger Vertiefungsschritte. Demnach seien mehrere Modelle möglich: »[A]uf die EU-Verträge und die EU-Institutionen zurückgreifen, einen zwischenstaatlichen Ansatz wählen oder einer Mischung aus beiden den Vorzug geben, wie schon gegenwärtig der Fall.«(Ebd., 27) Dabei sollte die weitere politische Integration schrittweise erfolgen und letztlich auch "mit den notwendigen rechtlichen Änderungen der EUVerträge oder internationalen Verträgen wie dem Fiskalpakt und dem ESM-Vertrag einhergehen.«(Ebd.) Auch die Frage der »Integrität«, der in Vorläuferpapieren der Kommission sehr viel Beachtung geschenkt wurde, widmet sich das Reflexionspapier und führt an, dass alle Mitgliedstaaten ein Interesse daran hätten, die EWWU gemeinsam fortzuentwickeln, wobei unter Einhaltung der nötigen Transparenz zwischenzeitlich auch über eine Stärkung der Euro-Gruppe nachgedacht werden könne, die gemeinsam mit dem Europäischen Parlament verbindliche Entscheidungen für den Euroraum herbeiführen könnte (vgl. ebd.). Auch langfristig schlägt das Reflexionspapier, wie bereits aus dem Fünf-Präsidenten-Bericht bekannt, eine Neuverteilung der Kompetenzen zwischen der Kommission und der Euro-Gruppe vor:

»Mit zunehmender relativer Größe des Euroraums innerhalb der Union könnte die Euro-Cruppe auf lange Sicht in eine Ratsformation umgewandelt werden. Darüber hinaus könnten die Funktion des ständigen Vorsitzes der Euro-Cruppe und des für die WWU zuständigen Kommissionmitglieds zusammengelegt werden.«(Ebd., 34)

Ebenfalls erneuert wird die Forderung nach einer geschlossenen Euro-Außenvertretung (vgl. ebd.). Bei den Fragen demokratischer Rechenschaftspflichten bleibt das Papier abermals blass. Neben der allgemeinen Absichtserklärung, dass die Parlamente ausreichend Kontrollbefugnisse erhalten sollten, verweist die Kommission bei Fragen mit Bezug zum Euroraum auf derzeitige informelle Dialoge mit dem Europäischen Parlament, die potenziell in einer »Abmachung « auch formal festgeschrieben werden könnten (vgl. ebd.). Auch andere Akteur*innen könnten, so der Vorschlag, untereinander solche Abmachungen mit dem Ziel fassen, diese später in die Verträge aufzunehmen (vgl. ebd.). Auch die Ideen zur Schaffung eines Euro-Schatzamtes sowie eines auf Grundlage des ESM weiterentwickelten Europäischen Währungsfonds werden im Reflexionspapier erneut präsentiert (vgl. ebd.), verharren dabei aber meist im Konjunktiv. In diesem Sinne ist auch die Möglichkeit der Überarbeitung der bestehenden Fiskalregeln einzuordnen:

»Während einige die heutigen Regeln für zu locker halten, betrachten andere sie als zu streng. Einigkeit herrscht jedoch darüber, dass die Regeln zu komplex geworden sind und damit der Eigenverantwortung und der wirksamen Umsetzung im Wege stehen. Im Zuge einer stärkeren Integration, die angemessene Schutzmechanismen und weitere Kanäle für den Umgang mit der wirtschaftlichen Verflechtung mit sich bringt, könnten die Fiskalregeln allmählich vereinfacht werden.« (Ebd., 36)

Am Reflexionspapier ist auffällig, dass seine Autor*innen bemüht waren, bisherige Reflexionsprozesse und Diskurse über die Zukunft der EWWU abzubilden. Dies äußert sich auf sprachlicher Ebene in vielen Konjunktiven und einer "sowohl-als-auch«Rhetorik. Auch wenn das Reflexionspapier im Unterschied zum Weißbuch eindeutiger in Richtung weiterer Integrationsschritte plädiert, verweist seine sprachliche und 
argumentative Anlage dennoch zugleich auf sein generelles Problem: Es bleibt an vielen Stellen diffus und vage und zeigt insofern nicht immer konkret auf, welche Integrationsschritte wirklich nötig seien und wie diese genau auszugestalten wären. Das Reflexionspapier ist, obwohl es die >Vollendung der Wirtschafts- und Währungsunion explizit zu begründen suchte (vgl. KOM 2017d, 12-18), insofern am ehesten als eine Fortschreibung des Fünf-Präsidenten-Berichts zu betrachten, der bereits ein eher überschaubares Leitbild einer >vollendeten EWWU< präsentierte.

Welche konkreten und handlungsleitenden Schlüsse die Kommission schlussendlich selber aus dem Reflexionspapier zog, zeigte sich in der 2017er Rede ihres Präsidenten zur >Lage der Union`, in der Juncker eine Politikagenda für die verbleibende Zeit seiner Präsidentschaft präsentierte. Einen Prozess hin zur Änderung der Verträge - als notwendige Voraussetzung der EWWU-Vollendung - wolle er dabei derzeit allerdings nicht anstoßen, stattdessen müssten »wir uns zunächst von der Vorstellung verabschieden, dass einige verlieren müssen, damit andere gewinnen können.« (KOM 2017c, 119) Weiter sagte er, dass er an institutionellen Reformen nur dann interessiert sei, »wenn sie zu mehr Effizienz der Europäischen Union führen« (ebd.) würden. Ein Beispiel für solche institutionellen Reformen ohne Vertragsrevision führt Juncker in seinen Äußerungen zu einer stärkeren Union aus. So schlägt er unter anderem in Fragen des Binnenmarktes häufiger qualifizierte Mehrheits- statt Einstimmigkeitsentscheidungen vor, die durch die in den Verträgen enthaltene >Brückenklauseln $<$ herbeigeführt werden könnten (vgl. ebd., 120; s. Art. 48, Abs. 7 EUV). Juncker verbindet hiermit auch das Ansinnen, die Wirtschafts- und Währungsunion handlungsfähiger zu machen (vgl. ebd.), zu deren Stärkung er - im Einklang mit dem Reflexionspapier - als anstehende Einzelprojekte die Überführung des ESM in einen Europäischen Währungsfonds innerhalb des Unionsrechts sowie die Schaffung eines »Europäischen Wirtschafts- und Finanzministers« (EMWF) vorschlägt (vgl. ebd., 121). Ganz im Sinne seines Ansatzes beschränkter institutionell-vertraglicher Reformen und des Reflexionspapieres soll dabei die Finanzminister"in-Funktion einem*einer Vizekommissionspräsident*in übertragen werden, die*der in dieser neuen Funktion zugleich der Euro-Gruppe vorsitzen solle (vgl. ebd.). Wie bereits in älteren Perspektivpapieren erneuert Juncker zugleich noch einmal die Zusicherung der vollen Integrität des Europäischen Parlamentes, indem er erneut der Forderung nach einem Eurozonen-Parlament eine Absage erteilt (vgl. ebd.). Dies gilt auch für ein eigenständiges Eurozonen-Budget: »Wir brauchen keine Parallelstrukturen. Wir benötigen deshalb keinen separaten Euro-Haushalt, sondern eine starke Eurozonen-Budgetlinie im Rahmen unseres EU-Haushaltes.« (Ebd.) Das Reflexionspapier war an dieser Stelle noch offener formuliert. Juncker verweist mit seinen Positionierungen zur EWWU insgesamt bereits auf das im Winter folgende Nikolauspaket.

\section{Die Februar-Initiativen des Europäischen Parlaments}

Das Europäische Parlament, das schon in den früheren Diskussionen um die Reformagenda und die Vertiefungsdiskussionen einen umfassenderen Ansatz notwendiger institutioneller Reformen und insbesondere eine genuin europäische Fiskalunion als Ergänzung der Wirtschafts- und Währungsunion propagierte, präsentierte einen Monat 
nach dem Kommissionsweißbuch und einen Monat vor dem Reflexionspapier in drei Entschließungen seine Vorstellung künftiger Reformschritte. Die Entschließungen basieren ebenfalls auf einem Stufenansatz, der sich im ersten Schritt auf die volle Ausschöpfung des Lissabon-Vertrags konzentrieren solle (vgl. EP 2017c) sowie im zweiten Schritt eine Vertiefung im Rahmen einer regulären Vertragsrevision anstrebt (vgl. EP 2017b). Zusammengenommen wird mit den Entschließungen ein Reformansatz entwickelt, der auf den Ausbau der Wirtschaftsunion, den Aufbau einer Fiskalunion und schließlich der politischen Union zielt. Dass diese Zukunftsvision dabei selbst innerhalb des Parlaments nicht unumstritten war, zeigt sich an der nur knappen Mehrheit für die von Guy Verhofstadt (ALDE) verantwortete Entschließung (EP 2017b):

Tabelle 31: Abstimmungsergebnisse der Februar-Initiativen des Europäischen Parlaments

\begin{tabular}{|c|c|c|}
\hline Initiative & $\begin{array}{l}\text { Mehrheitliche } \\
\text { Zustimmung } \\
\text { durch }\end{array}$ & Ja|Nein| Enth. \\
\hline $\begin{array}{l}\text { Mögliche Entwicklungen und Anpassungen der derzeitigen } \\
\text { institutionellen Struktur der Europäischen Union } \\
\text { (EP 2017b) }\end{array}$ & $\begin{array}{l}\text { S\&D, Grüne, ALDE, } \\
\text { PPE }^{1)}\end{array}$ & $283|269| 83$ \\
\hline $\begin{array}{l}\text { Verbesserung der Arbeitsweise der Europäischen Union } \\
\text { durch Ausschöpfung des Vertrags von Lissabon } \\
\text { (EP 2017c) }\end{array}$ & $\begin{array}{l}\text { S\&D, Grüne,ALDE, } \\
\text { PPE }\end{array}$ & $329|223| 83$ \\
\hline $\begin{array}{l}\text { Haushaltskapazität des Euro-Währungsgebiets } \\
\text { (EP 2017a) }\end{array}$ & $\begin{array}{l}\text { S\&D, Grüne,ALDE, } \\
\text { PPE }^{2)}\end{array}$ & $304|255| 68$ \\
\hline \multicolumn{3}{|c|}{$\begin{array}{l}\text { Anmerkungen: } \\
\text { 1) = Bei einer großen Anzahl von »Abweichler*innen« in allen benannten Fraktionen } \\
\text { 2) = Keine Absolute Mehrheit für den Vorschlag in der PPE-Fraktion }\end{array}$} \\
\hline
\end{tabular}

Quelle: Eigene Zusammenstellung auf Grundlage von EP (2017d)

Auf Grundlage der bestehenden primär- und sekundärrechtlichen Grundlagen forciert das Parlament insbesondere zwei Reformvorhaben zum Ausbau der Wirtschaftsunion. So werden zum einen prozedurale Änderungen am Europäischen Semester mit dem Ziel vorgeschlagen, den bestehenden wirtschaftspolitischen Dialog zwischen Kommission und Parlament zu intensivieren und die Überwachungsbefugnisse des Parlaments im Rahmen des Semesters in Form einer interinstitutionellen Vereinbarung zu formalisieren (vgl. EP 2017c, Rn. 59). Zugleich plädiert das Parlament für eine interinstitutionelle Vereinbarung zur Verbesserung der demokratischen Legitimität des Europäischen Semesters, die im Gegensatz zu den bisherigen Verfahrensabläufen auch eine parlamentarische Beteiligung bei der Gestaltung und Verabschiedung der Grundzüge der Wirtschaftspolitik und der beschäftigungspolitischen Leitlinien umfassen solle und insofern eine »tatsächliche und regelmäßige parlamentarische Überwachung des Verfahrens vorsehen « (ebd.) würde. Daneben fordert es die länderspezifischen Empfehlungen weiter zu stärken, indem sie »zielgerichteter « formuliert und in ihrer Anzahl weiter reduziert werden (vgl. ebd., Rn. 57). Zur zielgerichteteren Ausgestaltung schlägt das Parlament als zweiten, konkreten Reformbaustein einen »im ordentlichen Gesetzgebungsverfahren verabschiedeten Konvergenzkodex« (ebd., Rn. 53) vor. In ihm 
sollten »konvergierende Vorgaben« zu den Bereichen »Besteuerung, Arbeitsmarkt, Investitionen, Produktivität, gesellschaftlicher Zusammenhalt, Kapazität der öffentlichen Verwaltung und für verantwortungsvolles Management [...] festgelegt werden «, so das Parlament (2017b, Rn. 20). Die Einhaltung des Kodex solle, nach den Vorstellungen des EP, die Voraussetzung zur Teilnahme an der potenziellen Fiskalkapazität des EuroWährungsgebiets darstellen. Das Parlament nimmt mit diesem Vorschlag zugleich Bezug zu dem 2015 im Fünf-Präsidenten-Bericht eingeforderten neuen Konvergenzprozess, der nötig sei, um die EWWU dauerhaft zu sichern und krisenfester zu machen. Konkreten Einfluss auf die im Nikolauspaket (s.u.) präsentierten Reformmaßnahmen konnte der vorgeschlagene Konvergenzkodex des Parlaments hingegen nicht nehmen, was das Parlament in einer späteren Entschließung auch kritisierte (vgl. EP 2019a, Rn. 33). Der Duktus der Parlamentsentschließungen bleibt aber dennoch zugleich auch einer übergeordneten Wettbewerbsfähigkeits- und Strukturreformenagenda verpflichtet. So sollten für einen fünf Jahre umfassenden Zeitraum Strukturreformen unter anderem zur Verbesserung der Wettbewerbsfähigkeit festgelegt werden (vgl. EP 2017c, Rn. 54) und durch die konsequente Anwendung des Six-Packs beziehungsweise des Verfahrens bei makroökonomischen Ungleichgewichten »Anreize für faire und nahhaltige Strukturreformen geschaffen [...] werden« (ebd., Rn. 65). Auch unterstützt das Parlament »die Schaffung eines Systems aus Einrichtungen zur Stärkung der Wettbewerbsfähigkeit« (ebd., Rn. 76), wie es mit den Produktivitätsausschüssen (drittes EconomicGovernance-Paket 2015) bereits geschaffen wurde. In der längerfristigen Perspektive und auf neuer vertraglicher Grundlage schlägt das Parlament für die zweite Reformstufe weniger einzelne wirtschaftspolitische Vertiefungsoptionen als vielmehr eine komplette Neuordnung der politischen Prozesse innerhalb der Wirtschaftsunion vor, die eng verknüpft ist mit der vertieften Fiskalunion und insbesondere einer gestärkten demokratischen Legitimität im Rahmen der politischen Union.

Im Kontext der Vertiefung der Fiskalunion unter dem Dach der EWWU erneuert das Parlament seine Forderung nach der Überführung der außerunionsvertraglichen Bausteine reaktiver Krisenbewältigung in den Rechtsrahmen der Union (vgl. EP 2017c, Rn. 7; s. auch Rn. 69). Weiterhin fordert es in einem ersten Schritt die Schaffung eines Haushalts für die Eurozone, der im Mehrjährigen Finanzrahmen der EU integriert werden solle (vgl. ebd., Rn. 62). In der dritten Entschließung des 16. Februar 2017 führt das Parlament seine Überlegungen hierzu näher aus. So solle

»[z]unächst [...] die spezifische Haushaltskapazität für das Euro-Währungsgebiet Teil des Cemeinschaftshaushalts sein, über die derzeitigen Obergrenzen des mehrjährigen Finanzrahmens hinausgehen und vom Euro-Währungsgebiet und weiteren teilnehmenden Mitgliedern über eine Einnahmequelle finanziert werden, die zwischen den teilnehmenden Mitgliedstaaten zu vereinbaren und als zweckgebundene Einnahme und Garantie zu beachten ist.«(EP 2017a, Rn. 1.i)

Nach den Plänen des Parlaments könnte die Fiskalkapazität drei Säulen umfassen, die jeweils unterschiedlichen Zielsetzungen dienen. Die erste Säule solle sich am vom EP vorgeschlagenen Konvergenzkodex orientieren und »die wirtschaftliche und soziale Konvergenz im Euro-Währungsgebiet [fördern], um Strukturreformen voranzutreiben, die Volkswirtschaften zu modernisieren und die Wettbewerbsfähigkeit des 
Euro-Währungsgebiets zu verbessen« (ebd., Rn. 1.ii). Eine Investitionsstrategie, die diesen Zielsetzungen Rechnung trägt, wäre Grundlage für den ersten Teilhaushalt. In der zweiten Säule schlägt das Parlament eine Kapazität zur Abfederung asymmetrischer Schocks vor, die den ESM ergänzen solle. Allerdings sollte ein solches Stabilisierungssystem »klare Vorschriften über die innerhalb eines Zeitraums möglichen Zahlungen und Rückzahlungen enthalten, seine Größe und seine Finanzierungsmechanismen [...] klar definiert sein und [...] über einen längeren Zeitraum haushaltsneutral sein.«(Ebd.) Insofern wäre die zweite Säule weniger eine klassische Fiskalkapazität als vielmehr ein weiterer Mechanismus zur Gewährung von Darlehen, der den vorsorglichen ESMFinanzhilfen ähnelt. Letztlich könnte in einer dritten Säule eine Kapazität geschaffen werden, die bei symmetrischen Schocks abgerufen werden könnte, wobei sicherzustellen sei, dass der Umfang ausreiche, »um diese symmetrischen Schocks durch die Finanzierung von Investitionen zur Ankurbelung der Nachfrage zum Erreichen von Vollbeschäftigung [...] abzufedern.« (Ebd.) Diese Säule wäre im Sinne eines keynesianisch inspirierten Mechanismus zur Lancierung von europäischen Konjunkturpaketen zu verstehen. Etwaige Rückzahlungsmodalitäten innerhalb der dritten Säule werden im Vorschlag anders als bei asymmetrischen Schocks nicht genannt. Das für Finanzen und Haushalt zuständige Kommissionsmitglied solle in Zusammenarbeit mit den Euro-Finanzminister*innen für den neuen fiskalischen Rahmen der Eurozone die Verantwortung zeichnen und zugleich auch Präsident*in der Euro-Gruppe werden (vgl. ebd., Rn. 1.iii; EP 2017c, Rn. 31).

Bereits der kurz- und mittelfristige Maßnahmenkatalog des Parlaments gibt in einem der einleitenden Erwägungsgründe die grundsätzliche Zielsetzung künftiger Integrationsschritte in Richtung auf die politische Union vor. Dort heißt es,

»dass die institutionelle Struktur der WWU wirksamer und demokratischer gemacht werden sollte, wobei Parlament und Rat als gleichberechtigte Mitgesetzgeber handeln, die Kommission die Rolle der Exekutive ausfüllt, die einzelstaatlichen Parlamente die Maßnahmen der einzelstaatlichen Regierungen auf der EU-Ebene stärker überwachen, das Europäische Parlament die EU-Ebene der Entscheidungsverfahren überwacht und der Cerichtshof eine stärkere Rolle einnimmt« (EP 2017c, Rn. V).

Auf Grundlage der bestehenden Verträge fordert das Parlament, wie oben schon exemplarisch dargestellt, interinstitutionelle Vereinbarungen zu treffen, um die »legislativen Befugnisse und Kontrollrechte des Parlaments « zu garantieren, zu konsolidieren und $\mathrm{zu}$ stärken (vgl. ebd., Rn. 15). Es bemängelt zugleich die nicht vertragskonforme Stärkung des Europäischen Rates im Laufe der Euro-Krise, der häufig Legislativangelegenheiten verhandelte, die eigentlich Gegenstand des Ministerrates seien (vgl. ebd., Rn. 24). Der Europäische Rat solle sich daher wieder auf seine vertraglich zugedachte Funktion beschränken (vgl. ebd.). Auch schlägt das Parlament vor, die Ratsstruktur zu einer dem Parlament komplementären Gesetzgebungskammer weiterzuentwickeln. Hierzu sollten »die Ratsformationen durch einen Beschluss des Europäischen Rates beschränkt werden, sodass ein echtes, legislatives Zweikammernsystem aus Rat und Parlament mit der Kommission als Exekutive geschaffen wird« (ebd., Rn. 29). Den bisherigen Ratsformationen käme hierbei die Funktion vorbereitender Ausschüsse zu (vgl. ebd.). Weiterhin wird gefordert, dass der Rat »vollständig zur Beschlussfassung mit qualifizierter 
Mehrheit übergeht, wo immer dies vertragsgemäß möglich ist (ebd., Rn. 33). All dies wäre zudem damit verbunden, die Kommission in ihrer exekutiven Funktion zu stärken, wie mehrfach in der Entschließung eingefordert (vgl. u.a. ebd., Rn. X). In der Fortführung dieser Vorschläge bedürfe es in einer längerfristigen Perspektive zur Konsolidierung der vorgeschlagenen Regierungspraxen einer Reform der Verträge mit der grundsätzlichen Zielsetzung,

»dass die Kommission die Rolle einer wirklichen Regierung übernimmt, die dem Parlament rechenschaftspflichtig und in der Lage ist, die gemeinsamen haushaltspolitischen und makroökonomischen Maßnahmen, die das Euro-Währungsgebiet benötigt, zu konzipieren und umzusetzen, und die mit einer Finanzverwaltung und mit Haushaltsmitteln ausgestattet sein muss, die dem Ausmaß der zu bewältigenden Aufgaben angemessen sind« (EP 2017b, Rn. P; vgl. ebd., Rn. 47).

Neben der Reformierung des Rates zu einer einzigen Legislativkammer, in die nach der Vertragsänderung auch der Europäische Rat eingegliedert werden soll (vgl. ebd., Rn. 54), sieht der EP-Vorschlag zugleich - und mit gewissem Widerspruch zur generellen Stoßrichtung der EP-Entschließungen - die Weiterentwicklung der Euro-Gruppe vor, die als Komplementär zur*zum EU-Finanzminister*in »als formelle spezialisierte Ratsformation mit Legislativ- und Kontrollfunktion « (ebd., 57) in die Vertragsstrukturen überführt werden solle. Im neuen Zweikammerngesetzgebungsverfahren sollen nach den Vorstellungen der Parlamentarier*innen sowohl das Parlament als auch der Rat ein legislatives Initiativrecht erhalten (vgl. ebd., Rn. 62), das bisher ausschließlich der Kommission zusteht. Auch die nationalen Parlamente sollten in eine solche Richtung gestärkt werden, indem ihnen eingeräumt wird, Legislativvorschläge zur Prüfung an den Rat zu übermitteln (vgl. ebd., Rn. 60). Ergänzt werden sollten die Verträge zudem um direktdemokratische Elemente, so beispielsweise um ein »EU-Referendum zu Angelegenheiten, die für die Maßnahmen und Strategien der Union von Bedeutung sind (ebd., Rn. 46).

Alles in allem präsentiert das Parlament mit dieser institutionellen Reformagenda das bis dato umfangreichste Programm zur Verbesserung der interinstitutionellen Prozesse und Rechenschaftspflichten und somit zur Stärkung demokratischer Legitimität. Die EWWU-Perspektivpapiere des Rates, der Präsidenten oder der Kommission blieben hierzu im Vergleich blass. Zusammengenommen führe eine nach den Vorstellungen des Parlamentes weiterentwickelte EU/EWWU zu einem weithin sichtbaren Ausbau der EU-Staatlichkeit, der sich letztlich am Leitbild und der Etablierung einer umfangreichen Europäischen Wirtschaftsregierung verdichtet. In ihrem Zentrum stünde die Kommission, die in dieser Funktion gegenüber Parlament und Rat (respektive EuroGruppe) rechenschaftspflichtig wäre.

\subsection{Das Nikolauspaket und die Diskussion um die Fiskalunion}

Nach dem Weißbuch im Januar, den Parlamentsentschließungen im Februar, dem Reflexionspapier im März und Junckers Rede zur Lage der Union im September veröffentlichte die Kommission schließlich am 6. Dezember 2017 ein weiteres Maßnahmenpaket, 
das in Analogie zu den vorherigen Reformpaketen als viertes >Economic-GovernancePaket bezeichnet werden könnte, aufgrund seines Veröffentlichungsdatums allerdings weithin als >Nikolauspaket< bezeichnet wird. Neben der einleitenden Mitteilung (KOM 2017e) und zweier spezifischer Mitteilungen, die Themen des Reflexionspapieres näher ausführen (KOM 2017f \& 2017g), sind im Paket vier Legislativvorschläge enthalten (KOM 2017h-k), deren Beschlussfassung nach den Vorstellungen der Kommission (2017e) bis Mitte 2019 erfolgen sollte:

Tabelle 32: Viertes Economic-Governance-Paket vom 06.12.2017 (Nikolauspaket)

\begin{tabular}{|l|c|c|}
\hline Initiative & Art & Status \\
\hline Weitere Schritte zur EWWU-Vollendung & $\begin{array}{c}\text { Einleitende } \\
\text { Mitteilung }\end{array}$ & Mitteilung \\
\hline Neue Haushaltsinstrumente innerhalb des Unionsrahmens & $\begin{array}{c}\text { Mündete im } \\
\text { Fiskal-Two-Pack }\end{array}$ \\
\hline $\begin{array}{l}\text { Schaffung eines Europäischen Wirtschafts- und Finanzminis- } \\
\text { ters }\end{array}$ & Mitteilung & $\begin{array}{c}\text { Bisher keine } \\
\text { Folgeinitiative }\end{array}$ \\
\hline $\begin{array}{l}\text { Stärkung haushaltspolitischer Verantwortung } \\
\text { Erhöhung der Finanzausstattung des Programms für Struk- } \\
\text { turreform }\end{array}$ & RO-Vorschlag & $\begin{array}{c}\text { Bisher kein } \\
\text { Beschluss }\end{array}$ \\
\hline $\begin{array}{l}\text { Unterstützung von Strukturreformen } 2018 / 1671 \\
\text { Vorm }\end{array}$ & VO-Vorschlag & $\begin{array}{c}\text { Ablehnung durch } \\
\text { das EP }\end{array}$ \\
\hline $\begin{array}{l}\text { Einrichtung eines Europäischen Währungsfonds } \\
\text { VO-Vorschlag }\end{array}$ & $\begin{array}{c}\text { Mündete in der } \\
\text { "ESM-Reform« }\end{array}$ \\
\hline
\end{tabular}

Quelle: Eigene Zusammenstellung

Bereits bis Mitte 2018 war sowohl der Beschluss der Abänderungsverordnung zum Programm zur Unterstützung von Strukturreformen (KOM 2017i) als auch der Änderungsverordnung der gemeinsamen Bestimmungen der EU-Fonds mit dem Ziel, Mittel zur Unterstützung von Reformen in den Mitgliedstaaten umzuschichten (KOM 2017j), angestrebt (vgl. KOM 2017e, 16). Bis Ende 2018 wollte die Kommission schließlich den regelmäßigen Dialog mit dem Europäischen Parlament über wirtschaftspolitische Fragen formalisieren (vgl. ebd.) und das EP ebenso wie die mitgliedstaatlichen Parlamente mit »ausreichende[n] Aufsichtsbefugnisse[n]« (ebd., 15) ausstatten, wozu im Paket allerdings keine weiterführenden, konkreten Umsetzungsvorschläge enthalten sind. Bis Mitte 2019 schließlich erwartete die Kommission die Annahme der vorgeschlagenen EWF-Verordnung (KOM 2017k) sowie der haushaltspolitischen Richtline zur Überführung des SKS-Vertrags ins Unionsrecht (KOM 2017h). Zugleich erhoffte sie sich eine Beschlussfassung in Bezug auf die gemeinsame Außenvertretung (vgl. KOM 2017h, 16; vgl. auch KOM 2015d \& 2015i aus dem dritten >Economic-Governance-Paket $`$ und strebte an, die mit den beiden Mitteilungen anzustoßenden Erörterungen mit dem Ziel entsprechender Beschlussfassungen abzuschließen (vgl. KOM 2017h, 16).

Der unumstrittenste Vorschlag des Nikolauspakets stellte jener für eine Verordnung zur Erhöhung der Finanzausstattung des Programms zur Unterstützung von Strukturreformen 
dar. Hintergrund des Vorschlags ist die hohe Auslastung des 2017 gestarteten Programms zur Unterstützung von Strukturreformen, das als eine reduzierte Form des Pakts für Wettbewerbsfähigkeit gekennzeichnet wurde. So werde das Programm seit seinem Inkrafttreten »überaus intensiv in Anspruch genommen, und die Unterstützungsanträge übersteigen die jährlich verfügbaren Mittel deutlich «, wie die Kommission (2017i, 1) festhält. Entsprechend sieht die letztlich im Oktober 2018 verabschiedete Verordnung (EU) 2018/1671 eine Erhöhung der Finanzausstattung um 80 Millionen Euro vor (vgl. ebd., 2). Zugleich wird mit der Verordnung das übergeordnete Ziel des Programms um den Aspekt "soziale Eingliederung « erweitert und insgesamt darauf verpflichtet, einen Beitrag zur Konvergenz zu leisten sowie Nicht-Euro-Staaten bei ihren Vorbereitungsmaßnahmen auf die Teilnahme an der Gemeinschaftswährung zu unterstützen (vgl. Art. 4 VO (EU) 2017/825 i. d. F. VO (EU) 2018/1671). Diese Ergänzungen wurden dabei ebenso wie bereits die Ausgangsverordnung mit einer breiten Parlamentsmehrheit und einstimmig im Rat beschlossen und traten im Oktober 2018 in Kraft. Mit der auf den ersten Blick unscheinbaren Aufstockung des Budgets für das Strukturreformenprogramm und dem SRSS (Structural Reform Support Service) der Kommission (es geht lediglich um 80 Mio. €) nimmt zugleich aber auch schleichend der Einfluss der Kommission als Exekutivorgan weiter zu.

Anders als die Aufstockung des Programms zur Unterstützung von Strukturreformen konnte der Vorschlag für eine Änderungsverordnung zur Verordnung über gemeinsame Bestimmungen der Europäischen Fonds bisher nicht umgesetzt werden; sie scheiterte am Veto des Europäischen Parlaments (2018a). Ziel der Kommission war, die sogenannte »leistungsgebundene Reserve« der Europäischen Struktur- und Investitionsfonds, die $6 \%$ des Finanzvolumens ausmacht, »in voller Höhe oder teilweise anstatt zur Unterstützung spezifischer Projekte zur Förderung von Reformen einzusetzen.«(KOM 2017j, 1) Nach dem kommissionsseitig angedachten Verfahren könnte ein Mitgliedstaat bei der Kommission einen »detaillierten Katalog mit Maßnahmen« vorschlagen, »die für die Umsetzung von Strukturreformen [...] geeignet sind.« (Art. 23a, Abs. 1 VO (EU) Nr. 1303/2013 i. d. F. KOM 2017j) Anschließend würde die Kommission den Vorschlag bewerten und nach positiver Prüfung einen Durchführungsbeschluss herbeiführen, »dem die von dem jeweiligen Mitgliedstaat umzusetzenden Reformzusagen und der aus der leistungsgebundenen Reserve für deren Unterstützung bereitgestellte Betrag zu entnehmen sind." (Art. 23a, Abs. 3 VO (EU) Nr. 1303/2013 i. d. F. KOM 2017j) Die volle Auszahlung der Mittel wäre daran gekoppelt, dass der betreffende Mitgliedstaat die gemachten Zusagen vollständig umsetzt (vgl. Art. 23a, Abs. 5 VO (EU) Nr. 1303/2013 i. d. F. KOM 2017j). Berichtspflichten über die Fortschritte bestünden im Rahmen des Europäischen Semesters (vgl. Art. 23a, Abs. 6 VO (EU) Nr. 1303/2013 i. d. F. KOM 2017j). Mit einer so geänderten »Dachverordnung « der Struktur- und Investitionsfonds möchte die Kommission eine Pilotphase einläuten, die im nachfolgenden MFR nach 2020 in ein »neues Instrument zur Umsetzung von Reformen « (KOM 2017j, 1) münden und den Schwerpunkt auf Reformen legen solle,

»die die Widerstandsfähigkeit der einzelnen Volkswirtschaften am meisten stärken und positive Spillover-Effekte auf andere Mitgliedstaaten haben können. Dazu zählen Reformen der Produkt- und Arbeitsmärkte, Steuerreformen, der Ausbau von Kapital- 
märkten, Reformen zur Verbesserung der Rahmenbedingungen für Unternehmen sowie Investitionen in Humankapital und Reformen der öffentlichen Verwaltung.«(Ebd.)

Das Kalkül der vorgeschlagenen Verordnung scheint klar: Das aufgrund der finanziellen Ausstattung in seiner Reichweite überschaubare Programm zur Unterstützung von Strukturreformen (inkl. dem SRSS) soll über den Wege einer Veränderungsordnung zu den bestehenden EU-Fonds einen "großen« Bruder erhalten. Die Zielsetzungen gleichen jedenfalls denen des Strukturreformen-»Programms « bis auf kleinere Ausnahmen vollständig (vgl. KOM 2017j, I \& KOM 2017i, 1). Insofern wäre mit der Änderung der VO (EU) Nr. 1303/2013 ein weiterer Baustein zur Verwirklichung des Pakts für Wettbewerbsfähigkeit umgesetzt, auch wenn die Teilnahme - ebenso wie im »Programm« - weiterhin auf Freiwilligkeit beruhen würde. Dem Ansinnen aus der ursprünglichen technischen Unterstützung von Programmländern (Task-Force for Greece), über die Verordnungen (EU) 825/2017 und (EU) 1671/2018 nun mit einer weiteren Verordnung den Pakt für Wettbewerbsfähigkeit innerhalb des Unionsrahmens zu forcieren, setzte allerdings das Europäische Parlament ein jähes Ende. Zwar stellte das Parlament nicht die grundsätzliche Zielsetzung in Bezug auf die Fokussierung von Strukturreformen infrage, doch kritisierte es die finanzielle Basis hierfür: Es vertritt die Auffassung, »dass die Mittel in der leistungsgebundenen Reserve unbedingt wie ursprünglich beabsichtigt eingesetzt und nicht für strukturelle Reformen abgezweigt werden sollten.« (EP 2018, 7)

Einen weiteren Schwerpunkt neben Strukturreformen zur Stärkung der Wettbewerbsfähigkeit stellen die Maßnahmen zur Überführung der außerunionsvertraglichen Komponenten der Phase des reaktiven Staatlichkeitsausbaus in den Rechtsrahmen der Union dar. Mit der Verordnung über die Einrichtung des Europäischen Währungsfonds schlägt die Kommission vor, den ESM zu einem Unionsorgan weiterzuentwickeln. Die Kommission begründet eine solche Überführung mit einer Trias aus Einheit, Effizienz und demokratischer Rechenschaftspflicht. So sei ein EWF im Interesse aller EU-Mitgliedstaaten, da hierdurch die Stabilität des Euros und zugleich der Binnenmarkt gestützt werde, zumal er nach den Vorstellungen der Kommission im Rahmen der Bankenunion, an der nicht nur Euro-Staaten teilnehmen, auch die Letztsicherung für den einheitlichen Abwicklungsmechanismus übernehme solle (vgl. KOM 2017k, 3). Nach Meinung der Kommission könne mit dem EWF auch ein effizienterer Verfahrensund Verfassungsrahmen entstehen, denn letztlich bewirke "das Nebeneinander von EU-Institutionen und einem ständigen zwischenstaatlichen Mechanismus wie dem ESM komplexe Verhältnisse, bei denen Rechtsschutz, Achtung der Grundrechte und demokratische Rechenschaftspflicht zerspalten und uneinheitlich durchgesetzt werden« (ebd.). Die Erhöhung demokratischer Rechenschaftspflicht sucht die Kommission zudem dadurch zu erreichen, dass die Umwandlung des ESM in einen EWF

»mit einem Vorstoß kombiniert werden [könnte], seine Funktionsweise im belastbaren Rechenschaftsrahmen der Union zu verankern und gleichzeitig einer vollumfänglichen gerichtlichen Kontrolle zu unterwerfen. So würde insbesondere die Einbindung des Europäischen Parlaments die demokratische Kontrolle stärken, während die Rolle der nationalen Parlamente uneingeschränkt gewahrt bliebe, was die hohen mitgliedstaatlichen Beiträge zum EMF [sic!] gebieten würden.«(Ebd., 4) 
Der Vorschlag der Kommission basiert darauf, dass der künftige EWF als »eigenständige juristische Person« zu einer »Einrichtung der Union« weiterentwickelt werde, was wiederum zu einer Anpassung der bisherigen Herrschaftspraxen führen müsse (vgl. ebd., 6). Hierzu zählt insbesondere, dass dem Rat künftig die Letztbeschlussfassungskompetenz übertragen werden solle (vgl. ebd., 7), auch wenn der bis dato letztentscheidende Gouverneursrat im EWF weiter bestehen bliebe (vgl. Art. 5 EWF-Satzung in KOM $2017 \mathrm{k}$, Annex). Vorgeschlagen ist des Weiteren »die Möglichkeit einer schnelleren Beschlussfassung in bestimmten dringlichen Situationen « (KOM $2017 \mathrm{k}, 7)$ sowie »[e]ine verstärkte qualifizierte Mehrheit, bei der $85 \%$ der Stimmen erforderlich sind [...] für bestimmte Beschlüsse über Stabilitätshilfen, Auszahlungen und den Einsatz der Letztsicherung« (ebd., 7f.). Das Einstimmigkeitsprinzip bei »alle[n] wichtigen Beschlüsse[n] mit finanziellen Auswirkungen (z.B. Kapitalabrufe)« (ebd., 7) bleibe hiervon aber unberührt. Der Kommissionsvorschlag sieht außerdem vor, dass bei der Verwaltung der Hilfsprogramme, anders als der ESM, der EWF neben der Kommission direkt beteiligt sein soll (vgl. ebd., 8). Schließlich »wird im Vorschlag auf die Möglichkeit verwiesen, dass der Europäische Währungsfonds neue Finanzinstrumente entwickeln kann. Im Laufe der Zeit könnten solche Instrumente andere Finanzinstrumente und Programme der EU ergänzen oder unterstützen.« (Ebd.)

Versucht man sich an einer Bewertung des Kommissionsvorschlags zur Errichtung des EWF, bleibt erstens zu konstatieren, dass mit der Überführung des ESM in den Unionsrechtsrahmen tatsächlich eine Art demokratische Einhegung verbunden sein könnte. Als Unionsorgan unterläge der EWF den europäischen Verträgen explizit und würde nicht wie der ESM-Vertrag lediglich auf sie verweisen. Dies bedeutete auch, dass die vertraglichen Anforderungen vor dem EuGH justiziabel wären. Weiterhin sieht der Verordnungsvorschlag ausdrücklich Rechenschaftspflichten des EWF gegenüber dem Europäischen Parlament sowie den mitgliedstaatlichen Parlamenten vor (vgl. Titel III in KOM 2017k). Zugleich fiele der EWF unter die EU-Transparenzbestimmungen, die den Zugang zu EWF-Dokumenten ermögliche (vgl. Art. 46 EWF-Satzung in KOM 2017k, Annex). Der zwischenstaatliche ESM könne somit in Form des EWF zu einer suprastaatlichen EU-Institution transformiert werden; aber: Der EWF würde sich weiterhin am intergouvernementalen Herrschaftsmodus orientieren. Schließlich seien mit den Rechenschaftspflichten keine Beteiligungsrechte des EP verbunden. Neben dem Rat, der in die Herrschaftsausübung neu eingebunden wäre, bliebe der Gouverneursrat des EWF (wie im ESM) das wichtigste Entscheidungsgremium (vgl. Art. 5 EWF-Satzung in KOM 2017k, Annex). Er bestünde weiterhin aus den Finanzminister*innen der Eurostaaten. Denn anders als die Einheitssemantik der Kommission vermuten ließe, wären weiterhin lediglich Euro-Mitgliedstaaten auch EWF-Mitglieder (vgl. Art. 2 EWFSatzung in KOM 2017k, Annex). Zugleich erweiterte sich mit der Umwandlung in den EWF auch die Funktion des ehemaligen ESM. War der ESM offiziell bisher nicht selber in die Abwicklung der Finanzhilfeprogramme eingebunden, fiele dem EWF die Rolle zu, gemeinsam mit Kommission und der EZB (»die neue Troika«) die entsprechenden Programme auszuhandeln und später gemeinsam mit der Kommission deren Einhaltung zu überwachen (vgl. Art. 13 EWF-Satzung in KOM 2017k, Annex). Dies ist durchaus eine weitreichende Kompetenzausweitung für den zum ESM transformierten EWF, der an dieser Stelle zugleich den IWF ersetzen würde. Ist dessen Beteiligung im ESM-Vertrag 
noch ausdrücklich vorgesehen, spielte der Internationale Währungsfonds bei künftigen Stabilisierungsmaßnahmen keine exponierte Rolle mehr. Der zuständige Kommissar umschreibt dies so: Ein notwendiger »Schritt besteht darin, uns darauf vorzubereiten, in einer Welt zu agieren, in der der Internationale Währungsfonds nicht mehr dieselbe Rolle in der Eurozone spielen wird wie in der letzten Krise." (Moscovici 2017) Ob an dieser Einschätzung auch der "Streit« zwischen Kommission und IWF über die fiskalischen Multiplikatoren (s.o.) eine Rolle gespielt hat, muss unbeantwortet bleiben. Die neue Troika aus EWF, EZB und Kommission hätte sich jedenfalls eines zunehmend unliebsam gewordenen Akteurs der Euro-Rettungspolitik entledigt. An den Grundfesten des autoritär-intergouvernementalen Gläubigerregimes verändere der EWF indes wenig. Vielmehr bestünde die Gefahr, dass mit einem kompetenzerweiterten EWF in einer erneuten Krisensituation eine Art europäische Austeritätsagentur geschaffen wäre, die im Sinne der Gläubigerstaaten eine Rettungspolitik betreibt, wie wir sie bereits in den Hochzeiten der Euro-Krise beobachten konnten. Diese antizipierte Wirkung eines zum EWF erweiterten ESM wird in den Stellungnahmen weiterer institutioneller Akteur*innen allerdings nicht thematisiert. Vielmehr besteht Einigkeit darüber, dass die inhaltlich vorgeschlagenen Änderungen am ESM sinnvoll seien (vgl. EZB 2018a, EP 2019b). Die EZB kritisiert aber - mit Unterstützung des Parlaments (vgl. EP 2019b, Rn. 2) - die vorgeschlagene Umbenennung des ESM. Sie äußert Bedenken, dass der neue Name irreführend sein könne, da die Verwendung des Begriffs »Währungsfonds« ungenau sei (vgl. EZB 2018a, Rn. 3.1). So zeichne die EZB die Verantwortlichkeit für die Währungspolitik der Union und nicht der ESM, der - so das von der EZB zitierte EuGH-Urteil in der Rechtssache Pringle (s.o.) - nicht der Währungs- sondern der Wirtschaftspolitik zuzuordnen sei (vgl. ebd., Rn. 3.2). Weiterhin offenbare ein Abgleich der Funktionszuschreibungen zwischen dem EWF und dem IWF gravierende Unterschiede zwischen den beiden (vgl. ebd., Rn. 3.3). Das Parlament, das der Verordnung zwar zustimmen müsste, an dem Vorschlag aber selber keine Änderungen vornehmen darf (Zustimmungsverfahren), forderte neben der Namensbeibehaltung ESM an einigen Stellen weitere kleine Änderungen an der Verordnung und der vorgeschlagenen EWF-Satzung. So sei es nach Ansicht der Parlamentarier*innen beispielsweise nötig, dass der reformierte ESM allen Mitgliedstaaten offenstehen müsse (vgl. EP 2019b, Rn. 10). Entscheidungsblockaden antizipierend, schlägt das Parlament außerdem vor, »auf kurze Sicht eine sinnvolle Reform des ESM einzuleiten, indem der ESM-Vertrag überarbeitet wird, ohne dabei ambitionierte Entwicklungen in der Zukunft auszuschließen « (ebd., Rn. 7). Hierzu schlägt das EP weiterhin vor,

»mit sofortiger Wirkung ein Protokoll für eine vorläufige Kooperationsvereinbarung zwischen dem ESM und dem Parlament zu erarbeiten, um den interinstitutionellen Dialog [...] und die Transparenz und Rechenschaftspflicht des ESM zu verbessern, wobei die Rechte des Parlaments und seiner Mitglieder in Bezug auf Fragen, die dem reformierten ESM vorgelegt werden, regelmäßige Anhörungen, Nominierungsrechte und angemessene Haushaltskontrollrechte festgelegt werden« (ebd., Rn. 17).

Mit dem letzten legislativen Vorschlag des Nikolauspakets adressierte die Kommission schließlich den völkerrechtlichen SKS-Vertrag. Grundsätzliches Ziel der vorgeschlagenen Richtlinie zur Festlegung von Bestimmungen zur Stärkung der haushaltspolitischen Verant- 
wortung und der mittelfristigen Ausrichtung der Haushalte in den Mitgliedstaaten ist die weitestgehende Überführung des SKS-Vertrags ins Unionsrecht. Nachdem bereits in einem prozeduralen Prozess die wirtschaftspolitische Komponente des Vertrags (Stichwort: Vorabkoordinierung von Reformen) weitgehend durch das Streamlining in das Europäische Semester überführt wurde, zielt die neuerliche Initiative nun auf das »Herzstück des SKS-Vertrages« (KOM 2017h, 1), den »fiskalpolitischen Pakt« (Titel III SKS-V). Daran, dass dieser Vertragskern trotz der kriseninduzierten Fortentwicklung der vertragsbasierten EU-Fiskalverfassung auch weiterhin notwendig sei, lässt die Kommission keinen Zweifel. So treffe der Grundgedanke des fiskalpolitischen Pakts, nach dem es im Interesse der EU und der Eurozone liege, »eine verantwortungsvolle Haushaltspolitik zu fördern und übermäßige Defizite zu vermeiden« (KOM 2017h, 7) weiterhin zu. In diesem Sinne solle demnach durch die vorgeschlagene Richtlinie der bestehende sekundärrechtliche EWWU-Rahmen gestärkt werden. Zugleich verbindet die Kommission mit der Überführung des SKS-Vertrags die Vorstellung, den fiskalpolitischen Rechtsrahmen zu vereinfachen und die inhaltlichen Anforderungen im Zusammenhang mit dem SWP wirksamer und systematischer zu überwachen (vgl. ebd., 3). Letztlich wäre es »[m]it einem konsolidierten Rahmen, der dem EU-Recht unterliegt [...], leichter«, so die Kommission $(2017 \mathrm{~h}, 3)$, »eine kohärente und koordinierte Entwicklung der EUweiten und einzelstaatlichen Haushaltsregeln innerhalb des allgemeineren Prozesses zur Vertiefung der WWU sicherzustellen.«

Konkret setzt die Richtlinie am Artikel drei des SKS-Vertrags an, in dem die folgenden Aspekte kodiert sind: (1) Ziel des ausgeglichenen oder eines Überschuss aufweisenden Haushalts (Abs. 1a); (2) strukturelles Defizit von maximal 0,5\% des BIP bei einem Schuldenstand über $60 \%$ des BIP (Abs. 1b) sowie von maximal $1 \%$ bei einem Schuldenstand unter $60 \%$ des BIP (Abs. 1c); (3) Verpflichtung zur Einführung eines automatischen Korrekturmechanismus bei einer Abweichung von den Zielen (Abs. 1d); (4) Überführung des Absatzes 1 in mitgliedstaatliche Rechtsvorschriften »vorzugsweise mit Verfassungsrang « und (5) Etablierung einer Institution zur Überwachung der Einhaltung der fiskalischen Bestimmungen (Abs. 2). Da die Zielvorgaben eines ausgeglichenen oder eines Überschuss aufweisenden Haushalts (ad 1) bereits mit dem Six-Pack im SWP verankert wurden, wird dieser im Richtlinienvorschlag nicht noch einmal aufgegriffen. Dies betrifft grundsätzlich auch die kriterialen Normierungen des strukturellen Defizits (ad 2). Allerdings ist der SKS-Vertrag an dieser Stelle schärfer formuliert als die SWP-Verordnungen. Laut Verordnung (EU) Nr. 1075/2011 (Art. 2a) liegt die Spanne des strukturellen Defizits bei einem Schuldenstand über $60 \%$ des BIP zwischen - 1 \% des BIP und einem ausgeglichenen oder Überschuss aufweisenden Haushalt. Der Fiskalpakt definiert hingegen -0,5\% als maximales Defizit. Da mit der vorgeschlagenen Richtlinie allerdings keine neuen numerischen Haushaltsziele kodiert werden, würde an dieser Stelle keine vollständige Überführung des SKS-Vertrags vollzogen. Referenzgröße bliebe das aus der präventiven SWP-Komponente bekannte mittelfristige Haushaltsziel (MTO). Trotzdem lässt sich an einer anderen Stelle eine Verschärfung von Haushaltsregeln herauslesen. So schlägt die Kommission vor, dass neu gewählte Regierungen direkt nach ihrem Amtsantritt für die Dauer der Legislaturperiode den Wachstumspfad der Staatsausgaben festzulegen hätten, der in den jährlichen Haushaltsplänen eingehalten 
werden solle (vgl. Art. 3, Abs. ab in KOM 2017h). Eine solche Vorgabe ist bisher weder im SKS-Vertrag verankert, noch aus dem reformierten SWP bekannt.

Schließlich würde der automatische Korrekturmechanismus (ad 3) mit der Richtlinie, im Unterschied zur Grenze für das strukturelle Defizit, in den Rechtsrahmen der EU überführt (vgl. Art. 3, Abs. 2b in KOM 2017h), wie auch die Anforderung mitgliedstaatliche Rechtsvorschriften zu erlassen, welche die in der Richtlinie kodierten Anforderungen abdecken (ad 4) (vgl. Art. 3, Abs. 1 \& 2 in KOM 2017h). Allerdings ist hierbei nur von »dauerhafte[n] numerische[n] Haushaltsregeln« die Rede. Auf die Verpflichtung, ein Regelwerk möglichst mit »Verfassungsrang« zu erlassen, wäre hingegen verzichtet worden. Letztlich finden sich in der Richtlinie auch die aus dem SKS-Vertrag bekannten unabhängigen Institutionen zur Überwachung der Einhaltung der Haushaltsregeln (vgl. Art. 3, Abs. 4ff. in KOM 2017h) (ad 5). Interessant erscheint allerdings die im Vorschlag gestärkte Rolle dieser Institution im Vergleich zum SKS-Vertrag. So heißt es in Artikel 3, Absatz 6 der vorgeschlagenen Richtlinie, dass »[d]ie Mitgliedstaaten [...] sicher[stellen], dass ihre Haushaltsbehörden den Empfehlungen aus den Bewertungen der unabhängigen Einrichtungen [...] Folge leisten oder andererseits öffentlich begründen, warum sie sich entschieden haben, diesen Empfehlungen nicht Folge zu leisten." (Herv. J. G.)

Insgesamt ist auffällig, dass im Kommissionsvorschlag eine spannende Ambivalenz zwischen »Verschärfung « und »Lockerung« der SKS-Ziele erkennbar ist. Einerseits sollen die strikteren Defizitregeln des Vertrags nicht in den SWP integriert werden, andererseits würde der diskretionäre Spielraum der mitgliedstaatlichen Regierungen durch die »unabhängigen Institutionen« sowie den neuen »Wachstumspfad für die Staatsausgaben« weiter begrenzt. Neben dieser ambivalenten Vorgehensweise bleibt zudem zu konstatieren, dass mit der vorgeschlagenen Richtlinie der SKS-Vertrag nicht in allen Regelungstatbeständen ins Unionsrecht überführt worden wäre. So schreibt die Kommission in der Begründung ihres Vorschlags selber, dass der Artikel 7 des Vertrags - hierbei handelt es sich um die Selbstverpflichtung der Mitgliedstaaten, den Empfehlungen der Kommission zur Einleitung eines Defizitverfahrens zu folgen - von dem Vorschlag unberührt bleibe und weiterhin Gültigkeit besitzen solle; ebendies gelte für den Artikel 13, in dem die Zusammenarbeit zwischen den mitgliedstaatlichen Parlamenten und dem Europäischen Parlament im Rahmen des Vertrags geregelt werde (vgl. KOM 2017h, 6). Dies widerspricht letztlich dem Grundgedanken, nach dem mit der vorgeschlagenen Richtlinie das fiskalpolitische Regieren einheitlicher ausgestaltet werden soll; oder in den Worten der EZB (2018b, Rn. 2.1.3):

»Da der SKS-Vertrag [...] weiterhin für alle Mitgliedstaaten außer der Tschechischen Republik und dem Vereinigten Königreich gilt, scheint der Richtlinienvorschlag die Risiken, dass es zu Doppelarbeit und widersprüchlichen Vorgängen kommt, die mit der Koexistenz von zwischenstaatlichen Vereinbarungen und den im Unionsrecht vorgesehenen Mechanismen einhergehen, nicht zu verringern.«

Weitere Kommentierungen der EZB weisen indes darauf hin, dass mit dem Richtlinienvorschlag alte Grabenkämpfe erneut aufzubrechen drohten. Inhaltlich geht es hierbei um die Reichweite und notwendige Akzentuierungen im fiskalpolitischen Rahmen der EWWU. Die »Hardliner*innen der EZB«, die bereits im Zuge der Two-Pack- 
Verhandlungen für eine Überführung des SKS-Vertrags in das Sekundärrecht warben (vgl. EZB 2012a), begrüßen zwar grundsätzlich den Gedanken, den SKS-Vertrag in den Unionsrechtsrahmen zu integrieren (vgl. EZB 2018b, Rn. 1.2), haben aber »dennoch Bedenken, ob der Richtlinienvorschlag dieses Ziel tatsächlich erfüllt.« (Ebd., Rn. 2.1.1) Hauptkritikpunkt der EZB ist die fehlende Normierung der Defizitgrenze von 0,5\% des BIP und die sich hierdurch vollziehende Schwächung des fiskalpolitischen Pakts (vgl. ebd., Rn. 2.1.2 \& 2.2.1). Problematisch erscheint der EZB daran, dass die Verwirklichung dieser Defizitgrenze im Kontext des SKS-Vertrags innerhalb des mitgliedstaatlichen Rechts zu vollziehen war. Wird die Grenze nun nicht auch sekundärrechtlich verankert, bestünde nach Ansicht der Zentralbanker*innen die Gefahr, dass

»diejenigen Mitgliedstaaten, die den fiskalpolitischen Pakt noch nicht vollständig in ihr nationales Recht umgesetzt haben, die Bestimmungen des fiskalpolitischen Pakts mittels weniger strenger Vorschriften um[...]setzen bzw. [...] ihre nationalen Rechtsvorschriften auf diese Art und Weise [...] ändern«,

was dazu führe, »dass die Haushaltsregeln in der Union unterschiedlich bzw. nicht gleichrangig sind.«(Ebd., Rn. 2.1.4)

Neben den konkreten Legislativvorschlägen beabsichtigte die Kommission mit den zwei thematischen Mitteilungen zum Minister*inamt für Wirtschaft und Finanzen und neuen Haushaltsinstrumenten, bereits zuvor angestoßene Diskussionen im Rahmen ihrer leitbildlichen Papiere weiter zu forcieren. In ihrer Mitteilung zum Europäischen Minister für Wirtschaft und Finanzen (EMWF) gehe es der Kommission $(2017 \mathrm{~g}, 2)$ letztlich darum, aufzuzeigen, »welche Rolle ein künftiger Europäischer Minister für Wirtschaft und Finanzen in der Governance-Architektur der Wirtschafts- und Währungsunion spielen könnte.«Im Idealfall sehe eine solche Funktionszuschreibung im Sinne der Kommission wie folgt aus: die*der EMWF »verfolgt die allgemeinen Interessen der EU/des Euro-Währungsgebiets und vertritt sie auf internationaler Ebene«; »stärkt die politische Koordinierung und überwacht Wirtschafts-, Fiskal- und Finanzvorschriften«; "äußert sich zu einer angemessenen, der Geldpolitik der Europäischen Zentralbank dienlichen Fiskalpolitik für das Euro-Währungsgebiet« und »beaufsichtigt den Einsatz von Haushaltsinstrumenten der EU/des Euro-Währungsgebiets«, inklusiven den »Instrumenten zur Unterstützung von Strukturreformen sowie zur Förderung von makroökonomischer Stabilisierung [...] und Konvergenz [...]« (ebd., 3). Institutionell wäre die*der EMWF »rechenschaftspflichtig gegenüber dem Europäischen Parlament«; »Vizepräsident der Europäischen Kommission«; »Vorsitzender der Eurogruppe« und sie*er »überwacht die Arbeiten des zu errichtenden Europäischen Währungsfonds« (ebd.). Hinter der angedachten Vertretung auf internationaler Ebene steht die von der Kommission seit langem avisierten einheitliche Vertretung beim IWF (s. drittes >EconomicGovernance-Paket< 2015 sowie die länger zurückreichenden Aktivitäten der Kommission seit 1998; vgl. KOM 1998). Bisher sind ihre Aktivitäten in Richtung auf eine gemeinsame EU/EWWU-Stimme in den internationalen Finanzinstitutionen allerdings allesamt gescheitert; die Mitgliedstaaten konnten sich lediglich auf die Stärkung der Vorabkoordinierung verständigen (vgl. WFA 2016b). Mit der*dem EMWF entstünde jedoch eine zentrale Anlaufstelle, welche die Außenvertretungsfunktion übernehmen könnte. Hinter der Chiffre einer stärkeren politischen Koordinierung durch die*der EMWF ver- 
steckt sich weiterhin insbesondere der Wunsch nach einer besseren Durchsetzung von Strukturreformen in den Mitgliedstaaten, die durch den*die Minister*in in Form »regelmäßige[r] bilaterale[r] und multilaterale[r] Gespräche mit nationalen Behörden und dem Europäischen Parlament« (KOM 2017g, 4) aktiv begleitet werden könnte. In diesem Sinne fiele gemäß der Funktionszuschreibung der Kommission auch die Beaufsichtigung künftiger Haushaltsinstrumente oder des Fonds für Strukturreformen in den Aufgabenbereich des neuen Amtes. Die Aufgabe, sich zu einer der Geldpolitik unterstützenden, angemessenen Fiskalpolitik zu äußern, läuft dem Grunde nach auf die Überwachung des fiskalpolitischen Rahmens des SWP hinaus, der trotz seiner inkrementellen Weiterentwicklung (pragmatischer Austeritätsansatz) immer noch auf eine restriktive, anti-diskretionäre Fiskalpolitik ausgerichtet ist. Mit dem neuen Amt entstünde aber im Unterschied zur bestehenden Struktur eine sichtbare, personifizierte Anlaufstelle der EWWU, in der die Aktivitäten gebündelt sind. Die*der EMWF müsste somit zwischen den Extremen changieren: Einerseits wäre sie*er eine Art "Sparkommissar*in«, andererseits könnte sie*er sich die von der Juncker-Kommission angestoßene »neue Flexibilität« des SWP innerhalb des Interpretations- und Ermessensspielraums zu eigen machen und einen diskretionäreren Interventionismus begründen. Institutionell betrachtet bietet der EMWF-Vorschlag insbesondere dem Europäischen Parlament neue Beteiligungsmöglichkeiten, die sich nicht zuletzt darin zeigen, dass die*der EMWF als Kommissionsvizepräsident*in zu Beginn der Amtszeit vom Parlament bestätigt werden müsste. Somit würde letztlich das Parlament im neuen Arrangement auch den Vorsitz der Euro-Gruppe bestimmen, was bisher in die Verantwortung der mitgliedstaatlichen Regierungen fällt. Die Funktion der Kommission als Exekutivzentrum der EWWU wäre mit der*dem EMWF insofern weiter gestärkt. Demnach sei dieses Amt aus ihrer Sicht »ein wichtiger Schritt in Richtung einer kohärenteren, wirksameren und verantwortungsbewussteren wirtschaftspolitischen Steuerung der Europäischen Union.« (Ebd., 9) Entsprechend forderte die Kommission die anderen EUSA auf, sich mit dem Vorschlag auseinanderzusetzen und "auf eine gemeinsame Sichtweise hinzuarbeiten« (ebd.), wobei sie sich der Unterstützung des Europäischen Parlamentes sicher sein konnte, das bereits vor dem Nikolauspaket forderte, »dass die Exekutivbehörde in Form eines EU-Finanzministers in der Kommission gebündelt wird « (EP 2017b, Rn. 25). Hierdurch solle »die Kommission in die Lage versetzt [werden], eine gemeinsame EUWirtschaftspolitik zu konzipieren und umzusetzen, die makroökonomische, haushaltsund geldpolitische Instrumente kombiniert und von einer Haushaltskapazität für das Euro-Währungsgebiet gestützt wird« (Ebd.). In einem weiteren Beschluss begrüßte das Parlament zudem die Verschmelzung zwischen EMWF und dem Vorsitz der Eurogruppe (vgl. EP 2019a, Rn. 29).

Die zweite Mitteilung des Nikolauspakets widmete sich der Thematik neuer Haushaltsinstrumente für ein stabiles Euro-Währungsgebiet innerhalb des Unionsrahmens. In der Rückschau auf die fiskalischen Aktivitäten der EU im Rahmen ihres eigenen Haushalts stellt die Mitteilung einleitend fest, dass die EU

»zwar die soziale und wirtschaftliche Aufwärtskonvergenz stets gefördert und die Möglichkeiten der Darlehnsvergabe auf EU-Ebene in den vergangenen Jahren erweitert 
[hat], um auf außerordentliche Umstände zu reagieren, doch war die makroökonomische Stabilisierung bisher kein ausdrückliches Ziel des EU-Haushalts.«(KOM 2017f, 4)

Allerdings - so die Mitteilung weiter - habe die Eurokrise gezeigt, dass an dieser Stelle die bisherige EWWU-Architektur nicht ausreiche. In Bezug auf die Zielvorstellung einer Fiskalunion beschreibt die Kommission daher zwei zentrale Lehren, die gezogen werden müssten: So sei es - erstens - notwendig, Strukturreformen in den Mitgliedstaaten $\mathrm{zu}$ fördern und zu unterstützen, »um robustere Wirtschaftsstrukturen und eine stärkere Konvergenz der Wirtschaftsleistung zu erzielen.« (Ebd., 5) Wichtig seien weiterhin "moderne wirtschaftliche und soziale Strukturen, die umgehend auf Schocks reagieren können« (ebd.). Zweitens sei eine Unterstützung der Euro-Mitgliedstaaten nötig, »damit sie besser auf sich rasch wandelnde wirtschaftliche Umstände reagieren und ihre Wirtschaft bei großen asymmetrischen Schocks stabilisieren können.« (Ebd.) Als identifiziertes Grundproblem erscheint der Kommission hierbei, dass die Mitgliedstaaten in Krisensituationen nur auf begrenzte finanzielle Mittel zurückgreifen könnten (vgl. ebd.). Zusammengenommen laufen die beiden »Lehren« auf eine Fiskalunion hinaus, die auf zwei Säulen beruht: einer präventiven Strukturreformensäule, die proaktiv Reformen forciert sowie einer korrektiven Stabilisierungssäule, die bei asymmetrischen Schocks für eine makroökonomische Stimulierung sorgen kann. Diese sogenannte Stabilisierungsfunktion böte die Möglichkeit, bei Schocks Ressourcen zu aktivieren, welche die mitgliedstaatlichen Haushalte allerdings »nur« ergänzen sollten (vgl. ebd., 15). Konkret präferiert die Kommission einen Stabilisierungsmechanismus, der in Schocksituationen die Investitionstätigkeit eines Mitgliedstaats stützt (vgl. ebd., 17). Sie spricht sich somit gegen die im Reflexionspapier alternativ zur »Investitionsschutzregelung « andiskutierten Formate der »Arbeitslosenrückversicherung« oder eines »Schlechtwetterfonds« aus (vgl. ebd.; vgl. auch KOM 2017d). Der in der Mitteilung vorgestellte Mechanismus, der später als »Europäische Investitionsstabilisierungsfunktion« (KOM 2018c) bezeichnet wird, ist einer der drei konkreten Vorschläge der Kommissionsmitteilung. Für die präventive Säule schlägt die Kommission zwei Instrumente vor, bei denen eines auf die Euro-Mitgliedstaaten sowie ein zweites auf die Euro-Beitrittsstaaten zielt. Ersteres umfasst ein Umsetzungsinstrument zur Unterstützung der Reformzusagen der Mitgliedstaaten im Rahmen des Europäischen Semesters (vgl. KOM 2017f, 9ff.). Zweiteres besteht aus einer Konvergenzfazilität für Mitgliedstaaten, die dem EuroWährungsgebiet beitreten werden (vgl. ebd., 12f.). Alle drei in der Mitteilung vorgeschlagenen Instrumente mündeten schließlich im Mai 2018 im Fiskal-Two-Pack (s.u.). Augenscheinlich aber - das gilt es bereits festzuhalten - kommt es zu einer spannenden Verquickung zweier auf den ersten Blick konträrer Ideen, die in einer Kommissionssynthese mündete und eine potenzielle künftige Kompromisslinie andeutet: Gemeint ist die Synthese aus der Forderung nach einem Eurozonenhaushalt einerseits mit der weiterhin wirkmächtigen Idee des merkelschen Wettbewerbsfähigkeitspakts andererseits. Eine solche Synthetisierung beider Vorschläge umfasse somit zwar eine Budgetlinie für die Eurozone, die aber nicht im Sinne einer genuinen Wirtschaftsregierung diskretionär-politisch verhandelbar, sondern der angebotsökonomisch-eingefärbten Strukturreformenagenda untergeordnet wäre. 
Von den Vorschlägen des Nikolauspakets konnte zusammengenommen bis dato einzig die Änderungsverordnung zum Programm zur Unterstützung von Strukturreformen umgesetzt werden, die aufgrund ihrer begrenzten finanziellen Reichweite nur auf wenig Widerstand stieß. So auch im Rat, der die Verordnung einstimmig beschloss. Alle weiteren Kommissionsvorschläge wurden hingegen bisher nicht final beraten, vielmehr zeigt sich, dass die Mitgliedstaaten - nach der ersten Beratung des Nikolauspakets im ECOFIN-Rat - noch viele offene Fragen hatten, die einer zügigen Beschlussfassung im Wege standen. So lautete beispielsweise die Stellungnahme zum Richtlinienvorschlag zur Überführung des SKS-Vertrags in den Rechtsrahmen der Union:»[T]he proposal to integrate the EU's fiscal compact into the EU legal framework is not yet at a stage where it can be taken up by the Council« (ECOFIN 2018, 4). Auch die Überführung des ESM in einen EWF eröffne weitere Fragen, die es zuerst zu klären gelte (vgl. ebd.). Dies zu tun, überwies der Rat schließlich an die Euro-Gruppe (vgl. ebd.). Die Kommentierung der Mitteilung zu neuen haushaltspolitischen Instrumenten fällt ebenso knapp aus; hiermit wolle sich der Rat erst ausführlicher befassen, wenn die Kommission ihre Vorschläge aus der Mitteilung näher ausgeführt hat (vgl. ebd., 5). Zur EMWF-Mitteilung äußerten sich die mitgliedstaatlichen Finanz- und Wirtschaftsminister*innen gar nicht erst.

Das Treffen der Euro-Finanzminister*innen (Euro-Gruppe) am 4. Dezember 2017 - zwei Tage bevor das Nikolauspaket veröffentlicht wurde - hatte in Vorbereitung des im Dezember anstehenden Euro-Gipfels ebenso die Vertiefung der EWWU als Schwerpunktthema, wobei die Priorität auf weiteren Fortschritten im Kontext der Bankenunion lag (vgl. Euro-Gruppe 2017a). Hierbei stand letztlich auch die Reformierung des ESM, der als Backstop des Single Resolution Funds fungieren sollte, ganz oben auf der Tagesordnung (vgl. ebd.). Zugleich habe unter den Euro-Finanzminister*innen eine große Einigkeit darüber bestanden, die Rolle des ESM in der konkreten Krisenbearbeitung auszubauen (vgl. Euro-Gruppe 2017b, 2). Vereinbart wurde deshalb, dass der ESM künftig zusammen mit der Kommission stärker in die Erstellung und das Monitoring der >Hilfsprogramme eingebunden sowie die Effektivität des ESMInstrumentariums insgesamt erhöht werden solle (vgl. ebd.). Die in der Euro-Gruppe diskutierten ESM-Reformen ähneln deutlich jenen, die die Kommission in ihrem EWF-Vorschlag zwei Tage später präsentierte. Dass die Euro-Gruppe auf ihrer Sitzung bereits über das Nikolauspaket in Kenntnis gesetzt schien, zeigt sich auch in der »Agenda der EU-Führungsspitze« aus dem Dezember 2017, die zur Vorbereitung des Euro-Gipfels an die Staats- und Regierungschefs versendet wurde. Darin heißt es, dass die Euro-Gruppe eine Reihe von Ideen geprüft und dabei weitestgehendes Einvernehmen über »die Weiterentwicklung des Europäischen Stabilitätsmechanismus, möglicherweise zu einem sogenannten Europäischen Währungsfonds« (Euro-Gipfel $2017,2)$ erzielt habe. Anders gestaltet sich dies hingegen bei den weiteren Kommissionsvorschlägen: Kein Einvernehmen bestand in der Euro-Gruppe über »die Straffung der Haushaltsregeln« (SKS-Vertragsüberführung), »die Schaffung einer Fiskalkapazität für das Euro-Währungsgebiet« sowie »die Einsetzung eines europäischen Ministers für Wirtschaft und Finanzen« (ebd.). Dem Nikolauspaket wurde somit vorerst eine schnelle Umsetzung verwehrt. Der anschließende Euro-Gipfel bestätigte dies in seiner Priorisierung der weiteren politischen Arbeit, die sich auf den Ausbau der Bankenunion sowie der ESM-Reform fokussieren sollte und den Aufbau der Fiskalunion hinten 
anstellte (vgl. Euro-Gruppe 2018a, 3). Diese Schwerpunktsetzung erschien einigen hingegen zu einseitig, wie im Summing-up-Letter des Präsidenten der Euro-Gruppen vom Januar 2018 deutlich wird: »Some Ministers [...] argued in favour of exploring other issues - such as fiscal capacity and improved fiscal rules - in order to reach a comprehensive political decision by June 2018.« (Ebd.) Dass diese Hoffnung allerdings aufgrund der Meinungsverschiedenheiten unter den Mitgliedstaaten eher utopisch erschien, zeigt die Sitzungszusammenfassung vom März 2018, in der es heißt:

»[O]n fiscal issues, different views have been expressed. We focused the discussion on a possible central stabilisation function. Other objectives such as convergence or promotion of structual reforms are also important for a smooth functioning of EMU, but may be more appropriately discussed in the broader context of the EU budget debate. « (Euro-Cruppe 2018b, 2)

Dass aber auch die Diskussion über die Stabilisierungsfunktion nicht einhellig verlief, wird im nächsten Satz des Briefes deutlich: »There are different views on a central stabilisation function: on whether it is needed and on what instruments would be more suitable to this end." (Ebd.) Bis zum Sommer 2018 (vgl. Centeno 2018, 3) konnte somit weder in Bezug auf mögliche Budgets noch auf die Überführung der fiskalischen SKS-Regelungen in den Unionsrahmen eine einheitliche Sichtweise erreicht werden. Letztlich konnten sich die Euro-Finanzminister"innen lediglich auf die von ihnen selbst angestoßene und Ähnlichkeit zum EWF-Vorschlag aufweisende ESM-Reform verständigen.

\section{Reform des Europäischen Stabilitätsmechanismus}

Die im Dezember 2018 in der Euro-Gruppe erzielte Einigung über die Reform des ESM, die vom Euro-Gipfel am 14. Dezember gebilligt wurde (vgl. Euro-Gipfel 2018), sieht im Einklang mit dem EWF-Vorschlag die Letztsicherung für den SRF im Rahmen der Bankenunion durch den ESM vor. Daneben umfasst die Reform aber auch zwei die Kreditmodalitäten und Konditionen betreffenden Änderungen. So wurde folgende neue Zugangsregel für die sogenannten »vorsorglichen Finanzhilfen« vereinbart:

»Member States need to meet quantitative benchmarks (i.e. the debt benchmark, the minimum benchmark and a deficit below $3 \%$ of CDP) and to comply with qualitative conditions related to EU surveillance (i.e. not experiencing Excessive Imbalances and not being subject to the Excessive Deficit Procedure). (Euro-Gruppe 2018d, 5f.)

Werden diese Bedingungen nicht erfüllt, bleibt einem Mitgliedstaat lediglich die Möglichkeit, ein »klassisches « Finanzhilfegesuch zu beantragen, dessen Gewährung auf der Ausarbeitung der bekannten Memoranden basiert. De facto bedeutet diese Neuregelung eine Verschärfung der bisherigen ESM-Regularien, zumal beispielsweise van Roosebeke (2018) oder Guttenberg (2019) darauf hinweisen, dass nur wenige Eurostaaten die Voraussetzungen erfüllen könnten. Es ist insofern zu bezweifeln, ob die vorsorglichen Finanzhilfen im reformierten ESM überhaupt noch ihre ursprünglich zugedachte Funktion erfüllen können. Vielmehr eröffnet sich hier ein Bild, nach dem die Finanzminister*innen es lieber sähen, dass Mitgliedstaaten in finanziellen Notlagen direkt unter die wesentlich restriktiveren Fänge des Rettungsschirms gelangen. In diesem Sinne 
entwickelt sich der ESM zunehmend weiter in Richtung auf die oben im Kontext des EWF andiskutierte Europäische Austeritätsagentur. Hierfür spricht auch, dass der ESM künftig wesentlich stärker in die Programmausgestaltung und -überwachung eingebunden werden solle. Hierzu legten die Kommission und der ESM im November 2018 eine gemeinsame Erklärung für die künftige Kooperation beider Institutionen vor, die im Kern darauf hinausläuft, dass der ESM als vollwertiger Partner neben der Kommission und der EZB (»neue Troika«; s.o.) bei den sogenannten Rettungsaktivitäten des Stabilitätsmechanismus auftritt (vgl. KOM \& ESM 2018). Daneben wird der ESM zugleich stärker in die alltäglichen Kommissiontätigkeiten im Rahmen der Stabilitätsund Überwachungsunion eingebunden, was sich in einem intensiveren Austausch zwischen Kommission und ESM zeigt, innerhalb dessen der ESM die Kommission auch bei ihrer Bewertung der (Finanz-)Stabilität in den Eurostaaten unterstützen solle (vgl. ebd.).

Anders als von der Kommission in ihrer EWF-Initiative vorgeschlagen, wird mit den konkreten Reformabsichten der Euro-Gruppe schließlich auch die institutionelle Konstruktion des ESM als auf einem zwischenstaatlichen Vertrag basierende Institution festgeschrieben. Die ESM-Reformen bewegen sich entsprechend innerhalb des Rahmens, den das Europäische Parlament in einer ersten Reformstufe vorgeschlagen hatte, wenngleich die Forderung des Parlaments nach einer stärkeren parlamentarischen Kontrolle keine Berücksichtigung seitens der Mitgliedstaaten fand. Insgesamt verdeutlicht die ESM-Reform insofern, dass die inhaltlich-austeritären Reformideen des EWF-Vorschlags (Austeritätsagentur, neue Troika) mit dieser durchgesetzt und gar noch inhaltlich erweitert wurden (vorsorgliche Finanzhilfe), wohingegen die institutionell-demokratischen Reformbausteine (EU-Rechtsrahmen, Rechenschaftspflichten) schlussendlich keinen Eingang in den Reformprozess fanden.

\section{Fiskal-Two-Pack und das Haushaltsinstrument für Konvergenz und Wettbewerbsfähigkeit}

Mit ihrer Mitteilung zu neuen Haushaltsinstrumenten aus dem Nikolauspaket griff die Kommission die seit längerem geführten Diskussionen um einen eigenen Haushalt für die Eurozone und die Vertiefung der Fiskalunion auf. Sie präferiert hierbei allerdings einen Ansatz, der dieses Ansinnen im Rahmen des bestehenden EU-Haushalts einzugliedern versucht. Dies wurde bereits in den oben dargestellten Ausführungen zur entsprechenden Mitteilung aus dem Nikolauspaket herausgestellt, die durch die Vorlage zweier Verordnungsvorschläge im Mai 2018 weiter ausgearbeitet wurde:

Tabelle 33: Fiskal-Two-Pack vom 31.05.2018

\begin{tabular}{|l|c|c|}
\hline Initiative & Art & Status \\
\hline Reformhilfeprogramm & VO-Vorschlag & $\begin{array}{c}\text { Cegenstand der } \\
\text { Beratungen des } \\
\text { MFR 2021-27 }\end{array}$ \\
\hline Investitionsstabilisierungsfunktion für die Eurozone & VO-Vorschlag & \begin{tabular}{c} 
MFR \\
\hline
\end{tabular}
\end{tabular}

Quelle: Eigene Zusammenstellung

In den beiden Verordnungsvorschlägen, die in die Diskussionen um den Mehrjährigen Finanzrahmen 2021-2027 eingewoben sind, finden sich letztlich drei Bausteine: 
Ein sogenanntes Reformhilfeprogramm, die Fortführung und Erweiterung des bereits laufenden Strukturreformenprogramms und schließlich die Implementierung einer Investitionsstabilisierungsfunktion. Das vorgeschlagene Reformhilfeprogramm der Kommission basiert auf dem 2017 etablierten Programm zur Unterstützung von Strukturreformen (vgl. VO (EU) 2017/825). Kern des bereits laufenden Programms, dessen Finanzrahmen durch das Nikolauspaket nochmals erweitert wurde, stellt die technische Unterstützung der Mitgliedstaaten bei der Umsetzung von Strukturreformen dar. Im neuen Reformhilfeprogramm solle dieser Aspekt als »Instrument für technische Unterstützung « weitergeführt werden (vgl. Kapitel III in KOM 2018b). Der Finanzrahmen für die technische Unterstützung seitens der Kommission und ihrer entsprechenden Dienststelle (SRSS) bliebe dabei vergleichbar (vgl. Art. 7 in KOM 2018b \& Art. 10 VO (EU) 2017/825). Neu hingegen wären zwei weitere Finanzlinien des neuen Reformhilfeprogramms. Mit dem sogenannten »Reformumsetzungsinstrument« (vgl. Kapitel II in KOM 2018b) könnten im Rahmen des Programms künftig neben technischer Unterstützung auch direkt Strukturreformen (ko-)finanziert werden, »die zur Bewältigung von im Rahmen des Europäischen Semesters der wirtschaftspolitischen Koordinierung ermittelten Herausforderungen dienen." (Art. 8 in KOM 2018b) Die neue Schlagkraft des erweiterten Programms zeigt sich dabei auch in den für das Umsetzungsinstrument vorgesehenen Budgets. Für den Zeitraum des MFR stünden insgesamt bis zu 22 Milliarden Euro zur Verfügung (vgl. Art. 7 in KOM 2018b), die sich anhand einer eigenen Berechnungsformel auf alle EU-Mitgliedstaaten erstreckten. Die maximalen Fördersummen reichen demnach von potenziellen 22 Millionen Euro für Malta bis zu 4,088 Milliarden Euro für Deutschland (vgl. KOM 2018b, Anhang I, 2). Die Mitgliedstaaten können ihre Reformprojekte im Rahmen des Europäischen Semesters einreichen, wobei der Kommission die Aufgabe zufiele, diese auf ihre scompliance mit den allgemeinen Herausforderungen, die im Semester definiert werden, den länderspezifischen Empfehlungen an den betreffenden Mitgliedstaat sowie den gegebenenfalls im MIP ermittelten makroökonomischen Ungleichgewichten zu prüfen (vgl. Art. 11, Abs. 7 in KOM 2018b). Die Beschlussfassung über die Gewährung von Finanzmitteln obläge ihr ebenfalls (vgl. Art. 12 in KOM 2018b). Nach einer positiven Beschlussfassung über die vorgeschlagene Verordnung stünde der Kommission somit ein ausgebautes Interventionsinstrumentarium zur Verfügung, um die bereits in der Phase des inkrementellen Staatlichkeitsausbaus angelegte stärkere Fokussierung auf die Wettbewerbsfähigkeitsagenda weiter zu forcieren. In diesem Sinne wirkt auch die dritte Säule des vorgeschlagenen Reformhilfeprogramms, das anders als das Reformumsetzungsinstrument allerdings nur den Mitgliedstaaten, deren Währung noch nicht der Euro ist, zur Verfügung stünde, um diese auf dem Weg zur Euro-Einführung zu unterstützen. Die Verfahren und Anforderungen der sogenannten »Konvergenzfazilität « gleichen dabei dem des >Umsetzungsinstruments ( vgl. Kapitel IV in KOM 2018b). Für die Fazilität stünden weitere 2 Milliarden Euro zur Verfügung, von denen Polen mit maximal 772 Millionen Euro am stärksten profitierte (vgl. KOM 2018b, Anhang I, 3).

Mit dem zweiten Verordnungsvorschlag des Fiskal-Two-Packs schlägt die Kommission weiterhin eine Europäische Investitionsstabilisierungsfunktion (EISF) vor, »[u]m den Euro-Mitgliedstaaten dabei zu helfen, besser auf rasch wechselnde wirtschaftliche Rahmenbedingungen zu reagieren und ihre Wirtschaft bei großen asymmetrischen 
Schocks zu stabilisieren « (KOM 2018c, 2). Grundlage hierfür sei die Erkenntnis, nach der »[d]ie Jahre der Finanzkrise [...] gezeigt [haben], dass Architektur und Reichweite der öffentlichen Finanzen der EU noch nicht ganz dem spezifischen Bedarf der Wirtschafts- und Währungsunion entsprechen« (ebd.), schließlich habe »die Krise deutlich gemacht, wie begrenzt die Mittel sind, auf die ein einzelner Mitgliedstaat des Euro-Währungsgebiets zurückgreifen kann, um die Auswirkungen großer asymmetrischer Schocks zu absorbieren « (ebd.). Die vorgeschlagene EISF kann demgemäß Euro-Mitgliedstaaten (und den Teilnehmerstaaten am WKM II) bei einem asymmetrischen Schock finanzielle Unterstützung in Form von Darlehen und Zinszuschüssen für öffentliche Investitionen gewähren (vgl. Art. 1 in KOM 2018c). Voraussetzung hierfür solle sein, dass der betreffende Mitgliedstaat den Anforderungen des SWP und des MIP in den letzten beiden Jahren im ausreichenden Maße Folge geleistet habe (vgl. Art. 3 in KOM 2018c). Ob ein Mitgliedstaat in Krisensituationen Anspruch auf eine EISF-Hilfe hat, solle anhand der Arbeitslosenquote reguliert werden (vgl. Art. 4 in KOM 2018c). Die EISF-Hilfen würden über eine Kreditaufnahme der EU finanziert. EISF-Hilfen wiederum stellen allerdings nur Darlehen der EU an einen Mitgliedstaat dar, die verzinst werden und zurückzuzahlen wären. Das maximale Darlehensvolumen solle 30 Milliarden Euro betragen (vgl. Art. 7 in KOM 2018c) Um die Zinsbelastung für einen Empfängerstaat zu verringern, wird weiterhin die Gewährung von Zinszuschüssen vorgeschlagen. Hierzu solle ein sogenannter Stabilisierungsfonds eingerichtet werden, der sich durch Beiträge der Mitgliedstaaten sowie den Erlösen der investierten Fondsmittel speise (vgl. Art. 17 in KOM 2018c) und entsprechende Zinszuschüsse zur Verfügung stellen könnte.

Nachdem die ersten Äußerungen des Rates in Bezug auf die Mitteilung über neue Haushaltsinstrumente aus dem Dezember 2017 darauf hindeuteten, dass innerhalb des Rates und der Euro-Gruppe unterschiedliche Sichtweisen über die Notwendigkeit und die Priorisierung der vorgeschlagenen Einzelmaßnahmen bestanden (s.o.), nahm nach der Vorlage des Fiskal-Two-Packs auch die Diskussion unter den mitgliedstaatlichen Regierungen deutlich an Fahrt auf. Hatte man sich im Laufe des Jahres 2018 innerhalb des Rates und der Euro-Gruppe insbesondere mit der Letztsicherung für den SRF und der ESM-Reform beschäftigt, rückte die Thematik der Fiskalunion und des Eurozonenbudgets nun stärker in den Fokus.

Die Forderungen nach einer umfassenden Fiskalunion ist seit Krisenbeginn eine der Kernforderungen des Europäischen Parlaments, der allerdings im bisherigen Verlauf des Staatlichkeitsausbaus nur wenig Beachtung geschenkt wurde. Dies sollte sich nicht zuletzt auch durch Macrons »Initiative für Europa« ändern. Bereits im September 2017 - also zwei Monate vor der Vorstellung des Nikolauspakets - sagte der französische Präsident in seiner vielbeachteten Sorbonne-Rede, es brauche »Konvergenz und Stabilität durch nationale Reformen, aber auch durch eine Koordinierung unserer Wirtschaftspolitiken und einen gemeinsamen Haushalt.« (Französische Botschaft 2017, 12; Herv. J. G.) Weiter heißt es in seiner Rede:

»[W]ir [brauchen] mehr Investitionen, wir brauchen Mittel zur Stabilisierung angesichts der Wirtschaftskrisen. Ein Staat kann eine Krise nicht alleine durchstehen, wenn er nicht mehr über seine Währungspolitik entscheidet. Aus all diesen Gründen brauchen 
wir einen stärkeren Haushalt im Zentrum Europas, im Zentrum der Eurozone. [...] Ein Haushalt kann nur einhergehen mit einer starken politischen Steuerung durch einen gemeinsamen Minister und eine anspruchsvolle parlamentarische Kontrolle auf europäischer Ebene. Alleine die Eurozone mit einer starken und internationalen Währung kann Europa den Rahmen einer Weltwirtschaftsmacht bieten.« (Ebd.; Herv. J. G.)

Nachdem die ersten Reaktionen aus Berlin erwartungsgemäß verhalten ausfielen, einigten sich Deutschland und Frankreich schließlich im Juni 2018 auf ein abgestimmtes Vorgehen, das sie in der »Erklärung von Meseberg« festhielten. In dieser heißt es:

»Wir schlagen vor, beginnend im Jahr 2021 im Rahmen der Europäischen Union einen Haushalt für die Eurozone aufzustellen, um die Wettbewerbsfähigkeit, Annäherung und Stabilisierung in der Eurozone zu fördern. [...] Die Mittel würden [...] aus nationalen Beiträgen, aus Steuereinnahmen und aus europäischen Mitteln kommen. Der Haushalt für die Eurozone würde auf mehrjähriger Basis festgelegt. [...] Aus ihm könnten neue Investitionen finanziert werden und er könnte nationale Ausgaben ersetzen. Wir werden das Thema eines Europäischen Stabilisierungsfonds für Arbeitslosigkeit prüfen, für den Fall schwerer Wirtschaftskrisen, ohne dass es zu Transferzahlungen kommt. Frankreich und Deutschland werden eine Arbeitsgruppe einrichten, die bis zum Europäischen Rat im Dezember 2018 konkrete Vorschläge vorlegt. Strategische Beschlüsse zum Haushalt für die Eurozone werden von den Staaten der Eurozone getroffen. Entscheidungen über Ausgaben sollten durch die Europäische Kommission durchgeführt werden.« (Bundesregierung 2018; Herv. J. G.)

Letztlich vollzog auch der Euro-Gipfel im Dezember 2018 diese spolitischer Einigung zwischen Deutschland und Frankreich nach und beauftragte die Euro-Gruppe, »an der Konzeption, den Durchführungsmodalitäten und dem Zeitplan für ein Haushaltsinstrument für Konvergenz und Wettbewerbsfähigkeit für das Euro-Währungsgebiet und - auf freiwilliger Basis - für die Mitgliedstaaten des WKM II zu arbeiten. (Euro-Gipfel 2018, Rn. 4; Herv. J. G.) Nicht von ungefähr ähnelt der Name der neuen Haushaltslinie dem weitestgehend gescheiterten Vorschlag der Barroso-Kommission aus dem Jahr 2013, mit dem bereits die Schaffung eines »Instruments für Konvergenz und Wettbewerbsfähigkeit« etabliert werden sollte und das an die Idee des Paktes für Wettbewerbsfähigkeit angelehnt war (s.o.). Im Laufe des Jahres 2019 einigte man sich schließlich unter den Eurostaaten auf einen gemeinsamen Standpunkt zum neuen Haushaltsinstrument für Konvergenz und Wettbewerbsfähigkeit (vgl. Euro-Gruppe 2019, Anlage 1), das im Englischen als BICC (Budgetary Instrument for Convergence and Competitiveness) bezeichnet wird und sicherlich auch Assoziationen in seiner politischen Reichweite auslösen soll.

Die strategischen Prioritäten des Haushaltsinstruments sollen - so der Vorschlag durch die Euro-Gruppe und den Euro-Gipfel diskutiert und in die Eurozonen-Empfehlungen im Rahmen des Europäischen Semesters einfließen. Die Mitgliedstaaten wiederum sollen auf diese in ihren Nationalen Reformprogrammen Bezug nehmen und Vorschläge unterbreiten, die schließlich durch die Kommission vor dem Hintergrund der länderspezifischen Empfehlungen geprüft würden. Letztlich bestünde die Verpflichtung einer mitgliedstaatlichen Kofinanzierung von $25 \%$. Mindestens $80 \%$ 
der zur Verfügung stehenden Mittel würden dabei nach Bevölkerung und dem BIP (pro Kopf) unter den Eurostaaten verteilt, maximal $20 \%$ könnten anhand strategischer Überlegungen flexibel vergeben werden. Die Höhe der Finanzausstattung des BICC war derweil ebenso wenig Bestandteil der politischen Einigung in der Eurogruppe wie ein konkreter Vorschlag zur sekundärrechtlichen Verankerung, weshalb die Kommission (2019e) schließlich im Juli 2019 die Integration des BICC in das davon ihr vorgeschlagene Reformhilfeprogramm vorschlug.

\subsection{Der EU-Staatlichkeitsausbau zwischen Ambition und Stagnation}

"Die Reformdynamik hat durch die Krise stark zugenommen, doch der politische Wille, die Wirtschafts- und Währungsunion zu vollenden, ist vor dem Hintergrund günstigerer wirtschaftlicher Rahmenbedingungen etwas erlahmt«, stellt die Kommission (2019d, 2) in einer Zwischenbilanz zum Fünf-Präsidenten-Bericht fest. Dies zeigt sich auch daran, dass die von der Kommission seit 2017 vorgeschlagenen institutionellen Reformen (Euro-Außenvertretung, EMWF, EWF, Überführung des SKS-Vertrags in den Unionsrechtsrahmen) bis dato nicht umgesetzt wurden. Insofern bleibt letztlich für den hier dargestellten Zeitraum bis $2019 \mathrm{zu}$ konstatieren, dass neben den >politischen Grundsatzentscheidungen zum Aufbau einer (begrenzten) Fiskalkapazität für die Eurozone bisher lediglich die marginale Aufstockung des bestehenden Strukturreformenprogramms final umgesetzt werden konnte. Die politischen Absichtserklärungen zur weiteren EWWU-Vertiefung, bereits beginnend mit dem Vier-Präsidenten-Bericht und zunehmend stärker visionär als »Vollendung der Wirtschafts- und Währungsunion« (vgl. Van Rompuy et al. 2012; Juncker et al. 2015b; KOM 2017d; KOM 2017s) verpackt, wirken auf dieser Grundlage allerdings als bloße Lippenbekenntnisse mit nur geringem Einfluss auf die konkrete politische Agenda der EUSA. Demgemäß weist der Staatlichkeitsausbau im Kontext der ausgerufenen >EWWU-Vollendung $<$ letztlich eine Stagnation auf.

Trotz dieser Stagnation, die insbesondere vor dem Hintergrund der lancierten Vollendungsdebatten $\mathrm{zu}$ attestieren ist, weisen die Aktivitäten der letzten Jahre durchaus weiterhin partiell einen gewissen inkrementellen Fortgang auf. So werden mit der angestrebten ESM-Reform (der neue ESM-Vertrag ist bis heute allerdings noch nicht unterzeichnet) und weiteren Bausteinen der Bankenunion (SRF, Einlagensicherungssystem) Bemühungen der Staatlichkeitskonsolidierung und des Staatlichkeitsausbaus sichtbar. Zugleich zeigen die im Vergleich zu den Diskussionen zu Beginn der Euro-Krise zum Teil ambitionierten Vorschläge zur Stärkung der EU-Interventionsstaatlichkeit insbesondere in Form größerer fiskalischer Möglichkeiten zur Absicherung ihres Interventionismus (Parlament, Macron, Kommission), dass die Debatte um die Fortentwicklung der EWWU trotz Abschwächung der Krisensymptome und der krisengetriebenen Reformdynamik weiterhin latent schwellt. Auffällig ist hierbei auch, dass die im Februar 2017 vom Parlament lancierten kurzfristig umzusetzenden Reformvorschläge an vielen Stellen große Ähnlichkeit zu jenen des Nikolauspakets und des späteren Fiskal-Two-Packs aufweisen. Wie schon in vorausgegangenen Krisenphasen scheint sich eine Koalition zwischen Kommission und Parlament herauszubilden, die gemeinsam für eine Inte- 
grationsvertiefung eintritt, wobei das Parlament mit seinen langfristigen Reformvorschlägen und hier insbesondere jenen zur Stärkung der >politischen Union` weit über die konkreten Initiativen der Kommission hinausweist. Unverkennbar in den Papieren und Vorschlägen von Kommission und Rat ist aber auch, dass die eingangs attestierte Funktionskrise der EWWU hierin immer stärker in den Fokus der Auseinandersetzung rückt. Waren es zu Beginn der Euro-Krise noch die Verfehlungen der Mitgliedstaaten, welche die Krise ausgelöst hätten und eine zu lasche europäische Überwachung der Fiskalpolitiken (als light-Version der Funktionskrise) attestiert wurde, gerieten mit den Berichten der vier (2012) und fünf Präsidenten (2015) immer stärker auch die weiteren funktionalen Zusammenhänge einer Währungs- und Wirtschaftsunion ins Bewusstsein, die schlussendlich in die übergeordnete Diskussion um die »Zukunft Europas« (2017) eingebettet wurden.

Die skizzierte Entwicklung verweist letztlich auch noch einmal im Besonderen auf Veränderungen in den europäischen Kräfteverhältnissen, die sich im Laufe des letzten Jahrzehnts seit Ausbruch der transatlantischen Finanzkrise vollzogen haben. Mit abnehmender Intensität der Euro-Krise sind diese ab 2015 zunehmend von zwei Diskurssträngen im gesellschaftlichen Kräftefeld geprägt, die sich einerseits in der einsetzenden Diskussion um die >Vollendung der EWWU < als ein potenzielles politisches Projekt insbesondere proeuropäischer Kräfte - wie es beispielsweise in den Parlamentsentschließungen im Frühjahr 2017 Ausdruck findet - sowie andererseits im Kontext der Krise des europäischen Grenz- und Migrationsregimes und des Brexits in einer weiteren Diskursverschiebung nach rechts zeigen. Vor diesem Hintergrund sind es abermals auch strategische Suchprozesse im Inneren des neoliberalen Hegemonieprojekts, welche die ambitionierten Reformvorschläge bei gleichzeitig stagnierendem Staatlichkeitsausbau erklären helfen.

Nach dem Allianzwechsel der autoritären Fraktion im neoliberalen Hegemonieprojekt zu den moderat-neoliberale Kräften prägten letztere die Bewältigungsmaßnahmen und leitbildlichen EUSA-Papiere der Phase des inkrementellen Staatlichkeitsausbaus. Es war ihre Strategie der angestrebten nachholenden Hegemonialisierung, die in der Phase des inkrementellen Staatlichkeitsausbaus insgesamt eine stärkere Orientierung auf proeuropäische Akteur*innen aller Hegemonieprojekte begründete. Durch die Stimulierung eines Diskurses über die Vollendung der EWWU gelang es dabei, erneut einen Orientierungspunkt in den gesellschaftlichen Auseinandersetzungen zu setzen, der auch von Akteur*innen des proeuropäisch-sozialen Hegemonieprojekts aufgegriffen wurde. Die Debatte um die Vollendung der EWWU, ab 2017 zusätzlich eingebettet in die Frage nach der »Zukunft Europas«, bot in diesem Sinne durchaus das Potenzial eines neuen politischen Projekts, das je nach Ausgestaltung sogar einen gegenhegemonialen Impuls hätte setzen können. Für proeuropäisch-soziale Akteur*innen stellen hierbei der Aufbau einer demokratischen Europäischen Wirtschaftsregierung, die Anwendung einer expansiven Fiskalpolitik statt Austerität und die Etablierung einer Sozialunion (vgl. Busch 2017) die thematischen Bezugspunkte einer vollendeten EWWU dar. Diese drei Forderungen kumulieren letztlich in der Diskussion um eine genuin-europäische Fiskal- und letzten Endes auch Transferunion, deren Etablierung als Krisenbewältigungslösung propagiert wurde und beginnend mit der Diskussion um den Fünf-Präsidenten-Bericht erneut auch in den gesellschaftlichen Diskur- 
sen einen größeren Platz einnehmen konnte. Trotz wahrnehmbarer öffentlicher Diskussionen um die EWWU-Vollendung, wie sie sich beispielsweise im Aufruf französischer Ökonomen für einen >Vertrag zur Demokratisierung der Eurozone (Hennette et al. 2017), in Debattenbeiträgen aus dem Feld gewerkschaftlicher Akteur*innen (vgl. bspw. Busch et al. 2017) und der Unterstützung progressiver Parteien für ein erweitertes fiskalpolitisches Reformprogramm (vgl. u.a. Biegoń et al. 2018; Hacker \& Koch 2017), die mittlerweile beispielsweise in Portugal (2015) und in Spanien (2018) die Regierungsgeschäfte übernommen hatten, zeigte, kristallisierte sich dennoch mit dem Fünf-Präsidenten-Bericht und dem Weißbuch zur Zukunft Europas kein tragfähiger gesellschaftlicher Kompromiss oder gar Konsens heraus. Dies liegt letztendlich - wie bereits in den vorausgegangenen Krisenphasen sichtbar wurde - in der Multiskalarität des EU-Staatlichkeits-Zivilgesellschafts-Komplex begründet, durch die auf europäischer Ebene ein Ungleichgewicht in den Kräfteverhältnissen entsteht. Dieses deutet sich in der weiterhin mehrheitlichen Ablehnung weitreichender materieller Zugeständnisse auf dem Weg zu einer umfassenden Fiskal- und insbesondere einer Transferunion in den >nördlichen $<$ Mitgliedstaaten an, die am Leitbild der Stabilitätsunion festhalten (vgl. Hacker \& Koch 2017, 4; Biegoń et al. 2018, 12f.). Das Ungleichgewicht zeigt sich dabei beispielsweise auch in neuen, den EU-Institutionen vorgelagerten Koordinationsund Austauschzusammenhängen wie der >New Hanseatic League len Zusammenschluss der Finanzminister*innen Dänemarks, Estlands, Finnlands, Irlands, Lettlands, Litauens, der Niederlande und Schwedens (vgl. Finish Ministry of Finance o.J.). Die >Neue Hanse< positioniert sich deutlich auf der Seite stabilitätsorientierter Reformvorschläge zur Stützung des Status quo und gegen einen weitreichenden fiskal- und wirtschaftspolitischen Ausbauprozess der EU-Staatlichkeit und stützt in diesem Sinne die grundsätzliche Position der deutschen Bundesregierung (vgl. Guntrum 2019), der aufgrund der tradierten intergouvernementalen Aushandlungsstrukturen in der EU (Frankreich-Deutschland) bei der Formulierung eines tragfähigen Kompromisses eine entscheidende Rolle zufällt. Dem deutschen Ansatz der Stabilitätsunion steht der französische Ansatz einer suprastaatlichen Kompetenzausweitung gegenüber, der auch von Macron in seinem Präsidentschaftswahlkampf und insbesondere seiner >Initiative für Europa< prominent herausgestellt wurde (vgl. Schneider \& Syrovatka 2017, 656) und von den mediterranen Mitgliedstaaten unterstützt wird (vgl. Hacker \& Koch 2017, 3). Auf dieser Grundlage sind letztlich auch die europäischen Kräfteverhältnisse sowie etwaige Umsetzungsmöglichkeiten und Reformblockaden innerhalb des EU-Staatsapparate-Ensembles zu bewerten. Dies einerseits vor dem Hintergrund eines zunehmenden Auseinanderdriftens der ökonomischen Interessen Frankreichs und Deutschlands (vgl. Schneider \& Syrovatka 2017; Sablowski 2015, 582) sowie andererseits einer generellen Diskursverschiebung nach >rechts`, die sich bereits während der Hochphase der Euro-Krise in einer zunehmenden Radikalisierung am rechten Rand der konservativen Hegemonieprojekte fast überall in der EU anbahnte (s.o.) und sich im Kontext der sich parallel zur Diskussion um die EWWU-Vollendung verdichtenden Krise des europäischen Grenz- und Migrationsregimes (vgl. Tsianos \& Kasparek 2015) weiter verschärfen sollte. Diese `neue Krise schwellte zwar bereits seit Jahren latent, manifestierte sich jedoch erst 2015 in einer umfassenden politischen Krise. Nach einer Reihe von Tragödien, insbesondere im Mittelmeer, rückte die teilweise katastrophale humani- 
täre Lage an den europäischen Außengrenzen und die anhaltenden Fluchtbewegungen aus dem Nahen Osten und Afrika immer stärker in den medialen Fokus und lösten nicht zuletzt in den EU-Binnenstaaten ohne Außengrenze einen politischen Druck seitens der linksliberalen Öffentlichkeit aus (für Deutschland vgl. Georgi 2016, 191). Vor diesem Hintergrund entschied die deutsche Bundesregierung im Sommer 2015, die Weiterreise Geflüchteter von den Außengrenzen und den europäischen Hotspots nach Deutschland zu gestatten (vgl. ebd.). Hierbei verdichtete sich in Deutschland ein Kräfteverhältnis, in dem die »Strategien des proeuropäisch-sozialen und des linksliberalalternativen Hegemonieprojekts mit denen des neoliberalen koinzidierten « (Buckel et al. 2018, 66). Die Ereignisse und Entwicklungen des Sommers 2015 riefen zugleich allerdings im konservativen und auch im national-sozialen Hegemonieprojekt »eine massive, chauvinistische Gegenbewegung dieser Projekte aus, vor allem der völkischen Fraktion des konservativen Projekts.« (Ebd.) Gesetzesverschärfungen, Ausbau des Grenzschutzes und der EU-Grenzschutzagentur Frontex sowie das Aussetzen des SchengenAbkommens waren das Ergebnis des wachsenden Einflusses der benannten Kräfte nicht nur in Deutschland, sondern auch in anderen EU-Mitgliedstaaten (vgl. ebd.).

Die Krise des Migrations- und Grenzregimes markierte dabei abermals eine Funktionskrise der EU-Staatlichkeit, die sich am »hegemonialen Projekt des >Migrationsmanagements« (ebd., 65) abarbeitete, »dessen Rationalität - Transnationalisierung plus utilitaristische Steuerung - auf die Kräfte des neoliberalen Hegemonieprojekts zurückzuführen ist.« (Ebd.) Nach der Krise der finanzmarktdominierten Akkumulation, der Funktionskrise der neoliberalen EWWU, ist es nun erneut eine politische Krise, die sich auf ein vom neoliberalen Hegemonieprojekt maßgeblich vorangetriebenes 'politisches Projekt< richtete und sich in Form der Krise des europäischen Grenz- und Migrationsregimes offenbarte. Es ist demnach eine dreifache Herausforderung, vor der die Akteur*innen des neoliberalen Hegemonieprojekts in dieser Phase stehen: die Funktionskrise des Grenz- und Migrationsregimes, deren Parallelität zur Diskussion um die EWWU-Vollendung und letztlich die Diskursverschiebung nach rechts, in der es den rechten Akteur*innen gelingt, die gesellschaftlichen Diskurse »mit[zu]bestimmen und auf die etablierten Entscheidungsträger Druck aus[zu]üben, also indirekt auf die politische Agenda ein[zu]wirken.«(Bieling 2017, 557) Dies verdeutlicht nicht zuletzt auch der Brexit, der maßgeblich von rechts-konservativen Kräften protegiert wurde, oder die Konsolidierung der Regierungsparteien PIS in Polen und Fidesz in Ungarn, welche die gewachsene Anschlussfähigkeit rechter Parteien und ihrer illiberalen Demokratieverständnisse überall in der EU illustriert.

Vor diesem Hintergrund lassen sich dementsprechend auch die Synthetisierungsversuche verstehen, die im Kontext der EWWU-Vollendungsdiskussion und insbesondere in dem beabsichtigten Einstieg in den Aufbau einer genuinen Fiskalunion sichtbar werden. Grundlage hierfür ist eine stärkere Orientierung der neoliberalen Kräfte auf Akteur*innen anderer proeuropäischer Hegemonieprojekte, denen gegenüber wahrnehmbare Konzessionen in Form des BICC und der Budgetlinien des Fiskal-Two-Packs gemacht werden. Gleichzeitig werden diese Aktivitäten aber in die neoliberale Wettbewerbsfähigkeitsdoktrin einzuordnen und die institutionell-angestrebten Reformvorschläge zum Aufbau der politischen Union möglichst weitgehend einzugrenzen versucht. Solche Maßnahmen stünden letztlich in einem 
Widerspruch zu Leitbildern der Akteur*innen der autoritär-neoliberalen Fraktion und wären vor dem Hintergrund des Rechtsrucks und der leitbildlichen Orientierungen der Stabilitätsunion-Fraktion unter den Mitgliedstaaten nur schwer durchzusetzen. Es ist hier demnach eine Strategie der Einhegung am Werk, mit der sich bemüht wird, proeuropäische Kräfte hinter dem neoliberalen Hegemonieprojekts zu vereinen. Narrativ geschieht dies - ähnlich wie am Ausgangspunkt der Euro-Krise - in einem erneuerten Rettungsdispositiv, in dessen Zentrum aufgrund seiner Infragestellung von rechts abermals der Fortbestand des gesamten europäischen Integrationsprojekts zu garantieren ist. Exemplarisch hierfür steht der identifizierte Kommunikationsansatz des Kommissionsweißbuchs.

In der beschriebenen Phase des stagnierenden Staatlichkeitsausbaus ab 2017 wird demnach insgesamt erneut ein eher reaktiver Politikmodus im Inneren der EUSA und ihrer dominanten Akteur*innen sichtbar, wie er sich bereits ganz zu Beginn der EuroKrise zeigte. Begünstigt durch die politischen Fokusverschiebungen auf die Migrationspolitik und $\mathrm{ab} 2016$ zusätzlich auf den Brexit führte dies zur weitestgehenden Stagnation des EU-Staatlichkeitsausbaus im Kontext der Wirtschafts- und Währungsunion, auch wenn die neoliberalen Kräfte stärker auf proeuropäische Akteur*innen anderer Hegemonieprojekte angewiesen scheinen als zuvor. Trotzdem muss schlussendlich in diesem Sinne auch die Strategie nachholender Hegemonialisierung als - vorerst - gescheitert gelten. Ein tragfähiger gesellschaftlicher Konsens über die `Zukunft der EU، und die >Vollendung der EWWU < kristallisierte sich jedenfalls bisher nicht heraus. 


\section{Die Genese der EU-Staatlichkeit in der Euro-Krise und ihre Fragilität im Status quo}

Vor dem Hintergrund der drei beschriebenen Phasen des EU-Staatlichkeitsausbaus im Kontext der Euro-Krise bleibt abschließend die Frage zu klären, wie sich diese in einen übergeordneten Gesamtzusammenhang einordnen lassen und im Sinne von sStaatlichkeit als Projekt der ausgebauten EU-Staatlichkeit eine Art Telos einschreiben konnten beziehungsweise einer übergreifenden Zielsetzung folgten. Im Zentrum stehen hierbei auf Grundlage der dargestellten Transformations- und Ausbauprozesse der EU-Staatlichkeit (rekonstruktive Konstitutionalisierungsanalyse) sowie der Wandlungsprozesse in den Kräfteverhältnissen (Kräfteverhältnisanalyse) empirische Suchprozesse nach einem erneuerten, sich in den EUSA und dem EUStaatsapparate-Ensemble verdichtenden Staatsprojekt für die Europäische Union (Verdichtungsanalyse). Dass sich hierbei in der Euro-Krise ein gänzlich neues Staatsprojekt herauskristallisiert hätte, ist allerdings bereits an dieser Stelle zu negieren. Stattdessen lässt sich eine Fortschreibung des neoliberalen Staatsprojekts beobachten, das einerseits eine autoritäre Ausschärfung erfahren hat und anderseits aber zugleich in einem Zustand der Lethargie zu verharren scheint. Die demgemäß zu beschreibende Fragilität des Staatsprojekts und somit der EU im Gesamten legt insofern gar nach einer Dekade des kriseninduzierten Ausbau- und Transformationsprozesses Ansatzpunkte einer EU-Staatlichkeitskrise offen.

\subsection{Auf der Suche nach einem kohärenten Staatsprojekt in der Euro-Krise und die Persistenz seiner neoliberalen Variante}

Der kriseninduzierte Ausbau und die vollzogenen Transformationen der EUStaatlichkeit in der Euro-Krise führten, wie dargestellt, insgesamt zu einer Stärkung der europäischen Staatlichkeitsebene. Dies wurde anhand der drei Konstitutionalisierungsprozesse in der Phase des reaktiven Staatlichkeitsausbaus besonders deutlich (vgl. Kapitel 7), lässt sich aber ebenso in der Phase des inkrementellen Staatlichkeitsausbaus in Form veränderter Praxen und kleinerer Reformschritte beobachten (vgl. 
Kapitel 8), die teilweise und in überschaubarerem Ausmaß auch noch in der Phase des eigentlich stagnierenden Staatlichkeitsausbaus sichtbar wurden (vgl. Kapitel 9). Es konnte hierbei gezeigt werden, dass insgesamt ein erweiterter Handlungsrahmen implementiert wurde, innerhalb dessen der Interventionismus der EUSA sowohl im krisenbezogenen Ausnahme- als auch in einem sneuen Normalzustand c deutlich hervortritt. Folgen dabei die konkreten Staatlichkeits- und Herrschaftspraxen, die es in künftigen politikwissenschaftlichen Analysen vor dem Hintergrund des in dieser Arbeit entwickelten Staatlichkeitsbegriffs noch eingehender zu untersuchen lohnt, zwar je Verfassungskomponente unterschiedlichen >Logiken zusammengenommen dennoch eine starke Fokussierung auf exekutive Herrschaftsformen an. Im Rahmen der außerunionsvertraglichen Notstandsverfassung zeigt sich diese in Form des autoritär-intergouvernementalen Gläubigerregimes, im Kontext der EU-Fiskal- und Wirtschaftsverfassung anhand einer koproduktiven Exekutivstaatlichkeit, an deren Spitze unverkennbar eine gestärkte Europäische Kommission steht, und im Bereich der (impliziten) Finanzstabilisierungsverfassung durch die Selbstermächtigungsakte der EZB sowie der neuen Funktionszuschreibungen an die Zentralbank. Ausgerichtet sind die neuen Formen der EU-Interventionsstaatlichkeit am Herrschaftsmodus der (Selbst-)Disziplinierung, anhand dessen die Orientierung am Status quo ante vor der Euro-Krise, also am Staatsprojekt des neoliberalen Hegemonieprojekts, in aller Deutlichkeit zu Tage tritt. Durch entsprechende neue Infrastrukturen wird hierbei die Verpflichtung auf eine (verfassungs-)rechtlich festgeschriebene richtige Politik vorgenommen und notfalls auch von raußen (also von den EUSA) - und mit entsprechender Härte - in den Mitgliedstaaten durchzusetzen versucht.

Kennzeichen des neoliberalen Staatsprojekts vor der Euro-Krise war eine weltmarktorientierte Akkumulationsstrategie (Lissabon-Strategie), die bereits um entsprechende Disziplinierungsmomente im Inneren ergänzt wurde (disziplinierender Neoliberalismus, neoliberale Sachzwangslogik) und auf einer ordo- wie neoliberal eingefärbten Wirtschaftsverfassung in den europäischen Verträgen basierte. Zusammengenommen begründeten diese Charakteristika eine wettbewerbsstaatliche Integrationsweise, die den Integrationsprozess und die EU-Staatlichkeit unter den Vorzeichen einer Phase neoliberaler Hegemonie über viele Jahre prägen sollte (vgl. Kapitel 4). Nachdem am Ausgangspunkt der Euro-Krise aufgrund der transatlantischen Finanzmarktkrise und der Funktionskrise der im Kern neoliberal-orchestrierten EWWU genau eine solche Integrationsweise und das neoliberale Staatsprojekt infrage gestellt schienen, gelang es durch die skizzierten Reorganisationsprozesse im Inneren des neoliberalen Hegemonieprojekts und durch das Schnüren neuer (teilweise impliziter) Allianzen (reaktionäres Bündnis), eine Krisenbewältigungsstrategie in die EUSA einzuschreiben, die sich einer autoritär-neoliberalen Reformagenda verpflichtet fühlte. Grundlage hierfür waren die drei beschriebenen diskursiv-strategischen Momente neoliberaler Rückeroberung (vgl. Kapitel 6), die für eine ungebrochene Dominanz neoliberaler Kräfte innerhalb des EU-Staatsapparate-Ensembles und der EUSA sorgten, deren Akteur*innen schließlich die Phase des reaktiven Staatlichkeitsausbaus prägen sollten und demnach auch die Ziel- und Zweckbestimmung der Ausbauaktivitäten und Transformationen der EUStaatlichkeit maßgeblich beeinflussten. Das Besondere hierbei stellt die Stimulierung differenzierter Diskurse mit unterschiedlichen Anschlussfähigkeiten dar. So vermittelt 
das Rettungsdispositiv, das die Phase des reaktiven Staatlichkeitsausbaus besonders prägte, eine Form der Krisenlegitimität, mit der letztlich auch beabsichtigt schien, proeuropäische Kräfte jeglicher Colour im Sinne einer Art EU-Staatlichkeitsräson zu adressieren (vgl. bspw. Habermas 2013, 84). Nicht nur der Fortbestand der Gemeinschaftswährung stand hierbei im Mittelpunkt. Am Ende sollte die Bewältigungspolitik nicht weniger als den gesamten europäischen Integrationsprozess bewahren helfen. Auch die Europe-2020-Strategie als ein weiteres strategisch-diskursives Moment erscheint in diesem Sinne als ein >Angebot<, bei dem sich verschiedene Fraktionen, Kräfte und Akteur*innen mit durchaus unterschiedlichen Vorstellungen und Konzepten innerhalb des lancierten Wettbewerbsfähigkeitsdiskurses verorten konnten. Die Restauration der neoliberalen Akkumulationsstrategie aus der Zeit vor der Euro-Krise, wie sie in der Europe-2020-Strategie angelegt war, kann dabei als außerordentlich wichtig erachtet werden, insbesondere deshalb, da sich in ihr alle Fraktionen des neoliberalen Hegemonieprojekts einschreiben konnten. Selbst das Europäische Parlament, das in einer gewissen kritischen Distanz und in Teilen sogar oppositionell zu den offiziellen Krisennarrativen der EUSA stand, nahm immer wieder positiv Bezug zur Europe2020-Strategie (vgl. u.a. EP 2011m; 2010d) und mahnte in den Auseinandersetzungen mit Rat und Kommission fortwährend die Beachtung ihrer Zielsetzungen an. Europe2020 scheint in der gesamten Euro-Krise der Garant dafür zu sein, dass die sich immer wieder partiell andeutende EU-Staatlichkeitskrise (Stichwort »Krisenkaskade«; vgl. Kapitel 2.6) letztlich doch nicht vollends verdichten konnte (ausführlich s.u.). Anders gestaltete es sich im Kontext der Hinwendung auf die Staatsschuldenthematik, die weitaus geringere Anschlussfähigkeiten aufweisen konnte. Die Umdeutung der staatlichen Refinanzierungs- und Staatsschuldenkrise ist zwar das Schlüsselmoment, in dem das reaktionäre Bündnis aus der autoritären und der orthodoxen Fraktion im neoliberalen Hegemonieprojekt mit national-konservativen Kräften sichtbar wird, es ist aber zugleich permanenter Ausgangspunkt für die Kämpfe gegenhegemonialer Kräfte in der Euro-Krise. Gerade das den Krisenbewältigungsmaßnahmen eingeschriebene Austeritätsdogma ist es, welches eine Hegemonialisierung der Krisenbewältigungspolitik trotz Rettungsdispositiv und Akkumulationsstrategie schließlich verhindern sollte. In Conclusio führte dies letztlich zur diagnostizieren nicht-hegemonialen Staatlichkeits(re)produktion und einer fragmentierten Hegemoniekrise in der EU (vgl. Kapitel 7.6).

Gerade aber vor dem Hintergrund fragmentierter Hegemonie sowie der Materialität und der strategischen Selektivitäten der EUSA, die bis heute geprägt sind von der Phase neoliberaler Hegemonie in den 1990er und 2000er Jahren, gelang es den neoliberalen Akteur*innen ihr Staatsprojekt fortzuschreiben. Es blieb der dominante Bezugspunkt der Krisenbewältigungspolitik und leitete den Staatlichkeitsausbau der EU in punkto Disziplinierung, Wettbewerbsstaatlichkeit und Einschränkung demokratisch-diskretionärer Politikformulierung und Herrschaftsmodi in Form verankerter Euro-Heteronomien an. Als Staatsprojekt der Staatlichkeits-Genese (vgl. Kapitel 4.3) wirkte das neoliberale Staatsprojekt dabei mit Blick auf den nachgezeichneten Ausbau der EU-Staatlichkeit und ihrer neuen Interventionsarrangements durchaus erfolgreich. Schließlich sind mit diesem neue Hierarchien zwischen den Maßstabsebenen und entsprechende Kompetenzausweitungen der EUSA verbunden. Allerdings kommt 
hinzu, dass das Staatsprojekt vor der Euro-Krise selbst noch stark umkämpft war und nicht die gleiche Qualität aufwies, wie tradierte Staatsprojekte auf den mitgliedstaatlichen Scales. Man könnte sagen, dass das neoliberale EU-Staatsprojekt noch nicht den Zustand der Doxa erreicht hatte und dementsprechend nicht unhinterfragt als quasi ahistorisches Artefakt im Alltagsverstand verankert oder ausreichend hegemonial abgesichert war. Auch und insbesondere die in der Euro-Krise ausgebaute EU-Staatlichkeit befindet sich daher, mit Gramsci gesagt, in einem Zustand des Interregnums, in dem zwar `führende< Kräfte sichtbar werden, sie aber nicht mehr im integralen Verständnis `herrschend s sind (vgl. Gramsci 1991-2002, 354). Es ist diese Krise der neoliberalen Hegemonie, die in der Euro-Krise offen zu Tage trat und sich durch die Konstitutionalisierungsprozesse des reaktiven Staatlichkeitsausbaus weiter verschärfen sollte. Am Ende stehen hierbei eine Sozial- und Legitimationskrise als konkrete Ausdrucksformen der Hegemoniekrise (vgl. Kapitel 7.6 \& 8.6) und dementsprechend eine weiterhin prekäre EU-Staatlichkeit, in der das neoliberale Staatsprojekt aufgrund seiner fehlenden Verallgemeinerungsfähigkeit nicht ausreichend Kohäsion herzustellen vermag.

Ausgehend von der neoliberalen Hegemoniekrise und der gesellschaftlich weiterhin umkämpften Strategie zur Bewältigung der Euro-Krise, sahen sich die politisch handelnden Akteur*innen innerhalb des EU-Staatsapparate-Ensembles bereits während der Phase des reaktiven Staatlichkeitsausbaus mit der Herausforderung konfrontiert, nicht nur ein krisenbedingtes Reform-, sondern zugleich auch ein proaktives Vertiefungsprogramm künftiger Integrationsschritte zu skizzieren. Der damalige Ratspräsident Van Rompuy begann dementsprechend bereits im Jahr 2012 mit der Formulierung eines Perspektivpapiers, das später als Vier-Präsidenten-Bericht bezeichnet wurde und offiziell den Titel »Auf dem Weg zu einer echten Wirtschafts- und Währungsunion« (Herv. J. G.) trug. Der EWWU-Kompromiss des Maastrichter Vertrags erscheint in dieser Diktion als eine unechte oder gar falsche Wirtschafts- und Währungsunion, die es nun weiterzuentwickeln gelte. Auch wenn der Vier-Präsidenten-Bericht im Vergleich zu Van Rompuys ersten Zwischenberichten an Reformreichweite und konkreten Zeitperspektiven einbüßte, markierte er doch zugleich den Ausgangspunkt für eine Reihe von Reflexionsprozessen, die sich insgesamt als eine Suche nach einem kohärenten Staatsprojekt verstehen lassen. Die Reihe der leitbildlichen Papiere, die in den Staatsapparaten entstanden, ist lang: Parallel zum Vier-Präsidenten-Bericht legte die Kommission ein eigenes "Konzept « nicht nur für eine echte, sondern sogar »vertiefte und echte Wirtschafts- und Währungsunion« vor; 2015 folgte der Fünf-Präsidenten-Bericht und 2017 das Weißbuch zur Zukunft Europas sowie ein erneutes Reflexionspapier zur Vertiefung der Wirtschafts- und Währungsunion seitens der Kommission. Ergänzt werden könnte diese Liste um unzählige Papiere, mit denen zivilgesellschaftliche Akteur*innen, Thinktanks, Parteien oder Verbände die Reform- und Vertiefungsdebatte begleiteten, um ihre Sichtweisen in die konkreten Reformmaßnahmen einfließen zu lassen und deren systematische diskursanalytische Untersuchung lohnen würde, um die in der vorliegenden Arbeit aus forschungspragmatischen Gründen lediglich sekundäranalytischausgestaltete Kräfteverhältnisanalyse insbesondere für die Phasen des inkrementellen und des stagnierenden Staatlichkeitsausbaus weiter $\mathrm{zu}$ fundieren.

Insgesamt ist den Perspektivpapieren der EUSA trotz ihrer unterschiedlichen Akzentuierungen, Reformtiefen und Zeithorizonte gemein, dass sie in ihrer Selbstver- 
ortung mehr sein wollten als kurzfristige Aktionspläne. Mit ihnen sollten stattdessen Orientierungspunkte in der aufkommenden Debatte über die »Vollendung « der EWWU gesetzt werden, die aufgrund der sozialen Folgewirkungen der Krise und ihrer austeritären Bewältigungsstrategie sowie nicht zuletzt der Diskursverschiebungen nach rechts notwendig erschienen. Dabei darf die tatsächliche Reichweite der Papiere auf die konkreten Praxen der EUSA, auch vor dem Hintergrund einer kritischen Würdigung der in dieser Arbeit zur Anwendung gebrachten politikwissenschaftlichen Dokumentenanalyse, zugleich nicht überschätzt werden, dienen sie doch zuvorderst der Initiierung politischer Debatten sowie gesellschaftlicher Diskurse und weniger der Formulierung eines kurzfristigen Umsetzungsprogramms der in ihnen beschriebenen Vorschläge und Maßnahmen.

Indes übernahmen in der Debatte über die weiteren Reform- und Vertiefungsschritte immer deutlicher moderat-neoliberale Kräfte die Führung, die sich seit dem Sommer 2012 (impliziter Allianzwechsel der autoritär-neoliberalen Fraktion) stärker in die offiziellen EUSA-Politiken einschreiben konnten (vgl. Kapitel 8.6). Kulminationspunkt der sich wandelnden Kräfteverhältnisse war der Fünf-Präsidenten-Bericht und mit ihm einige durchaus kluge strategische Schachzüge des Kommissionspräsidenten Juncker. Zwar fiel der Fünf-Präsidenten-Bericht hinter die Ausführungen des Berichts der vier Präsidenten und auch dem Kommissionskonzept von 2012 zurück, doch schien sich hierdurch zugleich auch seine Fähigkeit zur Konsensstiftung und Kompromissfindung zu erhöhen. Dieses Vorgehen passt sich in die übergeordnete Strategie einer nachholenden hegemonialen Absicherung des reaktiven EU-Staatlichkeitsausbaus ein, die sich im Agieren der Juncker-Kommission $\mathrm{zu}$ verdichten schien. So konnte unter der Devise »Vertiefung durch Handeln« ein inkrementeller Ausbauprozess initiiert werden, an dessen Ende erweiterte Handlungs- und Ermessensspielräume der Kommission, ein pragmatischerer Austeritätsansatz und eine sozialpolitische Flankierung der EU-Staatlichkeit (ESSR, sozialpolitisches Scoreboard) standen. All dies zur Vorbereitung der letztlich als notwendig erachteten tiefergehenden Reformmaßnahmen in der sich an die inkrementellen Ausbauprozesse anschließenden und auch im Fünf-Präsidenten-Bericht angedachten Vertiefungsphase. Dass die Strategie nachholender Hegemonialisierung letztendlich scheiterte, lag daran, dass sich die erreichten Kompromisse und gemachten Zugeständnisse in der Phase des inkrementellen Staatlichkeitsausbaus nur an Oberflächenphänomenen abarbeiteten und insofern nicht auf die grundlegenden Prämissen der autoritär-neoliberalen Einschreibungen in die EU-Staatlichkeit konsensualisierend wirken konnten. Dies wurde besonders am Agieren gegenüber der SYRIZA-Regierung in Griechenland deutlich, in dem sich in aller Rücksichtslosigkeit zeigte, dass sich jedweder Reformprozess auf dem Weg zu einer vollendeten EWWU trotz leichter Reorientierungen innerhalb der EUSA weiterhin den Disziplinierungsarrangements und den richtigen Politiken der ausgebauten EU-Interventionsstaatlichkeit in seiner autoritär-neoliberalen Anlage unterzuordnen habe. Nach Jahren der Krise schienen selbst moderat-neoliberale Kräfte, die zu Beginn selber noch für eine alternative Bewältigungsstrategie warben, die in der Euro-Krise gestärkten, autoritär-neoliberalen Grundpfeiler der EU-Staatlichkeit nicht mehr prinzipiell infrage zu stellen. Dies beschränkte schließlich direkt wieder 
ihre Fähigkeit, anderen Hegemonieprojekten gegenüber konsensualisierend wirken zu können.

Ein neuer Anlauf für weitere Vertiefungs- und Vollendungsschritte stand mit den Papieren des Jahres 2017 bereits zusätzlich unter dem Eindruck der Krise des europäischen Grenz- und Migrationsregimes sowie des erfolgreichen Brexit-Referendums. Mit diesen rückte neben weiteren institutionellen Reformvorschlägen (Nikolauspaket) insbesondere das Projekt einer genuin-europäischen Fiskalunion immer deutlicher ins Zentrum der Debatte. Dieses Projekt wurde bereits seit der ersten Stunde vom Europäischen Parlament protegiert und fand zumindest auch in den Perspektivpapieren der vorausgegangen Jahre Erwähnung. Es gelangte allerdings erst auf die konkrete politische Agenda der EUSA und insbesondere des Europäischen Rates, als Emmanuel Macron mit seiner Initiative für Europa das Thema ebenfalls prominent besetzte. Aber selbst die starke Unterstützung für Maßnahmen zum Aufbau einer Fiskalkapazität oder gar eines Haushalts für die Eurozone, wie sie bei Macron als Vertreter des moderatneoliberalen Lagers sichtbar wird, scheint bis heute keine große hegemoniale Durchschlagskraft entfaltet $\mathrm{zu}$ haben. Letztlich wird auch die Fiskalunion in den sich derzeitig andeutenden Kompromissen (vgl. Kapitel 9.3) in der bekannten neoliberalen Einhegungsmentalität lediglich in das bisherige Telos der EU-Staatlichkeit einzuordnen versucht. Dass aus der Fiskalunion stattdessen ein politisches Projekt mit erweiterter Stahlkraft über die Absicherung der Wettbewerbsfähigkeitsagenda und die Flankierung der restriktiven mitgliedstaatlichen Fiskalpolitiken hinaus entstehen könnte, erscheint auf Grundlage des aktuellen Diskussionsstands und der angedeuteten Kompromisslinien mehr als abwegig. Es sind abermals sichtbare Zugeständnisse gegenüber den autoritären und orthodoxen Neoliberalen als auch den erstarkten rechts-konservativen Fraktionen unter den national-konservativen Kräften, die die Persistenz des neoliberalen Staatsprojekts trotz seiner fehlenden hegemonialen Absicherung weiter zu perpetuieren helfen.

\subsection{Zwischen Fragilität, Lethargie und latenter Staatlichkeitskrise - Die EU nach 10 Jahren Euro-Krise}

Der Status quo der EU-Staatlichkeit nach zehn Jahren Euro-Krise ist aufgrund der gesellschaftlichen Kräfteverhältnisse und ihrer Verdichtungen im EU-StaatsapparateEnsemble, wie dargelegt, von Fragilität geprägt. Ein hegemonial verankertes Staatsprojekt jedenfalls konnte sich in der Dekade des Staatlichkeitsausbaus im Kontext der Euro-Krise nicht herauskristallisieren. Stattdessen erscheint das neoliberale Staatsprojekt persistent und weiterhin dominant. Auch ist aus den bisherigen Diskussionen und Debatten rund um die Euro-Krise und die potenzielle >EWWU-Vollendung ‘ kein (neues) alternatives Staatsprojekt hervorgegangen, das derzeit ausreichend Anschlussfähigkeit aufweist und in diesem Sinne Kohärenz stiften könnte. Die mit den leitbildlichen Papieren angestoßenen Reflexionsprozesse über das Telos der E(WW)U mündeten zwar häufig in Hochglanzbroschüren, konnten jedoch wegen der Reformblockaden auf Grundlage ungleichzeitiger Krisenentwicklungen und differenzierter Kräfteverhältnisse auf den mitgliedstaatlichen Scales keinen weiterführenden, proaktiven Vertiefungs- und 
Vollendungsprozess initiieren. Auch das Changieren zwischen Ambition und Stagnation in der Phase des stagnierenden Staatlichkeitsausbaus verdeutlichte dies (vgl. Kapitel 9). Das EU-Staatsapparate-Ensemble habe sich zu einem blockierten System entwickelt (vgl. Bach 2015, 33) und ist »in einem Teufelskreis verstrickt, der rationale Lösungen erschweren oder gar verhindern kann. Die EU ist also selbst Teil des Krisengeschehens und zugleich einer der wichtigsten Krisenherde.« (Ebd.) Die EU-Staatlichkeit erscheint demgemäß nach zehn Jahren Euro-Krise nicht nur fragil, sondern bisweilen gar paralysiert und in einem Zustand der Lethargie gefangen. Zusammengenommen stellt dies den Nährboden einer in Permanenz latent schwelenden Staatlichkeitskrise der EU dar, die nur bis zu einem bestimmten Punkt durch das dominante, aber eben nicht hegemoniale, neoliberale Hegemonieprojekt abgewendet werden kann, das selber immer wieder von strategischen Suchprozessen zwischen seinen unterschiedlichen Fraktionierungen durchzogen wird. Dabei treten nicht nur innerhalb des neoliberalen Hegemonieprojekts, sondern in der Europäischen Union insgesamt immer wieder deutlich Friktionen und neue Krisenerscheinungen hervor, die fortwährend und Stück für Stück die Staatlichkeitskrise verschärfen. Ansätze der Auflösung des symbolischen Gewaltmonopols, als mögliche Folge einer Staatlichkeitskrise (vgl. Kapitel 2.6), lassen sich nicht nur in den mitgliedstaatlichen Alleingängen in der Krise des Migrations- und Grenzregimes beispielsweise in Form von innereuropäischen Grenzschließungen entdecken, sondern scheinen auch die derzeit durch das Corona-Virus ausgelösten Krisenerscheinungen zu begleiten. Börzel $(2016,9)$ spricht dabei von einer wachsenden Lücke zwischen den getätigten Zusagen beziehungsweise eingegangenen Verpflichtungen der Mitgliedstaaten einerseits sowie deren tatsächlicher Umsetzung andererseits und diagnostiziert infolgedessen eine >Krise der EU-Governance - oder anders ausgedrückt: eine EU-Regierungskrise.

Abgesehen davon, dass zurzeit nicht absehbar ist, welchen Einfluss die tagesaktuellen Entwicklungen in Europa auf künftige Transformationen der EU-Staatlichkeit nehmen werden (ausführlich s.u.), erscheint allerdings ein strategisches Dilemma dergestalt vorzuliegen, dass aufgrund der ökonomischen wie gesellschaftlichen Polarisierungslinien und ihrer Multiskalarität die Herausbildung eines neuen hegemonialen $\mathrm{Zu}$ stands in der EU erschwert wird. Die Diskursverschiebung nach rechts und die derzeitige Stärke seiner Kräfte auf der einen Seite stehen auf der anderen Seite jene Kräfte gegenüber, die weiter auf einen starken - teilweise vorbehaltlosen - Ausbauprozess der EU-Staatlichkeit setzen, wie er unter anderem in den Februar-Entschließungen des Jahres 2017 im Europäischen Parlament skizziert wurde. Das Zusammenführen beider Pole erscheint herausfordernd bis unmöglich. Zwar befinden wir uns »[a]uch unter den Bedingungen von fragmentierter Hegemonie [...] im zivilgesellschaftlichen Stellungskrieg, aber die Durchsetzung gegenhegemonialer Projekte ist [...] nicht leichter geworden«, so Martin \& Wissel $(2015,236)$. Der derzeitige (Selbst-)Erhaltungstrieb ohne hegemoniales Staatsprojekt bleibt daher prägend und nicht nur aktuell, sondern voraussichtlich auch in naher Zukunft weiter krisenanfällig. Ob und wann der latenten EU-Staatlichkeitskrise vollends der Durchbruch gelingen wird, kann natürlich nicht seriös prognostiziert werden. Entscheidend erscheinen hierbei aber drei grundlegende Herausforderungen, die als Präjudize einer potenziell manifesten Staatlichkeitskrise gelten können. 
Zum ersten steht die Europäische Union wie zu Beginn der Euro-Krise auch 2020 vor der Aufgabe, eine neue Wachstumsstrategie zu formulieren, welche die Grundlage für das wirtschaftspolitische Regieren der kommenden Dekade bildet. Nachdem es mit der Europe-2020-Strategie gelungen war, die neoliberale Akkumulationsstrategie der Vor-Krisen-Dekade (Lissabon-Strategie) am Ausgangspunkt der Euro-Krise zu restaurieren, bleibt noch abzuwarten, wie sich die neue >Unionsstrategie für Wachstum und Beschäftigung، in ihren genauen Implementationsdetails in ihre Vorläuferinnen einpassen wird. Anzeichen dafür, dass die shidden agenda der neuen Strategie letztlich in einer Fortschreibung der Wettbewerbsfähigkeitsdoktrin und ihrer Weltmarktfixierung bestehen wird, lassen sich bereits in der entsprechenden Kommissionsmitteilung aus dem Dezember 2019 viele finden (vgl. KOM 2019b). Auch der Verzicht auf die Überarbeitung der seit 2015 gültigen Grundzüge der Wirtschaftspolitik (Empfehlung (EU) 2015/1184), welche die Handschrift der Europe-2020-Strategie tragen, sowie ein Blick auf die Fortschreibung der im Oktober 2020 beschlossenen beschäftigungspolitischen Leitlinien (Beschluss (EU) 2020/1512), die trotz ausgeweitetem Umfang den Leitlinien der vorausgegangen Jahre treu bleiben, bestätigen dies. Zugleich fällt allerdings ebenso direkt ins Auge, dass sich die neue Strategie in ihrer Struktur von den beiden VorläuferStrategien deutlich abhebt. So wird mit ihr das Narrativ des »europäischen Grünen Deals« entwickelt und somit der mittlerweile in der Zivilgesellschaft außerordentlich stark geführte Diskurs über den Klimawandel und die als notwendig erachteten Schritte einer Klimapolitik mit in die Formulierung der Strategie einbezogen. So sei der »europäische Grüne Deal« laut Kommission (2019b, 2) als Antwort auf die aktuellen Diskussionen rund um die umweltbezogenen Herausforderungen zu verstehen. Es handele sich bei ihm

»um eine neue Wachstumsstrategie, mit der die EU zu einer fairen und wohlhabenden Gesellschaft mit einer modernen, ressourceneffizienten und wettbewerbsfähigen Wirtschaft werden soll, in der im Jahr 2050 keine Netto-Treibhausgasemissionen mehr freigesetzt werden und das Wirtschaftswachstum von der Ressourcennutzung abgekoppelt ist.« (Ebd.; Herv. J. G.)

Interessant ist an der neuen Strategie, dass sich mit ihr auch ein neues strategisch-diskursives Moment aufzutun scheint, in dem sich eine Synthetisierung des neoliberalangebotsökonomischen Wirtschaftsparadigmas mit Kernforderungen aus dem linksalternativen Hegemonieprojekt und hier insbesondere ihrer grünen Kapitalfraktionen anbahnt. Ob dies letztlich eine Momentaufnahme bleiben wird oder hierüber gar ein neuer hegemonialer Impuls gesetzt werden kann, gilt es künftig weiter zu beobachten. Zugleich ist aber ebenso auffällig, dass innerhalb der vorgeschlagenen Strategie insgesamt deutlich weniger sozialpolitische Akzente enthalten sind, als dies noch in der Europe-2020-Strategie und selbst in der Lissabon-Strategie der Fall war. Auch insofern drängt sich der Eindruck auf, als bilde sich hier eine neue (implizite) Allianz zu Lasten der Kräfte aus den sozialen Hegemonieprojekten heraus.

Zweite besondere Herausforderung stellt die im Grunde weiter fortbestehende Funktionskrise der EWWU dar. Hat zwar durch die Politik zur Bewältigung der Euro-Krise ein Ausbau der EU-Staatlichkeit stattgefunden, gilt es diesen nicht in einen solchem Sinne misszuverstehen, als dass hierdurch die grundsätzlichen Kon- 
struktionsmängel der neoliberalen EWWU überwunden worden seien (vgl. Kapitel 5). Vielmehr zeigt sich, dass die Ausbau- und Transformationstätigkeiten aufgrund ihrer Einseitigkeit die strukturellen Ungleichgewichte in der Währungsunion nicht haben beheben können. Mehrfach wurde in der Arbeit darauf hingewiesen, dass der Divergenzprozess in der Eurozone nicht nur ein Merkmal des ersten Jahrzehnts des Bestehens der Gemeinschaftswährung war, sondern auch während und nach der akuten Euro-Krise weiter wirkmächtig ist. Grundsätzliches Problem bleibt dabei, dass die EWWU aufgrund fehlender Ausgleichsmechanismen auch weiterhin nicht im Stande ist, ausreichend Konvergenz innerhalb der Währungsunion herzustellen und bei asymmetrischen Schocks ausgleichende Stabilisierungswirkungen und/oder notwendige Transfers zu generieren. Das kreditbasierte Hilfssystem, das in der Euro-Krise aufgebaut wurde, kann in diesem Sinne lediglich in akuten und bereits zugespitzten Problemlagen helfen, bleibt in seiner strukturellen Wirkung auf Grundlage einer volkswirtschaftlichen Gesamtbetrachtung der Eurozone allerdings unterkomplex. Der Lackmusstest bleibt daher ein künftiges ökonomischen Krisenszenario. Wenn die nächste Krise kommt, werden sich dementsprechend in aller Dringlichkeit die selben Fragen stellen, wie sie bereits in der Euro-Krise präsent waren. Die sich aus diesen Fragen und neuerlichen Krisenherausforderungen ergebenden Diskussionen, werden sich dabei sehr wahrscheinlich und notwendigerweise erneut in der Auseinandersetzung um eine genuin-europäische Fiskalunion mit überfälligem Transfermechanismus verdichten, die man mit Brunkhorst (2012, 91) als Voraussetzung einer »wirklichen« europäischen Demokratie verstehen kann. Da im Kontext der Corona-Pandemie, deren ökonomische und soziale Folgen auch im Zusammenhang mit dem wirkmächtigen neoliberalen Austeritätsdogma der letzten Dekade zu diskutieren sind, die EU auch in einen ökonomischen Krisenzustand zurückgeworfen ist, dessen endgültiges Ausmaß überhaupt noch nicht überblickt werden kann, wird dieses Thema schneller wieder auf der politischen Agenda stehen als von den neoliberalen Vordenker*innen der Politik zur Bewältigung der Euro-Krise angenommen und erhofft. Bereits in ihrem Frühjahrsgutachten 2020 ging die Kommission von einem Wirtschaftseinbruch von $-7,4 \%$ des BIP (Eurozone: $-7,7 \%$ ) aus und korrigierte ihre Prognose im Juli auf -8,3\% (EU-27) beziehungsweise $-8,7 \%$ des BIP (Eurozone) (vgl. KOM 2020h, 38). Einmal mehr verstellt allerdings der Blick auf die kumulierten Daten die regional sehr unterschiedlich ausgeprägte Krisenwirkung. So divergiert der Wirtschaftsabschwung in der Eurozone zwischen einer Staatengruppe, deren Wirtschaft in 2020 voraussichtlich um etwa 6 bis 7 Prozentpunkte schrumpfen wird (Malta, Luxemburg, Deutschland, Finnland, Niederlande) und einer Gruppe der am stärksten betroffenen Staaten, denen ein Wirtschaftseinbruch über der Schwelle von $10 \%$ prognostiziert wird. Mit Spanien (-10,9\%) und Italien (-11,2\%) gehören zwei Mitgliedstaaten $\mathrm{zu}$ dieser dreier-Staatengruppen (Frankreich: -10,6\%) (vgl. ebd.), die bereits von der Euro-Krise massiv betroffen waren und nun erneut in einen Krisen-Sog geraten. Es droht dabei aufgrund der nicht behobenen EWWU-Funktionskrise nicht weniger als die Gefahr einer zweiten Euro-Krise, deren Ausmaß die Krise der Jahre ab 2010 bei weitem übertreffen könnte (vgl. auch Schneider \& Syrovatka 2020).

Beide zuvor dargestellten Herausforderungen führen letztlich zum dritten Aspekt, der im Kontext der sich potenziell von der latenten zur manifesten Staatlichkeitskri- 
se wandelnden Konstellation fast schon banal wirkt. Dennoch ist und bleibt am Ende die zentrale Herausforderung, dass zur vollständigen Überwindung der latenten Staatlichkeitskrise nur ein neues hegemoniales Moment beitragen kann, das Auslöser für ein verallgemeinerungsfähiges sich verdichtendes Staatsprojekt in der EU ist. Dieses muss einerseits einen Gegenentwurf auf die beobachtbare diskursive Renaissance der 'nationalen Souveränität ‘ präsentieren, die nicht nur in Ost-Mitteleuropa zugegen ist (s. bspw. Polen, Ungarn oder Tschechien), sondern bis weit in die Gesellschaften der EU-Kernstaaten reicht (Stärkung von Parteien am rechten Rand der Parteiensysteme) und dabei auch auf Seiten linker Akteur*innen, welche die neoliberale EU für unreformierbar halten (vgl. bspw. Fazi 2018), eine gewisse Anschlussfähigkeit besitzt. In dieser Konstellation darf der Gegenentwurf dabei andererseits zugleich nicht in einem reinaffirmativen, unpolitischen EU-Positivismus à la >Pulse of Europeく (vgl. Guérot 2017) verfallen. Diese Herausforderung bleibt letztlich immens, ihr ist aber zwangsläufig zu begegnen, wenn die EU nicht in immer kürzeren Abständen in erneute Existenzkrisen geraten will.

\subsection{Die Corona- als neue Durchsetzungskrise des EU-Staatlichkeitsausbaus?}

Vor dem Hintergrund der geschilderten Herausforderungen und auf Grundlage der tagesaktuellen Geschehnisse im Kontext der Corona-Pandemie, deren Ausmaß während der letzten Korrekturschleifen an dieser Arbeit im Frühjahr 2020 lediglich in Ansätzen $\mathrm{zu}$ erahnen war und heute immer noch nicht in Gänze erfasst werden kann, stellt sich dennoch bereits die Frage, inwiefern die Politik zur Bewältigung der durch die CoronaPandemie ausgelösten Krise letztlich einen Integrations- und Vertiefungsschub bewirkt und die Corona- somit zu einer neuen Durchsetzungskrise des EU-Staatlichkeitsausbaus werden kann oder gar am Ausgangspunkt eines neuen hegemonialen Moments steht. Mit einem ersten vorläufigen und kursorischen Versuch zur Beantwortung dieser Frage möchte ich schließen und zugleich einen Ausblick auf künftig relevante politikwissenschaftliche Analysen geben.

Aufgrund der Erfahrungen aus den vorangegangenen Krisen stand auch zu Beginn der Corona-Pandemie in Europa die begründete Befürchtung im Raum, dass die EUMitgliedstaaten wie bereits in den Jahren 2007 bis 2010 die Krisenbewältigung allein zu schultern hätten; so wie sich die EU 2008 dazu entschied, die Rettungsmaßnahmen für Banken in die Hände der Mitgliedstaaten zu legen, sich 2009 lediglich auf eine Koordinierung der mitgliedstaatlichen Konjunkturprogramme verständigte, ohne ein nennenswertes eigenes Programm zu mobilisieren oder sich in der staatlichen Refinanzierungskrise Griechenlands noch zu Beginn des Jahres 2010 hinter der Chiffre der »mitgliedstaatlichen Eigenverantwortung« versteckte. Unter anderem die Alleingänge bei den pandemiebedingten Grenzschließungen einiger Mitgliedstaaten erhärteten diesen Eindruck (vgl. u.a. Zeit, 16.03.2020). Doch hat die EU offenbar auch aus den Fehlern der Vergangenheit gelernt. So kündigte die Kommission bereits am 20. März 2020 an, dass sie beabsichtige, die allgemeine Ausweichklausel des Stabilitäts- und Wachstumspakts (SWP) zu aktivieren (vgl. KOM 2020a). Die beiden SWP-Verordnungen, die im 
Zuge der Euro-Krise umfassend reformiert wurden (vgl. Kapitel 7.3), ermöglichen es, bei schwerwiegenden konjunkturellen Abschwüngen vom >Anpassungspfad in Richtung auf das mittelfristige Haushaltsziek abzuweichen (vgl. Art. 5, Abs. 1 \& Art. 9, Abs. 1 VO (EG) Nr. 1466/97). Corona-bedingte Mehrausgaben, erhöhte Aufwendungen für Sozialleistungen oder die durch Mitgliedstaaten ankündigten Konjunkturpakete und die hiermit einhergehende Verschlechterung der mitgliedstaatlichen Defizit- und Schuldenpositionen bleiben somit - anders als in Folge der transatlantischen Finanzkrise 2009/10 - kurzfristig ohne direkte Konsequenzen seitens der EUSA. Demgemäß wird bei Abweichung von den SWP-Zielkriterien vorerst kein Verfahren bei einem übermäßigen Defizit (VÜD) ausgelöst, in dessen Folge Euro-Mitgliedstaaten ein sogenanntes Wirtschaftspartnerschaftsprogramm (Two-Pack) vorzulegen hätten, das neben fiskalischen Korrekturmaßnahmen auch weiterführende Strukturreformen zur Verbesserung der Wettbewerbsfähigkeit beinhalten müsste (vgl. Kapitel 7.3). Ein Verfahren, das in dieser Form bis heute noch nicht zur Anwendung kam. Beruhigend wirkte weiterhin, dass die EZB - anders als noch zu Beginn der Euro-Krise - direkt auf den Sekundärmärkten für Staatsschuldentitel intervenierte. Mit dem Pandemic Emergency Purchase Programme (PEPP; Pandemie-Notfallankaufprogramm; Beschluss (EU) 2020/440), das mittlerweile ein Volumen von 1,85 Billionen Euro aufweist, konnte der zwischenzeitlich wieder stärker einsetzende Zinsspread zwischen Staatsanleihen unterschiedlicher Euro-Mitgliedstaaten, der in den Jahren 2010-12 zum Hauptindikator der Euro-Krise avancierte, vorerst begrenzt werden (vgl. Eurostat 2020). ${ }^{1}$

Daneben lancierte die Kommission im März eine Reihe weiterer Maßnahmen zur Bewältigung der Corona-Krise (KOM 2020b), die insbesondere auf einer Mobilisierung nicht verausgabter Mittel aus den EU-Fonds basierte (vgl. VO (EU) 2020/460, VO (EU) 2020/461 \& VO (EU) 2020/558) und durch weitere Programmlinien der Europäischen Investitionsbank (EIB) in Höhe von $200 \mathrm{Mrd}$. Euro ergänzt wurde. Bestandteil des Kommissionsvorschlags war auch das Instrument zur Minderung von Arbeitslosigkeitsrisiken (SURE), das mit 100 Mrd. Euro ausgestattet wurde und den Mitgliedstaaten Darlehen zur Kofinanzierung von Kurzarbeitsgeld zur Verfügung stellen kann (vgl. VO (EU) 2020/672). Hinzu kommt für Euro-Mitgliedstaaten die potenzielle Bereitstellung von Krediten in Höhe von maximal 240 Mrd. Euro aus dem ESM, auf die sich die Eurogruppe (2020a) Anfang April im Grundsatz verständigte und die seit Mitte Mai zur Verfügung stehen (vgl. ESM 2020). Zusammen kommt dieses erste Anti-CoronaMaßnahmenpaket des Jahres 2020 auf einen zusätzlichen fiskalischen Impuls seitens der EU von maximal $540 \mathrm{Mrd}$. Euro, wobei fraglich ist, ob insbesondere die Mittel aus dem sogenannten »ESM-Pandemic Crisis Support« überhaupt von einzelnen Mitgliedstaaten abgerufen werden. $\mathrm{Zu}$ schwer wiegen hier - trotz verminderter Anforderungen an kreditnehmende Mitgliedstaaten ${ }^{2}$ - die Erfahrungen der Euro-Krise, bei denen 
die Kreditnehmenden durch die Troika, die Memoranden und letztlich die dahinterstehenden Staatsapparate der EU und der Gläubigerstaaten des europäischen Nordens zu teilsouveränen Befehlsempfängern degradiert wurden (vgl. Kapitel 7.2). Auch wenn die Mittel aus dem SURE-Programm ebenfalls nur als zurückzuzahlende Darlehen an die Mitgliedstaaten weitergereicht werden, zeigte die erste Vergaberunde dennoch, dass diese durchaus von den Mitgliedstaaten nachgefragt werden. Hierbei floss allein an Italien und Spanien annährend die Hälfte der insgesamt zur Verfügung stehenden Mittel (vgl. KOM 2020c). Corona-Bonds, also die gemeinsame Ausgabe von Schuldtiteln der Mitgliedstaaten oder der EU im Gesamten zur allgemeinen Refinanzierung der gestiegenen pandemiebedingten Ausgaben und zusätzlicher Konjunkturimpulse der Mitgliedstaaten, wie sie insbesondere vom stark betroffenen Italien gefordert wurden (vgl. Süddeutsche Zeitung, 19.04.2020), fanden letztlich aber keinen Eingang in das erste EU-Maßnahmenpaket. Nicht zuletzt aufgrund ihres überschaubaren realen fiskalischen Impulses zur Krisenüberwindung lassen sich die kreditbasierten Maßnahmen des ersten Maßnahmenpaktes - insbesondere die angebotenen ESM-Kredite - daher alles in allem als symbolisch qualifizieren. Feigl \& Zotter $(2020,5)$ bringen dies auf den Punkt:

»Das beschlossene Krisenpaket ist [...] insgesamt zu beschränkt im Volumen, zu eng definiert im Verwendungszweck und zu defensiv orientiert, also nur zur Abfederung von eintretenden oder eingetretenen Krisenschäden. Damit ist es nicht geeignet für die große Herausforderung des Abbaus der Arbeitslosigkeit, der Konvergenz der Mitgliedstaaten und der Reduktion der Treibhausgase.«(Feigl \& Zotter 2020, 5)

Auch im zweiten Maßnahmenpaket zur Bekämpfung der Corona-Krise, das die Kommission im Mai 2020 vorstellte, finden sich abermals keine klassischen Euro- oder Corona-Bonds zur Unterstützung der mitgliedstaatlichen Fiskalpolitiken, wie sie zu Hochzeiten der Euro-Krise unter anderem vom Europäischen Parlament gefordert wurden (vgl. Kapitel $7 \&$ 8). Allerdings ist mit dem sogenannten Aufbauplan, der in den Mehrjährigen Finanzrahmen 2021 bis 2027 eingepasst ist, eine in der vorgeschlagenen Höhe nie zuvor erreichte Schuldenaufnahme durch die EU und die Weiterreichung eines Teils der kreditfinanzierten Mittel als nicht rückzuzahlende Zuschüsse an die Mitgliedstaaten vorgesehen (vgl. Art. 5, Abs. 1 Beschluss (EU, Euratom) 2020/2053). Dies kommt in Teilen einer Abkehr der bislang praktizierten Krisenbewältigungsstrategie aus der Hochzeit der Euro-Krise nahe, die beginnend mit den Reorientierungen in der Phase des inkrementellen Staatlichkeitsausbaus und der Diskussionen über fiskalpolitische Komponenten für die Eurozone in der stagnierenden Ausbauphase in den EUSA und hier insbesondere der Kommission vorbereitet wurde. Das sogenannte Aufbauinstrument (VO (EU) 2020/2094), das auch als »Next Generation EU« (NGEU) oder »EU Recovery Instrument « (EURI) bezeichnet wird, über das durch die Ausgabe von EU-Anleihen die zusätzlichen Finanzmittel zur Bekämpfung der Krisenfolgen am Kapitalmarkt mobilisiert werden (vgl. Art. 2 VO (EU) 2020/2094 i.V. m. Art. 5 Beschluss (EU, Euratom) 2020/2053), soll auch nach den Beratungen der Staats- und Regierungschefs im Europäischen Rat, wie von der Kommission vorgeschlagenen, insgesamt ein Volumen von 750 Mrd. Euro umfassen (vgl. ER 2020, Rn. A14; Beschluss (EU, Euratom) 
2020/2053). ${ }^{3}$ Die sogenannte Aufbau- und Resilienzfazilität (VO (EU) 2021/241) stellt das Herzstück des Aufbauplans dar und umfasst 672,5 Mrd. Euro (vgl. ER 2020, Rn. A14). Neben der finanziellen Ausstattung dieser neuen Fazilität sollen nach dem Vorschlag der Kommission mit den weiteren EURI-Mitteln entweder bestehende Programmlinien der EU-Fonds aufgestockt oder diese um neue Programmlinien ergänzt werden, welche beispielsweise sektorspezifische Förderungen oder direkte Hilfsfonds für Unternehmen umfassen könnten (vgl. KOM 2020e \& 2020f). Der Europäische Rat (2020) hat im Zuge der Beratungen um den MFR die Mittel für diese Programme allerdings an vielen Stellen zugunsten einer erhöhten Finanzausstattung der Aufbau- und Resilienzfazilität gekürzt oder gar ganz gestrichen, was nicht zuletzt auch auf Kritik des Europäischen Parlaments (2020, Rn. 19) stieß.

Wurde mit den Maßnahmen des ersten und den mittlerweile auch beschlossenen Maßnahmen des zweiten Krisenbewältigungspakets zwar aktuell eine zweite Euro- und die latent schwelende EU-Staatlichkeitskrise - vorerst ein weiteres Mal - vertagt, ist es nun geboten, die sekundärrechtliche Verankerung des Aufbauplans wie auch des neuen Mehrjährigen Finanzrahmens insgesamt in einer eigenständigen Staatlichkeitsanalyse $\mathrm{zu}$ untersuchen und die genauen Wirkungen der einzelnen Maßnahmen auf die EUStaatlichkeit im Detail zu analysieren. Dabei ist auch zu klären, inwiefern die einzelnen Maßnahmen in eine Kontinuitätslinie des EU-Staatlichkeitsausbaus während der Euro-Krise eingeordnet werden können oder ob sie gar einen Bruch mit diesem markieren. Eine solche weiterführende Staatlichkeitsanalyse kann an dieser Stelle zwar nicht geleistet werden, drei vorläufige Einschätzungen hierzu seien aber vor dem Hintergrund des in dieser Arbeit beschriebenen Transformations- und Ausbauprozesses der EU-Staatlichkeit in der Euro-Krise gestattet:

Aufbau einer genUin-europäIschen Fiskalunion? - Mit dem EURI wird wegen der avisierten gemeinschaftlichen Schuldenaufnahme der EU und der Weitergabe der durch EU-Anleihen finanzierten Mittel an die Mitgliedstaaten nicht nur aufgrund der Höhe des geplanten Anleihevolumens ${ }^{4}$ eine neue Stufe auf dem Weg zu einer genuinen europäischen Fiskalunion beschritten. Egal ob den Mitgliedstaaten EURI-Mittel als Zuschuss oder Darlehen gewährt werden, ergeben sich hierbei insgesamt positive Zinsvorteile für viele Mitgliedstaaten, wie bereits die bisherigen Emissionen der EU-Anleihen zur Refinanzierung des SURE-Programms zeigten. So wiesen die ersten zehnjährigen SURE-Bonds im Oktober 2020 eine negative Rendite von 0,238 \% auf (vgl. ARD-Börse, 22.10.2020) und bieten somit auch im Vergleich zum >Goldstandard der Eurozone, den deutschen Bundesanleihen (Rendite zehnjähriger Bundesanleihen am

Einen Eilantrag gegen das deutsche Ratifizierungsgesetz zum EU-Eigenmittelbeschluss und dem in ihm enthaltenenen Aufbauinstrument lehnte des Bundesverfassungnsgericht (2021) am 15.04.2021 ab.

4 Im Rahmen des Europäischen Finanzstabilitätsmechanismus (EFSM), der Fazilität zur Stützung der Zahlungsbilanz (VO (EG) Nr. 332/2002) sowie sogenannter Makrofinanzhilfen an Drittstaaten gibt die EU bereits eigene Anleihen heraus. Aktuell belaufen sich die Verbindlichkeiten aus den zuvor genannten Programmen auf ca. 50 Mrd. € (vgl. KOM 2020k, 14) und liegen somit deutlich unter der avisierten Kreditaufnahme von 100 Mrd. € für SURE sowie der weiteren 750 Mrd. $€$ für NGEU. 
29.10.2020: -0,63\%; vgl. Bloomberg, 29.10.2020), durchaus positive Refinanzierungskonditionen. Nicht nur vor diesem Hintergrund, sondern auch aufgrund des durch die errechneten Maximalzuweisungen je Mitgliedstaat aus der mit dem EURI finanzierten Aufbau- und Resilienzfazilität wird ein qualitativer Schritt zum Aufbau einer genuinen Fiskalunion unternommen. So entsteht mit der Fazilität zugleich ein Umverteilungsbeziehungsweise Transfereffekt, der sich aus der ihr zugrundeliegenden Berechnungsformel ergibt. Auf Grundlage dieser werden 70\% der nicht rückzahlbaren finanziellen Unterstützung ausgehend von »der Bevölkerung, des umgekehrten BIP pro Kopf und der relativen Arbeitslosenquote des jeweiligen Mitgliedstaats« (Art. 11, Abs. 1a VO (EU) 2021/241) auf die einzelnen Mitgliedstaaten verteilt. Zusätzlich sollen für die verbleibenden 30\% der nicht rückzahlbaren finanziellen Unterstützung an die Mitgliedstaaten die »Veränderung des realen BIP im Jahr 2020« sowie die kumulierte »Veränderung des realen BIP im Zeitraum 2020-2021“ (Art. 11, Abs. Ib VO (EU) 2021/241) mit in die Berechnung einbezogen werden. Ausgehend von dieser Berechnungsgrundlage werden somit insbesondere die am stärksten von der Corona-Pandemie betroffenen Mitgliedstaaten profitieren. Alleine mehr als die Hälfte der Mittel werden zusammengenommen an Spanien (20,57\%), Italien (20,39\%) und Frankreich (11,65\%) fließen und die ehemaligen fünf Programmländer der Euro-Krise werden insgesamt mit fast einem Drittel der Mittel (30,54\%) bedacht (vgl. Anhang IV VO (EU) 2021/241). Die Fazilität etabliert in diesem Sinne einen Transfermechanismus, der einen konvergenzstiftenden Beitrag abseits der bestehenden EU-Fonds leisten kann. Allerdings - dies ist ein Ergebnis der Europäischen Ratstagung (vgl. ER 2020) - wird dieser Transfermechanismus durch die Erhöhung des Darlehensanteils der EURI-Mittel zugleich wieder abgeschwächt. Hatte die Kommission im Mai 2020 noch vorgeschlagen, dass von den 750 Mrd. Euro 500 Mrd. Euro als sogenannte Ausgaben (hierunter fallen auch Zuschüsse an die Mitgliedstaaten) und lediglich 250 Mrd. Euro als rückzuzahlende Darlehen vorgesehen werden, einigten sich die Staats- und Regierungschefs - insbesondere auf Druck der selbsternannten >sparsamen Vier ( vgl. >Frugal Four < 2020) - letztlich auf ein Verhältnis von 390 Mrd. Euro (Ausgaben) zu 360 Mrd. Euro (Darlehen) (vgl. ER 2020, Rn. A14).

Auch wenn die EURI-Aktivitäten unter den zuvor genannten Gesichtspunkten einen Fortschritt auf dem Weg zum Aufbau einer Fiskalunion bedeuten, bleibt zugleich zu konstatieren, dass sowohl das EURI als auch die Aufbau- und Resilienzfazlität, inklusive der gemeinsamen Kreditaufnahme, lediglich befristete und außerordentliche Maßnahmen zur Krisenbewältigung darstellen. Ein Automatismus für eine dauerhafte fiskalische Flankierung auf EU-Ebene mit dem Ziel der Konvergenzstiftung abseits der bestehenden EU-Fonds, wie sie beispielsweise im Schlagwort des Eurozonenbudgets oder einer dauerhaften gemeinsamen Refinanzierungspolitik der Euro-Staaten (EuroBonds) Ausdruck fände, ist deshalb aus den Aktivitäten nicht zu schlussfolgern. Vielmehr zeigt sich stattdessen, dass durch die aktuellen Krisenbewältigungsaktivitäten die seit 2018 diskutierten und eigentlich mit dem MFR 2021-27 angestrebten fiskalpolitischen Instrumente wie das Reformhilfeprogramm und das BICC (vgl. Kapitel 8.3) zurückgestellt und vorerst nicht etabliert wurden (vgl. KOM 2020d, 2). Da zudem auf Druck des Europäischen Rates (2020, Rn. A15) vorgesehen wurde, dass alle Zahlungen 
aus dem EURI bis spätestens zum 31.12.2026 abgewickelt sein müssen und die Mittelbindung bereits zu einem Großteil in der ersten Hälfte des MFR zu erfolgen habe (vgl. Art. 3 VO (EU) 2020/2094), ${ }^{6}$ bleibt weiterhin fraglich, ob NGEU am Ende tatsächlich zu einem dauerhaften Einstieg in eine genuine Fiskalunion führen oder ob es sich hierbei lediglich um ein kurzes, krisenbedingtes fiskalpolitisches Intermezzo handeln wird.

WETTBEWERBSFÄHIGKEITSDOKTRIN \& WIRTSCHAFTSPOLITISCHES REGIEREN - Bereits in der Phase des inkrementellen Staatlichkeitsausbaus rückte die Thematik der Wettbewerbsfähigkeit immer stärker ins Zentrum der politischen Aktivitäten der EUSA (vgl. Kapitel 8). Mit dem Aufbau des SRSS und der Auflage des Programms zur Unterstützung von Strukturreformen (vgl. Kapitel 8.4) wurde ein Staatlichkeitsrahmen etabliert, der in der Phase des stagnierenden Staatlichkeitsausbaus in die Bemühungen zum Aufbau einer Fiskalunion eingebettet wurde und insofern bereits eine Kompromisslinie andeutete, in der sich eine genuine EU-Fiskalpolitik der Wettbewerbsfähigkeitsdoktrin unterordnet (vgl. Kapitel 9). Das EURI und die Aufbau- und Resilienzfazilität fügen sich schließlich in diese langen Linien ein. Mit der Fazilität sollen Maßnahmen unterstützt werden, die die Resilienz der EU wie ihrer Mitgliedstaaten stärken und zu einer wirtschaftlichen Erholung beitragen. Dabei definiert die Fazilitätsverordnung Politikbereiche, an denen sich die einzelnen Maßnahmen orientieren sollten:

»Diese Politikbereiche sind in folgende sechs Säulen [...] aufgegliedert: ökologischer Wandel; digitaler Wandel; intelligentes, nachhaltiges und integratives Wachstum, darunter wirtschaftlicher Zusammenhalt, Arbeitsplätze, Produktivität, Wettbewerbsfähigkeit, Forschung, Entwicklung und Innovation sowie ein gut funktionierender Binnenmarkt mit starken kleinen und mittleren Unternehmen (KMU); sozialer und territorialer Zusammenhalt; Gesundheit und wirtschaftliche, soziale und institutionelle Resilienz, um unter anderem die Krisenvorsorge und Krisenreaktionsfähigkeit zu erhöhen; und Maßnahmen für die nächste Ceneration, Kinder und Jugendliche, wie zum Beispiel Bildung und Kompetenzen.«(Erw. 10 VO (EU) 2021/241; vgl. Art. 3 VO (EU) 2021/241)

Die Darlehen und Zuschüsse aus der Fazilität werden auf Grundlage sogenannter "Aufbau- und Resilienzpläne« (Art. 18 VO (EU) 2021/241) gewährt, in denen »die Reform- und Investitionsagenda des betreffenden Mitgliedstaats festgelegt [wird].« (Art. 17, Abs. I VO (EU) 2021/241) Weiterhin wird an sie die Anforderung gestellt, dass diese mit den im Europäischen Semester verabschiedeten länderspezifischen Empfehlungen und allgemeinen Prioritäten sowie für Euro-Mitgliedstaaten mit den Prioritäten der Empfehlungen zur Wirtschaftspolitik des Euro-Währungsgebiets im Einklang stehen (vgl. Art. 17, Abs. 3 VO (EU) 221/241). Die vorzulegenden Pläne werden anschließend durch die Kommission geprüft und im Hinblick auf ihre »Relevanz, Wirksamkeit, Effizienz und Kohärenz [bewertet]« (Art. 19, Abs. 3 VO (EU) 2021/241),

6 Für 60\% der nicht zurückzuzahlenden Unterstützung müssen bis zum 31.12.2022 rechtliche Verpflichtungen eingegangen werden, für die weiteren 40\% gilt als Stichtag der 31.12.2023 (vgl. Art. 3, Abs. 4 VO (EU) 2020/2094). Beschlüsse über die Gewährung von Darlehen müssen spätestens bis zum 31.12.2023 getätigt werden (vgl. Art. 3, Abs. 5 VO (EU) 2020/2094). 
bevor sie schließlich vom Rat gebilligt werden müssen (vgl. Art. 19 VO (EU) 2021/241). Ein ähnliches Verfahren war auch für das Reformhilfeprogramm und das BICC vorgesehen und wurde in reduzierter Form bereits im Rahmen des 2017er Programms zur Unterstützung von Strukturreformen praktiziert, für dessen Abwicklung die Kommission allerdings noch alleine verantwortlich gewesen war (vgl. VO (EU) 2017/825). Das Genehmigungs- und Beschlussverfahren der Aufbau- und Resilienzpläne erinnert in diesem Sinne auch nochmals an die mit dem von Angela Merkel mehrfach vorgeschlagenen Pakt für Wettbewerbsfähigkeit geforderten svertraglichen Vereinbarungen` zur Erhöhung der Wettbewerbsfähigkeit der Mitgliedstaaten.

Dass die Fazilität dabei auf die in der Euro-Krise begründeten Traditionen des wirtschaftspolitischen Regierens im neuen Normalzustand rekurriert, zeigt auch die sie flankierende Verordnung (EU) 2021/240 zur Schaffung eines Instruments für technische Unterstützung, deren Zielsetzung darin bestehe, die nationalen Behörden beim Ausbau ihrer Kapazität für die Ausarbeitung, Entwicklung und Durchführung von Reformen sowie bei der Ausarbeitung, Änderung, Umsetzung und Überarbeitung der Aufbauund Resilienzpläne zu sekundieren (vgl. Art. 4 VO (EU) 2021/240). Diese zu unterstützenden »Anstrengungen zur Umsetzung von Reformen« in den Mitgliedstaaten seien leltztlich erforderlich,

»um Investitionen zu mobilisieren, die Wettbewerbsfähigkeit zu steigern und eine nachhaltige wirtschaftliche und soziale Konvergenz, Resilienz und Erholung zu erreichen. Dies ist außerdem erforderlich, um Mitgliedstaaten bei ihren Bemühungen um die Stärkung ihrer institutionellen und administrativen Kapazitäten [...] zu unterstützen, eine sozial inklusiven, grünen und digitalen Wandel zu ermöglichen, die im Rahmen der länderspezifischen Empfehlungen ermittelten Herausforderungen wirksam anzugehen und das Unionsrecht durchzuführen.«(Art. 3 VO [EU] 2021/240)

Das mit 864 Mio. Euro ausgestattete Instrument (vgl. Art. 6 VO (EU) 2021/240) wird innerhalb der Kommissionsstrukturen weiterhin durch den SRSS, der seit Januar 2020 gar zu einer eigenen Generaldirektion (DG REFORM) aufgewertet wurde (vgl. KOM o.J. g), verwaltet und umfasst wie bereits sein Vorläufer eine ebenfalls breite Palette möglicher förderfähiger Maßnahmen (vgl. Art. 8 VO (EU) 2021/240) in nahezu allen Politikbereichen (vgl. Art. 5 VO (EU) 2021/240). Der bereits in der Phase des inkrementellen Staatlichkeitsausbaus einsetzende Aufbau und sukzessive Ausbau der Staatlichkeitsinfrastrukturen zur Beratung der Mitgliedstaaten bei Strukturreformen und der direkten Mitwirkung bei deren Implementierung seitens der Kommission werden somit weiter forciert und tragen zu einer weiteren Konsolidierung des wirtschaftspolitischen Regierens bei.

AUfTAKT FÜR EIN JAHRZEHNT DER Ultra-AUSTERITÄT? - Mit dem Beschluss zur Aktivierung der allgemeinen Ausweichklausel des SWP besteht zwar vorerst nicht die Gefahr, dass einzelne Mitgliedstaaten aufgrund pandemiebedingter Mehrausgaben in die ausgebauten Interventionsfänge der EUSA geraten (vgl. Kapitel 7.5), wenngleich Vorsicht geboten ist: Aufgeschoben ist nicht aufgehoben. Generell gelten die kriterialen Normen des SWP weiterhin. Im Mai 2020 hat die Kommission deshalb folgerichtig für alle Mitgliedstaaten außer Rumänien, für das bereits im April 2020 ein VÜD eröffnet wurde, 
und Bulgarien formal festgestellt, dass das Defizitkriterium jeweils nicht eingehalten werde (vgl. KOM o.J. b). Im laufenden Semesterzyklus 2021 ging die Kommission gar bereits wieder soweit, Belgien, Frankreich, Griechenland, Italien, Portugal und Spanien explizit aufzufordern, dass sie ihre hohen Schuldenstände und die Herausforderungen einer nachhaltigen Haushaltspolitik stärker bei der Ergreifung fiskalischer Maßnahmen zur Krisenbewältigung zu berücksichtigen hätten (vgl. KOM 2020i, 2). Bleiben diese Feststellungen und Aufforderungen aufgrund der aktivierten SWP-Ausweichklausel zwar vorerst ohne direkte Folgen, steht vor dem Hintergrund der fiskalischen und ökonomischen (Langfrist-)Folgen der Corona-Pandemie zu befürchten, dass nach dem Ende der akuten Krisensituation auf die Europäische Union ein Jahrzehnt der UltraAusterität zurollt, das die Erfahrungen der Euro-Krise in den Schatten stellen könnte. Fritsche \& Harms $(2020,270)$ haben exemplarisch für Deutschland hervorgehoben, dass

»[d]er Angebotsschock und damit der Einbruch der Produktion [...] in jedem Fall so lange Bestand haben [wird], wie die Ausbreitung des Virus nicht gestoppt ist und die Maßnahmen zur Eindämmung andauern. Cleichzeitig gibt es derzeit keinen Crund anzunehmen, dass die einzelnen Nachfragekomponenten selbst im Falle der idealtypischen, schnellen Beendigung der Krise sofort und vollständig auf ihr altes Niveau ansteigen.«

Mit zunehmender Krisendauer bleibt deshalb auch ihre Schlussfolgerung richtig, dass "spätestens nach Ende der akuten Krise eine fiskalpolitische Expansion über die automatischen Stabilisatoren hinaus angezeigt [ist].« (Ebd.) Mehr als fraglich ist allerdings, ob NGEU in diesem Sinne einen ausreichenden fiskalischen Beitrag leisten kann, vor allem wenn die Mitgliedstaaten nach dem Ende der akuten pandemischen Krisensituation wieder an die SWP-Kriterien und Verfahren gebunden sein sollten. Dabei trifft die Corona-Krise als symmetrische Krise insgesamt auf

»höchst asymmetrische Kapazitäten für ein gesundheits-, wirtschafts- und finanzpolitisches Cegensteuern. Dies kann die Funktionsfähigkeit des europäischen Binnenmarkts ernsthaft beschädigen und im Extremfall die gesamte Europäische Union vor eine Zerreißprobe stellen, wenn lediglich einige finanzstarke Mitgliedstaaten große Rettungsschirme [...] aufspannen können, während andere Länder [...] nicht im selben Ausmaß dazu in der Lage sind «,

so Südekum $(2020,398)$. Insofern stellt sich mit aller Dringlichkeit die Frage, ob die EU nach dem Ende der Corona-Krise tatsächlich wieder auf einen austeritären Pfad einschwenken kann oder ob durch die Krise letztlich auch tiefgreifende fiskalpolitische Reflexionen einsetzen werden, die Staatlichkeitspraxen anleiten, die über die im SWP enthaltene >Flexibilität< (vgl. Kapitel 8.3) hinausgehen.

Die drei kursorischen Einschätzungen verdeutlichen, dass die Politik zur Bewältigung der Corona-Krise durchaus in eine Kontinuitätslinie des EU-Staatlichkeitsausbaus in der Euro-Krise und ihrer weiterführenden Diskussionen eingeordnet werden kann. Insofern stellt die Krise zugleich einen erneuten Durchsetzungsschub dar, wie im Kontext des wirtschaftspolitischen Regierens mit dem Ausbau der Staatlichkeitsinfrastrukturen oder beim Aufbau einer genuinen Fiskalunion deutlich wird. Insbesondere bei 
dieser ist allerdings fraglich, wie nachhaltig der eingeschlagene Weg sein wird. Zurzeit sind alle fiskalpolitischen Maßnahmen vor dem Hintergrund des akuten Handlungsdrucks in der aktuellen Krisensituation und insofern als zeitlich befristet anzusehen. Die grundlegenden Normen der Fiskalverfassung jedenfalls wurden bisher nicht angetastet, auch wenn die durch das EURI ausgedrückte Krisenbewältigungsstrategie sich von jener der Euro-Krise durchaus qualitativ unterscheidet. Werden allerdings keine dauerhaften Lösungen in Bezug auf die Fiskalunion mit dauerhaftem Transfermechanismus und einer gemeinsamen Politik zur staatlichen Refinanzierung im EuroRaum gefunden sowie eine Neuausrichtung der vertragsrechtlich-festgeschriebenen srichtigen ₹iskalpolitik (vgl. Kapitel 7.5) vorgenommen, wird die EU in einen neuerlichen fiskalischen Ausnahmezustand zurückgeworfen, der schlussendlich in einem Jahrzehnt der Ultra-Austerität münden könnte. Ob die Corona-Krise insofern neben einer neuerlichen Durchsetzungskrise des EU-Staatlichkeitsausbaus auch Ausgangspunkt für ein neues hegemoniales Moment sein wird, bleibt fraglich und wird nach dem Ende der akuten Krisensituation auch vor dem Hintergrund der latent schwelenden EU-Staatlichkeitskrise (vgl. Kapitel 10.2) erneut zu bewerten sein. 


\section{Abkürzungsverzeichnis}

ABl. Amtsblatt der Europäischen Union

ABS Asset-backed securities

AEUV Vertrag über die Arbeitsweise der Europäischen Union

AfD Alternative für Deutschland

ALDE Fraktion der Allianz der Liberalen und Demokraten für Europa (Europäisches Parlament)

AMUE Association for Monetary Union of Europe

ANEL Anexartiti Ellines (Unabhängige Griechen)

BICC Budgetary Instrument for Convergence and Competitiveness

BIP Bruttoinlandsprodukt

BMF Bundesministerium für Finanzen

BVerfG Bundesverfassungsgericht, Deutschland

CDA Christlich-Demokratische Arbeitnehmerschaft (CDU-Vereinigung)

CETA Comprehensive Economic and Trade Agreement (EU-Canada)

CSR Country-specific recommendations

Delvo Delegierte Verordnung

DGB Deutscher Gewerkschaftsbund

DIMAR Dimokratiki Aristera (Demokratische Linke) Griechenland

EAPP Expanded Asset-Purchase Programme

EBA European Banking Authority

ECB European Central Bank

ECOFIN Rat der Europäischen Union für Wirtschaft und Finanzen

ECR Fraktion der Europäischen Konservativen und Reformer (Europäisches Parlament)

EEA Einheitliche Europäische Akte (1986)

EFA Europäischer Fiskalausschuss (Europäische Kommission)

EFD Europa der Freiheit und der Demokratie (Fraktion im Europäischen Parlament)

EFSF Europäische Finanzstabilisierungsfazilität

EFSF-V EFSF Rahmenvertrag

EFSM Europäischer Finanzstabilisierungsmechanismus

EG Europäische Gemeinschaft(en)

EGMR Europäischer Gerichtshof für Menschenrechte 
EIB Europäische Investitionsbank

EIOPA European Insurance and Occupational Pensions Authority

EIP Excessive Imbalance Procedure

EISF Europäische Investitionsstabilisierungsfunktion

ELA Emergency Liquidity Assistance

EMU European Monetary Union

EMWF Europäische" $r$ Wirtschafts- und Finanzminister*in

EP Europäisches Parlament

EPAs Economic Partnership Agreements (EU-Africa)

EPSC European Political Strategy Center (Europäische Kommission)

ER Europäischer Rat

ERT European Roundtable of Industrialists

ESFS European System of Financial Supervision

ESM Europäischer Stabilitätsmechanismus

ESMA European Securities and Markets Authority

ESM-V Vertrag über den Europäischen Stabilitätsmechanismus

ESRB European Systemic Risk Board

ESSR Europäische Säule sozialer Rechte

ESZB Europäisches System der Zentralbanken

ETUI European Trade Union Institute

EU Europäische Union

EuGH Europäischer Gerichtshof

EuRH Europäischer Rechnungshof

EURI EU Recovery Instrument

Europol Europäisches Polizeiamt (EU-Agentur)

EUSA EU-Staatsapparat(e)

EUV Vertrag über die Europäische Union

EWF Europäischer Währungsfonds

EWG Europäische Wirtschaftsgemeinschaft

EWS Europäisches Währungssystem

EWU Europäische Währungsunion

EWWU Europäische Wirtschafts- und Währungsunion

EZB Europäische Zentralbank

FAZ Frankfurter Allgemeine Zeitung

FRONTEX Europäische Agentur für die Grenz- und Küstenwache (EU-Agentur)

G20 Gruppe der zwanzig wichtigsten Industrie- und Schwellenländer

GDP Gross domestic product

GUE/NGL Konföderale Fraktion der Vereinten Europäischen Linken/Nordische Grüne Linke (EP)

HMPA historisch-materialistische Politikanalyse

IPÖ Internationale Politische Ökonomie

IWF Internationaler Währungsfonds

KMU Kleine und mittlere Unternehmen

KOM Europäische Kommission

LGBTIQ* Lesbian, Gay, Bisexual, Transgender, Intersexual, Queer* 
LOLR Lender of Last Resort

LTRO Longer-Term-Refinancing-Operations

MBS Mortgage-backed securities

MEW Marx-Engels-Werke

MFR Mehrjähriger Finanzrahmen der Europäischen Union

MIP Macroeconomic Imbalance Procedure

MLG Multi-Level-Governance

MoU Memorandum of Understanding

MTO Medium Term Objective

ND Nea Dimokratia (Neue Demokratie), Griechenland

NGEU Next Generation EU

NGO Non-Governmental Organization

NRP Nationales Reformprogramm

OECD Organisation für wirtschaftliche Zusammenarbeit und Entwicklung

OFC Offshore Financial Centre

OMT Outright Monetary Transaction Programme

PASOK Panellinio Sosialistiko Kinima (Panhellenische Sozialistische Bewegung), Griechenland

PESCO Permanent Structured Cooperation

PPE Fraktion der Europäischen Volkspartei (Europäisches Parlament)

PSPP Public Sector Purchase Programme

RL Richtlinie

RQMV reversed qualified majority voting

S\&D Fraktion der Progressiven Allianz der Sozialdemokraten im Europäischen Parlament

SKP Stabilitäts- und Konvergenzprogramm

SKS-V Vertrag über Stabilität, Koordinierung und Steuerung

SMP Securities Markets Programme

SRF Single Resolution Fund

SRM Single Resolution Mechanism

SRSS Structural Reform Support Service (Europäische Kommission)

SSM Single Supervisory Mechanism

SWP Stabilitäts- und Wachstumspakt

SYRIZA Synaspismos Rizospastikis Aristeras (Koalition der Radikalen Linken), Griechenland

taz Die Tageszeitung

TFEU Treaty of the Functioning of the European Union

TISA Trade in Services Agreement

TNK Transnationale Konzerne

TTIP Trasatlantic Trade and Investment Partnership (EU-USA)

Vo Verordnung

VÜD Verfahren bei einem übermäßigen Defizit

WFA Wirtschafts- und Finanzausschuss (Hilfsorgan des Rates der Europäischen Union)

WKM-II Wechselkursmechanismus II

WWU Wirtschafts- und Währungsunion 



\section{Abbildungs- und Tabellenverzeichnis}

\section{Abbildungen}

Seite 52 | Abbildung 1: Potenzielle Krisenkaskade

Seite 54 Abbildung 2: Idealtypische Abfolge der historisch-materialistischen Staatlichkeitsanalyse

Seite 96 | Abbildung 3: Renditen ausgewählter Staatsanleihen mit 10-jähriger Laufzeit (2008-2018)

\section{Tabellen}

Seite 56 | Tabelle 1: Gattungen von EU Dokumenten

Seite 57 Tabelle 2: Sozialwissenschaftliche Leitlinien hermeneutischer Interpretation

Seite 68 Tabelle 3: Politische Projekte der neoliberalen Restrukturierung nach Bieling \& Steinhilber

Seite 81 Tabelle 4: Fünf europäische Hegemonieprojekte

Seite 114 | Tabelle 5: Integrierte wirtschafts- und beschäftigungspolitische Leitlinien 2010

Seite 123 |Tabelle 6: Übersicht zentraler leitbildpolitischer Dokumente aus dem Jahr 2010

Seite 126 | Tabelle 7: „Dreisäulenkonzept« der Europäischen Kommission

Seite 130 | Tabelle 8: Gesetzgebungsakte des Six-Packs

Seite 132 | Tabelle 9: Zentrale Dokumente zur Europe-2020-Strategie

Seite 133 Tabelle 10: Dokumente zum Europäischen Stabilitätsmechanismus

Seite 133 | Tabelle 11: Gesetzgebungsakte zur Etablierung der EFSF

Seite 136 | Tabelle 12: Parallele Krisenbewältigungsmaßnahmen des Europäischen Rates

Seite 136 | Tabelle 13: Gesetzgebungsakte des Two-Packs

Seite 137 | Tabelle 14: Unkonventionelle Krisenbewältigungsmaßnahmen der EZB im Rahmen der Euro-Krise

Seite 138 | Tabelle 15: Gesetzgebungsakte zur Umsetzung von >Basel III

Seite 139 | Tabelle 16: Gesetzgebungsakte zur Bankenunion

Seite 146 | Tabelle 17: Hilfskredite (2010-18): Höhe, Empfänger \& Gläubiger 
Seite 170 | Tabelle 18: Prüfungsergebnisse der Haushaltsplanentwürfe der Euroländer (Haushaltsjahre 2015-19)

Seite 178 | Tabelle 19: Indikatoren und Schwellenwerte des Scoreboards

Seite 181 | Tabelle 20: Länderspezifische Empfehlungen (CSR) im Rahmen der Europäischen Semester (2012-18)

Seite 182 | Tabelle 21: Umsetzung der länderspezifischen Empfehlungen, basierend auf dem MIP (2012-17)

Seite 182 | Tabelle 22: Durchschnittlicher Implementationsscore, nach Ländern (2013-17)

Seite 184 | Tabelle 23: Anzahl sozial- und arbeitsmarktpolitischer CSRs in den Europäischen Semestern (2012-19)

Seite 220 | Tabelle 24: EU-Interventionsstaatlichkeit im Herrschaftsmodus der (Selbst-) Disziplinierung

Seite 230 | Tabelle 25: Abstimmungskoalitionen im Rahmen der Six-Pack-Gesetzgebung

Seite 242 | Tabelle 26: Reformvorschläge der Barroso-Kommission 2013

Seite 250 | Tabelle 27: Kommissionsmaßnahmen zur Intensivierung der Investitionstätigkeit (2014/15)

Seite 252 | Tabelle 28: Szenarien des Weißbuchs und ihre potenzielle Wirkung auf die EWWU

Seite 284 | Tabelle 29: Argumente für die EWWU-Vertiefung laut Kommissionsmitteilung

Seite 286 | Tabelle 30: Abstimmungsergebnisse der Februar-Initiativen des Europäischen Parlaments

Seite 290 | Tabelle 31: Viertes Economic-Governance-Paket (Nikolauspaket) 2017

Seite 294 | Tabelle 32: Fiskal-Two-Pack 2018

Seite 306 | Tabelle 33: EU-Staatlichkeit zwischen Ausbau und Stagnation

Seite 394 | Tabelle 34: Übersicht der Verfahren bei einem übermäßigen Defizit (VÜD) in den Jahren 2009-19

Seite 396 | Tabelle 35: Anzahl und Ergebnisse der eingehenden Überprüfungen im Rahmen des MIPs (2012-19) 


\section{Literatur- und Quellenverzeichnis}

Abbas, Nabila/Förster, Annette \& Richter, Emanuel (2015): Supranationalität und Demokratie. In: Dies. (Hg.): Supranationalität und Demokratie. Die Europäische Union in Zeiten der Krise, Wiesbaden, S. 1-16, https://doi.org/10.1007/978-3-658-05335-2 -1.

Abels, Joscha (2018): Ein Europa der Finanzministerien? Die Eurogruppe im Projekt der austeritätspolitischen Restrukturierung der Eurozone. In: PROKLA, Nr. 3/2018, S. 399-415, https://doi.org/10.32387/prokla.v48i192.905.

Aglietta, Michel (2004): Economic Liberalism and Political Democracy in Europe. In: Puntscher Riekmann, Sonja/Mokre, Monika \& Latzer, Michael (Hg.): The State of Europe. Transformations of Statehood from a European Perspective, Frankfurt a.M., S. 95-114.

Alcidi, Cinzia/Giovannini, Alessandro \& Piedrafita, Sonia (2014): Enhancing the Legitimacy of EMU Governance [Studie hgg. von der Generaldirektion Interne Politikbereiche der Union des Europäischen Parlaments; PE 536.312].

Althusser, Louis (2010): Ideologie und ideologische Staatsapparate. In: Ders.: Gesammelte Schriften, Bd. 5.1, Hamburg, S. 37-102.

Altvater, Elmar (2009): Vom finanzgetriebenen zum staatsgetriebenen Kapitalismus. In: Ders./Bieling, Hans-Jürgen/Demirović, Alex/Flassbeck, Heiner/Goldschmidt, Werner/Payandeh, Mehrdad \& Wöhl, Stefanie: Die Rückkehr des Staates? Nach der Finanzkrise, Hamburg, S. 7-18.

- (1981): Der gar nicht diskrete Charme der neoliberalen Konterrevolution. In: PROKLA, Nr. 44, S. 5-23, https://doi.org/10.32387/prokla.v11i44.1544.

Altvater, Elmer \& Mahnkopf, Birgit (2007): Konkurrenz für das Empire. Die Zukunft der Europäischen Union in der globalisierten Welt, Münster.

Amable, Bruno \& Palombarini, Stefano (2018): Von Mitterrand zu Macron. Über den Kollaps des französischen Parteiensystems, Berlin, https://doi.org/10.1007/s42520019-00158-5.

Andor, László (2018): Ressourcen für mehr Wohlstand in Europa. Ansatzpunkte für ein progressives EU-Budget [Friedrich-Ebert-Stiftung: WISO Diskurs, Nr. 17/2018]. 
Angerer, Jost/Hagelstam, Kajus \& Ciucci, Matteo (2019): Country-specific recommendations: An overview - September 2019 [Briefing hgg. von der Economic Governance Support Unit des Europäischen Parlaments; PE 624.404].

Antpöhler, Carlino (2012): Emergenz der europäischen Wirtschaftsregierung. Das Six Pack als Zeichen supranationaler Leistungsfähigkeit. In: Zeitschrift für ausländisches öffentliches Recht und Völkerrecht, Nr. 72, S. 353-393.

ARD-Börse (22.10.2020): Lohnen sich die Corona-Anleihen?, https://boerse.ard.de/anla geformen/anleihen/lohnen-sich-die-corona-anleihen100.html; 05.02.2021.

Armingeon, Klaus/Guthmann, Kai \& Weisstanner, David (2015): Wie der Euro Europa spaltet. Die Krise der gemeinsamen Währung und die Entfremdung von der Demokratie in der Europäischen Union. In: Politische Vierteljahresschrift, Nr. 3/2015, S. 506-531, https://doi.org/10.5771/0032-3470-2015-3-506.

Babic, Milan (2019): Stabilisierung, Vertiefung und Konsolidierung der Economic Governance: Elitenstrategien in der europäischen Krise. In: Bieling, Hans-Jürgen \& Guntrum, Simon (Hg.): Neue Segel, alter Kurs? Die Eurokrise und ihre Folgen für das europäische Wirtschaftsregieren, Wiesbaden, S. 109-138, https://doi.org/10.100 7/978-3-658-25037-9_5.

Bach, Maurizio (2015): Krisen, Konflikte und Solidarität. Zur gegenwärtigen Lage der Europäischen Union. In: Brömmel, Winfried/König, Helmut \& Sicking, Manfred (Hg.): Europa, wie weiter? Perspektiven eines Projekts in der Krise, Bielefeld, S. 2741, https://doi.org/10.14361/9783839430101-002.

Bader, Pauline/Becker, Florian/Demirović, Alex \& Dück, Julia (2011): Die multiple Krise - Krisendynamiken im neoliberalen Kapitalismus. In: Dies. (Hg.): VielfachKrise. Im finanzmarktdominierten Kapitalismus, Hamburg, S. 11-28.

Baldi, Guido/Fichtner, Ferdinand/Michelsen, Claus \& Rieth, Malte (2014): Schwache Investitionen dämpfen Wachstum in Europa. In: DIW Wochenbericht, Nr. 27/2014, S. 637-651.

Balibar, Étienne (2018): Revolutionieren wir Europa, um es zu bewahren. In: Blätter für deutsche und internationale Politik, Nr. 3/2018, S. 79-87.

Ban, Cornel (2015): Austerity versus Stimulus? Understanding Fiscal Policy Change at the International Monetary Fund Since the Great Recession. In: Governance, Nr. 2/2015, S. 167-183, https://doi.org/10.1111/gove.12099.

Bandilla, Rüdiger (2017): Art. 119. In: Grabitz, Eberhard/Hilf, Meinhard \& Nettesheim, Martin (Hg.): Das Recht der Europäischen Union, 63. Ergänzungslieferung, München.

Becker, Peter (2011): Integration ohne Plan - Die neue EU-Wachstumsstrategie »Europa 2020«. In: Zeitschrift für Politik, Nr. 1/2011, S. 67-91, https://doi.org/10.5771/1430-63 87-2011-1-67.

Becker, Peter \& Müller, Ronny (2015): Die Kraft der Krise - die europäische Kohäsionspolitik und ihre Reform. In: integration, Nr. 3/2015, S. 231-247, https://doi.org/10.5 771/0720-5120-2015-3-231.

Beichelt, Timm (2015): Deutschland und Europa. Die Europäisierung des politischen Systems, 2. Auflage, Wiesbaden, https://doi.org/10.1007/978-3-531-19875-0.

- (2006): Politik in Europa zwischen Nationalstaat und Europäischer Union. In: Ders./Chołuj, Bożena/Rowe, Gerard \& Wagener, Hans-Jürgen (Hg.): Europa- 
Studien. Eine Einführung, Wiesbaden, S. 161-18, https://doi.org/10.1007/978-3-531 -90007-0_9.

Bekker, Sonja (2018): Flexicurity in the European Semester: still a relevant policy concept? In: Journal of European Public Policy, Nr. 2/2018, S. 175-192, https://doi.org/1 $0.1080 / 13501763.2017 .1363272$.

Bell, Stephen \& Hindermoor, Andrew (2009): Rethinking Governance. The Centrality of the State in Modern Society, Cambridge, https://doi.org/10.1017/cbo9780511814617.

Benz, Arthur (2001): Der moderne Staat. Grundlagen der politologischen Analyse, München.

Benz, Arthur \& Dose, Nicolai (2010): Governance - Modebegriff oder nützliches sozialwissenschaftliches Konzept? In: Dies. (Hg.): Governance - Regieren in komplexen Regelsystemen. Eine Einführung, 2. Auflage, Wiesbaden, S. 13-36, https://doi.org/1 0.1007/978-3-531-92325-3_1.

Beschluss (EU) 2020/1512 des Rates vom 13. Oktober $2020 \mathrm{zu}$ Leitlinien für beschäftigungspolitische Maßnahmen der Mitgliedstaaten.

Beschluss (EU) 2020/440 der Europäischen Zentralbank vom 24. März $2020 \mathrm{zu}$ einem zeitlich befristeten Pandemie-Notfallankaufprogramm.

Beschluss (EU) 2019/1001 des Rates vom 14. Juni 2019 zur Aufhebung der Entscheidung 2009/417/EG zum Bestehen eines übermäßigen Defizits in Spanien.

Beschluss (EU) 2015/774 der Europäischen Zentralbank vom 4. März 2015 über ein Programm zum Ankauf von Wertpapieren des öffentlichen Sektors an den Sekundärmärkten.

Beschluss (EU) 2015/1937 der Kommission vom 21. Oktober 2015 zur Einrichtung eines unabhängigen beratenden Europäischen Fiskalausschusses.

Beschluss (EU, Euratom) 2020/2053 des Rates vom 14. Dezember 2020 über das Eigenmittelsystem der Europäischen Union und zur Aufhebung des Beschlusses 2014/335/EU, Euratom.

Beschluss der Europäischen Zentralbank vom 14. Mai 2010 zur Einführung eines Programms für die Wertpapiermärkte [2010/281/EU].

Beschluss des Europäischen Rates vom 25. März 2011 zur Änderung des Artikels 136 des Vertrags über die Arbeitsweise der Europäischen Union hinsichtlich eines Stabilitätsmechanismus für die Mitglieder, deren Währung der Euro ist [2011/199/EU].

Beschluss des Rates vom 21. Oktober 2010 über Leitlinien für beschäftigungspolitische Maßnahmen der Mitgliedstaaten [2010/707/EU].

Bibow, Jörg \& Flassbeck, Heiner (2018): Das Euro-Desaster. Wie deutsche Wirtschaftspolitik die Eurozone in den Abgrund treibt, Frankfurt a.M.

Biegoń, Dominika/Klein, Julia/Plottka, Julian/Schilin, Alexander \& Schubert, Jana (2018): The Relaunch of Europe. Mapping Member States' Reform Interests: A Comparative Analysis [Friedrich-Ebert-Stiftung: International Policy Analysis].

Bieler, Andreas \& Morton, Adam David (2001): Conclusion: Thinking about Future European Social Relations. In: Dies. (Hg.): Social Forces in the Making of the New Europe. The Restructuring of European Social Relations in the Global Political Economy, New York, S. 207-217, https://doi.org/10.1057/9781403900814_10.

Bieling, Hans-Jürgen (2019): Entwicklung und Perspektiven des Wirtschaftsregierens im EU-Imperium. In: Ders. \& Guntrum, Simon (Hg.): Neue Segel, alter Kurs? Die Euro- 
krise und ihre Folgen für das europäische Wirtschaftsregieren, Wiesbaden, S. 28130, https://doi.org/10.1007/978-3-658-25037-9_11.

- (2018): Europäische Staatlichkeit. In: Voigt, Rüdiger (Hg.): Handbuch Staat, Wiesbaden, S. 305-316, https://doi.org/10.1007/978-3-658-20744-1_27.

- (2017): Aufstieg des Rechtspopulismus im heutigen Europa - Umrisse einer gesellschaftstheoretischen Erklärung. In: WSI-Mitteilungen, Nr. 8/2017, S. 557-565, https ://doi.org/10.5771/0342-300x-2017-8-557.

- (2013a): Das Projekt der Euro-Rettung und die Widersprüche des europäischen Krisenkonstitutionalismus. In: Zeitschrift für Internationale Beziehungen, Nr. 1/2013, S. 89-103, https://doi.org/10.5771/0946-7165-2013-1-89.

- (2013b): Zum gesellschafts- und integrationspolitischen Charakter des europäischen Krisenkonstitutionalismus. In: Forschungsjournal Neue Soziale Bewegungen, Nr. 1/2013, S. 51-60, https://doi.org/10.1515/fjsb-2013-0108.

- (2011): »Integraler Staat « und Globalisierung. In: Opratko, Benjamin \& Prausmüller, Oliver (Hg.): Gramsci global: Neogramscianische Perspektiven in der Internationalen Politischen Ökonomie, Hamburg, S. 87-105.

- (2009a): Metamorphosen des »integralen Staates«. Konkurrierende Leitbilder in der Krisendiskussion. In: Ders./Altvater, Elmar/Demirovic, Alex/Flassbeck, Heiner/Goldschmidt, Werner/Payandeh, Mehrdad \& Wöhl, Stefanie: Die Rückkehr des Staates? Nach der Finanzkrise, Hamburg, S. 37-60.

- (2009b): Neuer Staatsinterventionismus? Brüche und Kontinuitäten im marktliberalen Diskurs. In: Widerspruch, Nr. 2/2009, S. 41-52, http://doi.org/10.5169/seals-652 166.

- (2007): Die Konstitutionalisierung der Weltwirtschaft als Prozess hegemonialer Verstaatlichung - Staatstheoretische Reflexionen aus der Perspektive einer neo-gramscianischen Internationalen Politischen Ökonomie In: Buckel, Sonja \& FischerLescano, Andreas (Hg.): Hegemonie gepanzert mit Zwang. Zivilgesellschaft und Politik im Staatsverständnis Antonio Gramscis, Baden-Baden, S. 143-160, https://doi. org/10.5771/9783845201849-141.

- (2006): Europäische Staatlichkeit. In: Bretthauer, Lars/Gallas, Alexander/Kannankulam, John \& Stützle, Ingo (Hg.): Poulantzas lesen. Zur Aktualität marxistischer Staatstheorie, Hamburg, S. 223-239.

- (2001a): Staat, Zivilgesellschaft und New Governance in der Europäischen Union. In: Kurswechsel, Nr. 3/2001, S. 26-35.

- (2001b): European Constitutionalism and Industrial Relations. In: Bieler, Andreas \& Morton, Adam David (Hg.): Social Forces in the Making of the New Europe. The Restructuring of European Social Relations in the Global Political Economy, New York, S. 93-11, https://doi.org/10.1057/9781403900814_5.

Bieling, Hans-Jürgen \& Große Hüttmann, Martin (2016): Zur Einführung: Staatlichkeit der Europäischen Union in Zeiten der Finanzkrise. In: Dies. (Hg.): Europäische Staatlichkeit. Zwischen Krise und Integration, Wiesbaden, S. 11-30, https://doi.org /10.1007/978-3-658-03790-1_1.

Bieling, Hans-Jürgen \& Guntrum, Simon (2019): Einleitung: Ungleiche Entwicklung und asymmetrische Machtbeziehungen im Zeichen der Eurokrise In: Dies. (Hg.): Neue 
Segel, alter Kurs? Die Eurokrise und ihre Folgen für das europäische Wirtschaftsregieren, Wiesbaden, S. 1-19, https://doi.org/10.1007/978-3-658-25037-9_1.

Bieling, Hans-Jürgen/Haas, Tobias \& Lux, Julia (2013): Die Krise als Auslöser eines neuen europäischen Konfliktzyklus? In: Dies. (Hg.): Die Internationale Politische Ökonomie nach der Weltfinanzkrise. Theoretische, geopolitische und politikspezifische Implikationen, Wiesbaden, S. 231-249, https://doi.org/10.1007/978-3-658-04120-5 -14.

Bieling, Hans-Jürgen/Jäger, Johannes \& Ryner, Magnus (2016): Regulation Theory and the Political Economy of the European Union. In: Journal of Common Market Studies, Nr. 1/2016, S. 53-69, https://doi.org/10.1111/jcms.12331.

Bieling, Hans-Jürgen \& Lerch, Marika (2012): Theorien der europäischen Integration: ein Systematisierungsversuch. In: Dies. (Hg.): Theorien der europäischen Integration, 3. Auflage, Wiesbaden, S. 9-31, https://doi.org/10.1007/978-3-531-19715-9_1.

Bieling, Hans-Jürgen \& Steinhilber, Jochen (2000a): Einleitung: Theorie und Kritik der europäischen Integration. In: Dies. (Hg.): Die Konfiguration Europas: Dimensionen einer kritischen Integrationstheorie, Münster, S. 7-22.

- (2000b): Hegemoniale Projekte im Prozeß der europäischen Integration. In: Dies. (Hg.): Die Konfiguration Europas: Dimensionen einer kritischen Integrationstheorie, Münster, S. 102-130.

Bihr, Alain (2012): Der europäische Aufbau in der Krise. In: Emanzipation, Nr. 1/2012, S. 34-47.

Bloomberg (29.10.2020): German Rates \& Bonds, https://www.bloomberg.com/market s/rates-bonds/government-bonds/germany; 05.02.2021.

Blyth, Mark (2014): Wie Europa sich kaputtspart. Die gescheiterte Idee der Austeritätspolitik, Bonn.

Bodirsky, Katharina (2015): Nach der Krise wie vor der Krise? Die Antwort der EUStrukturfondspolitik auf ungleiche regionale Entwicklung. In: Emanzipation, Nr. 1/2015, S. 54-68.

Bohle, Dorothee (2012): Neogramscianismus. In: Bieling, Hans-Jürgen \& Lerch, Marika (Hg.): Theorien der europäischen Integration, 3. Auflage, Wiesbaden, S. 165-185, ht tps://doi.org/10.1007/978-3-531-19715-9_8.

Bontrup, Heinz-J. (2014): Die EU in der Krise. Die Wirtschafts- und Währungsunion endlich richtig aussteuern. In: perspektiven ds, Nr. 1/2014, S. 6-16.

- (2013): Krisenkapitalismus und EU-Verfall, Köln.

Börzel, Tanja A. (2016): From EU Governance of Crisis to Crisis of EU Governance: Regulatory Failure, Redistributive Conflict and Eurosceptic Publics. In: Journal of Common Market Studies, Annual Review 2016, S. 8-31, http://dx.doi.org/10.1111/jcms.12 431.

- (2013): EU-Staatlichkeit - Wie viel und wozu? [Berliner Arbeitspapier zur Europäischen Integration, Nr. 16], http://dx.doi.org/10.17169/refubium-22143.

Bourdieu, Pierre (2017): Über den Staat. Vorlesungen am Collège de France 1989-1992, Berlin.

- (2016): Sozialer Raum und »Klassen«. Leçon sur la leçon. Zwei Vorlesungen, 4. Auflage, Frankfurt a.M. 
- (1997): Über symbolische Macht. In: Österreichische Zeitschrift für Geschichtswissenschaft, Nr. 4/1997, S. 556-564.

- (1983): Ökonomisches Kapital, kulturelles Kapital, soziales Kapital. In: Kreckel, Reinhard (Hg.): Soziale Ungleichheiten, Göttingen, S. 183-198.

Bozay, Kemal (2016): Symbolische Ordnung im Spannungsverhältnis von "Macht«, »Herrschaft« und »Hegemonie«. Das kritische Erbe von Antonio Gramsci, Michel Foucault und Pierre Bourdieu. In: Ders. \& Arslan, Emre (Hg.): Symbolische Ordnung und Bildungsungleichheit in der Migrationsgesellschaft, Wiesbaden, S. 35-57, https://doi.org/10.1007/978-3-658-13703-8_3.

Brachthäuser, Franziska \& Haffner, Anton (2017): Gekommen, um zu bleiben. Das Krisenregime und die Rede vom Ausnahmezustand. In: Kritische Justiz, Nr. 1/2017, S. 19-29, https://doi.org/10.5771/0023-4834-2017-1-19.

Brand, Ulrich (2013): State, context and correspondence. Contours of a historical-materialist policy analysis. In: Österreichische Zeitschrift für Politikwissenschaft, Nr. 4/2013, S. 425-442, https://doi.org/10.15203/ozp.129.vol42iss4.

- (2011): Post-Neoliberalismus? Aktuelle Konflikte, Gegen-hegemoniale Strategien, Hamburg.

- (2010): Der Staat als soziales Verhältnis. In: Lösch, Bettina \& Thimmel, Andreas (Hg.): Kritische politische Bildung. Ein Handbuch, 2. Auflage, Schwalbach, S. 145-156.

- (2009a): Die Multiple Krise. Dynamik und Zusammenhang der Krisendimensionen, Anforderungen an politische Institutionen und Chancen progressiver Politik, Berlin.

- (2009b): Staatstheorie und Staatsanalyse im globalen Kapitalismus. Ein »neo-poulantzianischer« Ansatz der IPÖ. In: Ders./Hartmann, Eva \& Kunze, Caren (Hg.): Globalisierung, Macht und Hegemonie, Münster, S. 212-241.

- (2009c): Staatseuphorie ohne Strategie. Zur Lage der Linken im Postneoliberalismus. In: Blätter für deutsche und internationale Politik, Nr. 4/2009, S. 93-101.

- (2005): Gegen-Hegemonie. Perspektiven globalisierungskritischer Strategien, Hamburg.

Brand, Ulrich/Görg, Christoph \& Wissen, Markus (2007): Verdichtung zweiter Ordnung. Die Internationalisierung des Staates aus einer neo-poulantzianischen Perspektive. In: PROKLA, Nr. 2/2007, S. 217-234, https://doi.org/10.32387/prokla.v37i14 7.517.

Braun, Benjamin/Gabor, Daniela \& Hübner, Marina (2018): Governing through financial markets: Towards a critical political economy of Capital Markets Union. In: Competition \& Change, Nr. 2/2018, S. 101-116, https://doi.org/10.1177/10245294187594 76.

Bretthauer, Lars (2006): Materialität und Verdichtung bei Nicos Poulantzas. In: Ders./Gallas, Alexander/Kannankulam, John \& Stützle, Ingo (Hg.): Poulantzas lesen. Zur Aktualität marxistischer Staatstheorie, Hamburg, S. 82-100.

Breuss, Fritz (2017): The Crisis Management of the ECB. In: da Costa Cabral, Nazaré/Gonçalves, José Renato \& Rodrigues, Nuno Cunha (Hg.): The Euro and the Crisis. Perspectives for the Eurozone as a Monetary and Budgetary Union, Wiesbaden, S. 199-221, https://doi.org/10.1007/978-3-319-45710-9_13. 
Brunkhorst, Hauke (2017): Europa am Abgrund: Zwölf Jahre Merkel. In: Blätter für deutsche und internationale Politik, Nr. 7/2017, S. 55-62.

- (2014a): Das doppelte Gesicht Europas. Zwischen Kapitalismus und Demokratie, Berlin.

- (2014b): Auswege aus der technokratischen Falle? Die unbeachtete Wirtschaftsverfassung Europas. In: Leviathan, Nr. 4/2014, S. 508-523, https://doi.org/10.5771/0340 -0425-2014-4-508.

- (2012): Kollektiver Bonapartismus? Demokratie in der europäischen Krise. In: Blätter für deutsche und internationale Politik, Nr. 4/2012, S. 83-93.

Brunnermeier, Markus K./James, Harold \& Landau, Jean-Pierre (2018): Euro. Der Kampf der Wirtschaftskulturen, München.

Bruttel, Oliver (2014): Europäische Integration und Krise in der Eurozone: Akzeptanz und Ablehnung der EU in Deutschland, Frankreich, Spanien und Großbritannien. In: integration, Nr. 3/2014, S. 275-290, https://doi.org/10.5771/0720-5120-2014-2-2 75.

Bsirske, Frank \& Busch, Klaus (2017): Die Zukunft der EU: Integration statt Krisenverschleppung. In: Blätter für deutsche und internationale Politik, Nr. 9/2017, S. 89-95.

Buckel, Sonja (2018): Winter is coming. Der Wiederaufbau des europäischen Grenzregimes nach dem »Sommer der Migration«. In: PROKLA, Nr. 3/2018, S. 437-457, htt ps://doi.org/10.32387/prokla.v48i192.907.

- (2017): Dialektik von Kapitalismus und Demokratie heute. In: Eberl, Oliver \& Salomon, David (Hg.): Perspektiven sozialer Demokratie in der Postdemokratie, Wiesbaden, S. 19-41, https://doi.org/10.1007/978-3-658-02724-7_2.

— (2013): »Welcome to Europe« - Die Grenzen des europäischen Migrationsrechts. Juridische Auseinandersetzungen um das "Staatsprojekt Europa«, Bielefeld, https:// doi.org/10.14361/transcript.9783839424865.

- (2011): Staatsprojekt Europa. In: Politische Vierteljahresschrift, Nr. 4/2011, S. 636-662, https://doi.org/10.5771/0032-3470-2011-4-636.

- (2003a): Empire oder Rechtspluralismus? Recht im Globalisierungsdiskurs. In: Kritische Justiz, Nr. 2/2003, S. 177-191, https://doi.org/10.5771/0023-4834-2003-2-177.

- (2003b): Global »Non-State« - Überlegungen für eine materialistische Theorie transnationalen Rechts. In: Dies./Dackweiler, Regina-Maria \& Noppe, Ronald (Hg.): Formen und Felder politischer Intervention. Zur Relevanz von Staat und Steuerung, Münster, S. 50-68.

Buckel, Sonja/Fischer-Lescano, Andreas \& Oberndorfer, Lukas (2010): Postneoliberale Rechtsordnung? - Suchprozesse in der Krise. Einleitung in den Schwerpunkt. In: Kritische Justiz, Nr. 4/2010, S. 375-383, https://doi.org/10.5771/0023-4834-2010-4-3 75.

Buckel, Sonja/Georgi, Fabian/Kannankulam, John \& Wissel, Jens (2018): Die Krise des Europäischen Grenzregimes. Perspektiven kritischer Europaforschung. In: Eis, Andreas \& Moulin-Doos, Claire (Hg.): Kritische politische Europabildung - Die Vielfachkrise Europas als kollektive Lerngelegenheit? Immenhausen, S. 52-70.

- (2014): Theorie, Methoden und Analysen kritischer Europaforschung. In: Forschungsgruppe »Staatsprojekt Europa« (Hg.): Kämpfe um Migrationspolitik. Theorie, Me- 
thode und Analyse kritischer Europaforschung, Bielefeld, S. 15-84, https://doi.org/ 10.14361/transcript.9783839424025.15.

- (2012): »... wenn das Alte nicht stirbt und das Neue nicht zur Welt kommen kann.« Kräfteverhältnisse in der europäischen Krise. In: Forschungsgruppe >Staatsprojekt Europa< (Hg.): Die EU in der Krise. Zwischen autoritärem Etatismus und europäischem Frühling, Münster, S. 11-48.

Buckel, Sonja \& Martin, Dirk (2019): Aspekte einer gesellschaftskritischen Theorie der Politik. In: Bohmann, Ulf \& Sörensen, Paul (Hg.): Kritische Theorie der Politik, Berlin, S. 243-266.

Bundesministerium der Finanzen (2018): Fiskalregeln, https://www.bundesfinanzmini sterium.de/Web/DE/Themen/Oeffentliche_Finanzen/Stabilitaetspolitik/Fiskalrege ln/fiskalregeln.html; 05.02.2021.

- (2010): Key proposals to strengthen the euro area. [Beitrag zur »Arbeitsgruppe Wirtschaftspolitische Steuerung « des Europäischen Rates; ohne Dokumentenreferenz].

Bundesregierung (2018): Erklärung von Meseberg, https://www.bundesregierung.de/b reg-de/aktuelles/erklaerung-von-meseberg-1140536; 05.02.2021.

- (2013): Frankreich und Deutschland - Gemeinsam für ein gestärktes Europa der Stabilität und des Wachstums [Pressemitteilung Nr. 187/13 des Presse- und Informationsamts der Bundesregierung].

Bundesverfassungsgericht (2021): Beschluss vom 15. April 2021. EU-Eigenmittelbeschluss [2 BvR 547/21].

- (2020): Urteil vom 5. Mai 2020. PSPP [2 BvR 859/15, 2 BvR 1651/15, 2 BvR 2006/15, 2 BvR 980/16].

- (2016): Urteil vom 21. Juni 2016. OMT [2 BvR 2728/13, 2 BvE 13/13, 2 BvR 2731/13, 2 BvR 2730/13, 2 BvR 2729/13].

- (2014a): Beschluss vom 14. Januar 2014. OMT [2 BvR 2728/13].

- (2014b): Urteil vom 18. März 2014. ESM, Fiskalpakt [2 BvR 1390/12, 2 BvR 1421/12, 2 BvR 1438/12, 2 BvR 1439/12, 2 BvR 1440/12, 2 BvE 6/12].

- (2013): Beschluss vom 17. Dezember 2013. OMT [2 BvR 1390/12, 2 BvR 1421/12, 2 BvR 1438/12, 2 BvR 1439/12, 2 BvR 1440/12, 2 BvE 6/12].

- (2012): Urteil vom 12. September 2012. ESM, Fiskalpakt [2 BvR 1390/12, 2 BvR 1421/12, 2 BvR 1438/12, 2 BvR 1439/12, 2 BvR 1440/12, 2 BvE 6/12].

Busch, Klaus (2017): Wege aus der Krise - ein Reformprogramm für die Europäische Union. In: BdWi-Studienheft, Nr. 11, S. 13-15.

- (2016): Das Versagen Europas. Die Euro- und die Flüchtlingskrise sowie die »Brexit«Diskussion, Hamburg.

- (1993): Maastrichter Vertrag, EWS-Krise und optimaler Währungsraum. In: Gewerkschaftliche Monatshefte, Nr. 9/1993, S. 532-543.

Busch, Klaus/Hermann, Christoph/Hinrichs, Karl \& Schulten, Thorsten (2012): Eurokrise, Austeritätspolitik und das Europäische Sozialmodell. Wie die Krisenpolitik in Südeuropa die soziale Dimension der EU bedroht [Friedrich-Ebert-Stiftung: Internationale Politikanalyse].

Busch, Klaus \& Hirschel, Dierk (2012): Mehr Europa, aber anders. In: Zeitschrift marxistische Erneuerung, Nr. 91, S. 81-85. 
Busch, Klaus/Troost, Axel/Schwan, Gesine \& Bsirske, Frank (2017): Ausgleich statt Austerität. Für eine solidarische Europäische Union. In: Blätter für deutsche und internationale Politik, Nr. 1/2017, S. 93-104.

Business Europe (2010): Letter to the President of the European Council, 14.06.2010 [SGE10/06644].

Calliess, Christian (2015): The Governance Framework of the Eurozone and the Need for a Treaty Reform. In: Fabbrini, Federico/Hirsch, Ernst \& Somsen, Han (Hg.): What Form of Government for the European Union and the Eurozone? Oxford, S. 37-56, https://doi.org/10.5040/9781509901234.ch-003.

- (2013): Der ESM zwischen Luxemburg und Karlsruhe. Die Krise der Währungsunion als Bewährungsprobe der Rechtsgemeinschaft. In: Neue Zeitschrift für Verwaltungsrecht, S. 97-105.

Candeias, Mario (2011): Interregnum - Molekulare Verdichtung und organische Krise. In: Demirović, Alex/Dück, Julia/Becker, Florian \& Bader, Pauline (Hg.): VielfachKrise. Im finanzmarktdominierten Kapitalismus, Hamburg, S. 45-61.

Cencig, Elisa \& Sabani, Laura (2017): Voting behavior in the European Parliament and economic governance reform: does nationality matter? In: Open Economies Review, S. 1-21, https://doi.org/10.1007/s11079-017-9461-0.

Centeno, Mario (2018): Letter to the President of the Euro Summit (25.06.2018), https:/ /www.consilium.europa.eu/media/35798/2018-06-25-letter-president-centeno-topresident-tusk.pdf; 05.02.2021.

Clauwaert, Stefan (2019): The country-specific recommendations (CSRs) in the social field. An overview and comparison. Update including the CSRs 2019-2020 [etui Background analysis, Nr. 2019.03].

- (2018): The country-specific recommendations (CSRs) in the social field. An overview and comparison. Update including the CSRs 2018-2019 [etui Background analysis, Nr. 1/2018].

- (2017): The country-specific recommendations (CSRs) in the social field. An overview and comparison. Update including the CSRs 2017-2018 [etui Background analysis, Nr. 2/2017].

Colliot-Thélène, Catherine (2016): Das Monopol der legitimen Gewalt. In: Anter, Andreas \& Breuer, Stefan (Hg.): Max Webers Staatssoziologie. Positionen und Perspektiven, 2. Auflage, Baden-Baden, S. 39-55, https://doi.org/10.5771/9783845270746-39.

Cornillie, Jan (2017): "Die Bankenunion leidet an demselben Virus wie die Eurozone«., https:/www.ipg-journal.de/rubriken/europaeische-integration/artikel/die-b ankenunion-leidet-an-demselben-virus-wie-die-eurozone-2188/; 05.02.2021.

Corriere Della Sera (29.09.2011): Trichet e Draghi: un'azione pressante per ristabilire la fiducia degli investitori, https://www.corriere.it/economia/11_settembre_29/triche t_draghi_inglese_304a5fie-ea59-11eo-aeo6-4da866778017_print.html; 05.02.2021.

Cremer, Wolfram (2016): Auf dem Weg zu einer Europäischen Wirtschaftsregierung? In: Europarecht, 2016, S. 256-281, https://doi.org/10.5771/0531-2485-2016-3-256.

Crum, Ben (2018): Parliamentary accountability in multilevel governance: what role for parliaments in post-crisis EU economic governance? In: Journal of European Public Policy, Nr. 2/2018, S. 268-286, http://dx.doi.org/10.1080/13501763.2017.1363270. 
Curtin, Deirdre (2014): Challenging Executive Dominance in European Democracy. In: The Modern Law Review, Nr. 1/2014, S. 1-32, https://doi.org/10.1111/1468-2230.120 54.

Darvas, Zsolt \& Leandro, Álvaro (2015): Economic policy coordination in the euro area under the European Semester [Studie hgg. von der Generaldirektion Interne Politikbereiche der Union des Europäischen Parlaments; PE 542.680].

Dauderstädt, Michael (2020): The Lost Decade. Reducing European Income Disparities [Friedrich-Ebert-Stiftung: International Policy Analysis].

- (2015): Ungleichheit und Krise in Europa. In: Emanzipation, Nr. 1/2015, S. 15-34.

Dauner, Matthias \& Sohn, Klaus-Dieter (2015): Gesetzgebung im Trilog. Das Ende der transparenten repräsentativen Demokratie? [cepInput, Nr. 18/2015].

Decker, Frank (2011): Von der Euro-Krise zu neuen Ufern? Perspektiven des europäischen Integrationsprojekts. In: Zeitschrift für Politikwissenschaft, Nr. 2/2011, S. 303-312, https://doi.org/10.5771/1430-6387-2011-2-303.

Decker, Samuel \& Sablowski, Thomas (2017): Die G20 und die Krise des globalen Kapitalismus [Rosa-Luxemburg-Stiftung: STUDIEN, Nr. 4/2017].

de Finance, Stanislas (2016): Fiscal Compact Treaty: Scorecard 2015. How far are EU Member States meeting their European Council commitments? [Studie hgg. vom Wissenschaftlichen Dienst des Europäischen Parlaments; PE 581.403].

De Grauwe, Paul (2015): The Political Economy of the Euro. In: Bieling, Hans-Jürgen (Hg.): The Political Economy of the European Union [Exploring Europe's Future, Bd. 3], New York, S. 197-214.

- (2013): Design Failures in the Eurozone: Can they be fixed? [London School of Economics: >Europe in Question<, Nr. 57/2013], https://doi.org/10.2139/ssrn.2215762.

- (2011): The European Central Bank: Lender of Last Resort in the Government Bond Markets? [CESifo Working Paper, Nr. 3569], https://doi.org/10.1093/cesifo/ifto12.

De Grauwe, Paul \& Ji, Yuemei (2015): Correcting for the Eurozone Design Failures: The Role of the ECB. In: Journal of European Integration, Nr. 7/2015, S. 739-754, https:/ /doi.org/10.1080/07036337.2015.1079370.

Degryse, Christophe (2012): Die neue wirtschaftspolitische Governance der EU [etui Working Paper, Nr. 14/2012].

Degryse, Christophe/Jepsen, Maria \& Pochet, Philippe (2013): The Euro crisis and its impact on national and European social policies [etui Working Paper, Nr. 5/2013], h ttps://doi.org/10.2139/ssrn.2342095.

Deitelhoff, Nicole \& Steffek, Jens (2009): Staatlichkeit ohne Staat? In: Dies. (Hg.): Was bleibt vom Staat? Demokratie, Recht und Verfassung im globalen Zeitalter, Frankfurt a.M., S. 7-34.

Delegierte Verordnung (EU) Nr. 877/2013 der Kommission vom 27. Juni 2013 zur Ergänzung der Verordnung (EU) Nr. 473/2013 des Europäischen Parlaments und des Rates über gemeinsame Bestimmungen für die Überwachung und Bewertung der Übersichten über die Haushaltsplanung und für die Gewährleistung der Korrektur übermäßiger Defizite der Mitgliedstaaten im Euro-Währungsgebiet.

Demirović, Alex (2011a): Governance - eine neue Stufe staatlicher Herrschaft. In: Ders. \& Walk, Heike (Hg.): Demokratie und Governance. Kritische Perspektiven auf neue Formen politischer Herrschaft, Münster, S. 73-105. 
— (2011b): Ökonomische Krise - Krise der Politik? In: Ders./Dück, Julia/Becker, Florian \& Bader, Pauline (Hg.): VielfachKrise. Im finanzmarktdominierten Kapitalismus, Hamburg, S. 63-78.

- (2009): »Politik und Wirtschaft kann man nicht trennen«. Zur Aktualität eines Gemeinplatzes. In: Ders./Altvater, Elmar/Bieling, Hans-Jürgen/Flassbeck, Heiner/Goldschmidt, Werner/Payandeh, Merhad \& Wöhl, Stefanie: Die Rückkehr des Staates? Nach der Finanzkrise, Hamburg, S. 19-35.

- (2007a): Nicos Poulantzas. Aktualität und Probleme materialistischer Staatstheorie, Münster.

— (2007b): Politische Gesellschaft - zivile Gesellschaft. Zur Theorie des integralen Staates bei Antonio Gramsci. In: Buckel, Sonja \& Fischer-Lescano, Andreas (Hg.): Hegemonie gepanzert mit Zwang. Zivilgesellschaft und Politik im Staatsverständnis Antonio Gramscis, Baden-Baden, S. 21-41, https://doi.org/10.5771/978384520184919.

- (2001): NGO, Staat und Zivilgesellschaft. Zur Transformation von Hegemonie. In: Ders./Brand, Ulrich/Görg, Christoph \& Hirsch, Joachim (Hg.): Nichtregierungsorganisationen in der Transformation des Staates, Münster, S. 141-168.

Demirović, Alex/Hirsch, Joachim \& Jessop, Bob (2002): Einleitung der Herausgeber. In: Poulantzas, Nicos: Staatstheorie. Politischer Überbau, Ideologie, Autoritärer Etatismus, Hamburg, S. 7-34.

Demirović, Alex \& Sablowski, Thomas (2011): Finanzdominierte Akkumulation und die Krise in Europa. In PROKLA, Nr. 1/2011, S. 77-106, https://doi.org/10.32387/prokla. v42i166.19.

Demirović, Alex \& Walk, Heike (2011): Einleitung. In: Dies. (Hg.): Demokratie und Governance. Kritische Perspektiven auf neue Formen politischer Herrschaft, Münster, S. 7-17.

Department of Finance [Ireland] (2010a): Letter from Brian Lenihan to Jean Claude Trichet, https://www.ecb.europa.eu/press/shared/pdf/2010-11-04\%20\%20Letter_IE_Fi nMin_to_ECB_President.pdf?92646d18e42fa6c721ec6fccf42e1ac4; 05.02.2021.

- (2010b): Letter from Brian Lenihan to Jean-Claude Trichet, https://www.ecb.europa .eu/press/shared/pdf/2010-11-21_Letter_IE\%20FinMin_to_ECB_\%20President.pdf? 432af7ba36b71099b55893b819ae2502; 05.02.2021.

Deppe, Frank (2015): Der Staat, Köln.

Deters, Henning (2014): Deliberative Supranationalism in the Euro Crisis? The European Central Bank and The European Council in Times of Conflict. In: Joerges, Christian \& Glinski, Carola (Hg.): The European Crisis and the Transformation of Transnational Governance. Authoritarian Managerialism versus Democratic Governance, Oxford, S. 245-268, https://doi.org/10.5040/9781474201117.ch-010.

Deutschmann, Christoph (2015): Euro-Krise und internationale Finanzkrise. Die Finanzialisierung der Wirtschaft als politische Herausforderung für Europa. In: Brömmel, Winfried/König, Helmut \& Sicking, Manfred (Hg.): Europa, wie weiter? Perspektiven eines Projekts in der Krise, Bielefeld, S. 79-99, https://doi.org/10.14361/97 83839430101-005.

- (2014): Ein »hayekianisches « Regime in Europa? Zur Diskussion Wolfgang Streecks Buch »Gekaufte Zeit« [Institut für Sozialforschung: Working Paper Nr. 6/2014]. 
Diermann, Melanie/Staub, Julia \& Müller, Carolin (2015): Bankenkrise, Staatsschuldenkrise, Vertrauenskrise. Zum Framing von Krisenphänomenen in den EuropaWahlprogrammen deutscher Parteien. In: Kaeding, Michael \& Switek, Niko (Hg.): Die Europawahl 2014. Spitzenkandidaten, Protestparteien, Nichtwähler, Wiesbaden, S. 297-309, https://doi.org/10.1007/978-3-658-05738-1_25.

Dijsselbloem, Jeroen (2019): Die Eurokrise. Erfahrungsbericht eines Insiders, Wiesbaden, https://doi.org/10.1007/978-3-658-26464-2.

Draghi, Mario (2012): Speech at the Global Investment Conference in London 26 July 2012, https:/www.ecb.europa.eu/press/key/date/2012/html/sp120726.en.html; 05.02.2021.

Drahokoupil, Jan/van Apeldoorn, Bastian \& Horn, Laura (2009): Introduction: Towards a Critical Political Economy of European Governance. In: Dies. (Hg.): Contradictions and Limits of Neoliberal European Governance. From Lisbon to Lisbon, Basingstoke, S. 1-17, https://doi.org/10.1057/9780230228757_1.

Dullien, Sebastian (2014): Die Euro-Zone nach vier Jahren Krisenmanagement und Adhoc-Reformen: Was bleibt zu tun? [Friedrich-Ebert-Stiftung: WISO Diskurs].

Dusse, Birgita (2019): Krise des Kompromisses? Zur Kontinuität des selektiven Korporatismus am Beispiel der Arbeitsmarktpolitik Dänemarks, Deutschlands und Italiens, Münster.

Ebner, Alexander (2012): Austerität oder Innovation? Perspektiven einer nachhaltigen europäischen Wirtschaftspolitik. In: Wirtschaftsdienst, Nr. 4/2012, S. 230-234.

EFSF Rahmenvertrag.

Efstathious, Konstantinos \& Wolff, Guntram B. (2018): Is the European Semester effective and useful? [Bruegel Policy Contribution, Nr. 9/2018].

Ehnts, Dirk (2016): Geld und Kredit: eine €-päische Perspektive, Marburg.

Ellwein, Thomas (1992): Staatlichkeit im Wandel. Das Staatsmodell des 19. Jahrhunderts als Verständnisbarriere. In: Kohler-Koch, Beate (Hg.): Staat und Demokratie in Europa. 18. Wissenschaftlicher Kongreß der Deutschen Vereinigung für Politische Wissenschaft, Opladen, S. 73-82, https://doi.org/10.1007/978-3-322-95892-1 4 .

Empfehlung (EU) 2015/1184 des Rates vom 14. Juli 2015 über die Grundzüge der Wirtschaftspolitik der Mitgliedstaaten und der Europäischen Union.

Empfehlung des Rates vom 20. September 2016 zur Einrichtung nationaler Ausschüsse für Produktivität [2016/C 349/01].

Empfehlung des Rates vom 22. April 2013 zur Einführung einer Jugendgarantie [2013/C 120/01].

Empfehlung des Rates vom 13. Juli 2010 über die Grundzüge der Wirtschaftspolitik der Mitgliedstaaten und der Union [2010/410/EU].

Enderlein, Henrik (2016): Die Konstruktionsfehler der Währungsunion. In: Schellinger, Alexander \& Steinberg, Philipp (Hg.): Die Zukunft der Eurozone. Wie wir den Euro retten und Europa zusammenhalten, Bielefeld, S. 41-54, https://doi.org/10.14361/97 83839436363-003.

- (2011): Welche Economic Governance für Europa? Die Vorschläge zur wirtschaftspolitischen Steuerung im Euroraum. In: Jahrbuch der Europäischen Integration 2011, S. 37-44, https://doi.org/10.5771/9783845234731-37. 
- (2010): Die Krise im Euro-Raum: Auslöser, Antworten, Ausblick. In: Aus Politik und Zeitgeschichte, Nr. 43/2010, S. 7-12.

- (2006): The Euro and Political Union: Do Economic Spillovers from Monetary Integration Affect the Legitimacy of EMU? In: Journal of European Public Policy, Nr. 7/2006, S. 1133-1146, https://doi.org/10.1080/13501760600924266.

Engelen, Ewald \& Glasmacher, Anna (2018): The waiting game: How securitization became the solution for the growth problem of the Eurozone. In: Competition \& Change, Nr. 2/2018, S. 165-183, https://doi.org/10.1177/1024529418758579.

Engler, Philipp \& Klein, Mathias (2017): Austeritätspolitik hat in Spanien, Portugal und Italien die Krise verschärft. In: DIW Wochenbericht, Nr. 8/2017, S. 127-132.

EURACTIV (09.12.2011): EU-Gipfel bestätigt Spaltung Europas, https://www.euractiv. de/section/prioritaten-der-eu-fur-2020/news/eu-gipfel-bestatigt-spaltung-europa s; 05.02.2021.

Euro-Gipfel (2018): Erklärung des Euro-Gipfels (14.12.2018) [EURO 503/18 EUROSUMMIT 3 TSGC 10].

- (2017): Agenda der EU-Führungsspitzen: Wirtschafts- und Währungsunion (Dezember 2017), https://www.consilium.europa.eu/media/32093/de_leaders-agenda-note -on-emu.pdf; 05.02.2021.

- (2014): Euro-Gipfel (24.10.2014), https://www.consilium.europa.eu/media/21723/201 41024-euro-summit-statement-de.pdf; 05.02.2021.

- (2012a): Agreed lines of communication by euro area Member States, https://www.co nsilium.europa.eu/uedocs/cms_data/docs/pressdata/en/ec/127633.pdf; 05.02.2021.

— (2012b): Gipfelerklärung der Mitglieder des Euro-Währungsgebiets (29.06.2012), htt ps:/www.consilium.europa.eu/uedocs/cms_data/docs/pressdata/de/ec/131365.pdf; 05.02.2021.

- (2011a): Schlussfolgerung der Staats- und Regierungschefs der Mitgliedstaaten des Euro-Währungsgebiets, https://www.consilium.europa.eu/uedocs/cms_data/docs/ pressdata/de/ec/119824.pdf; 05.02.2021.

- (2011b): Erklärung der Staats- und Regierungschefs des Euro-Währungsgebiets und der EU-Organe, https://www.consilium.europa.eu/uedocs/cms_data/docs/pressda ta/de/ecofin/124012.pdf; 05.02.2021.

— (2011c): Euro Summit Statement, https://www.consilium.europa.eu/uedocs/cms_da ta/docs/pressdata/en/ec/125644.pdf; 05.02.2021.

- (2011d): Statement by the Euro Area Heads of State or Government, https://www.co nsilium.europa.eu/uedocs/cms_data/docs/pressdata/en/ec/126658.pdf; 05.02.2021.

- (2010a): Erklärung der Staats- und Regierungschefs des Euro-Währungsgebiets (07.05.2010), https://www.consilium.europa.eu/uedocs/cms_data/docs/pressdata/ de/ec/114297.pdf; 05.02.2021.

- (2010b): Statement by the Heads of State and Government of the Euro Area, https://www.consilium.europa.eu/uedocs/cms_data/docs/pressdata/en/ec/11 3563.pdf; 05.02.2021.

Euro-Gruppe (2020): Report on the comprehensive economic policy response to the COVID-19 pandemic [Pressemitteilung 223/20].

- (2019): Summing up letter: Eurogroup in inclusive format (09.10.2019) [ecfin. cef.cpe(2019)7057314]. 
- (2018a): Summing up letter: Eurogroup (22.01.2018) [ecfin.cef.cpe(2018)499615].

- (2018b): Summing up letter: Eurogroup (12.03.2018) [ecfin.cef.cpe(2018)1590044].

- (2018c): Remarks by M. Centeno following the Eurogroup meeting (21.06.2018), http s://www.consilium.europa.eu/de/press/press-releases/2018/06/22/remarks-by-mcenteno-following-the-eurogroup-meeting-of-21-june-2018/pdf; 05.02.2021.

- (2018d): Summing up letter: Eurogroup in inclusive format (03.12.2018) [ecfin. cef.cpe(2018)7016642].

- (2017a): Remarks by J. Dijsselbloem following the Eurogroup meeting in inclusive (04.12.2017), https://www.consilium.europa.eu/de/press/press-releases/2017/12/04 /remarks-by-j-dijsselbloem-following-the-eurogroup-meeting-in-extended-forma t-of-4-december-2017/pdf; 05.02.2021.

- (2017b): Summing up letter: Eurogroup in inclusive format (04.12.2017) [ecfin. cef.cpe(2017)6736960].

- (2015): Remarks by Jeroen Dijsselbloem at the press conference following the Eurogroup (16.02.2015), https://www.consilium.europa.eu/de/press/press-releases/20 15/02/16/eurogroup-remarks/pdf; 05.02.2021.

Europäische Kommission (o.J. a): National Productivity Boards, https://ec.europa.eu/i nfo/business-economy-euro/economic-and-fiscal-policy-coordination/national-pr oductivity-boards_de; 05.02.2021.

- (o.J. b): Excessive deficit procedures - overview, https://ec.europa.eu/info/businesseconomy-euro/economic-and-fiscal-policy-coordination/eu-economic-governanc e-monitoring-prevention-correction/stability-and-growth-pact/corrective-arm-ex cessive-deficit-procedure/excessive-deficit-procedures-overview_en; 05.02.2021.

- (o.J. c): Significant Deviation Procedure, https://ec.europa.eu/info/business-econo my-euro/economic-and-fiscal-policy-coordination/eu-economic-governance-mon itoring-prevention-correction/stability-and-growth-pact/preventive-arm/significa nt-deviation-procedure; 05.02.2021.

- (o.J. d): In-depth reviews, https://ec.europa.eu/info/business-economy-euro/econo mic-and-fiscal-policy-coordination/eu-economic-governance-monitoring-prevent ion-correction/macroeconomic-imbalance-procedure/depth-reviews; 05.02.2021.

- (o.J. e): Annual draft budgetary plans (DBPs) of euro area countries, https://ec.euro pa.eu/info/business-economy-euro/economic-and-fiscal-policy-coordination/eu-e conomic-governance-monitoring-prevention-correction/stability-and-growth-pac t/annual-draft-budgetary-plans-dbps-euro-area-countries_de; 05.02.2021.

- (o.J. f): Scoreboard, https://ec.europa.eu/info/business-economy-euro/economic-an $\mathrm{d}$-fiscal-policy-coordination/eu-economic-governance-monitoring-prevention-cor rection/macroeconomic-imbalance-procedure/scoreboard_de\#scoreboard-indicat ors; 05.02.2021.

- (o.J. g): Unterstützung von Strukturreformen, https://ec.europa.eu/info/departmen ts/structural-reform-support_de; 05.02.2021.

- (2020a): Mitteilung über die Aktivierung der allgemeinen Ausweichklausel des Stabilitäts- und Wachstumspakt [COM(2020) 123 final].

- (2020b): Mitteilung: Die koordinierte wirtschaftliche Reaktion auf die COVID-19Pandemie [COM(2020) 112 final]. 
- (2020c): Coronakrise: SURE - Kommission schlägt Bereitstellung von 81,4 Mrd. EUR an finanzieller Un-terstützung für 15 Mitgliedstaaten vor [IP/20/1496].

- (2020d): Vorschlag für eine Verordnung des Europäischen Parlaments und des Rates zur Einrichtung einer Aufbau- und Resilienzfazilität [COM(2020) 408 final].

- (2020e): Mitteilung: Der EU-Haushalt als Motor für den Europäischen Aufbauplan [COM(2020) 442 final].

- (2020f): Mitteilung: Die Stunde Europas - Schäden beheben und Perspektiven für die nächste Generation eröffnen [COM(2020) 456 final].

- (2020g): Investor Presentation. 30 September 2020, https://ec.europa.eu/info/sites/ info/files/economy-finance/eu_investor_presentation_en.pdf; 05.02.2021.

- (2020h): European Economic Forecast. Summer 2020 (Interim) [European Economy, Institutional Paper 132].

- (2020i): Communication on the 2021 Draft Budgetary Plans: Overall Assessment [COM(2020) 750 final].

- (2019a): Bericht über die Fortschritte bei der Umsetzung der Empfehlung des Rates vom 20. September 2016 zur Einrichtung nationaler Ausschüsse für Produktivität [COM(2019) 152 final].

- (2019b): Mitteilung: Der europäische Grüne Deal [COM(2019) 640 final].

- (2019c): Jährlicher Bericht über die Durchführung des Programms zur Unterstützung von Strukturreformen 2018 [COM(2019) 641 final].

- (2019d): Mitteilung: Vertiefung der europäischen Wirtschafts- und Währungsunion. Eine Bilanz vier Jahre nach dem Bericht der fünf Präsidenten. [COM(2019) 279 final].

- (2019e): Vorschlag für eine Verordnung über einen Steuerungsrahmen für das Haushaltsinstrument für Konvergenz und Wettbewerbsfähigkeit für das EuroWährungsgebiet [COM(2019) 354 final].

- (2018a): Europäische Kommission fordert Italien zur Vorlage eines überarbeiteten Haushaltsplans für 2019 auf [IP/18/6174].

- (2018b): Vorschlag für eine Verordnung zur Aufstellung des Reformhilfeprogramms [COM(2018) 391 final].

- (2018c): Vorschlag für eine Verordnung zur Schaffung einer Europäischen Investitionsstabilisierungsfunktion [COM(2018) 387 final].

- (2018d): Mitteilung: Semester 2018 - Länderspezifische Empfehlungen [COM(2018) 400 final].

- (2018e): Mitteilung zu den Übersichten über die Haushaltsplanungen 2019: Gesamtbewertung [COM(2018) 807 final].

- (2018f): Mitteilung: Überwachung der Umsetzung der europäischen Säule sozialer Rechte [COM(2018) 130 final].

- (2017a): Arbeitsunterlage der Kommissionsdienststellen: Sozialpolitisches Scoreboard [SWD(2017) 200 final].

— (2017b): Mitteilung zur Einführung einer Säule sozialer Rechte [COM(2017) 250 final].

- (2017c): Rede von Jean-Claude Juncker zur Lage der Union 2017 (13. September 2017), Luxemburg.

- (2017d): Reflexionspapier zur Vertiefung der Wirtschafts- und Währungsunion [COM(2017) 291 final]. 
-(2017e): Mitteilung: Weitere Schritte zur Vollendung der Wirtschafts- und Währungsunion. Ein Fahrplan [COM(2017) 821 final].

- (2017f): Mitteilung: Neue Haushaltsinstrumente für ein stabiles Euro-Währungsgebiet innerhalb des Unionsrahmens [COM(2017) 822 final].

- (2017g): Mitteilung: Ein europäischer Minister für Wirtschaft und Finanzen [COM(2017) 823 final].

- (2017h): Vorschlag für eine Richtlinie zur Festlegung von Bestimmungen zur Stärkung der haushaltspolitischen Verantwortung und der mittelfristigen Ausrichtung der Haushalte in den Mitgliedstaaten [COM(2017) 824 final].

- (2017i): Vorschlag für eine Verordnung zur Änderung der Verordnung (EU) 2017/825 zur Erhöhung der Finanzausstattung des Programms zur Unterstützung von Strukturreformen und zur Anpassung eines übergeordneten Ziels [COM(2017) 825 final].

- (2017j): Vorschlag für eine Verordnung zur Änderung der Verordnung (EU) Nr. 1303/2013 mit gemeinsamen Bestimmungen über den Europäischen Fonds für regionale Entwicklung, den Europäischen Sozialfonds, den Kohäsionsfond, den Europäischen Landwirtschaftsfonds für die Entwicklung des ländlichen Raums und den Europäischen Meeres- und Fischereifonds, sowie mit allgemeinen Bestimmungen über den Europäischen Fonds für regionale Entwicklung, den Europäischen Sozialfonds, den Kohäsionsfonds und den Europäischen Meeres- und Fischereifonds sowie zur Aufhebung der Verordnung (EG) Nr. 1083/2006 in Bezug auf die Unterstützung von Strukturreformen in den Mitgliedstaaten [COM(2017) 826 final].

- (2017k): Vorschlag für eine Verordnung über die Einrichtung des Europäischen Währungsfonds [COM(2017) 827 final].

- (2017): Mitteilung: Europäisches Semester 2017. Länderspezifische Empfehlungen [COM(2017) 500 final].

- (2017m): Dienst zur Unterstützung von Strukturreformen. Lage der Union 2017 [NA06-17-047-DE-N].

- (2017n): Mitteilung: Der Fiskalpakt. Bestandsaufnahme [C(2017) 1200 final].

- (20170): Weißbuch zur Zukunft Europas. Die EU der 27 im Jahr 2025 - Überlegungen und Szenarien [COM(2017) 2025].

- (2017p): Bericht: Vorlage gemäß Artikel 8 des Vertrags über Stabilität, Koordinierung und Steuerung in der Wirtschafts- und Währungsunion [C(2017) 1201 final].

- (2017q): Dienst zur Unterstützung von Strukturreformen. Beitrag der Kommission zur Agenda der Staats- und Regierungschefs [KC-07-17-086-DE-N].

- (2017r): Mitteilung: Übersichten über die Haushaltsplanung 2018. Gesamtbewertung [COM(2017) 800 final].

- (2017s): Erklärung von Rom (27.03.2017), https://ec.europa.eu/commission/presscor ner/detail/de/STATEMENT_17_767; 13.02.2021.

- (2016a): Mitteilung: Einleitung einer Konsultation über eine europäische Säule sozialer Rechte [COM(2016) 127 final].

- (2016b): Frühjahrspaket des Europäischen Semesters 2016: Kommission veröffentlicht länderspezifische Empfehlungen [IP/16/1724].

- (2016c): Präsident Juncker auf Staatsbesuch in Italien, 26. Februar, https://ec.europa .eu/commission/presscorner/detail/de/AC_16_2106; 05.02.2021. 
- (2016d): The Macroeconomic Imbalance Procedure. Rationale, Process, Application: A Compendium [European Economy, Institutional Paper 039].

- (2016e): 14. Norbert Schmelzer Lesung - Vortrag von EU-Kommissionspräsident Jean-Claude Juncker, »Die Europäische Union - eine Quelle der Stabilität in Krisenzeiten« [SPEECH/16/583].

- (2016f): Mitteilung: Europa investiert wieder: eine Bestandsaufnahme der Investitionsoffensive für Europa [COM(2016) 359 final].

- (2016g): Mitteilung: Übersichten über die Haushaltsplanung 2017. Gesamtbewertung [COM(2016) 730 final].

- (2016h): Europäischer Struktur- und Investitionsfonds 2014-2020. Offizielle Texte und Kommentare, Luxemburg.

- (2015a): Grünbuch: Schaffung einer Kapitalmarktunion [COM(2015) 63 final].

- (2015b): Mitteilung: Aktionsplan zur Schaffung einer Kapitalmarktunion [COM(2015) 468 final].

- (2015c): Mitteilung: Schritte zur Vollendung der Wirtschafts- und Währungsunion [COM(2015) 600 final].

- (2015d): Mitteilung: Ein Fahrplan für die Schaffung einer kohärenten Außenvertretung des Euro-Währungsgebiets in internationalen Foren [COM(2015) 602 final].

- (2015e): Mitteilung: Optimale Nutzung der im Stabilitäts- und Wachstumspakt vorgesehenen Flexibilität [COM(2015) 12 final/2].

- (2015f): Adding employment indicators to the scoreboard of the Macroeconomic Imbalance Procedure to better capture employment and social developments [Ref. Ares(2015)5426195].

— (2015g): Vorschlag für eine Verordnung über ein Programm zur Unterstützung von Strukturreformen für den Zeitraum 2017-2020 und zur Änderung der Verordnungen (EU) Nr. 1303/2013 und (EU) Nr. 1305/2013 [COM(2015) 701 final].

- (2015h): Empfehlung für eine Empfehlung des Rates zur Einrichtung nationaler Ausschüsse für Wettbewerbsfähigkeit im Euro-Währungsgebiet [COM(2015) 601 final].

- (2015i): Vorschlag für einen Beschluss des Rates über Maßnahmen zur schrittweisen Einrichtung einer einheitlichen Vertretung des Euro-Währungsgebiets im Internationalen Währungsfonds [COM(2015) 603 final].

- (2015j): The Euro Plus Pact. How Integration into the EU Framework can Give New Momentum for Structural Reforms in the Euro Area [European Political Strategy Center: Strategic Notes, Nr. 3/2015].

- (2015k): Mitteilung: Jahreswachstumsbericht 2016. Die wirtschaftliche Erholung konsolidieren und die Konvergenz fördern [COM(2015) 690 final].

- (2015l): Mitteilung: Gesamtbewertung der Übersichten über die Haushaltsplanung 2016 [COM(2015) 800 final].

- (2015m): Vorschlag für eine Verordnung über den Europäischen Fonds für strategische Investitionen und zur Änderung der Verordnungen (EU) Nr. 1291/2013 und (EU) Nr. 1316/2013 [COM(2015) 10 final].

- (2015n): Commission Staff Working Document: Assessment of the Social Impact of the new Stability Support Programme for Greece [SWD(2015) 162 final].

- (20150): Mitteilung: Den Binnenmarkt weiter ausbauen: mehr Chancen für die Menschen und die Unternehmen [COM(2015) 550 final]. 
- (2014a): Mitteilung: Bestandsaufnahme der Strategie Europa 2020 für intelligentes, nachhaltiges und integratives Wachstum [COM(2014) 130 final].

- (2014b): Mitteilung: Eine Investitionsoffensive für Europa [COM(2014) 903 final/2].

- (2014C): Mitteilung: Übersichten über die Haushaltsplanung für 2015. Gesamtbewertung [COM(2014) 907 final].

- (2013a): Mitteilung: Jahreswachstumsbericht 2014 [COM(2013) 800 final].

- (2013b): Vorschlag für eine Verordnung über die Bereitstellung und Qualität von Statistiken für das Verfahren bei einem makroökonomischen Ungleichgewicht [COM(2013) 342 final].

- (2013c): The Two-Pack on economic governance: Establishing an EU framework for dealing with threats to financial stability in euro area member states [European Economy, Occasional Papers 147].

- (2013d): Building a Strengthened Fiscal Framework in the European Union: A Guide to the Stability and Growth Pact [European Economy, Occasional Papers 150].

- (2013e): Der Pakt für Wachstum und Beschäftigung: Ein Jahr danach. Bericht an den Europäischen Rat, 27./28. Juni 2013, https://www.kas.de/documents/284153/28420 2/7_file_storage_file_10166_1.pdf/541bb333-2817-fe22-cfd9-ab5f4e105261?version=1. o\& $\mathrm{t}=1539655534569 ; 05.02 .2021$.

- (2013f): Mitteilung: Auf dem Weg zu einer vertieften und echten Wirtschafts- und Währungsunion. Einführung eines Instruments für Konvergenz und Wettbewerbsfähigkeit [COM(2013) 165 final].

- (2013g): Mitteilung: Auf dem Weg zu einer vertieften und echten Wirtschafts- und Währungsunion: Vorabkoordinierung größerer wirtschaftspolitischer Reformvorhaben [COM(2013) 166 final].

- (2013h): Mitteilung: Stärkung der sozialen Dimension der Wirtschafts- und Währungsunion [COM(2013) 690 final].

- (2012a): Mitteilung: Ein Konzept für eine vertiefte und echte Wirtschafts- und Währungsunion. Auftakt für eine europäische Diskussion [COM(2012) 777 final].

- (2012b): Commission Staff Working Document: Completing the Scoreboard for the MIP. Financial Sector Indicator [SWD(2012) 389 final].

- (2012c): European Economic Forecast. Autumn 2012 [European Economy, Nr. 7/2012].

- (2012d): Scoreboard for the surveillance of macroeconomic imbalances [European Economy, Occasional Papers 92].

- (2012e): Mitteilung: Einen arbeitsplatzintensiven Aufschwung gestalten [COM(2012) 173 final].

- (2012f): Mitteilung: Gemeinsame Grundsätze für nationale fiskalpolitische Korrekturmechanismen [COM(2012) 342 final].

- (2012g): Staatliche Beihilfen. Beihilfenanzeiger bestätigt Trend - trotz krisenbedingter Mehrausgaben weniger, dafür aber gezieltere Beihilfen [IP/12/1444].

- (2012h): Commission Staff Working Document: Open, dynamic and inclusive labour markets [SWD(2012) 97 final].

- (2012i): Mitteilung: Fahrplan für eine Bankenunion [COM(2012) 510 final].

- (2012j): Vorschlag für eine Verordnung zur Übertragung besonderer Aufgaben im Zusammenhang mit der Aufsicht über Kreditinstitute auf die Europäische Zentralbank [COM(2012) 511 final]. 
- (2012k): Vorschlag für eine Verordnung zur Änderung der Verordnung (EU) Nr. 1093/2010 zur Errichtung einer Europäischen Aufsichtsbehörde (Europäische Bankenaufsichtsbehörde) hinsichtlich ihrer Wechselwirkungen mit der Verordnung (EU) Nr. .../... des Rates zur Übertragung besonderer Aufgaben im Zusammenhang mit der Aufsicht über Kreditinstitute auf die Europäische Zentralbank [COM(2012) 512 final].

- (2011a): Grünbuch über die Durchführbarkeit der Einführung von Stabilitätsanleihen [KOM(2011) 818 endgültig].

— (2011b): Mitteilung: Ein Fahrplan für Stabilität und Wachstum [KOM(2011) 669 endgültig].

- (2011c): Commission Staff Working Paper: Scoreboard for the Surveillance of Macroeconomic Imbalances. Envisaged Initial Design [SEC(2011) 1361 final].

- (2011d): Vorschlag für eine Verordnung über den Ausbau der wirtschafts- und haushaltspolitischen Überwachung von Mitgliedstaaten, die von gravierenden Schwierigkeiten in Bezug auf ihre finanzielle Stabilität betroffen oder bedroht sind [KOM(2011) 819 endgültig].

- (2011e): Vorschlag für eine Verordnung über gemeinsame Bestimmungen für die Überwachung und Bewertung der Übersichten über die gesamtstaatliche Haushaltsplanung für die Gewährleistung der Korrektur übermäßiger Defizite der Mitgliedstaaten im Euro-Währungsgebiet [KOM(2011) 821 endgültig].

- (2011f): Commissioner Rehn comments on the new rules for EU economic governance [MEMO/11/664].

- (2010a): Mitteilung: Verstärkung der wirtschaftspolitischen Koordinierung [KOM(2010) 250 endgültig].

- (2010b): Mitteilung: Stärkung der wirtschaftspolitischen Koordinierung für Stabilität, Wachstum und Beschäftigung - Instrumente für bessere wirtschaftspolitische Steuerung der EU [KOM(2010) 367 endgültig].

- (2010c): Mitteilung: Europa 2020. Eine Strategie für intelligentes, nachhaltiges und integratives Wachstum [KOM(2010) 2020 endgültig].

- (2010d): Vorschlag für eine Verordnung zur Änderung der Verordnung (EG) Nr. 1467/97 über die Beschleunigung und Klärung des Verfahrens bei einem übermäßigen Defizit [KOM(2010) 522 endgültig].

- (2010e): Vorschlag für eine Richtlinie über die Anforderungen an die haushaltspolitischen Rahmen der Mitgliedstaaten [KOM(2010) 523 endgültig].

- (2010f): Vorschlag für eine Verordnung über die wirksame Durchsetzung der haushaltspolitischen Überwachung im Euroraum [KOM(2010) 524 endgültig].

- (2010g): Vorschlag für eine Verordnung über die Durchsetzungsmaßnahmen zur Korrektur übermäßiger makroökonomischer Ungleichgewichte im Euroraum [KOM(2010) 525 endgültig].

- (2010h): Vorschlag für eine Verordnung zur Änderung der Verordnung (EG) Nr. 1466/97 über den Ausbau der haushaltspolitischen Überwachung und der Überwachung und Koordinierung der Wirtschaftspolitiken [KOM(2010) 526 endgültig].

- (2010i): Vorschlag für eine Verordnung über die Vermeidung und Korrektur makroökonomischer Ungleichgewichte [KOM(2010) 527 endgültig]. 
- (2010j): The Economic Adjustment Programme for Greece [European Economy, Occasional Papers 61].

- (2010k): Wirtschaftspolitische Steuerung in der EU: Kommission legt umfassendes Legislativpaket vor [IP/10/1199].

- (2010l): Arbeitsdokument der Kommissionsdienststellen: Bewertung der LissabonStrategie [SEK(2010) 114 endgültig].

- (2010m): Mitteilung: Ein EU-Rahmen für Krisenmanagement im Finanzsektor [KOM(2010) 579 endgültig].

- (2009): Mitteilung: Europäische Finanzaufsicht [KOM(2009) 252 endgültig].

- (2006): Communication: Global Europe. Competing in the world. A Contribution to the EU's Growth and Jobs Strategy [COM(2006) 567 final].

- (2001): Europäisches Regieren - Ein Weißbuch. In: ABl. C 287 vom 12.10.2011, S. 1-29.

- (1998): Proposal for a Council Decision on the Representation and Position Taking of the Community at International Level in the context of Economic and Monetary Union [COM(1998) 637 final].

Europäische Kommission \& Europäischer Stabilitätsmechanismus (2018): Future cooperation between the European Commission and the European Stability Mechanism, https://www.consilium.europa.eu/media/37324/20181203-eg-1b-20181115-es m-ec-cooperation.pdf; 05.02.2021.

Europäische Säule Sozialer Rechte, https://ec.europa.eu/info/sites/info/files/social-su mmit-european-pillar-social-rights-booklet_de.pdf; 13.02.2021.

Europäische Zentralbank (2021): List of supervised entities, https://www.banking supervision.europa.eu/ecb/pub/pdf/ssm.listofsupervisedentities202102.en.pdf; 28.03.2021.

- (2018a): Stellungnahme der Europäischen Zentralbank vom 11. April $2018 \mathrm{zu}$ einem Vorschlag für eine Verordnung über die Einrichtung des Europäischen Währungsfonds $[\mathrm{CON} / 2018 / 20]$.

- (2018b): Stellungnahme der Europäischen Zentralbank vom 11. Mai 2018 zu einem Vorschlag für eine Richtlinie zur Festlegung von Bestimmungen zur Stärkung der haushaltspolitischen Verantwortung und mittelfristigen Ausrichtung der Haushalte in den Mitgliedstaaten [CON/2018/25].

- (2017): Agreement on emergency liquidity assistance, https://www.ecb.europa.eu /pub/pdf/other/Agreement_on_emergency_liquidity_assistance_20170517.en.pdf; 05.02.2021.

- (2013a): Stellungnahme der Europäischen Zentralbank vom 10. Oktober $2013 \mathrm{zu}$ einem Vorschlag für eine Verordnung über die Bereitstellung und Qualität von Statistiken für das Verfahren bei einem makroökonomischen Ungleichgewicht [CON/2013/72].

- (2012a): Stellungnahme der Europäischen Zentralbank vom 7. März 2012 zur gestärkten wirtschaftspolitischen Steuerung im Euro-Währungsgebiet [CON/2012/18].

- (2012b): Technical features of Outright Monetary Transactions, https://www.ecb.eur opa.eu/press/pr/date/2012/html/pr120906_1.en.html; 05.02.2021.

- (2011a): Stellungnahme der Europäischen Zentralbank vom 16. Februar 2011 zur Reform der wirtschaftspolitischen Steuerung in der Europäischen Union [CON/2011/13]. 
- (2011b): Stellungnahme der Europäischen Zentralbank vom 17. März 2011 zu einem Entwurf des Beschlusses des Europäischen Rates zur Änderung des Artikels 136 des Vertrags über die Arbeitsweise der Europäischen Union hinsichtlich eines Stabilitätsmechanismus für die Mitgliedstaaten, deren Währung der Euro ist [CON/2011/24].

- (2011c): Letter from Jean-Claude Trichet and Miguel Fernández Ordoñez to José Luis Rodríguez Zapatero (Prime Minister of Spain), https:/www.ecb.europa.eu/pub/p df/other/2011-08-05-letter-from-trichet-and-fernandez-ordonez-to-zapateroen.p df?e5c1a67f9627c5fo87d5c7fo2168eoda; 05.02.2021.

- (2011): ECB announces measures to support bank lending and money market activity, https://www.ecb.europa.eu/press/pr/date/2011/html/pr111208_1.en.ht $\mathrm{ml}$; 05.02.2021.

- (2010a): Reinforcing Economic Governance in the Euro Area, https://www.ecb. europa.eu/pub/pdf/other/reinforcingeconomicgovernanceintheeuroareaen.pdf; 05.02.2021.

- (2010b): Letter from Jean-Claude Trichet to Brian Lenihan (Minister of Finance of Ireland), https://www.ecb.europa.eu/press/shared/pdf/2010-11-19_Letter_ECB_Pre sident_to\%20IE_FinMin.pdf?31295060a74coffe738a12cd9139f578; 05.02.2021.

- (2010c): ECB Monthly Bulletin (June 2010).

- (2010d): Letter from Jean-Claude Trichet to Brian Lenihan (Minister of Finance of Ireland), https://www.ecb.europa.eu/press/shared/pdf/2010-10-15_Letter_ECB_ President_to_IE_FinMin.pdf?e19978a39fa112418947d2e16895009a; 05.02.2021.

Europäischer Fiskalausschuss (2018): Assessment of the fiscal stance appropriate for the euro area in 2019, https://ec.europa.eu/info/sites/info/files/20180603-june-report_ -final_en.pdf; 05.02.2021.

- (2017a): Assessment of the prospective fiscal stance appropriate for the euro area, https://ec.europa.eu/info/sites/info/files/prospective_euro_area_fiscal_stanc e_2017_0.pdf; 05.02.2021.

— (2017b): Annual Report 2017, https://ec.europa.eu/info/sites/info/files/2017_efb_ann ual_report_en_o.pdf; 05.02.2021.

Europäischer Gerichtshof (2018): Urteil vom 11. Dezember 2018 [C-493/17, Celex-Nr. 62017CJ0493].

- (2015): Urteil vom 16.06.2015 [C-62/14, Celex-Nr. 62014CJ0062].

- (2014): Beschluss vom 26.06.2014 [C-264/12, Celex-Nr. 62012CO0264].

- (2013): Beschluss vom 07.03.2013 [C-128/12, Celex-Nr. 62012CB0128].

- (2012): Urteil vom 27.11.2012 [C-370/12, Celex-Nr. 62012CJ0370].

Europäischer Rat (2020): Schlussfolgerungen der außerordentlichen Ratstagung (17.-21. Juli 2020) [EUCO 10/20].

- (2016a): Schlussfolgerungen des Europäischen Rates (18./19. Februar 2016) [EUCO 1/16].

- (2016b): Schlussfolgerungen des Europäischen Rates (17./18. März 2016) [EUCO 12/1/16 REV 1].

- (2016c): Schlussfolgerungen des Europäischen Rates (28. Juni 2016) [EUCO 26/16].

- (2015): Schlussfolgerungen des Europäischen Rates (17./18. Dezember 2015) [EUCO 28/15]. 
- (2014a): Schlussfolgerungen des Europäischen Rates (26./27. Juni 2014) [EUCO 79/14 in Verbindung mit EUCO 79/14 COR 3 (de)].

- (2014b): Schlussfolgerungen des Europäischen Rates (23./24. Oktober 2014) [EUCO 169/14].

- (2014c): Schlussfolgerungen des Europäischen Rates (18. Dezember 2014) [EUCO 237/14].

- (2013): Schlussfolgerungen des Europäischen Rates (19./20. Dezember 2013) [EUCO 217/13 in Verbindung mit EUCO 217/13 COR 1 REV 2].

- (2012a): Schlussfolgerungen des Europäischen Rates (13./14. Dezember 2012) [EUCO 205/12 in Verbindung mit EUCO 205/12 COR 1].

- (2012b): Schlussfolgerungen des Europäischen Rates (1./2. März 2012) [EUCO 4/3/12 REV 3].

- (2012c): Schlussfolgerungen des Europäischen Rates (28./29. Juni 2012) [EUCO 76/2/12 REV 2].

- (2012d): Remarks by President of the European Council Herman Van Rompuy following the informal dinner of the members of the European Council [EUCO 93/12].

- (2011a): Schlussfolgerungen des Europäischen Rates (24./25. März 2011) [EUCO 10/1/11/REV 1].

- (2011b): Schlussfolgerungen des Europäischen Rates (23./24. Juni 2011) [EUCO 23/11].

- (2011c): Remarks by President of the European Council Herman Van Rompuy following the meeting of the Euro Summit [EUCO 116/11].

- (2011d): Bericht der Minister der am Euro-Plus-Pakt teilnehmenden Mitgliedstaaten. Vermerk des Generalsekretariats des Rates für die Delegationen [EUCO 24/11].

- (2011e): Remarks by President Van Rompuy at the press conference following the Eurozone Summit [EUCO 54/11].

- (2011f): Schlussfolgerungen des Europäischen Rates (23. Oktober 2011) [EUCO 52/1/11 REV 1].

- (2010a): Schlussfolgerungen des Europäischen Rates (25./26. März 2010) [EUCO 7/1/10 REV 1].

- (2010b): Schlussfolgerungen des Europäischen Rates (17. Juni 2010) [EUCO 13/1/10 REV 1].

- (2010c): Statement by the Heads of State or Government of the European Union, htt ps:/www.consilium.europa.eu/media/21428/20100211-statement-by-the-heads-of -state-or-government-of-the-european-union-on-greece-en.pdf; 05.02.2021.

- (2010d): Schlussfolgerungen des Europäischen Rates (28./29. Oktober 2010) [EUCO 25/1/10 REV 1].

- (2010e): Schlussfolgerungen des Europäischen Rates (16./17. Dezember 2010) [EUCO 30/1/10 REV 1].

- (2010f): Abschlussbericht der Arbeitsgruppe an den Europäischen Rat [15302/10].

- (2009): Schlussfolgerungen des Europäischen Rates (10./11. Dezember 2009) [EUCO 6/09].

- (2000): Schlussfolgerungen des Vorsitzes vom Europäischen Rat am 23./24. März 2000 in Lissabon, https://www.europarl.europa.eu/summits/lisi_de.htm, 05.02.2021. 
Europäischer Rechnungshof (2018a): Prüfung des Verfahrens bei einem makroökonomischen Ungleichgewicht (MIP) [Sonderbericht Nr. 03/2018].

- (2018b): Wird das Hauptziel der präventiven Komponente des Stabilitäts- und Wachstumspakts erreicht? [Sonderbericht Nr. 18/2018].

- (2017): Die Rolle der Kommission in der griechischen Finanzkrise [Sonderbericht Nr. 17/2017].

Europäischer Stabilitätsmechanismus (2020): ESM Board of Governors backs Pandemic Crisis Support, https://www.esm.europa.eu/press-releases/esm-board-governorsbacks-pandemic-crisis-support; 05.02.2021.

Europäisches Parlament (2020): Entschließung vom 23. Juli $2020 \mathrm{zu}$ den Schlussfolgerungen der außerordentlichen Tagung des Europäischen Rates vom 17.-21. Juli 2020 [P9_TA-PROV(2020)0206].

- (2019a): Entschließung vom 13. Februar 2019 zum Stand der Debatte über die Zukunft Europas [P8_TA-PROV(2019)0098].

- (2019b): Entschließung vom 14. März $2019 \mathrm{zu}$ dem Vorschlag für eine Verordnung des Rates über die Einrichtung des Europäischen Währungsfonds [P8_TAPROV(2019)0218].

- (2018): Bericht über den Vorschlag für eine Verordnung zur Änderung der Verordnung (EU) Nr. 1303/2013 mit gemeinsamen Bestimmungen über den Europäischen Fonds für regionale Entwicklung, den Europäischen Sozialfonds, den Kohäsionsfonds, den Europäischen Landwirtschaftsfonds für die Entwicklung des ländlichen Raums und den Europäischen Meeres- und Fischereifonds sowie mit allgemeinen Bestimmungen über den Europäischen Fonds für regionale Entwicklung, den Europäischen Sozialfonds, den Kohäsionsfonds und den Europäischen Meeres- und Fischereifonds und zur Aufhebung der Verordnung (EG) Nr. 1083/2006 in Bezug auf die Unterstützung von Strukturreformen in den Mitgliedstaaten. [A8-0316/2018].

- (2017a): Entschließung vom 16. Februar $2017 \mathrm{zu}$ der Haushaltskapazität für das EuroWährungsgebiet [P8_TA(2017)0050].

- (2017b): Entschließung zu möglichen Entwicklungen und Anpassungen der derzeitigen institutionellen Struktur der Europäischen Union [P8_TA-PROV(2017)0048].

- (2017c): Entschließung vom 16. Februar 2017 zur Verbesserung der Funktionsweise der Europäischen Union durch Ausschöpfung des Potenzials des Vertrags von Lissabon [P8_TA-PROV(2017)0049].

- (2017d): Protokoll. Ergebnis der namentlichen Abstimmungen - Anlage (16.02.2017) [PE 600.408].

- (2016): Entschließung vom 26. Oktober $2016 \mathrm{zu}$ dem Europäischen Semester für die Koordinierung der Wirtschaftspolitik: Umsetzung der Prioritäten für 2016 [P8_TA(2016)0416].

- (2015): Entschließung vom 24. Juni 2015 zur Überprüfung des Rahmens für die wirtschaftspolitische Steuerung: Bestandsaufnahme und Herausforderungen [P8_TA(2015)0238].

- (2014a): Entschließung vom 13. März 2014 zu der Untersuchung über die Rolle und die Tätigkeit der Troika (EZB, Kommission und IWF) in Bezug auf die Programmländer des Euroraums [P7_TA-PROV(2013)0239]. 
- (2014b): Entschließung vom 13. März $2014 \mathrm{zu}$ dem beschäftigungs- und sozialpolitische Aspekten der Rolle und der Tätigkeiten der Troika (EZB, Kommission und IWF) in Bezug auf Programmländer des Euro-Währungsgebiets [P7_TAPROV(2014)0240].

- (2014c): Abänderungen vom 11. März $2014 \mathrm{zu}$ dem Vorschlag für eine Verordnung über die Bereitstellung und Qualität von Statistiken für das Verfahren bei einem makroökonomischen Ungleichgewicht (Ordentliches Gesetzgebungsverfahren: erste Lesung) [P7_TA(2014)0181].

- (2013a): Entschließung vom 16. Januar 2013 zur Durchführbarkeit der Einführung von Stabilitätsanleihen [P7_TA-PROV(2013)0018].

- (2013b): Standpunkt, festgelegt in erster Lesung am 12. März 2013 im Hinblick auf den Erlass der Verordnung über den Ausbau der wirtschafts- und haushaltspolitischen Überwachung von Mitgliedstaaten im Euro-Währungsgebiet, die von gravierenden Schwierigkeiten in Bezug auf ihre finanzielle Stabilität betroffen oder bedroht sind [EP-PE_TC1-COD(2011)0385].

- (2013c): Standpunkt, festgelegt in erster Lesung am 12. März 2013 im Hinblick auf den Erlass der Verordnung über gemeinsame Bestimmungen für die Überwachung und Bewertung der Übersichten über die Haushaltsplanung und für die Gewährleistung der Korrektur übermäßiger Defizite der Mitgliedstaaten im Euro-Währungsgebiet [EP-PE_TC1-COD(2011)0386].

- (2013d): Entschließung vom 25. Mai $2013 \mathrm{zu}$ künftigen Legislativvorschlägen zur Wirtschafts- und Währungsunion (WWU): Reaktion auf die Mitteilungen der Kommission [P7_TA(2013)0222].

- (2013e): Economic governance »two pack« background note [Ref.20130304BKG62 046].

- (2013f): Entschließung vom 12. Juni 2013 zur Stärkung der Demokratie in der EU in der künftigen WWU [P7_TA(2013)0269].

- (2013g): Entschließung vom 18. April 2013 zur Vollendung des Scoreboards zur Überwachung makroökonomischer Ungleichgewichte [P7_TA-PROV(2013)0188].

- (2013h): EU-Wirtschaftspolitik: Wider die Schuldenspirale [Blickpunkt; fortlaufendes Dossier] [20110429FCS18371].

- (2012a): Entschließung vom 15. Februar 2012 zu der Durchführbarkeit der Einführung von Stabilitätsanleihen [P7_TA(2012)0046].

- (2012b): Entschließung vom 20. November $2012 \mathrm{zu}$ einem Pakt für soziale Investitionen als Reaktion auf die Krise [P7_TA(2012)0419].

- (2012c): Entschließung vom 20. November 2012 mit Empfehlungen an die Kommission zum Bericht der Präsidenten des Europäischen Rates, der Europäischen Kommission, der Europäischen Zentralbank und der Euro-Gruppe »Auf dem Weg zu einer echten Wirtschafts- und Währungsunion« [P7_TA(2012)0430].

- (2012d): Bericht über den Vorschlag für eine Verordnung über den Ausbau der wirtschafts- und haushaltspolitischen Überwachung von Mitgliedstaaten, die von gravierenden Schwierigkeiten in Bezug auf ihre finanzielle Stabilität im EuroWährungsgebiet betroffen oder bedroht sind [A7-0172/2012].

- (2012e): Bericht über den Vorschlag für eine Verordnung über gemeinsame Bestimmungen für die Überwachung und Bewertung der Übersichten über die gesamt- 
staatliche Haushaltsplanung und für die Gewährleistung der Korrektur übermäßiger Defizite der Mitgliedstaaten im Euro-Währungsgebiet [A7-0173/2012].

- (2012f): Gemeinsamer Entschließungsantrag zu den Schlussfolgerungen der Tagung des Europäischen Rates (8.-9. Dezember 2011) zum Entwurf eines Internationalen Abkommens über eine verstärkte Wirtschaftsunion [B7-0003/2012 B7-0004/2012 B7-0005/2012 B7-0011/2012 RC 1].

- (2011a): Entschließung vom 23. März 2011 zu dem Entwurf eines Beschlusses des Europäischen Rates zur Änderung des Artikels 136 des Vertrags über die Arbeitsweise der Europäischen Union hinsichtlich eines Stabilitätsmechanismus für die Mitgliedstaaten, deren Währung der Euro ist [P7_TA(2011)0103].

- (2011b): Abänderungen vom 23. Juni 2011 zu dem Vorschlag für eine Verordnung über die Vermeidung und Korrektur makroökonomischer Ungleichgewichte (Ordentliches Gesetzgebungsverfahren: erste Lesung) [P7_TA(2011)0287].

- (2011c): Entschließung vom 6. Juli 2011 zu der Finanz-, Wirtschafts- und Sozialkrise: Empfehlungen in Bezug auf die zu ergreifenden Maßnahmen und Initiativen [P7_TA(2011)0331].

- (2011d): Entschließung vom 15. Dezember $2011 \mathrm{zu}$ der geplanten anfänglichen Auslegung des Scoreboards zur Überwachung makroökonomischer Ungleichgewichte [P7_TA-PROV(2011)0583].

- (2011e): FAQ on the economic governance »six pack « [Ref. 20110920BKG27073].

- (2011f): Entschließung vom 1. Dezember 2011 zu dem Europäischen Semester für die wirtschaftspolitische Koordinierung [P7_TA-PROV(2011)0542].

- (2011g): Bericht über den Vorschlag für eine Verordnung über Durchsetzungsmaßnahmen zur Korrektur übermäßiger makroökonomischer Ungleichgewichte im Euroraum [A7-0182/2011].

- (2011h): Bericht über den Vorschlag für eine Verordnung zur Änderung der Verordnung (EG) Nr. 1466/97 über den Ausbau der haushaltspolitischen Überwachung und der Überwachung und Koordinierung der Wirtschaftspolitiken [A7-0178/2011].

- (2011i): Bericht über den Vorschlag für eine Verordnung zur Änderung der Verordnung (EG) Nr. 1467/97 über die Beschleunigung und Klärung des Verfahrens bei einem übermäßigen Defizit [A7-0179/2011].

- (2011): Bericht über den Vorschlag für eine Verordnung über die wirksame Durchsetzung der haushaltspolitischen Überwachung im Euroraum [A7-0180/2011].

- (2011k): Bericht über den Vorschlag für eine Verordnung über die Vermeidung und Korrektur makroökonomischer Ungleichgewichte [A7-0183/2011].

- (2011l): Bericht über den Vorschlag für eine Richtlinie über die Anforderungen an die haushaltspolitischen Rahmen der Mitgliedstaaten [A7-0184/2011].

- (2011m): Entschließung vom 17. Februar $2011 \mathrm{zu}$ Europa 2020 [P7_TA(2011)0068].

- (2010a): Entschließung vom 7. Juli 2010 zum Thema Europäische Finanzstabilitätsfazilität und Europäischer Finanzstabilisierungsmechanismus sowie künftige Maßnahmen [P7_TA(2010)0277].

- (2010b): Protokoll. Ergebnisse der namentlichen Abstimmungen - Anlage (20.10. 2010) [PE 451.904]. 
- (2010c): Entschließung vom 20. Oktober 2010 mit Empfehlungen an die Kommission zur Verbesserung der Economic Governance und des Stabilitätsrahmens in der Union, vor allem im Euroraum [P7_TA-PROV(2010)0377].

- (2010d): Entschließung vom 10. März 2010 zur EU-2020-Strategie [P7_TA(2010)0053].

- (2010e): Entschließung vom 20. Mai $2010 \mathrm{zu}$ langfristig tragfähigen öffentlichen Finanzen für eine sich erholende Volkswirtschaft [P7_TA(2010)0190].

European Round Table of Industrialists (2013): Emailverkehr in Bezug auf und Ablaufplan für das Treffen im Bundeskanzleramt [Ref. Ares(2013)704472].

- (2010): ERT's Vision for a competitive Europe in 2025, https://www.ert.eu/sites/ert/ files/generated/files/document/ert_vision_report_final_2010.pdf; 05.02.2021]

Eurostat (o.J.): Information on indicators, https://ec.europa.eu/eurostat/web/macroec onomic-imbalances-procedure/indicators; 05.02.2021.

- (2020): Langfristige Rendite öffentlicher Anleihen [Data Browser, Datencode: TEIMF050]; https://ec.europa.eu/eurostat/databrowser/view/teimfo50/default/tab le?lang=de; 13.02.2021.

Evans, Bryan M. \& McBride, Stephen (2017): The Austerity State: An Introduction. In: Dies. (Hg.): The Austerity State, Toronto, S. 3-21, https://doi.org/10.3138/9781487515 171-002.

Evans, Trevor (2011): The crisis in the euro area. In: International Journal of Labour Research, Nr. 3/2011, S. 97-113.

Everson, Michelle \& Joerges, Christian (2014): Who is the guardian of constitutionalism in Europe after the financial crisis? In: Kröger, Sandra (Hg.): Political Representation in the European Union. Still democratic in times of crisis? Abingdon, S. 197-211, ht tps://doi.org/10.2139/ssrn.2287111.

Fabbrini, Federico (2015): From Executive Federalism to Executive Government: Current Problems and Future Prospects in the Governance of EMU. In: Ders./Hirsch, Ernst \& Somsen, Han (Hg.): What Form of Government for the European Union and the Eurozone? Oxford, S. 289-306, https://doi.org/10.5040/9781509901234.ch-016.

Fazi, Thomas (2018): Illusion: Die EU lässt sich demokatisieren, https://www.ipg-journ al.de/schwerpunkt-des-monats/illusionen/artikel/detail/illusion-die-eu-laesst-sic h-demokratisieren-3144/; 05.02.2021.

Featherstone, Kevin (2016): Conditionality, Democracy and Institutional Weakness: the Euro-crisis Trilemma. In: Journal of Common Market Studies, Annual Review 2016, S. 48-64, https://doi.org/10.1111/jcms.12411.

Feigl, Georg (2015): Auswirkungen der neuen europäischen wirtschaftspolitischen Steuerung am Beispiel Spaniens und Österreichs. In: Hagemann, Harald \& Kromphardt, Jürgen (Hg.): Für eine bessere gesamteuropäische Wirtschaftspolitik, Marburg, S. 43-82.

- (2013): Auf dem Weg zu einer »echten« Wirtschafts- und Währungsunion? In: Kurswechsel, Nr. 1/2013, S. 85-91.

Feigl, Georg \& Zotter, Thomas (2020): Covid-19-Rezession. EU-Krisenmanagement auf dem Prüfstand. In: infobrief eu \& international, Nr. 2/2020, S. 2-8.

Feigl, Georg \& Zuckerstätter, Sepp (2013): Mythos Wettbewerbsorientierung. In: Kromphardt, Jürgen (Hg.): Die Finanz- und Wirtschaftskrise und ihre Überwindung, Marburg, S. 109-143. 
Financial Stability Forum (2000): Grouping of Offshore Financial Centres (OFCs) to Assist in Setting Priorities for Assessment [Press release Ref. No. 15/2000E].

Finish Ministry of Finance (o.J.): Finance ministers from Denmark, Estonia, Finland, Ireland, Latvia, Lithuania, the Netherlands and Sweden underline their shared views and values in the discussion on the architecture of the EMU, https://vm.fi/d ocuments/10623/6305483/Position+EMU+Denmark+Estonia+Finland+Ireland+Latv ia+Lithuania+the+Netherlands+and+Sweden.pdf/; 05.02.2021.

Fisahn, Andreas (2020): Karlsruhe vs. EZB: Warum wir neue EU-Verträge brauchen. In: Blätter für deutsche und internationale Politik, Nr. 6/2020, S. 87-92.

- (2017a): Europäische Fliehkräfte. In: Candeias, Mario \& Demirović, Alex (Hg.): Europe - what's left? Die Europäische Union zwischen Zerfall, Autoritarismus und demokratischer Erneuerung, Münster, S. 93-114.

- (2017b): Substanzverlust der Demokratie. In: FORUM Wissenschaft, Nr. 2/2017, S. 2225.

— (2008): Herrschaft im Wandel. Überlegungen zu einer kritischen Theorie des Staates, Köln.

Fischer-Lescano, Andreas (2014): Troika in der Austerität. Rechtsbindungen der Unionsorgane beim Abschluss von Memoranda of Understanding. In: Kritische Justiz, Nr. 1/2014, S. 2-25, https://doi.org/10.5771/0023-4834-2014-1-2.

Fischer-Lescano, Andreas \& Kommer, Steffen (2011): Verstärkte Zusammenarbeit in der EU. Ein Modell für Kooperationsfortschritte in der Wirtschafts- und Sozialpolitik? [Friedrich-Ebert-Stiftung: Internationale Politikanalyse].

Fischer-Lescano, Andreas \& Oberndorfer, Lukas (2013): Fiskalvertrag und Unionsrecht. Unionsrechtliche Grenzen völkervertraglicher Fiskalregulierung und Organleihe. In: Neue Juristische Wochenschrift, Nr. 1-2/2013, S. 9-14.

Flassbeck, Heiner \& Lapavitsas, Costas (2015a): Against the Troika. Crisis and Austerity in the Eurozone, London.

- (2015b): Confronting the failure of the European Monetary Union. In: Jäger, Johannes \& Springler, Elisabeth (Hg.): Asymmetric Crisis in Europe and Possible Futures. Critical political economy and post-Keynesian perspectives, Abingdon, S. 131-148, h ttps://doi.org/10.4324/9781315764009.

Flassbeck, Heiner \& Steinhardt, Paul (2018): Gescheiterte Globalisierung. Ungleichheit, Geld und die Renaissance des Staates, Berlin.

Forschungsgruppe »Staatsprojekt Europa« (2014): Einleitung. In: Dies. (Hg.): Kämpfe um Migrationspolitik. Theorie, Methode und Analysen kritischer Europaforschung, Bielefeld, S. 9-12 https://doi.org/10.14361/transcript.9783839424025.intro.

Frankfurter Allgemeine Zeitung (31.08.2013): Portugals Verfassungsgericht kippt schon wieder Reformen https://www.faz.net/aktuell/wirtschaft/konjunktur/portugal/eur opas-schuldenkrise-portugals-verfassungsgericht-kippt-schon-wieder-reformen-1 2554311.html; 05.02.2021.

— (01.03.2011): Merkels Pakt ist kein Pakt mehr, https://www.faz.net/aktuell/wirtschaf t/konjunktur/reform-der-waehrungsunion-merkels-pakt-ist-kein-pakt-mehr-1603 971.html; 05.02.2021. 
- (21.10.2009): Griechenlands Defizit plötzlich verdoppelt, https://www.faz.net/aktue ll/wirtschaft/wirtschaftspolitik/aerger-in-bruessel-griechenlands-defizit-ploetzlic h-verdoppelt-1865830.html; 05.02.2021.

— (17.10.2002): Prodi nennt Stabilitätspakt »dumm« und »starr«, https://www.faz.net/ aktuell/wirtschaft/haushaltspolitik-prodi-nennt-stabilitaetspakt-dumm-und-starr -183467.html; 05.04.2021.

Französische Botschaft (2017): Rede von Staatspräsident Macron an der Sorbonne. Initiative für Europa, https://de.ambafrance.org/IMG/pdf/macron_sorbonne_europe _integral.pdf?23641/4be243b705d8068173926eeb032184acc4a1fo73; 05.02.2021.

Fratianni, Michele (2000): Governance of the EU in the twenty-first century. In: Prakash, Aseem \& Hart, Jeffrey A. (Hg.): Globalization and Governance, London, S. 289-309, https://doi.org/10.4324/9780203478790.

Fritsche, Jan Philipp \& Harms, Patrick Christian (2020): Corona-Krise: (Wirtschafts-)politische Perspektiven. Die Reflexe aus der Finanzkrise sind nicht genug! In: Wirtschaftsdienst, Nr. 4/2020, S. 266-271, https://doi.org/10.1007/s10273-020-2 630-6.

>Frugal Four (2020): Non-paper EU support for efficient and sustainable COVID-19 recovery, https://www.tweedekamer.nl/downloads/document?id=41d281d6-231c-4f $7 \mathrm{c}-\mathrm{a3c3}$-040dac383f4c\&title=Non-paper\%20EU\%20support\%20for\%20efficient $\% 20$ and\%20sustainable\%20COVID-19\%20recovery.pdf; 05.02.2021

Gallas, Alexander (2016): Konjunktureller Marxismus: Althusser und Poulantzas über den kapitalistischen Staat. In: Ekici, Ekrem/Nowak, Jörg \& Wolf, Frieder O. (Hg.): Althusser - Die Reproduktion des Materialismus, Münster, S. 140-168.

Gechert, Sebastian (2015): Öffentliche Investitionen und Staatsverschuldung im Euroraum [IMK Policy Brief].

Generalsekretariat des Rates (2019): Antwortschreiben vom 22. Februar 2019 der Generaldirektion Kommunikation und Information zum Antrag auf Zugang zu Dokumenten des Rates der Europäischen Union vom 26. Januar 2019 [U.Z.: 19/0268$\mathrm{em} / \mathrm{nb}]$.

Genschel, Philipp \& Jachtenfuchs, Markus (2018): From Market Integration to Core State Powers: The Eurozone Crisis, the Refugee Crisis and Integration Theory. In: Journal of Common Market Studies, Nr. 1/2018, S. 178-196, https://doi.org/10.1111/jcms.126 54.

- (2015): More integration, less federation: The European integration of core state powers [EUI Working Paper RSCAS 2015/33], https://doi.org/10.2139/ssrn.2631960.

- (2014): Introduction: Beyond Market Regulation. Analysing the Integration of Core State Powers. In: Dies. (Hg.): Beyond the Regulatory Polity? The European Integration of Core State Powers, Oxford, S. 1-23, https://doi.org/10.1093/acprof:0so/97801 99662821.003.0001.

Genschel, Philipp \& Zangl, Bernhard (2008): Metamorphosen des Staates - vom Herrschaftsmonopolisten zum Herrschaftsmanager. In: Leviathan, Nr. 3/2008, S. 430454, https://doi.org/10.1007/s11578-008-0022-1.

Georgi, Fabian (2016): Widersprüche im langen Sommer der Migration. Ansätze einer materialistischen Grenzregimeanalyse. In: PROKLA, Nr. 2/2016, S. 183-203, https:// doi.org/10.32387/prokla.v46i183.108. 
Georgi, Fabian \& Kannankulam, John (2015): Kräfteverhältnisse in der Eurokrise. Konfliktdynamiken im bundesdeutschen >Block an der Macht<. In: PROKLA, Nr. 3/2015, S. 349-369, https://doi.org/10.32387/prokla.v45i180.207.

- (2012): Das Staatsprojekt Europa in der Krise. Die EU zwischen autoritärer Verhärtung und linken Alternativen, Brüssel.

Georgi, Fabian/Kannankulam, John \& Wolff, Sebastian (2014): Multiskalare Kräfteverhältnisse in Europa. Vorbemerkungen zu den `Länderstudien $\prec$ In: Forschungsgruppe »Staatsprojekt Europa« (Hg.): Kämpfe um Migrationspolitik. Theorie, Methode und Analysen kritischer Europaforschung, Bielefeld, S. 87-91, https://doi.org/10.143 61/transcript.9783839424025.87.

Gericht der Europäischen Union (2018): Urteil vom 22. März 2018 [Rechtssache T540/15].

Gill, Stephen (2003): A Neo-Gramscian Approach to European Integration. In: Cafruny, Alan W. \& Ryner, Magnus (Hg.): A Ruined Fortress? Neoliberal Hegemony and Transformation in Europe, Lanham, S. 47-70.

- (2000): Theoretische Grundlagen einer neo-gramscianischen Analyse der europäischen Integration. In: Bieling, Hans-Jürgen \& Steinhilber, Jochen (Hg.): Die Konfiguration Europas. Dimensionen einer kritischen Integrationstheorie, Münster, S. 23-50.

- (1998): European Governance and New Constitutionalism: Economic and Monetary Union and Alternatives to Disciplinary Neoliberalism in Europe. In: New Political Economy, Nr. 1/1998, S. 5-26, https://doi.org/10.1080/13563469808406330.

Gischer, Horst/Herz, Bernhard \& Menkhoff, Lukas (2012): Geld, Kredit und Banken. Eine Einführung, Berlin, https://doi.org/10.1007/978-3-662-49227-7.

Glöckler, Gabriel (2015): Vorbemerkung zu den Artikeln 119 bis 144 AEUV. In: Groeben, Hans von der/Schwarze, Jürgen \& Hatje, Armin (Hg.): Europäisches Unionsrecht, 7. Auflage, Baden-Baden.

Gramsci, Antonio (1991-2002): Gefängnishefte [Bde. 1-10], Hamburg.

Grande, Edgar (2012): Governance-Forschung in der Governance-Falle? - Eine kritische Bestandsaufnahme. In: Politische Vierteljahresschrift, Nr. 4/2012, S. 565-592, https: //doi.org/10.5771/0032-3470-2012-4-565.

Grözinger, Gerd (2015a): Eurozone: multiple problems, multiple solutions. In: Ders./Brunkhorst, Hauke \& Gaitanides, Charlotte (Hg.): Europe at a Crossroad. From Currency Union to Political and Economic Governance? Baden-Baden, S. 209227, https://doi.org/10.5771/9783845261768-209.

- (2015b): Demokratisiert die EZB! In: Blätter für deutsche und internationale Politik, Nr. 4/2015, S. 37-40.

Guérot, Ulrike (2017): »Eine Art bürgerliches Kaffeetrinken«, http://taz.de/!5396168/; 05.02.2021.

- (2013): Zwischen Haushalts- und Legitimationsdefizit: Zur Zukunft der europäischen Demokratie. In: Aus Politik und Zeitgeschichte, Nr. 6-7/2013, S. 3-10.

Guntrum, Simon (2019): Frankreichs Widersacher, Deutschlands »bad cop«? Die Formierung der »New Hanseatic League« in den jüngsten Reformdiskussionen der Eurozone. In: PROKLA, Nr. 1/2019, S. 163-170, https://doi.org/10.32387/prokla.v49i194. 1773. 
Guth, Ralph (2013): EU-Krisenpolitik als Verrechtlichung der Demokratie: Autoritärer Europäischer Konstitutionalismus und die Negation der Volkssouveränität. In: momentum quarterly, Nr. 1/2013, S. 33-46.

Guttenberg, Lucas (2019): A missed opportunity - 5 reasons why ESM reform will fail to deliver [Jacques Delors Institute Berlin: Policy Brief].

Habermas, Jürgen (2013): Im Sog der Technokratie [Kleine Politische Schriften XII], Berlin.

- (2011a): Zur Verfassung Europas. Ein Essay, Berlin.

- (2011b): Der Konstruktionsfehler der Währungsunion. In: Blätter für deutsche und internationale Politik, Nr. 5/2011, S. 64-66.

Hacker, Björn (2018a): Soziales Europäisches Semester? Die Europäische Säule sozialer Rechte im Praxistest [Institut für Europäische Politik: Research Paper Nr. 02/18].

- (2018b): Die Europäische Säule sozialer Rechte: Nutzung und Nutzen. In: integration, Nr. 4/2018, S. 259-272, https://doi.org/10.5771/0720-5120-2018-4-259.

- (2017): Was von der Eurokrise übrig bleibt. Die Kontroverse um die Reform der Wirtschafts- und Währungsunion. In: Neue Gesellschaft/Frankfurter Hefte, Nr. 6/2017, S. 17-20.

Hacker, Björn \& Koch, Cédric M. (2017): The divided Eurozone. Mapping Conflicting Interests on the Reform of the Monetary Union [Friedrich-Ebert-Stiftung: politik für europa].

- (2016): Wer fordert was? Ein Mapping politischer Akteure und ihr Einfluss auf die Währungsunion. In: Schellinger, Alexander \& Steinberg, Philipp (Hg.): Die Zukunft der Eurozone. Wie wir den Euro retten und Europa zusammenhalten, Bielefeld, S. 89-107, https://doi.org/10.14361/9783839436363-006.

Hacker, Björn \& van Treeck, Till (2010): Wie einflussreich wird die europäische Governance? Reformierter Stabilitäts- und Wachstumspakt, Europa 2020-Strategie und »Europäisches Semester [ [Friedrich-Ebert-Stiftung: Internationale Politikanalyse].

Häde, Ulrich (2016): Titel VIII. Die Wirtschafts- und Währungsunion. In: Calliess, Christian \& Ruffert, Matthias (Hg.): EUV/AEUV. Das Verfassungsrecht der Europäischen Union mit Europäischer Grundrechtecharta (Kommentar), 5. Auflage, München.

Hallerberg, Mark (2011): Fiscal federalism reforms in the European Union and the Greek crisis. In: European Union Politics, Nr. 1/2011, S. 127-142, https://doi.org/10.1177/146 5116510387652.

Hallerberg, Mark/Marzinotto, Benedicta \& Wolff, Guntram B. (2012): An Assessment of the European Semester [Studie hgg. von der Generaldirektion Interne Politikbereiche der Union des Europäischen Parlaments; PE 475.121].

Haltern, Ulrich (2012): Integration durch Recht. In: Bieling, Hans-Jürgen \& Lerch, Marika (Hg.): Theorien der europäischen Integration, 3. Auflage, Wiesbaden, S. 339-358, https://doi.org/10.1007/978-3-531-19715-9_16.

Hattenberger, Doris (2012): Artikel 121. In: Schwarze, Jürgen/Becker, Ulrich/Hatje, Armin \& Schoo, Johann (Hg.): EU-Kommentar, 3. Auflage, Baden-Baden.

Haug, Frigga (2010): Krise. In: Historisch-Kritisches Wörterbuch des Marxismus, Bd. 7/II, Hamburg, Sp. 2121-2143.

Heckmann, Friedrich (1992): Interpretationsregeln zur Auswertung qualitativer Interviews und sozialwissenschaftlich relevanter »Texte«. Anwendungen der Hermeneu- 
tik für die empirische Sozialforschung. In: Hoffmeyer-Zlotnik, Jürgen H. P. (Hg.): Analysen verbaler Daten: über den Umgang mit qualitativen Daten. Opladen, S. 142167, https://doi.org/10.1007/978-3-322-90092-0_6.

Heimberger, Philipp (2016): Did Fiscal Consolidation Cause the Double-Dip Recession in the Euro Area? [Wiener Institut für Internationale Wirtschaftsvergleiche: Working Paper 130].

- (2015): Das Scheitern der europäischen Krisenpolitik. In: infobrief eu \& international, Nr. 3/2015, S. 11-15.

Heine, Frederic \& Sablowski, Thomas (2015): Zerfällt die Europäische Währungsunion? Handels- und Kapitalverflechtungen, Krisenursachen und Entwicklungsperspektiven. In: PROKLA, Nr. 4/2015, S. 563-591, https://doi.org/10.32387/prokla.v45i181.2 o1.

Heinrich, Mathias \& Jessop, Bob (2013): Die EU-Krise aus Sicht der Kulturellen Politischen Ökonomie. Krisendeutung und ihre Umsetzung. In: Das Argument, Nr. 1+2/2013, S. 19-33.

Heinrich, Michael (2010): Kapitalismus, Krise und Kritik. Zum analytischen Potenzial der Marxschen Theorie angesichts der gegenwärtigen Krise. In: Bude, Heinz/Damitz Ralf M. \& Koch, André (Hg.): Marx. Ein toter Hund? Gesellschaftstheorie reloaded, Hamburg, S. 124-148.

- (2008): Weltanschauung oder Strategie? Über Dialektik, Materialismus und Kritik in der Kritik der politischen Ökonomie. In: Demirović, Alex (Hg.): Kritik und Materialität, Münster, S. 60-72.

Heires, Marcel \& Nölke, Andreas (2014) (Hg.): Politische Ökonomie der Finanzialisierung, Wiesbaden, https://doi.org/10.1007/978-3-658-03778-9.

- (2011): Finanzkrise und Finanzialisierung. In: Kessler, Oliver (Hg.): Die Internationale Politische Ökonomie der Weltfinanzkrise, Wiesbaden, S. 37-52, https://doi.org/10.1 007/978-3-531-92083-2_3.

Hennette, Stéphanie/Piketty, Thomas/Sacriste, Guillaume \& Vauchez, Antoine (2017): Für ein anderes Europa. Vertrag zur Demokratisierung der Eurozone, München, h ttps://doi.org/10.17104/9783406714979.

Hennis, Wilhelm (1965): Aufgaben einer modernen Regierungslehre. In: Politische Vierteljahresschrift, Nr. 4/1965, S. 422-441.

Hillebrand, Ernst (2017): Zehn Jahre EU-Stresstest. Mehr Integration und neue Spannungen [Friedrich-Ebert-Stiftung: politik für europa].

Hilpold, Peter (2014): Eine neue europäische Finanzarchitektur - Der Umbau der Wirtschafts- und Währungsunion als Reaktion auf die Finanzkrise. In: Ders. \& Steinmaier, Walter (Hg.): Neue europäische Finanzarchitektur. Die Reform der WWU, Heidelberg, S. 3-82, https://doi.org/10.1007/978-3-642-37868-3.

Hirsch, Joachim (2005): Materialistische Staatstheorie. Transformationsprozesse des kapitalistischen Staatensystems, Hamburg.

- (2003): Was steuert der Staat und wer steuert ihn? In: Buckel, Sonja/Dackweiler, Regina-Maria \& Noppe, Ronald (Hg.): Formen und Felder politischer Intervention. Zur Relevanz von Staat und Steuerung, Münster, S. 16-29.

- (2002): Herrschaft, Hegemonie und politische Alternativen, Hamburg. 
- (2001): Die Internationalisierung des Staates. Anmerkungen zu einigen Fragen der Staatstheorie. In: Ders./Jessop, Bob \& Poulantzas, Nicos (Hg.): Die Zukunft des Staates, Hamburg, S. 101-138.

Hirsch, Joachim \& Kannankulam, John (2009): Die Räume des Kapitals. Die politische Form des Kapitalismus in der »Internationalisierung des Staates«. In: Hartmann, Eva/Kunze, Caren \& Brand, Ulrich (Hg.): Globalisierung, Macht und Hegemonie, Münster, S. 181-211.

Hirsch, Joachim/Kannankulam, John \& Wissel, Jens (2008a): Einleitung: Marx, Marxismus und die Frage des Staates. In: Dies. (Hg.): Der Staat der Bürgerlichen Gesellschaft. Zum Staatsverständnis von Karl Marx, Baden-Baden, S. 9-22, https://doi.or g/10.5771/9783845207001-9.

— (2008b): Die Staatstheorie des »westlichen Marxismus«. Gramsci, Althusser, Poulantzas und die so genannte Staatsableitung. In: Dies. (Hg.): Der Staat der Bürgerlichen Gesellschaft. Zum Staatsverständnis von Karl Marx, Baden-Baden, S. 92-115, https: //doi.org/10.5771/9783845207001-92.

Hirsch, Michael \& Voigt, Rüdiger (2017): Pierre Bourdieu und das politische Denken. In: Dies. (Hg.): Symbolische Gewalt. Politik, Macht und Staat bei Pierre Bourdieu, Baden-Baden, S. 11-15, https://doi.org/10.5771/9783845276441-9.

Hobolt, Sara B. \& Wratil, Christopher (2018): Public opinion and the crisis: the dynamics of support for the euro. In: Journal of European Public Policy, Nr. 2/2018, S. 238-256, https://doi.org/10.1080/13501763.2014.994022.

Hodson, Dermot (2017): Eurozone Governance in 2016: The Italian Banking Crisis, Fiscal Flexibility and Brexit (Plus Plus). In: Journal of Common Market Studies, Annual Review, S. 118-132, https://doi.org/10.1111/jcms.12602.

Hoffmann, Rhea Tamara \& Krajewski, Markus (2012): Staatsschuldenkrisen im EuroRaum und die Austeritätsprogramme von IWF und EU. In: Kritische Justiz, Heft 1/2012, S. 2-17, https://doi.org/10.5771/0023-4834-2012-1-2.

Hofmann, Andreas \& Wessels, Wolfgang (2009): Eine dauerhafte Verfassung für Europa? Die Beantwortung konstitutioneller Grundfragen durch den Vertrag von Lissabon. In: Decker, Frank \& Höreth, Marcus (Hg.): Die Verfassung Europas. Perspektiven des Integrationsprojekts, Wiesbaden, S. 69-95, https://doi.org/10.1007/978-3531-91336-0_5.

Hofmann, Julia (2018): Chancen und Grenzen europaweiter Mobilisierungen. Die Krisenproteste aus der Perspektive von Gewerkschaften zweier wenig betroffener Länder. In: Roose, Jochen/Sommer, Moritz \& Scholl, Franziska (Hg.): Europas Zivilgesellschaft in der Wirtschafts- und Finanzkrise. Protest, Resilienz und Kämpfe um Deutungshoheit, Wiesbaden, S. 141-162, https://doi.org/10.1007/978-3-658-20897-4 $-7$.

Höing, Oliver (2016): Weder Stabilitäts- noch Transferunion: der Europäische Stabilitätsmechanismus in einer reformierten Währungszone. In: integration, Nr. 1/2016, S. 17-31, https://doi.org/10.5771/0720-5120-2016-1-15.

Hooghe, Liesbet \& Marks, Gary (2008a): Die Entstehung eines politischen Gemeinwesens: Der Kampf um die europäische Integration. In: Höpner, Martin \& Schäfer, Armin (Hg.): Die Politische Ökonomie der europäischen Integration, Frankfurt a.M., S. 159-195. 
- (2008b): Politisierung und nationale Identität. Eine Nachbetrachtung. In: Höpner, Martin \& Schäfer, Armin (Hg.): Die Politische Ökonomie der europäischen Integration, Frankfurt a.M., S. 197-202.

Höpner, Martin (2016): Für ein soziales Europa - ohne den Euro. In: Blätter für deutsche und internationale Politik, Nr. 8/2016, S. 45-49.

Höpner, Martin \& Rödl, Florian (2012): Illegitim und rechtswidrig: Das neue makroökonomische Regime im Euroraum. In: Wirtschaftsdienst, Nr. 4/2012, S. 219-222.

Horn, Gustav (2016): Wirtschaftliche Krisen bewältigen, Wiesbaden, https://doi.org/10 .1007/978-3-658-05476-2.

Horn, Gustav \& van Treeck, Till (2011): Ungleichheit und außenwirtschaftliche Ungleichgewichte. Eine keynesianische Krisenerklärung. In: Helmedag, Fritz \& Kromphardt, Jürgen (Hg.): Nachhaltige Wege aus der Finanz- und Wirtschaftskrise, Marburg, S. 19-37.

Hufeld, Ulrich (2013): Das Lissabon-Urteil und die Folgerechtsprechung: Bewährungsproben und Rückwirkung auf die operative Europapolitik. In: Lhotta, Roland/Ketelhut, Jörn \& Schöne, Helmar (Hg.): Das Lissabon-Urteil. Staat, Demokratie und europäische Integration im »verfassten politischen Primärraum«, Wiesbaden, S. 191-215, https://doi.org/10.1007/978-3-531-94044-1_9.

- (2011): Zwischen Notrettung und Rütlischwur: der Umbau der Wirtschafts- und Währungsunion in der Krise. In: integration, Nr. 2/2011, S. 117-131, https://doi.org/10.57 71/0720-5120-2011-2-117.

Huke, Nikolai (2016): Krisenproteste in Spanien. Zwischen Selbstorganisation und Überfall auf die Institutionen, Münster.

Huke, Nikolai \& Wigger, Angela (2019): Vom beschränkenden Dissens zur desintegrierenden Polarisierung. Legitimitätsprobleme der Europäischen Union in der Eurokrise. In: Bieling, Hans-Jürgen \& Guntram, Simon (Hg.): Neue Segel, alter Kurs? Die Eurokrise und ihre Folgen für das europäische Wirtschaftsregieren, Wiesbaden, S. 201-227, https://doi.org/10.1007/978-3-658-25037-9_8.

Hunout, Patrick \& Ziltener, Patrick (1999): European Monetary Union: The New Leviathan. In: The International Scope Review, Nr. 1/1999, S. 1-38.

Husson, Michel (2012): Exit or Voice? A European Strategy of Rupture. In: Socialist Register 2012, S. 298-306.

Illing, Gerhard \& König, Philipp (2014): Die Europäische Zentralbank als Lender of Last Resort. In: DIW Wochenbericht, Nr. 24/2014, S. 541-554.

Isensee, Josef (2009): Europäische Nation? Die Grenzen der politischen Einheitsbildung Europas. In: Decker, Frank \& Höreth, Marcus (Hg.): Die Verfassung Europas. Perspektiven des Integrationsprojekts, Wiesbaden, S. 254-280, https://doi.org/10.1007 1978-3-531-91336-0_12.

Issing, Ottmar (2005): One size fits all! A single monetary policy for the euro area, http s://www.ecb.europa.eu/press/key/date/2005/html/sp050520.en.html, 05.02.2021.

Jachtenfuchs, Markus (2006): Das Gewaltmonopol: Denationalisierung oder Fortbestand? In: Leibfried, Stephan \& Zürn, Michael (Hg.): Transformationen des Staates? Frankfurt a.M., S. 69-91.

Jansen, Thomas (2005): Zur Europäisierung der >organisierten Zivilgesellschaft: ein Bericht aus der Praxis. In: Knodt, Michèle \& Finke, Barbara (Hg.): Europäische Zivil- 
gesellschaft. Konzepte, Akteure, Strategien, Wiesbaden, S. 153-169, https://doi.org/ 10.1007/978-3-322-95021-5_7.

Jellinek, Georg (1905): Das Recht des modernen Staates [Bd. 1: Allgemeine Staatslehre], 2. Auflage, Berlin.

Jessop, Bob (2015): Kritik, Staat, Emanzipation. In: Martin, Dirk/Martin, Susanne \& Wissel, Jens (Hg.): Perspektiven und Konstellationen kritischer Theorie, Münster, S. 86-103.

- (2014): Kapitalismus, Steuerung und der Staat, https://bobjessop.wordpress.com/20 14/01/11/kapitalismus-steuerung-und-der-staat/; 13.02.2021.

- (2011): »Regieren + Governance im Schatten der Hierarchie«: Der integrale Staat und die Herausforderungen der Metagovernance. In: Demirović, Alex \& Walk, Heike (Hg.): Demokratie und Governance. Kritische Perspektiven auf neue Formen politischer Herrschaft, Münster, S. 43-72.

- (2008): State Power. A Strategic-Relational Approach, Cambridge.

- (2007): Kapitalismus, Regulation, Staat. Ausgewählte Schriften, Hamburg.

- (2002): The Future of the Capitalist State, Cambridge.

- (2001): Die Globalisierung des Kapitals und die Zukunft des Nationalstaats. Ein Beitrag zur Kritik der globalen politischen Ökonomie. In: Ders./Hirsch, Joachim \& Poulantzas, Nicos (Hg.): Die Zukunft des Staates, Hamburg, S. 139-170.

- (1997): Die Zukunft des Nationalstaates: Erosion oder Reorganisation? In: Becker, Steffen/Sablowski, Thomas \& Schumm, Wilhelm (Hg.): Jenseits der Nationalökonomie? Weltwirtschaft und Nationalstaat zwischen Globalisierung und Regionalisierung, Hamburg, S. 50-95.

- (1990): State Theory. Putting the Capitalist State in its Place, Cambridge.

Joerges, Christian (2016): Pereat iustitia et fiat mundus? Die Krise des Rechts in der Krise Europas. In: Merkur, Nr. 803/2016, S. 17-31.

- (2013): Europe's Economic Constitution in Crisis and the Emergence of a new Constitutional Constellation [ZenTra Working Papers in Transnational Studies, Nr. 06/2012; überarbeitete Version, Sept. 2013], https://doi.org/10.2139/ssrn.2179595.

- (2012): Europas Wirtschaftsverfassung in der Krise. In: Der Staat, Nr. 3/2012, S. 357385, https://doi.org/10.3790/staa.51.3.357.

- (2010): Europa nach dem Ordoliberalismus: Eine Philippika. In: Kritische Justiz, Nr. 4/2010, S. 394-406, https://doi.org/10.5771/0023-4834-2010-4-394.

Juncker, Jean-Claude (2014): Ein neuer Start für Europa: Meine Agenda für Jobs, Wachstum, Fairness und demokratischen Wandel, https://ec.europa.eu/info/sites/info/fil es/pg_de_o.pdf; 13.02.2021.

Juncker, Jean-Claude/Tusk, Donald/Dijsselbloem, Jeroen \& Draghi, Mario (2015a): Vorbereitung der nächsten Schritte für eine bessere wirtschaftspolitische Steuerung im Euro-Währungsgebiet. Analytische Note, https://ec.europa.eu/info/sites/info/files/ analytical_note_de_0.pdf; 13.02.2021.

Juncker, Jean-Claude/Tusk, Donald/Dijsselbloem, Jeroen/Draghi, Mario \& Schulz, Martin (2015b): Die Wirtschafts- und Währungsunion Europas vollenden, https://ec.eu ropa.eu/info/sites/info/files/5-presidents-report_de_o.pdf; 13.02.2021. 
Kannankulam, John (2017): Der Verfall der Demokratie: Autoritärer Etatismus. Zur Aktualität von Nicos Poulantzas im Kontext der Finanz- und »Eurokrise«. In: FORUM Wissenschaft, Nr. 2/2017, S. 4-9.

- (2013): Die Euro-Krise zwischen miteinander ringenden Hegemonieprojekten und Autoritärem Etatismus. In: Büsing, Harald/Eis, Andreas \& Klöpper, Manfred (Hg.): Demokratie in der Krise. Krisenpolitik und demokratische Legitimation, Oldenburg, S. 17-33.

Kannankulam, John \& Georgi, Fabian (2012): Die Europäische Integration als materielle Verdichtung von Kräfteverhältnissen. Hegemonieprojekte im Kampf um das >Staatsprojekt Europa< [Arbeitspapier Nr. 30, Forschungsgruppe Europäische Integration am Institut für Politikwissenschaft der Philipps-Universität Marburg].

Karamessini, Maria (2014): Die griechische Tragödie. Neoliberale Radikalkur in einer Währungsunion des Gegeneinanders. In: Lehndorff, Steffen (Hg.): Spaltende Integration. Der Triumph gescheiterter Ideen in Europa - revisited. Zehn Länderstudien, Hamburg, S. 81-108.

Karrass, Anne (2009): Die EU und der Rückzug des Staates. Eine Genealogie der Neoliberalisierung der europäischen Integration, Bielefel, https://doi.org/10., 361/9783839410677.

— (2008): Die Europäische Union als Beispiel für institutionelle (Sach-)Zwänge. In: Butterwegge, Christoph/Lösch, Bettina \& Ptak, Ralf (Hg.): Neoliberalismus, Wiesbaden, S. 243-258, https://doi.org/10.1007/978-3-531-90899-1_14.

Kaufmann, Stephan \& Stützle, Ingo (2016): Ist die ganze Welt bald pleite? Populäre Irrtümer über Schulden, 2. Auflage, Berlin.

Keil, Daniel (2015): Territorium, Tradition und nationale Identität. Eine staatstheoretische Perspektive auf den Wandel nationaler Identität in der europäischen Integration, Münster.

Kelemen, R. Daniel (2015): Towards a New Constitutional Architecture in the EU? In: Fabbrini, Federico/Hirsch, Ernst \& Somsen, Han (Hg.): What Form of Government for the European Union and the Eurozone? Oxford, S. 197-215, https://doi.org/10.5 040/9781509901234.ch-011.

Kielmansegg, Peter (2015): Wohin des Wegs, Europa? Beiträge zu einer überfälligen Debatte, Baden-Baden, https://doi.org/10.5771/9783845261102.

Klatzer, Elisabeth \& Schlager, Christa (2011): Europäische Wirtschaftsregierung - eine stille neoliberale Revolution. In: Kurswechsel, Nr. 1/2011, S. 61-81.

Knipping, Oliver (2011): Schluss mit der Schuldenparty, https://www.insm-oekonomen blog.de/7148-schluss-mit-der-schuldenparty; 05.02.2021.

Knodt, Michèle \& Finke, Barbara (2003): Europäisierung der Zivilgesellschaften oder Europäische Zivilgesellschaft? In: Zeitschrift für Internationale Beziehungen, Nr. 2/2003, S. 413-420, https://doi.org/10.5771/0946-7165-2003-2-413.

Knodt, Michèle \& Große Hüttmann, Martin (2012): Der Multi-Level Governance-Ansatz. In: Bieling, Hans-Jürgen \& Lerch, Marika (Hg.): Theorien der europäischen Integration, 3. Auflage, Wiesbaden, S. 187-205, https://doi.org/10.1007/978-3-531-19715-9_9 
Kohler-Koch, Beate/Conzelmann, Thomas \& Knodt, Michèle (2004): Europäische Integration - Europäisches Regieren, Wiesbaden, https://doi.org/10.1007/978-3-531-90 o11-7.

Kohler-Koch, Beate \& Quittkat, Christine (2011): Die Entzauberung partizipativer Demokratie. Zur Rolle der Zivilgesellschaft bei der Demokratisierung von EUGovernance, Frankfurt a.M.

Koll, Willi \& Watt, Andrew (2018): Vertiefung und Konvergenz der Europäischen Wirtschafts- und Währungsunion durch konzeptionelle und institutionelle Reformen der makroökonomischen Koordinierung [IMK Study Nr. 61/2018].

Kompsopoulos, Jannis (2018): Neue Hoffnung im Süden? Erfahrungen linker Regierungspolitik in Zeiten der Austerität. In: PROKLA, Nr. 3/2018, S. 475-488, https:// doi.org/10.32387/prokla.v48i192.917.

Konecny, Martin (2015): Syriza unter Druck. Zu den strategischen Perspektiven des linken Regierungsprojekts in Griechenland. In: PROKLA, Nr. 2/2015, S. 325-337, https: //doi.org/10.32387/prokla.v45i179.224.

- (2012): Die Herausbildung einer neuen Economic Governance als Strategie zur autoritären Krisenbearbeitung in Europa - gesellschaftliche Akteure und ihre Strategien. In: PROKLA, Nr. 3/2012, S. 377-394, https://doi.org/10.32387/prokla.v42i168.2 98.

Kouki, Hara \& Fernandez Gonzalez, Joseba (2016): Syriza, Podemos und die AntiAusteritäts-Mobilisierung. In: Forschungsjournal Soziale Bewegungen, Nr. 1/2016, S. 61-71, https://doi.org/10.1515/fjsb-2016-0109.

Kritidis, Gregor (2014): Griechenland - auf dem Weg in den Maßnahmestaat? Autoritäre Krisenpolitik und demokratischer Widerstand, Hannover.

Kromphardt, Jürgen (2005): Die Reform des Europäischen Stabilitäts- und Wachstumspakts - Aufweichung oder sinnvollere Ausgestaltung? In: WSI Mitteilungen, Nr. 12/2005, S. 688-693.

Krugman, Paul (2013): Austerität: Der Einsturz eines Glaubensgebäudes. In: Blätter für deutsche und internationale Politik, Nr. 7/2013, S. 45-58.

Kühnhardt, Ludgar (2012): Regieren in der europäischen Föderation [Discussion Paper des Zentrums für Europäische Integrationsforschung, Nr. C212].

Kunstein, Tobias \& Wessels, Wolfgang (2011): Die Europäische Union in der Währungskrise: Eckdaten und Schlüsselentscheidungen. In: integration, Nr. 4/2011, S. 308322, https://doi.org/10.5771/0720-5120-2011-4-308].

Leibfried, Stephan \& Zürn, Michael (2006): Von der nationalen zur post-nationalen Konstellation. In: Dies. (Hg.): Transformation des Staates? Frankfurt a.M., S. 19-65.

Lequesne, Christian (2016): The Eurozone crisis and European integration. >New intergovernmentalism as a valid theory. In: Saurugger, Sabine \& Terpan, Fabien (Hg.): Crisis and Institutional Change in Regional Integration, London, S. 41-59, https://d oi.org/10.4324/9781315667959.

Leschke, Janine/Theodoropoulou, Sotiria \& Watt, Andrew (2014): Auf dem Weg ins »Europa 2020«? Austeritätskurs und neue Wirtschaftssteuerung auf EU-Ebene. In: Lehndorff, Steffen (Hg.): Spaltende Integration. Der Triumph gescheiterter Ideen in Europa - revisited. Zehn Länderstudien, Hamburg, S. 243-272.

Lindner, Fabian (2013): Banken treiben Eurokrise [IMK Report, Nr. 82]. 
Lindner, Kolja (2017): Die Hegemoniekämpfe in Frankreich. Laizismus, politische Repräsentation und Sarkozysmus, Hamburg.

López, Isidro \& Rodríguez, Emmanuel (2011): Das spanische Modell. In: PROKLA, Nr. 1/2011, S. 113-134, https://doi.org/10.32387/prokla.v42i166.21.

Maatsch, Aleksandra (2015): Empowered or Disempowered? The Role of National Parliaments during the Reform of European Economic Governance [Max-Planck-Institut für Gesellschaftsforschung: Discussion Paper Nr. 15/10].

Majone, Giandomenico (2012): Rethinking European Integration after the Debt Crisis [The European Institute Working Paper, Nr. 3/2012].

Mann, Dennis-Jonathan (2009): Ein Gebilde sui generis? Die Debatte um das Wesen der Europäischen Union im Spiegel der »Nature of the Union«-Kontroverse in den USA. In: Decker, Frank \& Höreth, Marcus (Hg.): Die Verfassung Europas. Perspektiven des Integrationsprojekts, Wiesbaden, S. 319-343, https://doi.org/10.1007/978-3-53191336-0_15.

Marks, Gary/Hooghe, Liesbet \& Blank, Kermit (1996): European Integration form the 1980s: State-Centric v. Multi-level Governance. In: Journal of Common Market Studies, Nr. 3/1996, S. 341-378, https://doi.org/10.1111/j.1468-5965.1996.tboo577.x.

Martin, Dirk (2019): Symbolische Gewalt. Überlegungen zur Analyse von Staat und Recht in der herrschaftskritischen Soziologie Pierre Bourdieus. In: Kretschmann, Andrea (Hg.): Das Rechtsdenken Pierre Bourdieus, Weilerswist, S. 145-163.

Martin, Dirk \& Wissel, Jens (2015): Fragmentierte Hegemonie. Anmerkungen zur gegenwärtigen Konstellation von Herrschaft. In: Dies. \& Martin, Susanne (Hg.): Perspektiven und Konstellationen kritischer Theorie, Münster, S. 220-238.

Marx, Karl \& Engels, Friedrich (1958-2018): Marx-Engels-Werke (MEW) [Bde. 1-44], Berlin.

Matthijs, Matthias \& Blyth, Mark (2018): When Is It Rational to Learn the Wrong Lessons? Technocratic Authority, Social Learning, and Euro Fragility. In: Perspectives on Politics, Nr. 1/2018, S. 110-126, https://doi.org/10.1017/S1537592717002171.

Mau, Steffen (2017): Das metrische Wir. Über die Quantifizierung des Sozialen, 2. Auflage, Berlin.

Mayntz, Renate (2010): Governance im modernen Staat. In: Benz, Arthur \& Dose, Nicolai (Hg.): Governance - Regieren in komplexen Regelsystemen. Eine Einführung, 2. Auflage, Wiesbaden, S. 37-48, https://doi.org/10.1007/978-3-531-90171-8_4.

McNamara, Kathleen (2018): Authority Under Construction: The European Union in Comparative Political Perspective. In: Journal of Common Market Studies, Nr. 7/2018, S. 1510-1525, https://doi.org/10.1111/jcms.12784.

Merkel, Angela (2013): Rede beim Jahrestreffen des World Economic Forum in Davos, https://archiv.bundesregierung.de/archiv-de/rede-von-bundeskanzlerin-m erkel-beim-jahrestreffen-2013-des-world-economic-forum-336072; 05.02.2021.

- (2010): Regierungserklärung vom 19. Mai 2010. In: Deutscher Bundestag (Hg.): Stenografischer Bericht der 42. Sitzung, S. 4125-4131.

Meyer, Dirk (2018): Schuldenerleichterungen für Griechenland - ein Überblick. In: Wirtschaftsdienst, Nr. 6/2018, S. 405-410, https://doi.org/10.1007/s10273-018-23085]. 
Mitchell, William (2017): Dystopie Eurozone. Gruppendenken und Leugnung im großen Stil, Berlin.

Möller, Kolja (2017): Formwandel des Konstitutionalismus. Zum Verhältnis von Postdemokratie und Verfassungsbildung jenseits des Staates. In: Eberl, Oliver \& Salomon, David (Hg.): Perspektiven sozialer Demokratie in der Postdemokratie, Wiesbaden, S. 179-205, https://doi.org/10.1007/978-3-658-02724-7_9.

Möllers, Christoph (2008): Der vermisste Leviathan. Staatstheorie in der Bundesrepublik, Frankfurt a.M.

Morisse-Schilbach, Melanie (2011): »Ach Deutschland!«. Greece, the Euro Crisis, and the Costs and Benefits of Being a Benign Hegemon. In: Internationale Politik und Gesellschaft, Nr. 1/2011, S. 26-41.

Moscovici, Pierre (2017): Wie ein Europäischer Währungsfonds aussehen müsste. Drei Schritte zur Weiterentwicklung des Europäischen Stabilitätsmechanismus (ESM), https://www.ipg-journal.de/rubriken/europaeische-integration/artikel/wie -ein-europaeischer-waehrungsfonds-aussehen-muesste-2423/; 05.02.2021.

Müller, Harald (2009): Staatlichkeit ohne Staat - ein Irrtum aus der europäischen Provinz? Limitierende Bedingungen von Global Governance in einer fragmentierten Welt. In: Deitelhoff, Nicole \& Steffek, Jens (Hg.): Was bleibt vom Staat? Demokratie, Recht und Verfassung im globalen Zeitalter, Frankfurt a.M., S. 221-258.

Müller, Torsten/Schulten, Thorsten \& Van Gyes, Guy (2016/Hg.): Lohnpolitik unter europäischer »Economic Governance«. Alternative Strategien für inklusives Wachstum, Hamburg.

Mullis, Daniel (2015): Demonstrieren! Blockieren! Okkupieren! - Blockupy Frankfurt und die Produktion des Politischen. In: Europa Regional, Nr. 1/2015, S. 20-31.

Nachtwey, Oliver (2017): Die Abstiegsgesellschaft. Über das Aufbegehren in der regressiven Moderne, 7. Auflage, Berlin.

Neubäumer, Renate (2011): Eurokrise: Keine Staatsschuldenkrise sondern Folge der Finanzkrise. In: Wirtschaftsdienst, Nr. 12/2011, S. 827-833, https://doi.org/10.1007/s1 0273-011-1308-5.

Neubert, Harald (2001): Antonio Gramsci: Hegemonie - Zivilgesellschaft - Partei. Eine Einführung, Hamburg.

Neues Deutschland (20.03.2002): Tony Blair - der rechte Bruder?, https://www.neuesdeutschland.de/artikel/14571.tony-blair-der-rechte-bruder.html; 05.02.2021.

Nicoll, Norbert (2012): Gramsci, Hayek und die unbestreitbare Nützlichkeit einer hegemonialen Strategie. In: Emanzipation, Nr. 1/2012, S. 72-86.

Nullmeier, Frank (2013): Transformationen demokratischer Staatlichkeit. In: Forschungsjournal Soziale Bewegungen, Nr. 1/2013, S. 32-41, https://doi.org/10.1515/fj sb-2013-0106.

- (2009): Formen der Staatlichkeit: $\mathrm{Zu}$ einer Analytik politischer Einheiten. In: Deitelhoff, Nicole \& Steffek, Jens (Hg.): Was bleibt vom Staat? Demokratie, Recht und Verfassung im globalen Zeitalter, Frankfurt a.M., S. 35-56.

Oberndorfer, Lukas (2017): Zwischen Normal- und Ausnahmestaat: Der Autoritäre Wettbewerbsetatismus und die Krise der Demokratie in Europa. In: Candeias, Mario \& Demirović, Alex (Hg.): Europe - what's left? Die Europäische Union zwischen Zerfall, Autoritarismus und demokratischer Erneuerung, Münster, S. 70-92. 
- (2016a): Europa und Frankreich im Ausnahmezustand? Die autoritäre Durchsetzung des Wettbewerbs. In: PROKLA, Nr. 4/2016, S. 561-581, https://doi.org/10.32387/prok la.v46i185.132.

- (2016b): Der neue Konstitutionalismus in der Europäischen Union und seine autoritäre Re-Konfiguration. WWU 2.0, New Economic Governance und Pakt(e) für Wettbewerbsfähigkeit. In: Bieling, Hans-Jürgen \& Große Hüttmann, Martin (Hg.): Europäische Staatlichkeit. Zwischen Krise und Integration, Wiesbaden, S. 177-200, https://doi.org/10.1007/978-3-658-03790-1_9.

- (2015): From new constitutionalism to authoritarian constitutionalism. New Economic Governance and the state of European democracy. In: Jäger, Johannes \& Springler, Elisabeth (Hg.): Asymmetric Crisis in Europe and Possible Futures. Critical political economy and post-Keynesian perspectives, Abingdon, S. 186-207, http s://doi.org/10.4324/9781315764009.

- (2013): Vom neuen, über den autoritären zum progressiven Konstitutionalismus? Pakt(e) für Wettbewerbsfähigkeit und die europäische Demokratie. In: juridikum, Nr. 1/2013, S. 76-86.

- (2012a): Hegemoniekrise in Europa - Auf dem Weg zu einem autoritären Wettbewerbsetatismus? In: Forschungsgruppe >Staatsprojekt Europa< (Hg.): Die EU in der Krise. Zwischen autoritärem Etatismus und europäischem Frühling, Münster, S. 4971.

- (2012b): Der Fiskalpakt - Umgehung der »europäischen Verfassung« und Durchbrechung demokratischer Verfahren? In: juridikum, Nr. 2/2012, S. 168-181.

- (2010): Post-neoliberale Integrationsweise der EU. Perspektivenwechsel an der Schnittstelle Politik/Ökonomie/Recht. In: Blaha, Barbara \& Weidenholzer (Hg.): Freiheit. Beiträge für eine demokratische Gesellschaft, Wien, S. 105-121.

Obwexer, Walter (2012): Das System der »Europäischen Wirtschaftsregierung« und die Rechtsnatur ihrer Teile: Sixpack - Euro-Plus-Pakt - Europäisches Semester - Rettungsschirm. In: Zeitschrift für öffentliches Recht, Nr. 2/2012, S. 209-252, https://d oi.org/10.1007/s00708-012-0135-5.

Offe, Claus (2008): Governance - »Empty signifier« oder sozialwissenschaftliches Forschungsprogramm? In: Schuppert, Gunnar Folke \& Zürn, Michael (Hg.): Governance in einer sich wandelnden Welt, Wiesbaden, S. 61-76, https://doi.org/10.1007/978-3531-91066-6_3.

Oppermann, Kai (2014): Argumentationsmuster zur Krise in der Eurozone. Eine Analyse von Debattenbeiträgen der Regierung Merkel im Bundestag 2009-2012. In: integration, Nr. 3/2014, S. 262-274, http://dx.doi.org/10.5771/0720-5120-2014-2-262.

Opratko, Benjamin (2014): Hegemonie, 2. Auflage, Münster.

Ortmann, Anke (2015): Die Abstimmungsregeln im Fiskalvertrag: Kollision von Völkerund Unionsrecht? In: Europäische Zeitschrift für Wirtschaftsrecht, 2015, S. 539-544.

Overbeek, Henk (2000): Auf dem Weg zu einer neo-gramscianischen Theorie der europäischen Integration. In: Bieling, Hans-Jürgen \& Steinhilber, Jochen (Hg.): Die Konfiguration Europas. Dimensionen einer kritischen Integrationstheorie, Münster, S. 162-188. 
Palmstorfer, Rainer (2013): Indirekter Bailout erlaubt, direkter Bailout verboten - Anmerkungen zum Urteil des EuGH v. 27.11.2012. In: Europarecht, Nr. 2/2013, S. 215224, https://doi.org/10.5771/0531-2485-2013-2-215.

Parker, Owen \& Pye, Robert (2018): Mobilising social rights in EU economic governance: a pragmatic challenge to neoliberal Europe. In: Comparative European Politics, Nr. 16/2018, S. 805-824, https://doi.org/10.1057/s41295-017-0102-1.

Payandeh, Mehrdad (2009): Finanzmarktkapitalismus am Ende? In: Ders./Altvater, Elmar/Bieling, Hans-Jürgen/Demirović, Alex/Flassbeck, Heiner/Goldtschmidt, Werner \& Wöhl, Stefanie: Die Rückkehr des Staates? Nach der Finanzkrise, Hamburg, S. 81-104.

Pereira, Javier (2011): Europe 2020 - The European Strategy for Sustainable Growth. What Does It Look Like from Outside? [Friedrich-Ebert-Stiftung: Perspective].

Petzold, Tino (2018): Austerity Forever?! Die Normalisierung der Austerität in der BRD, Münster.

Pilz, Stefan (2016): Der Europäische Stabilitätsmechanismus. Eine neue Stufe der europäischen Integration, Tübingen.

Plaßmann, Jan Hauke (2017): Demokratie jenseits welchen Staates? Eine konzeptionelle Neuausrichtung der Debatte um demokratisches Regieren jenseits des Nationalstaates, Baden-Baden, https://doi.org/10.5771/9783845279473.

Plehwe, Dieter/Neujeffski, Moritz \& Krämer, Werner (2018): Saving the dangerous idea: austerity think tank networks in the European Union. In: Policy and Society, Nr. 2/2018, S. 188-205, http://dx.doi.org/10.1080/14494035.2018.1427602.

Plehwe, Dieter \& Walpen, Bernhard (2006): Between network and complex organization. The making of neoliberal knowledge and hegemony. In: Ders. \& Neunhöffer, Gisela (Hg.): Neoliberal Hegemony. A Global Critique, Abingdon, https://doi.org/10 $.4324 / 9780203099506$.

Polster, Werner (2020): Wie das Virus die EU und Eurozone verändern wird, https://m akroskop.eu/wie-das-virus-die-eu-und-eurozone-verandern-wird/; 05.02.2021.

- (2014): Die Krise der Europäischen Währungsunion. Eine ordnungspolitische Analyse, Marburg.

Poppitz, Wolfgang \& Schöning, Stephan (2018): Euromärkte, https://wirtschaftslexiko n.gabler.de/definition/euromaerkte-35470/version-258951; 05.02.2021.

Poulantzas, Nicos (2002): Staatstheorie. Politischer Überbau, Ideologie, Autoritärer Etatismus, Hamburg.

Priewe, Jan (2017): Reform der Architektur der Europäischen Währungsunion. Die schwierige Suche nach einem neuen Kompass [Friedrich-Ebert-Stiftung: WISO Diskurs, Nr. 8/2017].

PROKLA 196 (Nr. 3/2019): Krise der (europäischen) Sozialdemokratie, https://doi.org/11 $0.32387 /$ prokla.49.196.18 40.

Protokoll (Nr. 4) der Europäischen Verträge über die Satzung des Europäischen Systems der Zentralbanken und der Europäischen Zentralbank.

Protokoll (Nr. 12) der Europäischen Verträge über das Verfahren bei einem übermäßigen Defizit. 
Puetter, Uwe (2015): Deliberativer Intergouvernementalismus und institutioneller Wandel: die Europäische Union nach der Eurokrise. In: Politische Vierteljahresschrift, Nr. 3/2015, S. 406-429, https://doi.org/10.5771/0032-3470-2015-3-406.

Puntscher Riekmann, Sonja (2004): The State of Europe. Towards a Theory of European Integration: From Grand Theories to Metaphorical Description and Back. In: Dies./Mokre, Monika \& Latzer, Michael (Hg.): The State of Europe. Transformations of Statehood from a European Perspective, Frankfurt a.M., S. 9-30.

Radice, Hugo (2014): Enforcing Austerity in Europe: The Structural Deficit as a Policy Target. In: Journal of Contemporary European Studies, Nr. 3/2014, S. 318-328, https ://doi.org/10.1080/14782804.2014.937409.

Rat der Europäischen Union [für Wirtschaft und Finanzen] (2019): Multiannual Financial Framework (MFF) 2021-2017: Negotiating Box with figures [14518/1/19 REV 1]

- (2018): Outcome of the Council meeting (23.01.2018) [5475/18].

- (2016): Outcome of the Council meeting (12.02.2016) [5936/16].

- (2015a): Outcome of the Council meeting (27.01.2015) [5607/15].

- (2015b): Outcome of the Council meeting (08.12.2015) [15068/15].

- (2014): Maßnahmen zur Förderung von Investitionen in Europa - Schlussfolgerungen des Rates [14334/14].

- (2013a): Economic governance: Council confirms agreement with EP [6866/13].

- (2013b): Mitteilung an die Presse (05.03.2013) [6962/13].

- (2013c): Regulation on common provisions for monitoring and assessing draft budgetary plans and ensuring the correction of excessive deficit of the Member States in the euro area. Note from General Secretariat of the Council to delegations [6727/13].

- (2013d): Regulation on the strengthening of economic and budgetary surveillance of Member States experiencing or threatened with serious difficulties with respect to their financial stability in the euro area. Note from General Secretariat of the Council to delegations [6726/13].

- (2013e): Mitteilung an die Presse (14.05.2013) [9405/13].

- (2013f): Mitteilung an die Presse (09.07.2013) [11849/13].

- (2013i): Gutachten des Juristischen Dienstes. Vorschlag für eine Verordnung über die Bereitstellung und Qualität von Statistiken für das Verfahren bei einem makroökonomischen Ungleichgewicht - Prüfung der Rechtsgrundlage für die vorgeschlagenen Sanktionen und Besuche in den Mitgliedsstaaten, Grundsatz der Verhältnismäßigkeit [14639/13].

- (2012a): Mitteilung an die Presse (13.11.2012) [16051/12].

- (2012b): Proposals for regulations (»Two-Pack«). Revised Note from the Presidency to Delegations [16493/1/12 REV 1].

- (2012c): Proposal for regulation on the strengthening of economic and budgetary surveillance of Member States experiencing or threatened with serious difficulties with respect to their financial stability in the euro area (Draft Compromise). Note from General Secretariat of the Council to Delegations [17150/12].

— (2012d): Proposal for regulation on Common provisions for monitoring and assessing draft budgetary plans and ensuring the correction of excessive deficit of the Member States in the euro area (Draft Compromise). Note from General Secretariat of the Council to Delegations [17152/12]. 
- (2012e): Entwurf eines Protokolls (04.12.2012) [17294/12].

- (2011a): Mitteilung an die Presse (15.03.2011) [7690/11].

- (2011b): Addendum zum Entwurf eines Protokolls (15.03.2011) [7824/11 ADD 1].

- (2011c): Ein Frühwarn-Scoreboard für die Überwachung makroökonomischer Ungleichgewichte. Schlussfolgerungen des Rates [15781/2/11 REV 2].

— (2011): Addendum zum Entwurf eines Protokolls (30.11.2011) [17907/11 ADD 1].

- (2011e): Entwurf eines Protokolls (30.11.2011) [17907/11].

- (2010a): Schlussfolgerung des Rates (09.05.2010) [9602/10].

- (2010b): Mitteilung an die Presse (07.09.2010) [13161/10].

- (2009): Mitteilung an die Presse (20.10.2009) [14601/09].

Reef, Bernd (2018): Ökonomische Probleme in der EU: Renationalisierung der Wirtschaftspolitik als Lösung? In: Eis, Andreas \& Moulin-Doos, Claire (Hg.): Kritische politische Europabildung - Die Vielfachkrise Europas als kollektive Lerngelegenheit? Immenhausen, S. 41-51.

Reh, Werner (1995): Quellen- und Dokumentenanalyse in der Politikfeldforschung: Wer steuert die Verkehrspolitik? In: Alemann, Ulrich von (Hg.): Politikwissenschaftliche Methoden. Grundriß für Studium und Forschung, Opladen, S. 201-259, https://doi .org/10.1007/978-3-663-05982-0_4.

Rhodes, Roderick A. W. (1996): The New Governance: Governing without Government. In: Political Studies Nr. 4/1996, S. 652-667, https://doi.org/10.1111/j.1467-9248.1996.t bo1747.x.

Richtlinie 2014/49/EU des Europäischen Parlaments und des Rates vom 16. April 2014 über Einlagensicherungssysteme.

Richtlinie 2014/59/EU des Europäischen Parlaments und des Rates vom 15. Mai 2014 zur Festlegung eines Rahmens für die Sanierung und Abwicklung von Kreditinstituten und Wertpapierfirmen und zur Änderung der Richtlinie 82/891/EWG des Rates, der Richtlinien 2001/24/EG, 2002/47/EG, 2004/25/EG, 2007/36/EG, 2011/35/EU, 2012/30/EU und 2013/36/EU sowie der Verordnungen (EU) Nr. 1093/2010 und (EU) Nr. 648/2012 des Europäischen Parlaments und des Rates.

Richtlinie 2013/36/EU des Europäischen Parlaments und des Rates vom 26. Juni 2013 über den Zugang zur Tätigkeit von Kreditinstituten und die Beaufsichtigung von Kreditinstituten und Wertpapierfirmen, zur Änderung der Richtlinie 2002/87/EG und zur Aufhebung der Richtlinie 2006/48/EG und 2006/49/EG.

Richtlinie 2011/85/EU des Rates vom 8. November 2011 über die Anforderungen an die haushaltspolitischen Rahmen der Mitgliedstaaten.

Rittberger, Berthold (2014): Integration without Representation? The European Parliament and the Reform of Economic Governance in the EU. In: JCMS, Nr. 6/2014, S. 1174-1183, https://doi.org/10.1111/jcms.12185.

Rittberger, Berthold \& Winzen, Thomas (2015): Parlamentarismus nach der Krise: Die Vertiefung parlamentarischer Asymmetrien in der reformierten Wirtschafts- und Währungsunion. In: Politische Vierteljahresschrift, Nr. 3/2015, S. 430-456, https://d oi.org/10.5771/0032-3470-2015-3-430.

Rödl, Florian (2012): EU im Notstandsmodus. In: Blätter für deutsche und internationale Politik, Nr. 5/2012, S. 5-8. 
Rodrigues, Maria João (2014): The Eurozone Crisis and the Transformation of EU Governance: From Internal Policies to External Action. In: Dies. \& Xiarchogiannopoulou, Eleni (Hg.): The Eurozone Crisis and the Transformation of EU Governance. Internal and External Implications, Farnham, S. 173-189, https://doi.org/10.4324/9781315 558462.

Roger, Léa/Otjes, Simon \& van den Veer, Harmen (2017): The financial crisis and the European Parliament: An analysis of the Two-Pack legislation. In: European Union Politics, Nr. 4/2017, S. 560-580, https://doi.org/10.1177/1465116517716311.

Ronald, Richard (2008): The Ideology of Home Ownership. Homeowner Societies and the Role of Housing, Basingstoke, https://doi.org/10.1057/9780230582286.

Roose, Jochen (2016): Was lernt die Bewegungsforschung aus der Eurozonen-Krise? In: Forschungsjournal Soziale Bewegungen, Nr. 1/2016, S. 20-28, https://doi.org/10.151 5/fjsb-2016-0105.

Rühmann, Peter (2009): Zur Bedeutung der räumlichen Mobilität in der EWU. In: Chaloupek, Günther \& Kromphardt, Jürgen (Hg.): Finanzkrise und Divergenzen in der Wirtschaftsentwicklung als Herausforderungen für die Europäische Währungsunion, Marburg, S. 167-189.

Sablowski, Thomas (2006): Krise und Staatlichkeit bei Poulantzas. In: Bretthauer, Lars/Gallas, Alexander/Kannankulam, John \& Stützle, Ingo (Hg.): Poulantzas lesen. Zur Aktualität marxistischer Staatstheorie, Hamburg, S. 257-273.

Sablowski, Thomas/Schneider, Etienne \& Syrovatka, Felix (2018): Zehn Jahre Krise. Regulation des Lohnverhältnisses und ungleiche Entwicklung in der Europäischen Union. In: PROKLA, Nr. 3/2018, S. 357-379, https://doi.org/10.32387/prokla.v48i192. 893.

Sack, Detlef (2011): Governance zwischen Gouvernementalität, Regierungsform und Regulation - Zur Prüfung des kritischen Gehalts einer Forschungsperspektive. In: Demirović, Alex \& Walk, Heike (Hg.): Demokratie und Governance. Kritische Perspektiven auf neue Formen politischer Herrschaft, Münster, S. 18-42.

Salheiser, Axel (2014): Natürliche Daten: Dokumente. In: Baur, Nina \& Blasius, Jörg (Hg.): Handbuch Methoden der empirischen Sozialforschung, Wiesbaden, S. 813827, https://doi.org/10.1007/978-3-531-18939-0_62.

Salomon, David (2013): Demokratie, wenn es ruhig ist. In der Krise muss entschieden werden! Zur Problematik des Demokratiebegriffs in der postdemokratischen Krise. In: Büsing, Harald/Eis, Andreas \& Klöpper, Manfred (Hg.): Demokratie in der Krise. Krisenpolitik und demokratische Legitimation, Oldenburg, S. 97-118.

Sandbeck, Sune \& Schneider, Etienne (2013): From the Sovereign Debt Crisis to Authoritarian Statism: Contradictions of the European State Project. In: New Political Economy 2013, S. 1-25, https://doi.org/10.1080/13563467.2013.861411.

Schäfer, David (2016): A Banking Union of Ideas? The Impact of Ordoliberalism and the Vicious Circle on the EU Banking Union. In: Journal of Common Market Studies, Nr. 4/2016, S. 961-980, https://doi.org/10.1111/jcms.12351.

- (2013): Der Fiskalvertrag - ein Ausdruck deutscher Hegemonie in der Europäischen Union? In: integration, Nr. 2/2013, S. 107-123, https://doi.org/10.5771/0720-5120-201 3-2-107. 
Scharpf, Fritz W. (2017a): Der europäische Währungsverbund: Von der erzwungenen Konvergenz zur differenzierten Integration. In: Rüttgers, Jürgen \& Decker, Frank (Hg.): Europas Ende, Europas Anfang. Neue Perspektiven für die Europäische Union, Frankfurt a.M., S. 197-211.

- (2017b): Südeuro, https://www.ipg-journal.de/rubriken/europaeische-integration/ar tikel/suedeuro-2449/; 05.02.2021.

Schmidt, Manfred G. (2010): Demokratietheorien. Eine Einführung, 5. Auflage, Wiesbaden.

Schmitter, Philippe C. (2006): Governance in the European Union. A viable mechanism for future legitimation? In: Benz, Arthur \& Papadopoulos, Yannis (Hg.): Governance and Democracy, New York, S. 158-175, https://doi.org/10.4324/9780203086162-18.

Schnabl, Gunther \& Zemanek, Holger (2011): Deutsche Wiedervereinigung und europäische Schuldenkrise. Die Persistenz von asymmetrischen Schocks im heterogenen Währungsraum. In: Wirtschaftswissenschaftliches Studium, Nr. 12/2011, S. 636-643, https://doi.org/10.15358/0340-1650-2011-12-636.

Schneider, Etienne (2017a): Raus aus dem Euro - rein in die Abhängigkeit? Perspektiven und Grenzen alternativer Wirtschaftspolitik außerhalb des Euro, Hamburg.

- (2017b): Der Euro - Kern der Krise oder nachrangiges Problem? Zur Bedeutung der Währungsfrage im Kontext von ungleicher europäischer Entwicklung, Euro-Krise und hierarchischer internationaler Arbeitsteilung. In: Candeias, Mario \& Demirović, Alex (Hg.): Europe - what's left? Die Europäische Union zwischen Zerfall, Autoritarismus und demokratischer Erneuerung, Münster, S. 115-133.

Schneider, Etienne \& Syrovatka, Felix (2017): Die Zukunft der europäischen Wirtschaftsintegration. Blockierte Vertiefung und wachsende Asymmetrie zwischen Frankreich und Deutschland. In: PROKLA, Nr. 4/0217, S. 653-673, https://doi.org/10.32387/pro kla.v47i189.62.

Schneider, Heinrich (2012): Die »Europäische Wirtschaftsregierung«. Ein altes Projekt - und was daraus werden mag. In: Zeitschrift für öffentliches Recht, Nr. 2/2012, S. 315-336, https://doi.org/10.1007/s00708-012-0139-1.

- (1992): Europäische Integration: die Leitbilder und die Politik. In: Politische Vierteljahresschrift, Nr. 1/1992, S. 3-35, https://doi.org/10.1007/978-3-322-88720-7_1.

Schoeller, Magnus G. (2018): The Rise and Fall of Merkozy: Franco-German Bilateralism as a Negotiation Strategy in Eurozone Crisis Management. In: Journal of Common Markt Studis, Nr. 5/2018, S. 1019-1035, https://doi.org/10.1111/jcms.12704.

Schönberger, Christoph (2010): Bundeslehre und Europäische Union. In: Franzius, Claudio/Mayer, Franz C. \& Neyer, Jürgen (Hg.): Strukturfragen der Europäischen Union, Baden-Baden, S. 87-96, https://doi.org/10.5771/9783845228792-85.

Schulmeister, Stephan (2018): Das Richtige im Falschen: Verteidigen wir den Euro! In: Blätter für deutsche und internationale Politik, Nr. 7/2018, S. 51-62.

Schulten, Thorsten \& Müller, Torsten (2013): Ein neuer europäischer Interventionismus? Die Auswirkungen des neuen Systems der europäischen Economic Governance auf Löhne und Tarifpolitik. In: Wirtschaft und Gesellschaft, Nr. 3/2013, S. 291-321.

Schuppert, Gunnar F. (2015): Legitimationsmodi eines Systems supranationaler Herrschaftsverflechtung: Das Beispiel der Europäischen Union. In: Abbas, Nabila/Förster, Annette \& Richter, Emanuel (2015): Supranationalität und Demokratie. Die Eu- 
ropäische Union in Zeiten der Krise, Wiesbaden, S. 37-61, https://doi.org/10.1007/9 78-3-658-05335-2_3.

- (2014): Verflochtene Staatlichkeit. Globalisierung als Governance-Geschichte, Frankfurt a.M.

- (2010): Staat als Prozess. Eine staatstheoretische Skizze in sieben Aufzügen, Frankfurt a.M.

Schwan, Gesine (2017): Neue Governance-Formen als Erweiterung der europäischen Demokratie. In: Rüttgers, Jürgen \& Decker, Frank (Hg.): Europas Ende, Europas Anfang. Neue Perspektiven für die Europäische Union, Frankfurt, S. 149-161.

Schwarzer, Daniela (2012): Economic Governance in der Eurozone. In: Aus Politik und Zeitgeschichte, Nr. 4/2012, S. 17-24.

Shore, Cris (2006): `Government Without Statehood ? Anthropological Perspectives on Governance and Sovereignty in the European Union. In: European Law Journal, Nr. 6/2006, S. 709-724, https://doi.org/10.1111/j.1468-0386.2006.00343.x.

Sikora, Patrick (2019): PSPP auf dem Prüfstand - Das Weiss-Urteil des EuGH. In: Europäisches Wirtschafts- und Steuerrecht, Nr. 3/2019, S. 139-149.

Simonis, Georg \& Elbers, Helmut (2011): Studium und Arbeitstechniken der Politikwissenschaft, 2. Auflage, Wiesbaden.

Sinn, Hans-Werner (2014): Austerity, Growth and Inflation: Remarks on the Eurozone's Unresolved Competitiveness Problem. In: The World Economy 2014, S. 1-13, https:/ /doi.org/10.1111/twec.12130.

Solty, Ingar \& Gill, Stephen (2013): Krise, Legitimität und die Zukunft Europas. In: Das Argument, Nr. 1+2/2013, S. 82-94.

Somek, Alexander (2010): Die Verfassung im Zeitalter ihrer transnationalen Reproduzierbarkeit. Gedanken zum Begriff der Konstitutionalisierung. In: Franzius, Claudio/Mayer, Franz C. \& Neyer, Jürgen (Hg.): Strukturfragen der Europäischen Union, Baden-Baden, S. 135-149, https://doi.org/10.5771/9783845228792-135.

Sommer, Michael (2010): Wenn nicht jetzt, wann dann? Das Soziale Europa braucht eine politische Grundsatzentscheidung. In: Ders./Bsirske, Frank \& Rhode, Wolfgang: Business as usual oder eine neue Zukunftsstrategie? Die Strategie Europa 2020 aus der Perspektive deutscher Gewerkschaften [Friedrich-Ebert-Stiftung: Internationale Politikanalyse], S. 4-7.

Spiegel (27.06.2012): Der Mogelpakt, https://www.spiegel.de/wirtschaft/soziales/eu-w achstumspakt-von-merkel-und-hollande-ist-eine-mogelpackung-a-841040.html; 05.02.2021.

- (26.06.2012): »Keine Euro-Bonds, solange ich lebe«, https://www.spiegel.de/politik/ ausland/kanzlerin-merkel-schliesst-euro-bonds-aus-a-841115.html; 05.02.2021.

- (31.05.2009): Konterrevolution im Krisenkampf, https:/www.spiegel.de/politik/de batte/ende-des-neoliberalismus-konterrevolution-im-krisenkampf-a-627631.html; 12.02.2021.

Spilker, Niels (2013): Lebenslanges Lernen als Dispositiv - Bildung, Macht und Staat in der neoliberalen Gesellschaft, Münster.

Statista (2020a): Entwicklung des Zinssatzes der Europäischen Zentralbank für das Hauptrefinanzierungsgeschäft von 1999 bis 2020, https:/de.statista.com/statistik/ 
daten/studie/201216/umfrage/ezb-zinssatz-fuer-das-hauptrefinanzierungsgescha eft-seit-1999/; 12.02.2021.

- (2020b): Bestand der von der EZB im Rahmen des Securities Markets Programme aufgekauften Staatsanleihen von Januar 2011 bis Dezember 2019, https://de.statist a.com/statistik/daten/studie/241285/umfrage/bestand-der-von-der-ezb--im-rahm en-des-smp-aufgekauften-staatsanleihen/; 12.02.2021.

Stiglitz, Joseph E. (2018): The euro. How a common currency threatens the future of Europe, New York.

Stockhammer, Engelbert (2016): Neoliberal growth models, monetary union and the Euro crisis. A post-Keynesian perspective. In: New Political Economy, Nr. 4/2016, S. 365-379, https://doi.org/10.1080/13563467.2016.1115826.

- (2008): Some Stylized Facts on the Finance-dominated Accumulation Regime. In: Competition \& Change, Nr. 2/2008, S. 184-202, https://doi.org/10.1179\%2F10245290 8X289820.

Streeck, Wolfgang (2015a): Gekaufte Zeit. Die vertagte Krise des demokratischen Kapitalismus, erweiterte Ausgabe, Berlin.

Stützle, Ingo (2014): Austerität als politisches Projekt. Von der monetären Integration Europas zur Eurokrise, 2. Auflage, Münster.

Süddeutsche Zeitung (20.06.2011): Bitte, bitte, rettet doch den Euro, https://www.sued deutsche.de/wirtschaft/2.220/deutsche-wirtschaft-anzeigenkampagne-bitte-bitte -rettet-doch-den-euro-1.1110669; 12.02.2021.

Südekum, Jens (2020): Die europäische Antwort auf die Corona-Pandemie. In: Wirtschaftsdienst, Nr. 6/2020, S. 397-400, https://doi.org/10.1007/s10273-020-2668-5.

Tagesschau (27.03.2020): Braucht Europa jetzt Corona-Bonds?, https://www.tagesscha u.de/wirtschaft/boerse/coronavirus-wirtschaft-eu-101.html; 13.02.2021.

taz (19.12.2018): Rom und Brüssel einigen sich, https://www.taz.de/Italiens-Schuldend efizit/!5557906/; 12.02.2021.

Thiel, Thorsten (2016): »Krisendiagnosen sind ein politisches Instrument «, https://ww w.ipg-journal.de/schwerpunkt-des-monats/krise/artikel/detail/krisendiagnosen-s ind-ein-politisches-instrument-1364/; 12.02.2021.

- (2015): Die Krise in Europa - und die Krise der Erforschung dieser Krise. In: Brömmel, Winfried/König, Helmut \& Sicking, Manfred (Hg.): Europa, wie weiter? Perspektiven eines Projekts in der Krise, Bielefeld, S. 101-123, https://doi.org/10.14361/ 9783839430101-006.

Thomas, Peter (2006): Konjunktur des integralen Staates? Poulantzas' Gramsci-Lektüre. In: Bretthauer, Lars/Gallas, Alexander/Kannankulam, John \& Stützle, Ingo (Hg.): Poulantzas lesen. Zur Aktualität marxistischer Staatstheorie, Hamburg, S. 307-323. Tokarski, Paweł (2016): Die Europäische Zentralbank als politischer Akteur in der Eurokrise. Mandat, Stellung und Handeln der EZB in einer unvollständigen Währungsunion [Stiftung Wissenschaft und Politik: SWP-Studie S 14].

Tooze, Adam (2018): Crashed. Wie zehn Jahre Finanzkrise die Welt verändert haben, München.

Trenz, Hans-Jörg (2005): Zivilgesellschaft und Öffentlichkeit im europäischen Integrationsprozess: normative Desiderate und empirische Interdependenzen in der Konstitution einer europäischen Herrschaftsordnung. In: Knodt, Michèle \& Finke, Barba- 
ra (Hg.): Europäische Zivilgesellschaft. Konzepte, Akteure, Strategien, Wiesbaden, S. 55-78, https://doi.org/10.1007/978-3-322-95021-5_3.

Tridimas, Takis (2019): The Constitutional Dimension of Banking Union. In: Grundmann, Stefan \& Micklitz, Hans-W. (Hg.): The European Banking Union and Constitution. Beacon for Advanced Integration or Death-Knell for Democracy? Oxford, S. 25-47, https://doi.org/10.5040/9781509907557.ch-002.

Truger, Achim (2018): Fiskalpolitik in der EWU. Reform des Stabilitäts- und Wachstumspakts nicht vergessen! [Friedrich-Ebert-Stiftung: WISO direkt, Nr. 10/2018].

Tsianos, Vassilis S. \& Kasparek, Bernd (2015): Zur Krise des europäischen Grenzregimes: eine regimetheoretische Annäherung. In: Widersprüche, Nr. 4/2015, S. 8-22.

Tuori, Kaarlo \& Tuori, Klaus (2014): The Eurozone Crisis. A Constitutional Analysis [Cambridge Studies in European Law and Policy], Cambridge, https://doi.org/10. 1017/CBO9781107297289.

van Apeldoorn, Bastian (2014): The European Capitalist Class and the Crises of its Hegemonic Project. In: Socialist Register 2014, S. 189-206.

- (2009): The Contradictions of >Embedded Neoliberalism Legitimacy Crisis: The European Project and its Limits. In: Ders./Drahokoupil, Jan \& Horn, Laura (Hg.): Contradictions and Limits of Neoliberal European Governance. From Lisbon to Lisbon, S. 21-43, https://doi.org/10.1057/9780230228757_2.

- (2002): Transnational Capitalism and the Struggle over European Integration, London, https://doi.org/10.4324/9780203166802.

- (2000): Transnationale Klassen und europäisches Regieren: Der European Round Table of Industrialists. In: Bieling, Hans-Jürgen \& Steinhilber, Jochen (Hg.): Die Konfiguration Europas. Dimensionen einer kritischen Integrationstheorie, Münster, S. 189-221.

van Apeldoorn, Bastian/Overbeek, Henk \& Ryner, Magnus (2003): Theories of European Integration. A Critique. In: Cafruny, Alan W. \& Ryner, Magnus (Hg.): A Ruined Fortress? Neoliberal Hegemony and Transformation in Europe, Lanham, S. 17-45.

Van Rompuy, Herman (2014) Der Europäische Rat 2013 von Herman Van Rompuy, Präsident des Europäischen Rates. In: Europäischer Rat (Hg.): Der Europäische Rat 2013, Luxemburg, S. 5-23.

- (2013a): Der Europäische Rat 2012. Der Präsident des Europäischen Rates, Herman Van Rompuy. In: Europäischer Rat (Hg.): Der Europäische Rat 2012, Luxemburg, S. 5-23.

- (2013b): Auf dem Weg zu einer echten Wirtschafts- und Währungsunion. Bericht von Präsident Van Rompuy (26. Juni 2012). In: Europäischer Rat (Hg.): Der Europäische Rat 2012, Luxemburg, S. 44-46.

- (2013c): Auf dem Weg zu einer echten Wirtschafts- und Währungsunion. Zwischenbericht von Präsident Van Rompuy (12. Oktober 2012). In: Europäischer Rat (Hg.): Der Europäische Rat 2012, Luxemburg, S. 53-56.

- (2012): Auf dem Weg zu einer stärkeren Wirtschaftsunion: Zwischenbericht vom 6. Dezember 2011 an den Europäischen Rat. In: Europäischer Rat (Hg.): Der Europäische Rat 2011, Luxemburg, S. 78-80.

- (2011): The European Council in 2010 by the president of the European Council. In: European Council (Hg.): The European Council in 2010, Luxemburg, S. 5-19. 
Van Rompuy, Herman/Barroso, José Manuel/Juncker, Jean-Claude \& Draghi, Mario (2012): Auf dem Weg zu einer echten Wirtschafts- und Währungsunion, https://www.consilium.europa.eu/uedocs/cms_data/docs/pressdata/de/ec/1342 06.pdf; 12.02.2021.

van Roosebeke, Bert (2018): Reform des Europäischen Stabilitätsmechanismus (ESM) [cepAdhoc vom 11.12.2018].

van Treeck, Till (2017): Die neoklassische Interpretation der Eurokrise, https://ww w.bpb.de/politik/wirtschaft/schuldenkrise/239935/neoklassische-interpretation; 12.02.2021.

Verdun, Amy (2013): The building of economic governance in the European Union. In: Transfer, Nr. 1/2013, S. 23-35, https://doi.org/10.1177/1024258912469343.

- (1999): The role of the Delors Committee in the creation of EMU: an epistemic community? In: Journal of European Public Policy, Nr. 2/1999, S. 308-328, https://doi.or g/10.1080/135017699343739.

Verordnung (EG) Nr. 223/2009 des Europäischen Parlaments und des Rates vom 11. März 2009 über europäische Statistiken.

Verordnung (EG) Nr. 1055/2005 des Rates vom 27. Juni 2005 zur Änderung der Verordnung (EG) Nr. 1466/97 über den Ausbau der haushaltspolitischen Überwachung und der Überwachung und Koordinierung der Wirtschaftspolitiken.

Verordnung (EG) Nr. 1056/2005 des Rates vom 27. Juni 2005 zur Änderung der Verordnung (EG) Nr. 1467/97 über die Beschleunigung und Klärung des Verfahrens bei einem übermäßigen Defizit.

Verordnung (EG) Nr. 332/2002 des Rates vom 18. Februar 2002 zur Einführung einer Fazilität des mittelfristigen finanziellen Beistands zur Stützung der Zahlungsbilanzen der Mitgliedstaaten.

Verordnung (EG) Nr. 1466/97 des Rates vom 7. Juli 1997 über den Ausbau der haushaltspolitischen Überwachung und der Überwachung und Koordinierung der Wirtschaftspolitiken.

Verordnung (EG) Nr. 1467/97 des Rates vom 7. Juli 1997 über die Beschleunigung und Klärung des Verfahrens bei einem übermäßigen Defizit.

Verordnung (EG) Nr. 3603/93 des Rates vom 13. Dezember 1993 zur Festlegung der Begriffsbestimmungen für die Anwendung der in Artikel 104 und 104b Absatz 1 des Vertrages vorgesehenen Verbote.

Verordnung (EG) Nr. 3604/93 des Rates vom 13. Dezember 1993 zur Festlegung der Begriffsbestimmungen für die Anwendung des Verbots des bevorrechtigten Zugangs gemäß Artikel 104a des Vertrags.

Verordnung (EU) 2021/240 des Europäischen Parlaments und des Rates vom 10. Februar 2021 zur Schaf-fung eines Instruments für technische Unterstützung.

Verordnung (EU) 2021/241 des Europäischen Parlaments und des Rates vom 12. Februar 2021 zur Einrich-tung der Aufbau- und Resilienzfazilität.

Verordnung (EU) 2020/460 des Europäischen Parlaments und des Rates vom 30. März 2020 zur Änderung der Verordnungen (EU) Nr. 1301/2013, (EU) Nr. 1303/2013 und (EU) Nr. 508/2014 im Hinblick auf besondere Maßnahmen zur Mobilisierung von Investitionen in die Gesundheitssysteme der Mitgliedstaaten und in andere Sekto- 
ren von deren Volkswirtschaften zur Bewältigung des COVID-19-Ausbruchs (Investitionsinitiative zur Bekämpfung der Coronavirus-Krise).

Verordnung (EU) 2020/461 des Europäischen Parlaments und des Rates vom 30. März 2020 zur Änderung der Verordnung (EG) Nr. 2012/2002 des Rates zur finanziellen Unterstützung von Mitgliedstaaten und von Ländern, die ihren Beitritt zur Union verhandeln und die von einer Notlage größeren Ausmaßes im Bereich der öffentlichen Gesundheit schwer betroffen sind.

Verordnung (EU) 2020/2094 des Rates vom 14. Dezember 2020 zur Schaffung eines Aufbauinstruments der Europäischen Union zur Unterstützung der Erholung nach der COVID-19-Krise.

Verordnung (EU) 2020/558 des Europäischen Parlaments und des Rates vom 23. April 2020 zur Änderung der Verordnungen (EU) Nr. 1301/20136 und (EU) Nr. 1303/2013 im Hinblick auf spezifische Maßnahmen zur Einführung einer außerordentlichen Flexibilität beim Einsatz der europäischen Struktur- und Investitionsfonds als Reaktion auf den COVID-19-Ausbruch.

Verordnung (EU) 2020/672 des Rates vom 19. Mai 2020 zur Schaffung eines Europäischen Instruments zur vorübergehenden Unterstützung bei der Minderung von Arbeitslosigkeitsrisiken in einer Notlage (SURE) im Anschluss an den COVID-19Ausbruch.

Verordnung (EU) 2018/1671 des Europäischen Parlaments und des Rates vom 23. Oktober 2018 zur Änderung der Verordnung (EU) 2017/825 zur Erhöhung der Finanzausstattung des Programms zur Unterstützung von Strukturreformen und zur Anpassung seines übergeordneten Ziels.

Verordnung (EU) 2017/825 des Europäischen Parlaments und des Rates vom 17. Mai 2017 über die Auflegung des Programms zur Unterstützung von Strukturreformen für den Zeitraum 2017-2020 und zur Änderung der Verordnung (EU) Nr. 1303/2013 und (EU) Nr. 1305/2013.

Verordnung (EU) 2015/1017 des Europäischen Parlaments und des Rates vom 25. Juni 2015 über den Europäischen Fonds für strategische Investitionen, die europäische Plattform für Investitionsberatung und das europäische Investitionsvorhabenportal sowie zur Änderung der Verordnungen (EU) Nr. 1291/2013 und (EU) Nr. 1316/2013 der Europäische Fonds für strategische Investitionen.

Verordnung (EU) Nr. 468/2014 der Europäischen Zentralbank vom 16. April 2014 zur Einrichtung eines Rahmenwerks für die Zusammenarbeit zwischen der Europäischen Zentralbank und den nationalen zuständigen Behörden und den nationalen benannten Behörden innerhalb des einheitlichen Aufsichtsmechanismus (SSMRahmenverordnung).

Verordnung (EU) Nr. 806/2014 des Europäischen Parlaments und des Rates vom 15. Juli 2014 zur Festlegung einheitlicher Vorschriften und eines einheitlichen Verfahrens für die Abwicklung von Kreditinstituten und bestimmten Wertpapierfirmen im Rahmen eines einheitlichen Abwicklungsmechanismus und eines einheitlichen Abwicklungsfonds sowie zur Änderung der Verordnung (EU) Nr. 1093/2010.

Verordnung (EU) Nr. 472/2013 des Europäischen Parlaments und des Rates vom 21. Mai 2013 über den Ausbau der wirtschafts- und haushaltspolitischen Überwachung von 
Mitgliedstaaten im Euro-Währungsgebiet, die von gravierenden Schwierigkeiten in Bezug auf ihre finanzielle Stabilität betroffen oder bedroht sind.

Verordnung (EU) Nr. 473/2013 des Europäischen Parlaments und des Rates vom 21. Mai 2013 über gemeinsame Bestimmungen für die Überwachung und Bewertung der Übersichten über die Haushaltsplanung und für die Gewährleistung der Korrektur übermäßiger Defizite der Mitgliedstaaten im Euro-Währungsgebiet.

Verordnung (EU) Nr. 575/2013 des Europäischen Parlaments und des Rates vom 26. Juni 2013 über Aufsichtsanforderungen an Kreditinstitute und Wertpapierfirmen und zur Änderung der Verordnung (EU) Nr. 646/2012.

Verordnung (EU) Nr. 1022/2013 des Europäischen Parlaments und des Rates zur Änderung der Verordnung (EU) Nr. 1093/2010 zur Errichtung einer Europäischen Aufsichtsbehörde hinsichtlich der Übertragung besonderer Aufgaben auf die Europäische Zentralbank gemäß der Verordnung (EU) Nr. 1024/2013.

Verordnung (EU) Nr. 1024/2013 des Rates vom 15. Oktober 2013 zur Übertragung besonderer Aufgaben im Zusammenhang mit der Aufsicht über Kreditinstitute auf die Europäische Zentralbank.

Verordnung (EU) Nr. 1303/2013 des Europäischen Parlaments und des Rates vom 17. Dezember 2013 mit gemeinsamen Bestimmungen über den Europäischen Fonds für regionale Entwicklung, den Europäischen Sozialfonds, den Kohäsionsfonds, den Europäischen Landwirtschaftsfonds für die Entwicklung des ländlichen Raums und den Europäischen Meeres- und Fischereifonds sowie mit allgemeinen Bestimmungen über den Europäischen Fonds für regionale Entwicklung, den Europäischen Sozialfonds, den Kohäsionsfonds und den Europäischen Meeres- und Fischereifonds und zur Aufhebung der Verordnung (EG) Nr. 1083/2006 des Rates.

Verordnung (EU) Nr. 1173/2011 des Europäischen Parlaments und des Rates vom 16. November 2011 über die wirksame Durchsetzung der haushaltspolitischen Überwachung im Euro-Währungsgebiet.

Verordnung (EU) Nr. 1174/2011 des Europäischen Parlaments und des Rates vom 16. November 2011 über Durchsetzungsmaßnahmen zur Korrektur übermäßiger makroökonomischer Ungleichgewichte im Euro-Währungsgebiet.

Verordnung (EU) Nr. 1175/2011 des Europäischen Parlaments und des Rates vom 16. November 2011 zur Änderung der Verordnung (EG) Nr. 1466/97 des Rates über den Ausbau der haushaltspolitischen Überwachung und der Überwachung und Koordinierung der Wirtschaftspolitiken.

Verordnung (EU) Nr. 1176/2011 des Europäischen Parlaments und des Rates vom 16. November 2011 über die Vermeidung und Korrektur makroökonomischer Ungleichgewichte.

Verordnung (EU) Nr. 1177/2011 des Rates vom 8. November 2011 zur Änderung der Verordnung (EG) Nr. 1467/97 über die Beschleunigung und Klärung des Verfahrens bei einem übermäßigen Defizit.

Verordnung (EU) Nr. 407/2010 des Rates vom 11. Mai 2010 zur Einführung eines europäischen Finanzstabilisierungsmechanismus.

Verordnung (EU) Nr. 1092/2010 des Europäischen Parlaments und des Rates vom 24. November 2010 über die Finanzaufsicht der Europäischen Union auf Makroebene und zur Errichtung eines Europäischen Ausschusses für Systemrisiken. 
Verordnung (EU) Nr. 1093/2010 des Europäischen Parlaments und des Rates vom 24. November 2010 zur Errichtung einer Europäischen Aufsichtsbehörde (Europäische Bankenaufsichtsbehörde), zur Änderung des Beschlusses Nr. 716/2009/EG und zur Aufhebung des Beschlusses 2009/78/EG der Kommission.

Verordnung (EU) Nr. 1094/2010 des Europäischen Parlaments und des Rates vom 24. November 2010 zur Errichtung einer Europäischen Aufsichtsbehörde (Europäische Aufsichtsbehörde für das Versicherungswesen und die betriebliche Altersversorgung), zur Änderung des Beschlusses Nr. 716/2009/EG und zur Aufhebung des Beschlusses 2009/79/EG der Kommission.

Verordnung (EU) Nr. 1095/2010 des Europäischen Parlaments und des Rates vom 24. November 2010 zur Errichtung einer Europäischen Aufsichtsbehörde (Europäische Wertpapier- und Marktaufsichtsbehörde), zur Änderung des Beschlusses Nr. 716/2009/EG und zur Aufhebung des Beschlusses Nr. 2009/79/EG der Kommission.

Vertrag über die Arbeitsweise der Europäischen Union.

Vertrag über die Europäische Union.

Vertrag über Stabilität, Koordinierung und Steuerung in der Wirtschafts- und Währungsunion.

Vertrag zur Einrichtung des Europäischen Stabilitätsmechanismus.

Vobruba, Georg (2015): Ambivalenzen der Krise. Währung, Konflikt und europäische Integration. In: Brömmel, Winfried/König, Helmut \& Sicking, Manfred (Hg.): Europa, wie weiter? Perspektiven eines Projekts in der Krise, Bielefeld, S. 43-60, https ://doi.org/10.14361/9783839430101-003.

Vogel, Steffen (2013): Europas Revolution von oben. Sparpolitik und Demokratieabbau in der Eurokrise, 3. Auflage, Hamburg.

Voigt, Rüdiger (2017): Das Machtdreieck: Staat - Macht - Legitimität. Bourdieus Versuch, die verborgenen Mechanismen der Macht zu entschlüsseln. In: Ders. \& Hirsch, Michael (Hg.): Symbolische Gewalt. Politik, Macht und Staat bei Pierre Bourdieu, Baden-Baden, S. 35-53, https://doi.org/10.5771/9783845276441-35.

Waschbusch, Gerd (2020): Staaten-Banken-Nexus, https://www.gabler-banklexikon.de /definition/staaten-banken-nexus-99663/version-377150; 12.02.2021.

Watt, Andrew (2013): Der Euroraum ist vorerst gerettet - Was nun? In: Zeitschrift für sozialistische Politik und Wirtschaft, Nr. 6/2013, S. 21-26.

Weber, Albrecht (2013): Europa- und völkerrechtliche Elemente der Gewährleistung von Haushaltsdisziplin in der Währungsunion. In: Europarecht, Nr. 3/2013, S. 375-389, https://doi.org/10.5771/0531-2485-2013-4-375.

Weber, Max (2008): Wirtschaft und Gesellschaft. Grundriss der verstehenden Soziologie, Frankfurt a.M.

Weiß, Wolfgang \& Haberkamm, Markus (2013): Der ESM vor dem EuGH - Widersprüchliche Wertungen in Luxemburg und Karlsruhe? In: Europäische Zeitschrift für Wirtschaftsrecht, Nr. 3/2013, S. 95-100.

Welt (04.05.2013): »Merkel versteht am besten, was in Europa passiert«, https://www. welt.de/politik/ausland/article115875909/Merkel-versteht-am-besten-was-in-Euro pa-passiert.html; 13.02.2021. 
Wessels, Wolfgang (1992): Staat und (westeuropäische) Integration. Die Fusionsthese. In: Politische Vierteljahresschrift, Sonderheft Nr. 23/1992, S. 36-61, https://doi.org/1 0.1007/978-3-322-88720-7_2.

Wigger, Angela (2015): Enhancing >competitiveness $<$ in response to the European crisis. A wrong and dangerous obsession. In: Jäger, Johannes \& Springler, Elisabeth (Hg.): Asymmetric Crisis in Europe and Possible Futures. Critical political economy and post-Keynesian perspectives, Abingdon, S. 114-130, https://doi.org/10.4324/97813157 64009.

Wigger, Angela \& Horn, Laura (2019): Neoliberale Industriepolitik im sozialen Schafspelz. Ein Nachruf auf die Europäische Sozialdemokratie. In: PROKLA, Nr. 3/2019, S. 407-425, https://doi.org/10.32387/prokla.v49i196.1827.

Winkler, Adalbert (2018): Zehn Jahre nach dem Konkurs von Lehman Brothers. Ordnungspolitische Irrtürmer in der Bewertung der EZB-Geldpolitik seit der globalen Finanzkrise. In: Perspektiven der Wirtschaftspolitik, Nr. 2/2018, S. 141-162, https:// doi.org/10.1515/pwp-2018-0015.

Wirtschafts- und Finanzausschuss (2018): 2018 European Semester Process: How to implement structural reforms [ecfin.cef.cpe(2018)5500779].

- (2017): European Semester Process: Peer pressure for better implementation [ecfin.cef.cpe(2017)5400982].

- (2016a): 2016 European Semester Process: Encouraging Implementation [ecfin. cef.cpe(2016)6258710].

- (2016b): External Representation: improving EU and euro area representation in international for a. EFC Report to ECOFIN [ecfin.cef.cpe(2016)1832252].

- (2015a): A Commonly Agreed Position on Flexibility within the Stability and Growth Pact. Flexibility for cyclic conditions, structural reforms and investment [ecfin.cef.cpe(2015)2843194rev].

- (2015b): 2015 European Semester Process: Lessons learned and ways forward [Ares(2015) 4008447].

- (2013a): The 2013 European semester process. Lessons learned and ways forward [ECFIN/EPC/2013/ARES/3115412].

- (2013b): Opinion on policy areas and indicators for strengthened economic policy coordination, following the European Council in June [ohne eigene Referenz; 14550/13].

Wissel, Jens (2019): Staatsprojekt Europa in Zeiten von Krise und gesellschaftlicher Desintegration. In: Ders. \& Keil, Daniel (Hg.): Staatsprojekt Europa. Eine staatstheoretische Perspektive auf die Europäische Union, Baden-Baden, S. 41-60, https://doi.o $\mathrm{rg} / 10.5771 / 9783748900900-41$.

- (2017): Autoritärer Wettbewerbsetatismus. Dynamiken der >marktkonformen Demokratie in Europa. In: Biebricher, Thomas (Hg.): Der Staat des Neoliberalismus, Baden-Baden, S. 263-283, https://doi.org/10.5771/9783845276045-263.

- (2015): Staatsprojekt EUropa: Grundzüge einer materialistischen Theorie der Europäischen Union, Münster.

- (2012): Krise, Staat und die Radikalisierung des Neoliberalismus. In: Kurswechsel, Nr. 2/2012, S. 6-19. 
- (2007): Die Transnationalisierung von Herrschaftsverhältnissen. Zur Aktualität von Nicos Poulantzas' Staatstheorie, Baden-Baden, https://doi.org/10.5771/97838452024 33.

Wissel, Jens \& Wöhl, Stefanie (2008): Staatstheorie vor neuen Herausforderungen. Einleitung. In: Dies. (Hg.): Staatstheorie vor neuen Herausforderungen. Analyse und Kritik, Münster, S. 7-22.

Wöhl, Stefanie (2016): Machtverschiebungen vom Parlament zur Exekutive. Demokratie in Zeiten multipler Krisen. In: Aus Politik und Zeitgeschichte, Nr. 40-42/2016, S. 4246.

Wolf, Frieder Otto (2012): Rückkehr in die Zukunft - Krisen und Alternativen. Beiträge zur radikalen Philosophie, Münster.

Woll, Cornelia (2011): Wer rettet die Banken? Staatliche Nothilfe im internationalen Vergleich. In: Max-Planck-Institut für Gesellschaftsforschung (Hg.): MPIfG Jahrbuch 2011-2012, Köln, S. 19-26.

Zeit (28.08.2020): AfD-Fraktion klagt wegen Corona-Hilfsmilliarden der EZB, https:// www.zeit.de/politik/deutschland/2020-08/bundesverfassungsgericht-afd-fraktion -klage-corona-nothilfen-ezb; 12.02.2021.

- (16.03.2020): Grenzschließungen. Wo ist das Europa, das schützt?, https://www.zei t.de/politik/deutschland/2020-03/grenzschliessungen-coronavirus-pandemie-deu tschland-eu; 13.02.2021.

- (17.11.2010): Van Rompuy übertreibt, https://www.zeit.de/wirtschaft/2010-11/euro-s chuldenkrise-van-rompuy-irland; 12.02.2021.

Zeitlin, Jonathan \& Vanhercke, Bart (2018): Socializing the European Semester: EU social and economic policy co-ordination in crisis and beyond. In: Journal of European Public Policy, Nr. 2/2018, S. 149-174, https://doi.org/10.1080/13501763.2017.1363269.

Zellentin, Gerda (1975): Übernationale Zusammenschlüsse als Bedingung der Globalsteuerung in Europa. In: Politische Vierteljahresschrift, Sonderheft Nr. 6/1975, S. 215-238, https://doi.org/10.1007/978-3-322-88629-3_8.

Ziltener, Patrick (2000): Die Veränderung von Staatlichkeit in Europa - regulationsund staatstheoretische Überlegungen. In: Bieling, Hans-Jürgen \& Steinhilber, Jochen (Hg.): Die Konfiguration Europas. Dimensionen einer kritischen Integrationstheorie, Münster, S. 73-101.

- (1999): Strukturwandel der europäischen Integration. Die Europäische Union und die Veränderung von Staatlichkeit, Münster.

Zinn, Karl Georg (2013): Eine keynesianische Einschätzung der Euro-Krise. In: Das Argument 2013, S. 47-60.

Zoppè, Alice (2018): Implementation of the Macroeconomic Imbalance Procedure: Stateof-play (December 2018) [Eingehende Untersuchung hgg. von der Generaldirektion Interne Politikbereiche der Union des Europäischen Parlaments; PE 497.739].

Zürn, Michael (2011): Perspektiven des demokratischen Regierens und die Rolle der Politikwissenschaft im 21. Jahrhundert. In: Politische Vierteljahresschrift, Nr. 4/2011, S. 603-635, https://doi.org/10.5771/0032-3470-2011-4-603. 

Anhang 


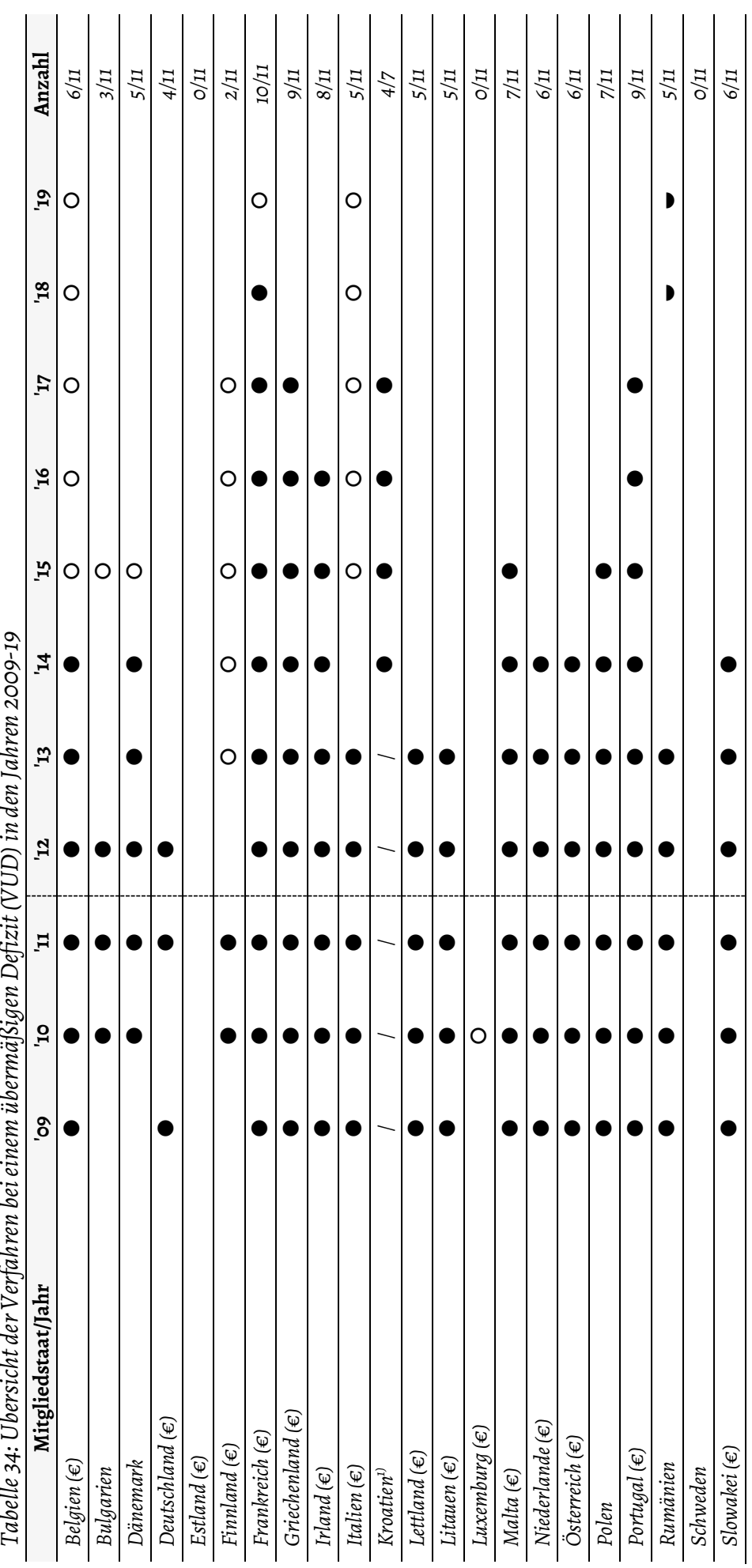




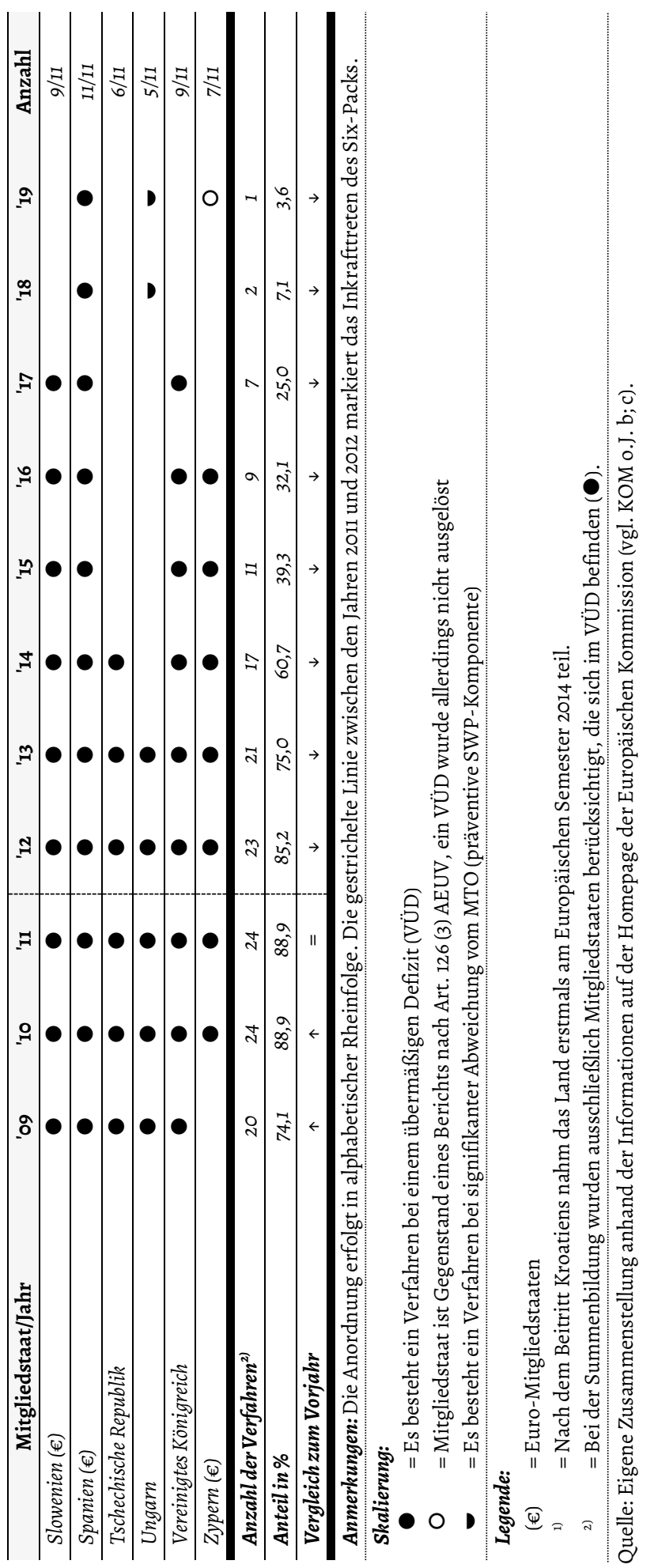




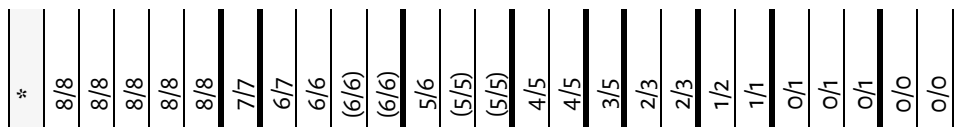

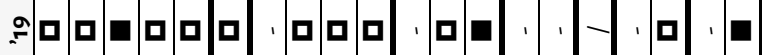

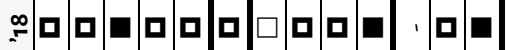

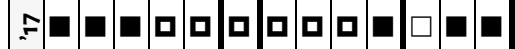

ๆ

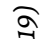

ำ

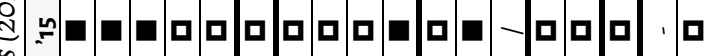

芒

$\frac{\pi}{\pi}$

है

की

ミ

芠

$\frac{\sqrt[3]{3}}{\sqrt[3]{2}}$

$\frac{2}{5}$

:

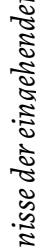

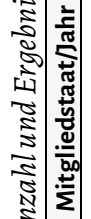

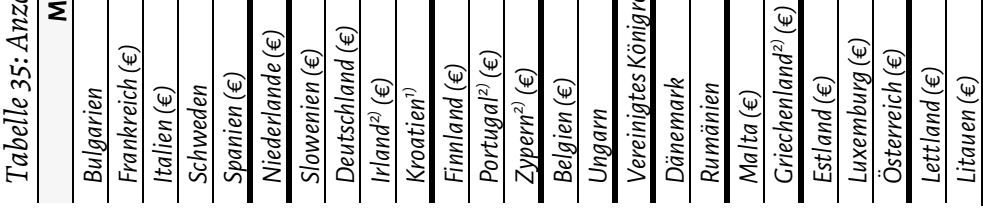




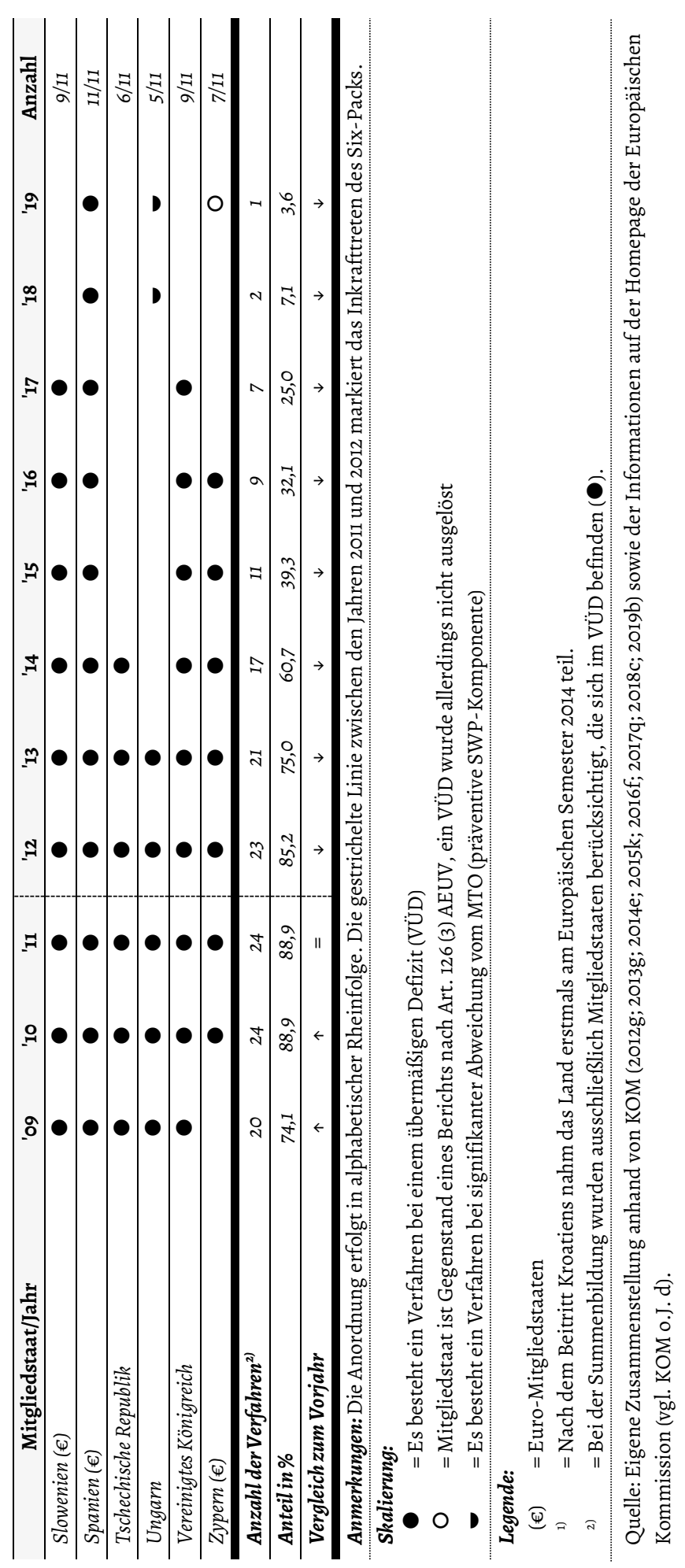




\section{Politikwissenschaft}

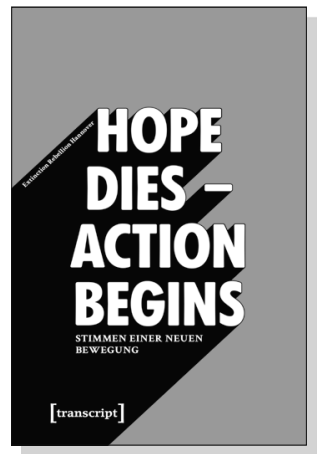

Extinction Rebellion Hannover

"Hope dies - Action begins":

Stimmen einer neuen Bewegung

2019, 96 S., kart.

7,99€ (DE), 978-3-8376-5070-9

E-Book: kostenlos erhältlich als Open-Access-Publikation, ISBN 978-3-8394-5070-3

EPUB: kostenlos erhältlich als Open-Access-Publikation, ISBN 978-3-7328-5070-9

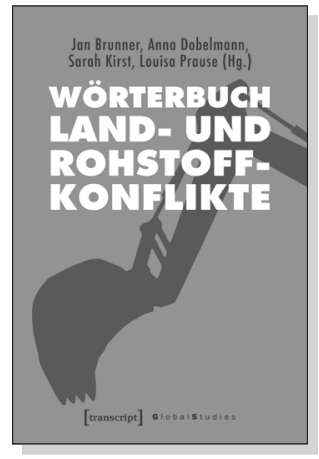

Jan Brunner, Anna Dobelmann,

Sarah Kirst, Louisa Prause (Hg.)

\section{Wörterbuch Land- und Rohstoffkonflikte}

2019, 326 S., kart., Dispersionsbindung, 1 SW-Abbildung 24,99€ (DE), 978-3-8376-4433-3

E-Book: 21,99 € (DE), ISBN 978-3-8394-4433-7

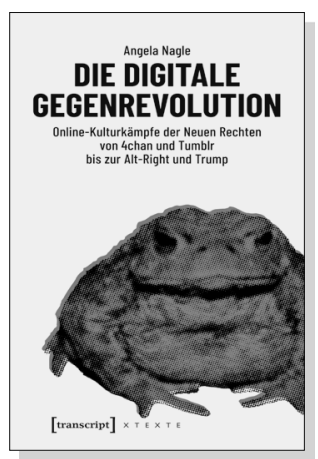

Angela Nagle

\section{Die digitale Gegenrevolution}

Online-Kulturkämpfe der Neuen Rechten

von 4chan und Tumblr bis zur Alt-Right und Trump

2018, 148 S., kart.

$19,99 €(D E), 978-3-8376-4397-8$

E-Book: 17,99 € (DE), ISBN 978-3-8394-4397-2

EPUB: $17,99 €$ (DE), ISBN 978-3-7328-4397-8 


\section{Politikwissenschaft}

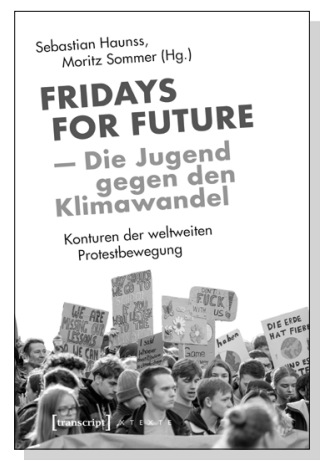

Sebastian Haunss, Moritz Sommer (Hg.)

Fridays for Future -

Die Jugend gegen den Klimawandel

Konturen der weltweiten Protestbewegung

Oktober 2020, 264 S., kart.

$22,00 €(D E), 978-3-8376-5347-2$

E-Book: kostenlos erhältlich als Open-Access-Publikation

PDF: ISBN 978-3-8394-5347-6

ISBN 978-3-7328-5347-2

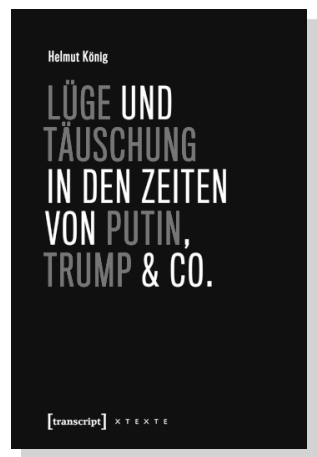

Helmut König

Lüge und Täuschung

in den Zeiten von Putin, Trump \& Co.

September 2020, 360 S., kart.

$29,50 €(D E), 978-3-8376-5515-5$

E-Book:

PDF: $26,99 €$ (DE), ISBN 978-3-8394-5515-9

EPUB: $26,99 €$ (DE), ISBN 978-3-7328-5515-5

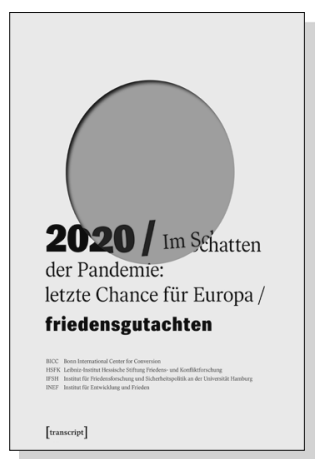

BICC Bonn International Center for Conversion, HSFK Leibniz-Institut Hessische Stiftung Friedens- und Konfliktforschung, IFSH Institut für Friedensforschung und Sicherheitspolitik an der Universität Hamburg, INEF Institut für Entwicklung und Frieden

\section{Friedensgutachten 2020}

Im Schatten der Pandemie: letzte Chance für Europa

Juni 2020, 160 S., kart., 33 Farbabbildungen

15,00€ (DE), 978-3-8376-5381-6

E-Book: kostenlos erhältlich als Open-Access-Publikation PDF: ISBN 978-3-8394-5381-0 
